\title{
Historic Archeological Investigations at Roberts Cemetery Near Troy, Bell County, Texas
}

Jennifer K. McWilliams

Texas Historical Commission

Catrina Banks Whitley

Jeremy W. Pye

Terri Myers

James T. Abbott

Texas Department of Transportation

See next page for additional authors

Follow this and additional works at: https://scholarworks.sfasu.edu/ita

Part of the American Material Culture Commons, Archaeological Anthropology Commons, Environmental Studies Commons, Other American Studies Commons, Other Arts and Humanities Commons, Other History of Art, Architecture, and Archaeology Commons, and the United States History Commons

Tell us how this article helped you.

This Article is brought to you for free and open access by the Center for Regional Heritage Research at SFA ScholarWorks. It has been accepted for inclusion in Index of Texas Archaeology: Open Access Gray Literature from the Lone Star State by an authorized editor of SFA ScholarWorks. For more information, please contact cdsscholarworks@sfasu.edu. 


\section{Historic Archeological Investigations at Roberts Cemetery Near Troy, Bell County, Texas}

\section{Authors}

Jennifer K. McWilliams, Catrina Banks Whitley, Jeremy W. Pye, Terri Myers, James T. Abbott, and Douglas K. Boyd

\section{Licensing Statement}

This is a work for hire produced for the Texas Department of Transportation (TxDOT), which owns all rights, title, and interest in and to all data and other information developed for this project under its contract with the report producer. The report may be cited and brief passages from this publication may be reproduced without permission provided that credit is given to TxDOT and the firm that produced it. Permission to reprint an entire chapter, section, figures or tables must be obtained in advance from the Supervisor of the Archeological Studies Branch, Environmental Affairs Division, Texas Department of Transportation, 125 East 11th Street, Austin, Texas, 78701 


\title{
HISTORIC ARCHEOLOGICAL INVESTIGATIONS AT ROBERTS CEMETERY NEAR TROY, BELL COUNTY, TEXAS
}

\author{
by \\ Jennifer K. McWilliams \\ Catrina Banks Whitley \\ Jeremy W. Pye \\ Terri Myers \\ James T. Abbott \\ and \\ Douglas K. Boyd
}

Principal Investigators: James T. Abbott and Douglas K. Boyd

REPORTS OF INVESTIGATIONS, NUMBER 169

Prewitt and Associates, Inc. Cultural Resources Services Austin, Texas

ARCHEOLOGICAL STUDIES PROGRAM, REPORT NO. 160

Texas Department of Transportation

Environmental Affairs Division

Archeological Studies Program

CSJ No. 0015-02-048 and 0015-04-067

PAI Project No. 212021

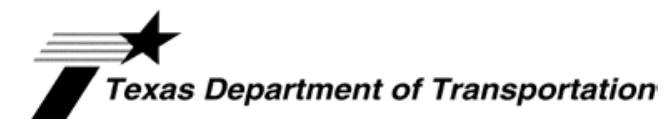

TEXAS ANTIQUITIES PERMIT NO. 6388 


\section{HISTORIC ARCHEOLOGICAL INVESTIGATIONS AT ROBERTS CEMETERY NEAR TROY, BELL COUNTY, TEXAS}

\section{COPYRIGHT @ 2014}

\section{Texas Department of Transportation (TxDOT)}

This is a work for hire produced by the Texas Department of Transportation (TxDOT), which owns all rights, title, and interest in and to all data and other information developed for this project under TxDOT Contract 571XXSA001, Work Authorization No. 57111SA001. Brief passages from this publication may be reproduced without permission provided that credit is given to TxDOT and Prewitt and Associates, Inc. Permission to reprint an entire chapter, section, figures, or tables must be obtained in advance from the Supervisor of the Archeological Studies Program, Environmental Affairs Division, Texas Department of Transportation, 125 East 11th Street, Austin, Texas, 78701. Copies of this publication have been deposited with the Texas State Library in compliance with the State Depository Requirement.

jointly published by the

Texas Department of Transportation

Environmental Affairs Division

Archeological Studies Program

Scott Pletka, Ph.D., Supervisor

Archeological Studies Program, Report No. 160

CSJ Nos. 0015-02-048 and 0015-04-067

Al McGraw, Series Editor

and

Prewitt and Associates, Inc.

Cultural Resources Services

Austin, Texas

PAI No. 212021

Reports of Investigations, No. 169

Printed by AlphaGraphics in Austin, Texas

ISBN: 978-1-935545-27-9 


\section{TABLE OF CONTENTS}

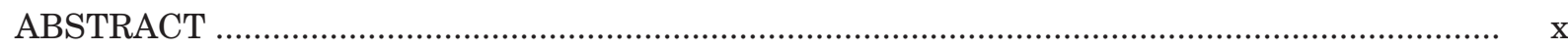

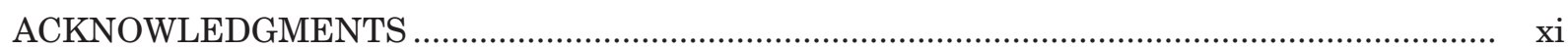

CHAPTER 1: INTRODUCTION AND PROJECT BACKGROUND ........................................ 1

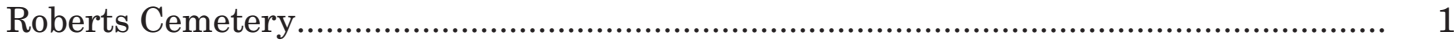

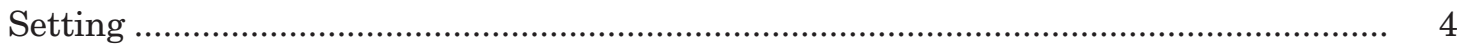

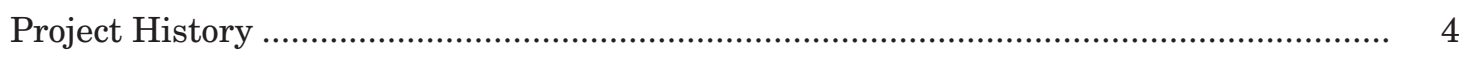

CHAPTER 2: METHODS OF INVESTIGATION, WORK ACCOMPLISHED, AND GEOARCHEOLOGICAL OBSERVATIONS ................................................ 7

Methods of Burial Prospection ......................................................................................... 7

Methods of Burial Excavation and Analysis................................................................ 8

Analysis of Casket Hardware and Personal Items .................................................. $\quad 9$

Osteological Analysis of Human Remains ................................................................. 9

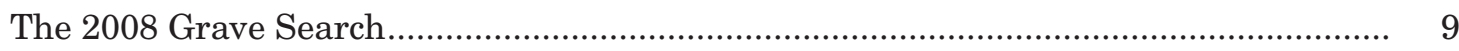

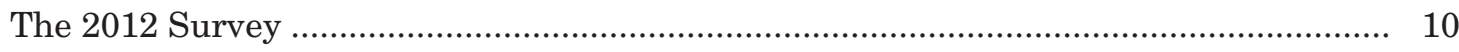

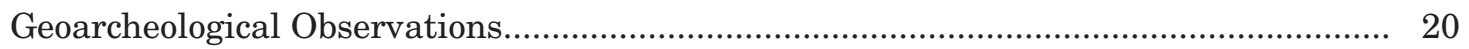

CHAPTER 3: BURIAL DESCRIPTIONS _......................................................................... 27

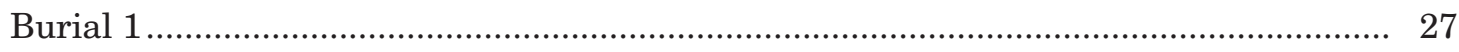

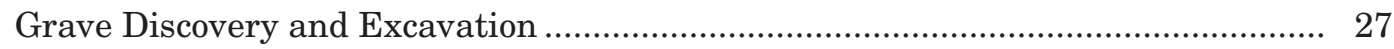

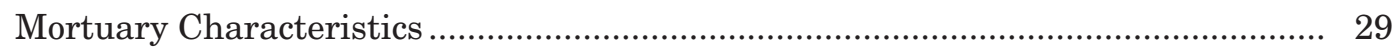

Osteological Characteristics ............................................................................. 34

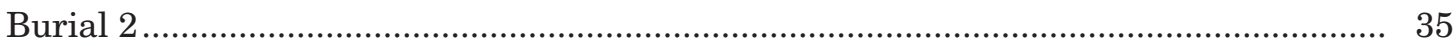

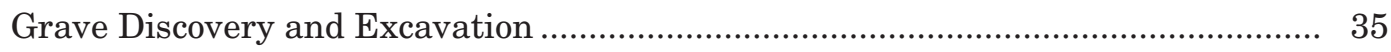

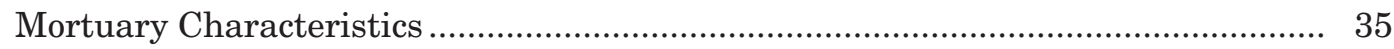

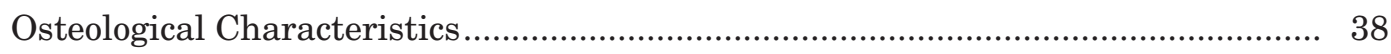

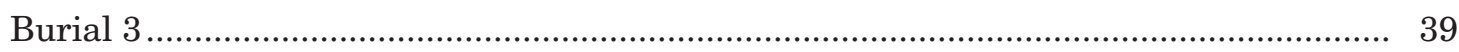

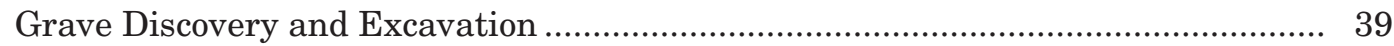

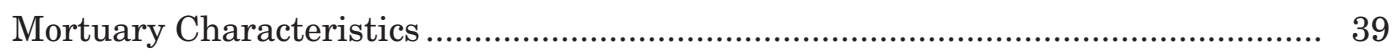

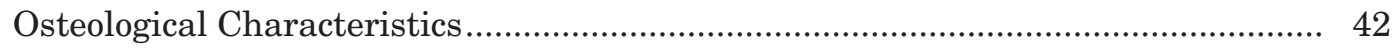

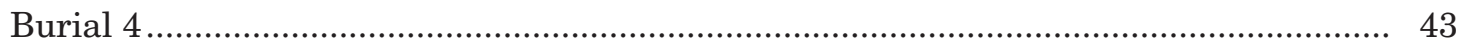

Grave Discovery and Excavation …................................................................. 43

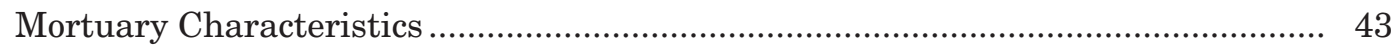

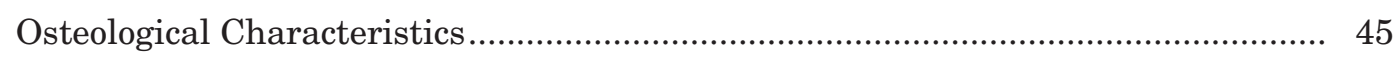

CHAPTER 4: TYPOLOGY AND ANALYSIS OF BURIAL CONTAINER HARDWARE ............. 47

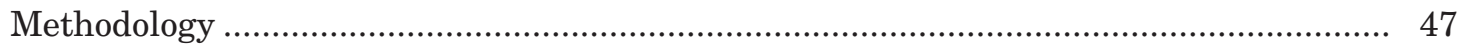

United States Patent Records: Utility Patents (1839-1965) ................................. 51

United States Patent Records: Design Patents (1843-1965)................................ 51

Manufacturers' Trade Catalogs....................................................................... 51

Previous Historic Cemetery/Burial Excavation Reports .................................... 51

Mortuary Artifact Descriptions and Typology ........................................................... 52 
Internal Burial Container Elements .............................................................. 52

External Burial Container Elements............................................................... 62

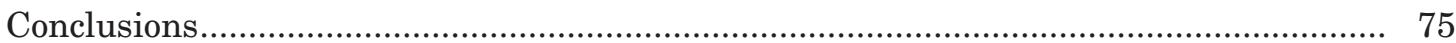

CHAPTER 5: OSTEOLOGICAL ANALYSIS OF HUMAN REMAINS .................................... 79

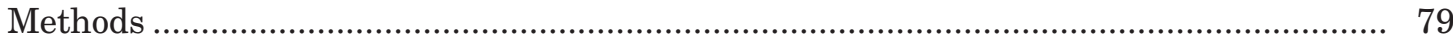

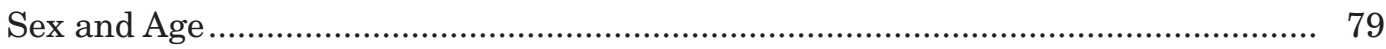

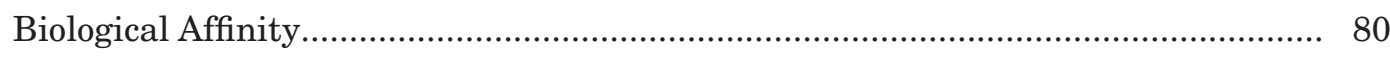

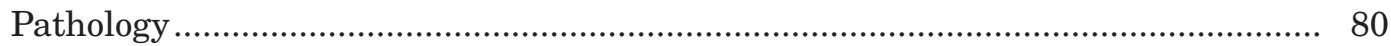

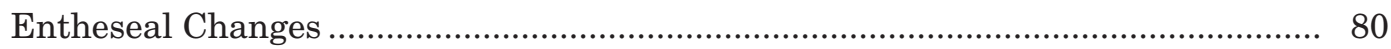

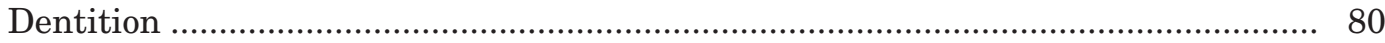

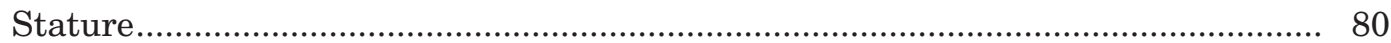

Discussion of the Roberts Cemetery Burials ............................................................ 81

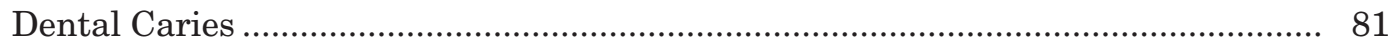

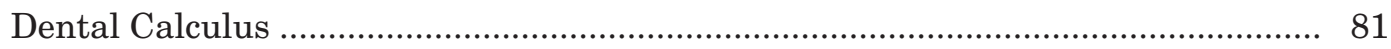

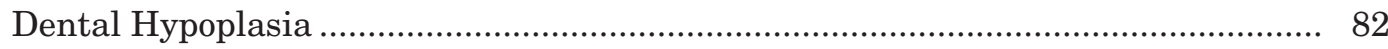

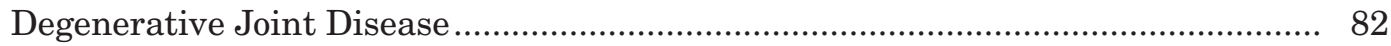

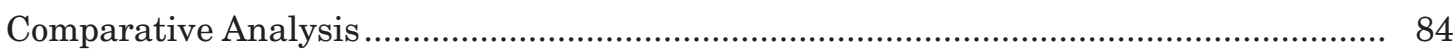

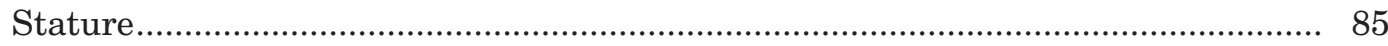

Population Data and Mortality Schedules .............................................................. 87

CHAPTER 6: HISTORY OF THE ROBERTS CEMETERY PROPERTY AND ARCHIVAL SEARCH FOR UNMARKED GRAVES ........................................................ 91

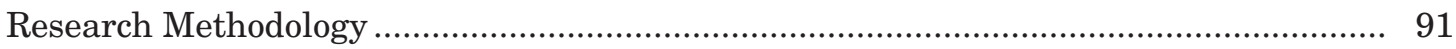

Historical Background for Roberts Cemetery ….......................................................... 92

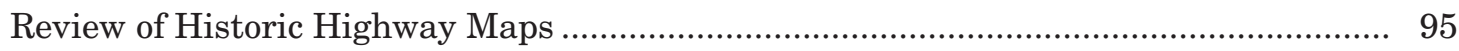

Chain of Title for the Roberts Cemetery ................................................................... 95

Search for Death Certificates as Indications of Possible Unmarked Graves.................... 106

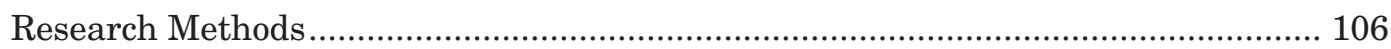

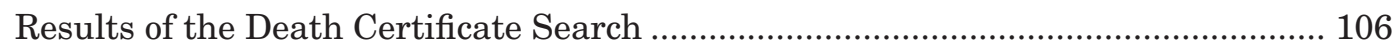

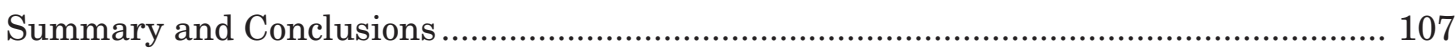

CHAPTER 7: PUBLIC INVOLVEMENT, SEARCH FOR LIVING RELATIVES, AND

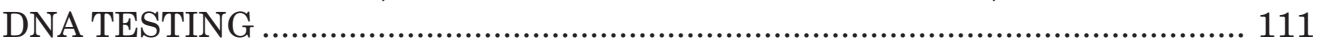

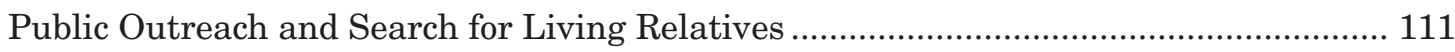

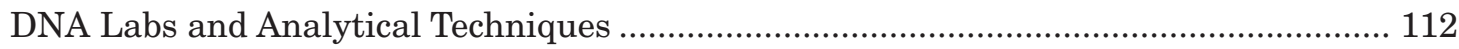

Overview of Commercial Laboratories and DNA Research....................................... 112

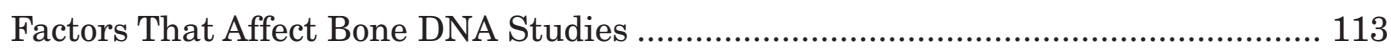

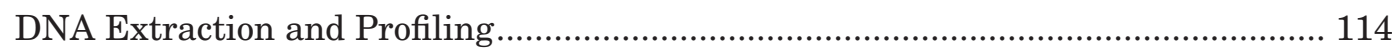

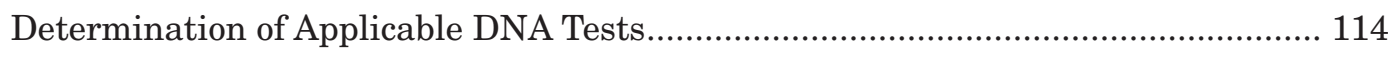

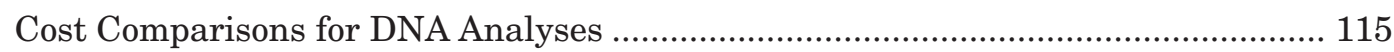

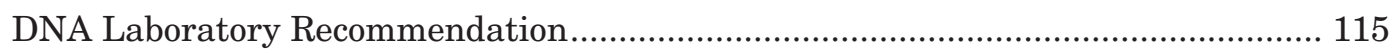

Potential Genetic Matches Between Ancestors and the Historic Burials ......................... 115

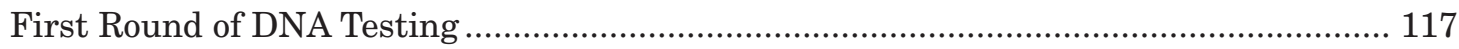

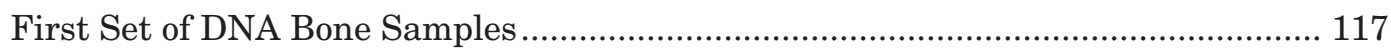




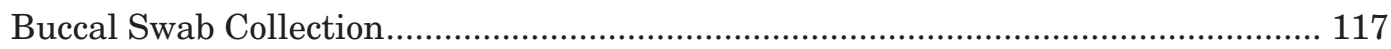

Comparison of DNA from Teeth and Buccal Swabs ................................................ 117

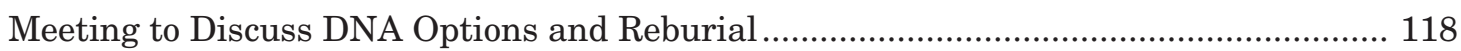

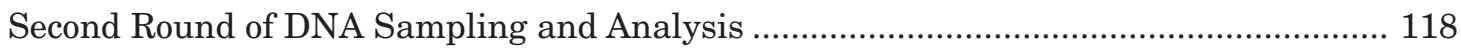

Discussion of DNA Results: Burial 2 and the Elliott Family......................................... 118

CHAPTER 8: PROJECT SUMMARY, REINTERMENT, AND CONCLUDING

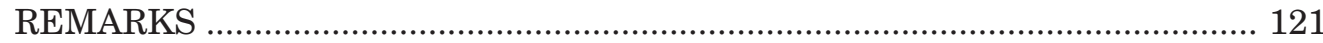

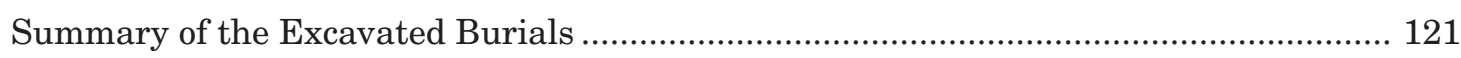

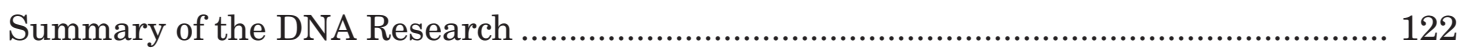

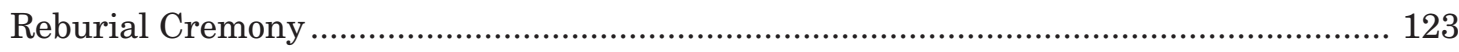

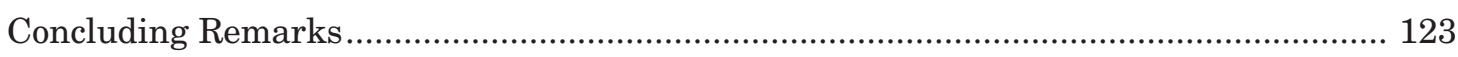

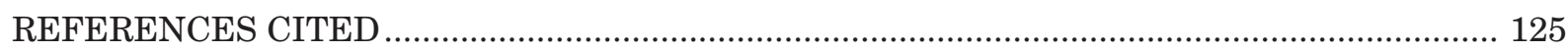

APPENDIX A: Tabulated Data on Mortuary Hardware: Hardware Catalogs, Historic Cemetery Reports, and Cemetery Artifact Comparisons ..................... 147

APPENDIX B: Tabulated Osteological Data for Four Excavated Historic Burials at Roberts Cemetery, Bell County, Texas ............................................................. 177

APPENDIX C: Lists of People Who Are or May Be Buried in Unmarked Graves at Roberts Cemetery as Revealed in an Analysis of Death Certificates ................. 189

APPENDIX D: List of Burials in Roberts Cemetery, Bell County, Texas, 1886 to 2004 ............... 195

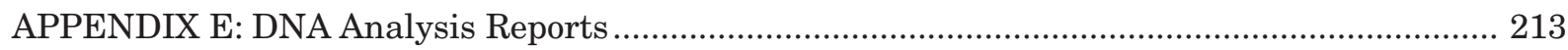

APPENDIX F: Reinterment Agreement between the Texas Department of Transportation and the Roberts Cemetery Association, September 2012 


\section{LIST OF FIGURES}

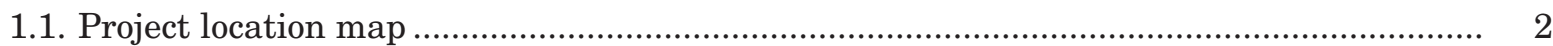

1.2. Annotated aerial photograph of the cemetery................................................................. 3

2.1. Photo looking east from the cemetery toward the TxDOT right of way ........................... 11

2.2. Initial stages of scraping using a trackhoe, looking west toward the cemetery ................. 12

2.3. Initial view of the shaft of what was later identified as Burial 1 ..................................... 12

2.4. View of trenching showing the character of the rubble fill ............................................ 14

2.5. Composite panoramic photograph, looking northeast, showing the

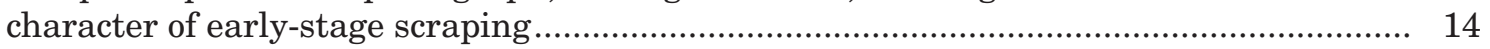

2.6. Two views of Feature 4, a posthole near Burial 1 ............................................................ 15

2.7. Photograph of Feature 5, a borehole near Feature 4 .................................................... 16

2.8. Stripping of the artificial fill from under the frontage road, looking south....................... 18

2.9. View eastward of the north end of the stripped area during

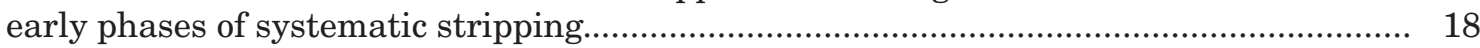

2.10. Systematic stripping of the A horizon beneath the frontage road

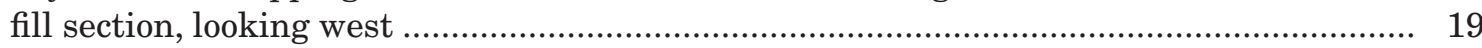

2.11. Systematic stripping of the lower B and C horizons, looking south............................ 19

2.12. Map of the mechanical search area showing the locations of unmarked graves and nonmortuary features found in the eastern side of Roberts Cemetery

2.13. Detail of the soils in the vicinity of Roberts Cemetery, as mapped by the USDA Natural Resource Conservation Service.

2.14. Photographs of the western wall of the scraped area and selected soil profiles............... 25

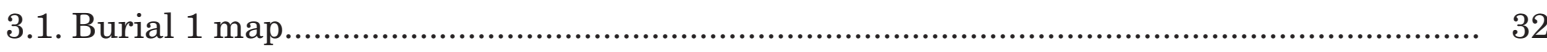

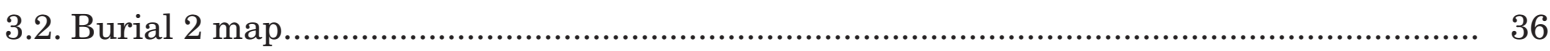

3.3. Cuff links (top) and collar eyelets (bottom) from Burial 2 ….......................................... 38

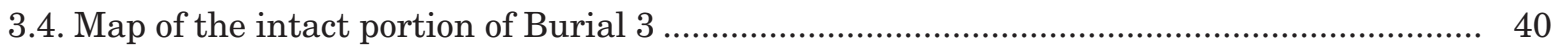

3.5. Map of lower leg and foot bones of Burial 3 found in a consolidated fill block displaced by machine excavation ........................................................................ 41

3.6. Adjustable coat collar spring from the 1895 Montgomery Ward Catalog ......................... 42

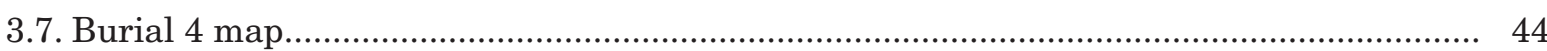

4.1. An 1883 advertisement for Stein Manufacturing Company's "Patent Fastener"

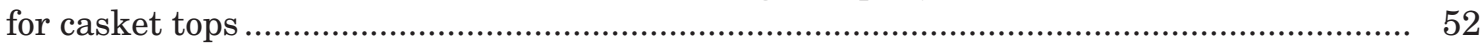

4.2. Selection of wire nails offered for sale on page 1837 of the 1903 Simmons

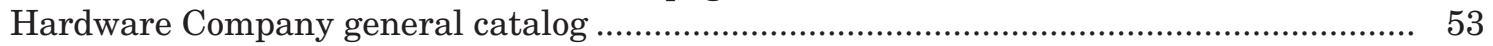

4.3. Selection of wire nails offered for sale on page 1838 of the 1903 Simmons Hardware Company general catalog

4.4. Selection of cut nails offered for sale on page 1238 of the 1903 Simmons Hardware Company general catalog..... 
4.5. A selection of nails and other construction hardware recovered from the Roberts Cemetery burial excavations

4.6. Selection of lining tacks illustrated on page 105 of the 1901 Gate City Coffin Company catalog.

4.7. U.S. Utility Patent No. 4,704 assigned to T. J. Sloan for a wood screw in 1846

4.8. Selection of American gimlet screws offered for sale on page 126 of the 1865 Russell \& Erwin Company general catalog

4.9. A selection of joining plates recovered from Roberts Cemetery Burial 1

4.10. U.S. Utility Patent No. 377,325 assigned to W. J. Noble for a coffin fastener in 1888

4.11. U.S. Utility Patent No. 401,663 assigned to William A. Sparks for a coffin fastener in 1889

4.12. Foot hook and foot plate of Top Fastener Type 1 recovered from Roberts Cemetery Burial 1

4.13. Head plate and spring of Top Fastener Type 1 recovered from Roberts Cemetery Burial 1

4.14. Top Fastener No. 35

4.15. Dowel Type 1 recovered from Roberts Cemetery Burial 1

4.16. Dowel No. 32 illustrated on page 32 of the 1920s-1930s Langenau Mfg. Company catalog.

4.17. U.S. Utility Patent No. 2,634,997 assigned to William R. Gallowitz in 1953 for a spring latch mechanism

4.18. U.S. Utility Patent No. 275,503 assigned to W. C. Langenau for a burial casket catch in 1883

4.19. Catch Type 1 recovered from Roberts Cemetery Burial 1

4.20. Catch No. 169

4.21. Page 22 of the 1920s-1930s Langenau Manufacturing Company catalog showing rectangular escutcheons similar to Catch Escutcheon Type 1

4.22. Handle Type 1 recovered from Roberts Cemetery Burials 2 and 3

4.23. U.S. Utility Patent No. 97,827 assigned to C. Strong for a coffin handle with early components of a short-bar handle in 1869

4.24. Handle Type 2 recovered from Roberts Cemetery Burial 1

4.25. U.S. Utility Patent No. 964,562 assigned to E. B. Sargent for a handle for caskets in 1910

4.26. U.S. Utility Patent No. 444,973 assigned to M. Bremer for a coffin handle with a swelled bar in 1891

4.27. Casket illustrated exhibiting a short-bar handle

4.28. Casket handle No. 225

4.29. Handle Type 3 recovered from Roberts Cemetery Burial 1 ......................................... 68

4.30. Outer box handle shown on page 458 of the 1908 Mound Coffin Company catalog ......... 69 
4.31. Examples of early "coffin plates" from ca. 1797 English hardware sample books 69

4.32. Plaque Type 1 recovered from Roberts Cemetery Burial 1 .......................................... 70

4.33. Plaque Type 2 recovered from Roberts Cemetery Burials 2 and 3.............................. 71

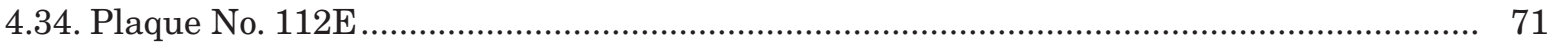

4.35. Thumbscrews recovered from Roberts Cemetery burials .............................................. 72

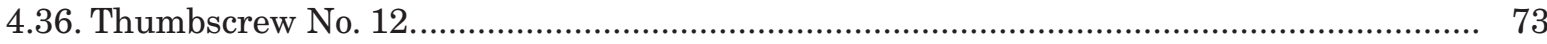

4.37. Thumbscrew and Escutcheon No. 64 ........................................................................... 73

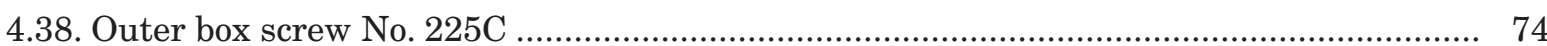

4.39. Escutcheons recovered from Roberts Cemetery burials .................................................. 74

4.40. Caplifter Type 1 recovered from Roberts Cemetery Burials 2 and 3............................ 75

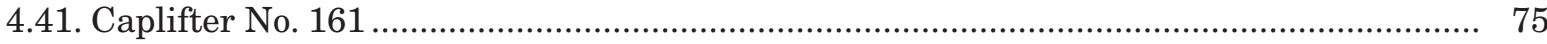

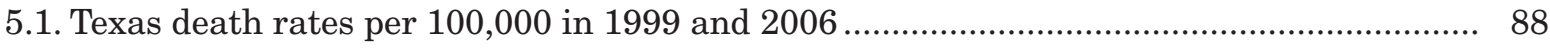

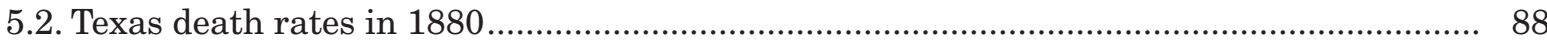

6.1. Graph of death dates by decades for 556 burials in the Roberts Cemetery....................... 94

6.2. Section of the 1921 State Highway Department map..................................................... 99

6.3. Section of the 1932 Bell County highway map.................................................................. 100

6.4. Section of the 1931-1932 State Highway Department map............................................. 101

6.5. Section of the 1949-1952 Texas State Highway Department map ..................................... 102

6.6. Sections of the 1957-1958 Texas State Highway Department map................................... 103

6.7. Aerial view of Roberts Cemetery with the Bell County Appraisal District

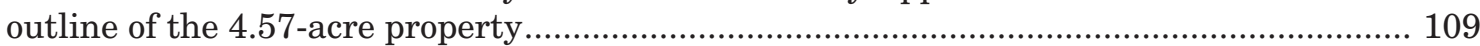

8.1. Photographs of the reburial ceremony at Roberts Cemetery on March 26, 2013............... 124 


\section{LIST OF TABLES}

2.1. Features found by TxDOT archeologists.

2.2. Sequence of events in the discovery and excavation of unmarked burials at Roberts Cemetery .....

3.1. Summary of unmarked burials at Roberts Cemetery

3.2. Summary of mortuary hardware and personal items recovered from four burials

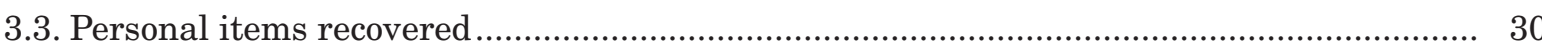

4.1. Description and measurements of the mortuary hardware ............................................ 48

4.2. Chronological summary of mortuary hardware by burial ............................................ 77

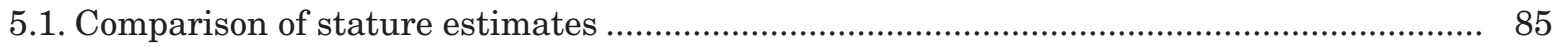

5.2. Comparison of selected osteological traits .................................................................. 86

5.3. Causes of death in Troy, Texas compared to Bell County and all of Texas, 1880 .............. 89

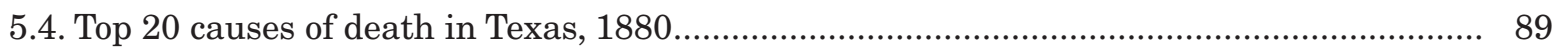

5.5. Causes of infant death in Troy and Bell County, Texas, 1880 ........................................ 90

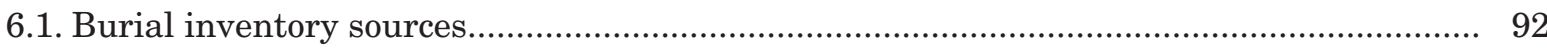

6.2. Annotated list of highway maps showing the Roberts Cemetery property relative to U.S. Highway 81 and Interstate Highway 35 ............................................... 96

6.3. Chain of title summary for the Roberts Cemetery property, Bell County, Texas ............... 104

6.4. Summary of people definitely or possibly buried in Roberts Cemetery between 1903 and 1940, according to Bell County death certificates................................ 108

7.1. People who contacted the Texas Department of Transportation with information about possible relatives buried in Roberts Cemetery

7.2. People who may be buried in unmarked graves at Roberts Cemetery and whose living relatives are potential DNA matches with exhumed burials.... 


\begin{abstract}
A preliminary archeological investigation was conducted in 2008 at Roberts Cemetery near Troy, Texas, as part of the Texas Department of Transportation's planned expansion of Interstate Highway 35. Mechanical trenching discovered one unmarked grave near the highway right of way, and this led to an extensive mechanical search of the eastern edge of the cemetery in 2012. Following the removal of the southbound access road and thick layer of artificial fill, five additional unmarked graves were discovered. Of the six unmarked graves, two are located in the cemetery property and were left in place, but the four burials inside the highway right of way were exhumed. They were reinterred in a nearby plot in Roberts Cemetery.

Analyses of the mortuary items and skeletal remains indicate that the three adult males and one child were interred between 1895 and the late 1930s. DNA analyses were used to try and match the four interred individuals with possible living relatives, but the results were negative or inconclusive. Archival research provided historical context for Roberts Cemetery and defined the sequence of road expansions that impacted the east side of the cemetery in the twentieth century.
\end{abstract}




\section{ACKNOWLEDGMENTS}

The board members of the Roberts Cemetery Association-Mrs. Heroldine Early, Mr. Joel Day, Mrs. Betty Jo Bulls, Mr. Wayne Randolph, and Mr. J. C. Alston-deserve special recognition for their cooperation and involvement throughout this project. From the initial written agreement for reburial to the final graveside reinterment, their efforts were critical to the success of the project and are greatly appreciated.

The work described in this report is the result of a joint project conducted by personnel from the Archeological Studies Branch of the Texas Department of Transportation and from Prewitt and Associates, Inc. Jim Abbott (TxDOT) and Doug Boyd (PAI) served as co-principal investigators. The mechanical search for unmarked graves was directed by Abbott, with TxDOT archeologists John Arnn, Jon Budd, Christopher Ringstaff, and Waldo Troell all working there at various times. Excavation machines were provided primarily by the construction contractor, James Construction Group, LLC, and their assistance is appreciated. TxDOT's Waco District office also provided machines and operators.

Project archeologist Jenny McWilliams (PAI) directed the burial excavations. She was assisted by Aaron Norment (PAI) and osteologist Catrina Whitley, who also served as the project's physical anthropologist for the analysis of the human remains. The analysis and reporting of the mortuary hardware was conducted by consultant Jeremy Pye, who was just finishing up his graduate studies in the Department of Anthropology, University of Florida, at the time he did the analysis (he now works for Cultural Resource Analysts, Inc., in Shreveport, Louisiana). Consultant Terri Myers (Preservation Central, Inc., in Austin) served as the project historian and conducted the archival research. Prewitt and Associates produced this report. It was edited by Elaine Robbins, and the figures were produced by Sandy Hannum and Brian Wootan. Thanks to the USGenWeb project and to Mary Duke for allowing us to reproduce the online burial inventory for Roberts Cemetery as an appendix to this report.

Many other TxDOT personnel contributed to this project. From the Waco District: Michael Rhodes and David Jayroe (Advanced Project Development); Ken Roberts (Public Information Officer); Ali Bashi, P.E. (Area Engineer, Belton Area Office); Clayton Zacha (Project Engineer); Mike Mazoch, P.E. (Assistant Area Engineer); James (Gary) Wagnon (Maintenance Supervisor Belton Area Office); and Bobby Littlefield, Waco District Engineer. From the Environmental Affairs Division in Austin: Scott Pletka (Supervisor of Archeological Studies); Leslie Wickersham (Contracting Officer); Jim Barta (Director of Technical Services); and Carlos Swonke (Director of Environmental Affairs). Pletka handled all of the complexities in navigating through the recently revised cemetery requirements in the Texas Health and Safety Code and the Texas Antiquities Code.

Many people contributed to the DNA studies for this project. Thanks to those people who provided family historical information and buccal swab samples for our DNA analyses. These people are: Cindy Black, Carolyn Pillans, and Georgia Elliott for the Elliott family; Florence Boren for the Gibson family; and Cindy Schleede, Don Thomas, and Dorothy Thomas for the Thomas family. Special thanks go to Dr. Michael Schmiederer with the DNA Processing division at LabCorp of Burlington, North Carolina. He guided us through all the phases of the analysis, helping us understand the various types of DNA studies that could be done, selecting the appropriate technique, taking the DNA samples, and conducting the extraction and analytical procedures.

Many people were involved with the reinterment of the exhumed burial remains on May 26,

2013. Thanks to Larry Granfor (Associate Pastor at Grace Baptist Church in Temple, Texas), who conducted the graveside service, Joseph Bedrich (Bedrich Services, Inc.), who provided the backhoe and excavated the reburial grave, and Heroldine Early, who made arrangements for the acquisition 
of a new grave marker. Phipps Memorial, Inc., of Waco, Texas, is acknowledged for their donation of the headstone, which they placed at the new gravesite. We thank all those people who attended the reburial ceremony to lay the remains of four unknown persons to rest once again. 


\section{INTRODUCTION AND PROJECT BACKGROUND}

This report describes archeological investigations conducted in late 2012 at Roberts Cemetery. Roberts Cemetery is in northern Bell County, Texas, just west of the Interstate Highway 35 frontage road, south of Big Elm Creek (Figure 1.1). The cemetery is about $2.5 \mathrm{~km}$ (1.5 mi) north of the town of Troy. The work was conducted in response to major improvements to Interstate Highway 35 by the Texas Department of Transportation (TxDOT), including rebuilding and expansion of the main lanes and replacement of the frontage roads (CSJ Nos. 0015-02-048 and 0015-04-067). The highway improvements are being conducted in stages to allow traffic flow to continue on this major arterial highway. The purpose of the archeological work was to ascertain whether burials associated with Roberts Cemetery were present in the portion of the highway right of way under construction, and if so, to remove them and rebury them inside the cemetery. Public outreach was conducted as part of this project in an attempt to identify the remains.

Mechanical trenching along the east edge of Roberts Cemetery in 2008 led to the discovery of one unmarked grave near (but outside) the state-owned right of way (Hatfield et al. 2009). This investigation proved there was a high potential for unmarked graves inside the road right of way. In August and September 2012, archeological staff from TxDOT's Archeological Studies Branch conducted additional mechanical scraping to locate any graves in the project area identifying two unmarked graves in the process. In September archeologists from Prewitt and Associates, Inc. (PAI), along with consulting bioarcheologist Catrina Whitley, excavated these two unmarked graves and two additional unmarked graves found in association within the TxDOT right of way just east of Roberts Cemetery. A fifth unmarked grave was tentatively identified, but it was entirely within Roberts Cemetery and was not excavated. From September 2012 to March 2013, the recovered remains and associated hardware were analyzed, and PAI and TxDOT conducted an unsuccessful effort to identify the individuals represented. In March 2013, the remains from these four graves were reburied in Roberts Cemetery. The work was conducted for TxDOT's Environmental Affairs Division (TxDOT-ENV) under Work Authorization No. 57111SA001 of Contract No. 571XXSA001 and authorized under Texas Antiquities Permit No. 6388.

\section{ROBERTS CEMETERY}

This active cemetery currently occupies an area of slightly less than 5 acres and contains more than 600 marked graves. It is well kept and managed by a volunteer cemetery association. The oldest marked grave dates to 1886 . Oral tradition related to TxDOT by Ms. Heroldine Early, a member of the cemetery association, suggests that the cemetery was established when one of the Roberts children, Maggie Roberts, was buried in 1886.

Viewed from above, Roberts Cemetery is trapezoidal in plan, with right-angle corners on the west side, parallel sides on the north and south, and a frontage along Interstate Highway 35 that runs south-southeast to northnorthwest (Figure 1.2). Other than the highway frontage, the tract boundaries are oriented to cardinal directions and measure approximately

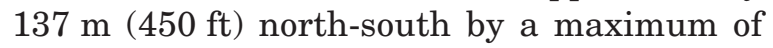




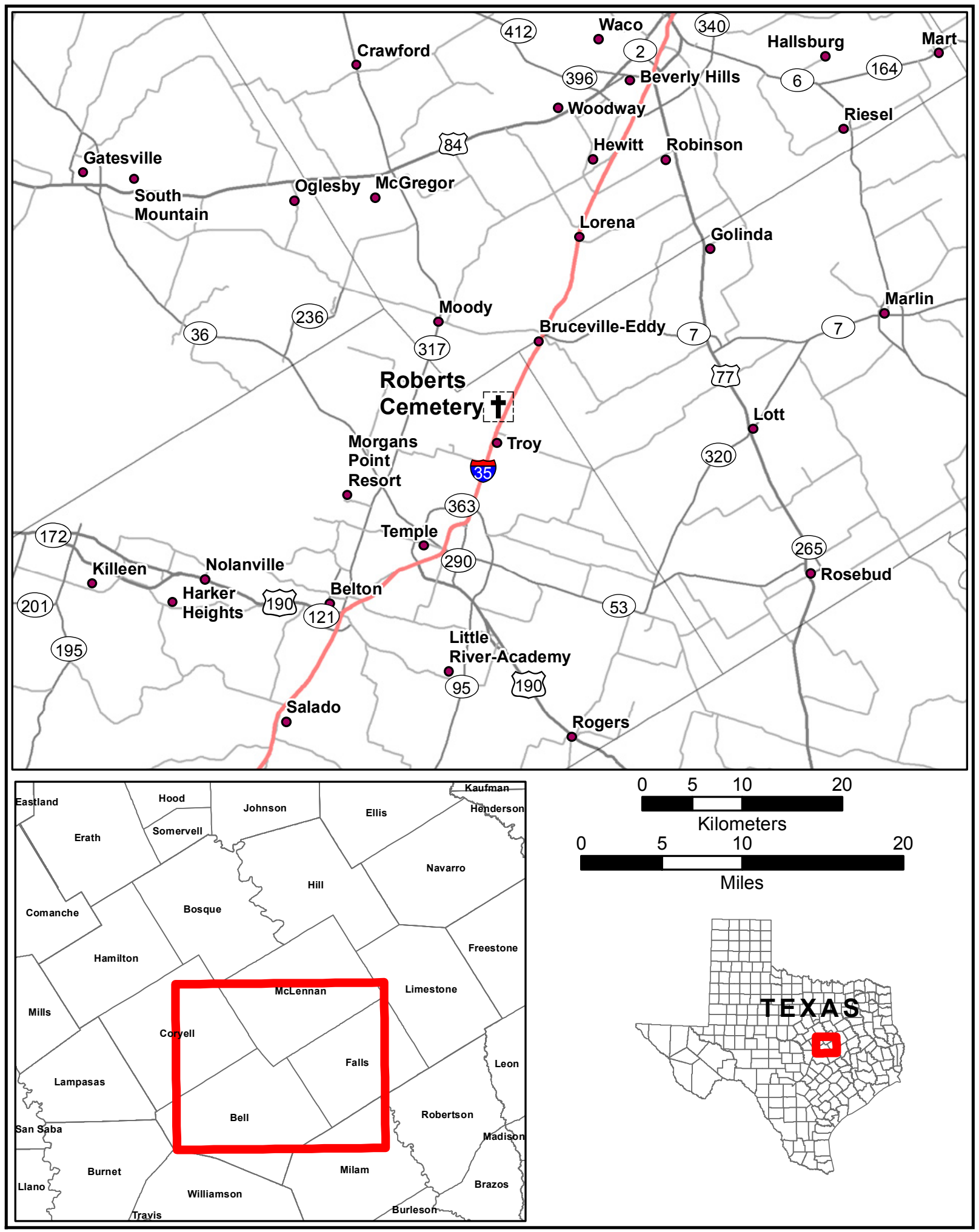

Figure 1.1. Project location map. 


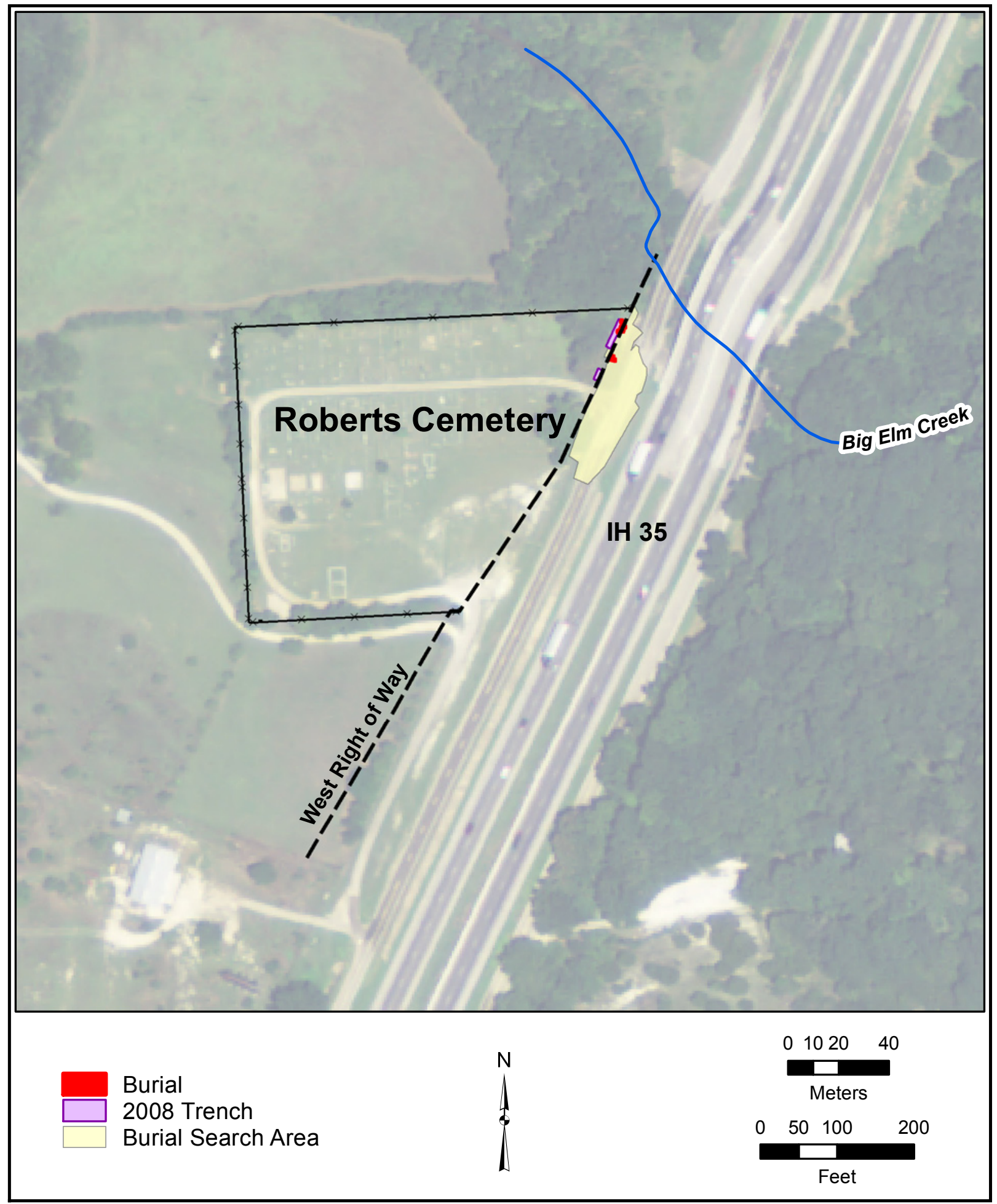

Figure 1.2. Annotated aerial photograph of the cemetery. 
approximately $180 \mathrm{~m}$ (590 ft) east-west along its northern boundary. The configuration of the cemetery suggests that the plot was originally rectangular but that the southeast corner of the property was taken for highway right of way. Review of available documentation, including a series of highway planning maps by the State Highway Department (TxDOT's predecessor) and Bell County, indicates that this is indeed the case. Property deed research was done to trace the history of the Roberts Cemetery property through time. Although there are some gaps in the records, the deeds and highway maps both indicated that the first taking of cemetery property for highway development was in the 1950s, when State Highway 81 was expanded into Interstate Highway 35.

\section{SETTING}

Bell County is in central Texas, along the Balcones Fault Zone. The cemetery is underlain by alluvial deposits near Big Elm Creek and by associated older terrace deposits and uplands to the south and west. The landscape rises from an elevation of approximately $625 \mathrm{ft}$ above sea level in the northeast corner near the creek to $650 \mathrm{ft}$ in the southwest.

The geology and soils of the cemetery and environs are relevant in several ways. First, it seems clear that the character of the substrate exercised a strong degree of control over early grave placement within the cemetery. The bedrock mapped in the area is the Upper Cretaceous Austin Chalk, which consists of chalk interbedded with thin beds of marl (Barnes 1970). The majority of marked graves are in the northern half of the cemetery, with a number of additional graves in the southwest quadrant. The thin soils of the southeast quadrant, in contrast, are very sparsely used even today (see Figure 1.2). Although chalk is a relatively soft rock, it is not surprising that most of the older, hand-dug graves are situated in the northeast quadrant of the cemetery, where relatively thick alluvium is present.

Second, as will be discussed later, the character of the soils had a significant influence on the visibility of grave shafts. The project area is part of the Texas Blackland Prairie, and Austin Chalk commonly weathers to a thick black clay. At Roberts Cemetery, however, soils mapped on the upland include Stephen and Eddy series
(USDA, NRCS n.d.), which are much thinner than the typical soils of the Blackland Prairie, probably as a result of ongoing sheet erosion. Field observations confirm that depth to bedrock in the upland part of the cemetery is typically a foot or less, with bedrock exposed occasionally on the steeper slopes. The alluvial terraces, in contrast, represent deposits of several different ages, and support heterogeneous soils that reflect this diverse origin. Although this diversity is not reflected in the USDA soils maps, it was clearly exposed in the wall of the scraped area. The character of these soils, and their influence on the survey, is discussed in more detail below.

\section{PROJECT HISTORY}

The project was undertaken to evaluate whether the planned improvements to Interstate Highway 35 would affect the cemetery, and to minimize and mitigate those effects. Although the improvements did not require additional right of way along the cemetery boundary, it was clear at the outset that one or more previous road expansions in the twentieth century encroached upon part of the original cemetery property. Since the impacted area was under the Interstate Highway 35 frontage road, where a concrete-lined ditch and apron flanked a thick fill section, these impacts could not be investigated until construction began. Therefore, the work was done in two phases. PAI conducted the initial investigation in 2008 (Hatfield et al. 2009). TxDOT and PAI conducted the second phase in 2012.

The 2008 investigation was designed to determine if burials were present inside the cemetery close to the eastern property boundary line. Because the right of way was covered with concrete or had buried utilities, the mechanical excavations focused on the portion of the cemetery adjacent to the west edge of the right of way. The idea was that if any unmarked graves were found in this area, it would increase the likelihood that unmarked graves probably existed in the adjacent state-owned right of way. This work included backhoe trenching and discovered one unmarked grave (containing remains of an infant burial), so when construction was initiated a few years later, an extensive mechanical search was conducted to find any burials remaining in the right of way. Five more burials were 
identified in this 2012 TxDOT survey, and the project was expanded to include the excavation and removal of four of the burials. The four exhumed burials were completely or partially inside the Interstate Highway 35 right of way. The other two were not disinterred because they were entirely outside the right of way.

All four of the unmarked graves that were excavated had been covered by the concrete apron along the west side of the southbound access road of Interstate Highway 35. By the end of September 2012, these four had been handexcavated and removed. The burial remains from these four graves, including the casket hardware, human remains, and personal items interred, were analyzed and identified as accurately as possible. The evidence was examined to infer the approximate burial dates and the age, sex, and health characteristics of the deceased.

This project also includes archival research that Austin historian Terri Myers (Preservation Central, Inc.) conducted to aid in the identification of the recovered remains. To accomplish this goal, Myers researched the history of the Roberts Cemetery property. She also examined the Vital Statistics for Bell County, noting people who lived in Troy and died during the period from 1903 (when filing of death certificates became routine) to 1940 (the probable latest date when any of the four exhumed burials occurred). This work identified 75 death certificates for people who lived in Troy or were buried in Roberts Cemetery. These names were compared with burial lists published online for Roberts Cemetery (Duke 2004) and three other cemeteries nearby: Old Troy (Find a Grave 2013; Todd and Todd 2006), Shiloh (includes LewAllen; Entrop 2013, transcribed from Bell County Historical Survey Committee n.d.), and Pleasant View (Badovinac 2001, transcribed from Bell County Historical Survey Committee n.d.). By this process, Myers identified eight people whose death certificates indicate that they were buried in Roberts Cemetery but whose names do not appear in the Roberts Cemetery burial list. In addition, this comparison identified 29 people who were from Troy and may have been buried in Roberts Cemetery, but whose death certificates do not indicate their place of burial. This suggests that there may be up to 37 burials (8 definite; 29 possible) that occurred during the 1903-1940 period that are now in unmarked graves.
Prior to the search for unmarked graves and throughout the excavation and analysis phase, TxDOT coordinated the effort with the Roberts Cemetery Association. Once burials were found, TxDOT attempted to identify the individuals and involve family members in the process. Under the leadership of Waco Public Information Officer Ken Roberts (no relation), television and print media were used to inform the public that the project was occurring and to solicit contact from individuals who believed that their ancestors might be affected. Nine individuals came forward as a result of this process. Of these individuals, three represented families searching for male ancestors whose physical descriptions broadly matched the characteristics of the human remains from one excavated burial (Burial 2), while the other six people were searching for female ancestors that clearly were not represented in any of the excavated burials. DNA testing was then conducted on teeth and long bone segments from each of the four burials, but only one (Burial 2) yielded a usable DNA profile. DNA was extracted from five descendant candidates from three families, and their profiles were compared with the DNA profile of Burial 2.

From the outset, TxDOT and the Roberts Cemetery Association agreed that any burials exhumed from the state-owned right of way would be reinterred at Roberts Cemetery. The burial remains from the four excavated unmarked graves were reinterred in a new location in Roberts Cemetery during a ceremony on March 26, 2013. ${ }^{1}$

\footnotetext{
${ }^{1}$ The burials that occurred within the TxDOT right of way are considered part of Roberts Cemetery as indicated by historic maps and property records research. No permission from plot owners or descendants was required for the exhumation of these unmarked graves or the relocation of the burials to a new location within the cemetery. In addition, a Disinterment Permit issued by the Texas Department of State Health Services was not required in this situation. The pertinent points, as defined in the state's Health and Safety Code (HSC) and the Texas Administrative Code (TAC), are:
}

(1) Cemeteries include all areas where one or more human burials occur, and a cemetery does not have to be formally dedicated in deed records or marked (HSC, Title 8, Section 711.035(g)(1)).

(2) Prior notification of plot owners, descendants, or other relations in advance of relocation of burials is not necessary if the relocation will occur from one plot to another within the same cemetery (HSC, Title 8 , Section 711.004(e)(1)). 
This report presents the results of the 2012 second phase of investigations at Roberts Cemetery. Chapter 2 offers a description of the methods, geoarcheological observations, and results of the mechanical search for unmarked graves and the burial excavations. Chapter 3 describes the excavation and details of the four unmarked graves discovered in the right of way, including the human skeletal remains, the burial containers and mortuary hardware, and the personal items (e.g., clothing items and jewelry) interred with each individual. Chapter 4 provides a detailed discussion of the mortuary hardware. Chapter 5 summarizes the osteological analysis of the human remains and presents comparative mortuary and morbidity data for the late-nineteenth and twentieth centuries to provide a historical context for the four exhumed burials. Chapter 6 presents the archival research conducted to trace the history of Roberts Cemetery through time using deed records and historic maps. It also describes Myers' search for and examination of death certificates in an attempt to identify who was buried in the un-

(3) The relocation of burials from the TxDOT right of way to the portion of Roberts cemetery beyond the right of way is consistent with all the provisions of Health and Safety Code pertaining to Removal of Remains (HSC, Title 8, Section 711.004).

(4) Relocation of burials within a cemetery does not require a permit from the State Registrar (Vital Statistics Unit, Texas Department of State Health Services) as stipulated in the Texas Administrative Code (TAC, Title 25, Part 1, Section 181.6(d)). marked graves. Chapter 7 describes the outreach efforts to potential family members and the DNA testing of remains. Chapter 8 provides a summary of the project findings, a description of the ceremony for the reinterment of the burials at Roberts Cemetery, and concluding remarks.

There are six appendixes in this report. Appendix A consists of the tabulated data for the mortuary hardware analysis. Appendix B presents the tabulated osteological data. Appendix C provides lists of people, derived from the death certificate research, who are or may be buried in the unmarked graves at Roberts Cemetery. Appendix D presents a complete chronological listing of 633 known burials (marked graves) in Roberts Cemetery, based on the burial inventory compiled by Duke (2004). Appendix E consists of the official laboratory reports presenting the results of the DNA tests. And finally, Appendix F is the "Agreement to Reinter Unmarked Burials" that was signed by a TxDOT representative and board members of the Roberts Cemetery Association. 


\section{METHODS OF INVESTIGATION, WORK ACCOMPLISHED, AND GEOARCHEOLOGICAL OBSERVATIONS}

Jennifer K. McWilliams, James T. Abbott, Catrina Banks Whitley, and Douglas K. Boyd

This chapter summarizes the methods and results of archeological field investigations conducted at Roberts Cemetery by Prewitt and Associates, Inc. (PAI) in 2008 and by the Texas Department of Transportation (TxDOT) and PAI in $2012 .{ }^{2}$ The work included mechanical scraping to search for grave shafts, the discovery of five unmarked graves, and the subsequent excavation of four of those graves located wholly or partially within the state-owned right of way.

\section{METHODS OF BURIAL PROSPECTION}

Prospection for unmarked graves in the frontage of Roberts Cemetery was conducted in several stages by a succession of archeologists from PAI and TxDOT's Environmental Affairs Division. The prospection strategy employed at Roberts Cemetery was based on scraping. Although remote sensing methodologies (e.g., ground-penetrating radar, magnetometry) have the potential to identify graves noninvasively, the only foolproof method is to excavate, and the only practical option for an area of any size is to use machinery. To be effective, machine excavation should employ an excavator that can peel the soil off carefully in a series of thin cuts, allowing the archeologist to observe large swaths of the cut surface. Because soils are typically horizonated (i.e., subdivided by soil processes into subhorizontal zones of differing color and texture) and an excavated grave shaft penetrates through these layers, grave shaft fills usually look different than the natural soil because spoil from the different horizons is

\footnotetext{
2 The TxDOT project is CSJ Nos. 0015-02-048 and 0015-04-067.
}

mixed in the refilled shaft. This distinction can be subtle, so it is important that the machine provide a wide, smooth, controlled cut. It is also important that the surface be disturbed as little as possible following the cut. For example, although a bulldozer has a wide, smooth-edged blade, it is not a practical machine for prospection because the cut surface is immediately rolled over and torn up by the treads, and any artifacts exposed on the surface are subject to disturbance and crushing. A rubber-tired vehicle like a road grader (maintainer) or belly loader can sometimes be employed to good effect, particularly when the search area is very large, but TxDOT's Archeology Branch generally prefers to use backhoes and excavators, which are able to reach out and peel sediment from a surface without then immediately driving over it.

In our experience, the effectiveness of a backhoe is highly dependent on the skill of the operator and the condition of the equipment. Because a backhoe is essentially an arm rotating relative to an adjustable pivot point, it naturally produces a curved cut. Scraping a level surface with a backhoe requires the operator to continually adjust the height of the arm and the angle of the bucket as a cut is made. If the operator is not highly skilled, if the sediment is hard, or if the hydraulic controls are not precise (as often happens with aged or poorly maintained equipment), trying to consistently peel thin, level cuts off a surface can be an exercise in frustration. Although TxDOT archeologists often have to work with what is available, and many areas are simply not accessible for equipment larger than a backhoe, most prefer a telescoping hydraulic excavator, which is tailor-made for making smooth, level cuts. There are sev- 
eral manufacturers of these machines, but they are commonly referred to by the trade name "Gradall ${ }^{\circledR}$ ". In addition to the style of the cut, telescoping excavators typically have a bucket five or six feet wide (the buckets of the relatively small backhoes used by TxDOT rarely exceed three feet) and are able to facilitate work that is quicker and more precise.

With the proper conditions and equipment, it is often possible to identify a grave shaft well above a body, so that the remains can be exposed entirely by hand. In some cases, however, soil conditions make it impossible to identify the shaft, and a burial can only be identified by exposure of the remains or the associated coffin (e.g., Hill and Pye 2012). Despite the common belief that historic graves are six feet deep, they can actually be excavated deeper or considerably shallower, depending on several factors. Moreover, post-burial alterations to the landscape (e.g., erosion, mechanical filling) can dramatically affect the depth of burial. During the initial work at Roberts Cemetery, Texas Historical Commission (THC) archeologists Jim Bruseth and Mark Denton stressed that assumptions should not be made about the depth of burial, and that grave shafts would not necessarily be identifiable. Accordingly, scraping on the project was designed to continue until grave shafts were identified or bedrock was encountered. This proved to be an important decision, because several of the bodies in the unmarked graves were discovered resting on bedrock, with no indication of burial shafts being observed in the overlying sediments.

\section{METHODS OF BURIAL EXCAVATION AND ANALYSIS}

PAI personnel, along with osteologist Dr. Catrina Whitley, excavated the four unmarked graves from the state-owned right of way at Roberts Cemetery in August and September 2012. Three of the four graves were excavated in multiple stages due primarily to delay in removing overburden adjacent to the AT\&T line that crossed over these graves. Documentation consisted of field notes, burial maps, photographs, and burial inventory forms. Burial inventory records were filled out sporadically due to the interruptions in the excavation schedule, but field notes were recorded, and photographs were taken regularly.
Mapping was done by TxDOT personnel after excavations were completed. TxDOT and PAI archeologist set nails in corners of grave stains or along edges of disturbed burials for horizontal control. For vertical control, elevation nails were placed near each grave by TxDOT and tied into PAI burial maps.

The burials were excavated following the protocols set by Tíne and Boyd (2003). Human remains, casket hardware, and personal items were collected by area (denoted as A, B, C, D, and $\mathrm{E}$ ), corresponding to different parts of the rectangular grave shaft. This method allowed items that were not found in situ to be assigned to specific areas within the burial. These zones assume that the body is lying on its back in a supine position, which is generally the case for historic Christian burials. Area A is the head of the grave, including everything above the shoulder blades. Area B is the left side of the upper body from the midline of the vertebral column to the left and from the top of the shoulder (left clavicle) down to the waist (includes left humerus). Area $\mathrm{C}$ is the right side of the upper body (a mirror image of Area B). Area D is the lower left half of the body, from the midline of the pelvis to the left and from the waist down to the distal end of the grave (including the left leg, foot, and forearm). Area $\mathrm{E}$ is the lower right half of the body (a mirror image of Area D). After all the burial elements were mapped, the skeletal elements were wrapped and collected individually. All of the skeletal elements, personal items, and casket hardware from each burial were placed in a box for transport, and the remains were taken to the PAI laboratory for analysis.

Mapping was done by TxDOT personnel after all the mechanical stripping and burial excavations were completed. TxDOT and PAI archeologist set nails in corners of grave stains or along edges of disturbed burials. Elevation nails were placed by TxDOT and tied into PAI burial maps.

Physical anthropologist Catrina Whitley conducted the osteological analysis of the four skeletons in the PAI laboratory October 1-2, 2012. Jennifer McWilliams created an inventory of mortuary hardware and personal items in the PAI laboratory and photographed the mortuary hardware, personal items, and bone pathologies identified by Dr. Whitley. Tabulated data and photographs of mortuary hardware were sent to Jeremy Pye, a mortuary hardware specialist 
who analyzed the diagnostic casket hardware in January 2013.

\section{Analysis of Casket Hardware and Personal Items}

Casket hardware was inventoried and measured, and within each hardware category, individual styles were assigned a type number. The identification of the diagnostic casket hardware (e.g., outer box and casket handles, thumbscrews and escutcheons, and lid latching mechanisms) was accomplished by comparing the styles and markings with mortuary hardware catalogs and data published in archeological reports on historic cemetery excavations. The analysis and identification of the burial container hardware was conducted by consultant Jeremy Pye, and the results of this intensive analysis are described in Chapter 4, with tabulated data in Appendix A.

McWilliams analyzed the nails and wood screws to reveal information about the construction of the burial containers. Nails were measured and sorted by type, and the groups were assigned descriptive names rather than type numbers. Nail attributes observed included head diameter and shank thickness. McWilliams also analyzed the personal items, which varied significantly from burial to burial. These included items like buttons, cuff links, a coat collar spring, safety pins, and remnants of fabric and floral displays. Detailed descriptions (including measurements) and identifications of these personal items are presented within each burial description in Chapter 2. When possible, personal items were linked to historical advertisements or patent dates to provide relative chronological information on the age of the interments.

\section{Osteological Analysis of Human Remains}

The analysis of the skeletal remains by Whitley followed the standardized protocols and recommendations in Buikstra and Ubelaker (1994). The osteological analysis involved data collection using standardized forms to document the condition of each skeletal element, age estimates, sex assessment, ancestry, cranial and postcranial metrics, pathology, taphonomy, dental pathology, dental nonmetric traits, and cranial and postcranial nonmetric traits. No dental metrics were taken. Photographs of skeletal elements exhibiting pathology or anomalies were taken in the laboratory. A complete description of each set of excavated skeletal remains is presented in Chapter 3, and the detailed osteological data for these burials are presented in Appendix B. The specific methodological details for osteological observations and assessments of sex and age, biological affinity, pathology, entheseal changes, dentition, and stature are discussed in Chapter 5.

With only four individuals-a child and three adult males - the burial population excavated from Roberts Cemetery is too small to be representative of the entire cemetery population. No detailed interpretations of demographics, health and mortality risks, mortuary trends, or socioeconomic status can be drawn from this small sample. In Chapter 5, however, Whitley does offer some general observations on individual health conditions and comparisons with other historic cemetery evidence. She also presents some late nineteenth- and twentiethcentury health and mortality data for Troy, Bell County, and Texas to provide a historic contextual framework for understanding the individuals whose remains were found in the unmarked graves at Roberts Cemetery.

\section{THE 2008 GRAVE SEARCH}

The 2008 investigations at Roberts Cemetery conducted by PAI are reported in detail in Hatfield et al. (2009) and are only summarized here. On September 22, 2008, PAI archaeologist Jennifer McWilliams inspected the cemetery in the vicinity of TxDOT's right of way and assessed access for mechanical trenching. No headstones were present in this portion of the cemetery, but many headstones were found west of a large bur oak close to the highway right of way. McWilliams met with Wayne Randolph, caretaker of the cemetery, who provided a handdrawn map ${ }^{3}$ of grave plots showing graves within $15-20 \mathrm{ft}$ of the TxDOT right of way (Hatfield et al. 2009).

\footnotetext{
3 The origin and date of this map are unknown, and it should not be considered historically accurate, nor is it a complete inventory of all the burials. It is likely that this map was initially created sometime after the 1930s as an inventory of grave markers and that additional interments were subsequently added as they occurred. This map does not show any of the six unmarked graves identified by archeologists in 2008 and 2012.
} 
Numerous disturbances were noted in the TxDOT right of way at that time. A massive concrete apron covered the road cut, the drainage ditch, and the slope up to the Interstate Highway 35 southbound frontage road, which was on top of a thick fill section and was nearly a meter and a half higher than the presumed natural terrace surface of the adjacent cemetery (Figure 2.1). Additionally, a buried AT\&T cable ran along the west side of the concrete apron. Consequently, prospection for graves in the right of way was precluded until the road was closed and the concrete apron and fill section were removed.

To better assess the potential for graves to occur in the right of way, PAI personnel returned to Roberts Cemetery a few months later to conduct mechanical trenching just inside the cemetery boundary. This survey, which was complicated by the presence of large trees and buried utilities, was conducted between November 12 and 17, 2008 (Hatfield et al. 2009). Because no graves were known in that area, it was reasoned that their presence would dramatically increase the likelihood that other graves were in the right of way. To prevent damage to the adjacent AT\&T cable, all trenching conducted was at least $1 \mathrm{~m}$ inside the property line.

Five trenches were excavated. No graves were present in the upland areas, but an unmarked grave was encountered in the far north end of Trench 1A, which traversed the stream terrace in the northeast corner of the cemetery. No grave shaft was observed, but bone was encountered $4.1 \mathrm{ft}$ below the surface. Hand excavation exposed the southern portion of the skeleton of a young child within an $8 \times 16$-inch area, but the burial continued into the north wall of the trench. This unmarked grave was located completely within the Roberts Cemetery, just a few feet from the TxDOT right of way. ${ }^{4}$ Artifacts associated with the burial included deteriorated casket wood fragments, a few small iron nails, and small bones, including skull fragments, a humerus, and other postcranial elements. These materials were returned to the grave, and the trench was backfilled. This child's burial was

\footnotetext{
4 It is probable that a second burial was clipped by Trench 1A in 2008, but no evidence of this grave was observed at that time. The 2012 investigations discovered that the 2008 trench excavation had impacted the skull and head end of the burial. This grave, designated as Burial 2, was excavated in 2012.
}

not assigned a feature or burial number at that time. ${ }^{5}$

Given that the historical evidence indicated that Interstate 35 (and possibly its predecessor, Highway 81) had been built over the eastern portion of Robert Cemetery property (Hatfield et al. 2009:8), and that at least one unmarked grave was present, Hatfield et al. concluded that it was "possible, and perhaps even likely, that unmarked graves are present underneath the concrete-lined ditch and apron, the frontage road, and even the main traffic lanes of IH-35" (Hatfield et al.2009:13-14). They recommended additional mechanical stripping to search for graves under the concrete-lined ditch, apron, frontage road, and the main traffic lanes of Interstate Highway 35 in advance of construction improvements (Hatfield et al. 2009:23).

Accordingly, TxDOT staff archeologist John Arnn and TxDOT's Waco District Environmental Coordinator Michael Rhodes developed an Environmental Permits, Issues, and Commitments (EPIC) document for the project that allowed it to be cleared for NEPA and released for letting (bidding and award). An EPIC is a mechanism TxDOT uses to incorporate environmental requirements into construction plans so that compliance commitments can be tracked and implemented during construction. The EPIC was inserted into the project construction plans in May 2010.

\section{THE 2012 SURVEY}

In mid-August of 2012, pursuant to the requirements of the EPIC, the construction contractor notified TxDOT staff archeologist John Arnn that construction was imminent at the cemetery. Arnn conducted an initial field visit, during which he observed the removal of portions of the concrete ditch liner and riprap by the highway contractor. Scott Pletka, supervisor of the Archeological Studies Branch of the Environmental Affairs Division, asked staff archeologist Jon Budd to survey the right of way and evaluate the amount of work necessary. On Wednesday, August 22, Budd and staff geoarcheologist Jim Abbott returned to Roberts Cemetery and initiated scraping of the TxDOT frontage between the northern access drive and the northeast corner of the cemetery,

\footnotetext{
TxDOT designated the child's grave as Feature 1 during the 2012 grave search.
} 


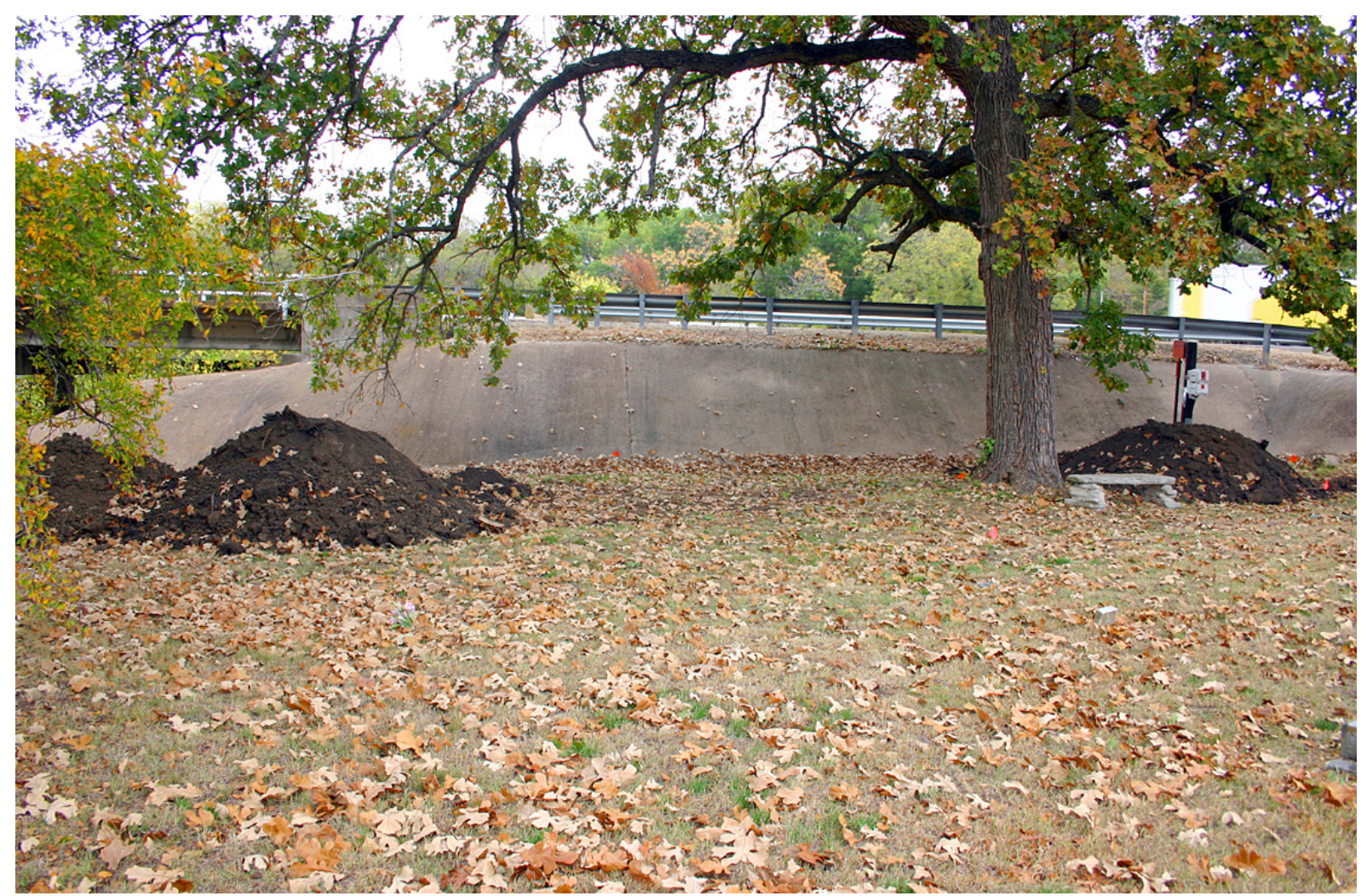

Figure 2.1. Photo looking east from the cemetery toward the TxDOT right of way. A corner of a footstone representing one of the marked graves closest to the property line is visible in the lower right of the photograph.

adjacent to PAI's Trench 1A. This initial phase of work, designed to determine whether human remains were present in the highway right of way, was performed in accordance with TxDOT's Memorandum of Understanding with the Texas Historical Commission for cultural resources compliance required by state and federal laws.

The initial field session was somewhat stressful for all concerned. When Budd and Abbott arrived at the site, they found that the frontage road surface had been removed, and nearly a meter of fill had already been removed from portions of the right of way. However, no natural deposits had yet been affected. Although Budd and Abbott had been told by their supervisor that they were empowered to direct the work, the construction company supervisor overseeing work on that part of the project was of the opinion that the archeologists were simply authorized to be passive observers, and he repeatedly showed up to give contradictory orders to the machine operator concerning the location, character, and speed of excavation. The archeologists, for their part, quickly escalated the question to Michael Rhodes at the Waco District, who contacted TxDOT project engineer Clayton Zacha. Zacha and Rhodes ultimately convinced the James Construction supervisor that the TxDOT archeologists had the authority to direct the work.

The work along the property line was also complicated by the presence of a large buried telephone cable and by the large trackhoe provided by the highway contractor, which did not fit well beneath the mature oak along the property line (Figure 2.2). This trackhoe was initially fitted with a 3 -ft-wide toothed bucket. Given the jurisdictional disagreement going on at the time, Budd and Abbott initially allowed the toothed bucket to be used to remove the remainder of the riprap and scrape the first few feet off the surface, but they quickly halted the scraping when a sharply bounded zone of discolored soil consistent with a grave shaft was noted about a meter below the surface (Figure 2.3). Work with the toothed bucket was suspended at the archeologists' insistence. This ultimately proved to be an unmarked grave (Burial 1). 


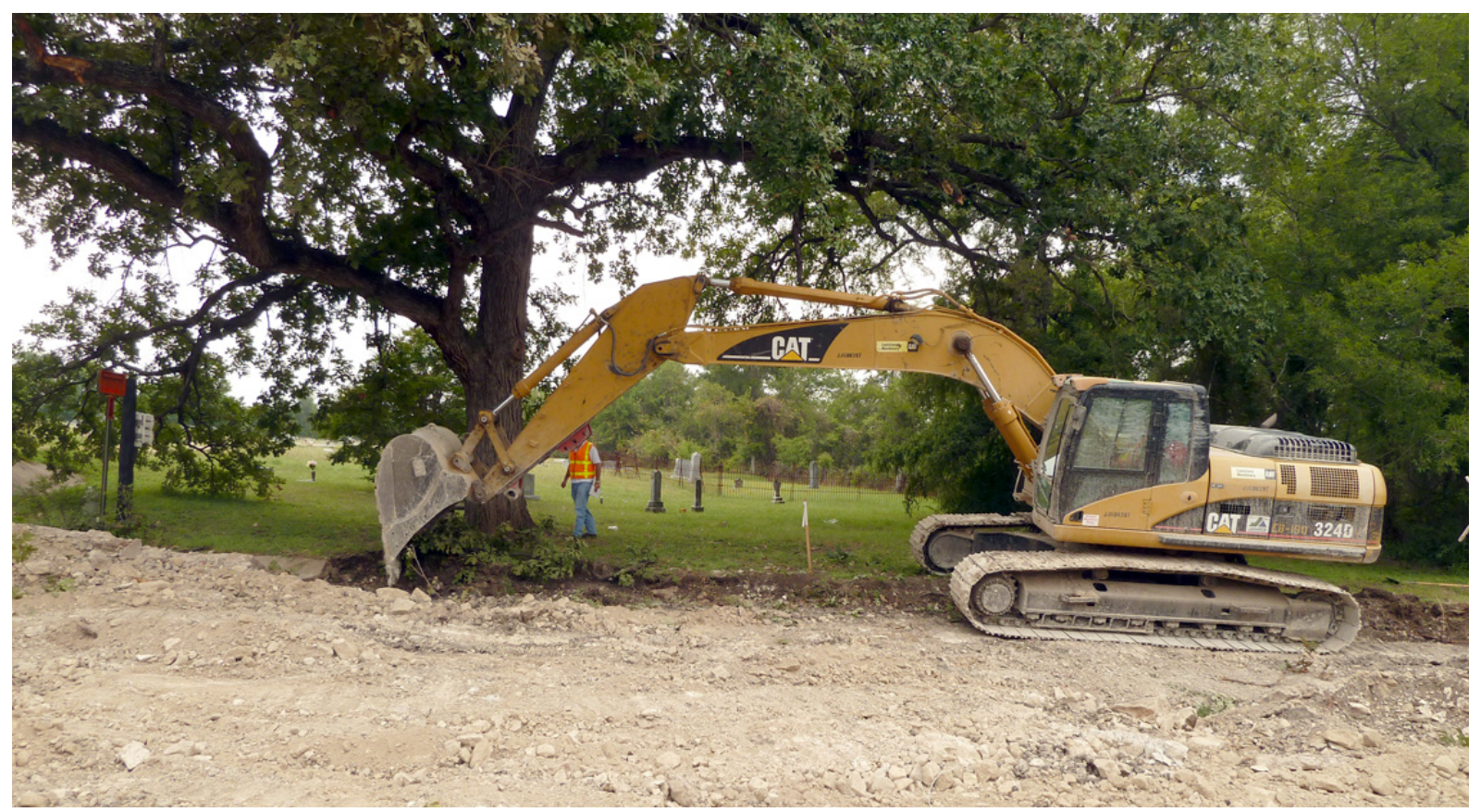

Figure 2.2. Initial stages of scraping using a trackhoe, looking west toward the cemetery.

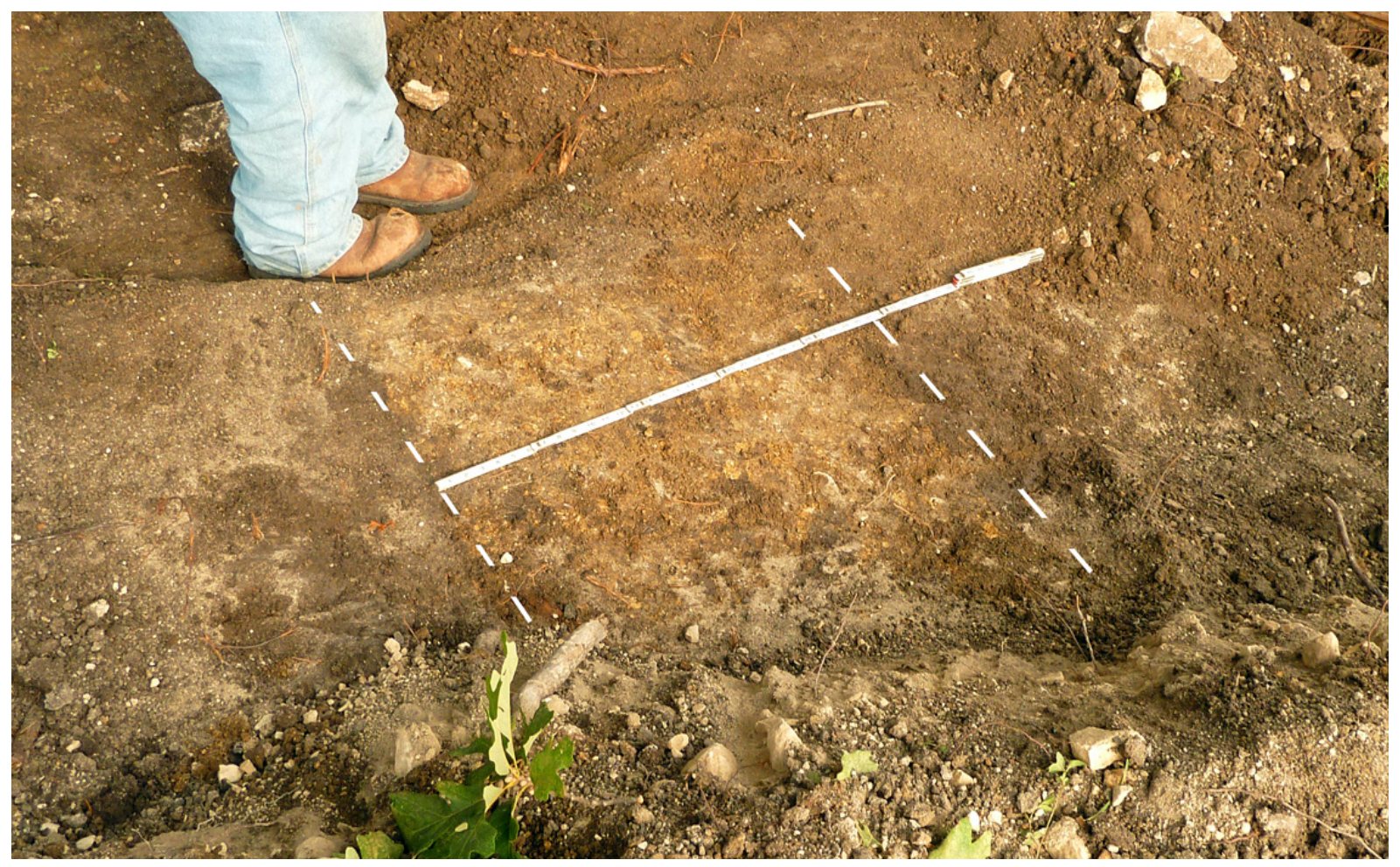

Figure 2.3. Initial view of the shaft of what was later identified as Burial 1.

To accommodate the request for a smoothbladed bucket, the highway contractor welded a steel plate across the teeth of the trackhoe to provide for a smooth cut. Although this dramati- cally improved the process, the plate was several inches shorter than the teeth. Because it was welded flush with the end of the teeth, gaps were left between the bucket and the plate that 
allowed some sediment to escape and partially obscure the fresh cut. The plate also broke off with initial use and had to be rewelded, further delaying the process. Nevertheless, the modified equipment provided a relatively smooth cut that gave the archeologists a reasonable opportunity to observe any grave shafts that might be exposed, and trenching resumed.

It was well past midday before the plate was welded to the teeth, and the latter part of the day was spent scraping from the oak tree north along the property line. The probable grave shaft was flagged and avoided. In areas where no indications of a grave shaft were seen, scraping continued to bedrock. The bedrock consisted of a relatively level shelf of limestone/chalk that was encountered at a depth of approximately 1.4-1.6 m below the ground surface. Near the northern boundary of the cemetery, Budd noted bone in the corner of the last scrape on the bedrock. This bone was examined and was determined to be the lower extremities of a human burial (Burial 2) extending less than a meter beyond (east of) the cemetery boundary and resting directly on the bedrock. ${ }^{6}$ The backdirt from the scrape was examined carefully, and all bone was placed back in the approximate location where it was encountered, covered with plastic, and reburied with loose sediment. Although it was not known at the time, this activity also impacted the third burial (Burial 3), a portion of which was later found, still fully articulated, in the sediment block placed to protect Burial 2. Although the profile above the known burial was hand-scraped and examined in detail, no visual evidence of a grave shaft could be observed in the dark gray clay loam soil (see discussion below).

Scraping was then continued to the east, roughly parallel with the original trench. Because most of the material consisted of rubble fill (Figure 2.4), dirt management became increasingly complex as the depth of fill thickened. The work was also constrained by an old bridge pier and shafts for the new frontage road bridge, which had been previously poured. Near the end of the day, Budd and Abbott consulted about the best course of action. At that point, it was known that one unmarked grave (Burial 2) extended less than a meter over the property line at the northeast corner of the cemetery, and a second

\footnotetext{
$\overline{6}$ Per current TxDOT policy, no photographs of human remains will be presented in this report.
}

probable grave shaft (Burial 1) was poorly defined but appeared to be primarily inside the highway right of way. Because it was considered possible that the human remains in this latter feature might have been moved during a previous construction episode, scraping of the eastern part of the feature was continued until cemetery hardware was encountered. At that point, the feature was covered in plastic and buried with backfill to protect it.

On Friday, August 24, 2012, Abbott returned to the cemetery with TxDOT archeologists Christopher Ringstaff and Waldo Troell to continue scraping and to determine if there was a burial in the previously discovered shaft. The loose backfill placed on the feature was shoveled off, and Ringstaff and Troell hand-excavated a 1x2-m unit over the area. While they worked on exposing this feature, Abbott monitored the expansion of the scraped area to the south and east performed with a backhoe supplied by TxDOT's Waco District (Figure 2.5). Given that the fill and underlying soil was several meters thick, and that there was no effective mechanism to remove the spoil produced, scraping was a slow and laborious process.

By noon of that day, Ringstaff had established that there was indeed a burial in the shaft of Burial 1, and he had exposed the wellpreserved bones of the feet and lower legs. Once the position and condition of the burial became apparent, the decision was made to rebury the feature and mark its location for subsequent disinterment.

Although the thickness of the fill slowed the work, scraping revealed two additional features within the natural deposits, neither of which was mortuary in nature. These features were designated Features 4 and 5. (The child burial discovered during the survey in 2009 was designated Feature 1, the burial Ringstaff was working on was designated Feature 2, and the burial near the corner of the cemetery was designated Feature 3.)

Feature 4 (Figure 2.6) was exposed and documented by Troell. It consisted of a tapered, round-bottomed hole that was $27 \mathrm{~cm}$ in diameter and approximately $25 \mathrm{~cm}$ deep. The top of the feature was first observed at the bottom of the A horizon, approximately $50 \mathrm{~cm}$ below the natural ground surface. A moderate number of historic artifacts were encountered, including three fence staples, half a dozen short scraps 


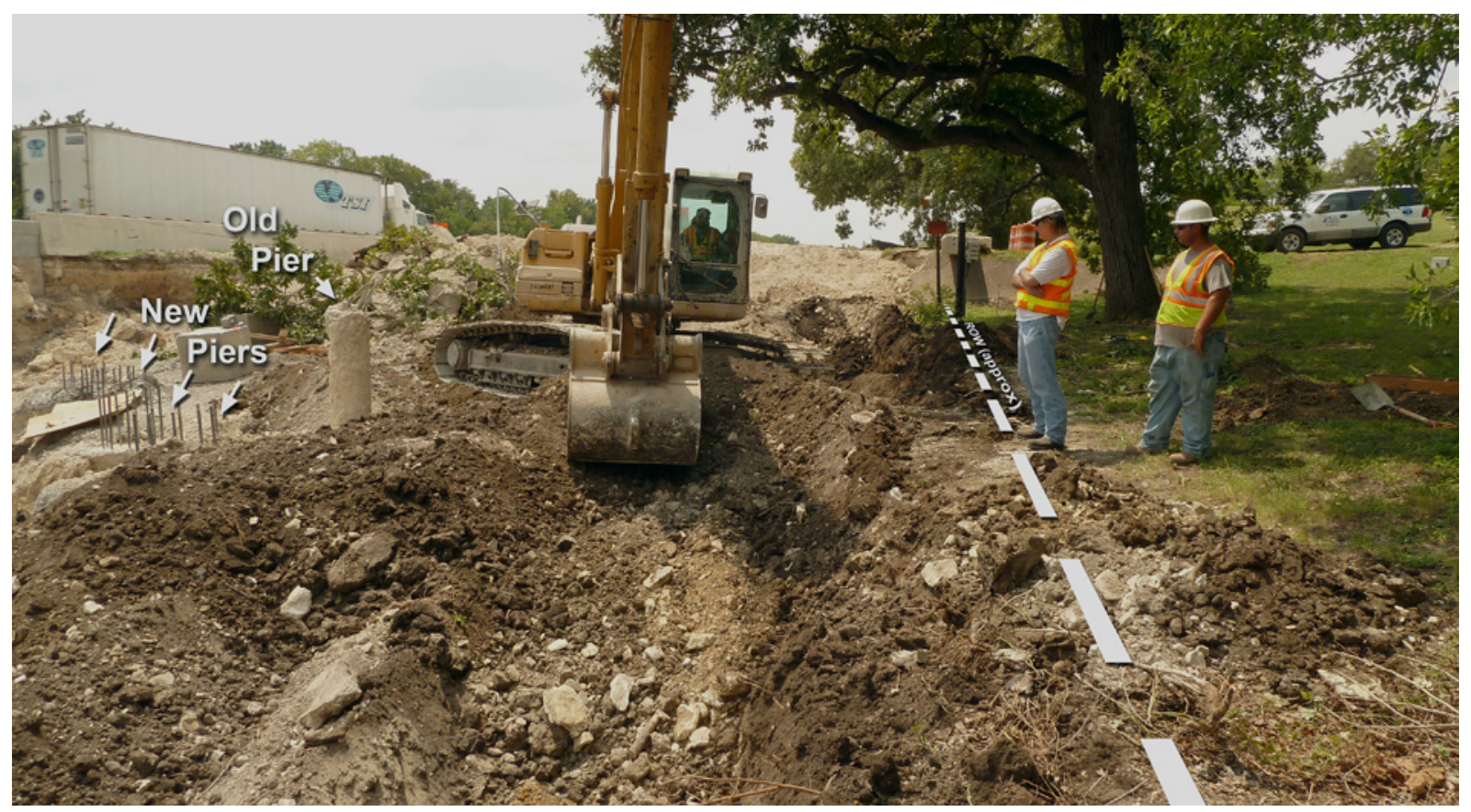

Figure 2.4. View of trenching showing the character of the rubble fill.

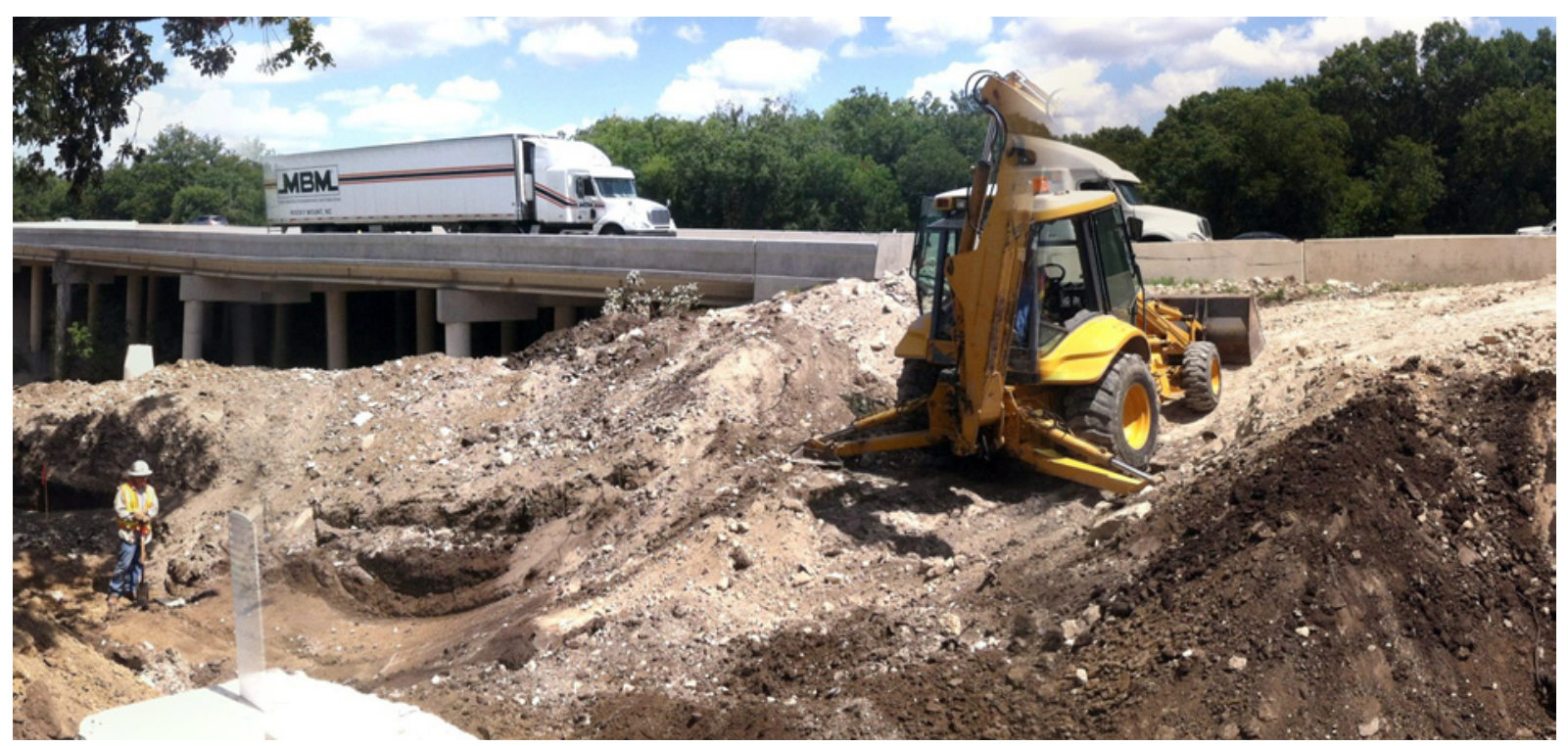

Figure 2.5. Composite panoramic photograph, looking northeast, showing the character of early-stage scraping.

of steel wire, four small sheet metal scraps, one fragment of ceramic whiteware, several large chunks of charcoal, and fragments of animal bone. These artifacts were concentrated at the top of the feature, which is interpreted as an infilled posthole. The bone was taken to the TxDOT office and examined by faunal specialist Jodi Jacobson. Working without benefit of her comparative collection, Jacobson identi- fied the bone as a fragmentary distal tibia of a large non-bovid mammal, such as a horse or an elk, and stated unequivocally that it was not human.

Feature 5 (Figure 2.7) was a vertical, cylindrical hole filled with sediment and limestone/chalk rubble. It was noted approximately $50 \mathrm{~cm}$ above the bedrock a few meters southeast of Feature 4 and was traced down vertically 

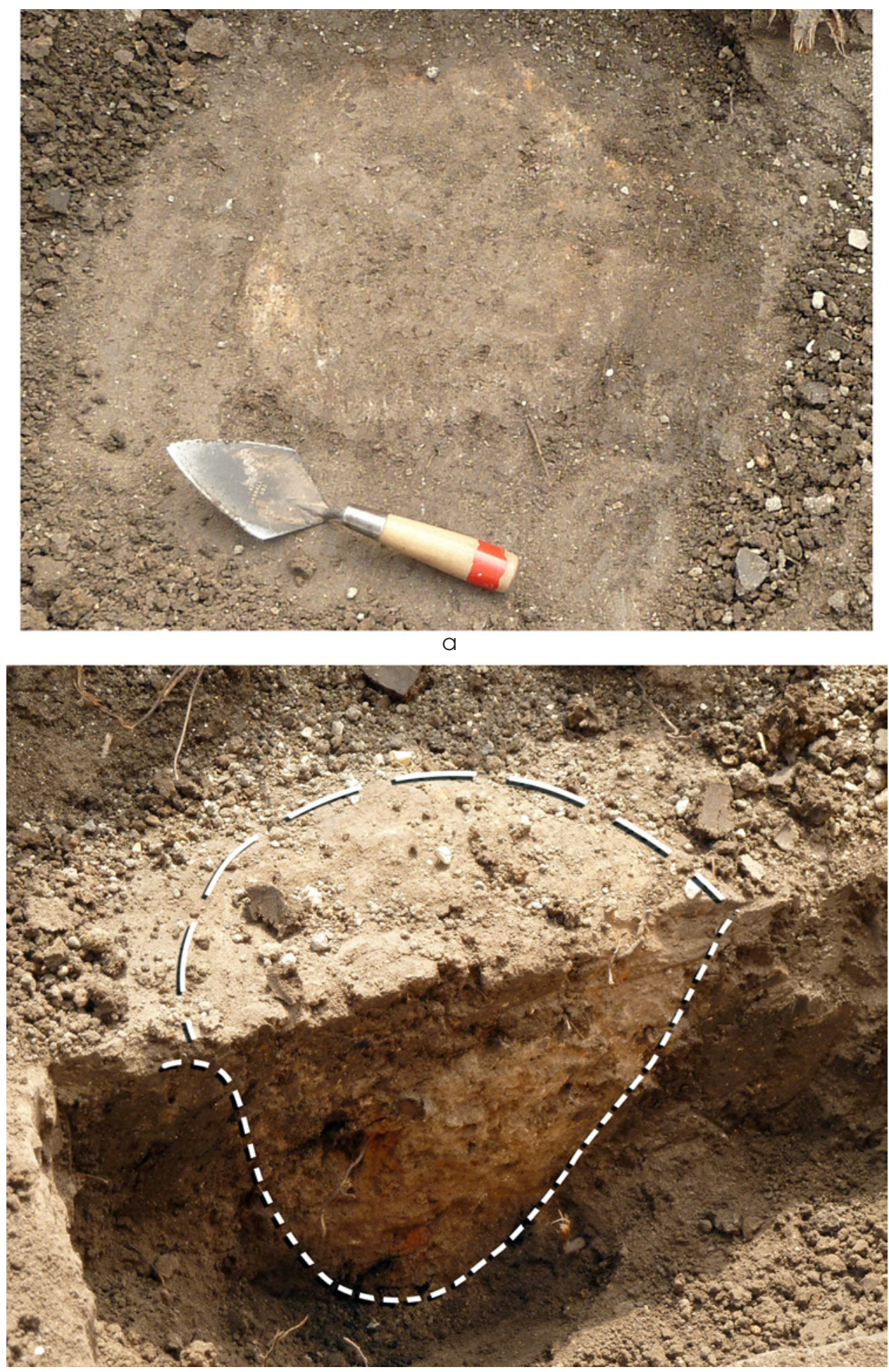

b

Figure 2.6. Two views of Feature 4, a posthole near Burial 1 .

into the bedrock. It had a consistent diameter of approximately $60 \mathrm{~cm}$ and is interpreted as an infilled geotechnical borehole associated with a previous phase of highway construction. 


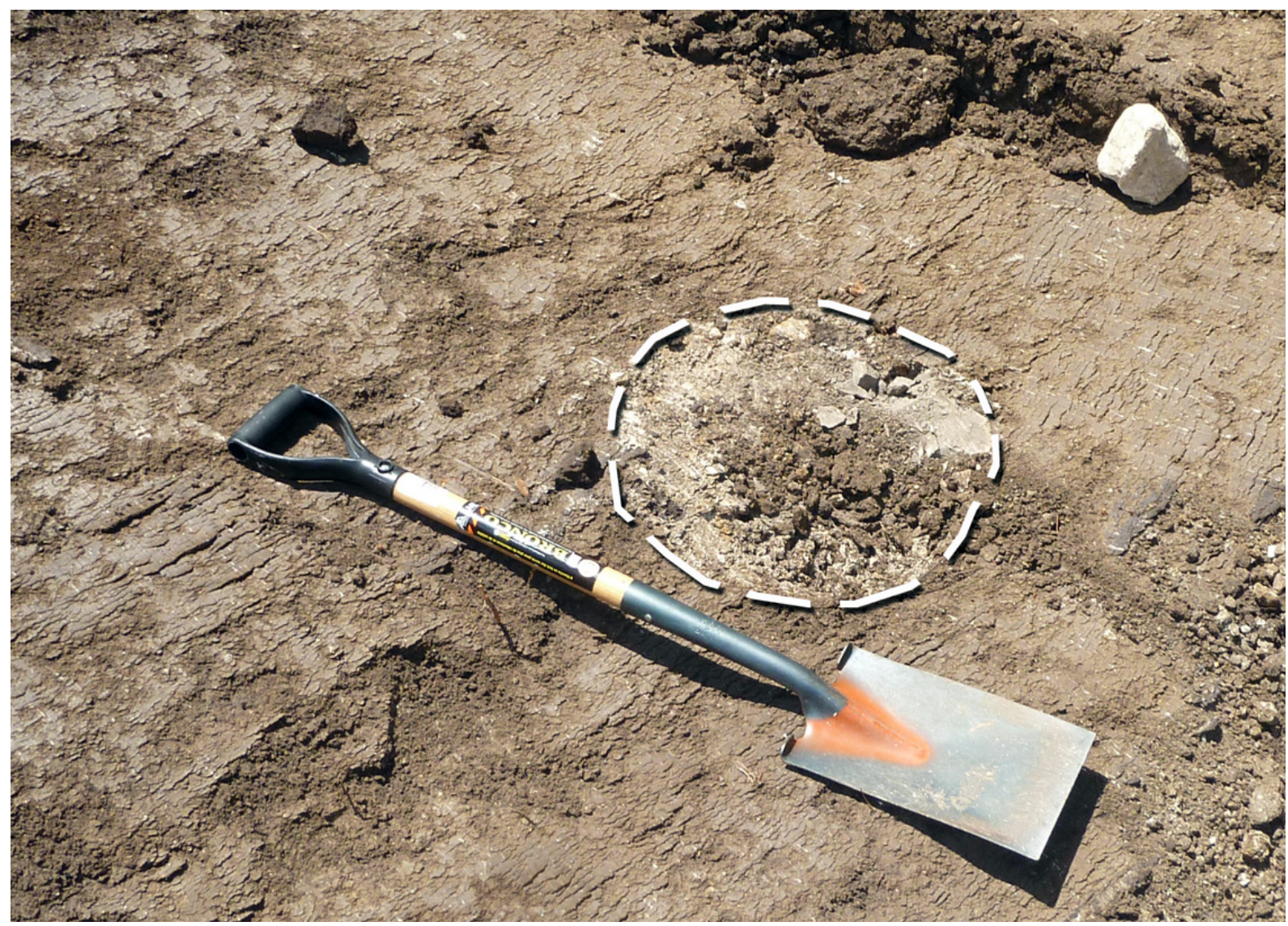

Figure 2.7. Photograph of Feature 5, a borehole near Feature 4.

At the close of the day on August 24, the following points were clear: (1) a strong potential existed for additional burials in the right of way; (2) an intensive and systematic investigation of the project area was warranted; and (3) such an investigation was impossible unless the thick fill underlying the highway frontage was removed. Accordingly, TxDOT's Archeological Studies Branch prepared a permit application to identify and exhume any unmarked graves in the Interstate Highway 35 right of way fronting Roberts Cemetery and to reinter them in the cemetery. TxDOT also negotiated a work authorization to conduct any necessary exhumations with PAI under an existing contract for archeological services. At the same time, TxDOT's Waco District negotiated a change to the contract specifying that the James Construction group would use their equipment and personnel to remove the overburden but that the Waco District office would supply a gradall, dump trucks, and operators for the mechanical grave search that would follow.
In response to the application, the Texas Historical Commission issued Texas Antiquities Permit No. 6388 on September 4, 2012. The scope of work outlined the following six points:

1. The construction contractor would strip the remaining gravelly road fill in the frontage area under monitoring by a TxDOT archeologist. This stripping would continue vertically until the buried terrace soil was encountered. The fill would then be stripped laterally from north to south. Due to the construction of the interstate highway, the original configuration of the stream terrace was poorly understood, but it was clear that the dark floodplain soil would pinch out laterally against the bedrock valley wall. Stripping would extend from just behind the existing bridge abutment headers to the point where the margins of the stream terrace were encountered. 
2. TxDOT would then carefully strip the floodplain soil to search for additional unmarked graves under the observation of an archeologist. Stripping would be conducted mechanically using a wide, smooth-bladed bucket. Any grave shafts detected would be re-covered and protected until they could be exposed, documented, and removed. Excavation of the burials would be conducted by personnel from PAI under supervision of a physical anthropologist and TxDOT's principal investigator.

3. Upon removal, the burials would be documented according to the standards used by PAI at the Pioneer Cemetery in Brazoria County. They would be stored at PAI's office in Austin until identification efforts were completed and reburial could be arranged.

4. Given that no graves were indicated in the area on cemetery association maps, it was considered unlikely that any individuals found would be identified. However, the surviving coffin hardware would be examined for temporal and economic implications, and the results of the osteological analysis would be summarized. It was anticipated that the reporting would be relatively descriptive unless the remains or grave furniture were considered to warrant more detailed treatment (e.g., evidence of ethnicity, signs of skeletal trauma, evidence of significant economic disparities).

5. Because the results would inform the next phase of work, investigation of the main lanes would be deferred until that part of the project was imminent. That work would be conducted under a modification of this permit or under a completely new permit.

6. All recovered remains and associated artifacts would be reinterred in Roberts Cemetery at the completion of the study.

Although the goal was to investigate the area under the southbound frontage road completely, it was not possible to work all the way up to the edge of the main lanes. Such an attempt would have undercut support for the active Interstate Highway 35 travel lanes, which were separated from the work area only by a concrete jersey barrier. Accordingly, based on field consultation with the project engineer, stripping of the overburden was discontinued at a point roughly equivalent to the base of the ditch between the main lanes and the frontage road. The highway fill was then beveled to a point that was more or less in line with the eastern edge of the frontage road pavement. Stripping of the natural soil was only performed between this line and edge of the cemetery, a distance of approximately $15 \mathrm{~m}$.

The week of September 4 was spent stripping and removing more than a meter of artificial overburden from a ca. 50x18-m area (Figure 2.8). This work was conducted by James Construction using a trackhoe and dump trucks under supervision of a TxDOT archeologist (Abbott).

On September 6, the PAI field crew, consisting of archeologists Jennifer McWilliams and Aaron Norment and bioarcheologist Dr. Catrina Whitley, joined Abbott in the field. At the end of the week, the artificial fill was largely removed down to the intact sediments.

During the week of September 10, a TxDOT operator and gradall replaced the construction contractor's equipment and operator, and stripping of the natural deposits was initiated. Stripping was initially concentrated at the north end of the area in the vicinity of the bridge pilings. This effort was conducted by Budd in a manner similar to the previous excavations, with scraping continued until bedrock was encountered. During this process, the edge of the bedrock strath was found in the northeast corner of the excavation, and the excavation was taken down another ca. $1 \mathrm{~m}$ (Figure 2.9).

Based on the stratigraphic exposures encountered in the project area, it was decided to systematically scrape the remaining area in three passes, removing material corresponding broadly to the three soil horizons (see Geoarcheological Observations below). Each swath, ca. $50 \mathrm{~cm}$ thick, was scraped incrementally, with the gradall moving from north to south in a hemispherical pattern (Figures 2.10 and 2.11). Stripping continued over the next three weeks and was overseen primarily by Abbott (September 12-13, 19-20, 24-26) with additional coverage by Budd (September 10-11) and Arnn (September 21). Several days were lost to rain, and the stripping effort was slowed because the excavator removed fill faster than it could be taken offsite by one or two dump trucks. 


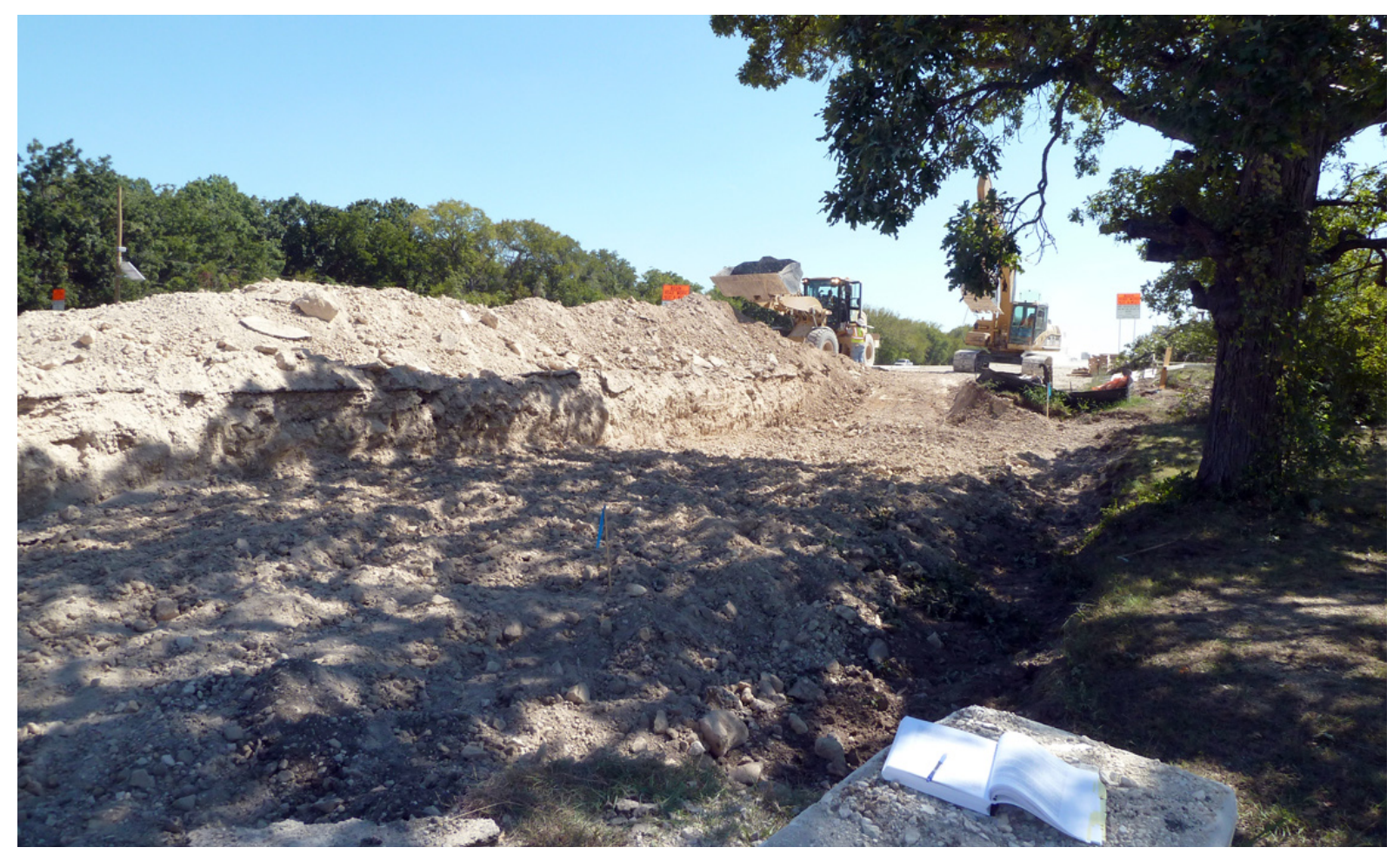

Figure 2.8. Stripping of the artificial fill from under the frontage road, looking south.

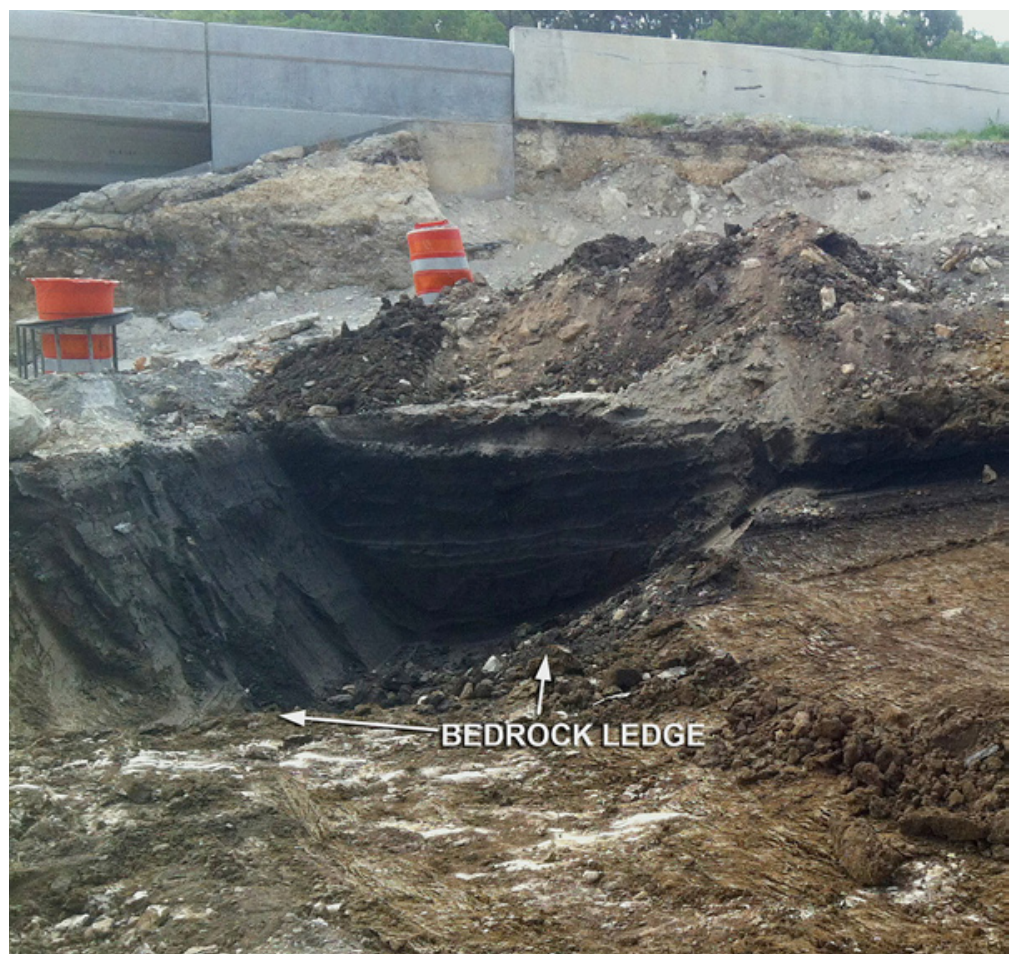

Figure 2.9. View eastward of the north end of the stripped area during early phases of systematic stripping. The far northern end has been stripped to bedrock, exposing a bedrock ledge and a deep pocket of dark clay in the northeast corner. 


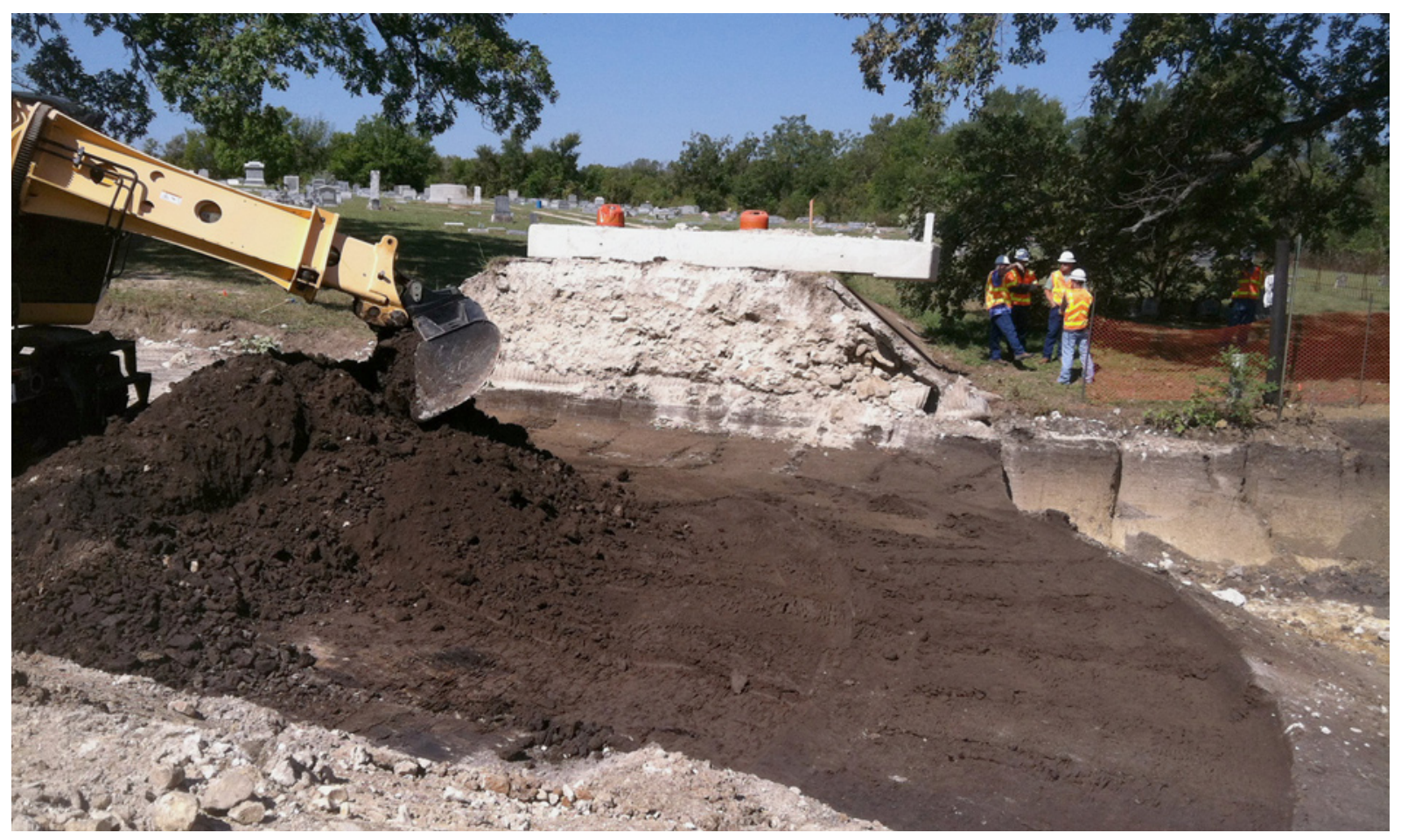

Figure 2.10. Systematic stripping of the A horizon beneath the frontage road fill section, looking west. Note the trapezoidal rubble fill section of the former cemetery entrance ramp in middle ground.

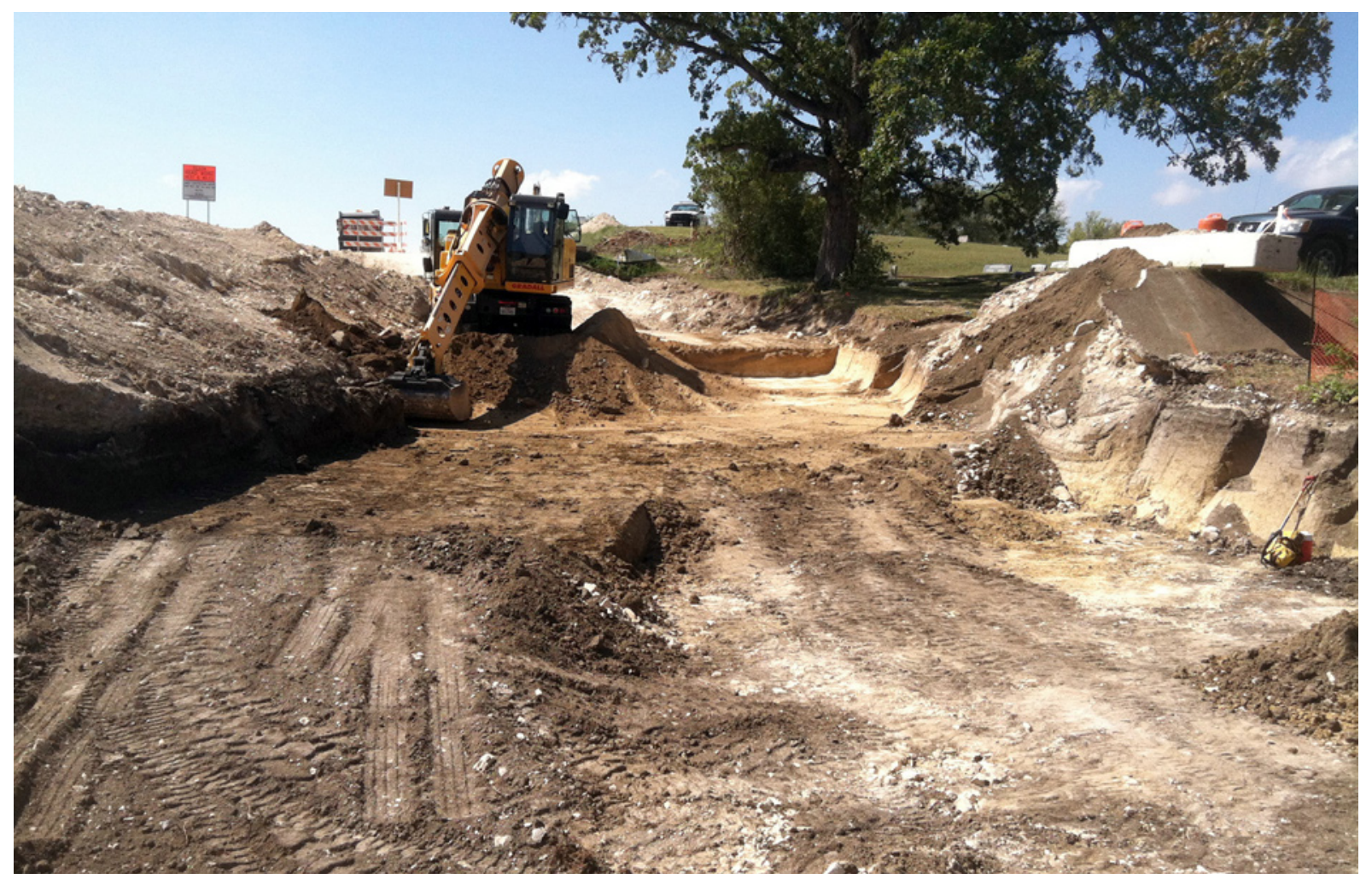

Figure 2.11. Systematic stripping of the lower B and C horizons, looking south. 
Additional mechanical stripping was conducted along the cemetery property line to facilitate removal of the known burials, each of which was crossed by the buried phone line. On September 21, McWilliams identified wood and nails indicating a possible additional burial in the wall of the excavation cut, immediately north of Burial 1. This feature was explored and proved to be the unmarked grave of a young child, designated Burial 4 (Feature 9). Like the other three burials, the buried cable cross-cut the child's grave. Norment identified the bottom of another probable burial pit southwest of Burial 3. This was designated as Burial 5 (Feature 10), but no further work was done because the unmarked grave was located entirely within the cemetery boundary.

The mechanical grave search was completed on September 26, when the stripped area reached the bedrock slope south of the terrace. Figure 2.12 shows the locations of the unmarked graves (mapped with survey-grade GPS equipment) and nonmortuary features (mapped with consumer-grade GPS locations and measured sketch maps; locations are approximate). The mechanically stripped area was approximately $957 \mathrm{~m}^{2}\left(10,300 \mathrm{ft}^{2}\right)$. The volume of fill removed is difficult to estimate precisely given that no detailed topographic mapping was done prior to stripping, but it is estimated at between 2,500 and 3,500 cubic yards, with roughly half of that figure representing intact soils and half representing overlying construction fill and road base.

At the completion of the mechanical stripping, the effort had discovered five additional unmarked graves (bringing the total number to six) and four nonmortuary features. Table 2.1 lists all the features that were discovered by TxDOT archeologists. Table 2.2 summarizes the sequence of events in the discovery and excavation of each of the unmarked graves investigated at Roberts Cemetery in 2008 and 2012. Although a few fragments of glass and metal were noted near the interface between the fill and the natural soil, and one fragment of prehistoric chipped stone debitage was noted (but not collected) during scraping, the only two relevant artifacts were discovered in a nonmortuary context: a galvanized guy-wire anchor approximately $3 \mathrm{~m}$ west of-and presumably associated with-Feature 8 , and a small section of unreinforced concrete curbing of the type that frequently surrounds cemetery plots. The concrete curbing fragment was recovered just above the bedrock contact (i.e., more than $1.5 \mathrm{~m}$ below the natural ground surface) during scraping in the vicinity of Features 4 and 5. Because soil horizonation was well developed in that area, and no evidence of significant disturbance of those horizons was apparent, it is considered likely that this block was part of the rubble fill of Feature 5.

\section{GEOARCHEOLOGICAL OBSERVATIONS}

The effort to locate and exhume any burials in the state right of way fronting Roberts Cemetery was a straightforward undertaking that required no formal geoarcheological planning. However, the prospection process exposed an extensive cross section of geological deposits and associated soils, and the character of those deposits had a significant influence on the visibility of the grave shafts. The nature of the geological deposits and lateral changes in stratigraphy are important considerations for understanding the decisions made during the mechanical stripping and the difficulties in recognizing unmarked graves.

As seen in Figure 2.13, the majority of the cemetery is mapped as Stephen silty clay (StC) with 1 to 3 percent slopes. However, the map unit fronting the majority of the Interstate Highway 35 right of way is Eddy-Stephen Complex (EsD) with 3 to 8 percent slopes, and the extreme northeastern corner mapped as unit Tinn (Ty) frequently flooded, with 0 to 1 percent slopes. Both Eddy soils and Stephen soils are thin, erosional upland soils developed on chalk and limestone. Eddy series soils are classified as Typic Ustorthents and are typified by an A1-A2-Cr profile that is less than $30 \mathrm{~cm}$ thick over bedrock. Stephen soils are classified as Udorthentic Haplustolls and are, if anything, even shallower. Neither of these soils bears any resemblance to the soils scraped in the right of way during this survey. In contrast, there was an area that resembled the description of the Tinn series, which is mapped in the axis of the Elm Creek stream valley. Tinn soils are thick, clayey soils typical of stream floodplains in the Blackland Prairies. They are classified as Typic Hapluderts and have a typical Ap-A-Bss1-Bss2Bss3-Bkss profile developed in dark gray to black 


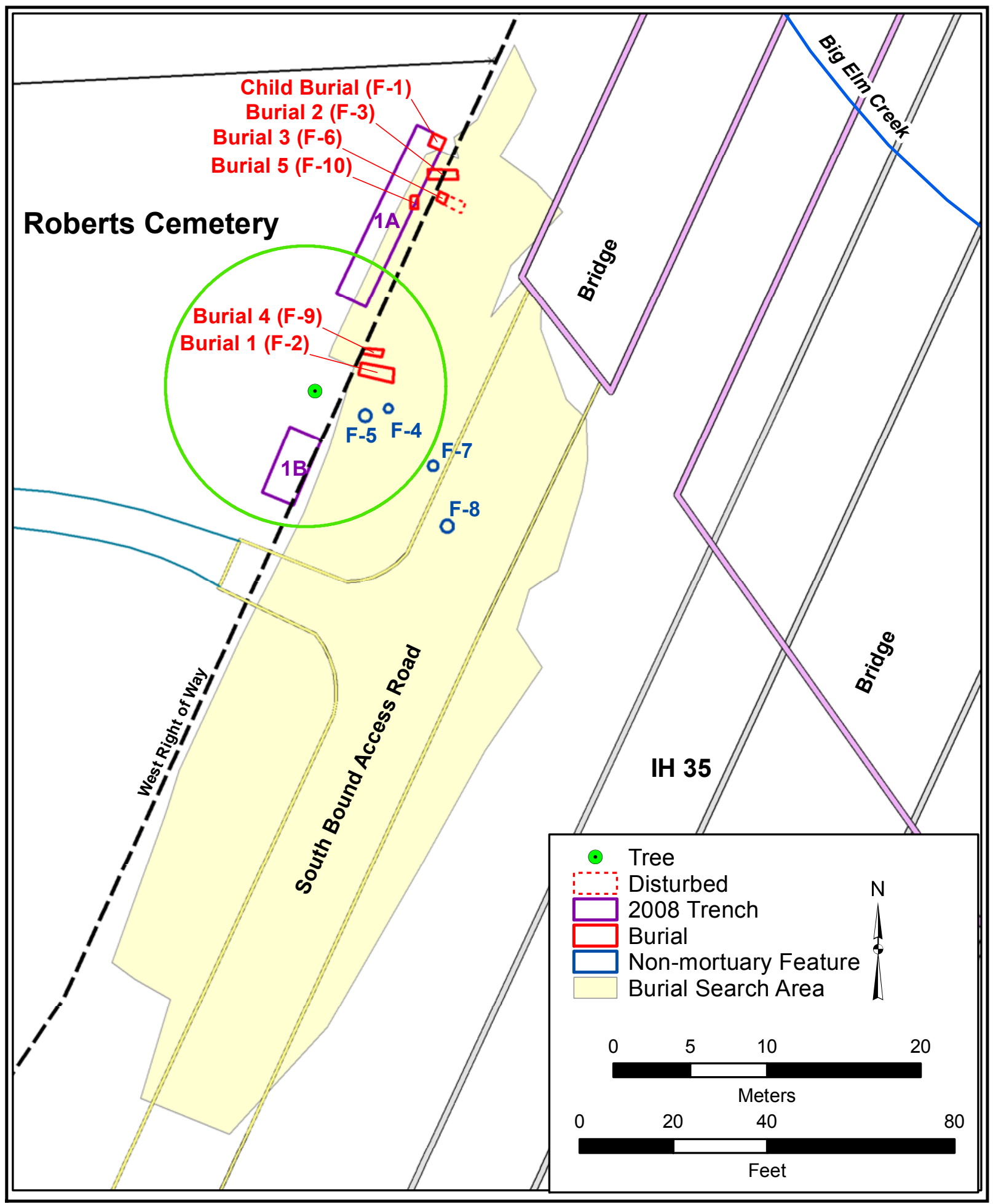

Figure 2.12. Map of the mechanical search area showing the locations of unmarked graves and nonmortuary features found in the eastern side of Roberts Cemetery. 
Table 2.1. Features found by TxDOT archeologists

\begin{tabular}{|c|c|c|}
\hline $\begin{array}{l}\text { TxDOT } \\
\text { Feature No. }\end{array}$ & Description & Burial No. \\
\hline Feature $1^{*}$ & Child burial found in Trench $1 \mathrm{~A}$ & $\begin{array}{l}\text { Unnumbered burial (not } \\
\text { excavated) }\end{array}$ \\
\hline Feature 2 & Adult burial & Burial 1 (excavated) \\
\hline Feature 3 & Adult burial & Burial 2 (excavated) \\
\hline Feature 4 & Posthole south of Burial 1; diameter $27 \mathrm{~cm}$ & - \\
\hline Feature 5 & $\begin{array}{l}\text { Probable geophysical hollow-core auger hole south of Burial 1; } \\
\text { diameter } 60 \mathrm{~cm}\end{array}$ & - \\
\hline Feature 6 & Adult burial & Burial 3 (excavated) \\
\hline Feature 7 & Probable geophysical core hole; diameter $10 \mathrm{~cm}$ & - \\
\hline Feature 8 & $\begin{array}{l}\text { Auger hole; diameter } 60 \mathrm{~cm} \text {. A nearby galvanized guy wire } \\
\text { anchor suggests that this hole was for a utility pole. }\end{array}$ & - \\
\hline Feature 9 & Child burial & Burial 4 (excavated) \\
\hline Feature 10 & Adult burial & Burial 5 (not excavated) \\
\hline
\end{tabular}

*Feature 1 was found in 2008; all other features were found in 2012.

expansive clays. This description conforms to the dark, homogeneous material at the north end of the cut, particularly in the northeast corner, where the bedrock dropped off.

Instead, the majority of the investigated area is characterized by soils that diverge from the mapped series. The reason for the discrepancies between the mapped and observed geology is simply that the cemetery spans a strath terrace landform that is not recognized in either the geological or soils maps. This terrace is inset against the upland, which is partially overlapped by the more recent floodplain clays. Although the terrace surface grades smoothly into the floodplain, it rests on an underlying bedrock strath that is $5-7 \mathrm{~m}$ above the modern channel, and the relatively thick deposits of the floodplain grade laterally into relatively thin $(1.5-2 \mathrm{~m})$, horizonated alluvial soils on the terrace, then into mixed alluvial/colluvial deposits near the terrace backslope. Soil processes have blurred these lateral contacts so that they are extremely gradual. As a result, the profile exposed in the Interstate Highway 35 frontage is a complex soil catena that displays lateral variability due to the combined effects of multiple soil processes operating on sediments of different ages, sources, and modes of deposition. Figure 2.14 presents a wide-angle composite photograph and details of the profile. Rather than try to define the diffuse lateral contacts, it is more instructive to illustrate representative vertical profiles that exemplify each unit exposed along the sequence. The three-frame photocomposite in the upper panel illustrates the western wall of the scraped area, and the four profiles detail that exposure at different points along the slope. The upland surface is visible where the trucks are parked on the left, and the stream is visible at the extreme right.

Profile A was near the upslope end of the scrape, roughly where the depth of the scraped material begins to thin as the deposit rides from the terrace strath onto the valley backslope. The material here consisted of a grayish brown to yellowish brown gravelly loam that was almost entirely colluvial in origin and supported a soil with an A-Bk-BCk-2R sequence. The A horizon was a stony loam, while the underlying $\mathrm{Bk}$ and BCk horizons were loam to clay loam. The soil exhibited a fine blocky structure and contained up to 2 percent fine soft carbonate nodules and occasional angular pebbles. It rested abruptly on a dipping limestone shelf at a depth of about $140 \mathrm{~cm}$, but thinned rapidly to about $40 \mathrm{~cm}$ on the lower slope. Given the color, the character of the A horizon, and the degree of soil development, it is likely that the soil is a Mollisol or an Inceptisol.

Profile B was situated slightly downslope from $\mathrm{A}$ at the rear of the terrace. The soil here was developed through a stacked sequence of 
Table 2.2. Sequence of burial discovery and excavation at Roberts Cemetery

\begin{tabular}{|c|c|c|c|}
\hline Burial No. & Date of Work & Investigator & Work Conducted \\
\hline $\begin{array}{l}\text { Unnumbered } \\
\text { Burial } \\
\text { (Feature 1) }\end{array}$ & November $12-16,2008$ & PAI & $\begin{array}{l}\text { A child's burial was exposed in Backhoe Trench } 1 \mathrm{~A} \text {. } \\
\text { The backdirt was screened, and deteriorated casket } \\
\text { wood, some nails, and some bones were recovered. } \\
\text { Hand excavations exposed the outline of the small } \\
\text { grave shaft. The recovered burial remains were } \\
\text { placed back on the intact portion of the burial, and } \\
\text { it was covered with protective fill (Hatfield et al. } \\
2009: 13-14) \text {. }\end{array}$ \\
\hline \multirow[t]{4}{*}{$\begin{array}{l}\text { Burial } 1 \\
\text { (Feature 2) }\end{array}$} & August 27-31, 2012 & TxDOT & $\begin{array}{l}\text { The grave shaft was outlined, and foot bones were } \\
\text { exposed to confirm that the feature was a human } \\
\text { burial. Displaced hardware was collected and } \\
\text { placed with the burial under plastic and earthen } \\
\text { fill for protection. }\end{array}$ \\
\hline & September 6-7, 2012 & PAI & $\begin{array}{l}\text { Excavation of lower portion of burial began. All } \\
\text { bones of the upper body (ribs, vertebra, humerus, } \\
\text { and skull) remained under the AT\&T cable. }\end{array}$ \\
\hline & September 20, 2012 & TxDOT/PAI & $\begin{array}{l}\text { Removal of overburden surrounding the AT\&T } \\
\text { cable }\end{array}$ \\
\hline & September 21, 2012 & PAI & Excavation of intact (upper) portion of the burial \\
\hline \multirow[t]{3}{*}{$\begin{array}{l}\text { Burial } 2 \\
\text { (Feature } 3 \text { ) }\end{array}$} & November $12-16,2008$ & PAI & $\begin{array}{l}\text { The head of the grave and upper part of the skull } \\
\text { were unknowingly impacted by Backhoe Trench } 1 \mathrm{~A} \\
\text { in } 2008 \text { (Hatfield et al. } 2009: 10-11,13-14) \text {. }\end{array}$ \\
\hline & August 27-31, 2012 & TxDOT & $\begin{array}{l}\text { Lower legs were displaced during the gradall } \\
\text { scraping. No shaft was detected; this exposure of } \\
\text { the bone was the first indication of the burial. }\end{array}$ \\
\hline & September 21, 2012 & PAI & Burial excavated \\
\hline \multirow[t]{3}{*}{$\begin{array}{l}\text { Burial } 3 \\
\text { (Feature 6) }\end{array}$} & August 27-31, 2012 & TxDOT & $\begin{array}{l}\text { The lower portion of this burial was accidentally } \\
\text { scraped up and added to the backfill pile. } \\
\text { Subsequently, the sediment in this backdirt pile } \\
\text { was used to cover and protect Burial } 2 \text {. Thus, the } \\
\text { disturbed remains of lower Burial } 3 \text { were deposited } \\
\text { on top of Burial } 2 \text {. Some remains were commingled } \\
\text { at that time, but they were later separated. }\end{array}$ \\
\hline & September 6, 2012 & PAI & $\begin{array}{l}\text { The bones of Burial } 3 \text { were discovered in the } \\
\text { process of removing the protective fill covering } \\
\text { Burial } 2 \text {. All of the removed fill was screened } \\
\text { to recover the remains of lower Burial } 3 \text {. Some } \\
\text { remains from Burials } 2 \text { and } 3 \text { had become } \\
\text { commingled, but they were separated in the } \\
\text { laboratory analysis phase. }\end{array}$ \\
\hline & September 13, 2012 & PAI & $\begin{array}{l}\text { The remaining intact portion of the burial was } \\
\text { excavated and removed. This consisted of some of } \\
\text { the midsection, shoulders, and skull. }\end{array}$ \\
\hline \multirow[t]{3}{*}{$\begin{array}{l}\text { Burial } 4 \\
\text { (Feature 9) }\end{array}$} & September 21, 2012 & PAI & $\begin{array}{l}\text { Casket nails from the edge of Burial } 4 \text { were } \\
\text { exposed in the balk (vertical wall) north of Burial } 1 \text {. }\end{array}$ \\
\hline & September 24, 2012 & TxDOT/PAI & $\begin{array}{l}\text { Overburden above and below AT\&T cable was } \\
\text { removed. }\end{array}$ \\
\hline & September 25, 2012 & PAI & Burial excavated \\
\hline $\begin{array}{l}\text { Burial } 5 \\
\text { (Feature 10) }\end{array}$ & September 25, 2012 & PAI & $\begin{array}{l}\text { A row of several casket nails was observed in the } \\
\text { excavation trench profile to the south of Burial } \\
3 \text { and along the north edge of the TxDOT right } \\
\text { of way. This burial was determined to be outside } \\
\text { the TxDOT right of way and was not investigated } \\
\text { further. }\end{array}$ \\
\hline
\end{tabular}




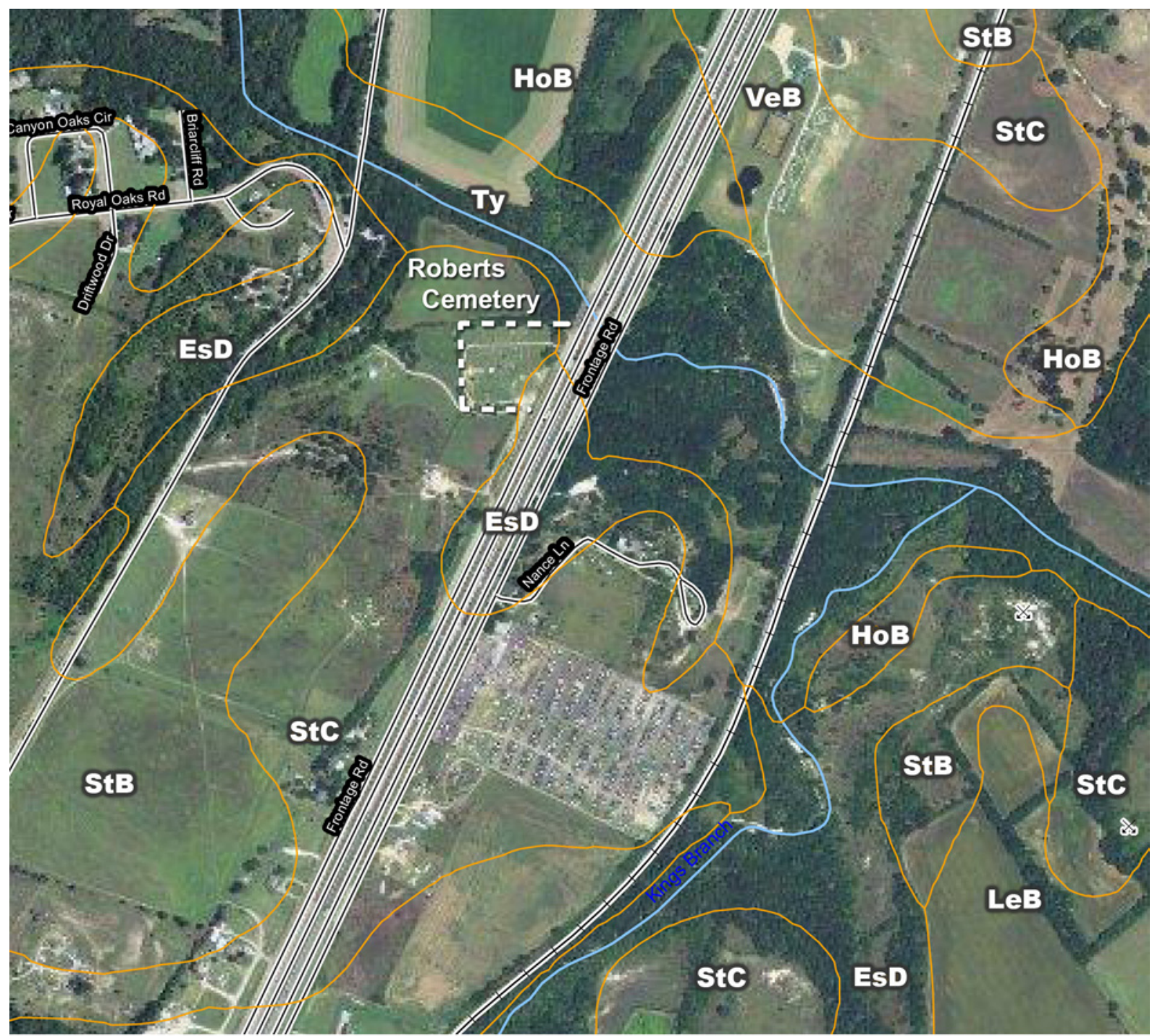

Map Scale: $1: 9,740$ if printed on C size $\left(17^{\prime \prime} \times 22 "\right)$ sheet.
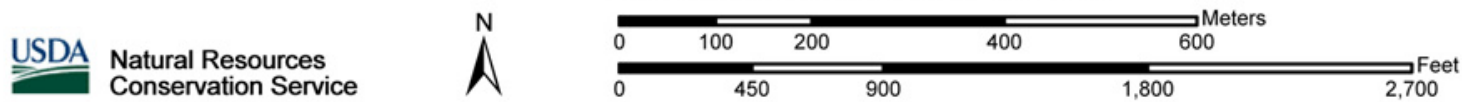

Figure 2.13. Detail of the soils in the vicinity of Roberts Cemetery, as mapped by the USDA Natural Resource Conservation Service (USDA, NRCS n.d.).

two discrete deposits. The upper part of the sequence (AC horizon) consisted of stony grayish-brown colluvium approximately $30 \mathrm{~cm}$ thick. It graded down into a dark grayish brown $2 \mathrm{~A}$ horizon, then into a strong brown, weakly to moderately structured $2 \mathrm{Bk} 1$ horizon with few to common carbonate filaments and soft nodules, and finally into a pale brown to yellowish brown $2 \mathrm{Bk} 2$ horizon with common carbonate masses, filaments, and matrix "clouds." The soil rested on a hard bedrock shelf ( $3 \mathrm{R}$ horizon) at a depth of about $170 \mathrm{cmbs}$. Given the character of the soil and the degree of soil development, the soil is likely a Mollisol or an Alfisol.

Profile $\mathrm{C}$ was situated in the middle section of the terrace, a few meters south of Burials 1 and 4 . The soil here was clay loam and exhibited a moderately structured A-BtkBk-Ck-2R profile. The A horizon was very dark grayish brown to black and graded into a very 


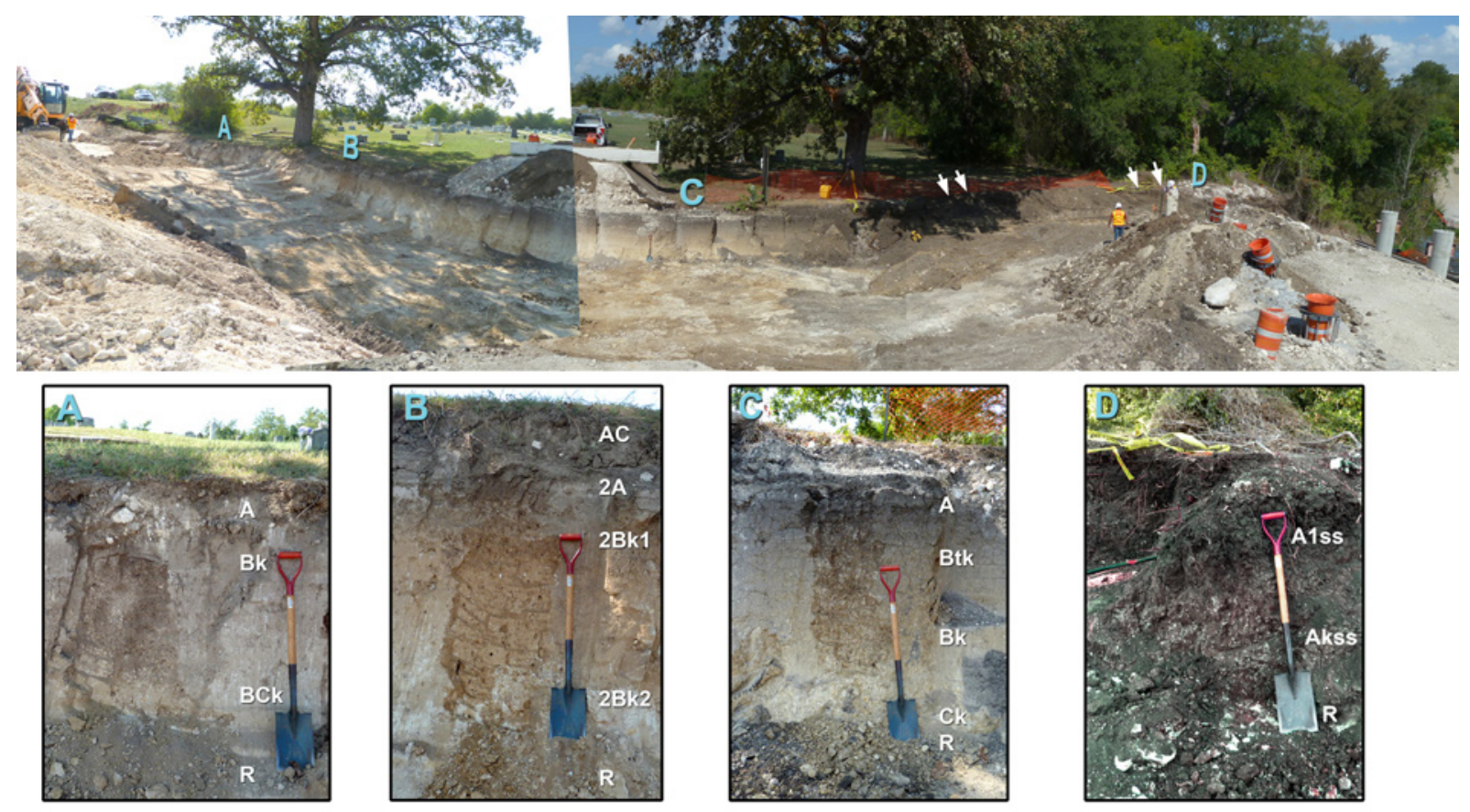

Figure 2.14. Photographs of the western wall of the scraped area and selected soil profiles. (Top) Photocomposite panorama of the west wall of the scraped area showing the locations of burials (marked with white arrows) and profiles (marked with letters). (Bottom) The profiles detail the soils exposed along the cut face.

dark grayish brown to grayish brown Btk horizon with occasional weak argillans on the faces of the moderate blocky peds. Fine carbonate nodules, filaments, and flecks were common through the horizon. This horizon graded into a yellowish brown subsoil that once again rested on a hard bedrock shelf. Although not present at the measured section, there were localized areas of thin (maximum $10 \mathrm{~cm}$ ), yellowish-brown, iron-stained limestone gravels at the bedrock contact in this part of the terrace. Given the character of the soil and the degree of soil development, the soil is likely a Mollisol.

Finally, Profile D was near Burials 2 and 3 on the proximal terrace overlooking the slope. It exhibited a very dark, structured soil with an A1ss-Akss-2R profile. The profile consisted of very dark grayish brown clay loam that lightened slightly with depth. Limited pressure faces on peds attested to shrink-swell processes, but no slickensides were noted. Secondary carbonate was common in the Akss horizon; it consisted of common soft masses, filaments, and concretions. Small angular fragments of limestone were also common. Given the character of the soil and the degree of soil development, the soil is broadly similar to the Tinn series and would likely classify as a Vertisol.

Although the soil catena reflects the input of material of alluvial and colluvial origin in different positions on the slope, the variability it exhibits also reflects deposits of differing ages that onlap and overlap each other. Based on a broad comparison with the sequence of soil units recognized for Fort Hood (e.g., Nordt 1992), it is likely that the more distal part of the terrace is of early to middle Holocene age (equivalent to Nordt's Fort Hood fill), while the medial terrace (probably equivalent to Nordt's lower or older West Range fill) and more homogeneous proximal terrace (probably equivalent to Nordt's upper or younger West Range fill) are of Late Holocene age. In other words, the more developed soils in the medial and distal parts of the terrace had horizons of contrasting color, while the clayey soil on the proximal terrace did not. As a consequence, grave shafts in the latter setting were not visible as the surface was scraped, and the machine scraping damaged these burials during the prospection process. Even after the burials were identified, close inspection of the adjacent cut wall failed to reveal any evidence of the grave shaft associated 
with Burial 2, even though it had to be there. Because the grave shafts were impossible to detect and no coffin remnants remained above
Burials 2 and 3, impacts to the remains in this part of the cemetery, although unfortunate, were largely unavoidable. 


\section{BURIAL DESCRIPTIONS}

The discovery of one unmarked grave at Roberts Cemetery in 2008 led to an extensive mechanical search for unmarked graves inside the state-owned right of way for Interstate Highway 35. The 2012 mechanical stripping covered an area of more than $10,000 \mathrm{ft}^{2}$ and discovered five more unmarked graves. Two of the six burials were left in place, and four were exhumed.

For a variety of reasons, the sequence of discovery and investigations of these burials was convoluted (see Table 2.2). Each burial was excavated in multiple stages due to scheduling problems caused by weather delays, logistical delays in the mechanical removal of the overburden above the burials, and the need to expose the overburden in segments to avoid impacting a buried AT\&T cable. Further complications arose when burials were impacted during the mechanical grave search.

The excavations of Burials 1 and 4 proceeded normally. The soil changes allowed for observation of the grave shaft above the casket remains, and the burials were intact at the time of excavation. Unfortunately, the two other burials were partially disturbed by the machine scraping because it was virtually impossible to see the grave shafts. A small portion of Burial 2 (the head end of the grave) was disturbed by the backhoe in 2008, and the lower half of Burial 3 was accidentally removed by the backhoe in 2012. The displaced fill from Burial 3 was screened, and all of the burial remains were recovered.

This section presents descriptions of the four excavated burials. The descriptions include information on shaft size and depth and body orientation and an inventory of casket and mortuary hardware and personal artifacts associated with the interred individual. Based on an examination of the human remains, an osteological inventory, pathological information, a dental inventory, and descriptions of dental pathology, anomalies, and modifications are also included. Casket hardware is described in more detail in Chapter 4 and Appendix A, and detailed osteological data tables are provided in Appendix B.

Table 3.1 summarizes the unmarked burials. Table 3.2 summarizes mortuary hardware and personal items recovered from the four excavated burials. Table 3.3 provides descriptions and measurements of the personal items.

\section{BURIAL 1}

Burial 1 is the grave of a $30-40$-year-old male buried in a rectangular casket (Figure 3.1).

\section{Grave Discovery and Excavation}

Burial 1, the southernmost grave, was first detected during trenching when TxDOT personnel observed a linear soil color change. The grave shaft was followed vertically until bones (at the foot) were found. TxDOT personnel exposed foot bones to confirm that the disturbance was in fact a human grave, and then covered the exposed bone with plastic topped with loose fill. Very little overburden was removed prior to excavation, primarily to protect the AT\&T cable, which crossed Burial 1 immediately over the head. Roots damaged the north side of the casket and also cut through the midsection of the grave. 
Table 3.1. Summary of unmarked burials at Roberts Cemetery

\begin{tabular}{l|c|c|c|c|c|c}
\hline Burial No. & Sex & Age & $\begin{array}{c}\text { Casket } \\
\text { Length }\end{array}$ & Casket Width & $\begin{array}{c}\text { Depth Below } \\
\text { Surface * }\end{array}$ & $\begin{array}{c}\text { Elevation } \\
\text { (ft amsl) }\end{array}$ \\
\hline Unnumbered & $\begin{array}{c}\text { Unknown/ } \\
\text { indeterminate, } \\
\text { not excavated }\end{array}$ & Child & $\begin{array}{c}16 \\
\text { inches** }\end{array}$ & 8 inches** & $\begin{array}{c}\text { ca. } 4 \mathrm{ft} \\
(49 \text { inches) }\end{array}$ & $\begin{array}{c}\text { N/A } \\
\text { (burial outside } \\
\text { the right of way) }\end{array}$ \\
\hline Burial 1 & Male & $30-40$ & $7 \mathrm{ft}$ & $2.7 \mathrm{ft}$ & $4.26-4.66 \mathrm{ft}$ & $618.50-617.78 \mathrm{ft}$ \\
\hline Burial 2 & Male & $45-60$ & Unknown & $2.13-2.40 \mathrm{ft} * *$ & $3.97-4.12 \mathrm{ft}$ & $616.29-616.45 \mathrm{ft}$ \\
\hline Burial 3 & Male & $20-27$ & Unknown & $2.1^{* *}$ & $4.15 \mathrm{ft}$ & $616.49-616.49 \mathrm{ft}$ \\
\hline Burial 4 & Indeterminate & 1.5 & $2.9 \mathrm{ft}$ & $0.72-0.85 \mathrm{ft}$ & $3.95-3.77 \mathrm{ft}$ & $618.14-618.21 \mathrm{ft}$ \\
\hline Burial 5 & $\begin{array}{c}\text { Unknown, } \\
\text { not excavated }\end{array}$ & Unknown & Unknown & Unknown & $\begin{array}{c}\text { Similar to } \\
\text { Burials 2 } \\
\text { and 3 }\end{array}$ & $\begin{array}{c}\text { N/A burial outside } \\
\text { the right of way) }\end{array}$ \\
\hline
\end{tabular}

* Ground surface measurements could not be taken above every grave, so estimates were made based on elevations nearby. Ground surface was fairly level near Burials 1 and 4, as contrasted with a steep slope in ground surface above Burial 3 and even steeper slope above Burial 2, the northernmost burial.

** Measurements represent only the excavated portion of the burial. No casket outline was identified, so measurements are only the approximate dimensions of the grave shaft.

Table 3.2. Summary of mortuary hardware and personal items recovered from four burials

\begin{tabular}{|c|c|c|c|c|c|}
\hline & Description & Burial 1 & Burial 2 & Burial 3 & Burial 4 \\
\hline \multicolumn{6}{|l|}{ Mortuary Hardware } \\
\hline \multicolumn{6}{|l|}{ Outer Box } \\
\hline Handles & Iron & 5 & & & \\
\hline Common nails & Iron & 12 & & & \\
\hline \multicolumn{6}{|l|}{ Casket } \\
\hline \multirow[t]{2}{*}{ Plaque or plate } & Type 1, iron & 1 & & & \\
\hline & Type 2, white metal & & 1 & 1 & \\
\hline \multirow[t]{2}{*}{ Handles } & $\begin{array}{l}\text { Type } 1 \text {, double lug, white } \\
\text { metal }\end{array}$ & 6 & & & \\
\hline & $\begin{array}{l}\text { Type } 2 \text {, swing bale, white } \\
\text { metal }\end{array}$ & & 6 & 6 & \\
\hline \multirow[t]{2}{*}{ Escutcheon (white metal) } & Type 1, white metal & & 3 & 4 & \\
\hline & Type 2, white metal & & 1 & & \\
\hline \multirow[t]{4}{*}{ Thumbscrew } & Heart-shaped, iron & 2 & & & \\
\hline & Type 1 , white metal & & 3 & 5 & \\
\hline & Type 2 , white metal & & 1 & 1 & \\
\hline & Type 3 , white metal & & 1 & & \\
\hline Cap lifter & White metal & & 1 & 1 & \\
\hline \multirow[t]{2}{*}{ Separable stop hinge (iron) } & Type 1 & 2 & & & \\
\hline & Type 2 & 2 & & & \\
\hline \multirow[t]{3}{*}{ Various lid mechanisms (iron) } & Stop plates & 2 & & & \\
\hline & Locking mechanism & 1 & & & \\
\hline & Flat iron plates or lid rods & 12 & & & \\
\hline \multirow[t]{7}{*}{ Nails (iron) } & Common & & 17 & 30 & \\
\hline & Short & & 22 & 19 & \\
\hline & Finishing & & 20 & 15 & \\
\hline & Extra-large & & & & 16 \\
\hline & Shanks & & & 5 & \\
\hline & Large & & 1 & 1 & \\
\hline & Square & & 1 & & \\
\hline
\end{tabular}


Table 3.2, continued

\begin{tabular}{|c|c|c|c|c|c|}
\hline & Description & Burial 1 & Burial 2 & Burial 3 & Burial 4 \\
\hline \multirow[t]{5}{*}{ Wood screws (iron) } & 1-inch & & 1 & & \\
\hline & 1.25-inch & & & & 4 \\
\hline & 1.5-inch & & 1 & & \\
\hline & 2-inch & & & 1 & \\
\hline & Shank & & 1 & 2 & \\
\hline \multirow[t]{3}{*}{ Tacks (various) } & Decorative, copper & & 2 & 1 & \\
\hline & Fabric, iron & 40 & 2 & 1 & 35 \\
\hline & Long Tacks, iron & 5 & 2 & & \\
\hline U-shaped unidentified & iron & & & 1 & \\
\hline \multicolumn{6}{|l|}{ Outer Box or Casket } \\
\hline \multirow[t]{4}{*}{ Nails (iron) } & Common, iron & 72 & & & \\
\hline & Finishing, iron & 21 & & & \\
\hline & Short, iron & 24 & & & \\
\hline & Wood & 4 & & & \\
\hline \multirow[t]{2}{*}{ Screws (iron) } & 1-inch & 6 & & & \\
\hline & 2-inch & 1 & & & \\
\hline \multicolumn{6}{|l|}{ Personal Items } \\
\hline \multirow[t]{3}{*}{ Buttons } & Shell, two-hole & 5 & $4^{*}$ & & 1 \\
\hline & Shell, four-hole & & 1 & 3 & \\
\hline & Composite metal & 2 & 3 & & \\
\hline Cuff links & White metal & & 2 & & \\
\hline Eyelet & Copper & & 2 & & \\
\hline Fabric remnant & & 3 & & & \\
\hline Floral wire & Iron & & & & $* *$ \\
\hline Neckpiece & & & & 1 & \\
\hline \multirow[t]{2}{*}{ Safety pins } & Copper & & & 1 & 3 \\
\hline & Iron & & & & 2 \\
\hline Snap & Copper & & & & 3 \\
\hline Unifacial scraper & & & & & 1 \\
\hline
\end{tabular}

\section{Mortuary Characteristics}

Burial Shaft Size and Depth: The grave shaft measured $7 \mathrm{ft}$ long by $2.7 \mathrm{ft}$ wide, and the bottom elevations ranged from $4.26 \mathrm{ft}$ to $4.66 \mathrm{ft}$ below the modern ground surface $(618.50-617.78 \mathrm{ft}$ amsl).

Burial Orientation: East-west, with the head to the west. The body was in an extended position, lying supine. The grave shaft orientation (headto-foot) was 285 degrees.

Outer Box Description: Burial 1 contained a rectangular, wooden outer box that probably served as a casket shipping container. Although no outer box wood was observed, alignments of nails and the location of the hardware determined its shape. The exact size of the outer box is not known, but the five handles and many nail alignments indicate that the outer box was slightly larger than the casket.

Outer Box Hardware: Evidence of the outer box includes five simple iron handles and several alignments of common nails. Two handles were found on the right of the mid and upper body and two paralleled those on the left. Another, recovered by TxDOT personnel, most likely came from the lower portion of the grave. It is assumed that the outer box handles originally totaled six and were laid out with three on either side of the box. The sixth handle was accidentally removed during the mechanical grave search. 


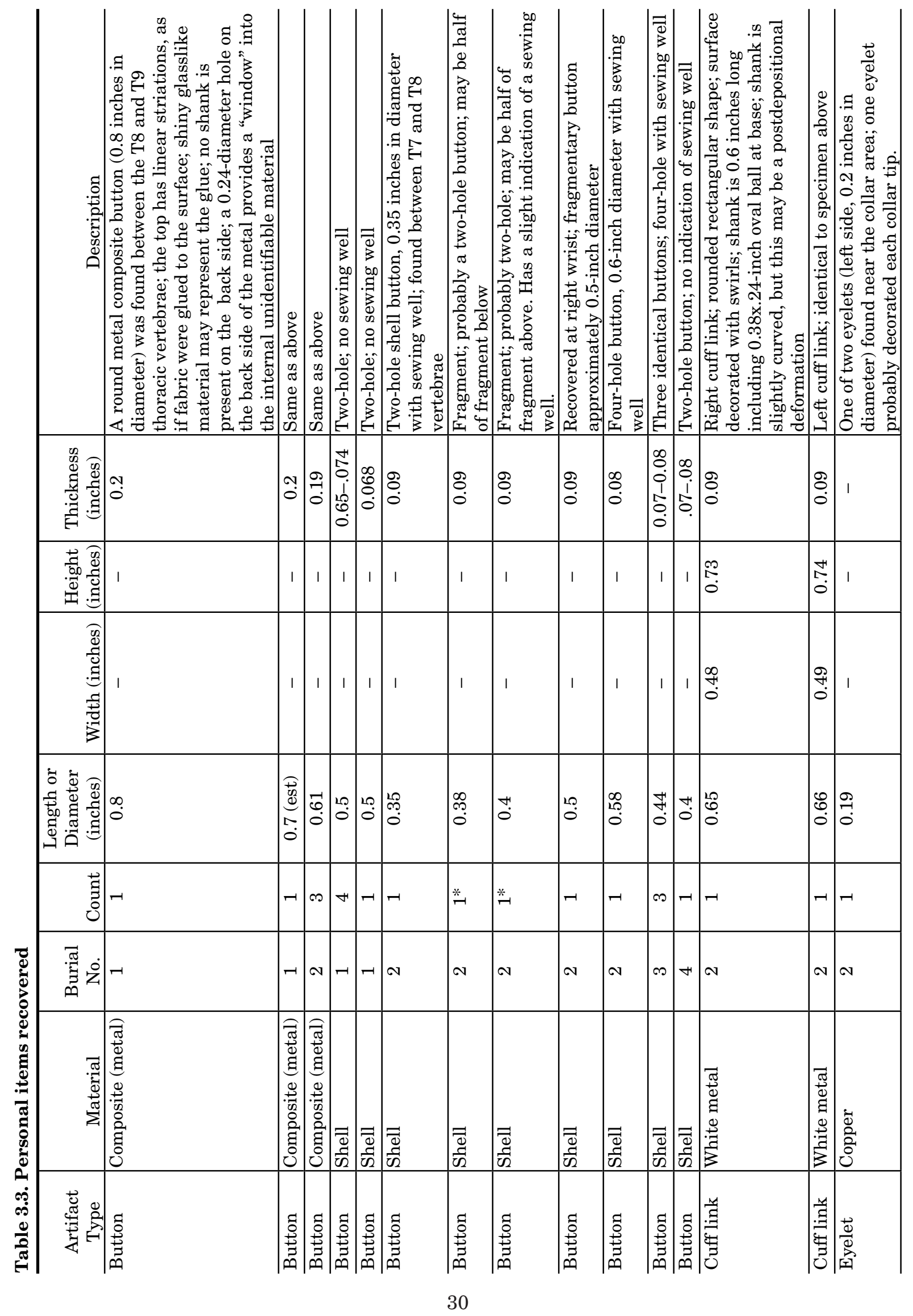


Chapter 3: Burial Descriptions

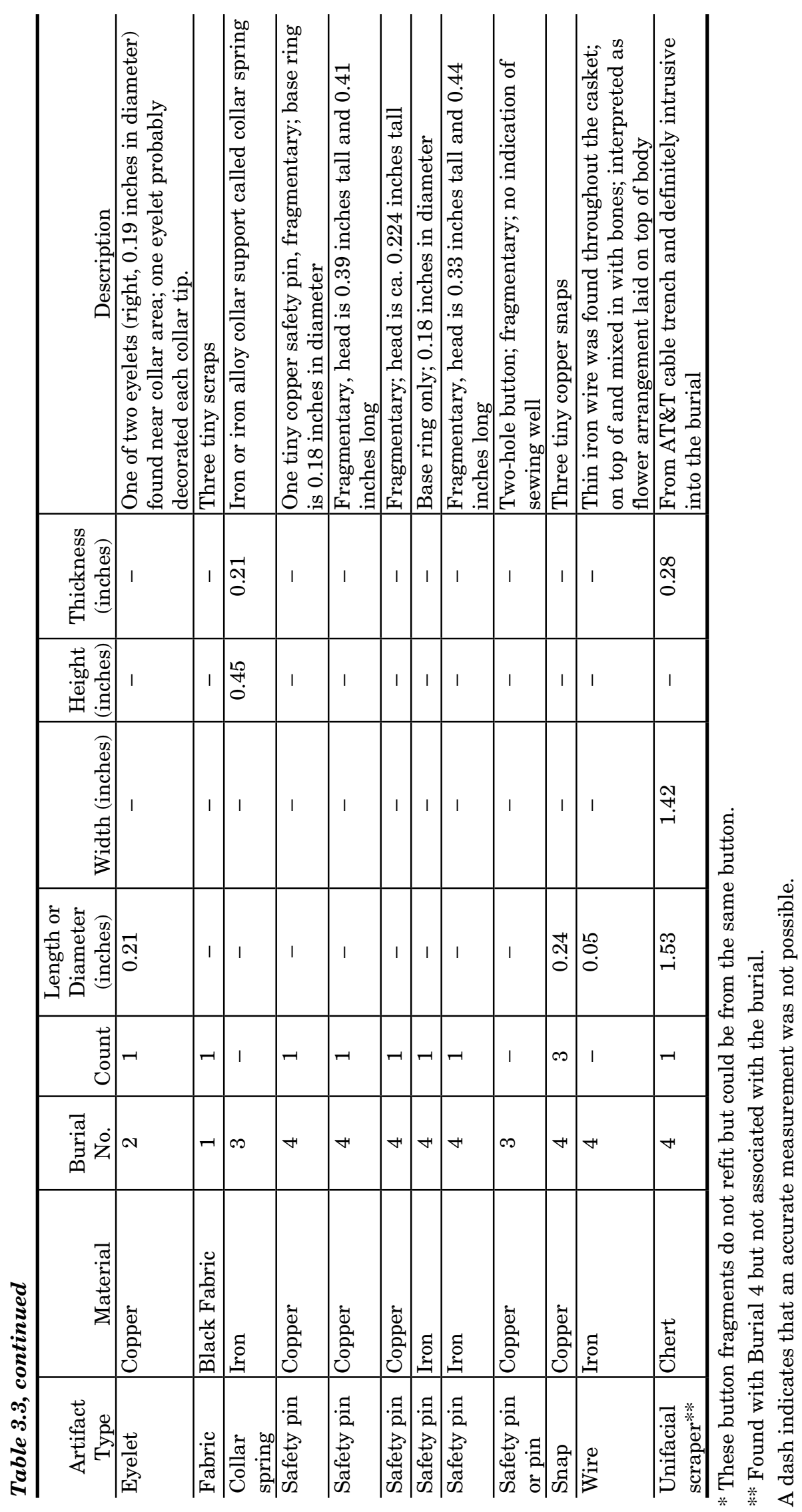




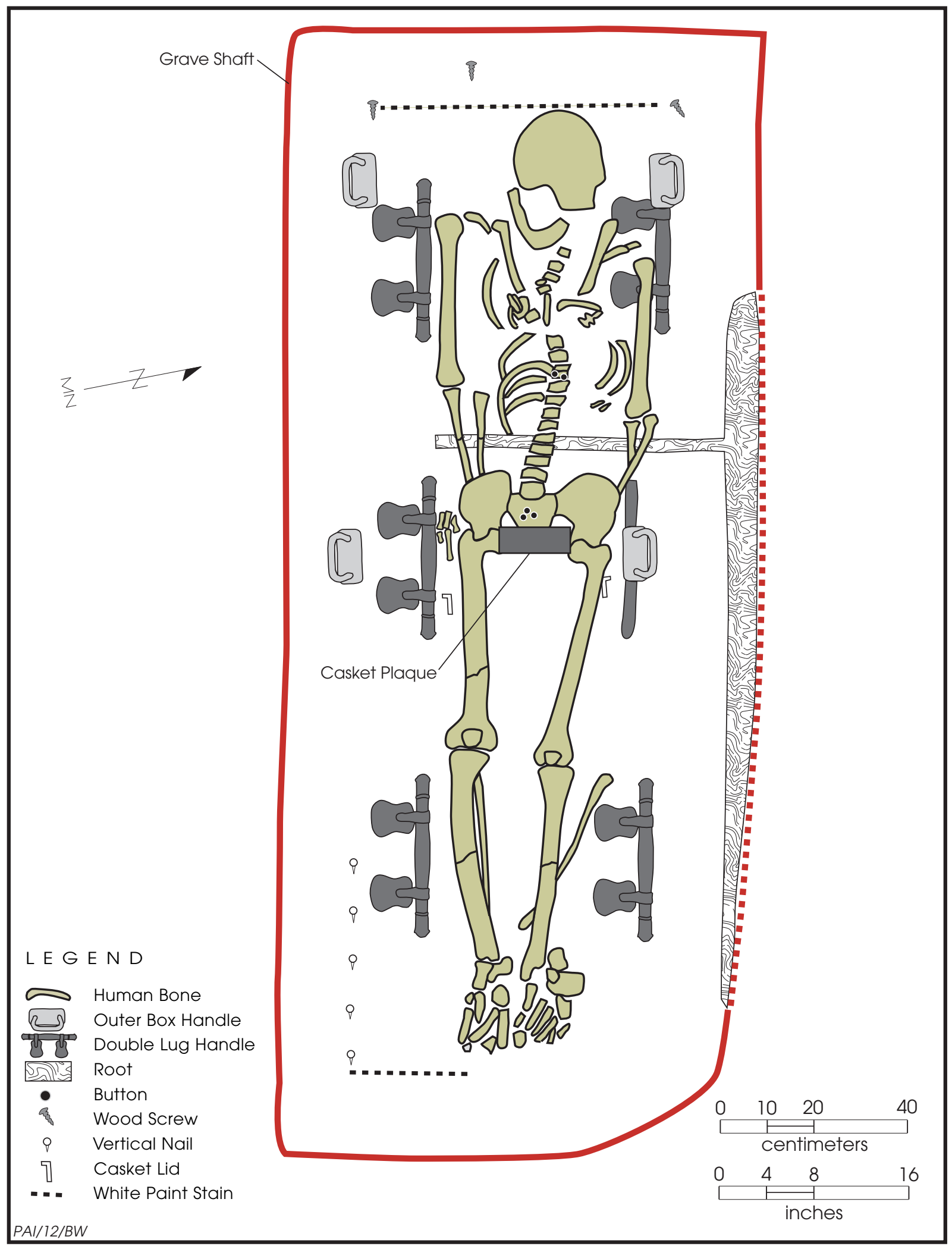

Figure 3.1. Burial 1 map. 
Several alignments of common nails were found with their tips pointing upward. They clearly had been nailed from the bottom of the outer box upward into the walls of the box. These alignments were found intermittently around the perimeter of the outer box, and 12 nails from one such alignment were collected separately.

Casket Description: The wooden casket measured $2 \mathrm{ft}$ wide and $7.3 \mathrm{ft}$ long. Faint evidence of deteriorated wood was observed. Additionally, two faint white lines-remains of white paint-were observed, indicating that the casket was painted white. These remnants were found at the head and base of the casket (see Figure 3.1).

Casket Hardware: Six white metal double-lug casket handles (Type 1) were found, three on either side of the casket. Two heart-shaped iron thumbscrews were found: one in the upper left corner of the casket and one in the lower right corner. Most likely, there were originally four (one in each corner); the other two were probably removed during the mechanical scraping. One thin iron casket plaque (Type 1) was found on top of the pelvic bones. The rusty and extremely fragmented iron plaque has scalloped edges and a 0.3-inch-high relief. No words, letters, or any indication of decoration are visible.

Casket construction hardware consists of a catch assembly, 2 sets of top fasteners (4 pieces in each set), and 12 rectangular iron pieces. The rectangular pieces collected from the top and bottom of the casket are joining plates used to attached two pieces of wood together. The other components are iron hardware used to attach and remove the casket lid for viewing the body; these mechanisms replaced the escutcheon and thumbscrew combination used in more modern caskets. These items were all badly corroded but were intact enough to be identified. Although only two of the components were mapped in place (see Figure 3.1), the general locations of the other components were documented and helped define how these items were used. The single iron catch assembly (Type 1) was recovered from the area to the right of the head; it is a latch mechanism for closing and latching the casket lid down. The top fasteners (all Type 1) consist of 8 items in 3 matched groups (4 each) that correspond with the right and left sides of the casket. The matched groups of fastener items are the head plate and spring assemblies, the foot plate and hook assemblies, and the dowels. The two head plate and spring assemblies were found in the upper part of the casket on either side of the ribcage. The two foot plate and hook assemblies were found in the lower part of the casket on either side of the lower legs. The two dowels were found on either side of the hips (mapped individual at the femur heads). All of the lid mechanism components are described and illustrated in Chapter 4, and this information provides a better understanding of how they functioned.

Eighty-four common nails were collected, of which 72 were found throughout the burial and 12 were from one of several alignments of the outer box. Additionally, 21 finishing nails, 24 short nails, and 4 wood nails were collected from throughout the burial. Finally, 40 fabric tacks and 5 long tacks are attributed to casket hardware.

Personal Items: Seven buttons and three tiny scraps of fabric were recovered from Burial 1 . The buttons from Burial 1 consist of larger composite buttons and smaller shell buttons.

Two round composite buttons composed of an outer iron alloy and an unknown inner material were recovered. The buttons measure $0.7-$ 0.8 inches in diameter and are 0.2 inches thick. The top of each button displays many faint linear striations and globs of shiny glass-like material. This is most likely glue used to attach fabric to the button's surface. Neither button retains its shank, but a hole ( 0.24 inches in diameter) in the backside of each suggests that the shanks were metal wire loops. This hole provides a "window" into the internal material, which may be wood or corroded metal but cannot be positively identified. Both buttons were found in the central chest area, and one was recovered from between the T8 and T9 thoracic vertebrae. The low number of these composite buttons, combined with the location in the lower chest, suggests these were jacket or vest buttons.

Five two-hole shell buttons were also recovered from Burial 1. These were all 0.5 inches in diameter and $0.65-0.74$ inches thick. Though highly degraded, none appear to have a sewing well. All five shell buttons were found in the pelvic area, 
and based on their small size and location, they were likely from an undergarment.

Finally, three tiny fragments of black fabric were recovered from the upper right side of the head. The source of the fabric scraps is unknown, but they may have been part of the interior casket decor, such as casket lining or a pillow, or may have been a personal item such as a hat. These were the only fabric specimens found in the excavations at Roberts Cemetery. The preservation of fabric in this burial suggests that the interment may be younger than the other unmarked graves that were excavated.

Burial Position/Taphonomy: The grave is a single primary inhumation, and the skeletal elements are articulated. The body was supine in an extended position. The arms were extended, with the hands at the sides and beneath the innominates; right palm facing anterior and left palm facing posterior. The right arm is in a pronated position. The legs were extended, and the collapse of the metatarsals and tarsals suggest that the individual was buried in shoes with the soles of the feet facing the east end of the casket. The skull was rotated, or turned, to the left side of the body with the eyes looking in a north/northeast direction. The mandible did not tilt with the skull. Tree roots disturbed the upper portion of the body. A large root extended under the body in a north-to-south direction. This root disturbed the radii and ulnae, resulting in an anterior curvature of the bone shaft. The right radius and ulna also exhibited a postmortem fracture due to the root. A second root disturbed the upper thoracic and cervical vertebrae. At first, the lateral movement of the spine seemed to indicate that the individual was afflicted with scoliosis. However, upon close inspection, it was apparent that a root grew in the area and the vertebrae were shifted lateral in a southward direction toward the right arm. Most of the trabecular bone was friable and collapsed under slight pressure. Overall, though, the skeleton was in good condition.

\section{Osteological Characteristics}

\section{Skeletal Preservation: Good.}

Sex: Male.
Age: $30-40$ years.

Stature: ${ }^{7} 172.17 \pm 3.62 \mathrm{~cm}, 5^{\prime} 6.2^{\prime \prime}-5^{\prime} 9.2^{\prime \prime}$

Biological Affinity: Caucasian.

Skeletal Inventory: The skeletal remains consist of complete skull and mandible, though highly fragmented smaller bones such as sphenoid and lacrimals were unable to be scored; both clavicles; partial scapulae; complete sternum; all ribs present but fragmented; complete right humerus; partial left humerus; complete radii and ulnae; most hand elements present; sacrum; partial left ilium; complete right ilium; right and left ischia; left pubis; right pubis; complete femora, though postmortem fracture in shaft required reconstruction; both patellae, fibulae, and tibiae; all tarsals and metatarsals; and most of the foot phalanges.

Degenerative Pathology: Mild osteophytosis is present on the head of the right humerus encompassing the superior and lateral margins. Pronounced osteophytes form a ridge extending $6.01 \mathrm{~mm}$ on the posterior-inferior aspect of the right glenoid fossa. Osteophytes are present on the dens of the axis and extend $2.86 \mathrm{~mm}$ superiorly, $10.54 \mathrm{~mm}$ in a posterior direction at the sulcus of the left ilium, $1.73 \mathrm{~mm}$ on the inferior margin of third lumbar body, and $5.57 \mathrm{~mm}$ on the superior edge of the fourth lumbar body. Osteophytosis is also present around the circumference of the dens facet and forms a mild ridge. Schmorl's nodes are present in the inferior body of the seventh, eighth, and ninth thoracic vertebrae and are moderately expressed. An osteochondrosis dessicans lesion is present on the right auricular surface of the sacrum.

Infectious Disease: New bone formation on the floor of the left maxillary sinus cavity is consistent with paranasal sinusitis. The external auditory meatus and canal exhibit both destructive and proliferative bone changes with some woven bone present. The changes are predominantly anterior and inferior to the external auditory meatus and inside the canal. Changes are more noticeable externally. These changes are most consistent with otitis externa. Otitis externa is

\footnotetext{
Estimated using Femur and Fibula stature regression formula in Trotter and Gleser (1958): 1.31: $(\mathrm{Fem}+\mathrm{Fib})+63.05 \pm 3.62$.
} 
an infection of the external auditory canal that produces swelling of the canal and pinna with discharge (Sander 2001).

Enthesopathy: Slight changes, level 1, are present on the flexor ligaments on the palmar surfaces of the medial phalanges. Enthesopathy development appeared to be stronger on the right side of the body than the left. A third trochanter is present on the right and left femora. Third trochanters are located at the superior border of the gleuteal tuberosity along the gluteus maximus attachment.

Soft Tissue Calcifications: Two fragments of calcified thyroid cartilage were found during excavation.

Dental Inventory: Maxilla and mandible; all teeth are present except M3, all of which are missing due to congenital loss.

Dental Pathology: Moderate alveolar resorption is present on all teeth. Dental calculus is present on all teeth in minor amounts, except moderate calculus development is present on maxillary teeth RM1 and LM1 and mandibular RI1. Heavy calculus development is present on the maxillary RC and mandibular LI1 and RI2 and covers the entire enamel surface. One carie is present on the maxillary RM2. It is a root carie on the mesial surface measuring $3.45 \mathrm{~mm}$ mesial-distal by $1.61 \mathrm{~mm}$ buccal-lingual. Hypoplasias are present on the following:

Maxillary Teeth

- RM2, hypoplasia Type 1, $5.04 \mathrm{~mm}$

- RC, hypoplasia Type 1, two hypoplasia present, 2.92 and $4.96 \mathrm{~mm}$

- LC, hypoplasia Type 1, two hypoplasia present, 2.84 and $4.85 \mathrm{~mm}$

- $\quad$ LM1, hypoplasia Type 1, $2.54 \mathrm{~mm}$

- $\quad$ LM2, hypoplasia Type 1, $2.89 \mathrm{~mm}$

Mandibular Teeth

- LM2, hypoplasia Type 1, $2.74 \mathrm{~mm}$

- LM1, hypoplasia Type 1, $3.01 \mathrm{~mm}$

- LC, hypoplasia Type 1, $5.07 \mathrm{~mm}$

- $\mathrm{RC}$, hypoplasia Type $2,4.0 \mathrm{~mm}$

- $\quad$ RM2, hypoplasia Type 1, $2.96 \mathrm{~mm}$
Dental Anomalies/Modifications: None observed.

\section{BURIAL 2}

Burial 2 is the grave of a $45-60$-year-old male buried in a rectangular casket (Figure 3.2 ).

\section{Grave Discovery and Excavation}

Burial 2, the southernmost grave, was located within a homogenous soil deposit, and no evidence of a grave shaft was observed. The burial was impacted or investigated in three different events. The uppermost portion of the skull and grave shaft were clipped by the backhoe trench dug in 2008, but the burial was not observed at that time. During current investigations, no grave shaft or soil color change was observed prior to the initial mechanical exposure of the bones. Burial 2 was accidentally bisected just above the knees, and the lower sections of the legs were removed, while the remainder was left in situ under ca. 4-6 ft of overburden due to the location of the AT\&T cable, which crossed the burial near the hips. The upper leg bones were covered with plastic and loose fill immediately after they were exposed. Because the majority of the burial extended west of the TxDOT right of way, PAI archeologists returned to this area later to excavate the intact portion of Burial 2. In the absence of a grave shaft, four nails - two at the head of the grave and two north and south of the remains-were placed around the burial for mapping control within the AT\&T trench. When the fill protecting the midsection of the burial was removed, it was discovered that it contained the displaced lower leg elements from Burial 2 as well as most of the remains accidentally removed from Burial 3 . The remains from both burials were commingled in the fill, but they were later separated during the laboratory analysis.

\section{Mortuary Characteristics}

Burial Shaft Size and Depth: Homogenous soil made identification of a shaft impossible; therefore, no data could be gathered on the burial shaft. It is estimated that the grave shaft was 


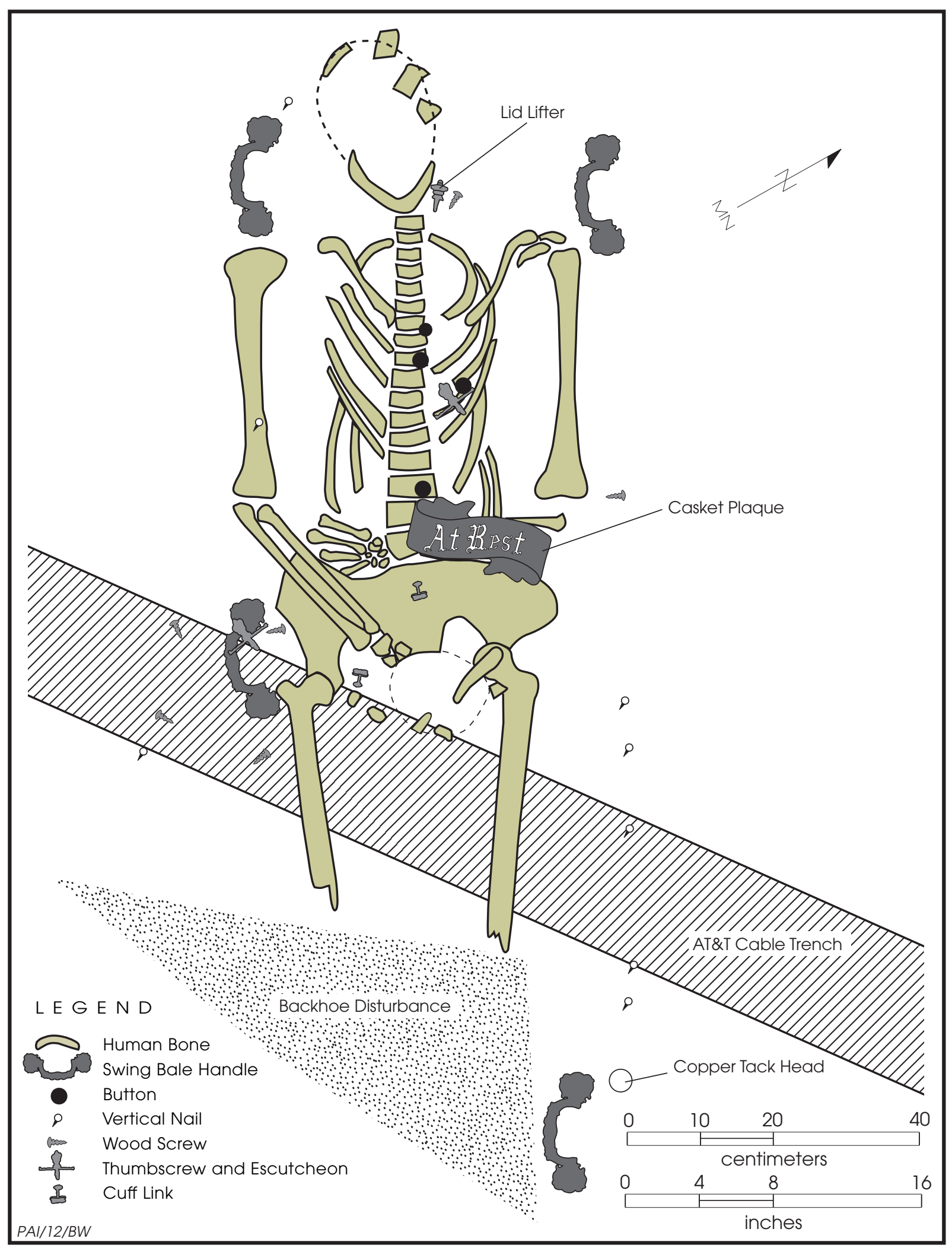

Figure 3.2. Burial 2 map. 
between 1.8 and $2.4 \mathrm{ft}$ wide, but its length is unknown. The burial is estimated to have been about $4 \mathrm{ft}$ below the original ground surface.

Burial Orientation: East-west, with the head to the west. The body was supine in an extended position. The grave shaft orientation (head-tofoot) was 262 degrees.

Casket Description: Based on casket hardware and nail alignments, the casket was rectangular, and no outer box was present. Wood was not observed around the skeleton but was found underlying the bones, immediately above the bedrock. The width of the casket, which was taken from nail alignments along the middle of the burial, was $2.13 \mathrm{ft}$ wide. The lower portion of Burial 2 had been removed just above the knee by the gradall; therefore, the length of the casket is not known.

Casket Hardware: Six swing bale handles, ${ }^{8}$ four thumbscrews and four escutcheons, one burial plaque, and one caplifter were recovered in Burial 2. All of this hardware is white metal. The six swing bale handles are Type 2 . Four of the handles were found in situ, indicating that they were most likely arranged with three handles on either side of the casket. The "At Rest" plaque (Type 2), which originally sat on top of the casket, was found just left of the lower thoracic vertebrae. The caplifter was found to the left of the chin and may have originally been attached to the casket lid to facilitate opening the upper half of the lid. Three of the four thumbscrews are Type 1, as are all four escutcheons. The fourth thumbscrew is a mismatch and is Type 2 . Thumbscrews and escutcheons were found on the upper left side (Type 1) and the lower right side (Type 1 and Type 2). A third set of Type 1 thumbscrew and escutcheon was displaced by the backhoe and later found in the backfill pile along with one handle, several nails, and a fabric tack.

Seventeen common nails, 22 short nails, 20 finishing nails, 1 large nail, and 1 square nail were recovered. The square nail, found in the backdirt pile along with other Burial 2 hardware, was

\footnotetext{
8 As noted earlier, some of the casket handles from Burials 2 and 3 were mixed together in the excavated fill, but they were easily identified and sorted during the analysis.
}

the only artifact type found in all four of the burials. Its context with Burial 2 is questionable. It could be not associated with Burial 2 at all, or a single older nail could have been used when the casket was built. An intermittent alignment of common nails associated with the casket was identified along the north (left) side of the casket between the hip and the lower-left handle. Only a few isolated casket nails were identified in rough alignment along the south (right) side of the casket, implying that the right side was more disturbed during decay of the casket. Backhoe disturbance was also more significant on the south side. One 1-inch screw, one 1.5-inch screw, one screw shank (probably from the burial plaque), two decorative copper tacks, two iron fabric tacks, and two long tacks were recovered.

Personal Items: Two cufflinks, three composite metal buttons, five shell buttons, and two copper eyelets (grommets) were recovered (Figure 3.3). The cuff links were perfectly placed at each wrist. Three iron buttons were generally in line with the lower half of the vertebrae and may have been jacket or vest buttons. One two-hole shell button was found between the $\mathrm{T} 7$ and T8 thoracic vertebrae, and one four-hole shell button was found in Zone C. One shell button was found slightly higher than the metal buttons, near the sternum. All of the shell buttons probably served as shirt buttons. The shirt had a collar style known as an "eyelet collar," as indicated by two tiny copper eyelets that flanked the sternum. Eyelet collars were pinned with a decorative thin metal rod called a collar pin, collar bar, or collar clip used to hold the collar in place. The use of collar pins as a men's fashion accessory began in the early twentieth century and was very popular in the 1920s and 1930s (Schneider 2010).

Burial Position/Taphonomy: The grave is a single primary interment with semiarticulated skeletal elements. The body was supine in an extended position. The head was slightly tilted to the right. Right and left humeri were extended along the sides of the body, and the arms were bent at the elbow with the hands placed on the pelvis. Skeletal elements were disturbed during scraping, with the tibiae, fibulae, feet, and femoral distal epiphyses removed during scraping. The skull was disturbed by exploratory 


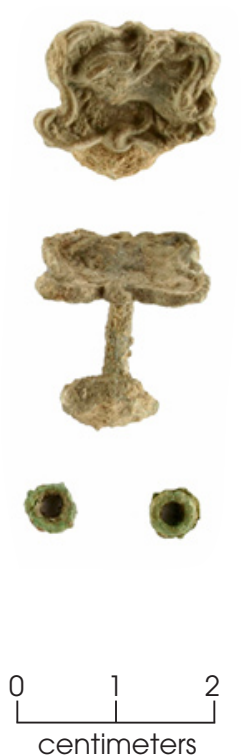

Figure 3.3. Cuff links (top) and collar eyelets (bottom) from Burial 2.

trenching in 2009 with most of the frontal bone and left side of the face removed.

\section{Osteological Characteristics}

Skeletal Preservation: Good to fair.

Sex: Male.

Age: $45-60$ years.

Stature: ${ }^{9} 178.72 \pm 4.37 \mathrm{~cm}, 5^{\prime} 8.7^{\prime \prime}-6^{\prime} .06^{\prime \prime}$

Biological Affinity: Caucasian.

Skeletal Inventory: The skull is in fair condition since many of the bones are missing due to disturbance. The skeletal remains consist of both clavicles; partial scapulae; most of the ribs, though they are fragmented; complete right and left humeri; complete radii and ulnae; most hand elements; partial sacrum; partial left and right ilium; partial right and left ischia; partial left pubis with damaged pubic symphysis; right pubis complete, though pubic symphysis is damaged; femora, which are in good condition but

\footnotetext{
9 Estimated using humerus and radius stature regression formula in Trotter and Gleser (1958): 1.82 $(\mathrm{Hum}+\mathrm{Rad})+67.97 \pm 4.31$. The humerus and radius were utilized because the femora, tibiae, and fibulae could not be reconstructed.
}

could not be reconstructed; partial right patella, partial tibiae; partial right fibula; left fibula in good condition but not reconstructable; most tarsals and metatarsals; most foot phalanges.

Trauma: Healed blunt force trauma is present on the right temporal bone. The lesion is superior to the mastoid process. The defect is $32.11 \mathrm{~mm}$ superior to inferior. Much of the defect is missing due to postmortem damage. The defect probably resulted from a depression fracture. Osteochondrosis dessicans is present on the sternal facet of the right clavicle. The lesion is $8.04 \mathrm{~mm}$ anterior-posterior and $11.07 \mathrm{~mm}$ superior-inferior.

Rheumatic Disease: Whittling of the distal first phalange is present on the right foot. The right second or third middle phalange exhibits whittling and a slight pencil-in-cup morphology. The left first distal phalange also exhibits minor whittling, with large osteophytes on the lateral proximal edge measuring $3.43 \mathrm{~mm}$ proximal to distal. An accessory facet is present between the left middle phalanges two and three. No tuft divots are present. These changes are consistent with spondyloarthropathy, and the involvement with only the distal interphalangeal joints and terminal phalanges is suggestive of psoriatic arthritis (Ortner, 2003:580; Rothschild and Behnam 2005:289; Schumacher, Jr., 1988:151152). Possible diagnoses include rheumatoid arthritis, diabetes (Rothschild and Behnam 2005), or other spondyloarthropathies.

Enthesopathy: Moderate changes, level 2, are present on the flexor ligaments on the palmar surfaces of the first right and left medial phalanges. A third trochanter is present on the left femur at the superior border of the gleuteal tuberosity along the gluteus maximus attachment. The right femur was damaged and unable to be scored for third trochanter presence. The supinator and brachialis insertions on the right and left ulna are strong, level 3.

Additional Observations: The humeri are thin in diameter compared to the size of the head and distal epiphyses and may indicate minor atrophy or limited use. Accessory facets are present on the distal articulations of all metatarsals; most extensive on the first, second, and third. The extensions are present on the superior surface 
of the distal articulation as a result of the hyperdorsiflexion of the metatarsal-phalangeal joints. The facet results from weight being placed on the toes with the heel raised and can arise from kneeling or sitting in a chair. This condition is known as "executive's foot" (Capasso et. al 1998:142). Both the right and left femoral head exhibit an increase in the articular area on the anterior-superior border of the femoral neck. This can result from sitting in a sartorial position (cross-legged) (Capasso et. al 2005:103).

Dental Inventory: Maxillary teeth: RM3, RM2, RP4, RP3, and LI1. Mandibular teeth: RM3, RPM4, RPM3, RI2, LI1, LI2, LPM3, LPM4, LM2.

Dental Pathology: Minor wear is present on all teeth, and resorption of the alveolar surface is only present at maxillary RM3 and RM2. Moderate dental calculus affects the mandibular LP4 and the maxillary RM2. Minor dental calculus was found on the mandibular LM2 and maxillary RM3, RP4, and RP3. One interproximal carie is located on the distal surface of mandibular LP4. The carie measures $1.37 \mathrm{~mm}$. Dental calculus formed at the cement-enamel junction. Hypoplasias is present on the following:

Mandibular Teeth

- $\quad$ LI2, hypoplasia type $5,7.53 \mathrm{~mm}$

Dental Anomalies / Modifications: Ante-mortem dental chipping of the enamel is present on the mandibular LM2. The chipped location is on the mesial lingual side of the molar and angled lingually. An enamel pearl is on the disto-buccal root of mandibular RP3.

\section{BURIAL 3}

Burial 3 is interpreted as the grave of a 20-27-year-old male who was probably buried in a rectangular casket (Figures 3.4 and 3.5).

\section{Grave Discovery and Excavation}

Burial 3 was just south of Burial 2. It also penetrated homogenous soil, and no grave shaft was observed prior to the exposure of bone. Burial 3 was only detected after the excavation of Burial 2. Burial 3 was almost completely removed (up to the chest area) by the backhoe and deposited into the backfill that was temporarily placed over Burial 2 to protect it. Portions of Burial 3, such as the feet and lower legs, were later found intact within large clumps of dirt in this backfill material (see Figure 3.5). Burial 3 was oriented at an odd angle (northwest-southeast). While a general northeast-southwest grave alignment, or cemetery row, can be discerned along the heads of Burials 2, 4, and 1, Burial 3 sits much farther south.

\section{Mortuary Characteristics}

Burial Shaft Size and Depth: Because no grave shaft or soil change was identified, the length of the burial is unknown. The width, based on minimal casket hardware that was left undisturbed, is estimated to be ca. $2.0 \mathrm{ft}$. No ground surface elevations were taken directly above Burial 3, where the current ground surface slopes significantly north, but the estimate of the grave's original depth is $4.15 \mathrm{ft}$.

Burial Orientation: Northwest-southeast, with the head to the northwest. The precise position of the body and the grave shaft orientation could not be determined due to mechanical disturbance of the grave.

Casket Description: Unknown. Although no deteriorated wood outline was preserved, wood remains were found underlying the remaining skeleton. The casket shape was likely rectangular. This assumption is based solely on the similarity of the hardware to that found in Burial 2, which had a rectangular casket.

Casket Hardware: Minimal casket hardware remained undisturbed in Burial 3, and the majority was recovered from either backfill pile or fill redeposited over Burial 2. Six swing bale handles, ${ }^{10}$ one burial plaque, and one caplifter were recovered from Burial 3. An odd mixture of thumbscrews $(n=4)$ and escutcheons $(n=6)$ was recovered, including one mismatched thumb-

\footnotetext{
10 Original field records indicate that five swing bale handles were found in Burial 3 and seven were found in Burial 2 but materials from these two burials were mixed when the majority of Burial 3 was disturbed with the backhoe, and the fill was deposited on top of Burial 2. Subsequent analysis determined that each burial originally had six handles.
} 


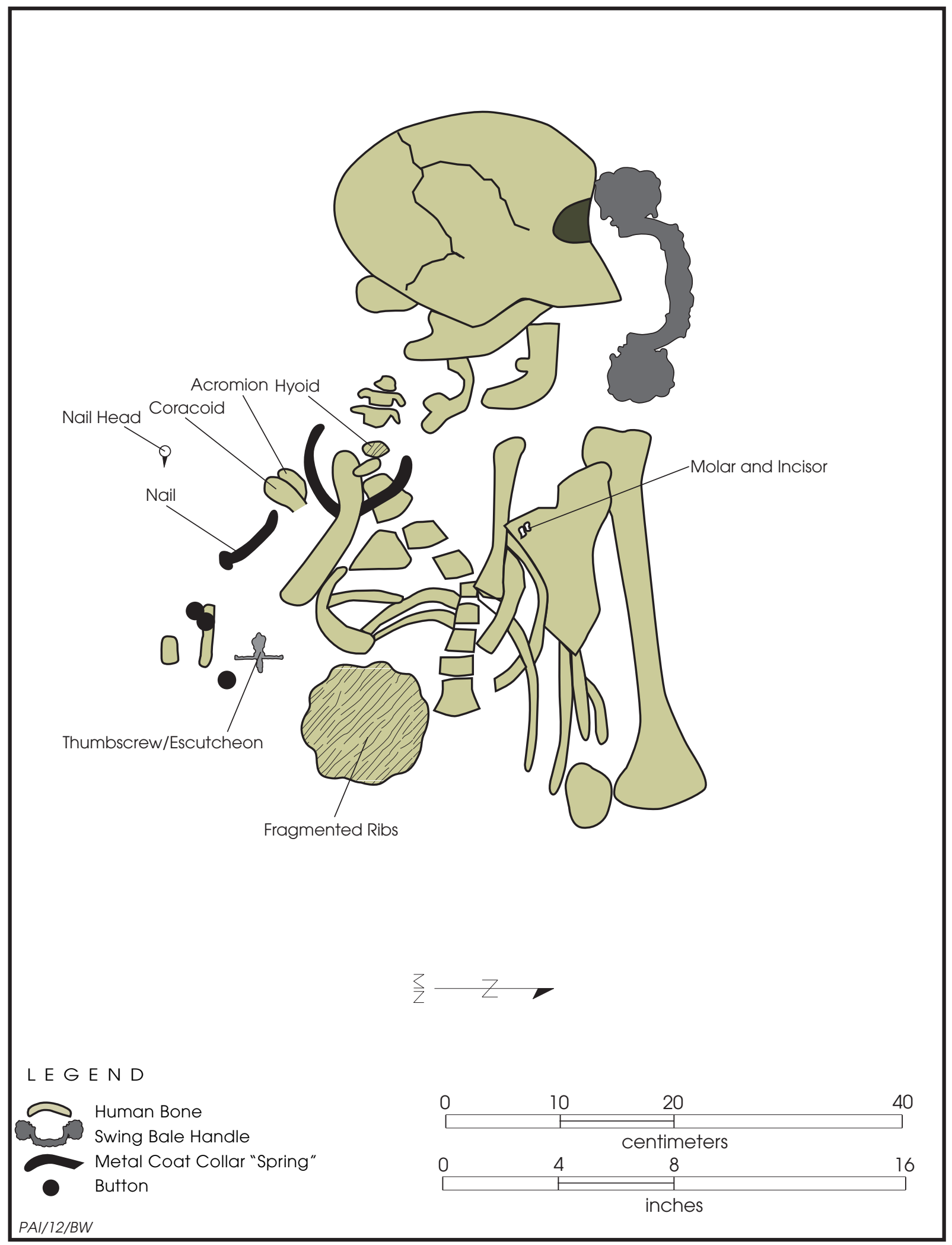

Figure 3.4. Map of the intact portion of Burial 3. 


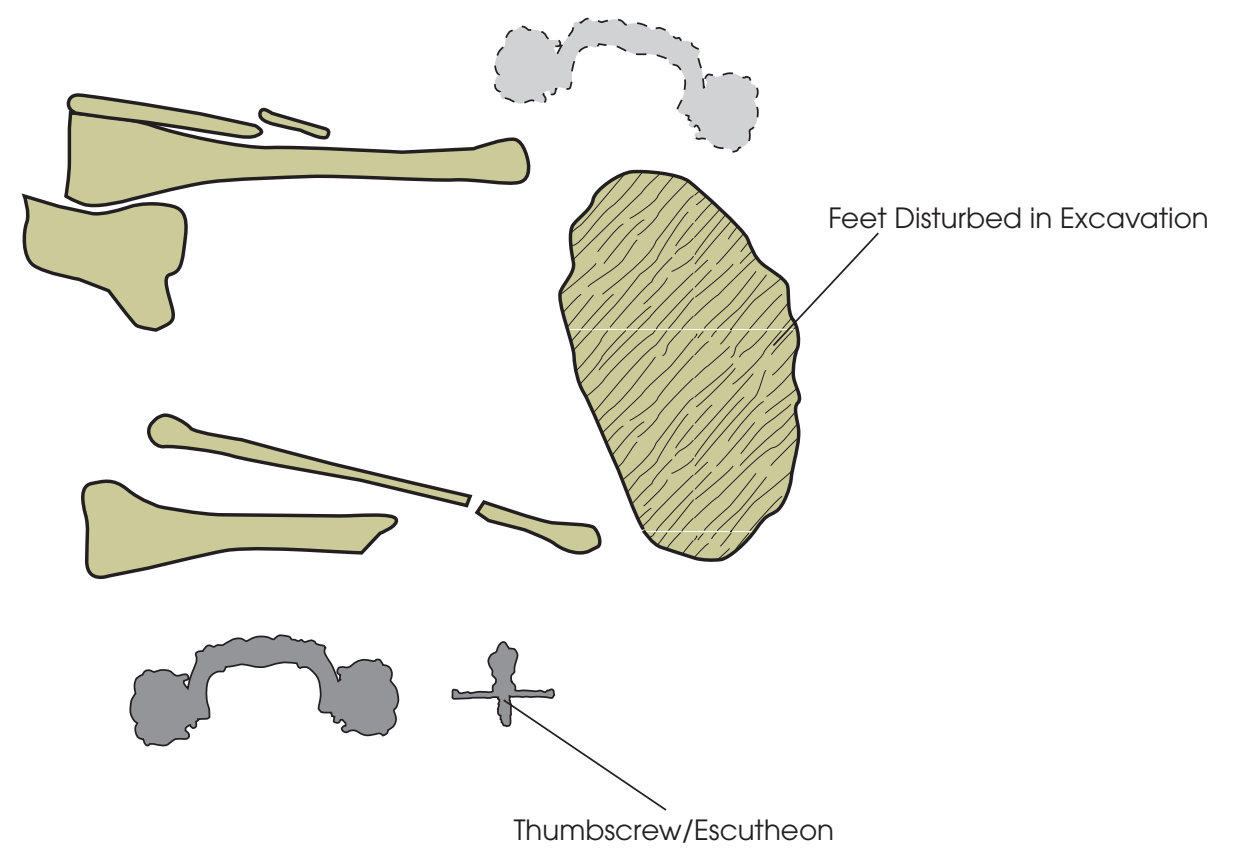

$L E G E N D$
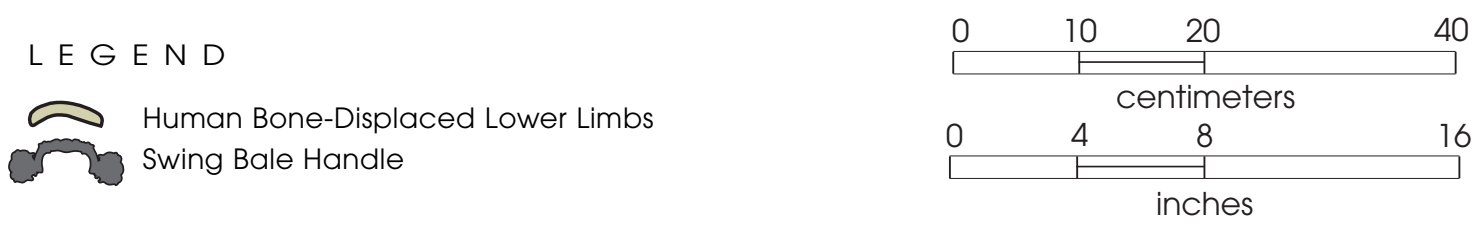

$\mathrm{PAl} / 12 / \mathrm{BW}$

Figure 3.5. Map of lower leg and foot bones of Burial 3 found in a consolidated fill block displaced by machine excavation.

screw. The casket hardware styles are similar to those in Burial 2, but not exactly the same. Like Burial 2, all of these are white metal, and the six swing bale handles are Type 1 and identical in style and size. One of the handles was found in situ to the right of the skull, and two were found in a large clump of dirt where the lower leg and foot bones remained articulated, though not in situ. It is presumed that, like Burial 2, the handles were arranged with three on either side of the casket. The caplifter was in situ near the head, suggesting that it had been located in the center of the upper half of the casket. Four Type 1 thumbscrew-escutcheon sets were recovered (two of which were corroded together). Only one of these sets was found in situ, near the right shoulder; the remaining sets were found in the loose overburden or backdirt pile along with one handle, several nails, a fabric tack. Finally, two independent escutcheons, one Type 1 and one Type 3, were collected from the backdirt. The "At Rest" plaque was found in the overburden but likely was attached to the central portion of the casket lid. 
Thirty common nails, 19 short nails, 15 finishing nails, 2 wood screw shanks, 1 decorative copper tack head, 1 fabric tack, and 1 two-inch screw were recovered. Five nail shanks recovered from the backfill are attributed to Burial 3. One square nail was recovered from the backdirt and also attributed to Burial 3. Its context is uncertain, however, since this was the only square nail recovered.

Personal Items: Personal items consisted of three shell buttons, a possible pin or safety pin shank, and a metal collar spring. The three shell buttons were found in the upper body and neck region and were most likely shirt buttons; each were four-hole with a sewing well. A straight copper pin or shank portion of a safety pin was found on the upper right side of the chest. Finally, a metal coat collar stay or "spring" was found around the neck (Figure 3.6). This long flat metal piece was found fragmented in situ, looped around the neck, with the two metal ends crossing over each other near the clavicle. The item was advertised in the 1895 Montgomery Ward (1969:87) catalog, which describes it as a "Patent Adjustable Coat Collar Spring. The spring is made from best oiltempered steel, formed to fit the coat under the collar. By its use the coat collar and lapels always retain their shape. SAVES the wear on button holes, which disfigures a coat so quickly." This item is pictured in the catalog and inscribed with "STONE'S / PAT. JULY 17, [18]83." U.S. Patent No. 281, 578 was issued to M. C. Stone on July 17, 1883 for a "coat-spring" (Stone 1883). The patent drawing is very similar to the illustration in the 1895 Montgomery Ward catalog.

Burial Position/Taphonomy: The body was supine and probably in an extended position. The arms were extended along the sides of the body, but hand placement cannot be determined. The head and mandible were rotated to the left, and a handle lug was found in the eye orbit, indicating that the casket wall collapsed inward. The cervical and upper thoracic vertebrae were shifted laterally to the right in a similar manner to Burial 1. Though no evidence of a root was present, it is highly probable that the lateral movement was caused by a root since the vertebrae did not exhibit characteristics consistent with scoliosis. All skeletal elements distal to the mid-chest were disturbed during scraping. The body was angled to the plane of

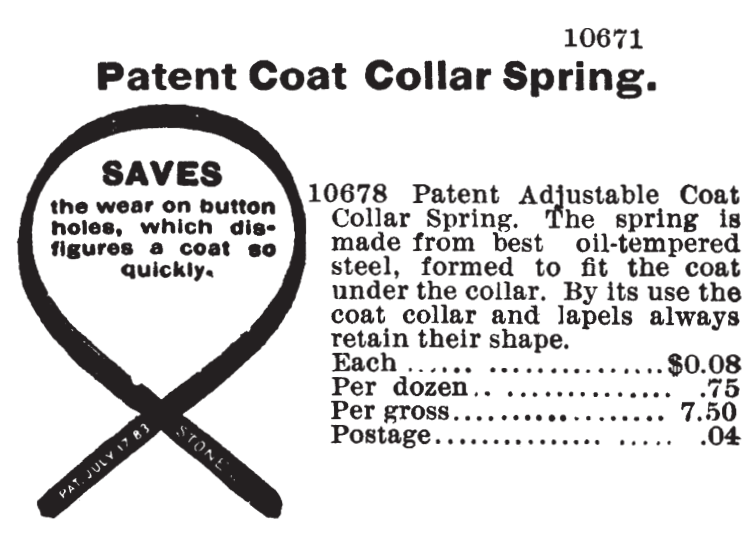

Figure 3.6. Adjustable coat collar spring from the 1895 Montgomery Ward Catalog.

the scraping, and this left the right humerus in situ while the left humerus, below the proximal third of the shaft, was disturbed. Tibiae, fibulae, and feet, along with some coffin hardware, were found articulated near the location of Burial 2. It appears the remains were removed during scraping and stayed articulated when that section of sediments was used to cover disturbed remains in Burial 2.

\section{Osteological Characteristics}

Skeletal Preservation: Good.

Sex: Male.

Age: 20-27 years.

Stature: ${ }^{11} 169.1 \pm 3.74 \mathrm{~cm}, 5{ }^{\prime 2} .2^{\prime \prime}-5 ’ 5.1 ”$.

Biological Affinity: Caucasian.

Skeletal Inventory: The skeletal remains consist of a partial skull, though highly fragmented smaller bones such as sphenoid and lacrimals were unable to be scored; partial right maxilla and palatine; partial left mandible; partial nasals; both clavicles; partial scapulae; small sternal fragments; hyoid; all ribs, though they were fragmented; complete right humeri, radii and ulnae; most hand elements; sacrum; partial right and left ilium; complete ischae; left pubis; partial right pubis; complete femora, though

\footnotetext{
$\overline{11}$ Estimated using femur and tibia stature regression formula in Trotter and Gleser (1958): 1.26 (Fem+Tib) $+67.09 \pm 3.74$.
} 
postmortem damage to the shaft required reconstruction; right patellae; fibulae, though unable to be reconstructed; complete tibiae; all tarsals and metatarsals; most foot phalanges.

Trauma: The left fifth metacarpal exhibits a fully healed greenstick fracture of the shaft. Osteochondrosis dessicans is present on the left superior facet of cervical vertebra six.

Degenerative Pathology: Osteophytes are present on the lateral proximal surface of the first distal phalange. The osteophytes are $4.63 \mathrm{~mm}$ in length.

Additional Observations: The proximal third and head of both fibulae exhibit lateral bowing. It is unclear if this is a result of rickets or was caused by root disturbance, as seen in Burial 1. An accessory facet is present on the superior-lateral edge of the distal articulation of the left fifth metatarsal. Accessory facets are present on the sacrum at the first and second sacral foramina. The facets are ovid and convex. Due to the condition of the ilium, facets on the surface of the posterior superior iliac spine could not be identified. A palatine torus is present, although it is small.

Dental Inventory: All teeth are present, but maxillary RM1, RM2, and RM3 and mandibular left M1, LP4, and LP3 are not in the occlusion, and the associated alveolar bone is missing.

Dental Pathology: Minor alveolar resorption affects all of the maxilla. Minor alveolar resorption is present on the mandibular LP3 and LC, and moderate resorption is present on LI1 and LI2. The mandibular RI1, RI2, RC, RP3, RP4, and LM1 could not be scored due to damage of the alveolar bone. Dental calculus is present on all teeth. Minor calculus formed on mandibular LM3, LM2, LP4, LP3, RM1, RM2, RM3, and all of the maxillary teeth except RP3 and LP4. These exhibit moderate calculus. Left mandibular C, RP3, and RP4 also have moderate calculus deposits. Heavy calculus deposits, which obscured observation of hypoplasia, are on the mandibular LI2, LI1, RI1, RI2, and RC. Hypoplasia is present on the following:

Mandibular Teeth

- LC, hypoplasia Type $1,3.78 \mathrm{~mm}$ and $4.85 \mathrm{~mm}$
Dental Anomalies/Modifications: Wear and polish is present on the anterior dentition. Wear is highest on the maxillary central incisors on the lingual surface. Corresponding wear is present on the mandibular incisors on the labial surface. Canines and the first premolars also exhibit a flattened and polished surface with wear on the distal lingual surface of the canines and P3 wear on the lingual cusp, mesial surface. Corresponding wear is on the mandibular canines and P3.

\section{BURIAL 4}

Burial 4 is the grave of an 18-month-old child of indeterminate sex, buried in a rectangular wooden casket or box (Figure 3.7).

\section{Grave Discovery and Excavation}

Burial 4 was located just north of Burial 1. The grave was first identified in the south profile of the Burial 1 excavation. Here, an extant soil balk had been used to step down from the ground surface into the Burial 1 excavation area. An alignment of nails was observed eroding out of the soil south of Burial 1. The backhoe was brought in to remove ca. $3 \mathrm{ft}$ of overburden. A clear grave shaft outline was observed for Burial 4. Like Burial 1, Burial 4 was located far south of the Elm Creek bank, where two distinct soil colors provided contrast between the fill and undisturbed sediment.

\section{Mortuary Characteristics}

Burial Shaft Size and Depth: The grave shaft was $0.72-0.85 \mathrm{ft}$ wide and $2.9 \mathrm{ft}$ long. The depth ranged from 3.69 to $3.90 \mathrm{ft}$ below the surface (618.143-618.218 ft amsl).

Burial Orientation: East-west, with head to the west. The body was supine in an extended position. The grave shaft orientation (head-to-foot) was 270 degrees.

Casket Description: The child's remains were enclosed inside a rectangular wooden container. Although no definitive mortuary hardware was found, the substantially preserved wood remains are presumed to be from a casket, and 


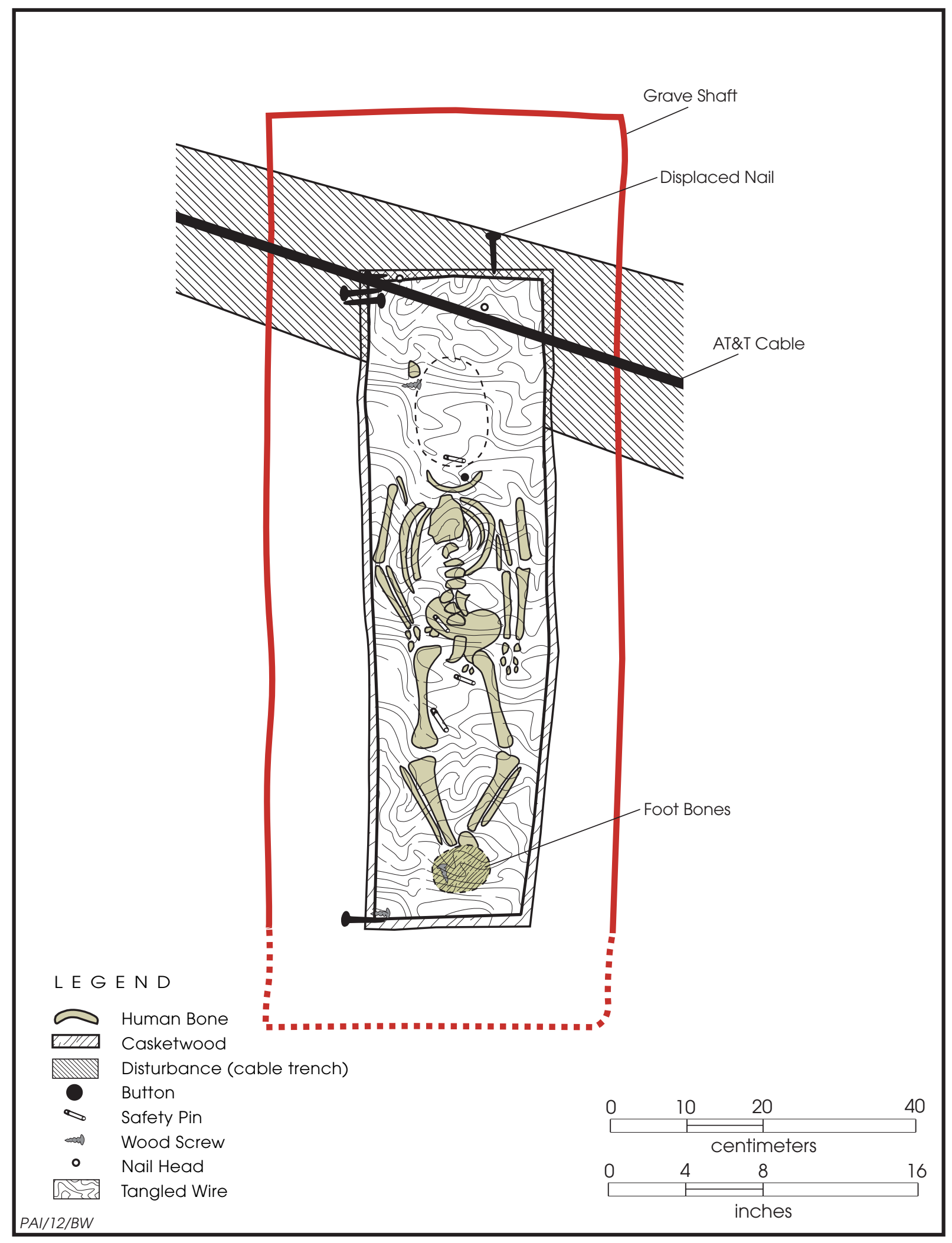

Figure 3.7. Burial 4 map. 
no evidence of an outer burial box was found. In fact, portions of the base and north (left) side of the caskets were still virtually intact, retaining both their original shape and height. The casket was $34.98 \times 10.22$ inches and probably originally measured $3 \mathrm{x} 1 \mathrm{ft}$.

Casket Hardware: No handles or other casket hardware were associated with this burial other than nails and screws. Sixteen extra-large nails, four 1.25-inch wood screws, and 35 fabric tacks were recovered.

Personal Items: Personal items consisted of five safety pins, three snaps, one shell button, and an abundance of fine wire fragments found throughout the casket. The safety pins were copper $(n=3)$ and iron $(n=2)$. One copper and one iron safety pin were found on the left side of the head, and the other was within the head area. These may have served as attachments for some sort of head wrap or ornamental cap. ${ }^{12}$ One copper and one iron safety pin were found in the pelvic region and certainly served as diaper pins. Three copper snaps were found just below the mandible and most likely were fasteners to a dress or baptismal gown. These fasteners are usually found on the backside of the gown. The shell button is a two-hole type with no sewing well. It was found on the left side under the left canine and probably decorated the front of the gown.

Large amounts of fragmentary wire were found throughout the casket, both on top of and intermixed between the bones. The wire is very thin (0.054 inches in diameter), and pieces were less than 2 inches long. This wire mass is interpreted as floral wire from a casket wreath or other floral decoration that was laid over and/or around the body prior to burial. Internet research revealed numerous images of Victorian-era death photographs with flower wreaths surrounding the body, but few had flowers across the entire body (Bien 2013; Frater 2012). In child death photos depicting flower wreaths, the flowers were around the body, pinned on the inside of the lid, or on top of the casket (either in addition to or instead of inside the casket).

$\overline{12}$ One example of a puffy headdress was found in a child's death photo from the Victorian era (Libra13Witch 2012).
Finally, a prehistoric unifacial scraper was found within the AT\&T cable trench that cut through the grave, above the top of the child's skull. The artifact is intrusive and clearly entered the burial feature through the trench. The chert scraper is 1.53 inches long, 1.42 inches wide, and 0.28 inches thick.

Of all the personal items recovered with Burial 4, only the iron safety pins and the snaps provide useful chronological information. The iron safety pins are a relatively modern style with a folded metal guard on one end. This improved style with a "sheet metal guard" was patented in 1900 (Patent No. 643,261; Boden 1900). This type of safety pin was found in four of the late period (1900 to 1907) burials at the Freedman's Cemetery in Dallas (Peter et al. 2000:426, Figure III-73). Similarly, the clothing snap, with its distinctive ball and socket fastening, was patented in 1902 (Patent No. 707,054; Dowse 1902).

Burial Position/Taphonomy: The body was supine in an extended position. Arms were placed along the sides with the hands to the sides of the pelvis and palms facing anterior. The legs were rotated laterally at the knees with the knees semi-flexed at 150 degrees, feet touching.

\section{Osteological Characteristics}

Skeletal Preservation: Good.

Sex: Indeterminate.

Age: 1 to 2 years.

Dental development estimates age-at-death at 1 year \pm 4 months, humeral length $1.5-2$ years, femoral length 1-1.5 years, clavicle length $1.5-2$ years, and pars basilaris length 1 year \pm 3 months.

Stature: Indeterminate.

Biological Affinity: Indeterminate.

Skeletal Inventory: The skull was highly fragmented, and time did not allow reconstruction to assess the presence of small bones such as the lacrimals and nasals. The skeletal remains con- 
sist of parietals, frontal, and occipital; mandible; left clavicle; partial right clavicle; scapulae; sacrum; right and left os coxae; all vertebrae; partial ribs; shaft of the right and left humeri; shaft of the right and left ulnae and radii; shaft and distal epiphyses of the right and left femora, with damage to the distal third of the left femoral shaft; shafts of the right and left tibiae and fibulae; most carpals, metacarpals, tarsals, metatarsals; and phalanges.

Pathology and Taphonomy: No pathology is present on the skeletal elements. Much of the cortical bone is eroded due the depositional environment.

Dental Inventory: Maxillary teeth were not in the occlusion, and associated alveolar bone could not be identified. Maxillary and mandibular teeth included the right and left Permanent M1, dM2, $\mathrm{dM} 1, \mathrm{dC}, \mathrm{dI} 2$, and dI1. Mandibular right and left I2 were missing due to congenital absence, and permanent left and right I1 were visible.

\section{Dental Development:}

Maxillary Teeth - right and left

- Permanent M1, 3-cusp outline complete

- $\quad \mathrm{dM} 1$, 9-root length $1 / 4$

- $\mathrm{dC}, 6$-crown complete

- $\mathrm{dI} 2,10$-root length $1 / 2$

- dI1, 10-root length $1 / 2$
Mandibular Teeth

Left

- Permanent M1, 3-cusp outline complete

- $\quad \mathrm{dM} 2,6$-crown complete

- $\quad \mathrm{dM} 1$, unable to score because in crypt

- $\mathrm{dC}, 9$-root length $1 / 4$

- dI2, congenital absence

- $\quad$ II1, 10-root length $1 / 2$

- Permanent I1, 4-crown $1 / 2$ complete Right

- Permanent M1, 3-cusp outline complete

- dM2, 6-crown complete

- $\quad \mathrm{dM} 1$, unable to score because in crypt

- $\mathrm{dC}, 9$-root length $1 / 4$

- dI2, congenital absence

- $\quad \mathrm{dI} 1,10$-root length $1 / 2$

- Permanent I1, 4-crown $1 / 2$ complete

Dental Pathology: None present.

Dental Anomalies / Modifications: None present. 


\section{TYPOLOGY AND ANALYSIS OF BURIAL CONTAINER HARDWARE}

Jeremy W. Pye

In November 2012, Prewitt and Associates, Inc. contracted with Jeremy W. Pye ${ }^{13}$ to analyze historic burial container hardware recovered from four unmarked graves at Roberts Cemetery (Table 4.1). The primary objective of the analysis was to infer the most likely dates for the four burials by identifying the types of hardware represented and the manufacture and common usage dates for those materials. The analysis was done by comparing the Roberts Cemetery hardware collection to United States patent records $(n=2,615)$, period manufacturers' trade catalogs $(\mathrm{n}=406)$, and archeological cemetery excavation literature $(\mathrm{n}=206)$. Supporting data for the identifications and interpretations of the hardware are presented in three tables in Appendix A. These tables summarize the specialized mortuary hardware and general hardware catalogs featuring mortuary furnishings (Table A.1), the published and unpublished historic cemetery reports used for comparisons (Table A.2), and specific comparisons of mortuary hardware from Roberts Cemetery with that reported from other historic cemeteries (Table A.3).

The analysis and historical study of burial container hardware and other mortuary artifacts is crucial in establishing a useful discourse between multiple lines of evidence recorded in historical cemetery investigations. Exact identification of types and styles of burial container hardware and other mortuary artifacts is vital in establishing the chronology of burial, particularly when dated grave markers are absent or when markers have been displaced. Variations in hardware styles and forms, as well as materials of manufacture, indirectly reflect aspects of socioeconomic class, status, and community involvement in the funeral process (Bell 1987, 1990; Davidson 1999, 2004; Little et al. 1992; Pye 2007). Additionally, the specialized burial container hardware introduced into the archeological record in early-twentieth-century contexts reveals the deepening control of the professional funeral industry in the production and distribution of funeral merchandise.

\section{METHODOLOGY}

This analysis was conducted using the methods established by Davidson (1999) for the classification of hardware from the Freedman's Cemetery project in Dallas, Texas. Essentially, a new type was designated whenever a different artifact form/style (or combination of elements) was encountered. Davidson (2006:120-121) gives the example, "the first thumbscrew ... was given the type designation Thumbscrew Type 1. . . [I]f the next burial excavated contained a thumbscrew with an even slightly different design motif, [then] it was assigned a new type number (e.g., Thumbscrew Type 2)."

Following Davidson (1999, 2006:121), these artifacts were dated and contextualized through three lines of evidence: patent dates, dates derived from period hardware catalogs, and known dates of cemetery use. A fourth line of evidence-the estimated interment ranges of burials from previously excavated cemeteries-can be included, but it must be critically analyzed based on the previous lines of evidence.
13 Department of Anthropology, University of Florida. 


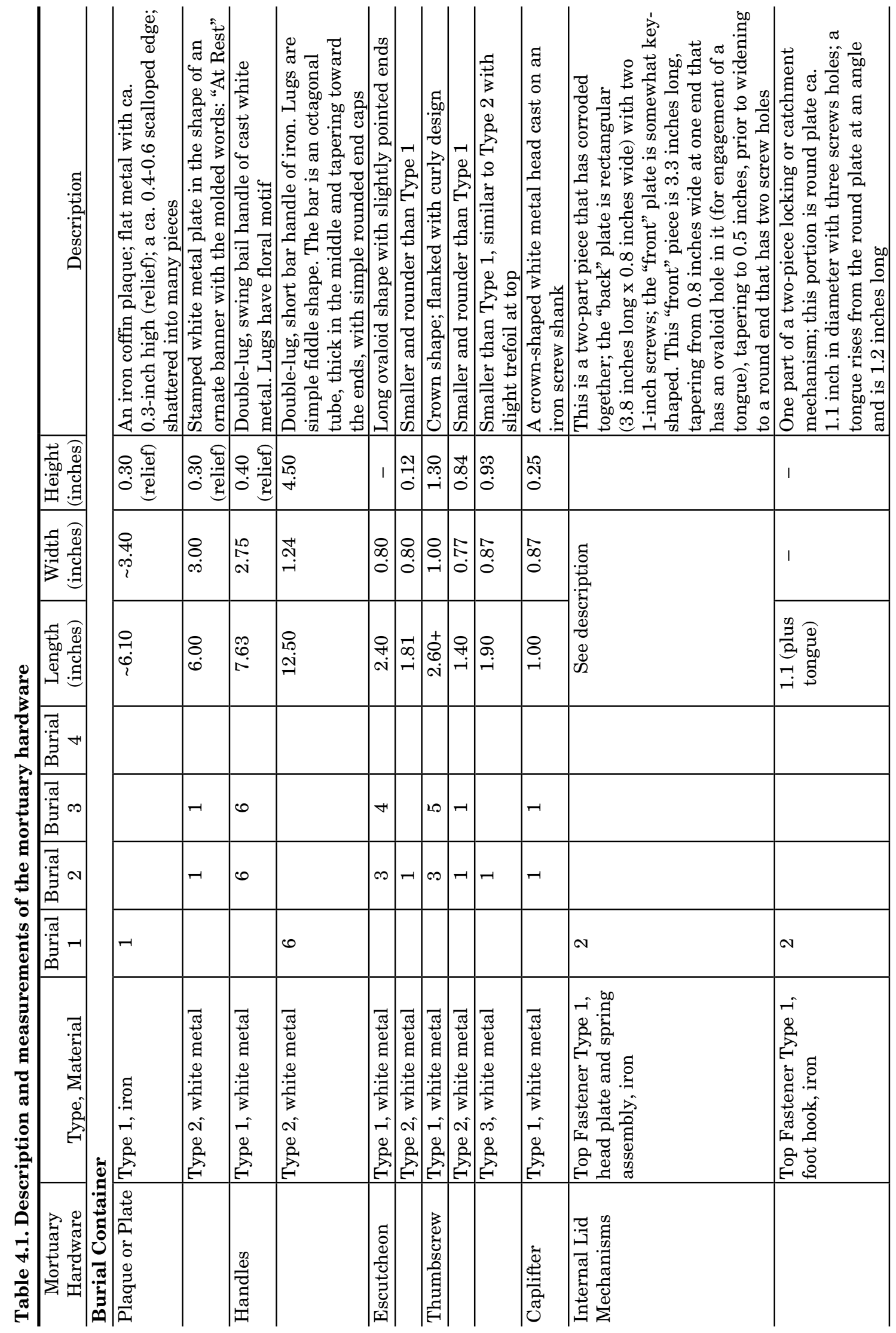




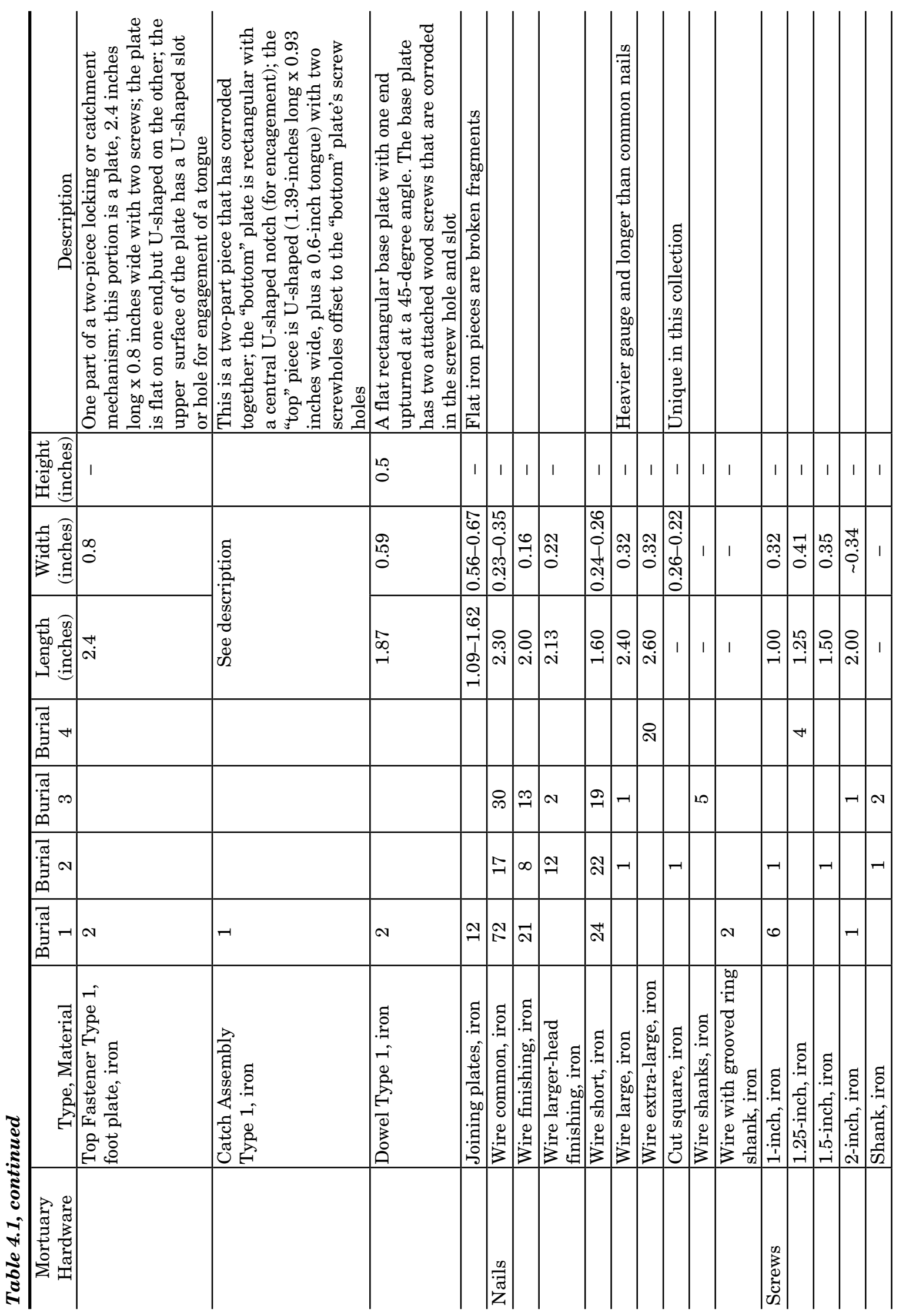




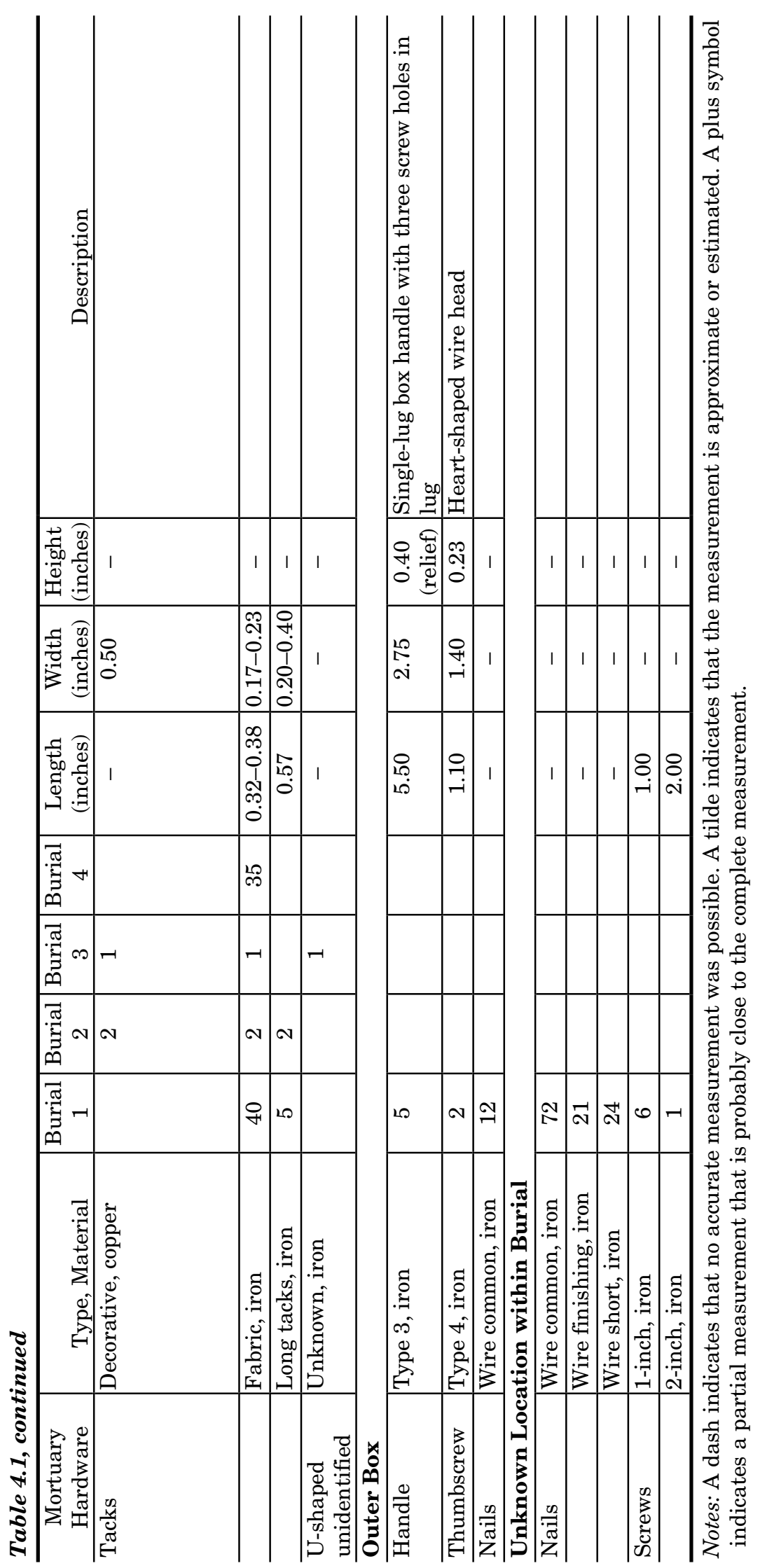




\section{United States Patent Records: Utility Patents (1839-1965)}

For this analysis, 2,160 utility patents related to burial containers, burial container hardware, and other types of mortuary merchandise that dated between 1839 and 1965 were viewed through the United States Patent Office (2011) online database during this analysis. Searches were restricted to between 1800 and 1965 and used the primary search terms "casket" and "coffin." It is extremely likely that pertinent patents have escaped the search due to simplicity of the search terms, flaws in the PDF OCR process, and human error in database entry. Exact and similar matches to hardware recovered from the Roberts Cemetery burial excavations are presented in Table A.3.

\section{United States Patent Records: Design Patents (1843-1965)}

In addition to patents awarded for utility, or function, 455 design patents related to burial containers, burial container hardware, and other types of mortuary merchandise that dated between 1843 and 1965 were viewed through the United States Patent Office (2011) online database during this analysis. Searches were restricted to between 1800 and 1965 and used the primary search terms "casket" and "coffin." It is extremely likely that pertinent patents have escaped the search due to simplicity of the search terms, flaws in the PDF OCR process, and human error in database entry. Exact and similar matches to recovered hardware from the Roberts Cemetery burial excavations are presented Table A.3.

\section{Manufacturers' Trade Catalogs}

For this analysis, 406 period mortuary hardware trade catalogs and price lists dating between 1797 and the present were examined for comparative purposes (see Table A.1). These catalogs were either viewed at several different libraries, museums, and companies throughout the country or are in my personal collections or that of colleagues. Most catalogs utilized were complete; however, some were only partial copies. Care should be taken in historic mortuary artifact analysis to identify exact stylistic matches to make definitive statements about possible temporal range or manufacturer. Sometimes, however, in the absence of exact matches, similar types may be identified. Highlighting similar forms can shed light on a general time period for a particular type. Exact and similar matches to recovered hardware from the Roberts Cemetery burial excavations are presented in the artifact comparison table (see Table A.3).

\section{Previous Historic Cemetery/ Burial Excavation Reports}

Also consulted were 206 reports of excavated historical period cemeteries (see Table A.2). This line of evidence is the least reliable in many cases for several reasons. The first is that mortuary artifacts recovered from burial contexts are often in a poor state of preservation. Poor preservation masks stylistic and form differences and often makes it difficult to make definitive comparisons. The second is that many older, and even some recent, archeological cemetery relocation reports either do not provide clear pictures (or illustrations) of recovered hardware and other artifacts, or they do not provide any pictures at all. To merely note that a burial contained six thumbscrews and four handles is not helpful for the purpose of comparison.

In historic cemetery relocations, it is a rare occurrence that death or interment dates are known. Circumstances leading up to the necessary removal of historic burials often involve a break in the social memory of the cemetery or burial, loss of historical record of the cemetery or burial, erasure of the aboveground presence of the cemetery or burial, and potentially the marginalization of or discrimination against the cemetery population. Assuming that preservation of mortuary artifacts is fair to good, and pictures or illustrations are presented in archeological reports, scholars become dependent on the knowledge of the individual cemetery researchers to make accurate observations of artifacts and derive appropriate chronologies for burials. Many archeologists conducting historic cemetery projects for the first time, or who conduct such projects infrequently, do not have enough knowledge about the mortuary artifacts, or access to historic mortuary catalogs, to make good temporal estimations. In recent years, with the greater accessibility of patent records online and the building of a larger library of period mortuary merchandise catalogs, our abilities to 
make reliable temporal estimates have greatly increased.

\section{MORTUARY ARTIFACT DESCRIPTIONS AND TYPOLOGY}

A contextual discussion of each mortuary artifact form encountered during the Roberts Cemetery excavations will be presented, followed by a description of each type. For more descriptive information about many of the nineteenth- and early twentieth-century general hardware types, see Davidson $(1999,2004)$ and Mainfort and Davidson (2006).

\section{Internal Burial Container Elements}

Internal burial container hardware is an extremely important part of any historic cemetery artifact analysis. These elements are what held the burial container together, and therefore they elucidate key aspects of change and variation in construction technique. These changes in construction took place over time due to technological innovation, which means that internal hardware is often a valuable temporal indicator.

Within historical archeology and material culture studies, a vast literature exists on the production and history of nails (Adams 2002; Baackes 1896; Benson 1983; Edgerton 1897; Edwards and Wells 1993; Epstein 1981; Fontana 1965; Fontana and Greenleaf 1962; Jurney 1987; Loveday 1983; Michael 1974; Nelson 1963, 1968; Phillips 1989; Priess 1970, 1973; Wells 1993, 1998; Young 1991). Rarely, however, are nails (or tacks) given appropriate analytical treatment in historic mortuary archeology reports.

Even less attention is given to the various esoteric complex fastening devices and other internal hardware used by burial container manufacturers in the late-nineteenth and twentieth centuries. These devices were used to secure the lid of the coffin or casket, secure the viewing window cover, allow for the viewing window to slide and lock closed, secure the closure of drop casket sides, as well as support the opening and hinging of burial container lids. An 1883 advertisement from the Stein Mfg. Company of Rochester, New York, presents, "The Most Serviceable Invention of the Age...Our 'Patent Fastener,' For Casket Tops" (Figure 4.1). While it is not specifically evident from the illustration or patent research which fastener they are referring to, the ad attests to the fact that this "perfect boon to the funeral director" was a major turning point in the industry and therefore should be addressed in greater detail.

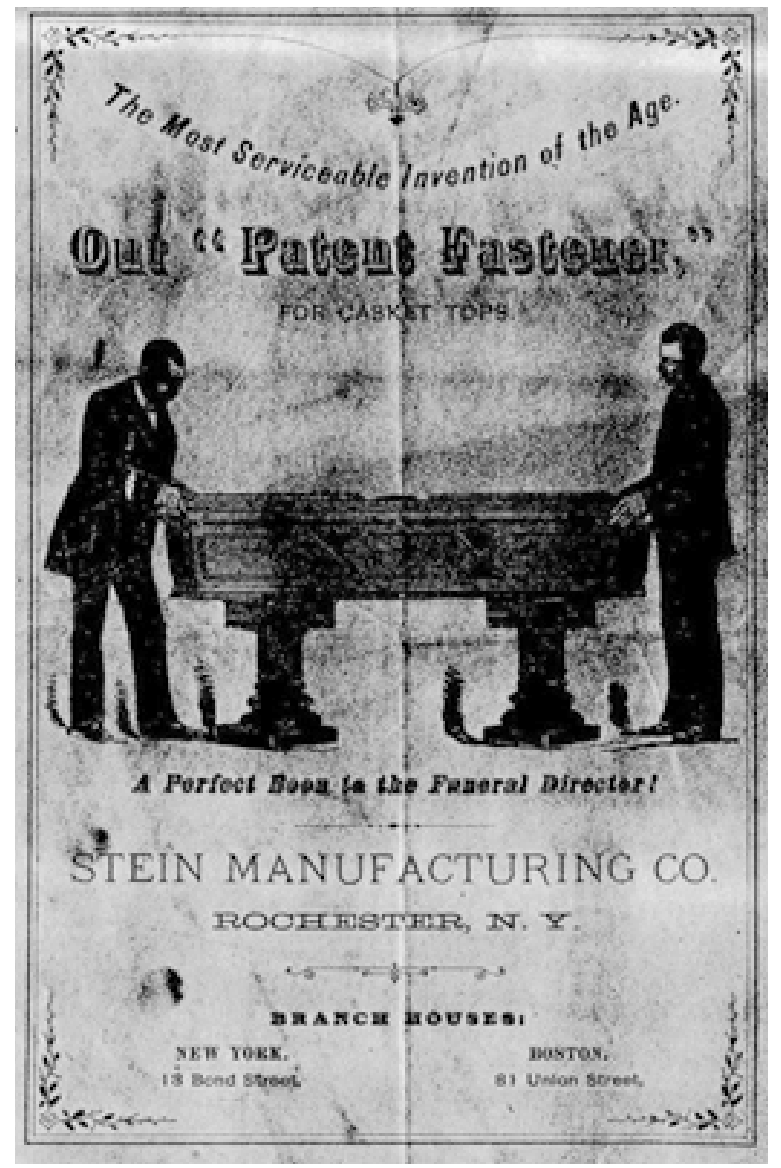

Figure 4.1. An 1883 advertisement for Stein Manufacturing Company's "Patent Fastener" for casket tops.

The few authors of historic cemetery excavation reports who attempt to accurately identify complex internal hardware elements are hindered by the general lack of preservation of ferrous materials or by a lack of knowledge of hardware function and hardware terminology. These artifacts are often classified collectively in such reports as latches (Dockall, Powell et al. 1996), iron closures (Davidson 1999), or even miscellaneous hardware (Davidson 2006). Davidson (2006) did make a concerted effort to present adequate discussions of the few complex internal hardware elements recovered from in the Becky Wright and Eddy cemeteries near Fort 
Smith, Arkansas, but he did not have access to catalogs or patents to assist in his work. The most informed discussions of internal hardware come from Trinkley et al. (2011) and Pye (2011b). Hopefully, the following description of the Roberts Cemetery internal hardware elements will add to the growing body of knowledge about these mortuary artifacts.

\section{Nails}

Nails are an essential and ubiquitous form of construction hardware used in the production of burial containers in the nineteenth and earlytwentieth centuries. There were three general types of nails in use in various regions and times in the nineteenth century: hand-wrought, square-cut, and wire. Hand-wrought nails were commonly used during the seventeenth and eighteenth centuries until the introduction of the cut nail around 1800 (Davidson 2006:115116). Cut nails declined in use toward the end of the nineteenth century as wire nails hit the market and became more widely used in the casket industry.

Based on Fontana and Greenleaf (1962), Fontana (1965), Edgerton (1897) and other reliable sources, Davidson (2006) has placed the introduction of wire nails to common usage in the funeral industry between 1890 and 1900 . In estimates of burial chronology, this date has been conventionalized to ca. 1895; the period prior to this date should be characterized by the exclusive use of cut nails, or the absence of wire nails. This dating has held true for comparable burials accurately dated by other artifact associations or historical records from Arkansas (Cande 1995:161-168, 249-251), Freedman's Cemetery in Dallas, Texas (Peter et al. 2000), Meadowlark Cemetery, Kansas (Pye 2007), and elsewhere. Turn-of-the-century hardware cata$\operatorname{logs}$, however, attest to the fact that while wire nails became more popular, cut nails continued to be sold into the twentieth century (Figures 4.2-4.4).

The archeological literature (see Table A.2) suggests that the most common sizes of nails used in the construction of coffins and caskets were smaller nails (i.e., 4d, 6d, and 8d) (Davidson 1999, 2006). It is reasonable to expect that there would be a certain degree of uniformity in the sizes of nails used for mass-produced coffins and caskets, and in fact, the most common

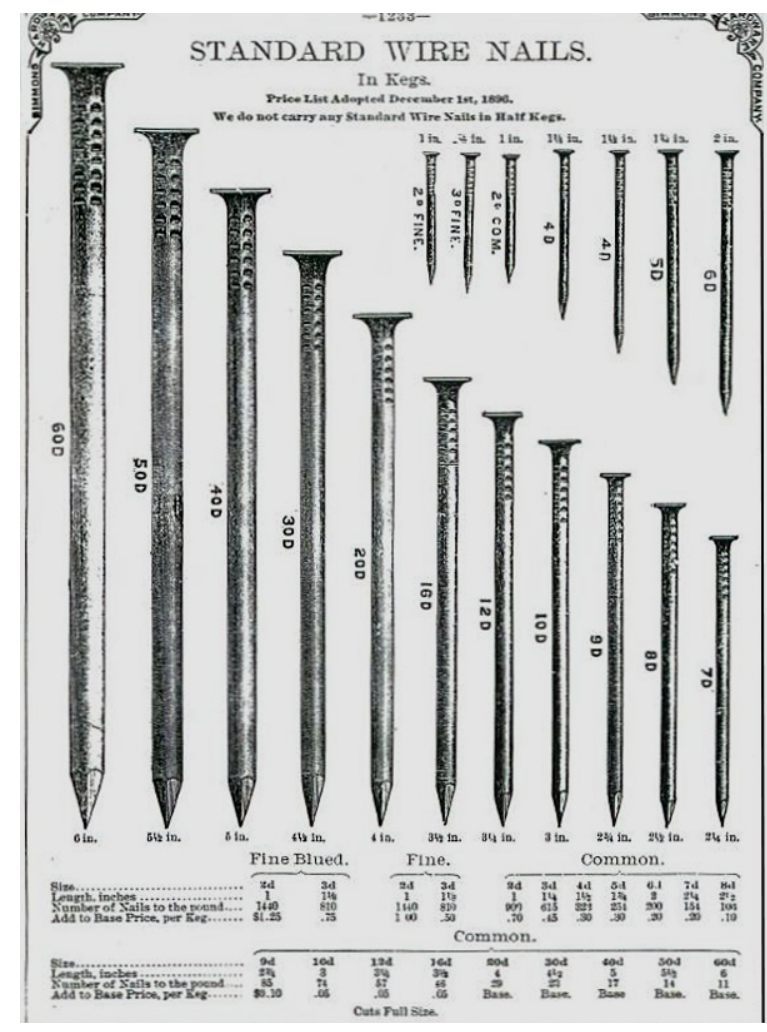

Figure 4.2. Selection of wire nails offered for sale on page 1837 of the 1903 Simmons Hardware Company general catalog.

nails listed in the archeological literature are $6 \mathrm{~d}$ and $8 \mathrm{~d}$ cut nails, with a bias toward the use of $6 \mathrm{~d}$ nails in both the cut and wire varieties (Davidson 2006:101).

No in-depth analysis of nails from the Roberts Cemetery excavations was conducted, mainly due to the poor preservation of the excavated ferrous materials. All burials contained at least some nails (Figure 4.5). Most of them were wire nails, placing the collection squarely in the twentieth century. It is noteworthy, however, that one cut nail was identified in Burial 2, suggesting that this burial probably took place somewhat earlier than the others.

\section{Lining Tacks}

The primary functions of lining tacks were to affix cloth lining to the interior of the burial container or to affix cloth covering to the exterior of the container. In some cases, tacks were arranged in a decorative pattern on the surface of the container. These tacks are typically small, with an iron shank and head (flat iron, domed 


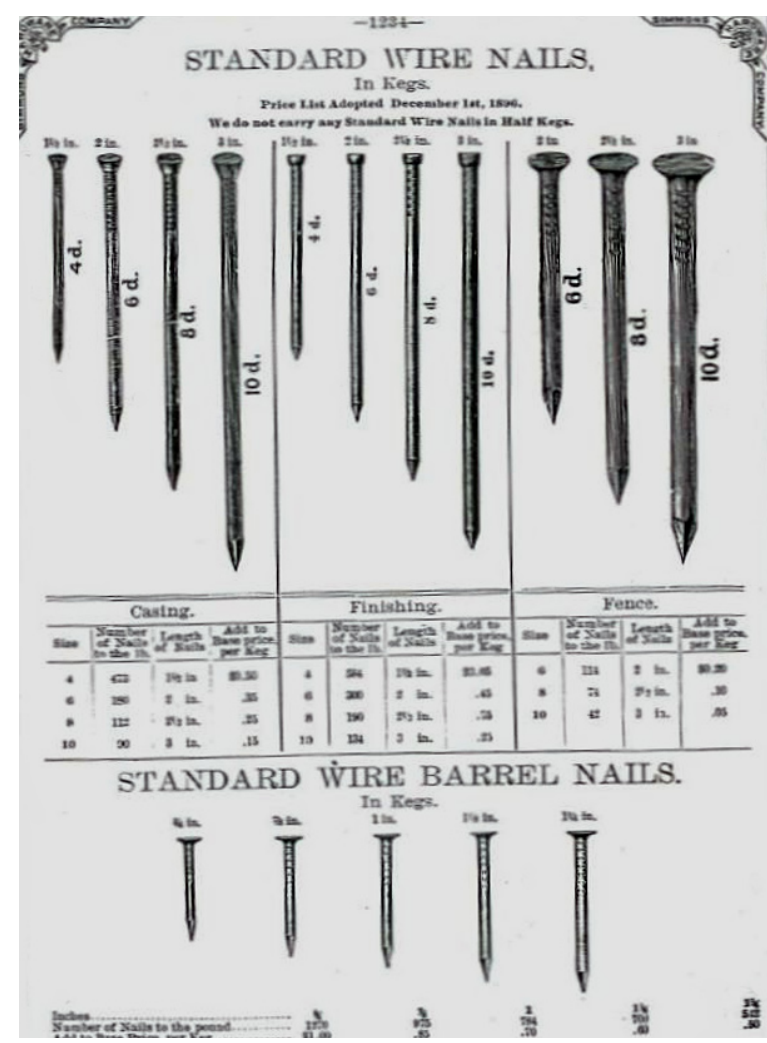

Figure 4.3. Selection of wire nails offered for sale on page 1838 of the 1903 Simmons Hardware Company general catalog.

iron, domed, brass, domed china, or domed lead/ white metal; Figure 4.6). Often the iron shank deteriorates or becomes detached and only the head remains (Davidson 1999). Since the presence or absence of lining or cloth covering is a basic economic indicator, the ability to identify lining tacks is important. Lining is not typically preserved except when lying in association with cuprous hardware, and even then it is difficult to distinguish cloth lining from clothing remnants; therefore, the recovery of lining tacks provides a more concrete indicator (Davidson 2004:418).

No in-depth analysis of tacks from the Roberts Cemetery excavations was conducted. All burials contained at least some tacks (see Table 4.1), a few of which can be seen in Figure 4.5. Three types of tacks were identified, including flat-headed tacks, fabric (most likely silk) headed tacks, and copper-headed tacks. The simple flat-headed tack is a ubiquitous form of lining tack and is present in at least 20 trade catalogs between 1865 and 1912. It is unknown when it was first marketed, but likely it had a very long history intimately connected with the history of the nail. In most archeological cem-

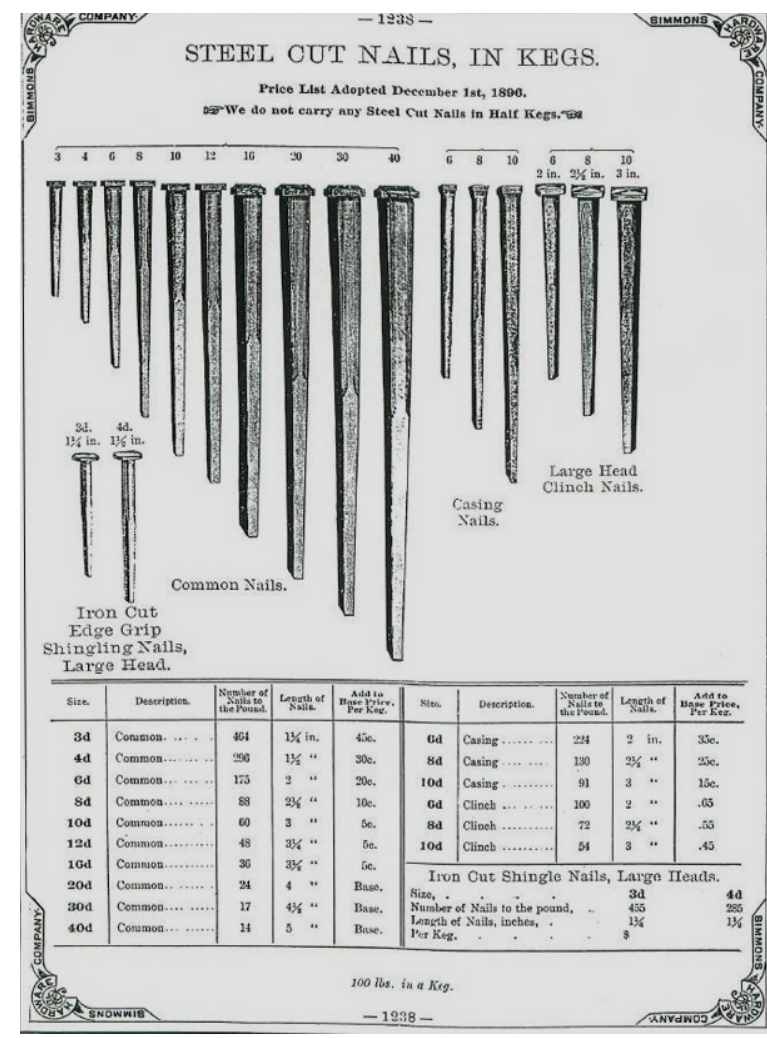

Figure 4.4. Selection of cut nails offered for sale on page 1238 of the 1903 Simmons Hardware Company general catalog.

etery excavation reports, not much attention is given to lining tacks, particularly simple iron tacks that are often mistaken for nail fragments; therefore, it is very difficult to determine with certainty the frequency of this type of tack in the archeological record.

\section{Screws}

Davidson (2006:144-145) reports that wood screws in some form have been around since the time of the ancient Greeks; however, prior to the nineteenth century, most screws had blunt points and could not self-start. The introduction of the gimlet wood screw, which has a tapered body and a pointed tip, has been attributed to Thomas J. Sloan, who was issued a U.S. Utility Patent (No. 4,704) in 1846 (Figure 4.7). The mass production of these gimlet screws was initiated the same year by Sloan's introduction of the machine capable of producing said screws (U.S. Utility Patent No. 4,864). While technically, a gimlet form had been introduced 10 years earlier by Thomas W. Harvey of Poughkeepsie Screw Company, and a machine capable of pro- 


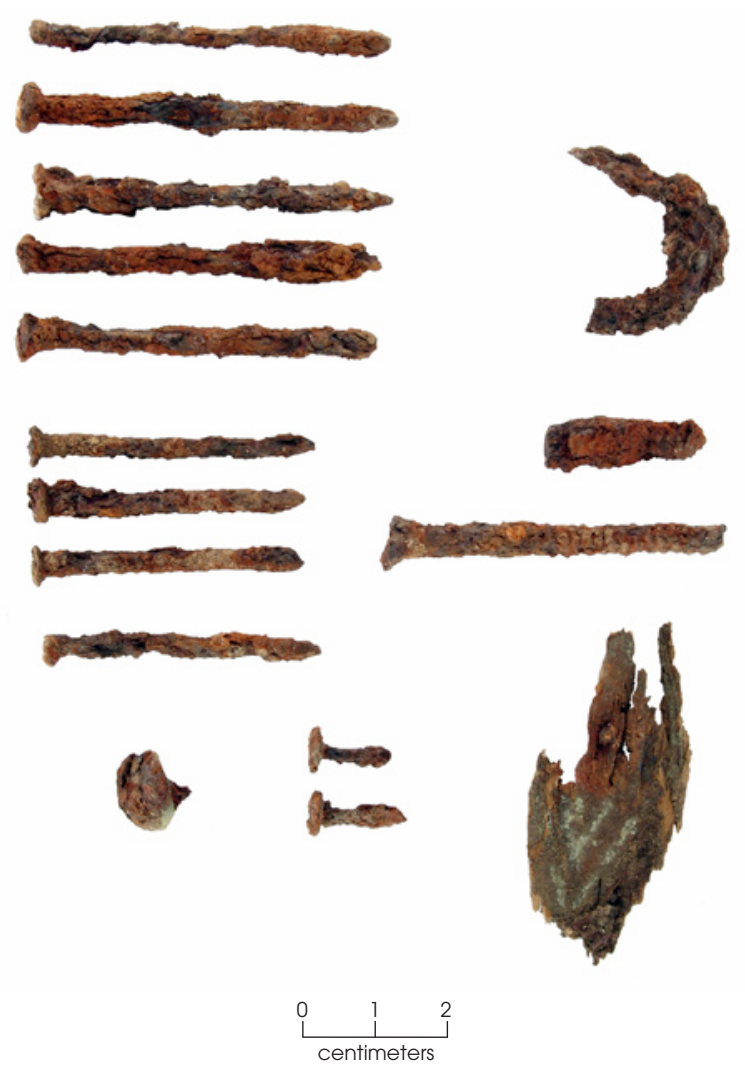

Figure 4.5. A selection of nails and other construction hardware recovered from the Roberts Cemetery burial excavations.

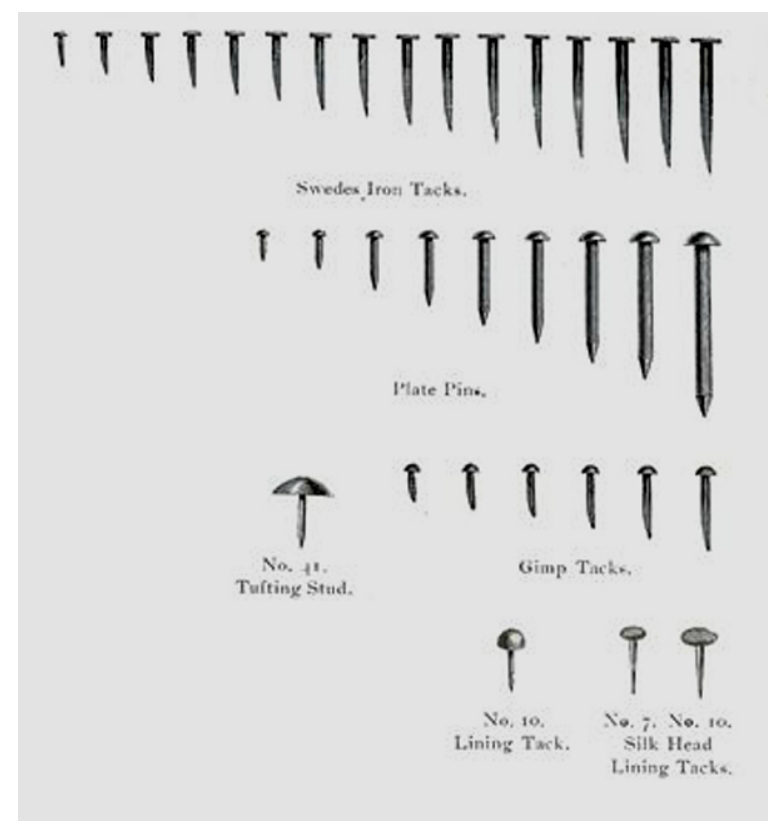

Figure 4.6. Selection of lining tacks illustrated on page 105 of the 1901 Gate City Coffin Company catalog.
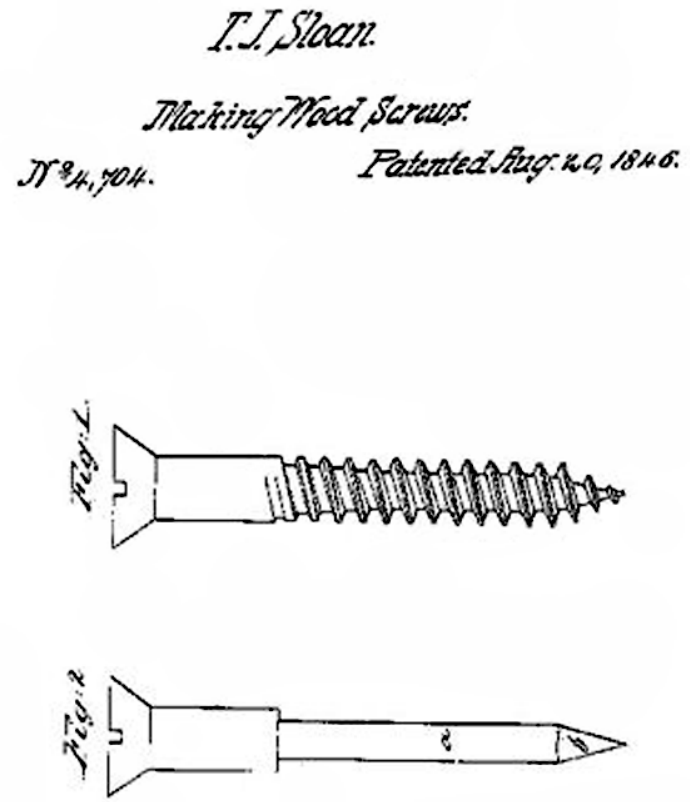

Figure 4.7. U.S. Utility Patent No. 4,704 assigned to T. J. Sloan for a wood screw in 1846.

ducing wood screws was introduced in 1834 , most early gimlet and blunt-tip forms had to be hand-turned and therefore were more costly to consumers than later machine-made screws (Davidson 2006:145).

Plain gimlet screws were commonly employed as burial container lid closures in the nineteenth century, though the earliest mention of some type of screw being used in mortuary contexts dates to 1748 (Davidson 2006:145; Tharp 1996:226). In the known sample of general hardware and mortuary catalogues available for comparison, flat, round, oval, and fillister headed gimlet screws were prominently advertised for sale (Figure 4.8). Davidson (2006:145) concludes after critical examination of archeological literature of pre- 1850 cemeteries that the presence of screws, particularly gimlet screws, was relatively rare. Additionally, in those burial containers where utilitarian gimlet screws were used as primary means of lid closure, there was an absence of formal coffin hardware, such as coffin screws or thumbscrews. Forms of ornamental tacks, however, were often used to mask the use of ordinary screws (Davidson 2006:146).

No in-depth analysis of screws from the Roberts Cemetery excavations was conducted, mainly due to the poor preservation of the excavated ferrous materials. All burials contained 
AMERICAN GIMLET-POINT SCREWS,

FLAT, ROUND, OVAL AND FILLISTER HEAD.

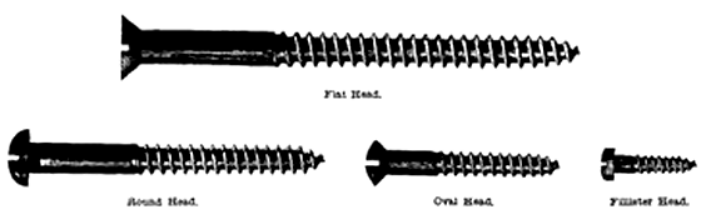

Figure 4.8. Selection of American gimlet screws offered for sale on page 126 of the 1865 Russell \& Erwin Company general catalog.

at least some screws, most of which were associated with other types of hardware. All screws for which the heads had lower amounts of masking corrosion appear to be slotted. No Phillips head screws were identified, which suggests (though does not unequivocally determine) that these burials occurred prior to the invention of the Phillips screw in 1936.

\section{Joining Plates}

The arbitrary term "joining plate" refers to thin, rectangular, ferrous metal plates used to join two boards together in the construction of the burial container (Figure 4.9). Various sizes of joining plates were recovered only from Burial 1 in Roberts Cemetery (see Table 4.1). The pres- ence of wood grains, which meet at a centerline on both faces, suggests that they could have been used as biscuits at a mitered corner joint. Specimens that exhibit angled wood grains on only one face suggest that they were also used at mitered corners but were possibly secured at the top or bottom of the corner and not within the joint. No nails or screws are associated with these plates, so they likely were secured with some type of adhesive. Joining plates offer information about the construction technique and skill of the carpenter, availability of other resources for construction, and possibly even the cost of a burial container.

\section{Top Fasteners}

Top fasteners are a form of complex burial container lid closure consisting of eight pieces in a full set: two foot plates, two foot hooks, two head body plates, as well as a left and a right spring. The springs and foot hooks are positioned along the sides of the lid, with the springs toward the head and the foot hooks toward the foot end of the burial container. The head and foot body plates are positioned on the sides of the burial container itself, in locations that match up with the elements secured to the lid. The foot hooks insert into holes in the foot plates and recesses
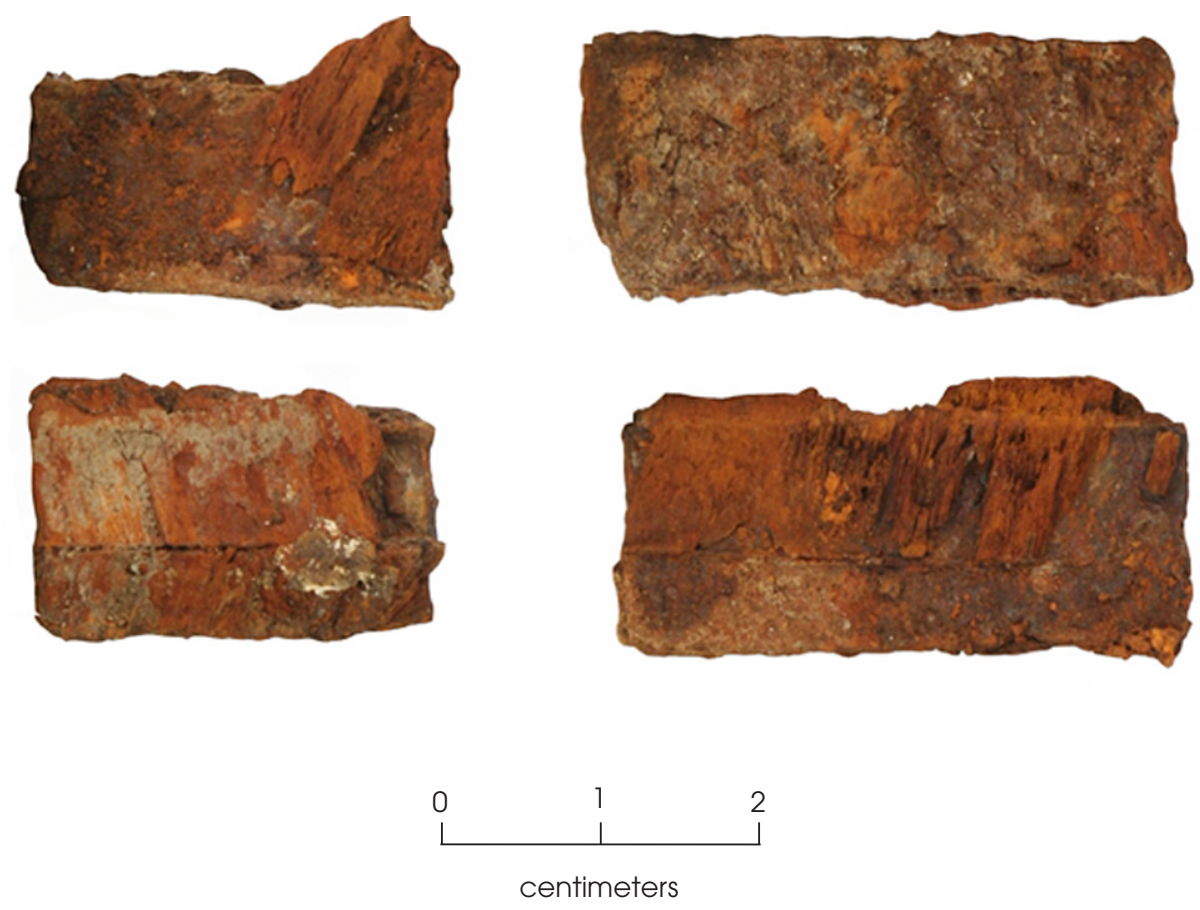

Figure 4.9. A selection of joining plates recovered from Roberts Cemetery Burial 1. 
cut into the top of the side wall below the plates. When the lid is secured, the spring hooks insert just as the foot hooks do, but the level end of the spring either fits onto a projecting fin on the base plate or descends into a recess cut into the top of the side wall, which limits horizontal movement of the lid.

The first known patent for a top fastener (U.S. Utility Patent No. 377,325) was granted to William J. Noble on January 31, 1888 (Figure 4.10), with a second soon following in May of the same year (U.S. Utility Patent No. 383,235). While these were the first known patents to be issued, they were not the first top fastener patents for which an application was filed. Although the patent was not granted until April 16, 1889, William A. Sparks of Rochester, New York, submitted his application for a "coffin-fastener" (U.S. Utility Patent No. 401,663) (Figure 4.11)
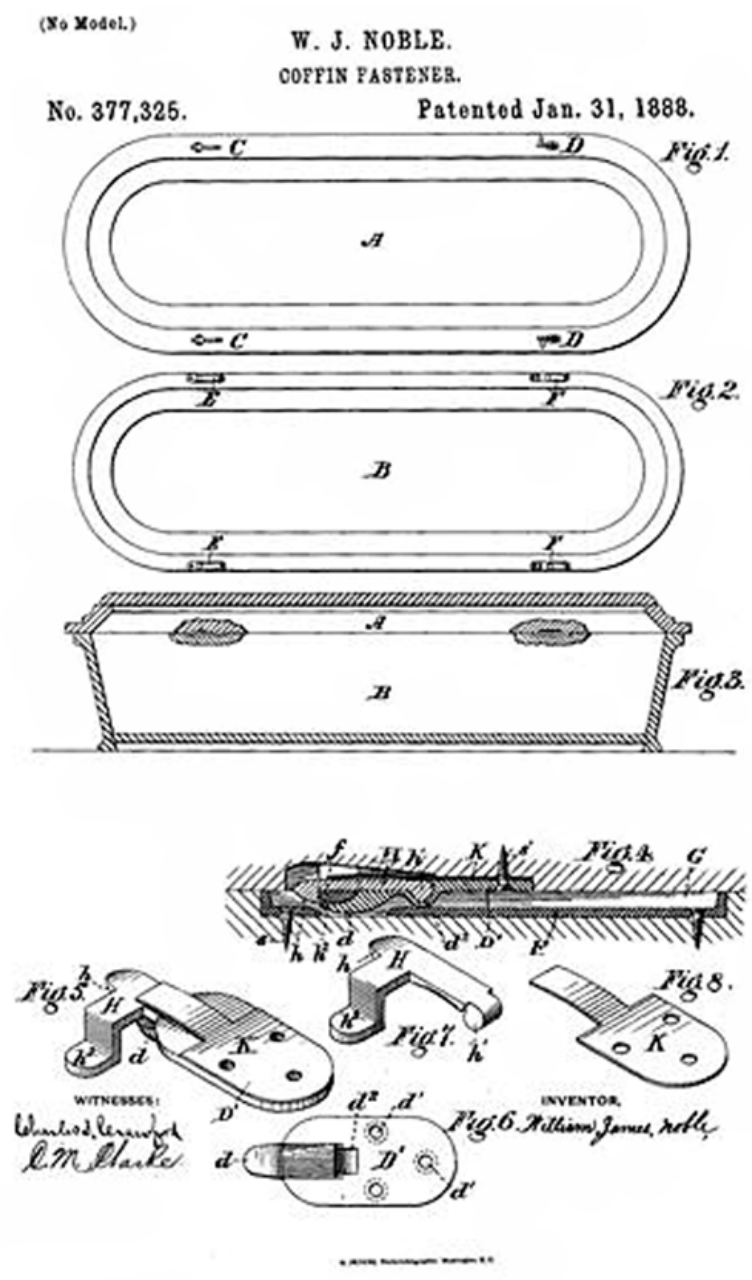

Figure 4.10. U.S. Utility Patent No. 377,325 assigned to W. J. Noble for a coffin fastener in 1888 .
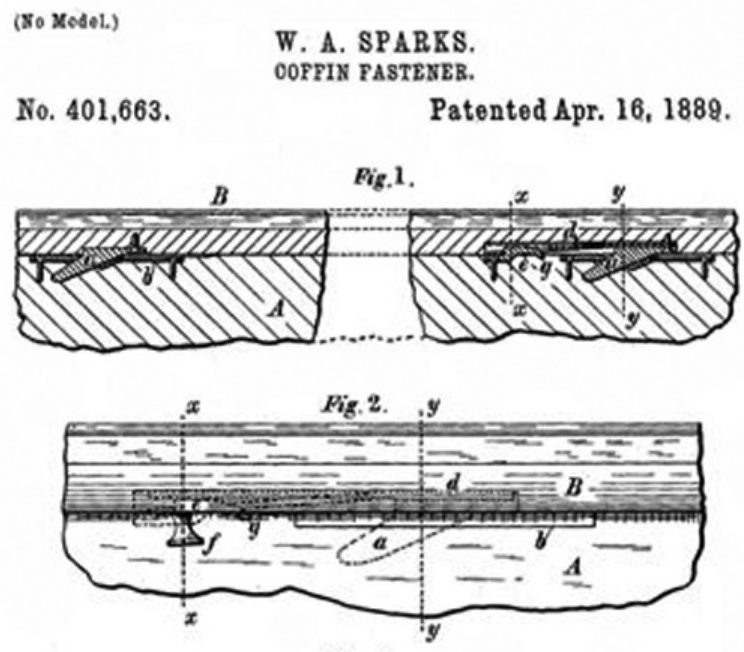

Fig. 3.
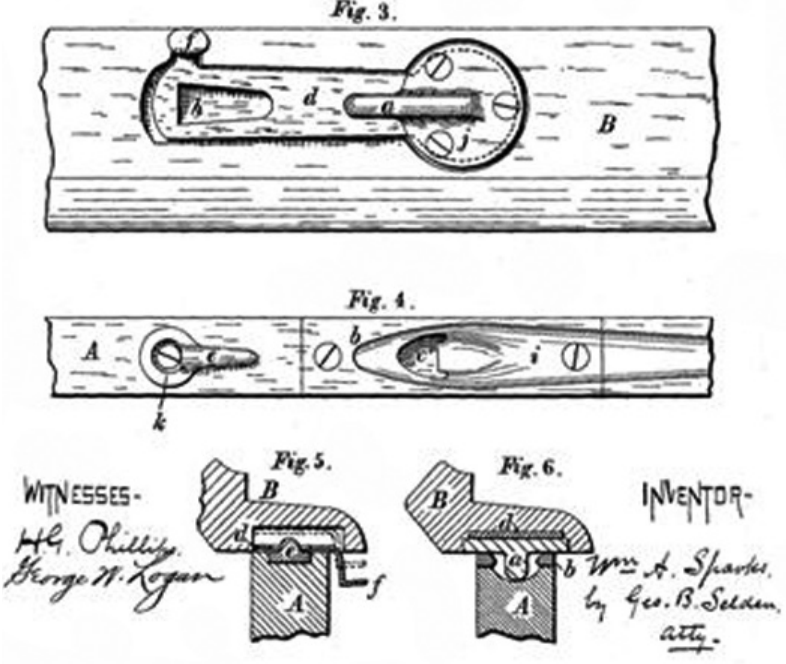

Figure 4.11. U.S. Utility Patent No. 401,663 assigned to William A. Sparks for a coffin fastener in 1889.

on November 4, 1886, well before the Noble applications were filed. Modern-day caskets do not use top fasteners, but it is not known when top fasteners fell out of favor. The ca. 1920s-1930s Langenau Mfg. Company (Cleveland, Ohio) internal specialty hardware catalog was the only extant period catalog available for comparison. Only one other extant internal hardware catalog, the undated Weber-Knapp Company Shell Hardware for Caskets, Catalog No. 52, is known to exist. It is owned by Michael Trinkley of Chicora Foundation (Columbia, South Carolina).

\section{TOP FASTENER TYPE 1}

Top Fastener Type 1 is represented by a complete set of six artifacts recovered from 
Burial 1 in Roberts Cemetery (see Table 4.1). The foot hook (Figure 4.12) is gently curved, and the plate is secured with three screws and is roughly circular with a small triangular notch on the side under the base of the hook. The hook itself is hollow on the underside and extends from the center of the circular base. The foot plate is rectangular with two screw holes at either end. There is also a wide flute running down the center with a hole meant to accept the foot hook toward one end of the plate. One end of the hole is gently curved, while the other end has a similarly curved finger, which is bent slightly down and extends into the hole.

The head spring (Figure 4.13) has a left and right variety, but both are identical in form, with the only difference being that the release tab is on one side or the other, depending on placement. The springs have a circular hook base with three screw holes. The neck of the spring is constricted near the circular base and tapers gently out for a short distance before widening and continuing to taper to the rounded end. An elongated triangular hole with a curved short side lies in this wider end portion of the spring. The spring release tab is also located at this end. The head plate is attached via two screws, one at each end. It is similarly designed as the foot plate, with two exceptions. It is much longer than the foot plate. In addition to the hook hole on one end, the opposite end has a small rectangular hole and an elongated triangular beak that matches the hole on the wide end of the spring.

Top Fastener Type 1 has only been identified in one mortuary catalog, the ca. 1920s-1930s catalog from the Langenau Mfg. Company (Figure 4.14). There is no known exact patent match to this variety of top fastener, but it is very similar to the fastener illustrated in Sparks's patent (see Figure 4.11). This same top fastener has been reported from 17 burials dating between 1907 and 1932 excavated from the grounds of the Texas State Cemetery. Six other historic cemetery relocations have yielded top fasteners that may be exact matches or may just be similar forms. Poor preservation often makes it difficult to tell from report images whether they are exact matches. These cemeteries are from Alabama, Kentucky, South Carolina, Georgia, Tennessee, and Ontario, and date between ca. 1877 and 1940 (see Table A.3 for a summary of these matches).

\section{Dowels}

Dowels are a versatile and esoteric hardware item that could have been used in a variety of purposes within the casket. Few have been

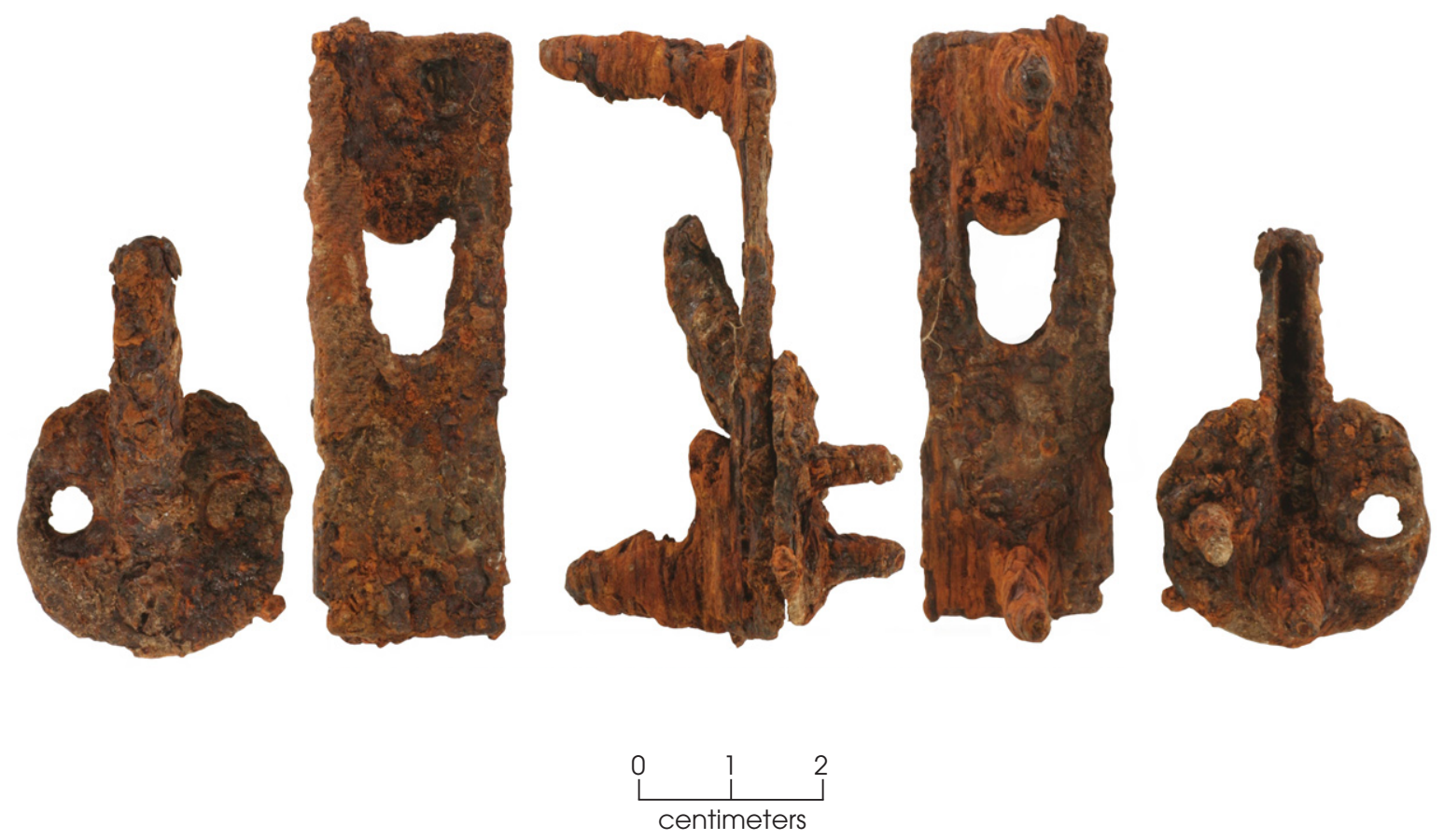

Figure 4.12. Foot hook and foot plate of Top Fastener Type 1 recovered from Roberts Cemetery Burial 1. 

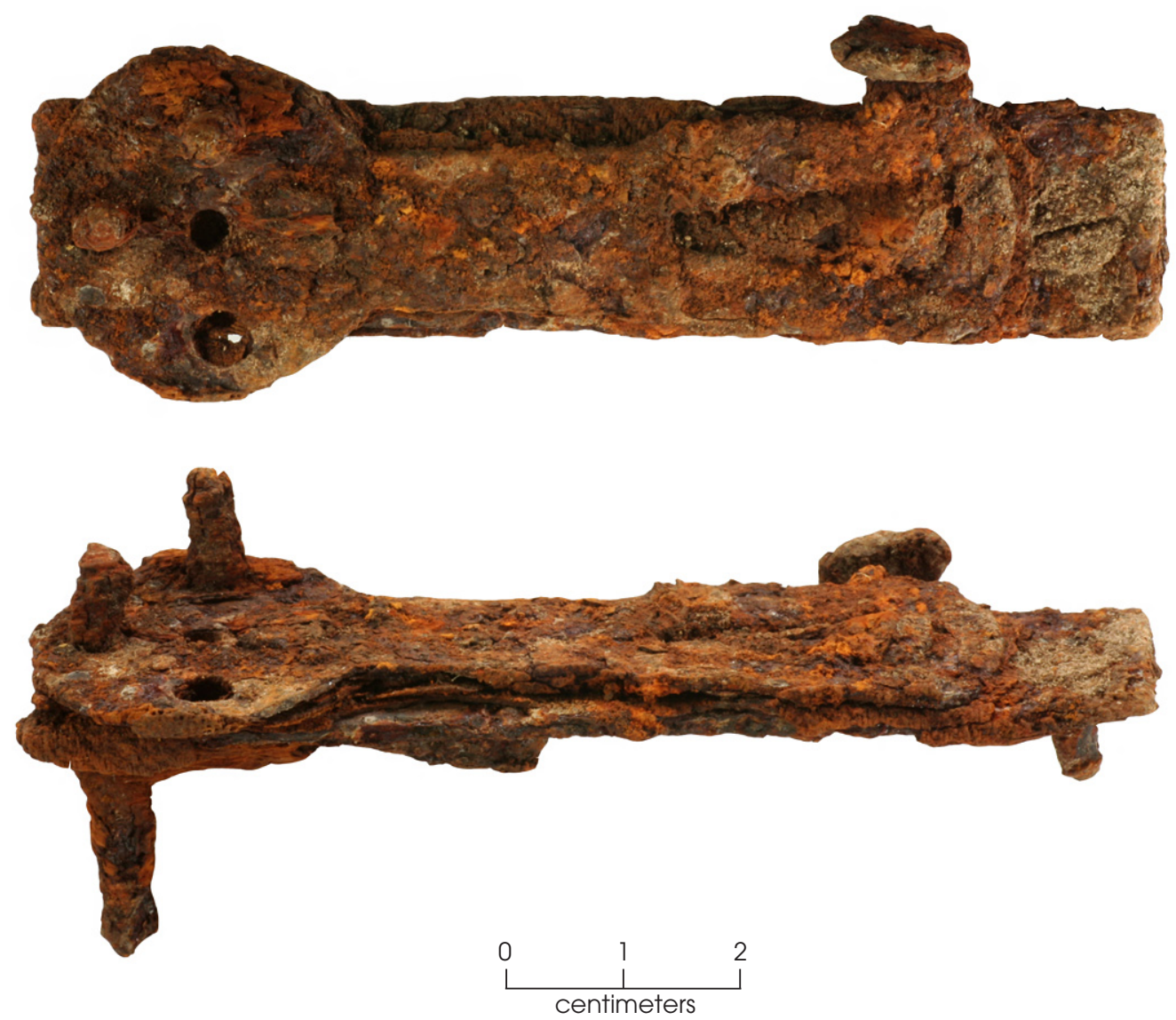

Figure 4.13. Head plate and spring of Top Fastener Type 1 recovered from Roberts Cemetery Burial 1.

reported in the archeological literature, so information from contextual relationships is scant. Additionally, only the 1920s-1930s Langenau Mfg. Company catalog is known to illustrate dowels. Given their form, they could have been used as stops or catches in securing the casket lid or in a similar capacity with other hardware in construction of the burial container.

\section{DOWEL TYPE 1}

Dowel Type 1 (Figure 4.15) is represented by two artifacts from Burial 1 in Roberts Cemetery (see Table 4.1). The dowels were located on the upper edge of the lid on either side of the casket, suggesting they were used as a guide for sliding the casket lid into place, or as stops for the casket lid. The base plate of the dowel has two screw holes, the interior one being elongated and running down the majority of the piece. After the termination of the elongated screw hole, the dowel is bent 90 degrees and a tab extends up, bending slightly outward before ending with a gentle curve. Dowel Type 1 appears to be a match to Dowel No. 32 illustrated on page 32 of the 1920s-1930s Langenau Mfg. Company catalog (Figure 4.16). No patent records have been located that match this type of hardware, but similar dowels have been recovered from four burials in two cemetery excavations, both in Texas. The four associated burials date from 1907-1908 and 1926-1960, respectively (see Table A.3 for a summary of these matches).

\section{Catch Assemblies}

Catches are small complex ferrous fastening devices that were used to secure the lid of a burial container or a viewing window cover. Figure 4.17 is the drawing page from a 1953 patent (U.S. Utility Patent No. 2,634,997) for a catch. While this is an admittedly recent piece of hardware, it does show an excellent exploded view of the components of a standard catch. 
Figure 1 in the patent shows a vertical section through the casket and lid so that the catch can be seen. Figure 2 is a front view of the catch. Figure 3 is a bottom plan view of the catch. Figure 4 is a top plan view. Figure 5 is a side view of the "latch guard and mounting ears." Figure 6 is a front view of the same. Figures 7 , 8 , and 9 are top, side, and end views of the wire spring. Figure 10 is a side view of the lever plate. Figure 11 is a front view of the base plate with latch guard and mounting ears. Figure 12 is a

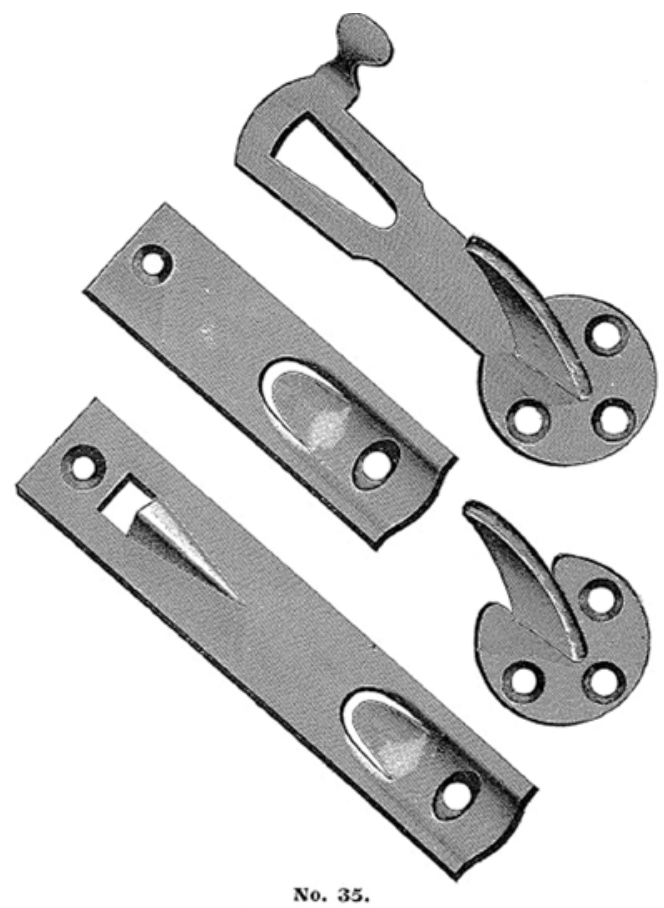

Figure 4.14. Top Fastener No. 35, which is similar to Top Fastener Type 1, as illustrated on page 76 of the 1920s-1930s Langenau Manufacturing Company catalog.
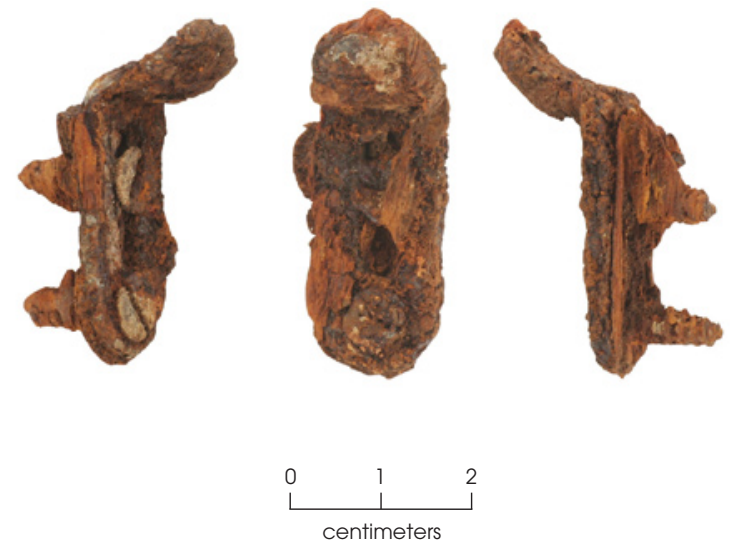

Figure 4.15. Dowel Type 1 recovered from Roberts Cemetery Burial 1.

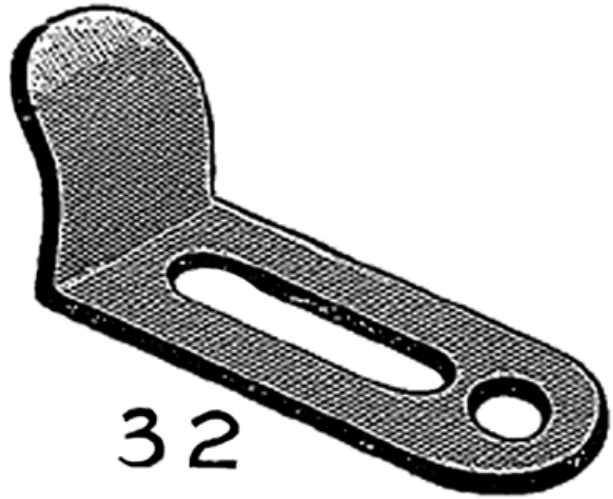

Figure 4.16. Dowel No. 32 illustrated on page 32 of the 1920s-1930s Langenau Mfg. Company catalog. This matches the Dowel Type 1 recovered from Roberts Cemetery Burial 1.

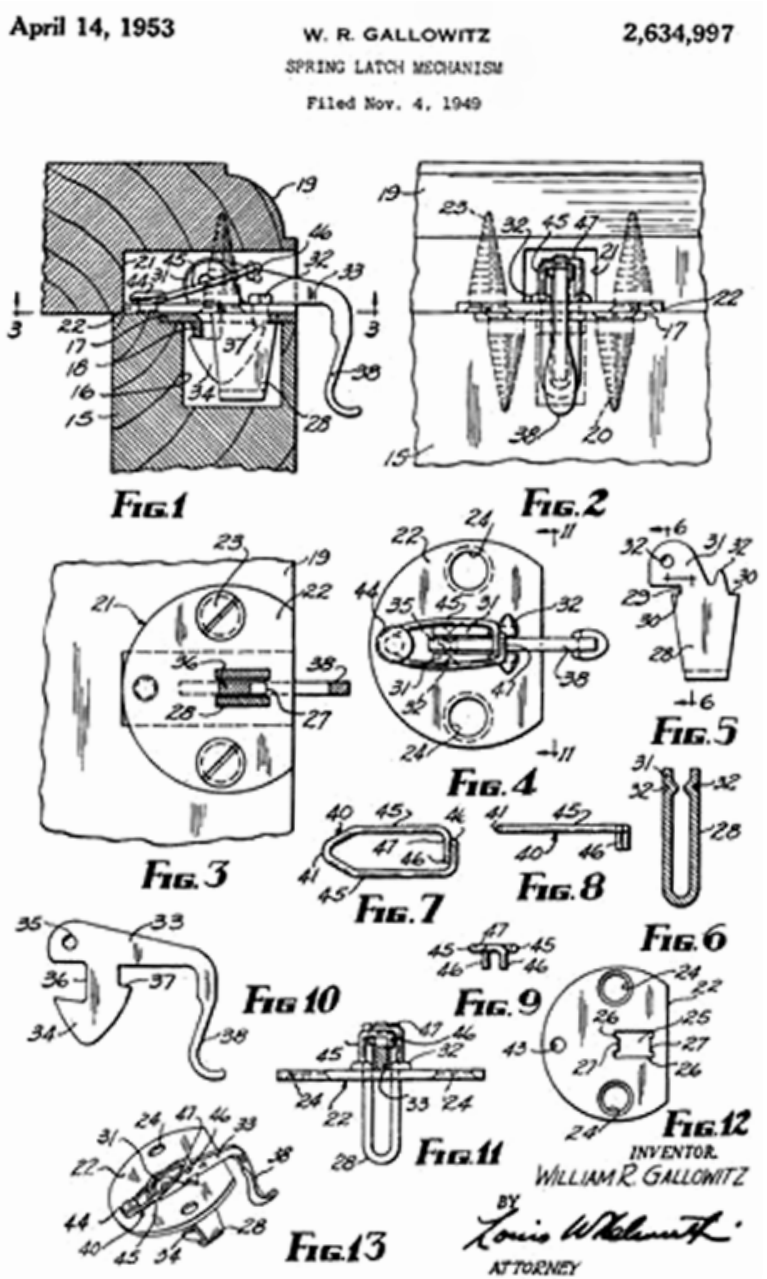

Figure 4.17. U.S. Utility Patent No. 2,634,997 assigned to William R. Gallowitz in 1953 for a spring latch mechanism. 
bottom plan view of the base plate. Figure 13 is the completed catch. The only major difference between this more modern catch and older examples is that most of the earlier devices used thin arched metal plates for the spring rather than wire. Finally, catches must be paired with a matching escutcheon through which the latch guard would pass, enabling the latch to hold when the lid is closed. Catch escutcheons were interchangeable to a certain degree in terms of size and shape, depending on the construction of the burial container and the function and type of catch being used.

The earliest located patent (U.S. Utility Patent No. 275,503) for a catch was issued to W. C. Langenau of Cleveland, Ohio, on April 10, 1883 (Figure 4.18). It was a simple design consisting of a rectangular base plate with latch guard and a lever connected to the latch plate. Langenau followed with a second similar patent (U.S. Utility Patent No. 281,277) in July of the same year. From these early patents, many varieties were patented throughout the latenineteenth and early-twentieth centuries. As evidenced by the 1953 patent discussed above, catches were still important pieces of hardware in the casket manufacturing industry into the 1950 s. It is not currently known whether these types of catches are used in present-day caskets, or if their popularity waned at some point after the 1950s.

\section{CATCH TYPE 1}

Catch Type 1 (Figure 4.19) is associated with Catch Escutcheon Type 1 and is represented by one artifact in Burial 1 in Roberts Cemetery (see Table 4.1). This catch is made of iron. The base plate has two screw holes and is circular with one side clipped. The latch guard is narrow and gently rounded at the top. The lever plate is thin but broadens out and morphs into a flat T-shaped head. The lever is depressed, extending in the opposite direction from the latch guard. The lever is kept in play by an arched metal spring plate on the bottom of the catch.

Catch Type 1 has been identified as Catch No. 169 in the ca. 1920s-1930s Langenau Mfg. Company catalog (Figure 4.20) (see Table A.3). This type of catch was designed for use on burial containers with clothwork, and the depressed levers were shaped specifically to conform to recessed top mouldings. The illustration for Catch
No. 169 bears the November 26, 1889 Langenau patent date (U.S. Patent 275,503), but this catch does not resemble the device in the patent illustration (see Figure 4.18). No other patents for
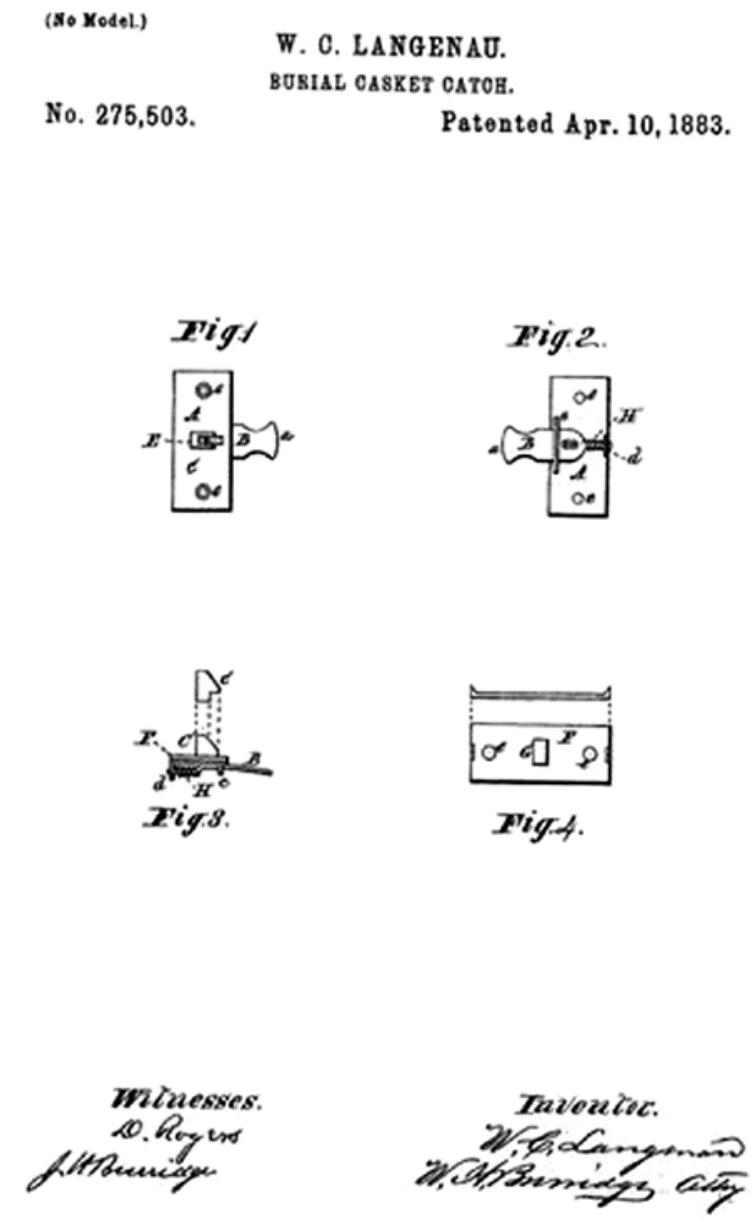

Figure 4.18. U.S. Utility Patent No. 275,503 assigned to W. C. Langenau for a burial casket catch in 1883 .

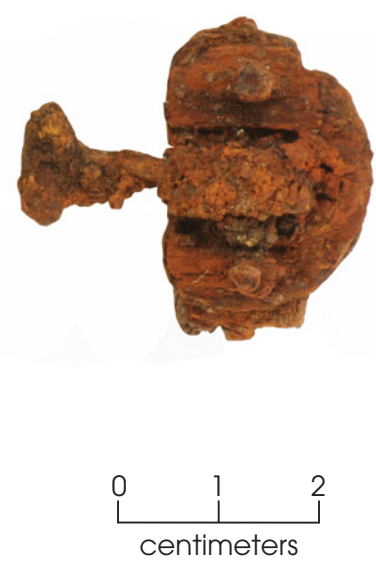

Figure 4.19. Catch Type 1 recovered from Roberts Cemetery Burial 1. 
catches bearing a resemblance to Catch Type 1 were located. This type, however, was recovered from two historic cemeteries in Texas with burial dates between 1907 and 1940. Catches of a similar type have also been recovered from one cemetery in Georgia and one in Kentucky. The two burials from the Georgia cemetery date to 1921 and 1943, while the 14 burials in Kentucky have been dated between 1890 and 1940 .

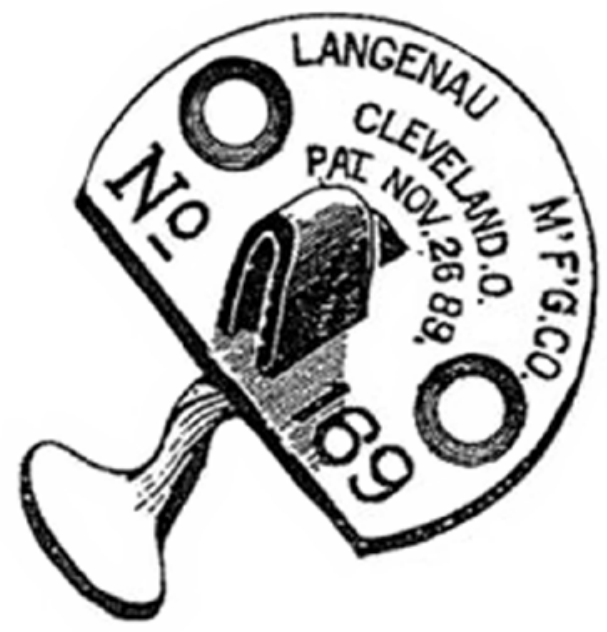

Figure 4.20. Catch No. 169, which is similar to Catch Type 1, as illustrated on page 20 of the $1920 \mathrm{~s}-1930 \mathrm{~s}$ Langenau Manufacturing Company catalog.

\section{CATCH ESCUTCHEON TYPE 1}

Catch Escutcheon Type 1 (see Figure 4.19) is represented by one artifact from Burial 1 in Roberts Cemetery and is associated with Catch Type 1 . This is a rectangular escutcheon that matches up with various sorts of catches for plush or cloth work. It is made of iron and has two screw holes. There are no specific patents known to exist for this escutcheon type, and because the exact form is not clear due to corrosion, it is not clear whether this particular escutcheon has been recovered in historic cemetery excavations (though it is extremely likely). Many types of rectangular interchangeable escutcheons are advertised in the ca. 1920s-1930s Langenau catalog (Figure 4.21). The Roberts Cemetery rectangular catch escutcheon could match any one of the illustrated escutcheons. The photograph of the catch assembly, however, appears to show side points on the escutcheon, suggesting that Langenau escutcheon numbers 17, 18, 22, or 31 would be high possibilities for a match.

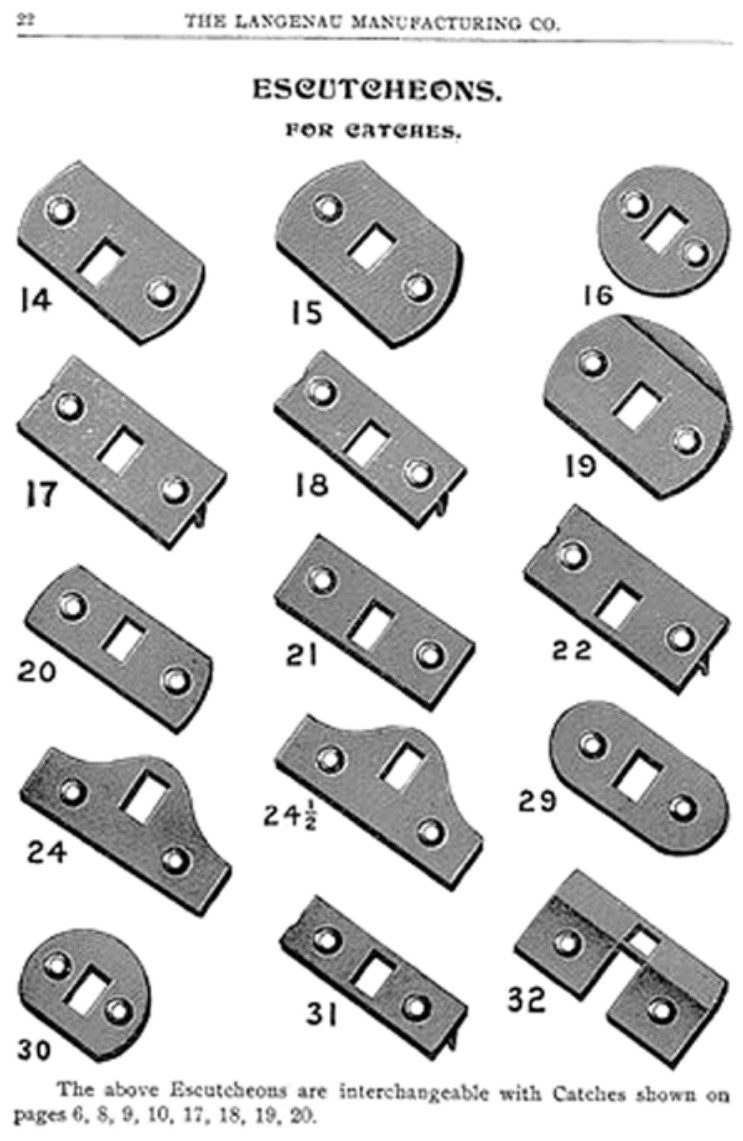

Figure 4.21. Page 22 of the 1920s-1930s Langenau Manufacturing Company catalog showing rectangular escutcheons similar to Catch Escutcheon Type 1.

\section{External Burial Container Elements}

External elements can be seen by mourners during the funeral and therefore play a key role in the social perception of the event, and by extension the social and economic status of the deceased and the deceased's family (Pye 2007). Changes in the type of external elements can also reflect changes in consumer culture as well as changes in or adherence to certain social and religious ideologies. For the keen archeologist, identification of changes in patterns of external elements can also provide important clues to chronology (Davidson 1999).

\section{Handles}

Davidson (2006:12-123) states that the earliest burial container handles were either made specifically for mortuary contexts (citing 
Rauschenberg 1990:43-44) or were utilitarian furniture hardware employed in a mortuary setting. Utilitarian handles were found in a burial in Delaware dating to 1780-1820 (DeCunzo et al. 1992:199). This practice was also noted in nineteenth-century Tucson, Arizona (Pye 2010a), and was likely used in other locales where necessity or scarce resources required creativity. The use of handles specifically designed for mortuary purposes date back to at least the eighteenth century. Tharp (1996:81-88) notes that British coffin handles were being imported and advertised for sale in the American colonies as early as 1738 .

Handles on burial containers serve multiple functions. A primary function of handles is to provide a means by which the burial container may be carried to the gravesite from the home or from whatever transportation device was employed to convey the deceased to the burial locale (Davidson 1999:535). The nineteenth and early-twentieth centuries saw great innovation in material, form, and style that cannot be explained by the transportation function. It should not be taken for granted that burial container handles serve broader social and ideological functions.

\section{DOUBLE-LUG, SWING-BAIL HANDLES}

The double-lug, swing-bail handle is one variant of the general swing-bail form. It is comprised of two lugs, which are affixed via screws, or occasionally nails, to the side of the coffin; and the bail, which forms the gripping portion of the handle. The bail is mounted into the lugs by the insertion of two metal pins (of iron or steel wire) at either end. Davidson (1999; 2004:407) reports that swing-bail handles have been in production since the eighteenth century. Their prominence did not wane until short-bar, and later extended-bar, handles became more popular in the late-nineteenth and early-twentieth centuries, but the form has never entirely disappeared.

\section{Handle Type 1}

Handle Type 1 (Figure 4.22) consists of a double-lug, swing-bail handle represented by six complete handles in Burial 2 and six complete handles in Burial 3 in Roberts Cemetery (see
Table 4.1) ${ }^{14}$ These handles were made of white metal with the white metal of the bail being cast over a reinforcing bar also made of some nonferrous metal. The lugs are attached to the burial container via two screws. The top and bottom edges of the lugs have a floral motif with three leaves or a three-petal blossom opening up to the outer central edge divided by a gently arching bridge. The bail is U-shaped and hollow-backed, exposing the inner bar. There is a similar floral design on the bail and a central fan or blossom element.

There are no known patent or catalog matches to this handle, although there were roughly similar types of handles present in hardware catalogs from 1890 through 1920. This exact handle has been recovered in three historic cemetery archeological excavations, one each from Arkansas, Texas, and Tennessee, dating between 1890 and 1933. Additionally, this handle type was present in an archeologically documented historical collection from the A. L. Calhoun General Store, South Carolina, which dated between 1894 and 1926 (see Table A.3).

\section{DOUBLE-LUG, SHORT-BAR HANDLES}

The double-lug short-bar handle is a variant of the short bar concept, the history of which has been outlined by Davidson (2006:122-128). This variety is more complex than earlier swingbail forms and can consist of up to nine parts: two lugs, two arms, two pins, a bar/tube, and two tips. The earliest patent dates for elements of the short-bar handle appears in 1866, with many stylistic variants (e.g., C. Strong's 1869 Coffin Handle, U.S. Utility Patent No. 97,827; Figure 4.23) being patented continuing through the 1870s and 1880s (Davidson 2006:125-126). Based on period trade catalogs available for current study, it is evident that early form, short-bar handles were for sale in 1871, as advertised in the 1871 H. E. Taylor \& Co. illustrated catalog. These handles grew in popularity in the 1880 s and made up a fair majority of the handles available in catalogs through the early twentieth century.

\footnotetext{
14 The original field records show that seven Type 1 handles were assigned to Burial 2 and only five were assigned to Burial 3, which was significantly disturbed. Subsequent analysis revealed that one of the Burial 3 handles was displaced and got commingled with Burial 2 (see Chapters 2 and 3 ).
} 

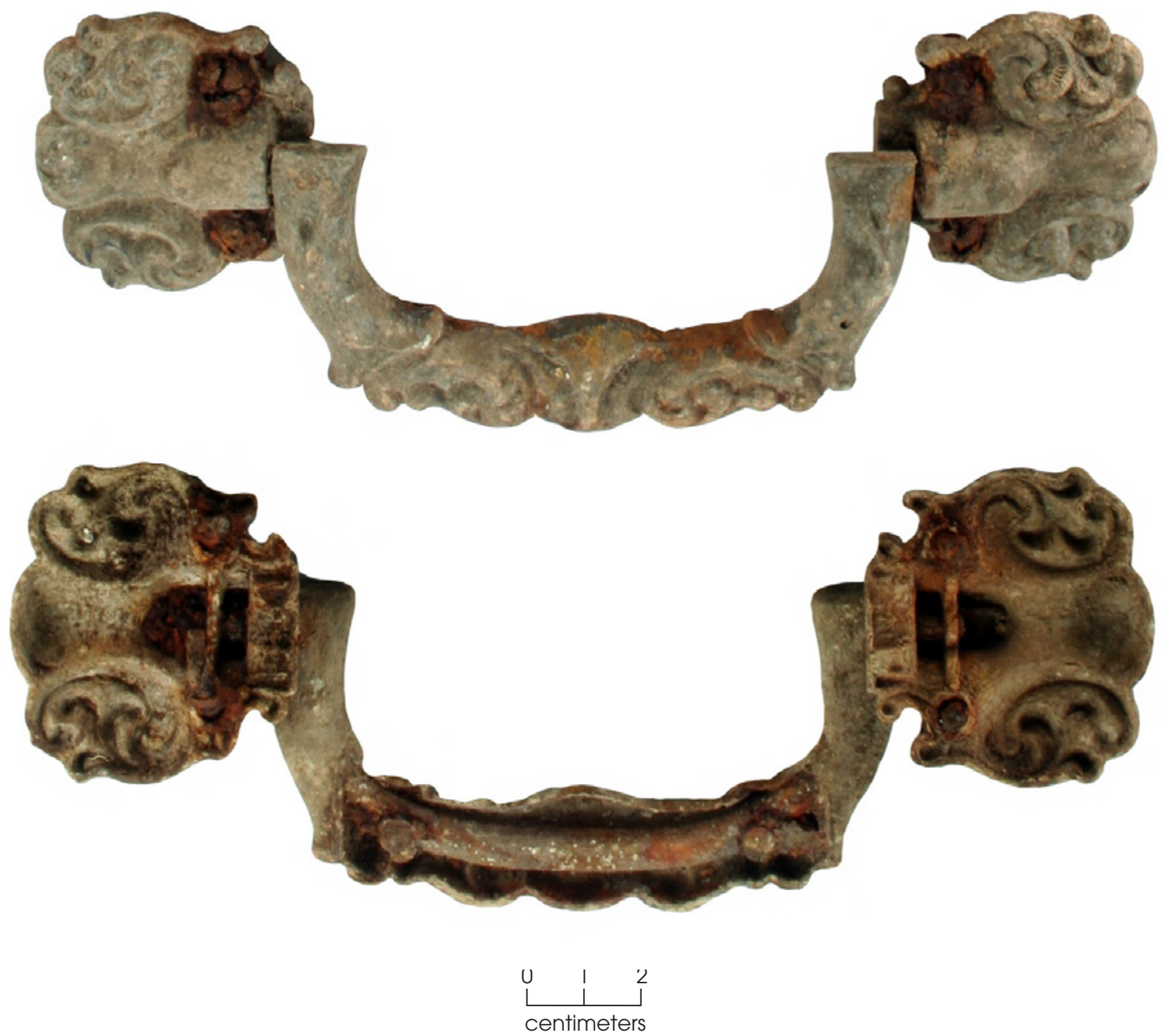

Figure 4.22. Handle Type 1 recovered from Roberts Cemetery Burials 2 and 3.

Handle Type 2

Handle Type 2 (Figure 4.24) is represented by six double-lug, short-bar handles recovered from Burial 1 in Roberts Cemetery (see Table 4.1). The lugs of this handle are shaped like fiddles. There are no apparent designs on the surface of the lugs. The end segments of the bar are circular, and the caps are domed with a raised ring at the base of the dome and another ring at the end of the cap. The bar has a swelled octagonal grip.

On July 19, 1910, U.S. Utility Patent No. 964,562 was granted to Edward R. Sargent for a casket handle that matches the form of the Handle Type 2 lugs and arm mechanism (Figure
4.25). The patent illustration, however, shows a square bar rather than a swelled round or octagonal bar. The earliest known patent depicting a swell bar variety of a short-bar handle was granted on January 20, 1891 to M. Bremer (U.S. Utility Patent No. 444,973) (Figure 4.26). Swell bars grew in popularity in the 1890s and became very common in catalogs of the first decade of the twentieth century. Swell bars were far less common in the 1940s, but the occasional piece does appear in catalogs into the $1950 \mathrm{~s}$. The fact that the Sargent patent shows a square bar is less important than the fact that handles with this lug type quickly grew in distribution after 1910. Octagonal swell bars were apparently coupled with the Sargent lug early on because 


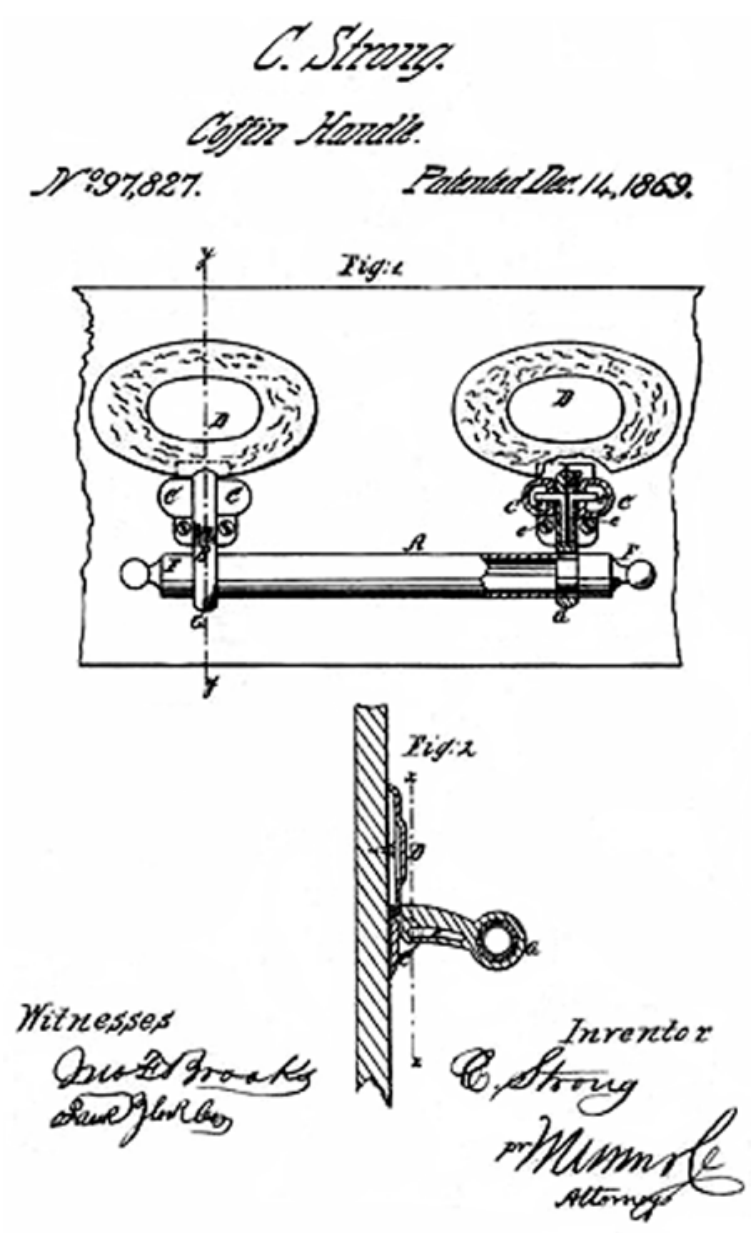

Figure 4.23. U.S. Utility Patent No. 97,827 assigned to C. Strong for a coffin handle with early components of a short-bar handle in 1869.

handles more or less similar to Handle Type 2 appear in at least 15 mortuary merchandise catalogs between ca. 1910 and 1950 (Figures 4.27 and 4.28) (see Table A.3).

It appears, however, that the popularity of the handle declined in the late 1920s or early 1930s. Three of the earlier appearances of the handle come from the catalogs of Boyertown Burial Casket Company. A look through available post-1930s Boyertown catalogs showed that this handle no longer appeared in the product line. Even though the handle may not have been carried by professional mortuary product manufacturers, it remained on the market at least up to 1950. The three latest occurrences of this handle in catalogs were in those produced by Belknap Hardware and Mfg. Company, who sold general merchandise and carried a slim selection of outdated casket hardware. Additionally, this handle has been recovered from one burial with a positive interment date of 1943 from the Nancy Creek Primitive Baptist Church Cemetery, Georgia. It was also recovered from one burial dated between 1910 and 1940 in New Home Cemetery, Texas (see Table A.3).

\section{Outer Box Handles}

In the 1850s most burial containers were fashioned by friends, family, or the local cabinetmaker. The Civil War promoted the expansion of transportation networks that in turn supported the growing desire to ship the remains of dead soldiers home for burial. The simple wooden receptacles into which the coffins of the deceased soldiers were placed for transport were referred to as shipping boxes and were often equipped with at least four single-lug box handles (Hacker-Norton and Trinkley 1984:10). As the years passed in the later nineteenth century, it became increasingly common for people to purchase factory-made coffins and caskets from large producers, who also shipped these items in shipping boxes. By the turn of the twentieth century, the purchase of ready-made burial containers, either ordered directly from the manufacturer or through the local funeral director, became the norm.

Shipping boxes, also referred to as outer boxes, were also frequently used as vault boxes. The outer boxes would be placed in the bottom of a grave, and the coffin or casket was lowered into it (Hacker-Norton and Trinkley 1984:10; Oster et al. 2005:191). Then the lid would be closed and the grave filled. The box handles of the outer box would therefore enter the archeological record (Buchner et al. 1999; Rose 1985).

\section{HANDLE TYPE 3}

Handle Type 3 (Figure 4.29) is represented by five artifacts found in association with Burial 1 in Roberts Cemetery (see Table 4.1). This handle is a single-lug box or shipping container handle. The lug is rectangular with rounded corners and is affixed to the container via three screws, one in the top center and the other two along the bottom margin nearly under the attachment of the handle bail. The handle is made of iron and has a hollow back. The bail is attached to the lug via side pins. The bail, too, is hollow-backed, although the grip portion of the bail is complete. A seam runs horizontally 


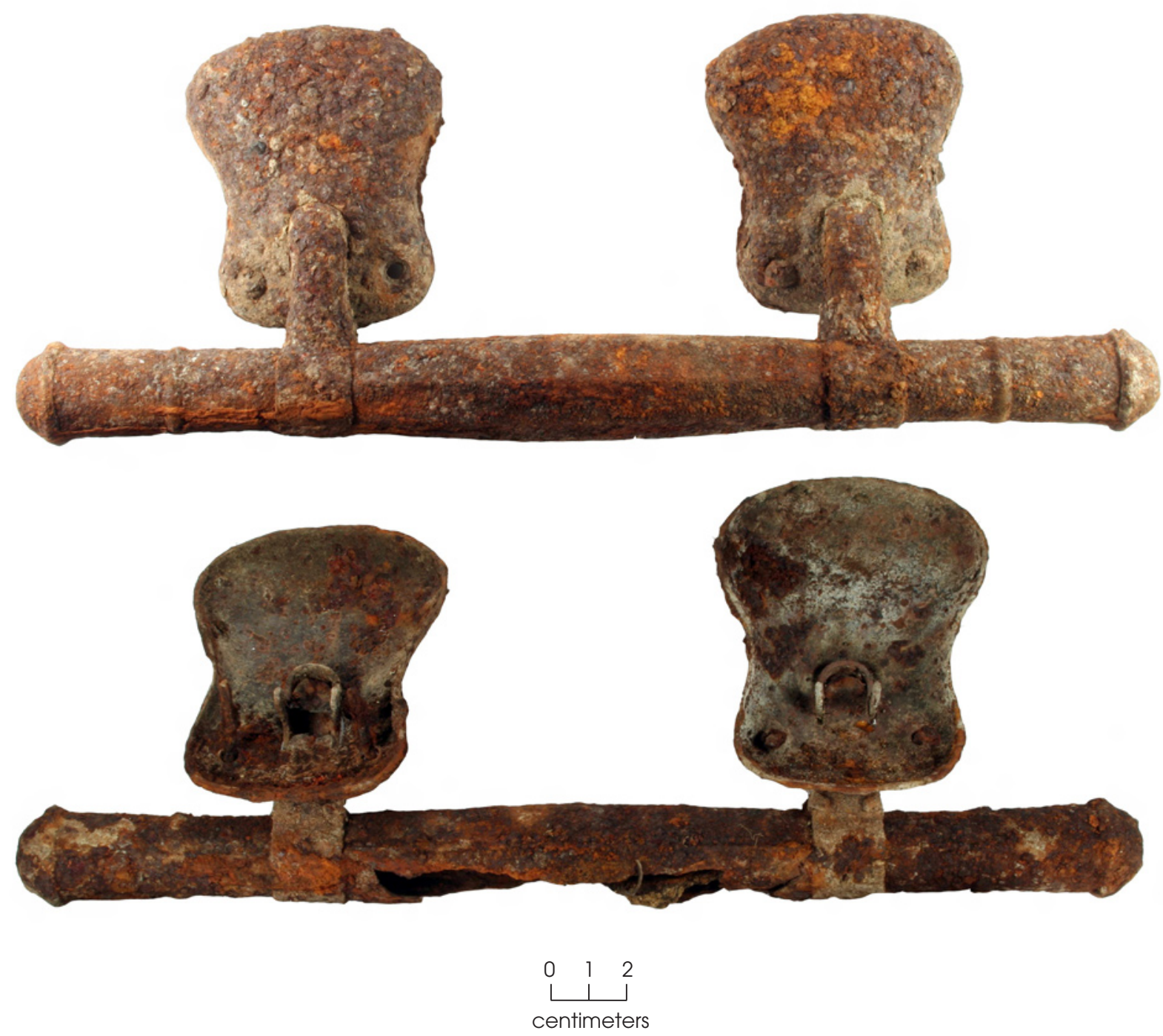

Figure 4.24. Handle Type 2 recovered from Roberts Cemetery Burial 1.

along the bottom margin of the lower portion of the bail where the metal was folded over to form the grip.

No definitive matches have been made to patent records, but this same type of box handle appeared in 13 period mortuary or general hardware catalogs ranging in date from 1900 to 1956. It also appeared in four archeological collections dating between 1840 and 1940 (see Table A.3). Figure 4.30 shows an illustration of this handle type as seen in the 1908 Mound Coffin Company catalog. Even though it is not visually depicted, a handle with the same product number is noted in the 1900 Mound Coffin Company price list, which provides the earliest record of this handle type. It is possible that the handle was on the market earlier in the $1890 \mathrm{~s}$, but the fact that available merchandise catalogs of that decade carried other outer box handles and not this one suggests that it likely entered the market sometime just before the turn of the century.

\section{Plaques}

Plaques, also known as coffin plates, refer to machine-stamped or cast-metal plates that would have been attached to the lid of a burial container (in the midsection over the body's thorax or hips) during a funeral, thus playing an important role in funeral pomp and ceremony (Davidson 1999:548; Gordon 2003:1). Plaques were produced from a variety of metals including various copper, tin, zinc, or lead-based alloys such as white metal, Britannia metal, 


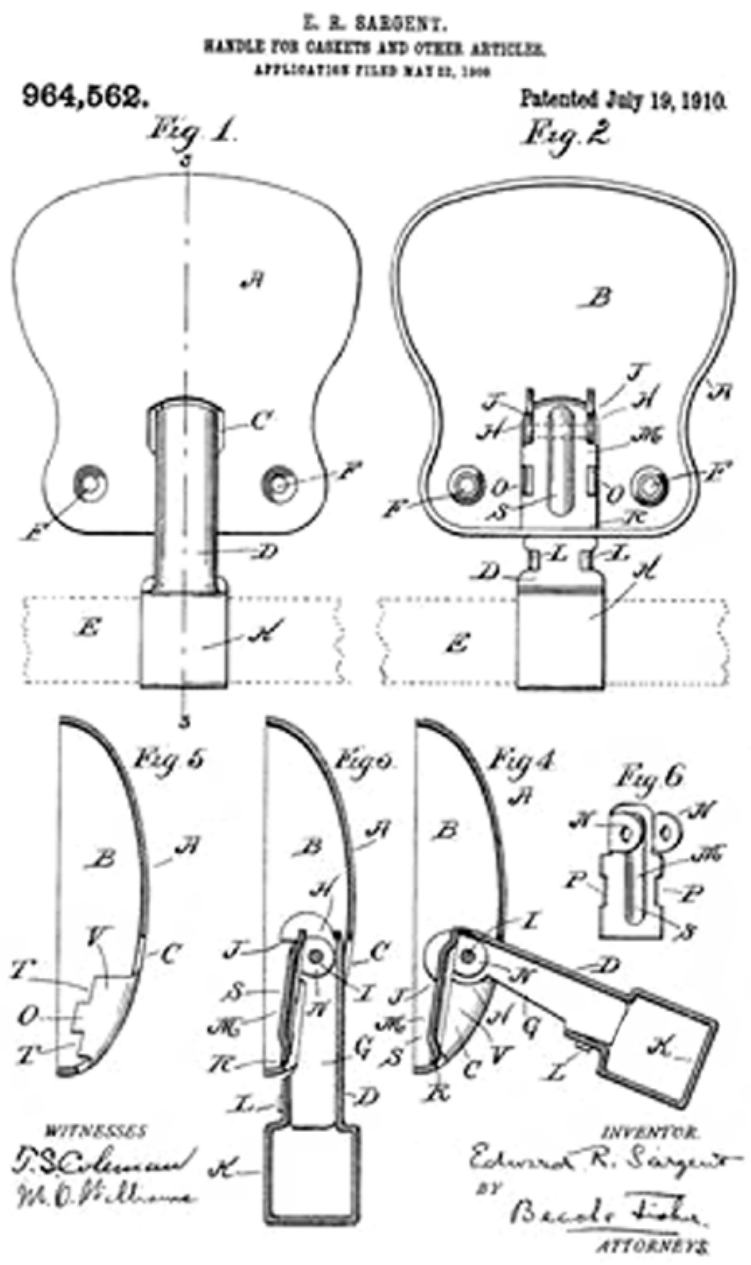

Figure 4.25. U.S. Utility Patent No. 964,562 assigned to E. B. Sargent for a handle for caskets in 1910.

pewter, brass, and bronze (Davidson 1999:548, 2006:151).

Plaques are one of the earliest forms of mortuary hardware. They appear in two English sample books from 1797 (Figure 4.31), which are the earliest mortuary hardware catalogs that have been located as of yet (see Table A.1). Many of these early forms of coffin hardware were produced in Britain and exported to the United States prior to the establishment of the U.S. funeral product manufacturing industry. The extra cost of the importation, along with the fact that most of these early forms of hardware were actually made of silver rather than cheaper materials, made them less accessible to the masses in the eighteenth and early-nineteenth centuries. The iron coffin handles recovered from the eighteenth-century African Burial Ground
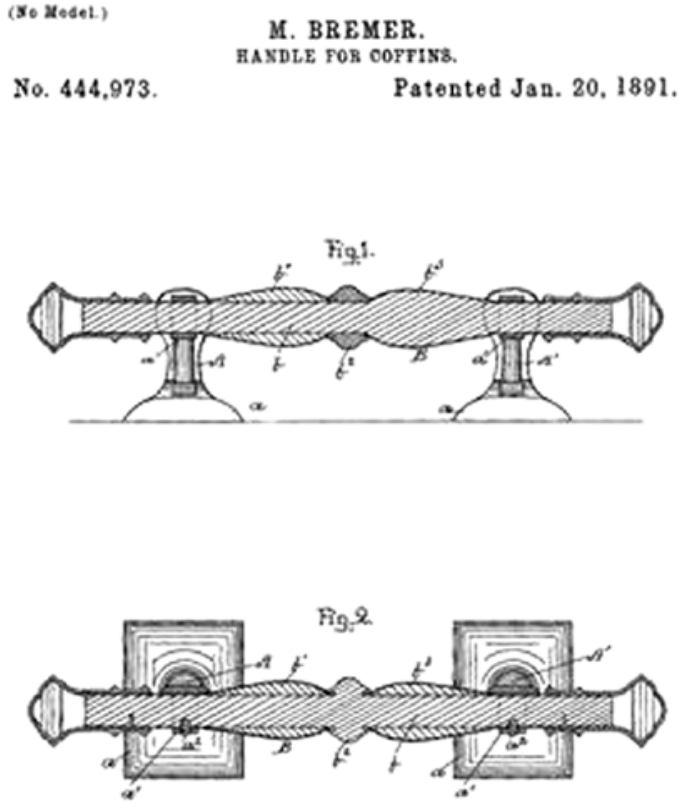

Witqesmes.
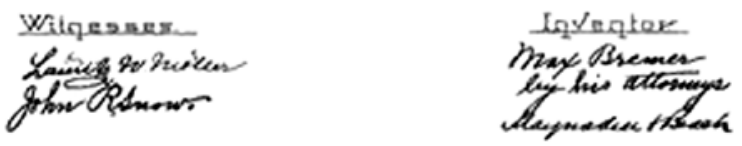

Figure 4.26. U.S. Utility Patent No. 444,973 assigned to M. Bremer for a coffin handle with a swelled bar in 1891 .

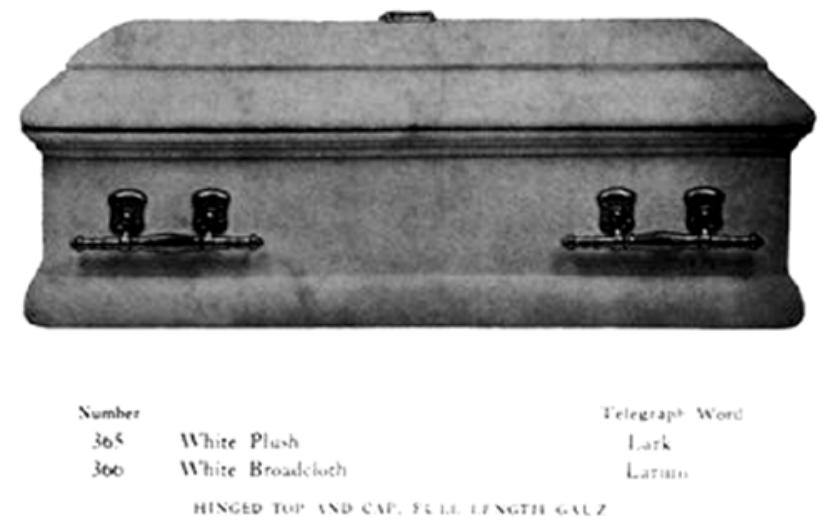

Figure 4.27. Casket illustrated exhibiting a short-bar handle similar to Handle Type 6 on page 30 of the ca. 1910 Dallas Coffin Company catalog.

in New York (Perry et al. 2006), as well as the stamped-tin coffin handle plates from the early nineteenth-century Tenth Street First African 


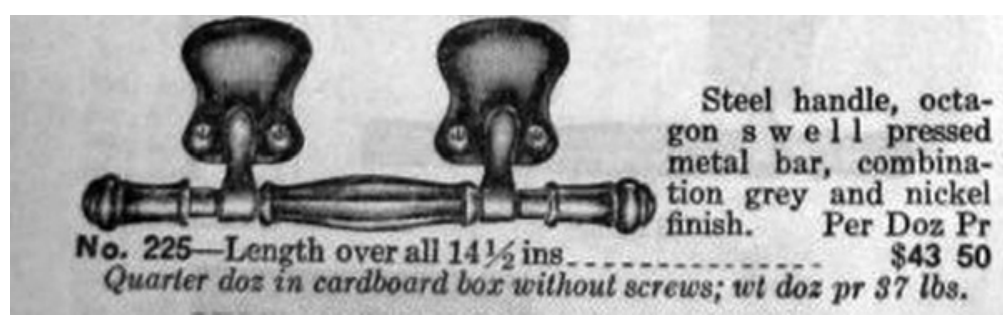

Figure 4.28. Casket handle No. 225 as shown on page 966 of the 1940 Belknap Hardware and Mfg. Company.
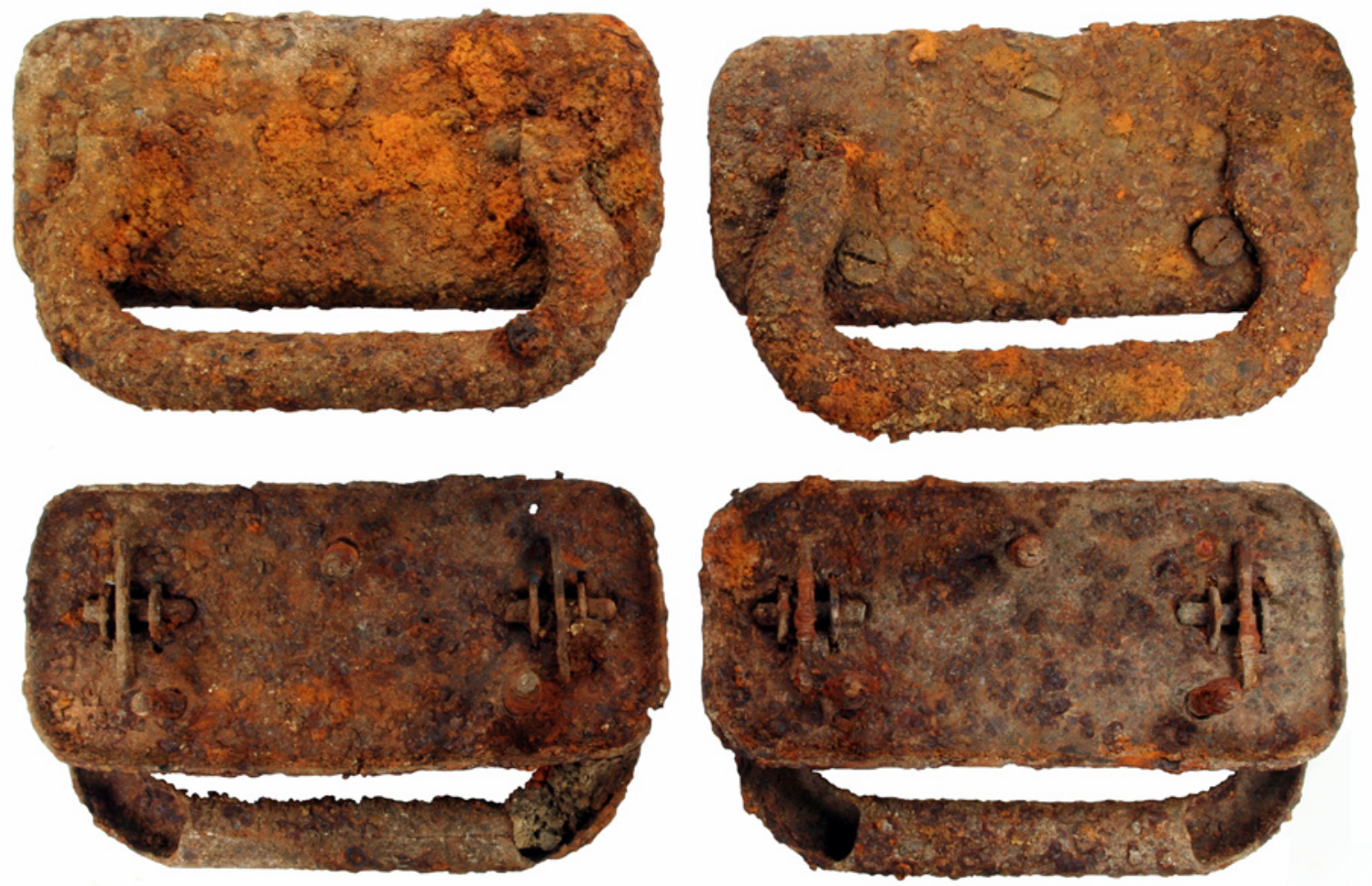

$$
\begin{array}{lll}
0 & 1 & 2 \\
\text { centimeters } & \multicolumn{1}{l}{\mid} & \mid
\end{array}
$$

Figure 4.29. Handle Type 3 recovered from Roberts Cemetery Burial 1.

Baptist Church Cemetery (Crist et al. 1996) in Philadelphia, represent exceptions to this general pattern (Springate 2011).

In their early period of use, plaques generally were blanks upon which the name and personal information of the deceased could be hand-engraved or painted (Pike and Armstrong 1980:149-150). While hand-engraved blanks persisted through the nineteenth century, it became much more common to purchase factory-stamped or engraved plates exhibiting common nineteenth-century phrases or sentiments, such as "At Rest," "Our Darling," "Rest in Peace," etc. (Davidson 2006:151). At the end of the funeral, most plaques were probably buried with the deceased to identify their remains if disturbed at a later date. However, during the nineteenth and early twentieth centuries, it was also fashionable for some Americans to remove plaques after the funeral but before committal and keep them as mementos of the deceased (Gordon 2003). 


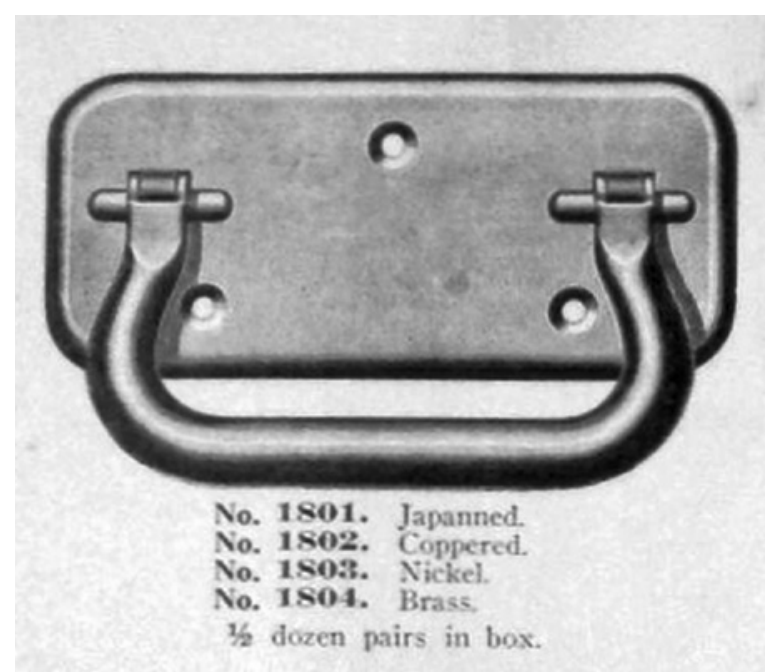

Figure 4.30. Outer box handle shown on page 458 of the 1908 Mound Coffin Company catalog.

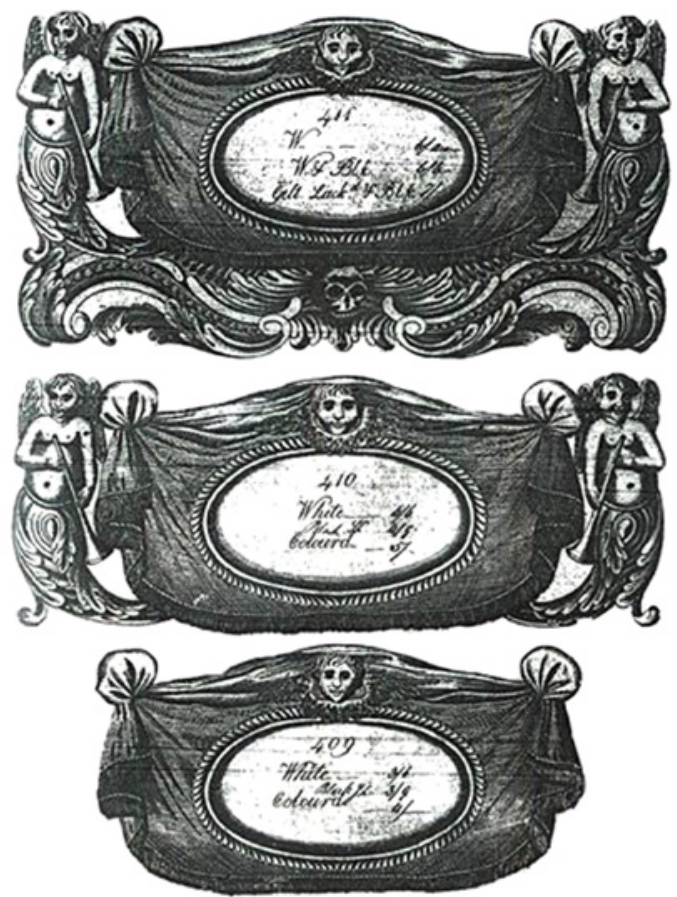

Figure 4.31. Examples of early "coffin plates" from ca. 1797 English hardware sample books.

\section{PLAQUE TYPE 1}

Plaque Type 1 (Figure 4.32) is represented by at least 14 fragments of one ferrous metal plate recovered from Burial 1 in Roberts Cemetery (see Table 4.1). This plate is generally rectangular; however, it appears to have raised shoulder corners and possibly an elevated lip on the upper margin of the plaque. There is no evidence of embossed or engraved lettering on the face of this plate. Due to its fragmentary nature, it is not possible to definitively match it to any patent records, catalogs, or cemetery excavation reports (see Table A.3).

\section{PLAQUE TYPE 2}

Plaque Type 2 (Figure 4.33) is represented by two artifacts in Roberts Cemetery, one each in Burials 2 and 3 (see Table 4.1). This plaque is made of white metal and was affixed to the burial container via two screws, nails, or pins, one in the upper left corner of the piece and the other in the lower right. The plaque is shaped like a ribbon or banner with forked ends, which are flowing behind the midsection of the banner. "At Rest" is molded onto the face of the banner in Old English Text MT type font. "At Rest" was a common phrase found on plaques in the latenineteenth and early-twentieth centuries. The reverse face of the plaque is hollow-backed, and the impressions on the "est" of "Rest," as well as a mold mark "92E" just to the left of the "t," are visible.

This same plaque type has been recovered from six other historic cemetery excavationsfour in Texas, one in Tennessee, and one in Arkansas-from burials that range in dates from 1891 to 1935 . In addition, this plaque appears in eight period mortuary hardware catalogs dated from 1901 to 1949 (e.g., Figure 4.34) (see Table A.3). The "92E" mold mark on Plaque Type 2 is significant, however, because it suggests that this particular plaque came from the Chattanooga Coffin Company (Chattanooga, Tennessee), which was founded in 1887 and closed sometime in the 1930 s, possibly as the result of losses from the Great Depression. It is not known when Chattanooga Coffin Company began to produce this particular plaque because the 1905 catalog and price list are the only known extant ephemera from this company. This evidence indicates that the Type 2 plaques associated with Burials 2 and 3 were manufactured after 1887 and no later than the 1930s. It is likely that Burials 2 and 3 occurred before ca. 1940.

\section{Thumbscrews}

Thumbscrews evolved out of earlier forms of coffin screws with the first identified iteration 


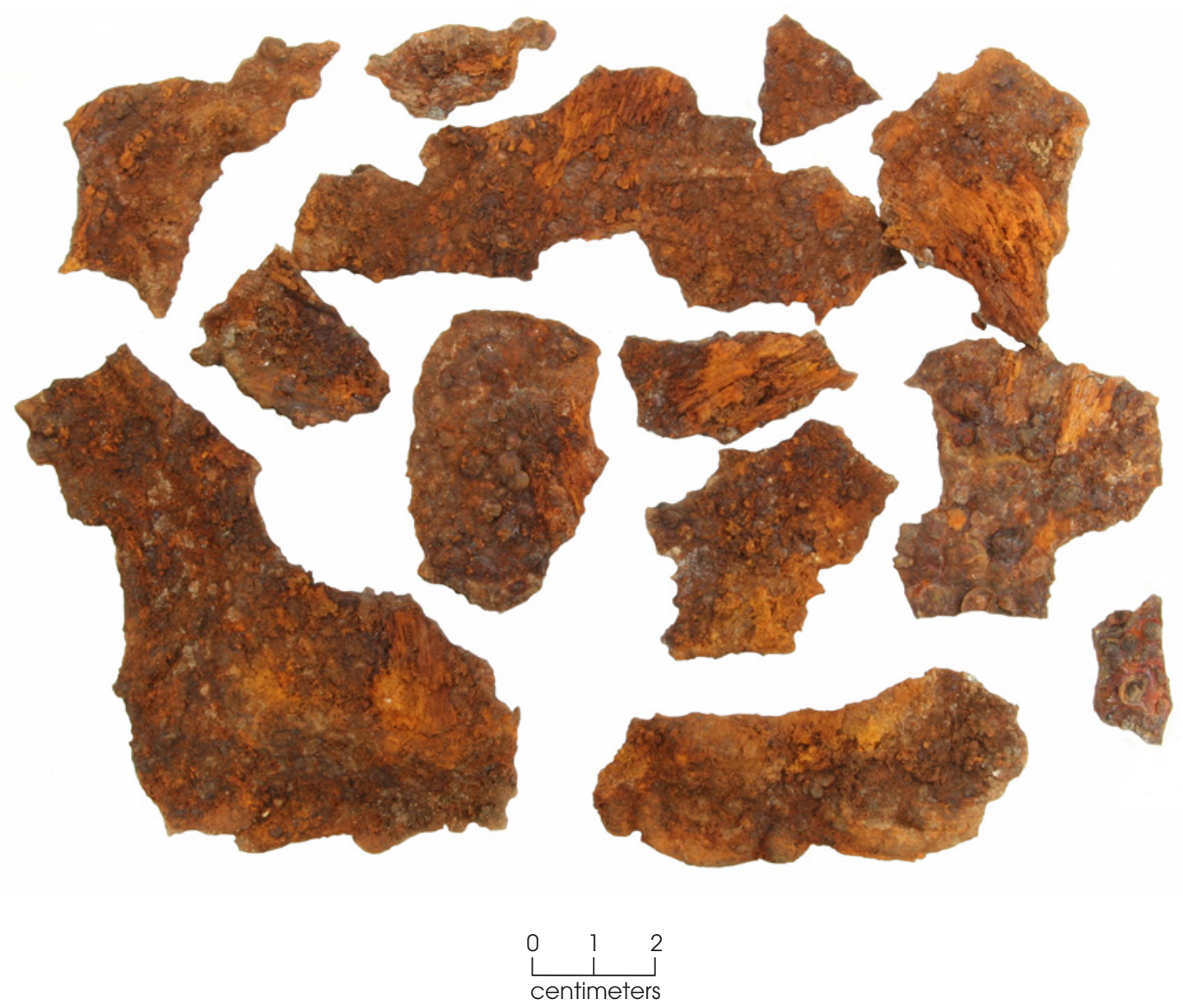

Figure 4.32. Plaque Type 1 recovered from Roberts Cemetery Burial 1.

appearing in an 1859 patent issued to $\mathrm{Mr}$. H. Marshall for an innovative type of rectangular metal casket (U.S. Utility Patent No. 25,659). The flat-bodied forms, like those recovered from the Roberts Cemetery excavations, first appear with an 1874 patent issued to W. M. Smith (U.S. Utility Patent 7,797) for a flat-bodied, urnshaped design. These new types of thumbscrews soon hit the market, appearing in catalogs in 1875. Thumbscrews are great temporal diagnostics because continued advancements and variations in designs yielded further registered patents even up to 1884. Even into the twentieth century, companies and individuals continued to produce new forms (though few were patented) (Davidson 2006:133-134). Due to the increased use of complex lid fasteners, such as the ones already discussed in this analysis, the popularity of thumbscrews as lid fasteners declined in the first two decades of the twentieth century.
As evidenced by the presence of only two forms of thumbscrews in the 1959 Victor Casket Hardware Company catalog, a greatly reduced and simplified selection of thumbscrews was sold even up to the $1960 \mathrm{~s}$, mostly as outer box fasteners.

\section{THUMBSCREW TYPE 1}

Thumbscrew Type 1 (Figure 4.35) is associated with Escutcheon Type 1 and is represented by three artifacts from Burial 2 and five artifacts from Burial 3 in Roberts Cemetery (see Table 4.1). It consists of a flat-bodied head made of white metal cast upon a iron shank. The head has a tri-lobed crown motif, with floral tendrils curling inward along each side margin at the lobes, and two lines extending from the apex of the crown to the bottom corners. A constricted neck and a raised cylindrical base lay below the crown. 

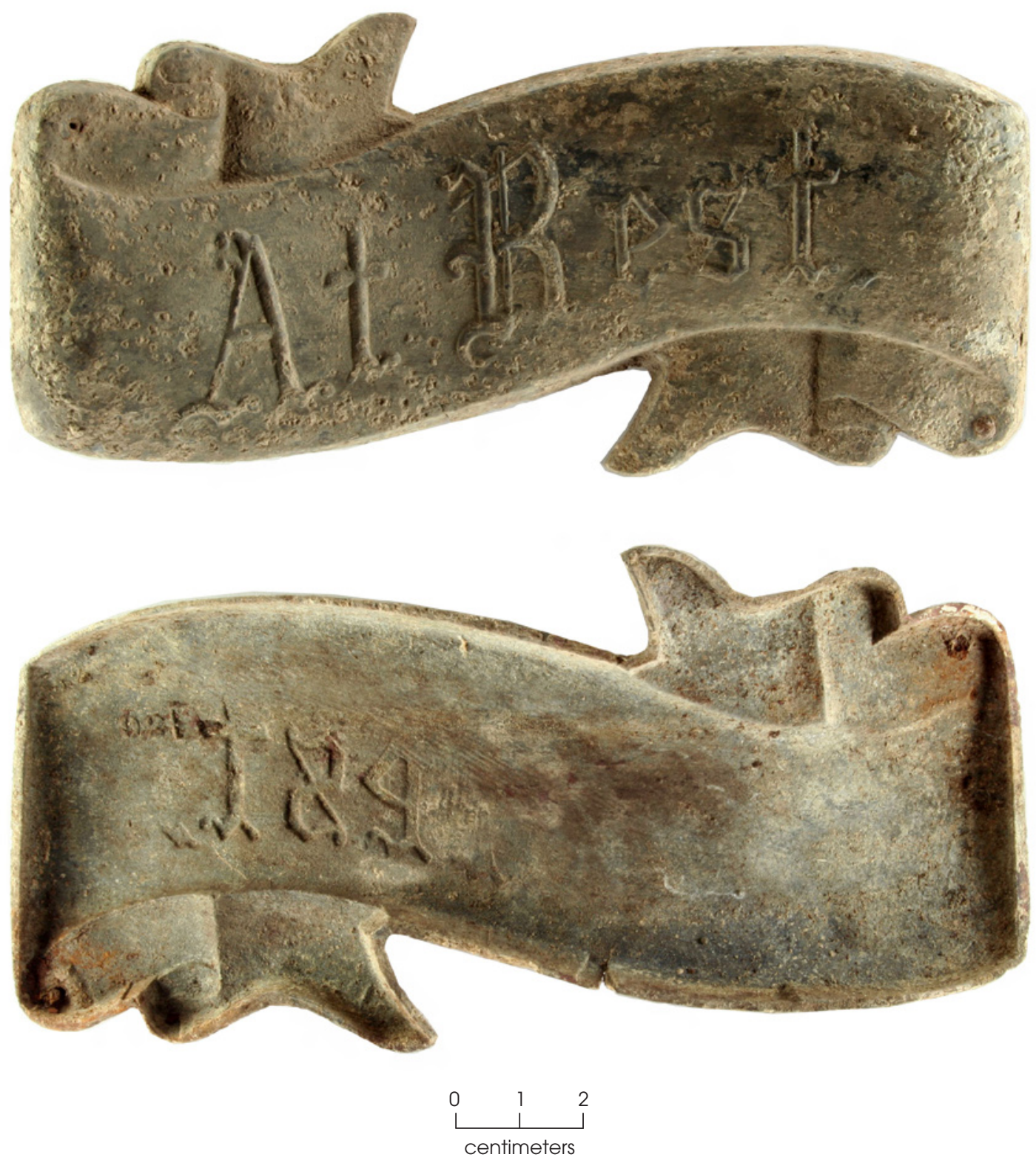

Figure 4.33. Plaque Type 2 recovered from Roberts Cemetery Burials 2 and 3.

Exact matches have been not been located in any patent records or period trade catalogs. This screw has, however, been identified in the archeological excavations of three other historic cemeteries, one in Georgia from a burial dating between 1875 and 1930, one in Arkansas from a burial dating between 1890 and 1927, and the third in Texas from a burial dating between 1895 and 1905 (see Table A.3). This time window brackets the range of common use for thumbscrews in general and therefore does not provide much aid in determining a tighter chronology.

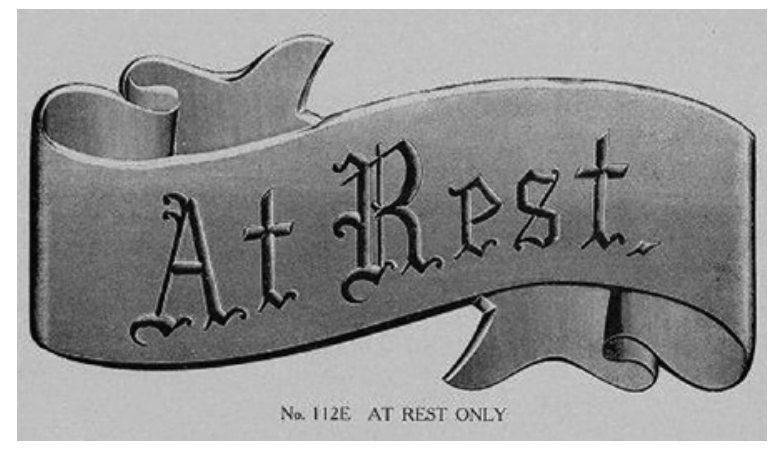

Figure 4.34. Plaque No. $112 \mathrm{E}$, which is a match to Plaque Type 2, as illustrated on page 66 of the ca. 1911 Hearne Bros. \& Company catalog. 

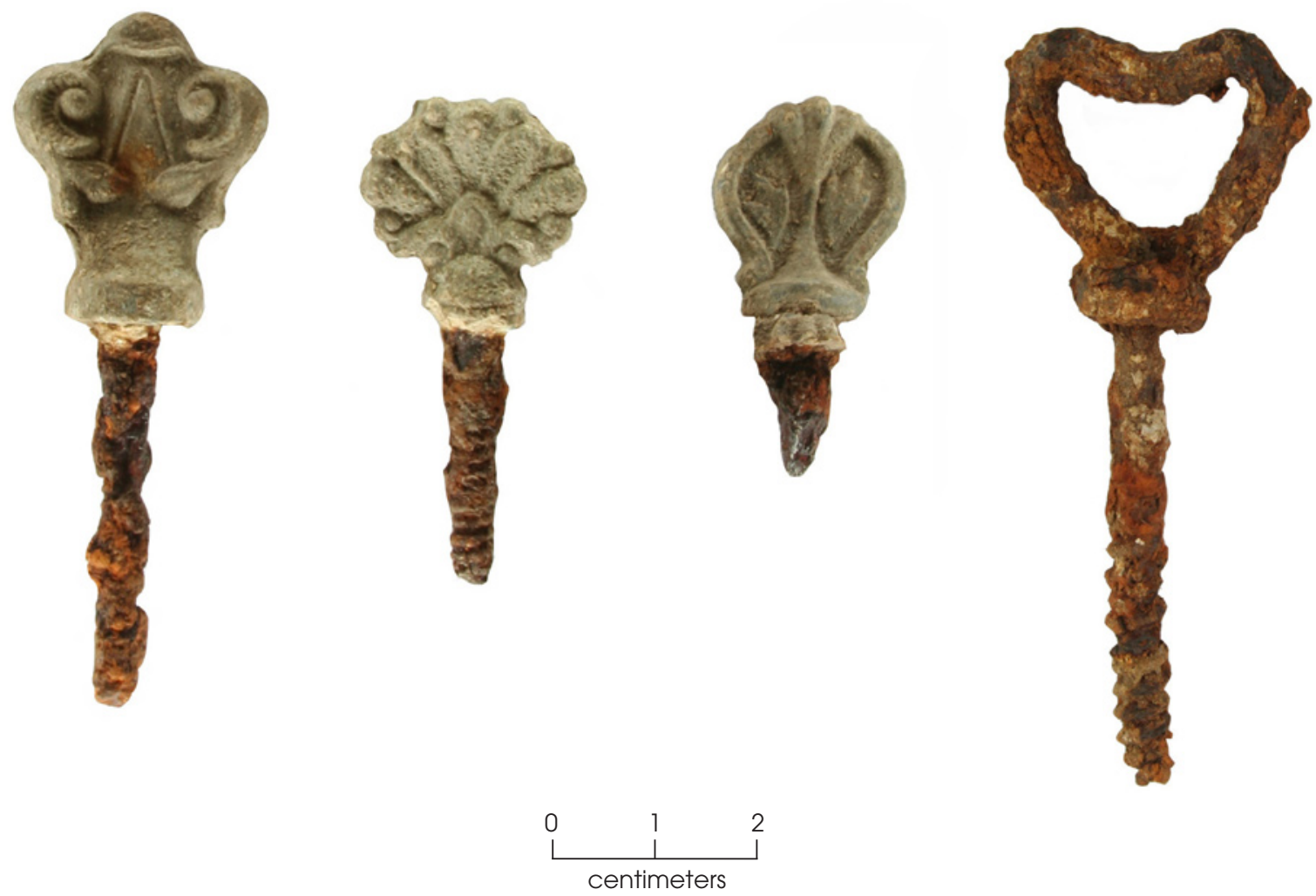

Figure 4.35. Thumbscrews recovered from Roberts Cemetery burials: (from left to right) Thumbscrew Type 1, Burials 2 and 3; Thumbscrew Type 2, Burials 2 and 3; Thumbscrew Type 3, Burial 2; Thumbscrew Type 4, Burial 1.

\section{THUMBSCREW TYPE 2}

Thumbscrew Type 2 (see Figure 4.35) is represented by two artifacts in Roberts Cemetery, one each coming from Burials 2 and 3 (see Table 4.1). This thumbscrew is made of white metal cast on a metal screw shank. The head shape is reflective of a lotus flower. Within this conception, there are five petals extending from a central stylized three-leaf blossom. The first, third, and fifth petals are convex, while the second and fourth petals are concave. Small beads sit atop the edge of the screw head between the petals.

Exact matches to this thumbscrew have been not been located in any patent records, but it has been identified in two period trade catalogs, one from 1901 (Figure 4.36) and one from ca. 1904. This screw has been recovered in the archeological excavations of three other historic cemeteries, two in Georgia from burials dating between 1875 and 1930, and one in Texas from a burial dating between 1900 and 1907 (see Table A.3). This time window brackets the range of common use for thumbscrews in general and therefore does not provide much aid in determining a tighter chronology. It is evident at least that this thumbscrew was on the market in the first decade of the twentieth century. When it entered the market or fell out of favor is not known.

\section{THUMBSCREW TYPE 3}

Thumbscrew Type 3 (see Figure 4.35) is represented by one artifact in Burial 2 in Roberts Cemetery (see Table 4.1). This thumbscrew is made of white metal cast on a metal screw shank. The head shape of these white metal thumbscrews is rounded with a raised edge and a central floral element growing out of the rounded base and blossoming into three petals at the top of screw head. On either side of the raised stem is a raised leaf with three points toward their top edges.

Exact matches to this thumbscrew have not been located in any patent records, but it has been identified in three period trade 


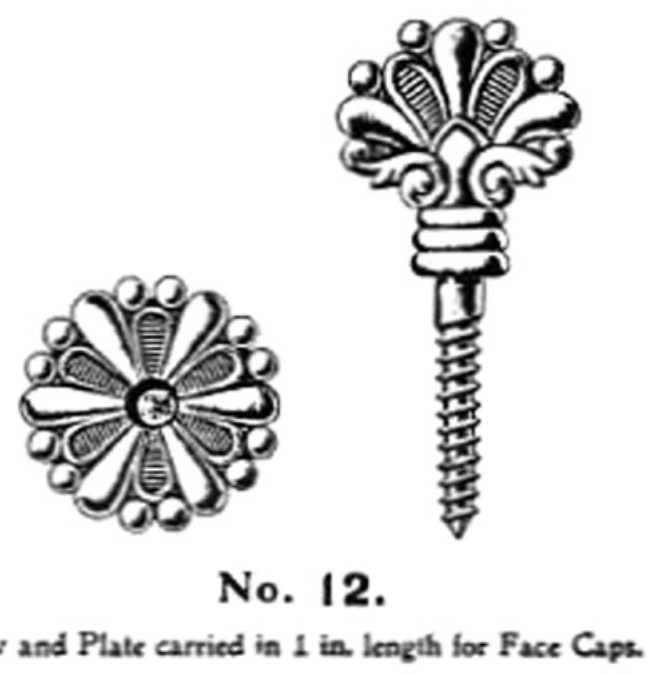

Figure 4.36. Thumbscrew No. 12, which is similar to Thumbscrew Type 2, as illustrated on page 264 of the 1901 St. Louis Coffin Company catalog.

catalogs again from a narrow time window, ca. 1904 (Figure 4.37) to 1905. This screw has been recovered in the archeological excavations of two other historic cemeteries, one in Texas from burials dating between 1900 and 1907, and one in Tennessee from burials dating between 1899 and 1933 (see Table A.3). This at least suggests that this screw appeared sometime in the late 1890s and was most popular in the first decade of the twentieth century. When exactly it fell out of favor is not clear.

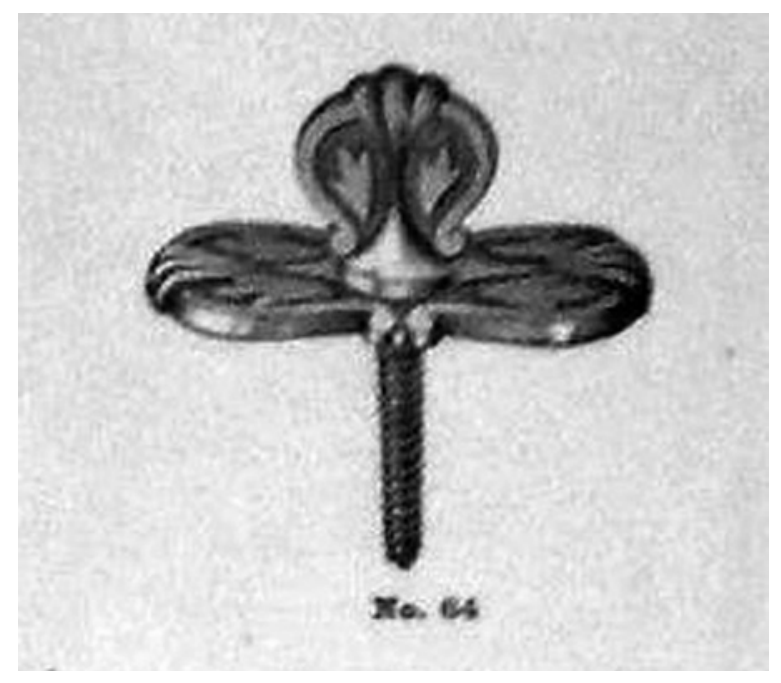

Figure 4.37. Thumbscrew and Escutcheon No. 64, which are similar to Thumbscrew Type 3 and Escutcheon Type 2, as illustrated on page 181 of the ca. 1904 Gate City Coffin Company catalog.

\section{THUMBSCREW TYPE 4}

Thumbscrew Type 4 (see Figure 4.35) is represented by two artifacts from Burial 1 in Roberts Cemetery (see Table 4.1). This thumbscrew is made of iron, and the head is formed by bending the ferrous wire around into the shape of a heart and twisting it off at the base of the head. This was a rough utilitarian form of thumbscrew used to secure the lids of outer boxes, or shipping crates, during transport of a coffin or casket from a manufacturer. That is why it is also referred to as a "box screw" or an "outer box screw." The shipping crate was often placed within the grave, and the burial container was placed within it before the grave was filled. In this capacity, it was used as a type of vault, and the box screws, therefore, entered the archeological record.

Exact matches to this thumbscrew have been not been located in any patent records, but it has been identified in 11 period trade catalogs from ca. 1895 to 1966 (e.g., Figure 4.38). This screw has been recovered in the archeological excavations of seven other historic cemeteries, one each in Arkansas, Georgia, Tennessee, Kentucky, Illinois, Virginia, and Ontario, Canada. The associated burials within six of these cemeteries provide a date range of 1890-1935, which is in agreement with the catalog ranges. The final cemetery, Terre Haute Cemetery (Virginia) was dated between 1790 and 1865, which is extremely suspect (see Table A.3). This thumbscrew type was definitely not in production that early. The comparison data illustrates the fact that this thumbscrew had a wide geographic and temporal range, which is not extremely helpful in producing tight chronologies, but does suggest that a ca. 1890 date of entry onto the market is reasonable.

\section{Thumbscrew Escutcheons}

The term "escutcheon" refers to decorative screw plates with a central hole through which a thumbscrew can pass for mounting. These accessories were first known to have been illustrated on page 331 of the 1865 Russell \& Erwin Mfg. Co. hardware catalog. The early varieties consisted largely of simple diamond-shaped forms. It was not until the widespread introduction of thumbscrews in the 1870s that escutcheon designs began to evolve so that they could be sold 


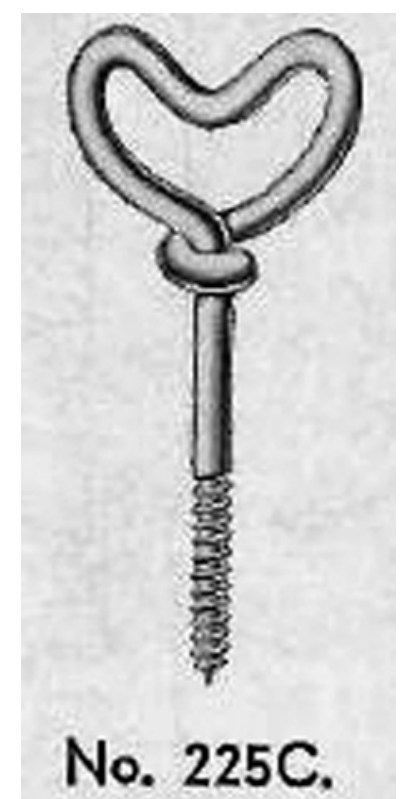

Figure 4.38. Outer box screw No. 225C, similar to Thumbscrew Type 4, as illustrated on page 76 of the ca. 1925 Sargent and Company Catalog No. 18.

with thumbscrews as matched sets. This type of artifact has a broad temporal range of approximately 1865-1920s (Davidson 2006:147).

\section{THUMBSCREW ESCUTCHEON TYPE 1}

Thumbscrew Escutcheon Type 1 (Figure 4.39) is represented by seven artifacts recovered from Roberts Cemetery, with three coming from Burial 2 and four coming from Burial 3 (see Table 4.1). It has been found in association with Thumbscrew Type 1. It shares some stylistic elements with its associated thumbscrew, and likely came as a set. The plate has a central hole from which extends two leaf-like elements that make up the body of the plate. The leaves have two inward-facing floral tendrils running lengthwise along the piece. Where the leaves join along the side margins are what appear to be floral buds flanking the center hole. No matches have been located in period trade catalogs or patent records, but this type has been recovered from one historic burial in New Home Cemetery, Texas, dated between 1895 and 1905. Because of the lack of comparative matches, it is difficult to accurately date this artifact. It likely has a production period comparable to that of its associated thumbscrew, which was found in archeologically relocated burials dating between 1875 and 1930 (see Table A.3).

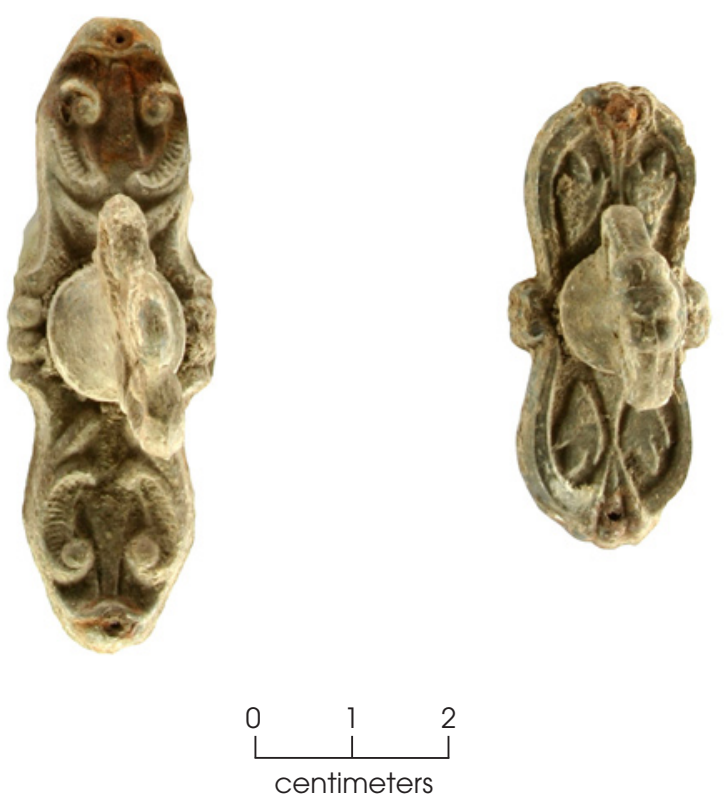

Figure 4.39. Escutcheons recovered from Roberts Cemetery burials: (from left to right) Escutcheon Type 1, Burials 2 and 3; Escutcheon Type 2, Burial 2.

\section{THUMBSCREW ESCUTCHEON TYPE 2}

Thumbscrew Escutcheon Type 2 (see Figure 4.39) is represented by one artifact recovered from Burial 2 in Roberts Cemetery (see Table 4.1). It was found in association with Thumbscrew Type 3. It shares stylistic elements with its associated thumbscrew, and likely came as a set. Each side of the thumbscrew is a mirror image of the other. Each side is rounded with a raised edge and a central floral element growing out of the central hole area and blossoming into three petals at the terminal ends. On either side of the raised stem is a raised leaf with three points toward their top edges. Where the two sides come together in the center are squared short projections.

Exact matches to this escutcheon have not been located in any patent records, but it has been identified (along with the associated thumbscrew) in three period trade catalogs from ca. 1904 (see Figure 4.37) to 1905. This escutcheon has been recovered in the archeological excavations of two other historic cemeteries, one in Texas from burials dating between 1900 and 1907, and the other in Tennessee from burials dating between 1899 and 1933. This escutcheon was also recovered from the 1894-1926 A. L. Calhoun General Store collection in South Carolina (see Table A.3). As was the case with 
the associated thumbscrew, this escutcheon probably appeared on the market sometime in the late 1890s and was most popular in the first decade of the twentieth century. When exactly it fell out of favor is not clear.

\section{Caplifters}

Caplifters are a class of burial container hardware designed to be affixed to the panel covering a viewing window on a burial container. They acted as a pull that would facilitate the drawing off of the cover to expose the window glass and view the enclosed decedent. Many caplifters were not remarkably different from the vast majority of thumbscrews and, in fact, thumbscrews were sometimes used as caplifters and vice versa. Davidson (2006:163) notes that the earliest "caplifter" forms can be found on the metallic caskets and burial cases of the 1850s and $1860 \mathrm{~s}$, such as those produced by Crane, Breed \& Company, but these were not referred to by name. The earliest catalog known to exist where caplifters are offered for sale as a separate hardware class is the $1875 \mathrm{H}$. E. Taylor \& Co. catalog. Within this catalog, the "Rose-Leaf Lifter" was described as being used for "Panels, etc." Caplifters became common throughout the catalogs of the late 1870 s and fell out of use in the 1920s (Davidson 2006:164).

\section{CAPLIFTER TYPE 1}

Caplifter Type 1 (Figure 4.40) is represented by two artifacts recovered from Roberts Cemetery, one each from Burials 2 and 3 (see Table 4.1). This caplifter has a white metal head cast on an iron shank. The head is roughly the shape of a full-bodied crown with a broad base and a constricted neck upon which is a rounded band. Above the neck sits a saucer platform with a scalloped edge upon which sits a two-tiered pinnacle. No caplifter base or escutcheon was found in association with this caplifter.

Exact matches to this caplifter have been not been located in any patent records, but it has been identified in one period trade catalog from ca. 1911 (Figure 4.41). This caplifter has also been recovered in the archeological excavations of two other historic cemeteries, one in Tennessee from a burial dating between 1899 and 1933, and one in Georgia from a burial dating between 1875 and 1930. Additionally, this
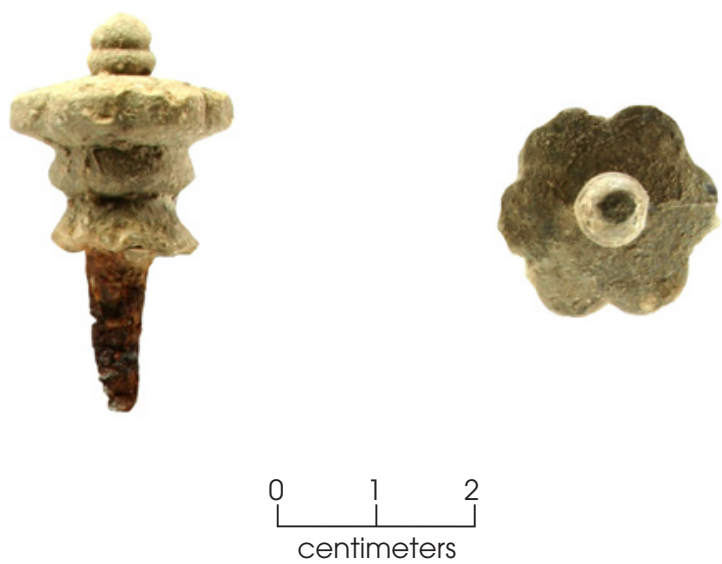

Figure 4.40. Caplifter Type 1 recovered from Roberts Cemetery Burials 2 and 3.

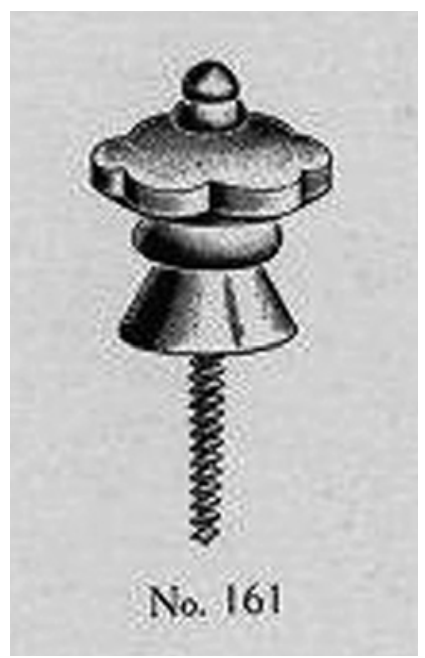

Figure 4.41. Caplifter No. 161, which is similar to Caplifter Type 1, as illustrated on page 81 of the ca. 1911 Hearne Bros. \& Company catalog.

escutcheon was recovered from the 1894-1926 A. L. Calhoun General Store collection in South Carolina (see Table A.3).

\section{CONCLUSIONS}

This chapter has explored the types of burial container hardware recovered from four historic burials in Roberts Cemetery, Bell County, Texas. The collection contained three handle types, four thumbscrew types, two thumbscrew escutcheon types, one caplifter type, two plaque types, one dowel type, one type of top fastener assembly, and one catch assembly. The artifacts were compared to U.S. patent records, period mortuary hardware catalogs, as well as published and 
unpublished reports of other archeologically relocated historic cemeteries and isolated burials (see Tables A.1,A.2, and A.3). Table 4.2 presents a chronology of burials, as well as a summary of the chronologies for each artifact type as derived from the aforementioned comparisons, which are laid out in Table A.3.

Burial 1 has a terminus post quem (TPQ) of 1910 because a patent matching the lug and arm of Handle Type 2 dates to that year. A terminal date is more problematic. Handle Type 2 is the most informative piece of hardware. It has been located in period hardware catalogs up to at least 1950, however, ca. 1935 is the last known appearance of the handle in an actual mortuary merchandise catalog. The three later appearances of this handle are in general hardware catalogs. It is unclear how wide an impact this venue would have had on the marketing of this handle. It is likely the popularity of the handle waned in the 1930s when it no longer appears in mortuary catalogs.

Burials 2 and 3 contain such a similar assortment of hardware that it is very probable that they were interred at the same time, or very soon after one another sometime between ca. 1895 and the 1930s. The widespread use of wire nails inform the beginning date of this estimate (the TPQ), while the decline in the use of the varied white metal thumbscrews mark the ending. The presence of Plaque Type 2 in both of these burials provides an additional piece of evidence to support a terminus ante quem (TAQ) of the 1930s. Plaque Type 2 had a "92E" mold mark indicating that it was produced by the Chattanooga Coffin Company. It is not known when the company acquired the mold for this plaque and started production, because only the 1905 catalog and price list are known to have survived. The Chattanooga Coffin Company was founded in 1887 and appeared in the city directories for Chattanooga, Tennessee, through 1930. However, the company apparently hit hard times during the Great Depression, and they were no longer in business when the 1940 city directory was prepared. Companies did occasionally sell old hardware molds, but rather than altering the mold number, companies purchasing old molds would adopt the product number of the mold. One post-1940 appearance of this plaque type has been documented in a 1949 Philadelphia Mfg. Company catalog, but the mold number is not the same. At this time it does not appear that the Chattanooga molds continued to be used after the failing of the company in the 1930s.

Burial 4 contained no decorative hardware, but the presence of wire nails suggest an interment after ca. 1895. The fact that Burial 4 contained no decorative hardware potentially indicates that the individual was of limited economic means compared to the other individuals represented in this sample. A much larger sample of burials would be needed, however, to make grander observations about socioeconomics within this cemetery population. In the absence of diagnostic hardware, a TAQ of the 1930s has been applied to this burial as well, due in part to its proximity to Burial 1.

Based on the matches between the recovered hardware and this compendium of comparative materials, the four burials collectively appear to date between ca. 1895 and the 1930s, with Burial 1 being more specifically dated between 1910 and the 1930s. The estimated interment dates are based on the period of peak popularity and usage for the combined burial hardware associated with each grave. As has been discussed for some hardware types, the estimated ending dates are not the maximum possible span that includes the latest advertising and sale of out-of-style or surplus hardware. The ending date estimates also do not consider the possibility that there could have been lag time between the manufacture and sale of mortuary hardware in rural areas, a problem that has been discussed by several scholars (e.g., Buchner et al. 1999; Hacker-Norton and Trinkley 1984; Mainfort and Davidson 2006). Setting aside the possibility of prolonged use of certain artifact types beyond their period of peak popularity, there remains one final reason why the burials appear to date to the early part of the twentieth century. There is a distinct lack of formal embalming paraphernalia recovered from the burials. Burials dating to the late 1940s through the 1960s that have been archeologically recovered commonly include embalming items like trocar buttons, mouth formers, eye caps, etc. (Dockall, Boyd et al. 1996; Pye 2011b; Trinkley et al. 2011). By the mid-twentieth century, embalming was so commonplace that the absence of associated items is a potential, although an admittedly speculative, temporal indicator. 
Table 4.2. Chronological summary of mortuary hardware by burial

\begin{tabular}{|c|c|c|c|c|c|c|}
\hline $\begin{array}{l}\text { Mortuary } \\
\text { Hardware }\end{array}$ & Type & Type Dating & $\begin{array}{c}\text { Burial } \\
1 \\
\end{array}$ & \begin{tabular}{|c|} 
Burial \\
2 \\
\end{tabular} & \begin{tabular}{|c|} 
Burial \\
3 \\
\end{tabular} & $\begin{array}{c}\text { Burial } \\
4 \\
\end{array}$ \\
\hline \multicolumn{7}{|c|}{ Burial Container } \\
\hline \multirow[t]{2}{*}{ Plaque or plate } & Type 1 , iron & circa 1900 & 1 & & & \\
\hline & Type 2, white metal & circa 1900-1930s & & 1 & 1 & \\
\hline \multirow[t]{2}{*}{ Handles } & Type 1, white metal & circa 1890-1940 & & 6 & 6 & \\
\hline & Type 2, white metal & circa 1910-1950 & 6 & & & \\
\hline \multirow[t]{2}{*}{ Escutcheon } & Type 1, white metal & circa 1875-1930 & & 3 & 4 & \\
\hline & Type 2, white metal & circa 1900-1930 & & 1 & & \\
\hline \multirow[t]{3}{*}{ Thumbscrew } & Type 1, white metal & circa 1875-1930 & & 3 & 5 & \\
\hline & Type 2, white metal & circa $1875-1930$ & & 1 & 1 & \\
\hline & Type 3, white metal & circa 1900-1930 & & 1 & & \\
\hline Caplifter & Type 1, white metal & circa 1875-1930 & & 1 & 1 & \\
\hline \multirow[t]{6}{*}{$\begin{array}{l}\text { Internal lid } \\
\text { mechanisms }\end{array}$} & $\begin{array}{l}\text { Top Fastener Type 1, spring assembly, } \\
\text { iron }\end{array}$ & after 1889 & 2 & & & \\
\hline & Top Fastener Type 1, foot hook, iron & after 1889 & 2 & & & \\
\hline & Top Fastener Type 1, foot plate, iron & after 1889 & 2 & & & \\
\hline & Catch Assembly Type 1, iron & after 1889 & 1 & & & \\
\hline & Dowel Type 1, iron & after circa $1880 \mathrm{~s}$ & 2 & & & \\
\hline & Joining plates, iron & & 12 & & & \\
\hline \multirow[t]{9}{*}{ Nails } & Wire common, iron & after 1895 & 72 & 17 & 30 & \\
\hline & Wire finishing, iron & after 1895 & 21 & 8 & 13 & \\
\hline & Wire larger-head finishing, iron & after 1895 & & 12 & 2 & \\
\hline & Wire short, iron & after 1895 & 24 & 22 & 19 & \\
\hline & Wire large, iron & after 1895 & & 1 & 1 & \\
\hline & Wire extra-large, iron & after 1895 & & & & 20 \\
\hline & Cut square, iron & after 1830 & & 1 & & \\
\hline & Wire shanks, iron & after 1895 & & & 5 & \\
\hline & Wire with grooved ring shank, iron & & 2 & & & \\
\hline \multirow[t]{5}{*}{ Screws } & 1-inch, iron & after 1846 & 6 & 1 & & \\
\hline & 1.25-inch, iron & after 1846 & & & & 4 \\
\hline & 1.5-inch, iron & after 1846 & & 1 & & \\
\hline & 2-inch, iron & after 1846 & 1 & & 1 & \\
\hline & Shank, iron & after 1846 & & 1 & 2 & \\
\hline \multirow[t]{3}{*}{ Tacks } & \begin{tabular}{|l|} 
Decorative, copper \\
\end{tabular} & & & 2 & 1 & \\
\hline & Fabric, iron & & 40 & 2 & 1 & 35 \\
\hline & Long tacks, iron & & 5 & 2 & & \\
\hline $\begin{array}{l}\text { U-shaped } \\
\text { unidentified }\end{array}$ & Unknown, iron & & & & 1 & \\
\hline \multicolumn{7}{|l|}{ Outer Box } \\
\hline Handle & Type 3, iron & circa 1890-1960 & 5 & & & \\
\hline Thumbscrew & \begin{tabular}{|l|} 
Type 4, iron \\
\end{tabular} & circa 1890-1966 & 2 & & & \\
\hline Nails & Wire common, iron & after 1895 & 12 & & & \\
\hline \multicolumn{7}{|c|}{ Unknown Location within Burial } \\
\hline \multirow[t]{3}{*}{ Nails } & Wire common, iron & after 1895 & 72 & & & \\
\hline & Wire finishing, iron & after 1895 & 21 & & & \\
\hline & Wire short, iron & after 1895 & 24 & & & \\
\hline \multirow[t]{2}{*}{ Screws } & 1-inch, iron & after 1846 & 6 & & & \\
\hline & 2-inch, iron & after 1846 & 1 & & & \\
\hline \multicolumn{3}{|c|}{ Estimated Date Range for Interments Based on Mortuary Hardware } & $\begin{array}{l}1910- \\
1930 s\end{array}$ & $\begin{array}{l}1895- \\
1930 \mathrm{~s}\end{array}$ & $\begin{array}{l}1895- \\
1930 \mathrm{~s}\end{array}$ & $\begin{array}{c}1895- \\
1930 \text { s (?) }\end{array}$ \\
\hline
\end{tabular}





\section{OSTEOLOGICAL ANALYSIS OF HUMAN REMAINS}

Catrina Banks Whitley

This chapter describes the methods and results of an osteological analysis of the remains of one child and three adults excavated from the Roberts Cemetery. Brief osteological summaries were presented in the individual burial descriptions in Chapter 3, but this chapter provides a more detailed comparative look at the osteological interpretations. Because the number of exhumed burials is so small, it is not a representative population sample for the Troy community or the central Texas area, so local health and mortality risks cannot reasonably be interpreted. However, comparisons with selected state and regional historic mortality data and other historic cemetery populations are made. General observations on individual health status provide a limited historic context for understanding the late-nineteenth- and early-twentieth-century burials at Roberts Cemetery.

\section{METHODS}

Data on burial excavation followed the protocols set by Tíne and Boyd (2003). The osteological analysis of the Roberts Cemetery skeletal remains followed the recommendations in Buikstra and Ubelaker (1994). Forms designed by Prewitt and Associates, Inc., were used to collect data on the remains, and the collected data are presented in Appendix B. Osteological information collected includes the condition of each skeletal element, sex, age estimations, ancestry, cranial and postcranial metrics, pathology, taphonomy, dental pathology, dental nonmetrics, and cranial and postcranial nonmetric traits. Dental metrics were not taken. Photographs of skeletal elements exhibiting pathology or anomalies were taken in the laboratory.

\section{Sex and Age}

Sex estimation was based on os coxae and cranial morphology. The characteristics followed recommendations identified in Buikstra and Ubelaker (1994) and Bass (2005). When possible, os coxae and cranial morphology was used, with priority on the os coxae. In cases in which these elements were not available or observations were limited, humeral and femoral head diameters and biepicondylar widths were used to support the analyses (Stewart 1979, as reported in Bass 2005).

Age estimations included analysis of the pubic symphysis and/or the auricular surface. Damage precluded the use of pubic symphyseal changes in most instances; age estimates relied more heavily on the auricular surface. Pubic symphyseal scoring followed Suchey-Brooks phases (Brooks and Suchey 1990; Katz and Suchey 1986) and Todd (Todd 1921). Auricular surface morphology scoring followed the standards defined in Buikstra and Ubelaker (1994).

For the infant, dental development and skeletal element length was used to estimate age-at-death. Crown, root, and apex formation was scored for each tooth and compared to dental development charts (Ubelaker 1989). Pars basilaris sagittal length, maximum width, and maximum length were measured and compared to postnatal dry bone charts (Scheuer and MacLaughlin-Black 1994). Clavicle, humeral, and femoral lengths were also compared to dry bone postnatal charts to assess age. Documented remains from the Spitafields, St. Bride's, St. Barnabas, and Lisbon collections provided data for age-at-death postnatal measurements of the clavicle (Black and Scheuer 1996; Schaefer, 
Black, and Scheuer 2009:144). Humeral and femoral age was based on data from radiographic postnatal measurements (Maresh 1970; Schaefer, Black, and Scheuer 2009:174).

\section{Biological Affinity}

Biological affinity was assessed from traits listed in Rhine (1990). Observation of many of the markers to determine biological affinity was precluded by the damage to the cranial elements. Nonmetric evaluation of the mid-face was not possible on all individuals, including prognathism, eye orbit shape, nasal spine, nasal sill, zygomatics presence of wormian bones, shape of dental arcade, and nasal root. Of the markers that could be observed, such as carabelli's cusps, sutures, oval window, inion hook, and bilobate chin, all indicate each male was Caucasian. For Burial 3, the intercondylar notch of the distal femur was also measured to assist in the determination of biological affinity. The distal intertrochanteric length measured $30.13 \mathrm{~mm}$ on the left and $30.08 \mathrm{~mm}$ on the right. These measurements classify Burial 3 as Caucasoid since the measurement is equal to or below $32 \mathrm{~mm}$ (Baker, Gill, and Kieffer 1990).

\section{Pathology}

Pathology and entheseal changes were recorded for each burial. Overall presence for pathological changes was scored on a diagnosis form, and descriptions of each incidence were written in narrative form. Osteophyte formation was noted by location, and measurements were taken to define the extent of the osteophytes formation. Other changes consistent with degenerative joint disease, such as eburnation and surface porosity, were not present on any of the individuals. Schmorl's nodes were scored according to presence/absence and location on the vertebral body. All pathological changes were analyzed using at least a 10x stereomicroscope. Due to erosion of the cortex on the infants' skeletal elements, each bone was inspected with the microscope to ensure differentiation between cortical bone erosion and pathology.

\section{Entheseal Changes}

Entheseal changes were scored according to the system established by Hawkey and
Merbs (1995). No forms were used to record entheseal changes, but narrative descriptions were included on the pathology form. A complete assessment of entheseal changes by muscle insertion was not recorded since indepth comparisons would not be performed. Only general robusticity observations were made, except for the flexor ligament attachments on the hand phalanges. The following scores were assigned for each MSM type: Level 0 = no expression; Level 1 = faint expression; Level 2 = moderate expression; and Level $3=$ strong expression.

\section{Dentition}

Dental data were collected according to standards established in Buikstra and Ubelaker (1994). Visual recording forms for permanent dentition included observation of wear, caries, calculus deposits, and tooth presence. Metrics were not collected. Dental observation forms included data collection on presence, alveolar resorption, abscess type and size, calculus formation, hypoplasia type and metric location, caries location and size, dental modifications, and any other anomalies. Dental development of deciduous and permanent dentition crown, root, and apex were scored according to the Moorees, Fanning, and Hunt codes (Moorees et al. 1963a, 1963b; reported in Buikstra and Ubelaker 1994).

\section{Stature}

Stature estimates were calculated from regression formulae in Trotter and Gleser (1958). The regression equation with the lowest standard error for which measurements were available was used to estimate stature. Trotter and Gleser (1958:119-120) indicate that lower limb bones correlate with stature more highly than upper limb bones, and upper limb bones should only be used in the absence of lower limb bone measurements. When deciding between equations, Trotter and Gleser (1958:119-120) recommend preference be given to the equation with the lowest standard error as it is more accurate in estimating living stature. Thus, for white males, the preferred stature estimate uses the femur and fibulae, and the least accurate estimate uses the ulna (Trotter and Gleser, 1958:120; Table 12). 


\section{DISCUSSION OF THE ROBERTS CEMETERY BURIALS}

The four individuals excavated from Roberts Cemetery are three adult males and one child. The osteological interpretations for these individuals are summarized as follows:

Burial 1 30- to 40-year-old male, $5 \mathrm{ft} 6$ inches to $5 \mathrm{ft} 9$ inches $(172.17 \pm 3.62 \mathrm{~cm})$

Burial 2 45- to 60-year-old male, $5 \mathrm{ft} 9$ inches to $6 \mathrm{ft} 1$ inch $(178.72 \pm 4.37 \mathrm{~cm})$

Burial 3 20- to 27-year-old male, $5 \mathrm{ft} 2$ inches to $5 \mathrm{ft} 5$ inches $(169.1 \pm 3.74 \mathrm{~cm})$

Burial 4 infant, unknown sex, ca. 1.5 years old

Due to the small number of individuals excavated at Roberts Cemetery, demographic profiles for the Troy community cannot be calculated. The sample is also too small to assess meaningful age-at-death reconstructions or discuss childhood mortality rates for Bell County, Texas. However, a few observations can be made regarding the health status of each of these individuals when the Roberts Cemetery data are compared with mortality schedules and data from other historic cemeteries.

Data collected on teeth provide evidence of diet, oral hygiene, access to dental care, stress in-vivo and during childhood, including diseases and nutritional deficiencies. Data regarding health and nutrition by the analysis of teeth are more robust since teeth are often the only part of the body that survives. Evidence of health, diet, and disease is evaluated by the presence of dental caries, hypoplasia, extent of dental calculus, periodontitis, attrition, dental abscess, and wear.

\section{Dental Caries}

The individuals from Roberts Cemetery exhibited few dental caries. Dental caries is a disease in which food particles and plaque bacteria work together to demineralize the tooth, resulting in opaque spots to large cavities (Roberts and Manchester 1995). Caries rates increase as a population has greater access to refined sugars, sucrose, fine flours, and carbohydrates. Only two of the adults at Roberts Cemetery had caries. Burial 1 had one dental carie on the upper right first molar and Burial 3 had two caries, one on the upper right third molar and lower left premolar four. Only 3 of the 68 observable teeth had caries, which is much lower than the expected frequency, since the Burial 1 male was between 30 and 40 years of age and the Burial 2 male was 45 to 60 years.

\section{Dental Calculus}

Dental calculus develops on teeth closest to the salivary glands (Roberts and Manchester 1995:55). It is a matrix that adheres to the teeth and is comprised of organisms, proteins and saliva. Dental calculus is useful in that microscopic particles of food, such as starch granules, and DNA from the individual can be embedded in the matrix (Hardy, et al. 2009). Recent research being conducted by Warinner (2012) reveals that pathogenic bacteria from the nasal passages and bacteria from the upper respiratory tract and gut systems also are detectable in calculus. Dental calculus increases as a softer diet, due to refined flours or corn, poor oral hygiene, or increased carbohydrate consumption allows plaque to accumulate (Cox and Mays 2002:230; Hillson 1996:260). Prevention requires removal with a toothbrush and dental floss (Sivapathasundharan 2009:379).

Deposits of calculus are moderate to severe on all three adults from Roberts Cemetery. All teeth from Burial 3 had dental calculus deposits. Several of the teeth are encased in calculus, preventing observation of caries or hypoplasia. The oldest of the males, Burial 2, had the least dental calculus, though two dental caries were present.

Though there were only 14 teeth present for evaluation, the mild calculus deposits and small number of caries suggests he had access to dental care or that he ate a diet with fewer refined flours and low in sugars. Hillson (1996:278) notes that a diet high in starchy foods and sugars can lead to an increase in cavities, while a diet of starchy foods with lower sugar consumption can result in fewer cavities. Foods commonly consumed in nineteenth-century Texas generally consisted of bacon/salt pork, corn pancakes or cornbread, sweet potatoes, coffee, and molasses (Fehrenbach 2000:299), and 
the accumulation of calculus in these individuals is consistent with this starchy diet.

\section{Dental Hypoplasia}

Dental hypoplasia are indicators of stress, and the defects occur during tooth development, providing a chronological record of stress episodes. These defects are areas of decreased enamel thickness and are evident as pits, furrows, or exaggerated lines (Lewis 2007:105). Hypoplasia can occur on deciduous dentition as well as adult dentition. Deciduous hypoplasia indicate stress during fetal growth, particularly corresponding with a deficient maternal diet. Hypoplasia on permanent teeth develop between birth and 7 years of age, peaking at 2-4 years of age (Lewis 2007:106). Though the exact causes of the defects are unknown, they can be broadly separated into two categories: malnutrition and illness (Roberts and Manchester 1995:58). Cases of malnutrition do not necessarily indicate that calorie intake was deficient; they could also result from diets lacking certain vitamins (e.g., lack of B12, D, and niacin may be associated with anemia, cribra orbitalia, or pellagra) or dysentery/bowel diseases preventing absorption. Most of the defects develop between 2 and 4 years of age and may be related to complications as children are being weaned, losing the protective immunity provided by the mother's milk. During weaning, children are exposed to changes in the quality of food and are often introduced to contaminated water supplies. Illness-associated stress include high fevers, potentially from ear infections, measles, cholera, typhoid, malaria, or other childhood diseases. The presence of hypoplasia in adults reflects the individual's ability to survive these childhood health insults and correlates with a decreased life expectancy (Lewis 2007:106). Burials 2 and 3 had one to two teeth with a hypoplasia defect. Burial 3 had two bands present on the lower left canine. Based on Reid and Dean (2006) estimates, location of the hypoplasia in Burials 2 and 3 correlate with them being between 2 to 3.5 years of age at development. Thus, the location of the hypoplasia indicates stress consistent with weaning and exposure to changes in food. More hypoplasia may have been present, but the encasement of several teeth with calculus prevented observation. Burial 1, however, had 10 teeth with one or more hypoplasia. All canines were affected and other bands were present on the molars (see Appendix B). The location of the first hypoplasia on the canines occurred between 1 and 2.5 years of age. The second hypoplasia is consistent with 3 to 4 years of age. Of the molars, the hypoplasia in the upper left M1 corresponds with the canines, indicating the lines are probably caused by the same stressors. However, the hypoplasia on the upper left M2 and upper right M2 both indicate a second period of stress between 4.5 and 6 years of age. Hypoplasia on mandibular teeth resulted in stress at ages congruent with the maxillary hypoplasia.

\section{Degenerative Joint Disease}

Due to the chronic nature of degenerative joint disease, it is one of the more recognizable changes in skeletal remains. Degenerative joint disease refers to chronic changes of joint cartilage that results in the destruction, formation, or both of bone in a clearly defined distribution pattern (Roberts and Manchester 1995:100), all of which are classified as rheumatic diseases (Schumacher 1988). Degenerative joint diseases are segmented into four classifications: neuromechanical, inflammatory, immune, and metabolic (Roberts and Manchester 1995:101). Neuromechanical includes primary and secondary stages of osteoarthritis and is a noninflammatory disease that affects synovial joints. Increasing age, repetitive activities, lifestyle, mechanical loading, obesity, and environment (urban versus rural populations) can all affect the presence of these neuromechanical joint diseases (Larsen 1997; Roberts and Manchester 1995:106;). Compared to mechanical insults, inflammatory, immune, and metabolic forms of joint disease are rarely seen in the archeological record. Inflammatory joint disease includes septic arthritis, while rheumatoid arthritis, anklyosing spondylitis, and psoriatic arthritis-which sometimes may be categorized as inflammatory-are typically categorized as immune joint disease. Gouty arthritis is listed as a metabolic joint disease.

Archeological reports typically focus on findings of neuromechanical degenerative joint disease, osteoarthritis, as it is one of the most commonly occurring joint diseases. Osteophytosis, or bone spurs, are outgrowths of bone tissue that form around these damaged joints. Only one individual from Roberts 
Cemetery exhibited notable osteoarthritic changes. In Burial 1, osteophytes at the right shoulder, lower and middle thoracic vertebrae, odontoid process, and Schmorl's nodes in the thoracic vertebrae are consistent with an individual with an occupation or lifestyle requiring heavy lifting or heavy and continuous work activity, such as farming. Osteophytes are present on the right humeral head and correspond with osteophytes on the glenoid fossa of the right scapula. When coupled with the more pronounced musculoskeletal stress markers, or entheses, in the right arm, these changes indicate that this individual was probably right-handed and performed strenuous tasks or heavy lifting with this arm. Additional evidence of heavy labor included osteophytes on the sulcus of the left innominate, an osteochondrosis dessicans of the right acetabulum of the sacrum, and osteophytes on the circumference of the inferior body of Lumbar 3 and superior body of Lumbar 4. Disc pressure is greatest on the third lumbar disk during bending and lifting. While holding a 20-pound weight, the load being placed on the third lumbar vertebrae increases by 100 percent over standing, and the pressure being placed on the disk increases as the disk degenerates (Jensen 1980:770). Extreme flexion and bending, particularly when lifting heavy loads, can result in Schmorl's nodes, which are herniations of the nucleus pulposa of the vertebral disc. Schmorl's nodes were present on the inferior vertebral body of Thoracic 7, inferior and superior bodies of Thoracic 8 , and the superior body of Thoracic 9 . The presence of osteophytosis in the lumbar vertebrae and Schmorl's nodes, particularly since this individual was a young to middle-age adult, indicates heavy and continuous working activity, and the extent and severity of the changes at such a young age are striking.

Degenerative joint disease changes in Burial 2 are consistent with an immune form of joint disease, specifically spondyloarthropy. Spondyloarthropies are a group of rheumatic diseases that cause arthritis, mainly affecting the spine. They include ankylosing spondylitis, reactive arthritis, psoriatic arthritis, and inflammatory bowel disease (Kataria and Brent 2004). Skeletal changes in Burial 2 include extensive whittling of the shaft of the first right distal phalanx with distal tuft resorption and osteophytes on the proximal end. The left first distal phalanx also exhibits minor shaft whittling and distal tuft resorption. A large osteophyte on the lateral proximal edge is present. The second and third medial phalanges in the right foot have whittling of the distal end, exhibiting a slight pencil-in-cup morphology. Tuft divots are absent, and there are no arthritic changes or ossification of the ligaments in the spine. Osteochondritis dessicans is present on the right clavicle on the sternal facet. Both right and left humeri are circumferentially small, have little entheseal changes, and exhibit thinning consistent with atrophy. These changes are consistent with spondyloarthropathy, and the involvement with only the distal interphalangeal joints and terminal phalanges is suggestive of psoriatic arthritis (Ortner 2003:580; Rothschild and Behnam 2005:289; Schumacher 1988:151-152). Of the spondyloarthropies, psoriatic arthritis is associated with the skin disease psoriasis, and arthritis may be mild, affecting only a few joints, especially those at the end of the toes or fingers, while ankylosing spondylitis targets the spine. Approximately 95 percent of the cases involve peripheral joints, and the majority exhibit asymmetric involvement (Rothschild and Behnam 2005:289; Schumacher 1988:151). Rothschild and Behnam (2005) studied digital tuft and shaft changes related to leprosy and spondyloarthropies and also included changes to the tufts consistent with diabetes, syphilis, and scleroderma. Spondyloarthropathy was associated with both tuft and shaft whittling, tuft resorption, stress fractures, and periostitis. In psoriatic arthritis, inflammation can occur at the periosteum, insertion areas of the entheses along tendons, and inflammation of other joints (Schumacher 1988:151-152). Considering leprosy was not common in the United States in the late 1800 s to early 1900 s, differential diagnosis is closest to psoriatic arthritis.

Additionally, inflammation of the sternoclavicular joint is associated with polyarthritis or spondyloarthritis, which clinically affects 15 percent of patients with psoriatic arthritis (Taccari et al. 1992). Joint pain is associated with rheumatic diseases and is one of the cardinal symptoms (Hassett and Barnsley 2001). Burial 2 had changes in the proximal upper limb, the humerus, consistent with atrophy. Pain in the lower neck, shoulder, sternoclavicular joint, and acromioclavicular joint affect the use of the upper limb (Hassett and Barnsley 2001). The 
sternoclavicular joint is commonly affected in rheumatological pathologies. Movement of the upper arm requires movement in the sternoclavicular joint. Movement of the scapula and shoulder motion are associated with movement at the sternoclavicular joint, and inflammation or pain associated with this joint will limit shoulder motion (Plausinis et al. 2006:170). Thus raising the arm above the shoulder, anterior and posterior movement of the shoulder or upper arms, and circular movement of the shoulder will result in movement at the sternoclavicular joint. Hassett and Barnsley (2001) reported that pain in the sternoclavicular joint was present in the area of the sternocleidomastoid and trapezius muscles in the neck area and could radiate down the ipsilateral arm to the elbow. Thus, the atrophic changes in the upper arms may be associated with swelling of the sternoclavicular joint, which is common in psoriatic arthritis; however, it must be noted that associated swelling in the acromioclavicular joint or shoulder would result in similar disuse of the upper arm. Osteochondritis dessicans was present on the right clavicle at the sternal facet. Osteochondritis dessicans commonly occurs from trauma to the location, particularly when the location is subjected to "repeated, low-grade chronic or microtrauma." (Aufderheide and Rodriguez-Martin 1998:81). The presence of the osteochondritis dessicans, though not typically found at this location, is more probably associated with trauma and not related to degenerative joint disease and could be an alternative explanation for the arm atrophy.

\section{COMPARATIVE ANALYSIS}

Comparisons with other cemetery populations and mortality data can provide insights into the lives of the four individuals excavated from Roberts Cemetery. These comparisons will not provide interpretations on the health and demography of the population of Troy or Bell County in the late nineteenth or early twentieth centuries, but they will indicate if the diseases, age, and life stress factors correlate with expectations based on regional data. The majority of the comparative populations discussed here are pioneer families. Generally, the cemeteries chosen for comparison are small family or community cemeteries in rural areas that date to the late 1800 s.
- Sinclair Cemetery, 41DT105 (1850 1880): A small family cemetery in Delta County, Texas. The residents belonged to a community called Granny's Neck, which was 3 miles south of Cooper, the county seat. The burial population consists of white farmers (Lebo 1988; Winchell et al. 1995).

- Tucker Cemetery, 41DT104 (1880-1942): A small family cemetery near Sinclair Cemetery in Delta County (Lebo 1988; Winchell et al. 1995).

- Reynolds Cemetery (1832-1900): A small rural cemetery in Kanawha County, West Virginia. The founding Reynolds family were interred here-and potentially other locals after the Reynolds family moved (Bybee 2002).

- Morgan Chapel (1891-1937): A historic cemetery in Bastrop County, Texas (Taylor et al. 1986).

- Brunson-Sisson Cemetery (1836-1892): A small rural cemetery of pioneers and farmers near Joliet, Illinois. Three related Caucasian families were buried here (Cobb 1999).

- Pioneer Cemetery (1880-1921): These burials represent a small portion of the Pioneer Cemetery in Dallas, Texas. The relocated individuals are Caucasian (Cooper et al. 2000).

- Texas State Cemetery (1844-1951): A relocation project due to renovation activities moved several White Confederate soldiers. These burials represent slightly later interments, most in the early 1900 s (Dockall, Boyd et al. 1996).

- Cross Homestead Cemetery (1820-1849): Caucasian tenant farmers are buried in this cemetery in Springfield, Illinois (Craig and Larsen 1993).

- Choke Canyon Cemeteries (1860-1930): Combined data from five small Caucasian cemeteries in south-central Texas (Fox 1984).

- Voegtly Cemetery (1883-1861):A cemetery in the churchyard next to the Voegtly Church in Pittsburgh, Pennsylvania. The first interments were Swiss-German settlers (Ubelaker and Jones 2003). 
The Texas Almanac documents a notable increase in the population of Bell County in the three decades from 1880 to 1910 (Texas Almanac 2010), with Texas legislators encouraging an influx of settlers from other parts of the country and foreign immigrants (Rozek 2003). Since the Roberts Cemetery burials may date to this period, it is possible that these adult males were immigrants rather than native Texans. The comparative sample described above contains individuals from Texas and other parts of the United States, including some European immigrants. In addition to the historic cemetery evidence, general health and mortality data for the United States taken from McDowell et al. (2008) are used for comparison.

\section{Stature}

Stature of the three adult males from Roberts Cemetery can be compared to stature estimates from other cemetery excavations and the modern U.S. population (Table 5.1). Unfortunately, the stature estimates recorded in the historic cemetery literature do not include the minimum and maximum statures. The only data provided are the average statures for each cemetery, many with a sample of only two to six individuals. Stature estimates for the adult males (Burials 1, 2, and 3) range from 169.1 to $178.72 \mathrm{~cm}$ ( $5 \mathrm{ft} 6.5$ inches to $5 \mathrm{ft} 10.5$ inches). When compared to stature estimates from other historic cemeteries and the modern U.S. population, the individual in Burial 2 is taller than average, and the individuals in Burials 1 and 3 are shorter than average (see Table 5.1). The average

Table 5.1. Comparison of stature estimates

\begin{tabular}{l|c|c|c|c}
\hline \multirow{2}{*}{ Burial Sample } & \multicolumn{2}{c|}{ Male } & \multicolumn{2}{c}{ Female } \\
\cline { 2 - 5 } & $\begin{array}{c}\text { Stature } \\
(\mathrm{cm})\end{array}$ & $\begin{array}{c}\text { No. of } \\
\text { Burials }\end{array}$ & $\begin{array}{c}\text { Stature } \\
(\mathrm{cm})\end{array}$ & $\begin{array}{c}\text { No. of } \\
\text { Burials }\end{array}$ \\
\hline Roberts Cemetery, Burial 1 & 172.17 & 1 & - & - \\
\hline Roberts Cemetery, Burial 2 & 178.72 & 1 & - & - \\
\hline Roberts Cemetery, Burial 3 & 169.10 & 1 & - & - \\
\hline Cross Homestead Cemetery & 174.80 & 5 & 163.30 & 6 \\
\hline Brunson-Sisson Cemetery & 175.80 & 4 & 169.00 & 1 \\
\hline Choke Canyon Reservoir & 174.10 & 2 & 159.90 & 8 \\
\hline Texas State Cemetery & 174.67 & 47 & 160.90 & 5 \\
\hline Modern U.S. Data & 174.00 & $?$ & 161.00 & $?$ \\
\hline
\end{tabular}

stature for the three Roberts Cemetery adults is $173.33 \mathrm{~cm}$, which is only slightly shorter than averages for the other small samples.

A comparison of other osteological traits is informative (Table 5.2). Voegtly Cemetery in Pennsylvania is the best comparison for average rates of disease, caries, trauma, and occupational changes. This excavated skeletal population is large and better representative of a community. However, the rates of degenerative disease, Schmorl's nodes, and trauma may be lower since the individuals in Texas were pioneers and farmers that probably lived a more rugged life. Rates of degenerative disease and Schmorl's nodes are high in the Texas State Cemetery population, but that is not out of the ordinary, since most of the individuals were soldiers. The presence of Schmorl's nodes in Roberts Cemetery Burial 1 is not unexpected since other evidence of an active lifestyle is present. He was righthanded-or his occupation required greater use of the right arm-and degenerative changes in the right shoulder show a preference for using this arm. Additional degenerative evidence in the vertebrae also support an active lifestyle. Most of the hypoplasia reported in Table 5.2 are associated with this individual. He experienced several episodes of childhood stress, probably in the form of unexplained high fevers, nutritional deficiencies, digestive disorders, poor sanitary conditions, or infectious diseases such as cholera, typhoid, or pneumonia.

Dental caries rates are low for the individuals in Roberts Cemetery. Hillson (1996) notes that we should expect historic populations to have 25 percent caries rates due to access to sugar, fructose, and lactose. Roberts Cemetery is not necessarily representative of the Troy community and is a small sample, but it is interesting to note the low caries rate when reported as number of caries per teeth observed (see Table 5.2). In comparison to Voegtly (the cemetery with the largest sample of observable teeth), the caries rate for Roberts cemetery is only 4.4 percent (of 68 teeth observed) while Voegtly has a caries rate at 28.5 percent (of 2,738 teeth observed). The low rate could be related to differ- 


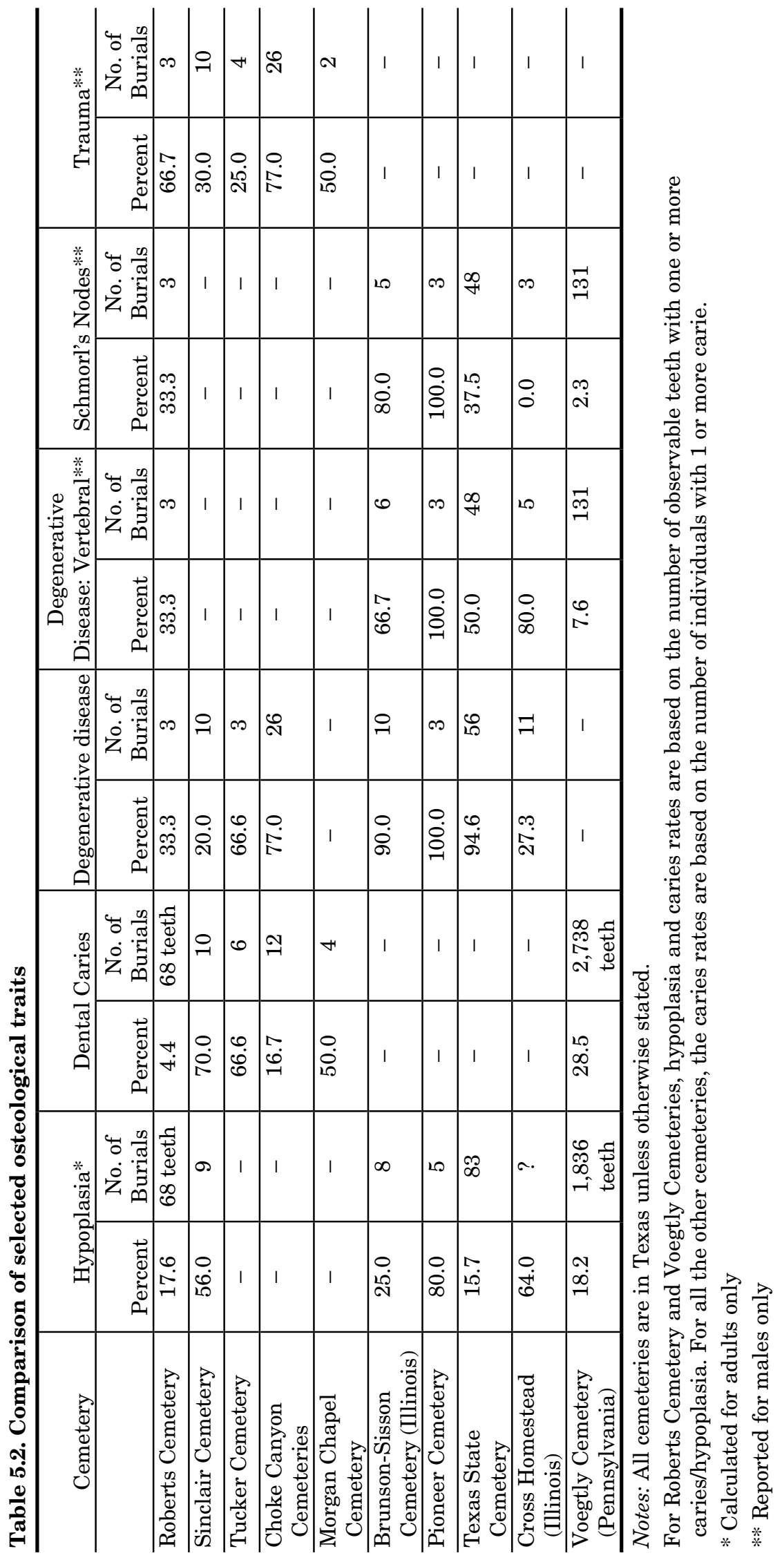


ences in access to sugary foods or the small sample size for Roberts Cemetery. If Roberts rates are reported per individual, the caries rate would be 66.6 percent ( 2 of 3 ). That rate is comparable to those reported for the smaller Texas cemeteries.

\section{Population Data and Mortality Schedules}

Prior to antibiotics, reliable clean water supplies, and vaccines, life expectancy was significantly lower, than today and childhood mortality was high. In Texas in 1999, the death rate was 649.4 per 100,000 for children under 1 year; but it dropped to 35.1 per 100,000 for children 1-4 years of age (Figure 5.1; Centers for Disease Control and Prevention 2013). ${ }^{15}$ In comparison, the 1880 death rates for Texas, gathered from mortality statistics per state from the 1880 U.S. census, show a different pattern (Billings 1885). Children under 1 year old did have the highest death rate, but there also was a second spike in death between ages 15 and 35 (Figure 5.2). As can be seen by comparing Figures 5.1 and 5.2 , the death rate charts depict these different trends in 1880 and 1999 (Billings 1885; Centers for Disease Control and Prevention 2013).

The ages at death of the four individuals at the Roberts Cemetery are consistent with expected ages at death for the time period. In Texas in $1880,26.7$ percent of all reported deaths were infants under one and 19.8 percent were under 5 (based on data reconstructed from Billings 1885). The individual in Burial 2 lived a long life for the period, living to an "older" age between 45 and 60 years. Age-at-death of the individuals in Burial 1 (30-40 years) and Burial 3 (20-27 years) are also consistent with higher rates of death in Texas documented in the 1880 census (see Figure 5.2). ${ }^{16}$

Exposure to unsanitary environments, nutritional stress from a limited diet with few vegetables available for much of the year, and

\footnotetext{
15 The 2006 data show the same trend at 629.5 per 100,000 children under 1 year and 29.3 per 100,000 children 1-4 years of age (Centers for Disease Control and Prevention 2013).

16 The 1880 census was chosen because it is the latest known mortality schedule and is most likely to represent the period in which these individuals lived. Census records for 1890 are not available. Also, based on the known burial dates in the cemetery, the earliest dates are in the $1880 \mathrm{~s}$.
}

endemic and epidemic diseases are probably the greatest causes of death. In infants, the summer months were a dangerous time as diarrheal diseases from drought, poor quality of weaning foods, and dilution of foods with contaminated water which young children cannot tolerate, resulted in higher death rates. Saunders et al. (1995:81) report that 39 percent of infant deaths occurred between June and August. In Massachusetts in 1840, most of the children died before reaching 5 years of age, with more than half of those from bowel trouble. In 1850, children under 5 years old accounted for $45-50$ percent of all deaths (Larsen et al. 1995).

An examination of the 1880 mortality schedules for Bell County and Troy, Texas, give a good indication of the most common causes of death (United States Census 1880). Most serious environmental problems faced by infants and children took the form of acute infection rather than chronic undernutrition or chronic infectious diseases (Saunders et al. 1995). The 1880 mortality census data compiled by Billings (1885) support the conclusions of Saunders et al. (1995), since most of the cases of reported deaths are from contagious diseases resulting in high fevers or hives, including typhoid, consumption (tuberculosis), pneumonia, and bronchitis (Tables 5.3 and 5.4). Diarrhea, croup, and teething were limited to children under 5 years of age-at-death. Teething was only attributed to children between 1 and 2 years of age. This is probably due to high fevers that can occur during the teething process, along with a misdiagnosis and assumption that the tooth development caused the high fevers rather than recognizing underlying illnesses that result in high fevers. Among the causes of death, dysentery ranks fourth for the State of Texas (see Table 5.4). However, this information does not include age of the individuals at death, making it difficult to ascertain whether dysentery disproportionally affected children.

A detailed examination of the "Troy, Texas" and "Bell County Unknown District, Texas" data for 1880 indicates a wide range of causes of death (Table 5.5; United States Census 1880). In the "Bell County Unknown District," the highest cause of death was stillborn children. This indicates genetic abnormalities or stress in the mother during fetal growth. Childhood diseases were prevalent as a cause of death, such as diarrhea-possibly caused by poor sanitation, hives, 


\section{Texas Death Rates by 10-year Age Groups}

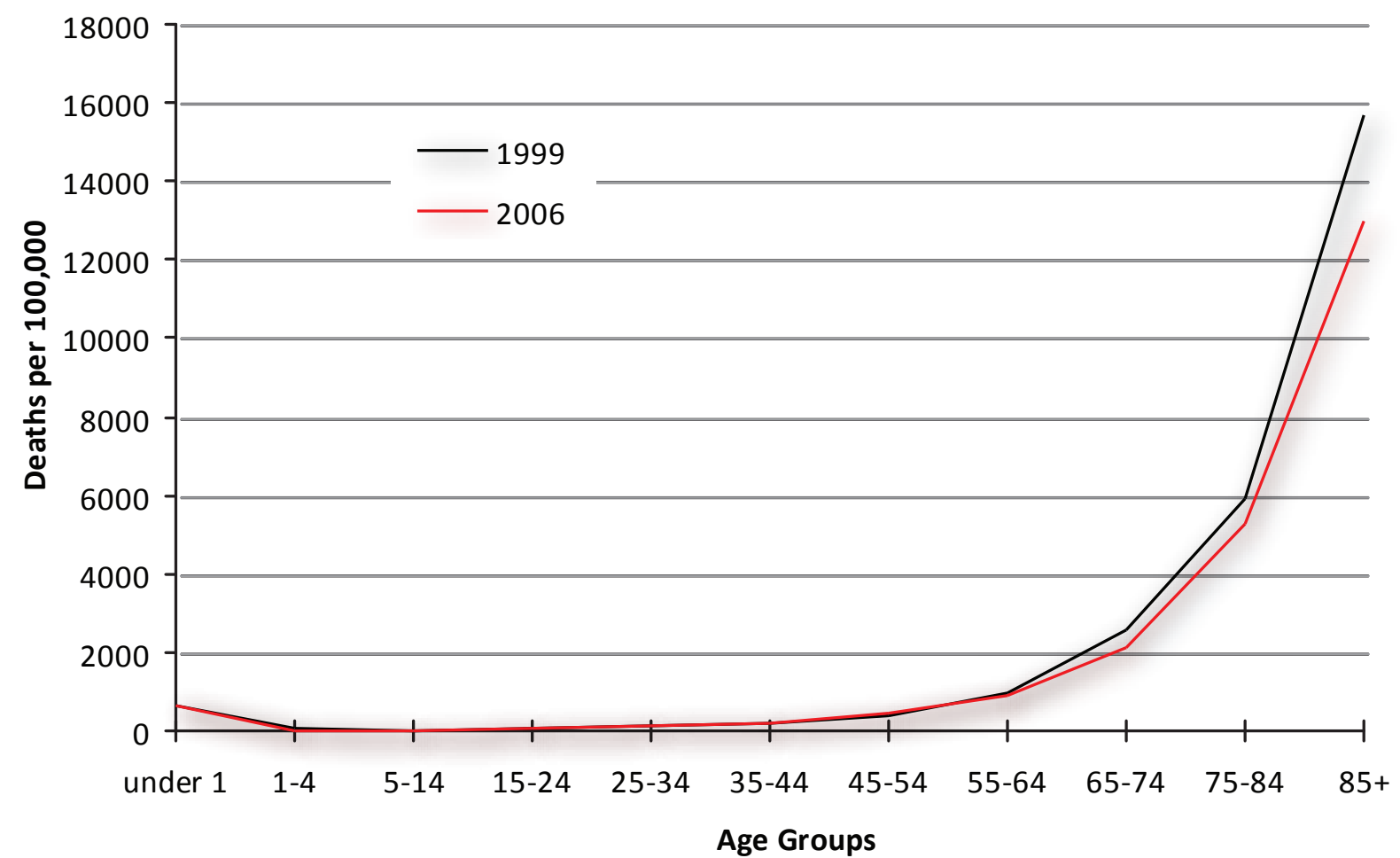

Figure 5.1. Texas death rates per 100,000 in 1999 and 2006. Data are from the Centers for Disease Control and Prevention (2013).

\section{Texas Death Rates}

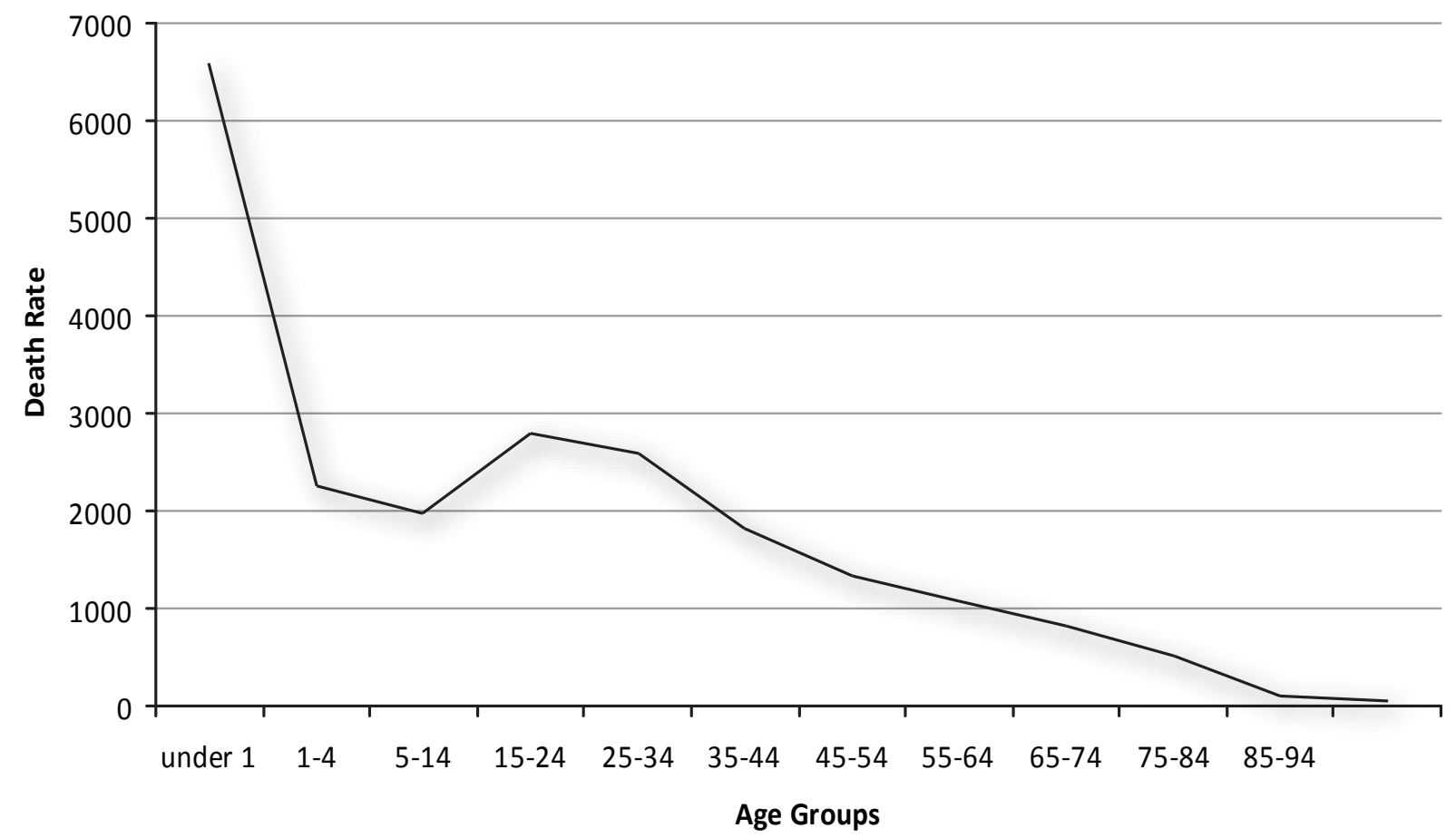

Figure 5.2. Texas death rates in 1880. Compiled from 1880 Mortality Schedule data in Billings (1885). 
Table 5.3. Causes of death in Troy, Texas compared to Bell County and all of Texas, 1880, compiled from 1880 mortality schedule data (Billings 1885)

\begin{tabular}{|c|c|c|c|c|c|c|}
\hline \multirow[b]{2}{*}{ Cause of Death } & \multicolumn{2}{|c|}{ Troy, Texas } & \multicolumn{2}{|c|}{ Bell County, Texas } & \multicolumn{2}{|c|}{ Texas } \\
\hline & No. & Percent & No. & Percent & No. & Percent \\
\hline Unknown & 6 & 18.2 & - & - & 1,885 & 7.6 \\
\hline Cerebro Spinal Fever & 3 & 9.1 & - & - & - & - \\
\hline Cholera Infantum & 3 & 9.1 & - & - & 551 & 2.2 \\
\hline Malaria & 3 & 9.1 & & & 1,489 & 6.0 \\
\hline Pneumonia & 3 & 9.1 & 24 & 14.3 & 2,514 & 10.2 \\
\hline Dropsy & 2 & 6.1 & 6 & 3.6 & 400 & 1.6 \\
\hline Inflammation of Bowels & 2 & 6.1 & - & - & - & - \\
\hline Catarrhal Fever & 1 & 3.0 & - & - & - & - \\
\hline Congestion of Bowels & 1 & 3.0 & 2 & 1.2 & - & - \\
\hline Congestion of Brain & 1 & 3.0 & - & - & 534 & 2.2 \\
\hline Consumption & 1 & 3.0 & 11 & 6.5 & 1,602 & 6.5 \\
\hline Croup & 1 & 3.0 & 7 & 4.2 & 641 & 2.6 \\
\hline Fever & 1 & 3.0 & - & - & - & \\
\hline Inflammation of Brain & 1 & 3.0 & - & - & 354 & 1.4 \\
\hline Internal Injuries & 1 & 3.0 & - & - & - & - \\
\hline Palpitation of Heart & 1 & 3.0 & - & - & - & - \\
\hline Perpural Fever & 1 & 3.0 & - & - & - & - \\
\hline Apoplexy & 1 & 3.0 & 1 & 0.6 & - & - \\
\hline Total & 33 & 100.0 & 168 & 30.4 & 2,4735 & 40.3 \\
\hline
\end{tabular}

Notes:

Cerebro spinal fever $=$ meningitis

Dropsy = collection of fluid

Congestion of brain = brain swelling

Apoplexy $=$ cerebral hemorrhage or stroke

cholera, pneumonia, typhoid, and "teething." For "Troy, Texas," 16 of the reported 33 deaths were children under 5 years old, representing 48.5 percent of the population. For the "Bell County Unknown District," 65 of the 168 reported deaths were children under 5 years old, representing 38.7 percent of the population.

When the four individuals excavated from Roberts Cemetery are compared with other historic cemetery and U.S. populations, they correspond with the expectations for age-atdeath, exposure to infections and nonchronic illnesses, and stature. The death of the infant, Burial 4, is not unusual since up to 50 percent of the population deaths in 1880 occurred in children under 5 years of age. For the adult males in Burials, 1, 2, and 3, each represents a different age group. Hypoplasia in the Burial 1 individual (age 30-40) indicates that this person suffered from several bouts of childhood stress. When compared to causes of childhood deaths,
Table 5.4. Top 20 causes of death in Texas, 1880 compiled from 1880 mortality schedule data (Billings 1885)

\begin{tabular}{l|c|c}
\hline \multicolumn{1}{c|}{ Cause of Death } & No. & Percent \\
\hline Pneumonia & 2,514 & 10.2 \\
\hline Unknown & 1,885 & 7.6 \\
\hline Consumption & 1,602 & 6.5 \\
\hline Dysentery & 1,586 & 6.4 \\
\hline Malaria & 1,489 & 6.0 \\
\hline Typhoid & 1,081 & 4.4 \\
\hline Still-born & 839 & 3.4 \\
\hline Enteritis & 795 & 3.2 \\
\hline Croup & 641 & 2.6 \\
\hline Whooping-Cough & 584 & 2.4 \\
\hline Cholera Infantum & 551 & 2.2 \\
\hline Brain, Disease of & 534 & 2.2 \\
\hline Small-pox & 517 & 2.1 \\
\hline Convulsions & 488 & 2.0 \\
\hline Dropsy & 400 & 1.6 \\
\hline Brain, Inflammation & 354 & 1.4 \\
\hline Child-birth & 327 & 1.3 \\
\hline Diarrhea & 318 & 1.3 \\
\hline Premature Birth & 265 & 1.1 \\
\hline Bronchitis & 262 & 1.1 \\
\hline Measles & 261 & 1.1 \\
\hline Total & & 69.9 \\
\hline
\end{tabular}


Table 5.5. Causes of infant death in Troy and Bell County, Texas, 1880, compiled from the 1880 mortality schedules (Billings 1885)

\begin{tabular}{|c|c|c|c|c|}
\hline \multirow[b]{2}{*}{ Cause of Death } & \multicolumn{2}{|c|}{ Troy, Texas } & \multicolumn{2}{|c|}{ Bell County, Texas } \\
\hline & $\begin{array}{c}\text { Under } 1 \\
\text { Year Old } \\
\end{array}$ & $\begin{array}{c}1 \text { to } 5 \text { Years } \\
\text { Old }\end{array}$ & $\begin{array}{c}\text { Under } 1 \\
\text { Year Old } \\
\end{array}$ & $\begin{array}{c}1 \text { to } 5 \text { Years } \\
\text { Old }\end{array}$ \\
\hline Bold Hives & - & - & 4 & - \\
\hline Bursitis & - & - & - & 1 \\
\hline Cerebro-Spinal Fever & 2 & - & - & - \\
\hline Cholera Infantum & 2 & 1 & 2 & 1 \\
\hline Congestion of Bowels & 1 & - & 1 & - \\
\hline Congestion of Brain & 1 & - & - & - \\
\hline Consumption & - & - & - & 2 \\
\hline Croup & - & 1 & 4 & 1 \\
\hline Cyanosis & - & - & 2 & - \\
\hline Debility & - & - & 1 & 1 \\
\hline Diarrhea & - & - & - & 5 \\
\hline Dropsy of Heart & 1 & - & - & 2 \\
\hline Fever & - & - & - & - \\
\hline Flux & - & - & - & 1 \\
\hline Inflammation of Bowels & 1 & 1 & 2 & - \\
\hline Internal Injuries & 1 & - & - & - \\
\hline Lung Disease & - & - & 1 & \\
\hline Malarial Fever & 1 & - & - & - \\
\hline Meningitis & - & - & - & 1 \\
\hline Paralysis & - & - & - & 1 \\
\hline Perpural Fever & - & 1 & - & - \\
\hline Premature Birth & - & - & 2 & - \\
\hline Pneumonia & - & - & 2 & 5 \\
\hline Poison & - & - & - & 1 \\
\hline Spinal Disease & - & - & - & 2 \\
\hline Stillborn & - & & 12 & - \\
\hline Teething & - & - & 1 & 4 \\
\hline Typhoid Fever & - & 1 & - & 3 \\
\hline Unknown & 1 & - & 2 & 3 \\
\hline Total & 11 & 5 & 32 & 33 \\
\hline
\end{tabular}

it is highly possible he contracted one of the diseases mentioned above and survived or had several bouts of dysentery cause by poor sanitary conditions. This individual also had indications of working hard and could have been from a poor family. Cuff links and few muscle changes associated with Burial 2 (age 45-60) suggest a higher socioeconomic status. Psoriatic arthritis is rarely encountered in archeological populations and represents an important observation of a rare disease. The presence of psoriatic arthritis, along with possible partial atrophy of the upper arms and the "old age" of this individual, also suggests that he came from a higher socioeconomic status. Musculoskeletal stress markers in the skeletal remains also indicate that he did not perform strenuous labor. The Burial 3 male died in his twenties. Figure 5.2 shows a spike in age-atdeaths in the 20 s to 30 s for 1880 , so a death at this age is not unexpected. Though the deaths of these four individuals are not necessarily representative of the Troy community at large and cannot provide interpretable demographic data, their ages-at-death do conform to the norm expected in late nineteenth- and early-twentieth-century rural Texas. 


\section{HISTORY OF THE ROBERTS CEMETERY PROPERTY AND ARCHIVAL SEARCH FOR UNMARKED GRAVES}

6

Terri Myers and Douglas K. Boyd

The archival research effort for Roberts Cemetery, Bell County, Texas, was conducted by project historian Terri Myers ${ }^{17}$. The work had two primary goals. The first was to develop a history of Roberts Cemetery, including defining the chain of title and determining the cemetery's boundaries, how they changed over time, and why. This required the use of county deed records, marriage records, death certificates, census records, obituaries published in newspapers, and other primary sources. The second was to try to identify the people in the unmarked graves. This effort involved: (1) compiling a list of people who are or might have been buried in Roberts Cemetery using Bell County death certificates; and (2) comparing this list of people with online published inventories of graves in Roberts Cemetery and three nearby cemeteries. In this manner, it was possible to compile lists of people who were definitely or possibly buried in unmarked graves in Roberts Cemetery.

\section{RESEARCH METHODOLOGY}

The project historian conducted initial research to serve as the basis for more extensive investigation. She reviewed documents and old highway maps provided by the Texas Department of Transportation and Prewitt and Associates, Inc., and conducted online searches to learn more about the Roberts Cemetery, other cemeteries in the vicinity of Troy, about 1.4 miles south of the cemetery, and about the origins of Troy and the nearby towns of Belton and Temple. She examined Bell County census records from 1870 to 1920 to learn more about

\footnotetext{
$\overline{17}$ Myers served as the project historian. She operates
} Historic Preservation, Inc., in Austin, Texas. the F. H. Roberts family, for whom the cemetery is named. The inception of the cemetery is clearly linked with the Roberts family; it was carved out of one of the Roberts family farms around 1886. The Roberts' daughter Maggie appears to have been one of the two earliest burials in the cemetery, according to her 1886 headstone (Duke 2004). Census records show that many relatives and friends of the Roberts family are among the earliest graves. Census records also show that another Roberts child died at a young age, though his or her headstone has not been found in the cemetery and is not listed on the Roberts Cemetery inventory (Duke 2004; U.S. Bureau of the Census, 1900, 1910).

On her first trip to Belton, the project historian met with volunteers in the genealogical section of the public library. They described the collections and shared a book on Bell County history that discussed the origins of Troy (Bell County Historical Society 1988). It contained a 1907 photograph of F. H. Roberts' mercantile store in the town. The historian copied several items and perused the obituary files in the genealogy section. Data found in the library's vertical files, along with discussions with the volunteers, enabled the historian to compile a list of known cemeteries in the vicinity of Troy. The list became useful in later research using the county death certificates. The other cemeteries in the vicinity are:

- Shiloh Cemetery, possibly used as a "burying place" as early as 1860. Located 1.3 miles southeast of Roberts Cemetery.

- Old Troy Cemetery, established before 1882. Located 0.8 miles northwest of 
Roberts Cemetery.

- Pleasant View Cemetery, established 1888. Located 2.8 miles south-southwest of Roberts Cemetery.

- 10.Llewellen Cemetery, established in the early- to mid-twentieth century. Located 2.5 miles east-southeast of Roberts Cemetery.

- Eddy Cemetery, established ca. 1930s. Located 4.8 miles northeast of Roberts Cemetery.

Three of these six cemeteries are located within 3 miles of Roberts Cemetery, and they contain burials dating before the turn of the century. These cemeteries became the focus of additional research, and the online burial inventories (based on transcribed headstones) were reviewed and compared with the Roberts Cemetery inventory. The sources for the online burial inventories for the cemeteries in this study are listed in Table 6.1.

Table 6.1. Burial inventory sources

\begin{tabular}{l|l}
\hline $\begin{array}{l}\text { Roberts } \\
\text { Cemetery }\end{array}$ & $\begin{array}{l}\text { Duke (2004); this burial inventory is } \\
\text { reproduced in Appendix D }\end{array}$ \\
\hline Shiloh & $\begin{array}{l}\text { Entrop (2013) } \\
\text { Cemetery }\end{array}$ \\
Bell County Survey Committee (n.d.) \\
\hline Pleasant & Badovinac (2001) \\
View & Bell County Survey Committee (n.d.) \\
\hline Old Troy & Todd and Todd (2006) \\
Cemetery & Find a Grave (2013) \\
\hline
\end{tabular}

The second phase of research involved the use of primary records at the Bell County Clerk's Office in Belton and online census records (using HeritageQuest and FamilySearch) to research the Roberts family. Extensive research at the Bell County Clerk's Office in Belton focused on property deed records, marriage records, and death certificates. The deed records were examined to establish, as fully as possible, the chain of title for the Roberts Cemetery property and changes in the cemetery boundaries through time. Death certificates from 1903 through 1940 were reviewed to identify people who were buried in Roberts Cemetery or died in Troy and may have been buried in Roberts Cemetery. The deed records for cemetery plot sales from the cemetery trustees to local resi- dents were also reviewed. Of six cemetery plot sales, only one person's name appears on the Roberts Cemetery burial inventory by Duke (2004). The fact that the other five names did not appear in the burial inventory is probably due to the recent nature of these transactions and means that the buyers are probably still alive. Finally, the researcher examined selected obituaries in Belton area newspapers for names not recorded in the inventory. The examination of county death certificates, and the comparisons of these data with published cemetery burial inventories, are discussed in more detail later in this chapter.

\section{HISTORICAL BACKGROUND FOR ROBERTS CEMETERY}

This brief narrative provides the historical context for the Roberts Cemetery, the Roberts family, and the community of Troy. It was compiled largely from secondary sources (Bell County Historical Commission 1988; Odintz 2012), along with information from the Belton Journal-Reporter (1899-1917), online census records, and death certificates and marriage records on file at the Bell County Clerk's Office. Several earlier cemeteries, such as Shiloh and Old Troy, served pioneer settlements in northern Bell County. A town called Troy, which later became Old Troy, was established before the Missouri, Kansas, and Texas Railroad came through Bell County in 1882. When the railroad bypassed Old Troy by several miles, a new town named Troy (initially called New Troy) grew up around the railroad station located about 7 miles north of Temple. With the advantage of a railroad terminal in its midst, New Troy supplanted the original town of that name, though the two towns coexisted for some time. Old Troy was soon abandoned, and New Troy was simply called Troy thereafter.

By 1884, the community of Troy (formerly New Troy) had 250 inhabitants, a post office, two churches, a gin and mill, three saloons, a hotel, and a cooperative association. By 1900, it boasted an estimated 500 residents and the largest school district in the county. Troy prospered as a shipping point for cotton, livestock, and the other agricultural products of the region. One of the town's merchant-farmers was Ferdinand "F. H." Roberts. Roberts likely established Roberts Cemetery on his land. 
F. H. Roberts variously appears in census and deed records as Ferdinand, Ferd, or F. H. He claimed he was born in Texas, which meant that his parents were early residents who had come to the state from Tennessee by about 1852 , when F. H. was born. One of the first events documenting F. H. Roberts' life in central Texas is his marriage to Ida Ellington (Bell County, Marriage Certificate F:478). F. H. was about 26 years old when he married 17-year-old Ida, whose parents were early residents of Bell County.

F. H. Roberts and his young wife, Ida, were counted in the 1880 census. They had been married one year and had no children (U.S. Bureau of the Census, Bell County 1880). The couple settled near present Troy, where F. H. already owned land. Their daughter Maggie was born in January the following year.

When the Missouri, Kansas, and Texas Railway passed through Bell County in 1882, F. H. Roberts granted the railroad company about 150 acres of right of way out of one of his farms. F. H. was listed as a farmer in the 1880 , 1900, and 1910 census records (U.S. Bureau of the Census, Bell County 1880, 1900, 1910). However, Bell County historical records show that he also had a general merchandise store in Troy by 1907 (Bell County Historical Society 1988:213), and possibly earlier. Numerous deed records examined by the author show that F. H. Roberts was an industrious merchant and land developer, buying and selling many lots in Troy, Belton, and Temple.

During this time, Ida Roberts had seven children, only five of which survived by 1900 . Maggie was probably their first child, born in 1881. Iva followed in 1883, and Maud in 1886. Garic or Godric was born about 1892; Ovia, about 1895; and Cecil, the baby, in 1899. In between the children who were enumerated in the 1900 census, Ida gave birth to another child who died soon afterward (U.S. Bureau of the Census, Bell County 1900 and 1910). His or her name is unknown.

Born in 1881, Maggie C. Roberts only lived for just over 5 years before she died in 1886. She was buried on the Roberts family property, and this was probably the first grave in the area that became known as the Roberts Cemetery. A Roberts family friend named Soloman O. Bowers also died and was buried there that same year. One of Maggie's siblings, who was born and died sometime before 1900 and whose name is unknown, may also be buried there. Few details are known about his/her life and death. While it is likely that this child was buried near Maggie, no headstone marks this grave (Duke 2004; see Appendix D).

That the new burial ground became known as Roberts Cemetery in the 1880s is not surprising. Aside from Maggie's burial being one of the first interments there, the Roberts family owned the cemetery land until 1887, when the land may have first been set aside as a cemetery. And the Roberts family continued to own the land surrounding it well into the twentieth century.

While Ida cared for the household, F. H. opened his mercantile store and continued to buy and sell land in Bell County. Roberts may have gone into business with his father-in-law, D. G. Ellington, who worked in a dry goods store. About 1909, however, Roberts began preparing to move his family to Johnson County. He started selling off farmland and town lots, settling his debts, and generally getting his business in order. In 1910, the family appeared in the census records for Venus, Johnson County. The Roberts household was F. H. and Ida and their children Iva (26), Godric (18), Ovia (15), and Cecil (10). Their 24-year-old daughter, Maud, had been married to a man named Davis, but in 1910 she was a widow living with her parents along with her two young children, Monroe (5) and Ferdinand (3). For the next half decade, Roberts occasionally appeared in the Bell County deed records to settle claims and clarify earlier agreements, but the family never returned to Troy.

The little cemetery where Soloman Bowers and Maggie Roberts (and possibly her sibling) lay, however, continued to grow. At first, most burials were family members or close neighbors. Family included Mary Ellington, either Ida's mother or sister-in-law, and G. D. Ellington, her brother. Husband and wife B. F. and Mary Sue Finnell were related to Ida by marriage; her brother lived with the family in 1900. Close neighbors were Soloman Bowers, Elizabeth Bowers, Ira Watson, Cleo Maegden, and Dr. D. Claywell (Duke 2004; see Appendix D). Although other cemeteries like Llewellen, Old Troy, Shiloh, Pleasant View, and Eddy also served the same region, Roberts Cemetery became known as the Troy Cemetery, and it is identified as such in current Bell County Tax Appraisal District records. 
The inventory for Roberts Cemetery lists 633 graves, but death dates are available for only 556 of the burials (Duke 2004; see Appendix D). The death dates for these burials are plotted by decade in Figure 6.1, and the data show the intensity of use through time. At first glance, it appears that there were very few burials prior to 1900 , and that the number increased suddenly after the turn of the century. The number of burials per decade generally increased through time, with notable exceptions of three decades when the number of burials decreased (i.e., the $1950 \mathrm{~s}, 1970 \mathrm{~s}, 1980 \mathrm{~s})$. The apparent decrease in the number of burials after 2000 is skewed by the fact that the inventory only represents the first four years (from 2000 to 2004) rather than a full decade.

While the burial graph would suggest limited use of Roberts Cemetery prior to the turn of the century, this interpretation must be viewed with caution. Experience with archeological grave searches in Texas demonstrates that when unmarked graves are discovered in a historic cemetery, the unmarked burials are generally old and date to the early days of the cemetery. This is not unexpected for two reasons. First, older graves are much more likely to have had ephemeral grave markers that can easily become lost through time (e.g., wooden markers that deteriorate). And second, older graves have had more time for their headstones and grave markers to disappear, sometimes falling and becoming buried by sediment, or being destroyed or removed completely (by vandals or looters). The suggestion that Roberts Cemetery probably contains additional unmarked graves that are relatively old is supported by the fact that the archeological investigations there have discov-

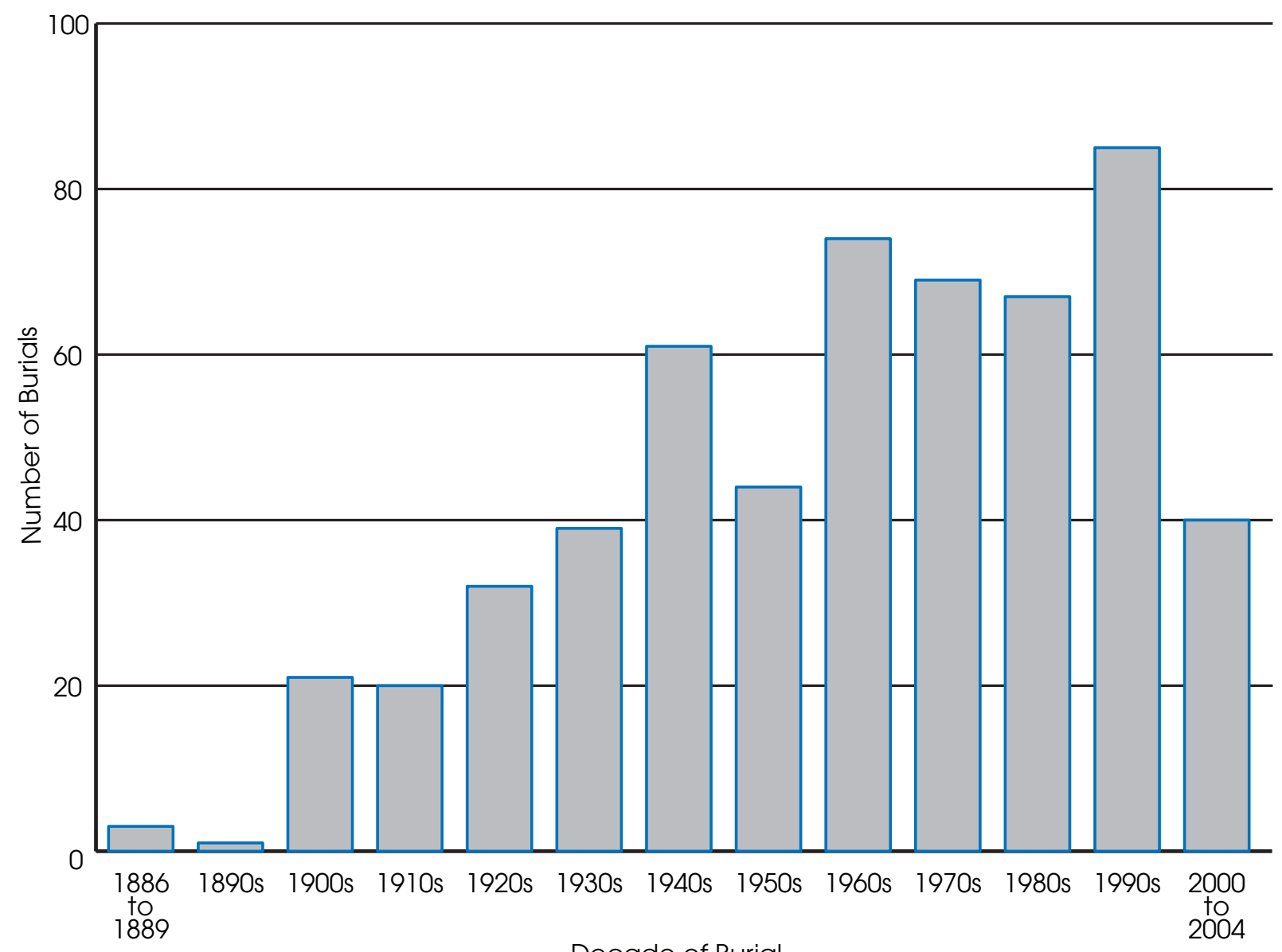

Decade of Burial

Figure 6.1. Graph of death dates by decades for 556 burials in the Roberts Cemetery. Compiled from the online inventory of graves at Roberts Cemetery (Duke 2004: see Appendix D). 
ered six unmarked graves and that the four exhumed graves probably date from ca. 1895 to the 1930s (see Chapters 3 and 4). All these graves were located in the northeast corner of the cemetery, in close proximity to the oldest marked graves in the cemetery. A map of burials kept by the Roberts Cemetery Association shows that many older graves are located in the northeast corner of the cemetery. Of 17 marked graves within about $75 \mathrm{ft}$ of the modern road right of way in this corner of the cemetery, 11 of the graves date between 1886 and 1916 (Roberts Cemetery Association 2012).

\section{REVIEW OF HISTORIC HIGHWAY MAPS}

At the inception of this project, TxDOT provided PAI with photocopies of sections of five historic highway maps: State Highway Department (1921), Bell County (1932), State Highway Department (1931-1932), Texas State Highway Department (1949-1952), and Texas State Highway Department (1957-1958). TxDOT provided title pages and the map sections pertaining to the road crossings at Big Elm Creek and the Roberts Cemetery property on the west side of the road and south of the creek. An examination of these maps by the project historian and PAI archeologists provides many interesting clues to the history of the Roberts Cemetery property, especially as it relates to one major roadway that began as U.S. Highway 81 and was later expanded into Interstate Highway 35. Table 6.2 is an annotated list of these maps, with comments on the historical significance of each. Figures 6.2 through 6.6 provide illustrations of the cemetery property shown on these five maps.

Based on an examination of these maps, it appears that no cemetery property was taken for the construction of U.S. Highway 81 and that the first time the state encroached on the cemetery property was for the creation of Interstate Highway 35 in the 1950s. In the $1950 \mathrm{~s}$, a triangular portion at the northeast corner of the cemetery was acquired by the state so that the existing U.S. Highway 81 could be expanded to the west to create the multiple lanes and access roads of Interstate Highway 35. As discussed below, the Bell County deed records provide more historical data that support this interpretation.

\section{CHAIN OF TITLE FOR THE ROBERTS CEMETERY}

It was difficult to establish a complete chain of title for the Roberts Cemetery property because modern transactions, specifically those made by Roberts Cemetery Trustees, erroneously trace the property's beginnings to an 1871 Bell County Deed Record (Vol. O:460-461) in which Joanna Scott donated two acres of land for a cemetery, church, and school. The Scott parcel was out of the Taliferro Hughes League, like the Roberts Cemetery, but Scott's donation proved to be the origin of the Shiloh Cemetery, not the Roberts Cemetery. A subsequent deed record from 1950 (BCDR Vol. 628:78) relates to land acquired by the State of Texas for the Interstate Highway 35 roadway, but it erroneously attributes the 1871 Joanna Scott deed to the beginning of the Roberts Cemetery. Since this 1950 deed record was the starting point for the historian's research, it led to much confusion until this error was discovered.

Another handicap in tracing the Roberts Cemetery deed chain stemmed from the fact that F. H. and Ida Roberts bought and sold hundreds of properties in the more than 30 years they lived in Bell County. They bought farms; purchased town lots in Belton, Troy, and Temple; took out mortgages on land and buildings; and subdivided some of their earlier purchases. The project historian concentrated on searching deed records pertaining to lands in or adjacent to the Roberts homestead. Roberts' first land purchase in Bell County consisted of a 66-acre parcel in the Rebecca Edwards League (BCDR Vol. 29:151) on February 20, 1878. Roberts Cemetery lies in the adjacent Taliferro Hughes League, however, and thus is beyond what was thought to be the original homestead.

The historian traced each deed record in both the direct and reverse indexes to deeds for Roberts, finding only a few deeds that seemed to describe the cemetery property. Numerous transactions referred to the cemetery as a landmark for surveying adjacent properties, but few deeds relate to ownership of the cemetery itself. It has been assumed that Roberts Cemetery is located on property owned by Roberts, yet none of Roberts' deeds makes reference to it except to describe it as it related to other nearby properties. One such deed for 114 acres was issued from F. H. Roberts to G. W. Porter in 1910 (BCDR Vol. 
Table 6.2. Annotated list of highway maps showing the Roberts Cemetery property relative to U.S. Highway 81 and Interstate Highway 35

State Highway Department

1921 Plan and Profile of Proposed State Highway. Bell County, from Falls County to Williamson Co. Line. State of Texas, State Highway Department. Map identification numbers illegible.

PAI examined two sheets of this map. Sheet 1 is the overview map, but the copy is poor, and the map identification numbers are illegible. Sheet 11 shows a curvy road that crosses Big Elm Creek, and the property at the southwest corner of this intersection is listed as "F. H. Roberts" and the next property to the south is listed as "Carpenter." The Roberts property abuts the creek (runs west to east) on the north side and abuts the curvy road on the east side. This map does not depict the cemetery, but there are two points that were plotted by triangulation from the road centerline with a notation of a "Rocky Hill" nearby, about 300 to $400 \mathrm{ft}$ south of Big Elm Creek. These two triangulation points are $100 \mathrm{ft}$ and $200 \mathrm{ft}$ west of the road, and they could denote the northeast and southeast corners of the cemetery property. The Rocky Hill notation is located between these points, and it probably refers to the isolated limestone hill that is located in the southeast portion of the modern cemetery property.

\section{Bell County}

1932 Right of Way Map of State Highway No. (2) US 81. F. A .P. No. 40-Rev. From Sta. $402+78$ to Falls County Line. Scale 1"=400'. Office of the Resident Engineer, Waco, Texas, February 1932.

PAI examined two sheets of this map. One is the ending sheet (at the Falls/Bell County line, which is labeled "Section 3 of 3 Sections." This sheet was originally titled "HIGHWAY NO. 2," but this was changed to "HIGHWAY NO. (2)" with the handwritten parentheses added, along with the designation "US 81."

The second sheet (no number on the photocopy) runs from the start of the road at Station $402+78$ on the south to Station 460 on the north. This sheet shows "Big Elm Creek" running west to east, and a "Present Hwy. No. 2" crossing the creek to the west of the highway. The map also shows the planned right of way for the bigger road, which may be U.S. Highway 81. It depicts details of the properties on either side of the right of way. The property located at the southwest corner of Big Elm Creek and the highway is labeled:

MRS. M. K. CARPENTER EST.

STA. $434+41$ to $441+85$

VOL. 416 PG. 576-9

2.791 ACRES

The second sheet map apparently refers to the 2.791-acre strip taken by the State out of the Carpenter Estate for the roadway. At Station 440 and heading northward to a point near the edge of Big Elm Creek, the map shows the northeast and southeast corners of a area with the Carpenter property that is labeled "CEMETERY." The east edge of this property is estimated to be about $175 \mathrm{ft}$ long as depicted on this map, which corresponds with the length of the east border of the cemetery in deed records from 1931 and 1932 (see Table 6.2).

This map indicates that the cemetery tract was completely outside, and west of, the Highway 81 right of way in 1932.

Note that George Porter, who was one of the Roberts Cemetery Trustees listed in the 1930s deed records, owned the property just south of the Carpenter Estate. 
Table 6.2, continued

State Highway Department

1931-1932 Plan and Profile of Proposed State Highway. Bell County From 2 MI. N. of Temple to Falls County Line. Approved July 15, 1931. Fiscal Year 1932. Scale 1 IN = 3000 FT.

PAI examined three sheets of this map. One is the cover sheet from Temple to Falls County Line. A notation says the State Project No. is "64-REOP." There are no notations that would indicate this is U.S. Highway 81, but notations show that this was a "FEDERAL AID PROJECT."

The next are Sheets 15 and 16 (out of 139 sheets). Sheet 16 shows the proposed road crossing at Big Elm Creek. Immediately to the south there is a strip of land labeled "NATHAN CARPENTER" that runs along the west side of the proposed road to the creek. Just west of this, three sides of a "CEMETERY" tract area are shown: the south, east, and north. All of these boundaries are at right angles. The northeast corner of this cemetery tract is shown about $20 \mathrm{ft}$ south of the creek and about $75 \mathrm{ft}$ west of the highway right of way. The southeast corner of this tract is about $195 \mathrm{ft}$ south of the creek and $100 \mathrm{ft}$ west of the highway right of way.

This map suggests that entire cemetery property was outside the highway right of way in 1931-1932.

Texas State Highway Department

1949-1952 Right of Way Map. Bell County from North of Temple to Falls Co. Line. U.S. Highway No. 81. Control 15, Section 4, Job 13. Office of the Resident Engineer, Belton, Texas. District No. 9. July, 1949.

PAI examined two sheets of this map. One is the cover sheet. It is signed "Correct" by Resident Engineer Joe T. Brown on July 16, 1949 and "Recommended for Approval" by District Engineer D. M. (?) Puckett on February 8, 1952.

The second sheet (no number on the photocopy) shows "Big Elm Creek," the proposed road running parallel to another small north-south road to the west, and the north-south railroad tracks to the east. The proposed road right of way is shown, with notations on the property lines and owners listed. Immediately south of Big Elm Creek, three boundaries of the "ROBERTS CEMETERY" are shown: the south, west, and north. This west edge of this tract runs almost due north-south, and it is approximately $400 \mathrm{ft}$ long. But the cemetery property runs at an angle to the road, which runs about 30 degrees east of north. The east boundary of the original cemetery tract is not shown, but it is clear that it extended into the proposed road right of way.

The notation at the top of this sheet is:

John F. Bowers (et al) Trustee for Roberts Cemetery

Sta. $437+71-441+45$

0.398 Acres

Vol. 628 Page 78

Deed

This map appears to show the existing U.S. Highway 81 right of way, and not the proposed roadway. It is presumed that it was created during the advanced planning for IH 35 work that would begin several years later. 
Investigations at Roberts Cemetery

\section{Table 6.2, continued}

Texas State Highway Department

1957-1958 Plans of Proposed State Highway Improvement, Bell County, I.H. 35 (U.S. Highway No. 81) from 2.0 Miles North Temple to Falls Co. Line. Federal Aid Project No. I 40 (16) OLD and I-35-4(3)307 NEW. Certified Correct, December 20, 1957. Recommended for Approval, January 3,1958 .

PAI examined four sheets (Title Sheet and Nos. 10, 23, and 26) from this 1957-1958 highway map.

The Title Sheet has both the old and new Federal Aid project numbers on it. The Resident Engineer certified the maps as correct on December 20, 1957, and the District Engineer Recommended for Approval on January 3, 1958. The Title Sheet indicates the "State Control No." is "15-4-16" while the other three sheets have "Control 15, Section 4, Job 16" on them. Sheet 10 has a handwritten notation "0015-04-024 ROW Acquisition" on it, but this job number may be a more recent addition. All of the sheets have notations of "IH 35."

Sheet 10 shows "Big Elm Creek" with the four lanes of proposed IH 35 crossing it. The north and south borders of the "ROBERTS CEMETERY" tract are shown, and they run due east-west while the road runs about 28 degrees east of north. The width of the cemetery tract as depicted on this sheet is approximately 380 to $390 \mathrm{ft}$.

Sheet 23 is the construction details (plan and profile) of the southbound access road bridge over Elm Creek, from Station $441+89$ to $444+30$. The plan view shows that the south end of the bridge has a concrete and riprap embankment on the west side of the access road, and it runs parallel to the "Proposed R. O. W." located a few feet to the west. Just west of this ROW line (at Station 441+50), the map has a "CEMETERY" label and depicts four rectangles labeled as "Graves." These plotted graves are oriented east-west and are within an area about $30 \mathrm{ft}$ north-south.

Sheet 26 is the road cross-section data south of and at Big Elm Creek bridge. This sheet shows the north and south edges of the "CEMETARY" [sic] property just south of the creek, and like Sheet 10, the property boundaries are skewed relative to the road. The sheet depicts four lanes, and shows a dashed line under the proposed road. It is labeled as "Private Drive" and ends at the west side of the northbound access road. It appears that this was the original road that went from Highway 81 to the cemetery before the construction of IH 35. For the proposed IH 35 roadway, it appears that the northbound access road on the east side is part of the original U.S. Highway 81 . This section of the roadway was later expanded to become $\mathrm{IH} 35$.

207:129). It called out the cemetery corners for landmarks in the property description, but did not describe or explain the cemetery itself.

When the historian tracked backwards from more modern deeds, she was able to find a more relevant chain. In 1950 , the cemetery trustees sold a part of the cemetery to the State of Texas, and it referred to a deed from W. B. and his wife, Sara Ford McCall (BCDR Vol. 532:523). That deed, filed in 1945, was from the McCalls to the Roberts Cemetery Trustees. It contained $2 \frac{1}{4}$ acres and an addition 388 square yards of land. The previous owner was Sara's mother, Mrs. P. S. B. Ford, who sold it as part of a 28.66acre parcel to her son-in-law in 1932 (BCDR Vol. 442:284).
Mrs. Ford had received the land from three men, Earl Thompson, John B. Daniel, and Roy Koos, in 1932. Part of the land was slated for sale to the State of Texas. Another part mentioned the cemetery (BCDR Vol. 416: 312). Earl Thompson obtained the land from M. L. Thompson, likely his mother, in 1931 (BCDR Vol. 416:140). She inherited the land from her husband, John Quincy Thompson, who acquired 3.75 acres of land from F. H. and Ida Roberts on December 29, 1887 (BCDR Vol. 62:639). This property, " 3.75 acres, more or less," probably included the cemetery, judging by the chain of title stemming from the sale of part of the property from the cemetery trustees to the State of Texas. 


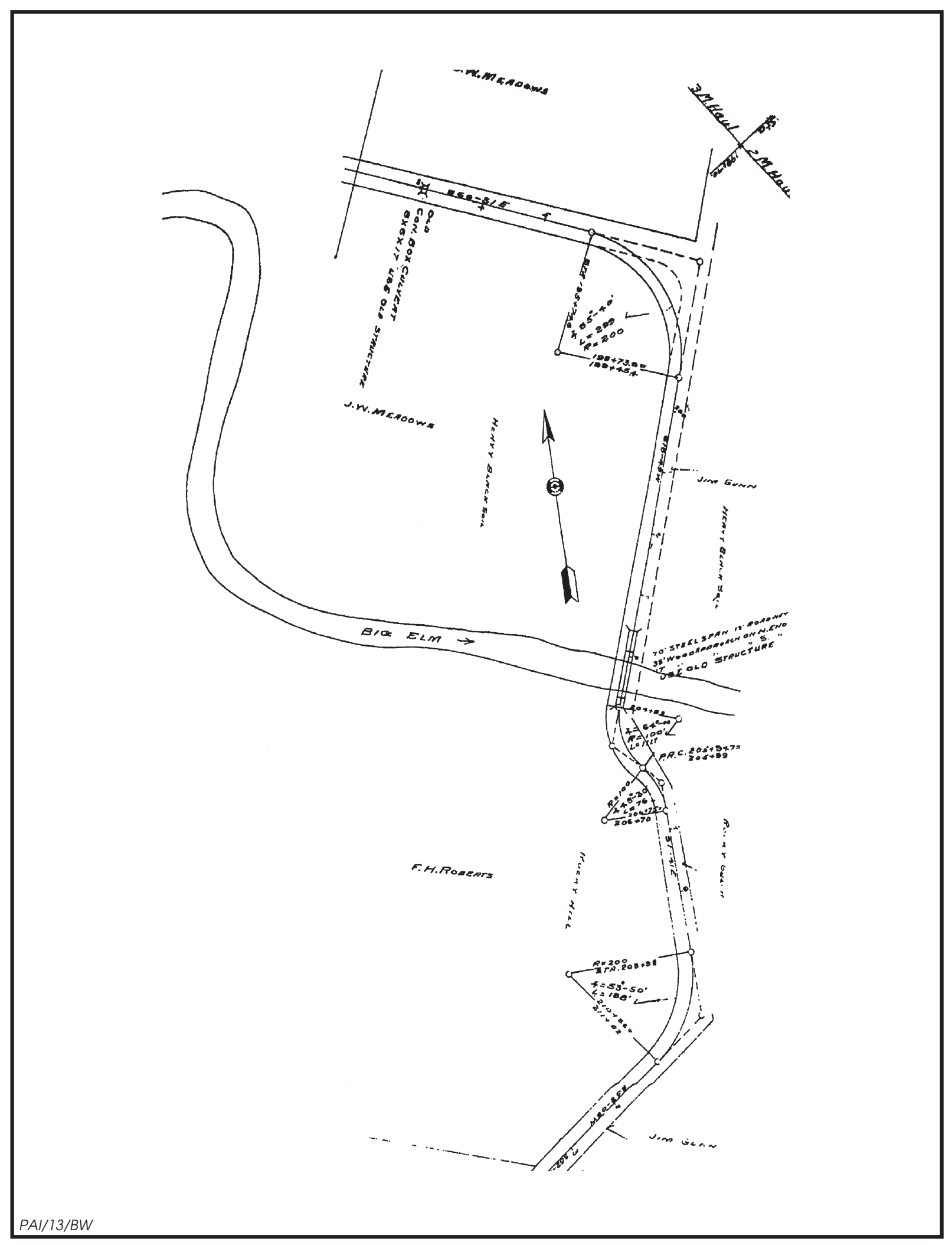

Figure 6.2. Section of the 1921 State Highway Department map, Sheet No. 11. Map data are summarized in Table 6.2. 


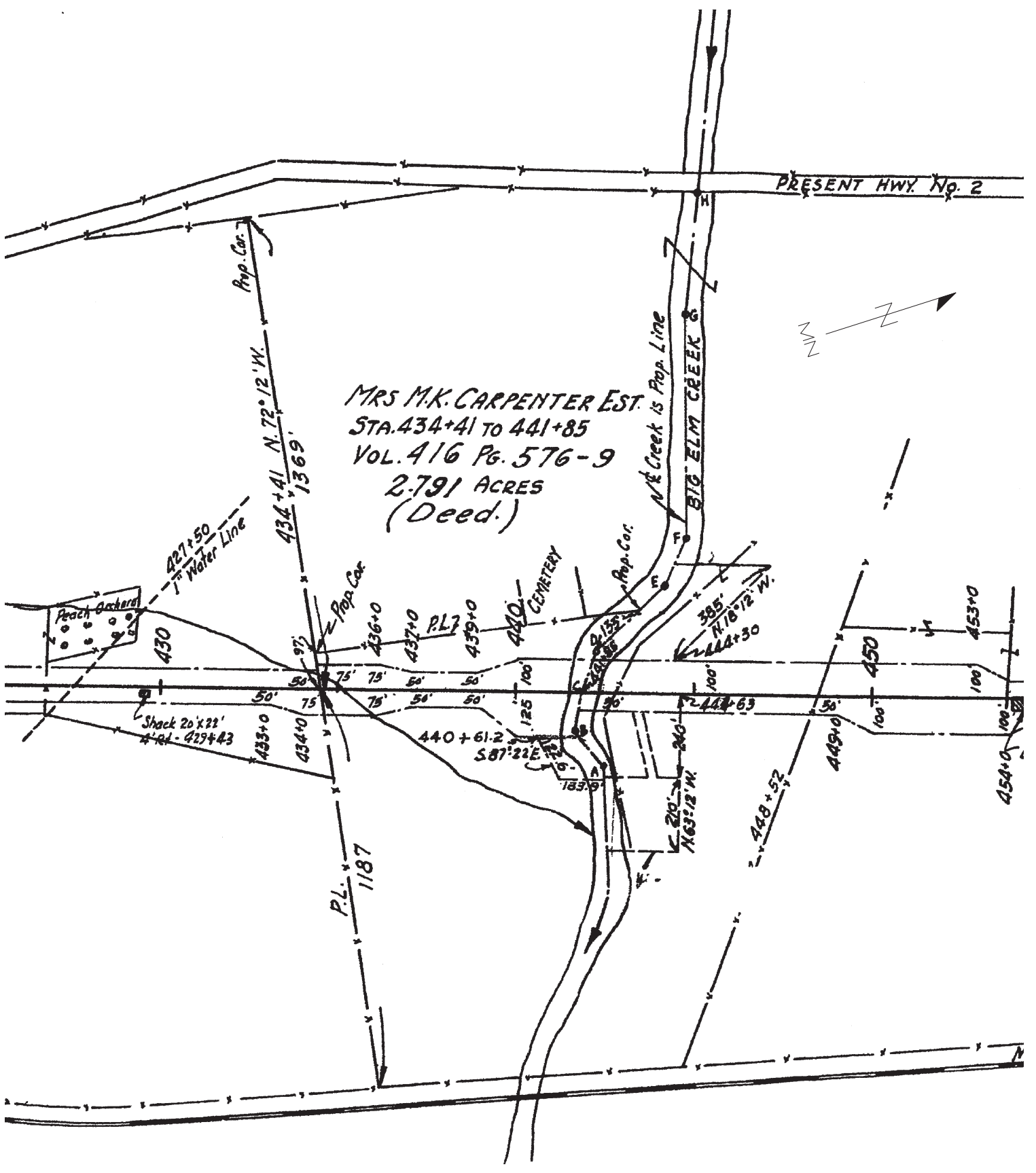

PAl/13/BW

Figure 6.3. Section of the 1932 Bell County highway map, no sheet number. Map data are summarized in Table 6.2. 


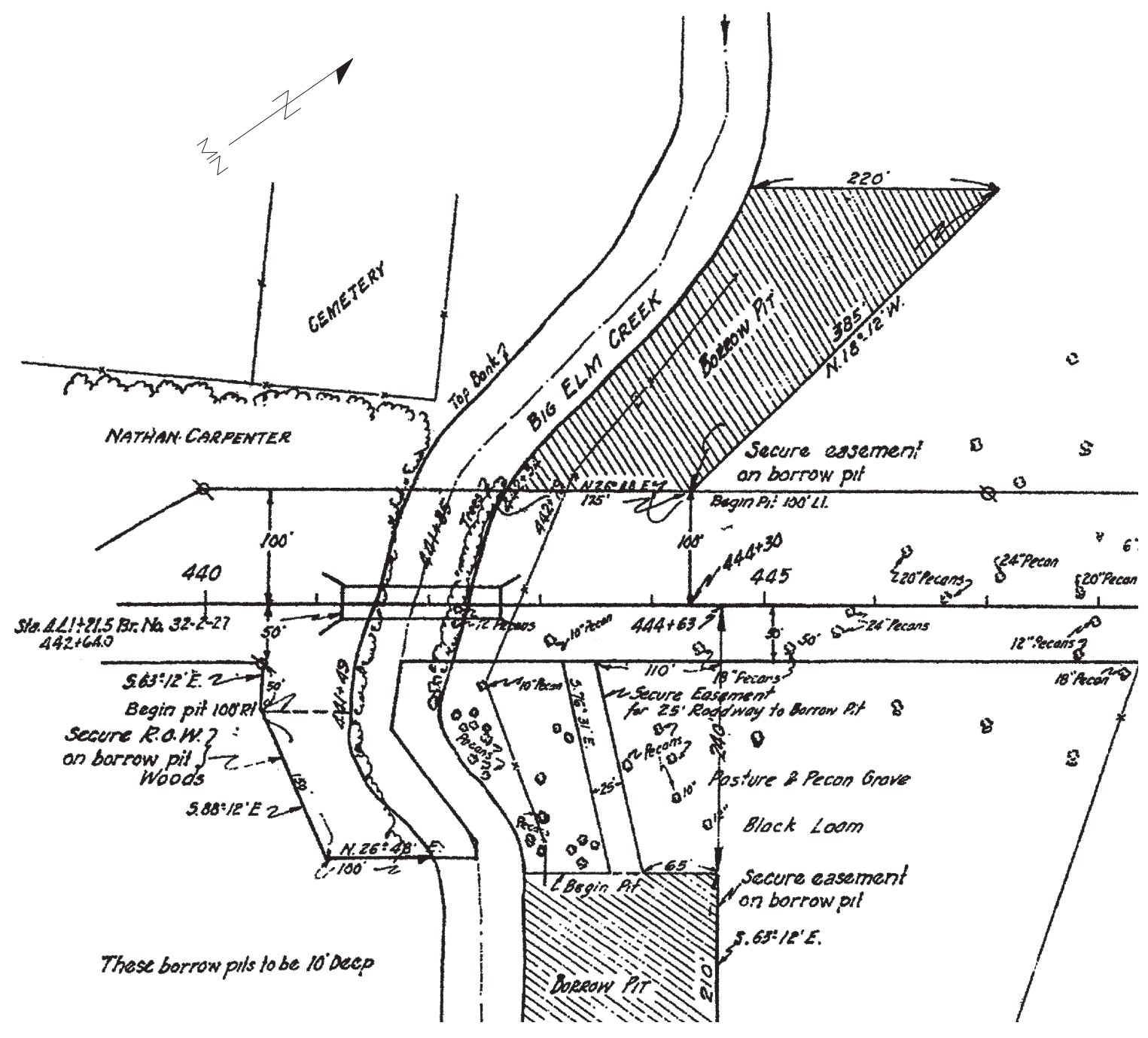

PAI/73/BW

Figure 6.4. Section of the 1931-1932 State Highway Department map, Sheet 16. Map data are summarized in Table 6.2.

Despite the research setbacks, the project historian was able to construct a relatively complete chain of title for the cemetery property, from 1887 to the present. The key deed records that pertain to the cemetery property are summarized in Table 6.3.

As of 1887 , some portion of the 3.75acre property transferred from F. $\mathrm{H}$. and Ida
Roberts to John Quincy Thompson was being used as a burial ground. The property already contained the 1886 graves of Soloman O. Bowers and Maggie C. Roberts. The next known burial occurred three years later in 1889 , suggesting that the use of the property as a burial ground was still in its infancy and it had not yet become a community cemetery. 


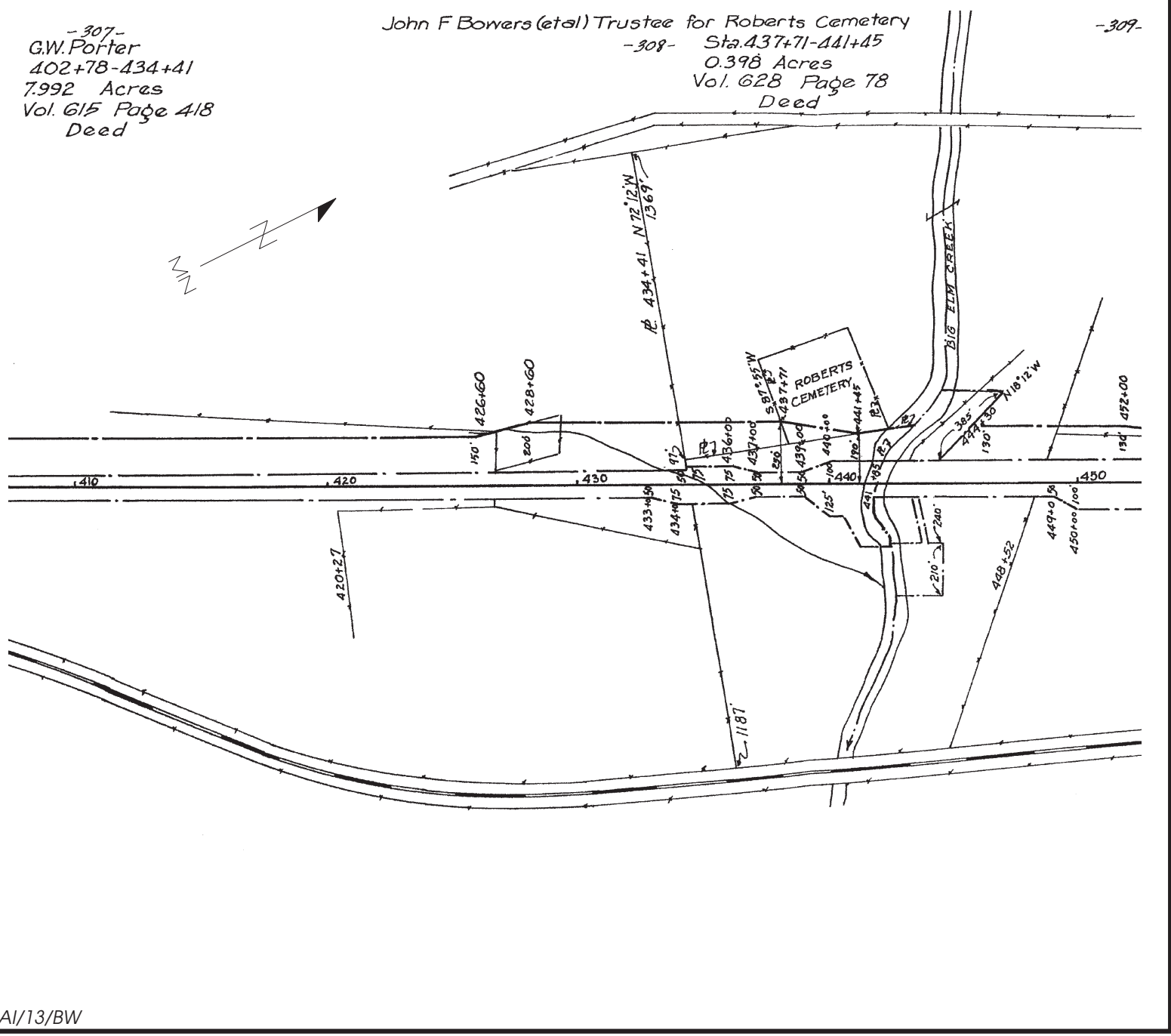

Figure 6.5. Section of the 1949-1952 Texas State Highway Department map, no sheet number. Map data are summarized in Table 6.2.

It is interesting that the 1887 transaction does not refer to the property as a cemetery or mention the burials. John Quincy Thompson could have been one of the earliest cemetery trustees because his descendants were later closely associated with the Roberts Cemetery. It is also notable that when the 1927 transaction occurred, the 3.75 -acre property was still not called a cemetery despite the fact that there were at least 69 burials there (Duke 2004; see Appendix D).
The size of the Roberts Cemetery property changed through time. From 1887 through 1927, the cemetery appears to have been located on the 3.75 -acre property owned by John Quincy Thompson or his estate. But it is not clear if the entire 3.75 acres was considered to be the cemetery or if the cemetery was only a portion of this tract. From 1927 to ca. 1950, there is no indication that the cemetery changed in size, but it continued to be used as a burial ground. By January of 1950 , there were 177 burials on the 


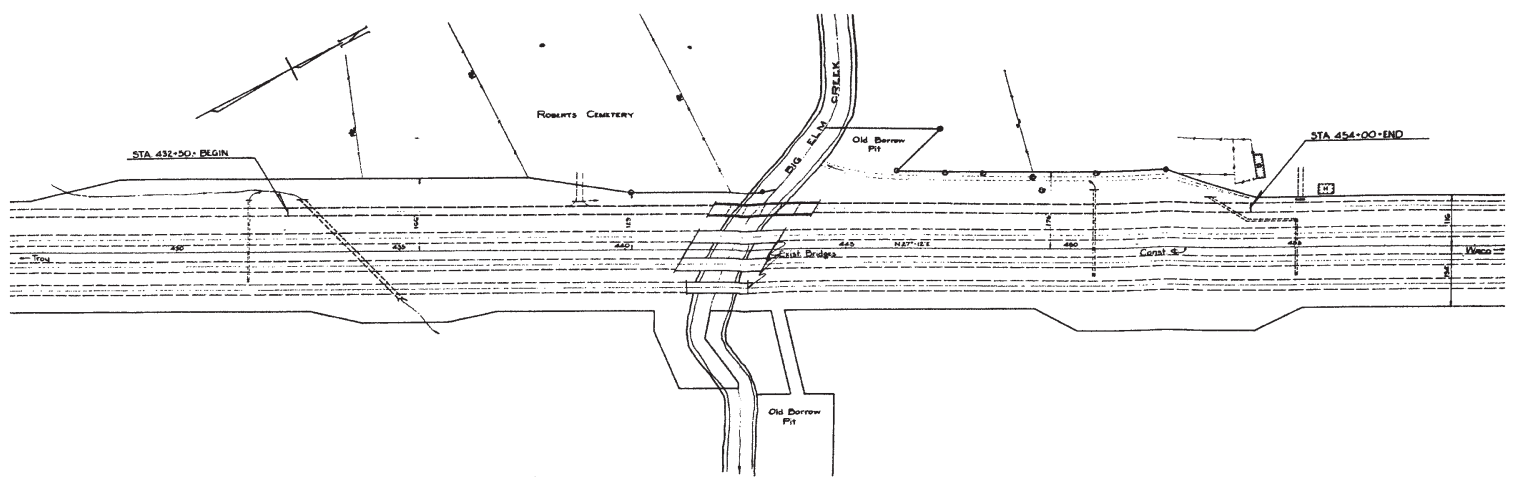

a

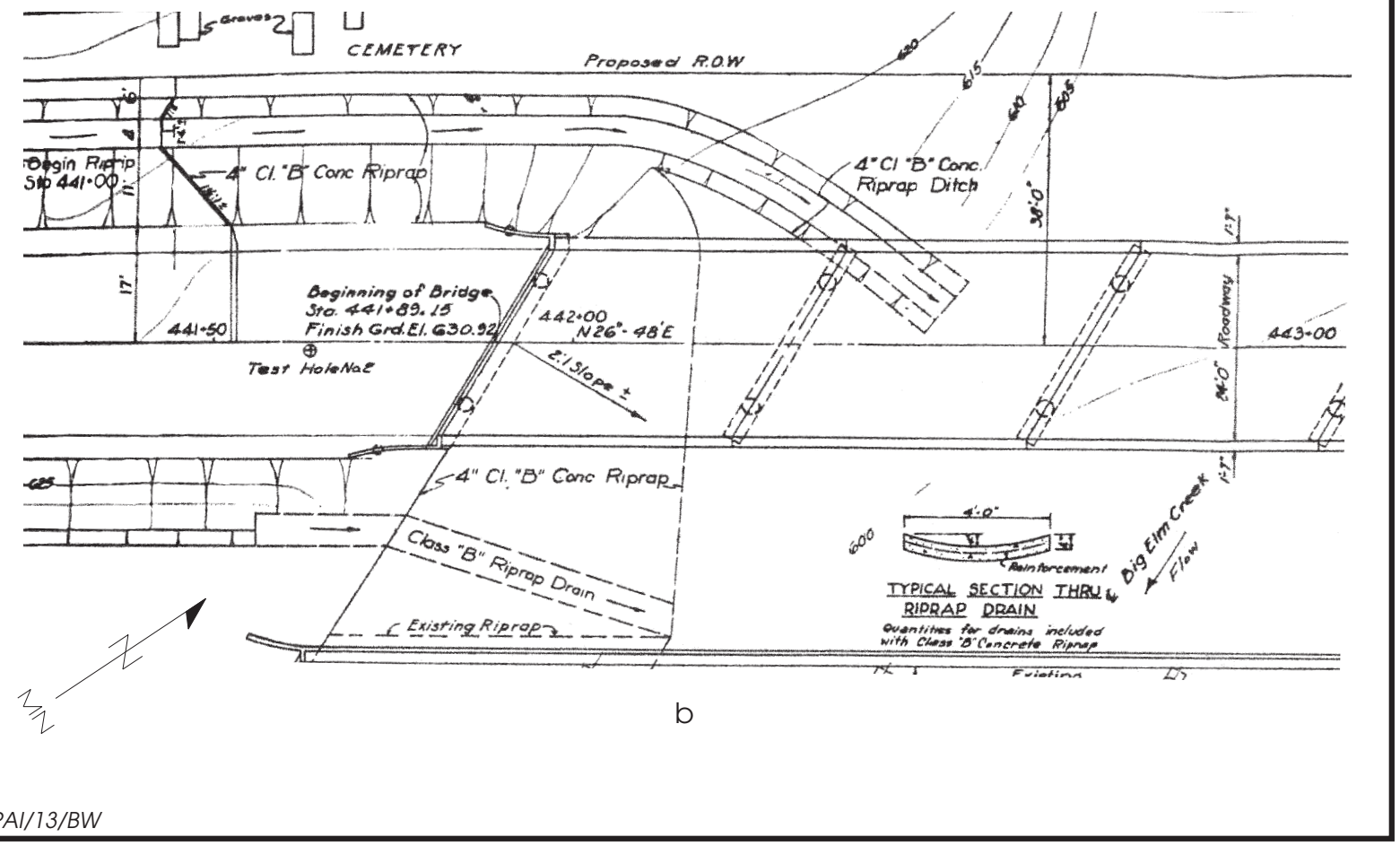

Figure 6.6. Sections of the 1957-1958 Texas State Highway Department map. (a) Sheet No. 10. (b) Sheet No. 23. Map data are summarized in Table 6.2. 
Table 6.3. Chain of title summary for the Roberts Cemetery property, Bell County, Texas

1887 F. H. and Ida Roberts to John Quincy Thompson,* 3 3/4 acres (BCDR** Vol. 62:137, December 29, 1887). The deed states:

Being on the waters of Big Elm Creek...Beginning at the southwest corner of a small tract of land sold by T. H. Roberts to John Spohn, Beginning at a point fifty feet from center of M. P. Rail Road from which a small Elm marked x bears S. 48? E 23 vrs. Thence S 48 1/4 E. 45 1/2 vrs. To center of Kings Branch. Thence with meanders of said Branch S 48 3/4 W. 115 vrs. Thence S 56 W. 20 vrs. Thence S 34 $1 / 260 \mathrm{vrs}$. Thence S $6341 / 4 \mathrm{~W} 160 \mathrm{vrs}$. Thence S $761 / 4 \mathrm{~W} .27 \mathrm{vrs}$. To Right of way of said Rail Road. Thence S 44 3/4 W. 80 vrs. Thence S. 41 W $1031 / 2$ vrs. Thence S 49 $1 / 2$ W. 100 vrs. Thence S 43 1/4 W. 110 vrs. to O. S. Carpenter's north east corner. Thence N. 71 W. 22 vrs. To said Rail Road Right of Way. Thence with the Right of Way northeasterly to the place of beginning variation 9'45 containing three and three fourth acres of land.

This deed does not specifically call this property a cemetery, but some portion of this 3.75-acre property became the Roberts Cemetery. According to the list of known burials at Roberts Cemetery (Duke 2004), there was only two graves on this property as of December 1887.

1927 From John Quincy Thompson to the J. Q. Thompson Estate, 245 acres, including F. H. Roberts' 3.75-acre tract and a 4.86-acre tract (BCDR Vol. 378:622).

This deed does not specifically call this 3.75-acre property a cemetery, but this is the F. H. Roberts tract mentioned in the 1887 deed, and some portion of it was being used as the Roberts Cemetery. The Roberts Cemetery burial list (Duke 2004) indicates that there were 70 burials on this property as of March 1927.

1931 M. L. (Martha, wife of John Quincy) Thompson to Earl F. Thompson (son) being a part of the 245 acres granted to J. Q. Thompson Estate (BCDR Vol. 416:140).

This is the 245 acres descended to Thompson's son, but this deed does not specifically relate to or mention the cemetery. M. L. and Earl are the heirs of J. Q. Thompson, who inherited the 245-acre parcel. A portion of this parcel, being 28.66 acres, went to Earl and two other men, and some of it was eventually added to the Roberts Cemetery (see below).

1931 Earl Thompson, John B. Daniel, and Roy Koos, to Mrs. P. S. B. Ford, a feme sole, a tract (bounded by the cemetery) of 28.66 acres of land (BCDR Vol. 416:312).

This deed pertains to the sale of a property that abuts the Roberts Cemetery on the south and west. The deed refers to the dimensions of the south, west, and north boundaries of the cemetery. For the property boundaries next to the cemetery, the deed states:

...being the SE corner of a 7 acre tract conveyed to J. R. Gunn; Thence North 1937 East 620 feet, with the Carpenter West line to the SE corner of old cemetery; Thence South 89-53 West with the South line of the cemetery lot 386.5 feet to the corner; Thence North 0-07 176.5 feet with the West line of cemetery lot to the NW Cor of same; Thence North 89-53 East 451 feet with the North line of cemetery to a corner in the west line of the Carpenter tract; Thence North 19-37 East 87.6 feet to center of Big Elm Creek; Thence North 30-09 West 257.5 feet with the meanders of said creek; Thence North 61-30 West 1167.4 feet up said creek to the place of beginning and containing 28.66 acres of land more or less, and being tract No. 3 of a subdivision of the J. R. Gunn Estate.

1932 Ford to W. B. McCall, her son-in-law, husband of her daughter, Sarah Ford McCall (BCDR Vol. 442:284).

This is the same tract of land (28.66 acres) that was sold to her by Thompson et al. in 1931.

* John Quincy Thompson II died on the day of his birth in 1916 and is buried in the Roberts Cemetery along with many other Thompsons (Duke 2004). It is possible that John Quincy Thompson Sr. may be buried in an unmarked grave at Roberts Cemetery since his name is not listed among the burials at any of the nearby cemeteries (i.e., Old Troy, Shiloh, and Pleasant View).

** BCDR refers to Bell County Deed Record 
Table 6.3, continued

1945 W. B. McCall and Sarah Ford McCall sold to O. S. Curtis, J. F. Bowers, and G. W. Porter, Trustees for the Roberts Cemetery, two and one-fourth acres and 388 square yards of land (BCDR Vol. 532:523, June 23, 1945). The deed states:

...That certain tract or parcel of land lying and being in Bell County, Texas a part of the T. Hughes Survey designated and described as follows: Beginning at the north west corner of Roberts Cemetery for stake, the same being the north west corner of Lot No. 32 in Block H south with the west line of said cemetery, 175 feet to south west corner of said cemetery for stake, thence east with south line of said cemetery 387 feet to south east corner of said cemetery for stake; Thence south westerly in line with the westerly line of a plot of land owned by the heirs of O. S. Carpenter and wife, M. K. Carpenter, 221.5 feet for corner, being 208 feet south of said cemetery at right angles to the south line of said cemetery; Thence west 390 feet for corner; Thence north 354 feet for corner; Thence northeasterly 83.5 feet to place of beginning, containing two and one-fourth acres and 388 square yards of land.

This deed refers to the addition of a parcel (2.25 acres plus 388 square yards) to the existing Roberts Cemetery.

1950 Trustees John F. Bowers, O. S. Curtis, and G. W. Porter sold a small tract of land, "containing 0.398 acres more or less," to the State of Texas. The tract is described as "being a part of 2 acres out of the T. Hughes Survey, 2.23 acres out of the T. Hughes Survey, conveyed by Joanna Scott to Roberts Cemetery; W. B. McCall to Roberts Cemetery by deed dated the 11 day of Aug. 1871; 23 day of June 1945..." (BCDR Vol. 628:78, May 23, 1950).

This deed is confusing and contains errors. This deed correctly denotes the 0.398 acres of the Roberts Cemetery that was sold to the State of Texas. Part of this tract came out of a 2-acre property previously conveyed by Joanna Scott (by deed dated August 11, 1871; Vol. O:460) and another part came out of a 2.23-acre property previously conveyed by W. B. McCall (by deed dated June 23, 1945; Vol. 532:523). The reference to the 2.23-acre McCall property is correct (see above) but the reference to the 2-acre property being previously conveyed by Joanna Scott is incorrect. Research shows that the August 11, 1871, deed from Joanna Scott relates to the Shiloh Cemetery property, located along Elm Creek, about 1.25 miles southeast of the Roberts Cemetery. This interpretation is confirmed by personnel at the Bell County Tax Appraisal District office. Unfortunately, the correct deed reference for this 2-acre property has not been located.

1957 J. F. Bowers, O. S. Curtis, and G. W. Porter, as Trustees for Roberts Cemetery... “\$55 paid by the State of Texas, grant etc. all that certain tract...conveyed by Joanna Scott to W. M. McCall and wife Sarah McCall, being two tracts out of the T. Hughes Survey" (Vol. 765:133, September 30, 1957). The deed states:

Being a parcel of land along the west side of US Interstate Highway No. 81, approximately 1.3 miles north of Troy. 1) Beginning at a point which bears N62 degrees 48'W, 129 feet from Construction Center Line Sta. 440+15.50 of US 81, 2) Thence N 27 degrees 12'E, 219.90 feet to a point in the North property line, said point bears N90 degrees 12'E, 522 feet from the northwest property corner, 3) Thence N90 degrees 00'E, 12.23 feet to a point in the west ROW line of US 81, 4) Thence S18 degrees 42 'W, 82.29 feet along said ROW line to a point, 5) Thence S36 degrees 18'W, 145.90 feet along said ROW line to the place of beginning and containing 0.069 acres more or less.

This deed refers to the sale of a small parcel from the Roberts Cemetery to the State of Texas. The parcel is 0.069 acres on the far east side of the cemetery It mentions the previous deeds of the Scott property (BCDR Vol. O:460) and the McCalls' property (BCDR Vol. 532:523). But the reference to the Scott deed is incorrect as stated above.

1966 W. B. and Sara McCall to Trustees O. L. Randolph, E. H. Porter, and J. B. Lancaster Trustees for Roberts Cemetery Association of Troy, 0.97 acres of land (BCDR Vol. 967:610, October 25, 1966).

This deed grants 0.97 additional acres to the Roberts Cemetery Trustees from the McCalls out of the 28.66-acre tract that was sold to Mrs. P. S. B. Ford in 1931 and then to her son-in-law and daughter in 1932. 
property (Duke 2004; see Appendix D). The size of the cemetery property is more clearly defined in the deed records from 1950 to the present (see Table 6.3), and the pertinent information is summarized as follows:

- As of 1950, it appears that the Roberts Cemetery Association considered the cemetery to be a 4.23-acre property consisting of two parcels, a 2-acre tract (the one erroneously attributed to Joanna Scott) and a 2.23-acre tract that came from the McCalls.

- In 1950, the Cemetery Trustees sold 0.398 acres out of Roberts Cemetery to the State of Texas. Following this transaction, the cemetery size was 3.832 acres.

- $\quad$ In 1957, the Cemetery Trustees sold 0.069 acres out of Roberts Cemetery to the State of Texas. Following this transaction, the cemetery size was 3.763 acres.

- In 1966, the McCalls gave 0.97 acres to the Trustees of Roberts Cemetery. Following this transaction, the cemetery size was 4.733 acres.

- As of 2013, the Bell County Appraisal District listed the size of Roberts Cemetery as 4.578 acres.

Notably, the cemetery size as listed by the Bell County Appraisal District (4.578 acres) is very close to the size as calculated from 1950 to 1966 deed records (4.733 acres). The two pieces of cemetery property that were acquired by the State of Texas for road improvements are the 0.398- acre tract in 1950 and the 0.069 -acre tract in 1957. Together, these tracts comprise 0.467 acres, or just short of half an acre.

\section{SEARCH FOR DEATH CERTIFICATES AS INDICATIONS OF POSSIBLE UNMARKED GRAVES}

\section{Research Methods}

The objective of this research was to examine death certificates as a means of identifying people who might be buried in unmarked graves at Roberts Cemetery. Death certificates for Bell County were available for all deaths starting in
1903. From that time to the present, informative records on the deceased were archived in bound volumes, and these books are stored in the Bell County Clerk's Office in Belton. The historian examined every entry from 1903 to 1940 , comprising nearly 7,000 records in six volumes. The entries were scanned to look for notations that a person was buried in Roberts Cemetery (or the Troy Cemetery) or the person died in or near Troy with no indication of their burial location.

Notably, the death certificates changed in format through time, and the later ones were more informative than the earlier ones. Death certificates dating between 1903 and 1916 contain minimal information, including the deceased's name, age, residence, and cause of death. In these early years, the death certificates recorded only the deceased's home community, but usually not the place where he or she was buried. Rarely was a cemetery listed on the death certificates from 1903 to 1916 , but some people were buried on their "home farms."

Starting in 1917, the state's official death certificates became more sophisticated and were issued on standardized forms requiring more detailed information from a doctor or the county coroner. Recorded data included a primary cause of death, mitigating circumstances (such as "old age"), the doctor or coroner involved, the undertaker's name, and the burial date and cemetery where the burial occurred. From 1917 forward, the death certificates indicated that most people were being buried in local cemeteries, and only a few burials occurred on the "home farm" during this period.

From the examination of the death records, the project historian compiled of list of names and data for people whose death certificates stated they were buried in Roberts Cemetery or the Troy Cemetery or that they died in or near Troy with no stated burial place. This list was then checked against the burial inventories for the Roberts, Shiloh, and Pleasant View Cemeteries and Old Troy.

\section{Results of the Death Certificate Search}

Based on the examination of the death certificates, the project historian estimates that as many as one-fifth to one-quarter of Troy-area 
residents who died between 1903 and 1940 were buried in the Roberts Cemetery. Because the post-1917 death certificates are more detailed, the period between 1917 and 1940 was most productive for identifying people who were buried in Roberts Cemetery according to official records, but whose names do not appear in the current cemetery inventories. The death certificates in Volumes 3 and 4 of the county records clearly show that most Troy residents were buried in Roberts Cemetery after 1917. And by this time, Roberts Cemetery was commonly known as the "Troy Cemetery" because of its proximity to the town and because so many of its citizens were already buried there. For these reasons, it is believed that any Troy resident whose death certificate lacked a cemetery notation was likely to have been buried in the Roberts (or Troy) Cemetery.

The review of the Bell County Death Certificates dating from 1903 to 1940 was quite productive for identifying people who were definitely buried in Roberts Cemetery or were likely to have been buried there. The detailed data are presented in Appendix C, while Table 6.4 summarizes the results of this research. Sixty-seven people were identified and placed into one of three groups based on their likelihood of being buried at Roberts Cemetery:

- Group A consists of 28 people, each of whom had a death certificate indicating that they were buried in Roberts Cemetery. Each name also appears in the Roberts Cemetery inventory.

- Group B consists of 10 people who had a death certificate indicating that they were buried in Roberts Cemetery. However, their names do not appear in the Roberts Cemetery burial inventory (or the burial inventories for Old Troy, Shiloh, or Pleasant View). Consequently, it is assumed that these 10 people are buried in unmarked graves at Roberts Cemetery.

- $\quad$ Group C consists of 29 people who died in or near Troy but whose names do not appear in burial lists for Roberts, Old Troy, Shiloh, or Pleasant View. It is assumed that any of these people may be buried in an unmarked grave at Roberts Cemetery.

\section{SUMMARY AND CONCLUSIONS}

F. H. and Ida Roberts are believed to have started Roberts Cemetery with the death of their first child, Maggie, in 1886. This occurred just a few years after railroad came and caused the community of Troy to spring up and the town of Old Troy to begin its slow demise. The use of the Roberts property as a community burial ground increased through time (see Figure 6.1), and at some point in its history, Roberts Cemetery also became known as the Troy Cemetery. As of 2004, the cemetery contained more than 600 graves, and it continues to be used for the interment of local citizens of Troy and Bell County.

While its use as a cemetery is fairly documented, the precise history of the cemetery property is not as well defined. The deed research for Roberts Cemetery was difficult because an erroneous reference to Shiloh Cemetery has appeared in deed records since about 1945. It was also cumbersome because F. H. and Ida Roberts bought and sold more than 100 tracts of land in the Taliferro Hughes and adjacent Rebecca Edwards Leagues between 1878 and 1910. Despite these pitfalls, a chain of title was traced from Roberts' sale of $33 / 4$ acres of land to John $Q$. Thompson in 1887 to the sale by his descendants to the Roberts Cemetery Trustees. Small portions of land were added or subtracted from the main property over the year, and the current cemetery property totals 4.733 acres according to deed records. The County Tax Appraisal District lists the Roberts Cemetery property as 4.578 acres (Figure 6.7), a close figure.

The planned expansion of the U.S. Highway 81 into Interstate Highway 35 in the 1950s led to the acquisition of a portion of the original Roberts Cemetery property by the State of Texas. The area that was acquired by the state for these road improvements was just under half an acre, and it forms a triangular tract removed from the northeast corner of the original cemetery. As documented in this report, the archeological investigations by PAI revealed that unmarked graves were present inside the state-owned right of way (the four unmarked graves that were exhumed) and on the cemetery property immediately to the west (two unmarked graves that were left in place).

Historical evidence indicates that there are probably many more unmarked graves elsewhere in Roberts Cemetery. The evidence is from 
Table 6.4. Summary of people definitely or possibly buried in Roberts Cemetery between 1903 and 1940, according to Bell County death certificates

\begin{tabular}{|c|c|c|c|c|}
\hline $\begin{array}{l}\text { Bell County Death } \\
\text { Certificates }\end{array}$ & $\begin{array}{l}\text { Group A: } \\
\text { Marked Grave in } \\
\text { Roberts Cemetery }\end{array}$ & $\begin{array}{c}\text { Group B: } \\
\text { Unmarked Grave in } \\
\text { Roberts Cemetery }\end{array}$ & $\begin{array}{c}\text { Group C: } \\
\text { Possible Unmarked } \\
\text { Grave in Roberts } \\
\text { Cemetery }\end{array}$ & Total \\
\hline Vol. I: 1903-1908 & & & 13 & 13 \\
\hline Vol. I: 1903-1908 & 2 & & & 2 \\
\hline Vol. II: 1908-1917 & & & 15 & 15 \\
\hline Vol. II: 1908-1917 & & 2 & & 2 \\
\hline Vol. III: 1917-1919 & & 4 & & 4 \\
\hline Vol. III: 1917-1919 & & & 1 & 1 \\
\hline Vol. IV: 1920-1932 & 3 & & & 3 \\
\hline Vol. IV: 1920-1932 & & 3 & & 3 \\
\hline Vol. IV: 1920-1932 & 7 & & & 7 \\
\hline Vol. V: 1933-1937 & 10 & & & 10 \\
\hline Vol. VI: 1938-1939 & & 1 & & 1 \\
\hline Vol. VI: 1938-1939 & 6 & & & 6 \\
\hline Total & 28 & 10 & 29 & 67 \\
\hline
\end{tabular}

Notes:

Volumes I and II do not state the cemetery where a person was buried. Volumes III-VI do list the cemetery where a person was buried. This entry was usually filled in, but was sometimes left blank

Group Definitions:

Group A: Marked graves in Roberts Cemetery. Death certificate says the person died in Troy and/or was buried in Roberts Cemetery, and the person's name is listed in the Roberts Cemetery inventory by Duke (2004).

Group B: Unmarked grave in Roberts Cemetery. Death certificate shows "Roberts" as place of burial, but the person's name is not listed in the Roberts Cemetery inventory by Duke (2004). Person's name does not show up on the inventories for Old Troy Cemetery (Find A Grave 2013; Todd and Todd 2006); Pleasant View Cemetery (Badovinac 2001), or Shiloh Cemetery (Bell County Historical Survey Committee n.d.; Entrop 2013).

Group C: Possible unmarked graves in Roberts Cemetery. Death certificate does not indicated place of burial, but the person died in Troy and is not listed on the Roberts Cemetery inventory by Duke (2004). Person's name does not show up on the inventories for Old Troy Cemetery (Find A Grave 2013; Todd and Todd 2006); Pleasant View Cemetery (Badovinac 2001), or Shiloh Cemetery (Bell County Historical Survey Committee n.d.; Entrop 2013). 


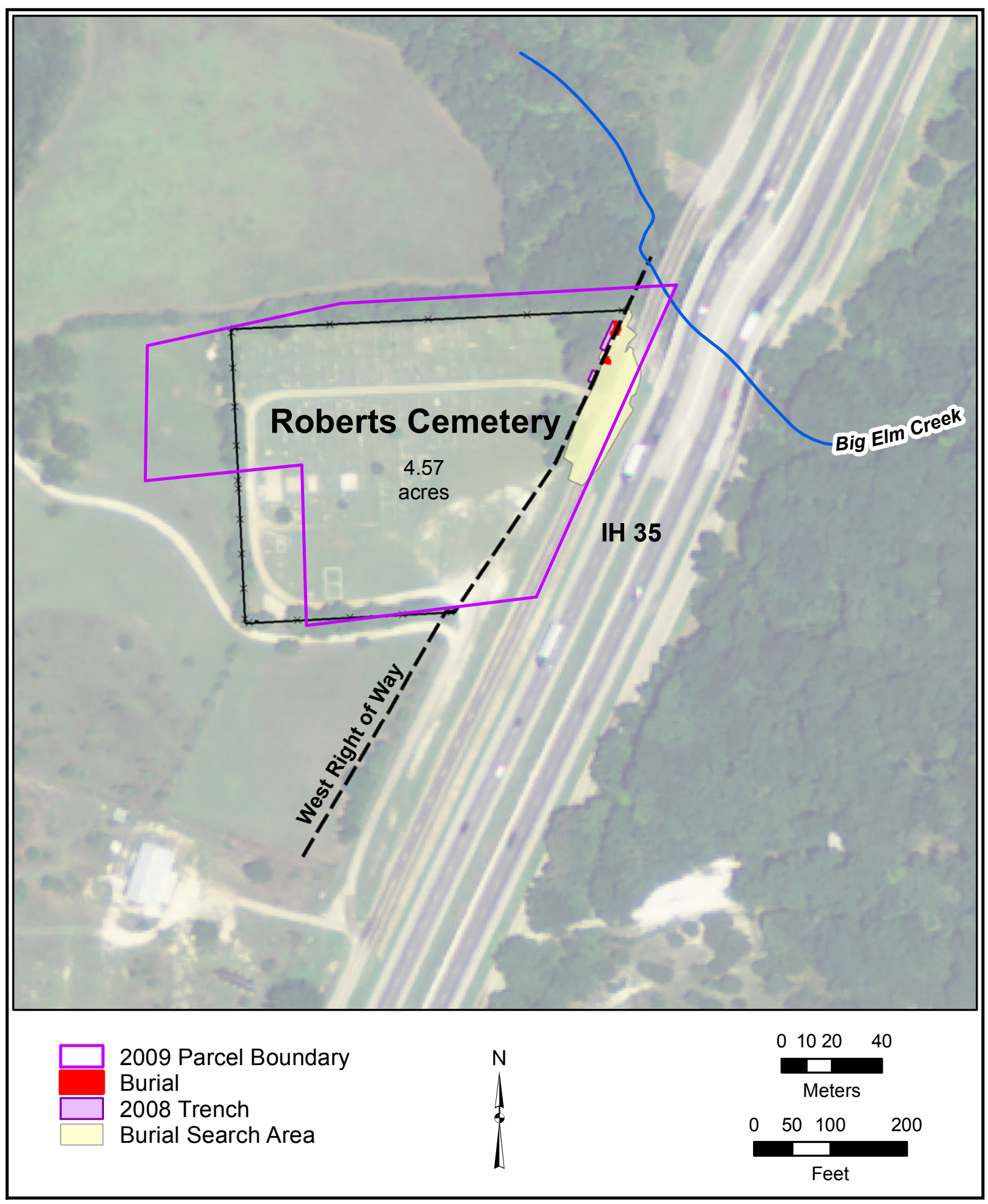

Figure 6.7. Aerial view of Roberts Cemetery with the Bell County Appraisal District outline of the 4.57-acre property. 
Bell County death certificates dating from 1903 to 1940 and the comparison of the mortality data with online burial inventories for the Roberts, Shiloh, Old Troy, and Pleasant View Cemeteries. Appendix $\mathrm{C}$ lists the names of 10 people who are definitely buried in unmarked graves at Roberts
Cemetery (Group A), along with the names of 29 others who may be buried there (Group B). Additional unmarked graves may be present in the cemetery as well, especially burials of people who died before 1903, when the use of death certificates became standard practice. 


\title{
PUBLIC INVOLVEMENT, SEARCH FOR LIVING RELATIVES, AND DNA TESTING
}

\author{
Jennifer K. McWilliams, James T. Abbott, and Douglas K. Boyd
}

This chapter summarizes TxDOT's efforts to inform the public about the cemetery project and to identify the recovered unknown individuals. Because these remains were associated with Roberts Cemetery, which is clearly an active cemetery governed by Title 8, Chapter 711 of the Texas Health and Safety Code (General Provisions Relating to Cemeteries), and the remains were being moved to a different location within the same cemetery (per Title 13, Part 2, Chapter 22, Rule 22.5(d)), the administrative provisions governing the removal of unknown remains under an Antiquities Code permit (Title 13, Part 2, Chapter 22, Rule 22.5(c)(2)) did not apply. Consequently, the only permissions needed for the removal, genetic testing, and reburial of the remains were secured from the cemetery association. Nevertheless, the work performed was consistent with the requirements of the Title 13 statute for personnel and character of investigations. The remains were removed by professional archeologists and a professional physical anthropologist; the physical anthropologist conducted detailed physical examination of each set of remains and documented evidence of age, gender, stature, trauma, and skeletal pathologies; the casket hardware and funerary objects were examined and documented in detail; and the results are being fully reported.

\section{PUBLIC OUTREACH AND SEARCH FOR LIVING RELATIVES}

TxDOT's outreach efforts were designed to help identify the recovered individuals, if such was possible. Before the project was initiated, TxDOT discussed the project with the State
Historic Preservation Officer (SHPO) and the Roberts Cemetery Association and reached an agreement in principal that if burials were found, the state would exhume them according to prevailing archeological standards, attempt to identify them, and rebury them elsewhere in the cemetery. Once it was established that burials were in fact present inside the state-owned right of way in late August 2012, the members of the cemetery association were notified (this was initially accomplished in person, as Mrs. Heroldine Early, Mr. J. C. Alston, and Mr. Wayne Randolph were all frequent visitors during the discovery phase), and the agreement to reinter the remains in the cemetery was formalized (see Appendix F).

Although TxDOT had always planned to do public outreach, the nature and timing of that outreach were adjusted in response to circumstance. TXDOT had intended to complete the prospection process and determine how many burials were present in the right of way prior to notifying the public about the finds, so that a full and comprehensive statement could be released. However, on August 29, 2012, the Temple Daily Telegram reported that two unmarked graves had been discovered in the highway frontage of Roberts Cemetery during construction of Interstate Highway 35 improvements (Ersland 2012). Ken Roberts, TxDOT's Waco District Public Information Officer, then produced and distributed a press release and scheduled a press conference at the cemetery for Tuesday, September 5, 2012, while the prospection effort was ongoing. This press conference was attended by several reporters and news crews. Other reporters visited the cemetery in the days that followed and were provided essentially 
the same information by TxDOT archeological personnel working in the field. In addition to simply informing the public, these presentations actively encouraged individuals with knowledge about the cemetery, or who thought that there was a possibility that the recovered remains might be their ancestors, to contact the Waco District. Over the next few days, the story was run by several local television and print media, including KCEN-TV, KWTX-TV, YNN-TV (Texas cable news), and the Waco Tribune-Herald (Cox, 2012; Ersland 2012; KCEN-TV 2012; Robertson 2012; Smith 2012) as well as the local weekly newspaper in Troy (Troy Country Sun 2012). Each of these stories repeated the appeal for individuals with interest to come forward. As a result of these appeals, nine individuals contacted TxDOT's Waco District office because they believed that they have a deceased relative who might be buried in an unmarked grave at Roberts Cemetery (Table 7.1).

The next step was to begin to look for possible age and sex matches between the missing relatives and the unidentified remains in the exhumed burials. Of the six unmarked graves identified in the 2008 and 2012 archeological investigations (see Chapters 1 and 2), two were examined only at the time of their discovery and were not disinterred. ${ }^{18}$ The four sets of human remains exhumed from unmarked graves in 2012 are summarized as follows:

\section{UNMARKED GRAVES NOT EXCAVATED}

- Unnumbered burial, child, unknown sex

- Burial 5, probable adult, unknown sex

\section{EXHUMED GRAVES}

- Burial 1, adult male, age 30-40

- Burial 2, adult male, age 45-60

- $\quad$ Burial 3, adult male, age 20-27

- Burial 4, child, approximately 1.5 years, sex unknown

\footnotetext{
18 The other two unmarked graves are mentioned here because their spatial proximity to the exhumed burials could be indicative of potential family relations. If any of the exhumed burial remains could be linked to living relatives through DNA analysis, the locations of the other unmarked graves might help shed some light on other possible family members.
}

When the osteological analysis was completed, we knew that three exhumed graves contained the remains of adult males, and the fourth individual was an infant. Based on this evidence, the list of families that were potentially related to the burial remains was reduced considerably. Seven people whose missing relatives were females were notified that the disinterred remains were not related to them. This left three families whose missing relatives were adult males and young children:Thomas, Gibson, and Elliott. The three missing adult relatives and family contacts warranting further consideration were:

- John A. Thomas (1850-1904); contact Cindy (Thomas) Schleede (lives near Troy)

- John J. Gibson (1861-1935); contact Florence (Gibson) Boren (lives in Temple)

- Nathan Elliott (1833-1900 or 1901); contact Cindy Black (lives in Corsicana)

\section{DNA LABS AND ANALYTICAL TECHNIQUES}

DNA testing of the four unmarked burials from Roberts Cemetery was conducted in an attempt to identify genetic relations among the four burials and possible genetic matches between the burials and living descendants. DNA extracted from the bones/teeth of the four burials would be compared genetically as a group to determine if any of the deceased were related to each other. Burial 4, for example, was a child who might have been buried in close proximity to another family member. Before analyzing bone samples to determine if viable DNA was preserved, research had to be done to determine which commercial laboratory should do the DNA study.

\section{Overview of Commercial Laboratories and DNA Research}

The project archeologist (Jennifer McWilliams) talked to seven genetic labs to review their services and costs. Most labs are set up and funded by paternity cases and therefore only deal with Y-chromosome tests. Such labs are common now, and one, LabCorp, even dubbed itself the "Walmart of genetic testing" because 
Table 7.1. People who contacted the Texas Department of Transportation with information about possible relatives buried in Roberts Cemetery

\begin{tabular}{l|l|l|l|l}
\hline Informant Name & Name of Missing Ancestor & $\begin{array}{c}\text { Description of Missing } \\
\text { Ancestor and Age at } \\
\text { Death }\end{array}$ & $\begin{array}{l}\text { Death Date of Missing } \\
\text { Ancestor }\end{array}$ & $\begin{array}{c}\text { Potential } \\
\text { Burial } \\
\text { Matches }\end{array}$ \\
\hline Cindy Schleede & John A. Thomas & Male, age 53 & February 4, 1904 & Burial 2 \\
\cline { 2 - 5 } & unknown child & $\begin{array}{l}\text { Young child } \\
\text { (sex unknown) }\end{array}$ & $\begin{array}{l}\text { Possibly died in } \\
\text { February 1904 }\end{array}$ & Burial 4 \\
\hline Florence Boren & John Gibson & Male, age 74 & Burial 2 \\
\hline $\begin{array}{l}\text { Larry W. } \\
\text { Warneke }\end{array}$ & Tamsy Jane Davis & Female, age not specified & 1911 & None \\
\hline Alvin Brooks & Mary Polly Roberts Early & Female, age 24 years & 1844 & None \\
\hline $\begin{array}{l}\text { Johnney } \\
\text { Williams }\end{array}$ & $\begin{array}{l}\text { Martha Angeline } \\
\text { Ledbetter }\end{array}$ & Female, age 46 years & 1887 & None \\
\hline Randy Todd & $\begin{array}{l}\text { Martha Angeline } \\
\text { Ledbetter }\end{array}$ & Female, age 46 years & 1887 & None \\
\cline { 2 - 5 } Cindy Black & $\begin{array}{l}\text { Lou Ella (Richardson) } \\
\text { Elliott }\end{array}$ & Female, age not specified & $\begin{array}{l}\text { Between 1889 and } \\
1901\end{array}$ & None \\
\cline { 2 - 5 } & $\begin{array}{l}\text { Laura Elliot (Nathan and } \\
\text { Lou Ella's daughter) }\end{array}$ & Female, age 1 or 2 & 1900 or 1901 & Burial 4 \\
\hline Barbara Biskup & Bessie Cook & Female, age not specified & 1908 & None \\
\hline Dottie Tate & $\begin{array}{l}\text { Rebecca Burnley Porter } \\
\text { Shepperd }\end{array}$ & Female, age 52 & November 24, 1868 & None \\
\hline
\end{tabular}

they have a lab in almost every county in every state in the United States. These commercial labs are set up specifically for legal DNA testing, and they follow rigorous procedures that enable them to present results that "hold up in court." Alternatively, they offer what labs call "peace of mind" testing, the results of which are not legally binding or meant to stand up in a court of law.

The Roberts Cemetery project had two types of DNA sources available for comparison: bone/teeth of the four deceased individual from the unmarked graves, and buccal (cheek) swabs taken from living descendants who have missing relatives that may be buried in unmarked graves at Roberts Cemetery. The important considerations for these samples were:

- Bone/Tooth: Because the bones/teeth are old (roughly 100 years) and were in the ground, exposed to moisture and drying, DNA was difficult to extract. The labs recommend testing a 2-4-inch piece of femur, if available. The inner (cortical) portion of teeth can also be used, but such samples are small, and it is less likely that uncorrupted DNA can be extracted.
- Buccal (or cheek) swabs: These were taken from living descendants, one swab on each side of the cheek. Traditionally, samples are taken by a trained and certified professional to produce legally binding results.

\section{Factors That Affect Bone DNA Studies}

To produce conclusive DNA results, the Roberts Cemetery project had two major hurdles to overcome: differential bone preservation and the generational span between the deceased and living genetic samples. ${ }^{19}$ Although DNA can be extracted from blood, cells, hair, sperm, and other parts of the body, bone offers the longest preservation. For historic burials, bone is the only option available, but when bone is buried in the ground, it is vulnerable to many environmental variables. Good bone preservation is critical to the success of DNA extraction; however, bone that may seem well preserved to

19 The information regarding DNA extraction and analytical techniques in this section comes primarily from Dr. Michael Schmiederer at LabCorp. 
an archeologist may actually contain poorly preserved or contaminated DNA. In short, the older the bone, the more problematic it is to extract the DNA. Groundwater intrusion can leach out bone material containing DNA and introduce microorganisms and compounds that accelerate deterioration. Tree roots and burrowing animals (e.g., earthworms) can cause physical damage and contaminate bone by adding nonhuman DNA. All of these factors may affect the state of DNA preservation in bone samples.

The next challenge was to find potential relatives for DNA comparisons. What living offspring were available to provide buccal swab DNA samples for comparison? First-generation offspring produce the best statistical comparisons, but for the Roberts Cemetery project, no first-generation descendants were still living. The DNA collected from grandchildren display a weaker genetic relationship than those DNA from children, but a group of multiple secondgeneration and third-generation relatives can supplement data sets. For the Roberts Cemetery project, grandchildren and great-grandchildren of potential relatives were identified and contacted. Several people agreed to provide cheek swabs to contribute to the DNA data pool of living people who might be descendants. Fourth and fifth generations of potential relatives were also available, but they were not tested because their DNA would have had an even weaker connection to their ancestor.

\section{DNA Extraction and Profiling}

The first step in DNA analysis is to determine if the sample is viable-that is, if it contains readable and repeated DNA sequences. There are various ways to extract DNA from the calcium in a bone sample using chemicals and dye to highlight sections or loci on the DNA. ${ }^{20}$ The extraction time for various methods ranges from several days to weeks. When one method is unsuccessful, a different method may be tried, and this process may continue for several weeks. However, at LabCorp the cost is by sample, so the cost remains the same no matter how many methods of extraction are attempted. Samples

\footnotetext{
${ }_{20}$ Bone compaction is a recently discovered method of increasing the chances of DNA extraction. This method requires specialized machines that few DNA labs can afford, and the costs of this type of DNA extraction are significantly higher than the standard practices.
}

from living descendents (buccal swabs) take only a day or two to process since variable preservation is not an issue. Once the lab has extracted the DNA, the computer-generated analytical comparisons are accomplished quickly, but the results may vary depending on the goals and methods used. LabCorp suggested that it was not prudent to push the turnaround time for the DNA extraction since the goal is to create repeatable alleles.

\section{Determination of Applicable DNA Tests}

McWilliams collected the following information regarding current DNA testing procedures from two sources: Dr. Melton, lab director at Mitotyping Technologies, and Dr. Schmiederer at LabCorp. Note that the accuracy percentages stated below are only rough estimates provided to give a general impression of the level of statistical confidence in the results that might be expected.

Three primary categories of DNA testing can be run: Y-chromosome, mitochondrial, and simple short tandom repeats (STRs). In all tests that attempt to compare the deceased's DNA with buccal swab DNA from living descendants, the closer the genetic relationship, the better. Father-to-son or mother-to-daughter relationships have the best chance of obtaining numerous repeats in the genetic code (something like 99.8 percent confidence). Grandparent-to grandchild tests are not as strong, but can produce good results (say, 98-99 percent confidence). And great-grandparent-to-great-grandchild comparisons are weaker still, but can produce results with a fairly high percentage of accuracy (say, 98 percent confidence) in some cases.

During Y-chromosome tests, the nuclear DNA is extracted, but only the Y-chromosome, or male alleles, are mapped. These alleles are plotted and their STRs are studied. This type of analysis, called YSTR, can produce high-accuracy results (95 percent confidence or greater). This type of analysis can be used if all relatives within a lineage are male.

Mitochondrial DNA (MtDNA) labs are less common and more specialized. MtDNA tests require a straight female lineage. Results are often inconclusive. Simple short tandom repeat tests can be run for anyone, regardless of sex. While these tests are not as conclusive in deter- 
mining relationships, they can produce enough repeated alleles that a strong case can be built in regards to genetic relationship (ca. 95 percent confidence). When these tests yield strong but inconclusive results, other data such as historical evidence can lend additional support, resulting in reasonably concrete determinations in "peace of mind" cases.

\section{Cost Comparisons for DNA Analyses}

Prices for DNA testing range dramatically depending upon the goals and methods, with MtDNA being the most expensive. ${ }^{21}$ YSTR and Simple STR ranges from $\$ 325$ to $\$ 1,345$ per bone/tooth sample, and $\$ 210$ is fairly standard for buccal swabs. MtDNA prices range from $\$ 1,250$ to $\$ 1,345$ for a bone/tooth sample and $\$ 100$ to $\$ 1,200$ for a buccal swab sample.

\section{DNA Laboratory Recommendation}

McWilliams had in-depth discussions with experts at three commercial labs: Dr. Melton at Mitotyping Technologies; Kathy Segal at DDC DNA Diagnostic Center; and Dr. Schmiederer at LabCorp. Dr. Melton provided extensive information on MtDNA only, and Mitotyping Technologies has extensive experience in forensic and genealogy testing. Prices were expectedly high. The DDC DNA Diagnostic Center lab conducts both MtDNA and YSTR, and prices were low to average when compared with other labs. Dr. Schmiederer with LabCorp provided the most information, asked the most relevant questions, and was immediately engaged in the project. LabCorp prices were quite reasonable, and the company said it would provide DNA reports with the following information:

- Identification of each bone/tooth sample by burial number and possible relationships to living persons (e.g., Burial $\mathrm{X}$ is possible paternal grandfather to Person A)

- Buccal (cheek swab) sample labeled with the donor's name and his or her possible relationship to specific burials (e.g., Person $\mathrm{A}$ is a possible maternal granddaughter of

\footnotetext{
21 Prices for tests were obtained from Mitotyping Technologies, LabCorp, Selmark Forensics, and DDC DNA Diagnostic Center.
}

\section{Burial X)}

- The allele calls (a list of the repeated alleles) for each sample

- The statistical probability of the proposed relationship

- A written assessment of the likelihood of genetic relationships

Although the Roberts Cemetery case was quite unusual for LabCorp-like most DNA labs, it primarily handles paternity-oriented cases and litigation-Dr. Schmiederer thoroughly described each step in the process and the choices that needed to be made regarding test options and sample selection. PAI recommended to TxDOT that working with LabCorp for the genetic testing was the best option. TxDOT concurred, and the project moved on to the next step: researching the families who had ancestors that were potential matches with the burial remains.

\section{POTENTIAL GENETIC MATCHES BETWEEN ANCESTORS AND THE HISTORIC BURIALS}

Three families-Thomas, Gibson, and Elliott-had valid reasons for believing that their ancestor may have been buried in Roberts Cemetery. Table 7.2 summarizes the missing relative and descendant family information for the three families, including the living relatives who could provide buccal swabs for DNA analysis. Family trees were created primarily to establish family relations between living persons and their ancestry in order to convey the possible genetic relations between the burials and the living DNA donors to Dr. Schmiederer (LabCorp). This work provided a visualization of the direct male lineage between a deceased ancestor and each living DNA donor. This information was necessary so that LabCorp and PAI could determine the most appropriate type of DNA testing. McWilliams constructed two family trees (for Thomas and Gibson) using Ancestry.com, and Cindy Black provided a family tree for Elliott.

For the exhumed burials, the estimated ages of the three adult males range from 20 to 60 years old. The child is estimated at 18 months old. The missing relatives from the three families were all adult males 53 years or older at the 


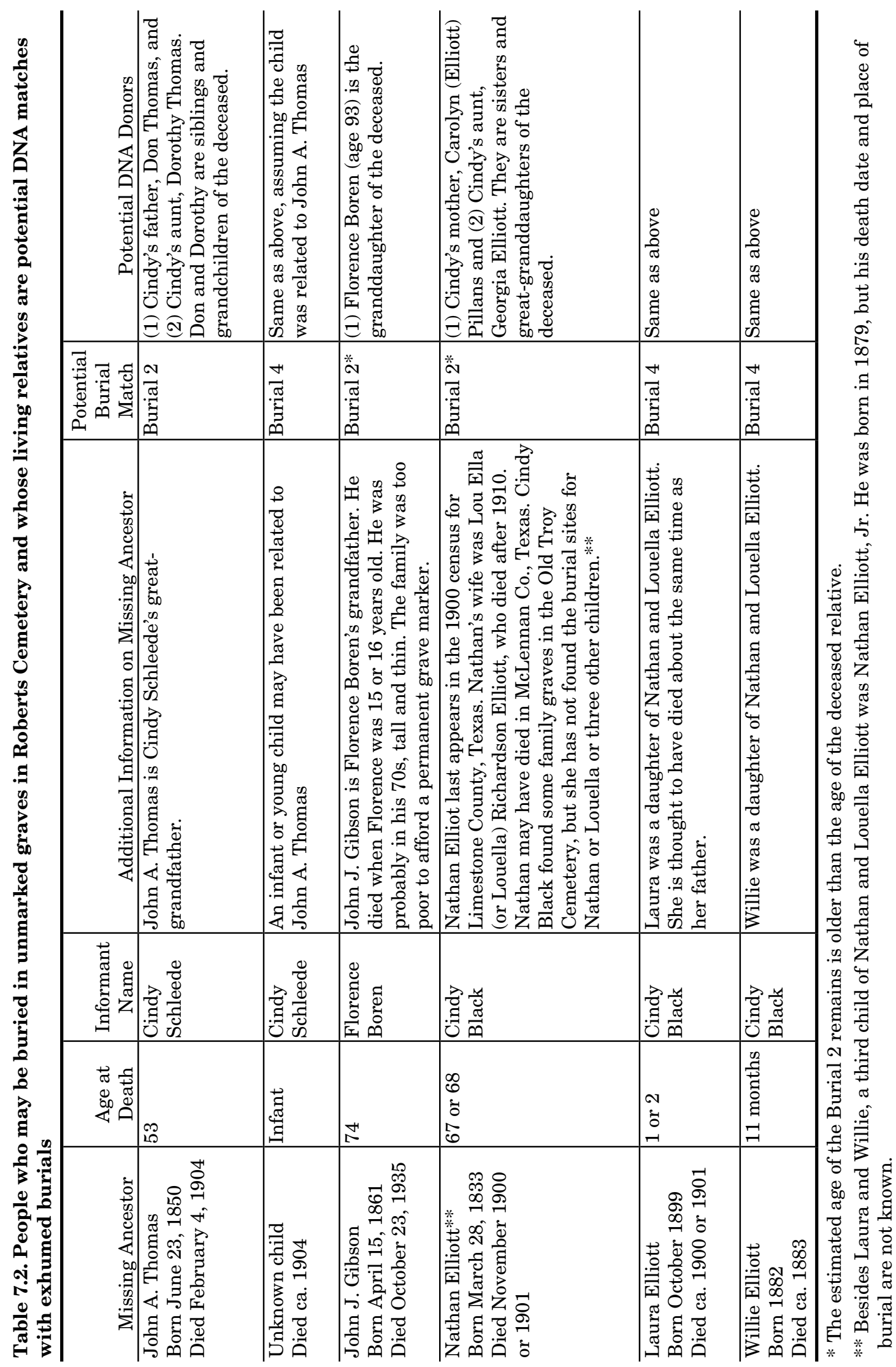


time of their death. This immediately ruled out a match with the child in Burial 4, the young adult (20-27 years old) in Burial 3, and the middle-aged adult (30-40 years old) in Burial 1. Burial 2, however, was a possible match. John Thomas died at age 53, and he is a good age match for Burial 2. Both John Gibson, who died at 74, and Nathan Elliott, who died at 67 or 68, were older than the person in Burial 2, but only by 14 and 7 years respectively. Given the inherent problems with osteological age estimation for older adults, John Gibson and Nathan Elliott were also both considered potential matches for Burial 2.

\section{FIRST ROUND OF DNA TESTING}

It was concluded that submitting samples for a DNA testing using YSTR had a reasonable chance to help these families find lost ancestors. The cost to the state would be minimal, especially when compared with the cost of MtDNA testing. For the YSTR study, each bone/tooth sample would cost $\$ 325$, regardless of the number of attempts the lab has to make in extracting the DNA. Each buccal swab from a living person would cost $\$ 210$. PAI identified five candidates for DNA testing in the three families: siblings Don and Dorothy Thomas; siblings Carolyn (Elliott) Pillans and Georgia Elliott; and Florence (Gibson) Boren. ${ }^{22}$

\section{First Set of DNA Bone Samples}

Before extracting any DNA swab samples from living people, the archeologists had to determine if DNA was preserved and could be extracted from the human remains exhumed from the unmarked graves. LabCorp had recommended that a 2- to 4-inch femur section be submitted for DNA extraction because the likelihood of success is best when using dense, weight-bearing bone. The cortical bone protected inside the enamel of a well-preserved tooth is also a candidate for testing. TxDOT preferred the use of teeth only for the initial samples because it was less destructive (i.e., less bone is destroyed to extract the DNA). So the first round of DNA testing was conducted on teeth

\footnotetext{
22 In an interesting side note, when Cindy Schleede was visiting with Carolyn Pillans and her sister Georgia Elliott during the reburial ceremony (see Chapter 8), they discovered that they are related by marriage.
}

samples from three of the four burials (all the adults). However, no teeth were submitted for the 1.5-year-old child in Burial 4 because the teeth were so small.

For the three adult males in Burials 1, 2 , and 3 , sets of teeth samples (two from each burial) were collected by PAI personnel (Boyd and McWilliams) on March 18, 2012. They were shipped to LabCorp in special styrofoam shipping boxes and sample envelopes provided for this purpose. The goals of this analysis were to determine the level of DNA preservation in Burials 1, 2, and 3, and, if viable DNA were recovered, to determine if there were any genetic relationships between any of these adult males.

LabCorp processed the teeth samples over several months and provided results in September 2012. As stated in the LabCorp reports (see Appendix E), the DNA extractions were not successful (i.e., no readable DNA was preserved) for Burials 3 or 4, but viable DNA was obtained from Burial 2.

\section{Buccal Swab Collection}

To test for potential matches with the DNA obtained from Burial 2, PAI obtained buccal samples to be taken from the living donors. LabCorp provided PAI with five swab test kits that contained long Q-tip-style cotton swabs, self-sealing sample envelopes, rubber gloves, and FedEx mailing envelopes. McWilliams collected the buccal swab samples on December 21, 2012. Each sample envelope was filled in with the donor's name, signature, date, and the sample collector's initials. A digital photograph of each donor was taken and emailed to LabCorp.

\section{Comparison of DNA from Teeth and Buccal Swabs}

LabCorp processed the buccal swabs and ran the comparative analyses to look for genetic relationships between living candidates in three families and Burial 2. As stated in the LabCorp reports (see Appendix E), the tests yielded negative findings for two of the three families and an inconclusive result for the third. A comparison of Florence (Gibson) Boren's DNA to Burial 2 resulted in a statistical ratio of 0.0056 to 1 , which is an extremely low probability that Mrs. Boren is related to the person buried in Burial 2. 
A comparison of DNA from the Thomas siblings with DNA from Burial 2 resulted in the absolute determination, based on numerous key DNA markers, "that the individual labeled Burial Two is not the paternal grandfather of Dorothy Thomas and Don Thomas." The unrelated individuals were informed of the negative results. This finding was disappointing to these people because they have been searching for their missing relatives for many years.

The comparison of DNA from siblings Georgia Elliott and Carolyn (Elliott) Pillans with DNA from Burial 2 was inconclusive. The evidence fails to answer the question of whether the remains from Burial 2 might be the paternal great-grandfather of Elliott and Pillans. The LabCorp results state that:

Using the genetic markers found in the testing, the likelihood ratio for great-grandfather vs. unrelated is 0.3 to 1 . This value is inconclusive as to biological relationship. A more definitive conclusion may be reached if additional relatives are submitted for testing.

From a statistical standpoint, this finding suggests that it is more likely that the people are not related, but the possibility cannot be ruled out. A discussion of this statistical relationship is provided at the end of this chapter.

\section{MEETING TO DISCUSS DNA OPTIONS AND REBURIAL}

At this point, a decision was needed to determine if additional bone samples, specifically long bone segments that might have a better chance of yielding viable DNA, should be taken before reinterring the remains. It was also time to begin planning for the reburial, so TxDOT, PAI, and Roberts Cemetery Association members arranged for a meeting to discuss these topics. The meeting was attended by TxDOT personnel (Mike Rhodes, Jim Abbott, and Ken Roberts), PAI's archeologist (McWilliams), and several Roberts Cemetery Association members (Heroldine Early, Joel Day, Betty Bullis, Wayne Randolph, and J. C. Alston). TxDOT and PAI presented an overview of the excavations, the results of the osteological analyses, and the results of the DNA analysis. Roberts Cemetery
Association members agreed that the removal of a segment of femur bone from Burials 1, 3, and 4 for DNA extraction was appropriate and should be done. Plans for the reburial ceremony were also made at this meeting. The minister was selected, a burial plot was found, and backhoe services were lined up. It was decided that the remains of the four individuals would be buried in one cemetery plot. Finally, arrangements were made for the selection, creation, and installation of a headstone.

\section{SECOND ROUND OF DNA SAMPLING AND ANALYSIS}

Bone samples were taken from three of the four exhumed burials: Burials 1, 3, and 4. Since the tooth sample from Burial 2 had produced viable DNA, no bone sample was necessary. PAI lab manager Robert Thrift collected the long bone samples following sampling instructions providing by LabCorp. The samples were packaged in the special sample envelopes and styrofoam shipping boxes sent by LabCorp.

This second round of DNA testing proved inconclusive. LabCorp was unable to extract any viable DNA from the long bone samples from Burials 1, 3, and 4 .

\section{DISCUSSION OF DNA RESULTS: BURIAL 2 AND THE ELLIOTT FAMILY}

As mentioned earlier, the comparisons of DNA from buccal swabs and Burial 2 yielded inconclusive results in the case of the Elliott family. In this final section, the Elliott family history is considered in more detail to see if it sheds light on the DNA testing results. The following information is based on extensive Elliott family research done by Cindy Black and her aunt, Georgia Elliott.

- Nathan Elliott married his third wife, Louella (also seen Lou Ella) in Cameron, Milam County, in 1875 . The family lived in Old Troy and ran a stagecoach station and a store of some sort. Like many people in the South, they were financially ruined after the Civil War.

- The last census information for Nathan Elliott indicates that in 1900 he was living 
in Prairie Hill, Limestone County. But the family thinks that he may have died in McLennan County.

- Many of Nathan Elliott's relatives were buried in Old Troy Cemetery, which became basically inactive around the turn of the century, right around the time when Elliott died (1900 or 1901). Other Elliott family relatives are buried in Corsicana and Kilgore. After 1900, most local people who died in the Troy area were buried in Roberts Cemetery, which had become the de facto Troy community cemetery (see Chapter 6).

- Nathan Elliott's name does not appear on the burial inventory for Roberts Cemetery (Duke 2004; see Appendix D) or those of the nearby cemeteries of Old Troy (Find a Grave 2013; Todd and Todd 2006), Shiloh (Bell County Survey Committee n.d.; Entrop 2013), or Pleasant View (Badovinac 2001; Bell County Survey Committee n.d.).

- Nathan Elliott's name does not appear in the list of names of people whose death certificates indicate they may be buried in unmarked graves at Roberts Cemetery (see Chapter 6 and Appendix C).

- Cindy Black has located graves of other Elliott family members in the Old Troy Cemetery, and the online burial inventory lists 11 Elliotts buried there (Find a Grave 2013). But she has not located the gravesites for Nathan Elliott, his wife, and two daughters. Nathan's wife, Louella Richardson Elliott, died ca. 1889-1901, and the couple had two daughters who died very young. Their daughter Willie was born in 1882 and died when she was 11 months old. Laura was born in 1899 and may have died around the same time as her father, in 1900 or 1901.

- Nathan Elliott died at age 67 or 68 , which makes him at least 7 or 8 years older than the male in Burial 2, whose age is estimated to be $45-60$ years old. However, because age estimates based on human skeletal remains are not always precise, especially in older people, the difference of 7-8 years does not rule out the possibility that Burial 2 remains are those of Nathan Elliott.

Does this historical evidence fit with the DNA results? It provides no definitive answer to the question of where Nathan Elliott, his wife, and two young daughters might be buried. Because of their family history and ties to the Troy community and Old Troy Cemetery, it is certainly possible that Nathan Elliott and his family members were buried at Roberts Cemetery, but no documents or oral history confirm this. The DNA analysis indicates that the probability that the Burial 2 remains are those of Nathan Elliott, the great-grandfather of the Georgia Elliott and Carolyn (Elliott) Pillans, is 0.3 to 1 . These siblings are three generational steps removed from Nathan Elliott, and this gap is considered significant, biologically speaking. The DNA testing result does not prove or disprove a genetic relationship between the Elliott sisters and Burial 2. 



\section{PROJECT SUMMARY, REINTERMENT, AND CONCLUDING REMARKS}

In 2011, TxDOT contracted with the James Construction Group, L.L.C., to construct a series of improvements along Interstate Highway 35 in Bell, Falls, and McLennan Counties. As part of the planning process for this project, TxDOT conducted an archeological evaluation of the corridor, followed by a preliminary survey of several cemetery frontages in Bell and Falls County (Hatfield et al. 2009). This survey indicated that there was cause for concern at Roberts Cemetery, situated on the south bank of Big Elm Creek on the western side of Interstate Highway 35. Because the area to be affected was covered with concrete, fill, and an active southbound frontage road, no archeological work was possible until the highway project was initiated and the frontage road was closed. This report describes the process of prospecting for burials in the stateowned right of way fronting Roberts Cemetery, the archeological excavation and recovery of remains from four unmarked graves, the analyses of the remains from these graves (including human bones, mortuary hardware, and personal items), and the attempts to identify the possible relatives through historical research, public outreach, and comparative DNA analyses.

\section{SUMMARY OF THE EXCAVATED BURIALS}

The four unmarked graves that were exhumed in 2012 contained the remains of three adult males and one child, but these individual are not a representative sample of the local central Texas population or even of the population within the cemetery itself. Interpretation of the material remains in the ground is further complicated by postdepositional processes that alter the evidence that survives. Nevertheless, the bioarcheological data obtained during this project are important and contribute to a growing body of data from historic cemetery investigations across the United States. Archeological mortuary evidence and personal effects interred with individuals offer a snapshot in time that represents the interplay of social, philosophical, and religious beliefs tempered by particular historical circumstances (Carr 1995).

The three adults exhumed from Roberts Cemetery were of different ages at death: the youngest being 20-27 years old (Burial 3); one being $30-40$ years old (Burial 1), and the oldest being 45-60 years old (Burial 2). The fourth burial is that of an infant about 1.5 years old (Burial 4). All four were typical Christian-tradition burials in wooden caskets oriented with the head to the west.

The mortuary hardware described in Chapter 4 provides some chronological information regarding the deaths and interments of these four individuals. The hardware indicates that all four burials date after ca. 1895, based primarily on the use of wire nails in casket construction, and the patented Type 2 casket handles in Burial 1 date this interment after 1910 (see Table 4.2). Collectively, the casket hardware styles also suggest that all three of the adult burials had occurred before 1940 . The clothing items provide additional evidence that dates two of the burials after the turn of the century. The patented styles of safety pin and clothing snaps indicate that that Burial 3 postdates 1900 and Burial 4 postdates 1902 (see Table 3.3).

The combined chronological evidence, from mortuary hardware and personal items, 
indicates the following as the most likely dates of interment:

$\begin{array}{ll}\text { Burial 1 } & 1910 \text { to late } 1930 \mathrm{~s} \\ \text { Burial 2 } & 1895 \text { to late } 1930 \mathrm{~s} \\ \text { Burial 3 } & 1900 \text { to late } 1930 \mathrm{~s} \\ \text { Burial 4 } & 1902 \text { to late } 1930 \mathrm{~s}\end{array}$

Based on this evidence, three of the interments definitely occurred in the early twentiethcentury, while Burial 2 could date to the last half decade of the nineteenth century. Based on the similarities in the casket hardware, however, Burial 2 likely occurred in the early twentieth century.

The osteological evidence derived from an analysis of the skeletal remains (see Chapter 5) reveals no bone anomalies, trauma, or pathological evidence that would indicate how these people might have died. However, the various ages at death fits the general pattern of latenineteenth-century mortality in Texas. The burial of a young child is certainly not unusual since infant mortality rates were quite high in the late-nineteenth- and early-twentieth-century Texas. This child could have died from a wide range of diseases or accidents that were common in Troy and Bell County more than a century ago (see Table 5.5), many of which are preventable today. The infant was buried in a cloth or a gown held together with one button and several safety pins. It was wearing a bonnet fastened with metal snaps and probably had with a floral arrangement inside the casket. During the Victorian era, it was common for child burials to be covered in flowers. An 1886 Harper's Bazaar article on appropriate mourning behavior and funeral etiquette recommended:

In dressing the remains for the grave, those of a man are usually "clad in his habit as he lived." For a woman, tastes differ; a white robe and cap, not necessarily shroud-like, are decidedly unexceptionable. For young persons and children, white cashmere robes and flowers are always most appropriate (Harper's Bazaar 1886:250; Victoriana 2012).

The remains in Burial 1 display evidence of hypoplasia, indicating that this individual suffered from bouts of childhood stress. His well- developed muscle attachments indicate that he was accustomed to hard labor. In contrast, the older man in Burial 2 may have come from a higher social status. He was buried in more elaborate clothing (wearing an eyelet-collared shirt and cuff links), his minimal muscle development indicates that he did not do hard labor, and he had psoriatic arthritis (a condition rarely seen in historic archeological populations) that may have caused partial atrophy of his upper arms.

The four burials were all clustered in the northeast corner of the Roberts Cemetery, which is the area of the cemetery where the oldest burials occurred. Since all four date before the late 1930s, they are among the oldest burials in Roberts Cemetery. Roberts Cemetery contains 633 marked burials dating from 1886 through 2004 , and 21 percent of all the known burials occurred before 1940 (see Figure 6.1 and Appendix D). ${ }^{23}$

Because the four exhumed burials are among the easternmost graves in Roberts cemetery, they have twice been affected by road construction activities. They were covered over during road improvements in the 1950s, when State Highway 81 was expanded into Interstate Highway 35, suggesting that the graves were not marked or their grave markers had disappeared at least 60 years ago. These burials were impacted once again during the current interstate highway expansion project that led to their exhumation in 2012 and reinterment in 2013.

\section{SUMMARY OF THE DNA RESEARCH}

Attempts to establish the identity of the four individuals recovered during the project were unsuccessful. Preserved DNA was extracted from Burial 2, but no viable DNA was recovered from Burials 1, 2, or 4. Buccal swab DNA samples taken from five people in three families reveal no conclusive matches with the DNA profile of the 45-60 year old male in Burial 2. Members of the Thomas and Gibson

\footnotetext{
23 It must also be noted that other unmarked graves probably exist in Roberts Cemetery. Archeological experiences at many historic cemeteries in Texas and across the United States teach us that older cemeteries commonly contain many unmarked graves, and that the unknown graves tend to be the older burials rather than younger ones.
} 
families are not related, and DNA comparison of the two Elliott siblings and the Burial 2 remains is inconclusive.

LabCorp will retain the DNA samples (buccal swabs and the small amounts of bone remaining) in perpetuity, along with the DNA analysis data and comparative profiles. The bone DNA data for Burial 2 will be accessible to any other people looking for an older male relative who might have been buried at Roberts Cemetery. If new and better DNA extraction methods become available in the future, additional DNA testing could be conducted on the bones from Burials 1, 3, and 4 .

\section{REBURIAL CEREMONY}

On March 26, 2013, all four sets of unidentified human remains, associated mortuary hardware, and personal items were reinterred at Roberts Cemetery. Larry Granfor (Associate Pastor at Grace Baptist Church in Temple, Texas) officiated over the short reburial ceremony (Figure 8.1). The service was attended by the members of the Roberts Cemetery Association, a Troy city official, several of the individuals who were looking for ancestors possibly buried in the cemetery, representatives of Prewitt and Associates, Inc., representatives of TxDOT's Waco District and Environmental Affairs Division, and members of the local media. Joseph Bedrich, who works at Roberts and other surrounding cemeteries, provided backhoe services for the reburial.

The remains from each unmarked grave were placed in separate wooden reburial boxes, and all four boxes were placed in an excavated shaft within a single grave plot located in the northeast corner of the cemetery. The reburial plot was not far from their original gravesites. Within the new grave shaft, Burial 1 was placed in the northeast quadrant, Burial 2 was in the southeast quadrant, Burial 3 was in the northwest quadrant, and Burial 4 was in the southwest quadrant.

In the days following the ceremony, McWilliams arranged for a headstone to be erected at the gravesite. This was coordinated by Mrs. Heroldine Early, president of the Roberts Cemetery Association, and the headstone was donated by Phipps Memorial of Waco. The headstone was installed at the reburial plot on July 26, 2013. It reads:

$$
\begin{array}{cc}
\text { Unidentified Male } & \text { Unidentified Male } \\
\text { Unidentified Male } & \text { Unidentified Child } \\
\text { Removed from TxDOT ROW September } 2012 \\
\text { Reinterred March 26, 2013 } \\
\text { REST IN PEACE }
\end{array}
$$

\section{CONCLUDING REMARKS}

The main objective of the work at Roberts Cemetery was to locate and remove any unmarked burials from the TxDOT right of way and reinter them elsewhere in the cemetery in a responsible and respectful manner. We believe that goal was accomplished. Although it is unfortunate that we were unable to identify any of the individuals interred in the unmarked graves through historic research and DNA testing, the archived bones from Burials 1, 3, and 4 and the DNA profile associated with Burial 2 make such identification possible in the future. 

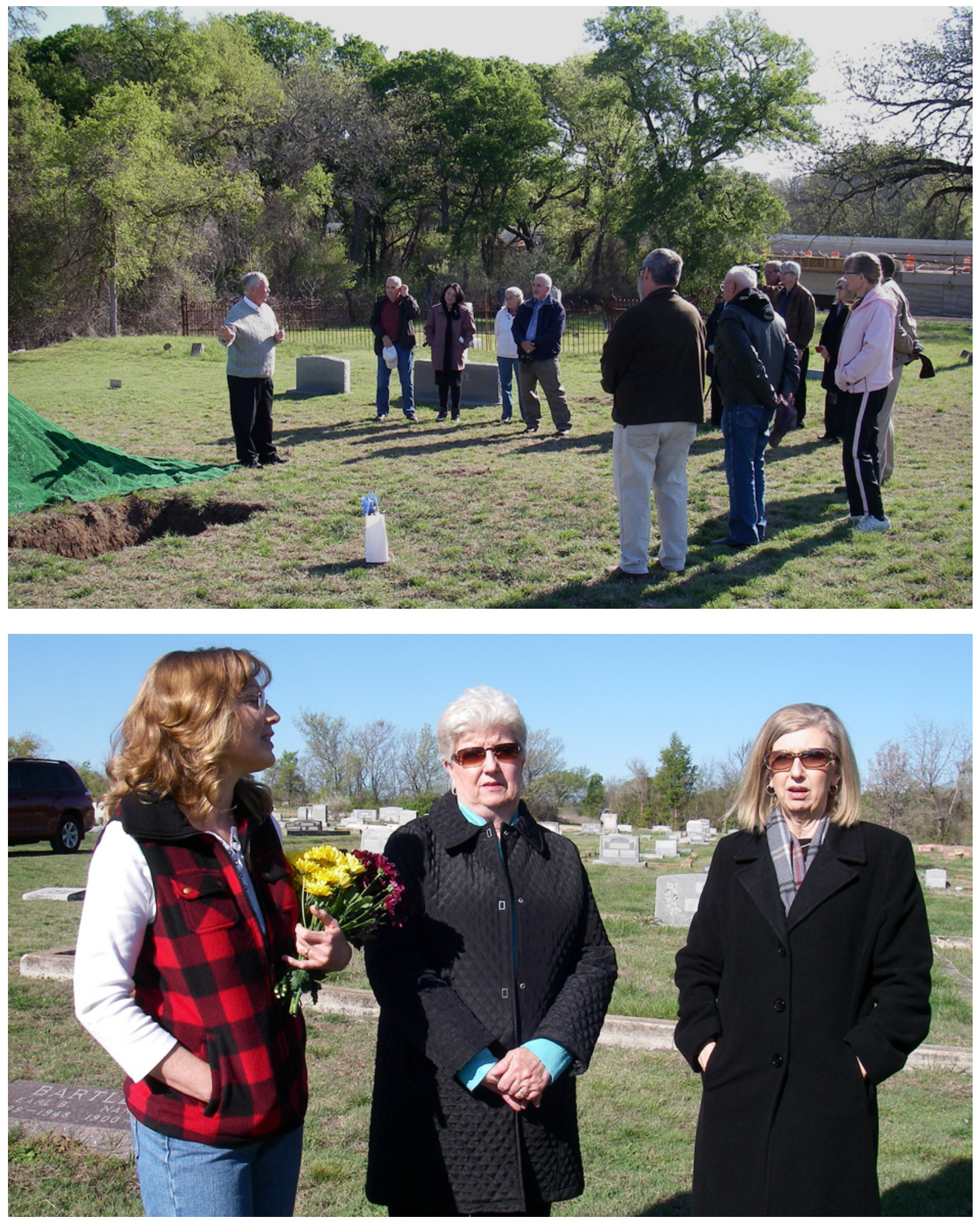

Figure 8.1. Photographs of the reburial ceremony at Roberts Cemetery on March 26, 2013. (Top) Minister Larry Granfor conducting the reburial service. Note that the newly constructed bridge for the southbound frontage road, in the background on the right, is the area where the unmarked graves were found. (Bottom) Attending the ceremony were three people with missing ancestors who may be buried in unmarked graves at Roberts Cemetery. From left to right, they are Cindy (Thomas) Schleede, Carolyn (Elliott) Pillans, and Georgia Elliott. 


\section{REFERENCES CITED}

Adams, William Hampton

2002 Machine Cut Nails and Wire Nails: American Production and Use for Dating 19th-Century and Early-20th-Century Sites. Historical Archaeology 36(4):66-88.

Archaeological Services, Inc.

1992 Archaeological Mitigation of the Cheyne Cemetery, Part Lot 14, Concession 1, E.H.S., Toronto Township, City of Brampton, Regional Municipality of Peel. Archaeological Services, Inc., Toronto, Ontario.

ca. 2000 Archaeological Report on the Salvage Recovery of Human Remains at Trinity Anglican Church Cemetery, 79 Victoria Street, Town of Aurora, Regional Municipality of York, Ontario. Archaeological Services, Inc., Toronto.

Archaeological Services, Inc., and Gary Warrick 2005 Archaeological Investigation of the Pea Hill Site, City of Hamilton. Archaeological Services, Inc., Burlington, Ontario.

Atkinson, J. R., and Kenneth R. Turner

1987 The Blackburn Cemetery: An Abandoned Burial Site on the Old Natchez Trace in Maury County, Tennessee. Southeast Archaeological Center, National Park Service, Tallahassee, Florida.

Atz, Leiellen

2005 Crawford Cemetery Relocation, Gwinnett County, Georgia. Brockington and Associates, Inc., Atlanta, Georgia.

Atz, Leiellen, and Wendy Weaver

2006 Relocation of the Roughton/Browne Cemetery, Sandersuille, Washington County, Georgia. Project FLF 540(29). Brockington and Associates, Inc., Atlanta, Georgia.
Aufderheide, Arthur C., and C. Rodriguez-Martin 1998 The Cambridge Encyclopedia of Human Paleopathology. University of Cambridge Press, Cambridge, United Kingdom.

Baackes, Michael

1896 The History of the American Wire Nail Industry. The Iron Age 57:105-106.

Badovinac, Rose Mary (submitter)

2001 Pleasant View Cemetery, Bell County, Texas. USGENWEB. Electronic document, http://files.usgwarchives.net/tx/bell/cemetery/pleasant.txt, accessed January 15 2013.

Bailey, Ralph, Jr., Gwendolyn Moore, Lenna Nash, and Charles F. Philips, Jr.

2009 Relocation of a Portion of Hampstead Cemetery, 46 Reid Street, Charleston, South Carolina. Brockington and Associates, Inc., Charleston, South Carolina.

Baker, Scott J., George W. Gill, and David A. Kieffer 1990 Race and Sex Determination from the Intercondylar Notch of the Distal Femur. In Skeletal Attribution of Race: Methods for Forensic Anthropology, edited by George W. Gill and Stanley Rhine, pp. 9196. Anthropological Papers No. 4. Maxwell Museum of Anthropology, University of New Mexico, Albuquerque.

Barnes, V. E.

1970 Geologic Atlas of Texas, Waco Sheet (Lloyd William Stephenson Memorial Edition). Bureau of Economic Geology, University of Texas at Austin.

Bass, William M.

2005 Human Osteology: A Laboratory and Field Manual, 5th ed. Special Publication No. 2. Missouri Archaeological Society, Columbia. 
Bastis, Kristen

2006 Health, Wealth, and Available Material: The Bioarchaeology of the Bulkeley Tomb in Colchester, Connecticut. M.A. thesis, University of Connecticut, Storrs-Mansfield.

Beaty, John, and Leiellen Atz

2002 Relocation of an Abandoned Cemetery in Augusta, Richmond County, Georgia. Project-NH-117-1(114). Brockington and Associates, Inc., Atlanta, Georgia.

Beck, Lane, John McClelland, and J. Homer Thiel 2005 Excavation and Analysis of Burial 12 from the Court Street Cemetery, AZ BB:13:156 (ASM), Tucson, Pima County, Arizona. In Project Report No. 05-172. Desert Archaeology, Inc., Tucson.

Bell County

1932 Right of Way Map of State Highway No. (2)

US 81. F.A.P. No. 40-Rev. From Sta. 402+78 to Falls County Line. Office of the Resident Engineer, Waco, Texas.

Bell County Clerk's Office

Death Certificates

Deed Records

Marriage Records

Bell County Historical Commission

1988 The Story of Bell County, Vols. I and II. Eakin Press, Bell County, Texas.

Bell County Historical Survey Committee

n.d. Bell County Cemetery Records. 2 vols. Bell County Historical Survey Committee in cooperation with the Agnes Woodson Chapter Daughters of the American Revolution. Published ca. 1970s.

Bell County Tax Appraisal District

Bell County Property ID: 18897. Legal Description: AO385BC T Hughes, Shiloh Cemetery, Acres 2.0.

Bell County Property ID: 118245. Legal Description: AO385BC T Hughes, 58, Cemetery, Acres 4.57.

Belton Journal-Reporter

1899-1917 Microfilm on file at the Briscoe Center for American History, Austin, Texas.

Benson, Donna L.

1983 A Taxonomy for Square Cut Nails. In The Conference on Historic Site Archaeology, edited by S. South, pp. 123-152. University of South Carolina, Columbia.

Berg, Richard E.

1990 An Investigation of Burials at the Scisson Family Cemetery in Gregory County, South Dakota. South Dakota Archaeology 14(36-92).

Beynon (Landers), Diane E.

1989 Remember Me As You Pass By: Excavation of the Voegtly Cemetery. A 19th Century German-American Churchyard in Pittsburgh, Pennsylvania. 3 vols. GAI Consultants, Inc., Monroeville, Pennsylvania.

Bien, Laura

2012 "In theArchives:Victorian Era Death Photos: 'Secure the shadow before it fades...", The Ann Arbor Chronicle, July 14, 2010. Electronic document, http://an$\mathrm{n}$ a r bor chroni cle.com/2010/ 07/14/in-the-archives-victorian-era-deathphotos, accessed January 2, 2013.

Billings, John S

1885 Report on the Mortality and Vital Statistics of the United States as Returned at the Tenth Census (June 1, 1880), Part I. Department of the Interior, Census Office, Government Printing Office, Washington, D.C.

Bird, M. Catherine

2000 Final Report: Phase III Mitigation of the Burying Ground at Vandaworker's Corners (11-L-572), Village of Deer Park, Ela Township, Lake County, Illinois. Cultural Resource Management Report No. 811. Midwest Archaeological Research Services, Inc., Harvard, Illinois.

Bird, M. Catherine, Anne L. Grauer, and Jenna Tedrick Kuttruff

2003 Data Recovery at the Thurston Cemetery within the County Right-of-Way, York Township, DuPage County, Illinois. Midwest Archaeological Research Services, Inc., Harvard, Illinois.

Black, Sue, and Louise Scheuer

1996 Age Changes in the Clavicle: From the Early Neonatal Period to Skeletal Maturity. The International Journal of Osteoarchaeology $6: 425-434$. 
Blakely, Robert L., and Lane A. Beck

1982 Bioarchaeology in the Urban Context. In Archaeology of Urban America: The Search for Pattern and Process, edited by R.S. Dickens, Jr., pp. 175-207. Academic Press, New York.

Boden, G.

1900 Safety Pin. Patent No. 643,261.

Application filed February 21, 1898.

Patented February 13, 1900. Electronic document, http://www.google.com/patents ?id=heVjAAAAEBAJ \&pg=PA1\&dq= snap+fastener+clothing\&source=gbs_selected_pages\&cad $=2 \# \mathrm{v}=$ onepage $\& \mathrm{q} \& \mathrm{f}=\mathrm{fa}$ lse, accessed January 17, 2013.

Boen, R. M., and Candy Taft

$199939 M N 7$ Howard Cemetery, Accession Number 99-103. Draft Burial Report \#1999-11. South Dakota State Historical Society, Archaeological Research Center, Rapid City, South Dakota.

Boudreaux, Jennifer R.

n.d. The Mortuary Analysis of a Historical Cemetery: St. Joseph's (LA 49791). Ms. on file with author.

Bowden, Bradley

1999 Data Recovery of an Unmarked Cemetery Within Site 44CF568 at the Defense Supply Center Richmond, Chesterfield County, Virginia. Gray \& Pape, Inc., Richmond, Virginia.

Bradle, Michael R., James S. Belew, and Susan Maki Wallace

2002 Archaeological Survey of the Connally I.S.D. School Tract and Cemetery Relocation, McLennan County, Texas. Report of Investigations Number 26. American Archaeology Group, Inc., Lampasas, Texas.

Braley, Chad O.

1992 Archaeological and Archival Investigations at the Deepstep A.M.E. Church Cemetery, Washington County, Georgia. Southeastern Archaeological Services, Inc., Athens, Georgia.

Braley, C. O., and William G. Moffat

1995 Archaeological and Historical Investigations of Redfield Cemetery, Jones County, Georgia. Vol. 1. Southeastern Archaeological Services, Inc., Athens, Georgia.
Brauner, David R., and Paul Christy Jenkins

1980 Archeological Recovery of Historic Burials within the Applegate Lake Project Area, Jackson County, Oregon. Department of Anthropology, Oregon State University, Corvallis, Oregon.

Brock, J., and Steven J. Schwartz

1991 A Little Slice of Heaven: Investigations at Rincon Cemetery, Prado Basin, California. Historical Archaeology 25(3):78-90.

Broehm, C. J., Douglas K. Boyd, and Martha Doty Freeman

2004 Archaeological Excavation and Reburial of Historic Graves in the Oscar Abstein Cemetery (41HR976), Harris County, Texas. Report 64, Archaeological Studies Program, Environmental Affairs Division, Texas Department of Transportation. Reports of Investigation No. 140, Prewitt and Associates, Inc., Austin, Texas.

Bromberg, Francine W., Steven J. Shepard, Barbara H. Magid, Pamela J. Cressey, Timothy Dennée, and Bernard K. Means

2000 "To Find Rest from All Trouble": The Archaeology of the Quaker Burying Ground, Alexandria, Virginia. Alexandria Archaeology, Office of Historic Alexandria, Alexandria, Virginia.

Brooks, S. T., and J. M. Suchey

1990 Skeletal Age Determination Based on the Os Pubis: a Comparison of the AcsádiNemeskéri and Suchey-Brooks Methods. Human Evolution 5:227-238.

Buchner, C. A., Emanuel Breitburg, Charles Williams, and Elizabeth A. Williams

1999 At Rest, Again: The Ridley Graveyard (40WM208) Archaeological Relocation Project, Williamson County, Tennessee. Panamerican Consultants, Inc., Memphis, Tennessee.

Buikstra, Jane, Jodie A. O'Gorman, and Cynthia Sutton

2000 Never Anything So Solemn: An Archeological, Biological, and Historical Investigation of the Nineteenth-Century Grafton Cemetery. Kampsville Studies in Archeology and History No. 3. Center for American Archeology, Kampsville, Illinois. 
Buikstra, Jane, and Douglas Ubelaker 1994 Standards for Data Collection from Human Skeletal Remains. Arkansas Archeological Survey, Fayetteville.

Burnston, Sharon Ann, and Ronald A. Thomas 1981 Archaeological Data Recovery at Catoctin Furnace Cemetery, Frederick County, Maryland. Mid-Atlantic Archaeological Research, Inc., Newark, Delaware.

Burton, Jeffery F., Jeremy D. Haines, and Mary M. Farrell

2001 “I Rei To": Archaeological Investigations at the Manzanar Relocation Center Cemetery, ManzanarNational Historic Site, California. Publications in Anthropology 79. Western Archeological and Conservation Center, National Park Service, U.S. Department of the Interior, Washington, D.C.

Bybee, Alexandra D.

2002 Bioanthropologial Investigations of the Reynolds Cemetery (46KA349) in Kanawha County, West Virginia. Contract Publications Series WV01-111. Cultural Resource Analysts, Inc., Hurricane, West Virginia.

2003a Bioanthropological Investigations of the Burning Spring Branch Cemetery (46KA142) in Kanawha County, West Virginia. Cultural Resource Analysts, Inc., Hurricane, West Virginia.

2003b Bioarchaeological Investigations of Unmarked Graves at the Samuel Robinson and Upper Prater Cemeteries (15PI190 and 15PI191), Pike County, Kentucky (Item No. 12-263.00). Cultural Resource Analysts, Inc., Lexington, Kentucky.

2003c Bioanthropological Investigations of a 19th Century Cemetery (15CP61) in Campbell County, Kentucky. Cultural Resource Analysts, Inc., Lexington, Kentucky.

2004 Old Branham (15Fd94): Bioarchaeological Investigations of an Historic Cemetery, Floyd County, Kentucky (Item No. 12301.00). Cultural Resources Analysts, Inc., Lexington, Kentucky.

2007a Bioarchaeological Investigations of the Evans Cemetery (46MD62), McDowell County, West Virginia. Contract Publication Series WV07-03. Cultural Resource Analysts, Inc., Hurricane, West Virginia. 2007b Bioarchaeological Investigations of the Alderson-Jackson Cemetery (15JS174), Jessamine County, Kentucky. Cultural Resource Analysts, Inc., Lexington, Kentucky.

2007c Bioarchaeological Investigations of an Unmarked Grave at the Rudy Cemetery (15JF675), Jefferson County, Kentucky (Item No. 5-28.10). Cultural Resource Analysts, Inc., Lexington, Kentucky.

2009 Bioarchaeological Investigations of an African-American Cemetery (15SC292) at the Ward Hall Development Property, Georgetown, Scott County, Kentucky. Cultural Resource Analysts, Inc., Lexington, Kentucky.

2010 Bioarchaeological Investigations of the Gee-Cabbage Cemetery (12W595), Hart Township, Warrick County, Indiana. Cultural Resource Analysts, Inc., Lexington, Kentucky.

2011a Bioarchaeological Investigations of the Bennett Cemetery (15OH176) for the Proposed Equality Boot Mine in Ohio County, Kentucky (Permit Application Number 892-0110). Cultural Resource Analysts, Inc., Lexington, Kentucky.

2011b Bioarchaeological Investigations of the Douthitt Cemetery (12SU825), Jefferson Township, Sullivan County, Indiana. Cultural Resource Analysts, Inc., Lexington, Kentucky.

Bybee, Alexandra D., and Sarah E. Hope

2011 Bioarchaeological Investigations of the Bowling Cemetery (11WH265), Hawthorne Township, White County, Illinois. 3 vols. Cultural Resource Analyst, Inc., Lexington, Kentucky.

Bybee, Alexandra D., and Michael Richmond 2003 Data Recovery at a Nineteenth Century Cemetery (15MM137) in Montgomery County, Kentucky (Item No. 7-320.00). Cultural Resource Analysts, Inc., Lexington, Kentucky.

Cande, Kathleen

1995 The Ozarks as Destination: Phase III Archeological Investigations at the Lambert Farmstead (3CW674) and Phase II Testing at the Dement Farmstead and Cemetery (3CW685), Crawford County, 
Arkansas. Arkansas Archeological Survey, Fayetteville.

Capasso, L., K. A. R. Kennedy, and C. A. Wilczak 1999 Atlas of Occupational Markers on Human Remains, 1st ed. Journal of Paleontology Monographic Publication Edigrafital S.p.A., Teramo, Italy.

Carr, Christopher

1995 Mortuary Practices: Their Social, Philosophical-Religious, Circumstantial, and Physical Determinants. Journal of Archaeological Method and Theory 2(2):105-200.

Centers for Disease Control and Prevention

2013 Death Rates by 10-Year Age Groups: United States and Each State, 1999-2007.

National Vital Statistics System. Centers for Disease Control and Prevention. Electronic document, http://www.cdc. gov/nchs/nvss/mortality/gmwk23r.htm, accessed March 21, 2013.

Cobb, Dawn E.

1999 “...Such a Lonely Place..”:An Archaeological and Osteological Investigation of the Brunson-Sisson Cemetery (11WI874), Will County, Illinois. Technical Report No. 981264-26. Quarternary Studies Program, Illinois State Museum, Springfield.

Cobb, Dawn E., Michael D. Wiant, and Melinda L. Carter

2000 Human Skeletal Remains Protection Act Investigations Number 9: A NineteenthCentury Cemetery on Kaskaskia Island, 11R675, Randolph County, Illinois. In Quaternary Studies Program Technical Report No.99-000-32. Illinois State Museum, Springfield.

Condon, Cynthia G., Joy L. Becker, Heather J. H. Edgar, James M. Davidson, Juerna R. Hoffman, Patricia Kalima, Daniel Kysar, Susan Moorehead, Victoria M. Owens, and Keith Condon

1998 Freedman's Cemetery: Site 41DL316, Dallas, Texas, Assessments of Sex, Age at Death, Stature, and Date of Interment for Excavated Burials. Report No. 9. Archaeology Studies Program, Environmental Affairs Division, Texas Department of Transportation, Austin.

Connolly, Thomas J., Christopher L. Ruiz, Jeanne McLaughlin, Guy L. Tasa, and Elizabeth Kallenbach
2008 Rediscovery and Recovery of the Stevens Family Pioneer Cemetery at River Bend, Springfield, Oregon. Museum Report 2008058. Museum of Natural and Cultural History and State Museum of Anthropology, University of Oregon, Eugene.

2010 The Archaeology of a Pioneer Family Cemetery in Western Oregon, 1854-1879. Historical Archaeology 44(4):28-45.

Cooper, Judy H., Angela L. Tine, Marsha Prior, Charles M. Clow, David Shanabrook, and Ed Salo

2000 Cultural Resources and Bioarchaeological Investigations at the Dallas Convention Center and Pioneer Cemetery, Dallas, Texas. Miscellaneous Reports of Investigations No. 205. Geo-Marine, Inc., Plano, Texas.

Costello, Julia G.

1991 Excavation of Burials from the Madam Felix/Hettick Cemetery, CA-CAL-1122H. Foothill Resource Associates, Mokelumne Hill, California.

Cox, Margaret, and Simon Mays

2002 Human Osteology in Archaeology and Forensic Science. Cambridge University Press, New York.

Cox, R.

2012 "Construction Halted After Unmarked Graves Found Near I-35 Expansion." News report on KWTX-TV, September 5, 2012. Electronic document, http:// www.kwtx.com/home/headlines/ 168646186.html.

Craig, Joseph, and Clark Spencer Larsen

1993a Life and Death on the Illinois Prairie: Archaeological and Osteological Investigations at the Cross Cemetery, Springfield, Illinois. Hanson Engineers, Inc., Springfield, Illinois.

1993b Archaeological and Osteological Investigations at the Cross Cemetery, Sangamon County, Illinois. Hanson Engineers, Inc, Springfield, Illinois.

Crawford, Kristine

2003 Archaeological Investigations of St. Peter's Anglican Church Property, 240 College Street, Cobourg, County of Northumberland, Ontario. Archaeological Services, Inc., Toronto. 
Crawford, Kristine, Alexis Hutcheson, Eva MacDonald, Brian Nahri, David Robertson, and Ronald Williamson

2008 Ontario Cemeteries Act Site Investigation, The Old Don Jail Burial Area, Proposed Draft Plan of Subdivision, Part of Lot 15, Concession 1 From the Bay, Geographic Township of York and Part of Block U, Don Improvement Plan, City of Toronto. Archaeological Services, Inc., Toronto.

Crist, Thomas A. J., William H. Henry, Joe W. Joseph, Reginald H. Pitts, Wade P. Catts, Alex Caton, Arthur Washburn, and Sean Norris

2000 With Death Came Liberty:The Archaeology and History of the Sam Goode Cemetery, Mecklenburg County, Virginia. In New South Associates Technical Report, No. 747. New South Associates, Stone Mountain, Georgia.

Crist, Thomas A. J., Reginald H. Pitts, Arthur Washburn, John P. McCarthy, and Daniel G. Roberts

1996 "A Distinct Church of the Lord Jesus": The History, Archaeology, and Physical Anthropology of the Tenth Street First African Baptist Church Cemetery, Philadelphia, Pennsylvania. Site Number 36PH72.Vine Expressway (I-676), Letter Report 67045. John Milner Associates, Inc., Philadelphia, Pennsylvania.

Crow, Michael S.

2004 Mortuary Practice in Sociohistorical and Archaeological Contexts: Texas, 18211870. M.A. thesis. Texas A\&M University, College Station.

Cultural Resources, Inc.

2002 Results of Excavation of a Human Burial at Site 44SK481 Located at the Former Nansemond Ordnance Station, Suffolk, Virginia. Cultural Resources, Inc., Fredericksburg, Virginia.

Davidson, James M.

1999 Freedman's Cemetery (1869-1907): A Chronological Reconstruction of an Excavated African-American Burial Ground, Dallas, Texas. M.A. thesis, Department of Anthropology, University of Arkansas, Fayetteville.

2004 Mediating Race and Class Through the Death Experience: Power Relations and Resistance Strategies of an AfricanAmerican Community, Dallas, Texas
(1869-1907). Ph.D. dissertation, The University of Texas at Austin. University Microfilm International, Ann Arbor, Michigan.

2006 Material Culture, Chronology, and Socioeconomics. In Two Historic Cemeteries in Crawford County, Arkansas, edited by R. C. Mainfort, Jr., and James M. Davidson, pp. 97-218. Arkansas Archeological Research Series No.62. Arkansas Archeological Survey, Fayetteville.

DeCunzo, LuAnn., Angela Hoseth, Jay Hodny, JoAnn E. Jamison, Wade P. Catts, and David C. Bachman

1992 Final Archaeological Investigations at the John Darrach Store Site, Delaware Route 6-Woodland Beach Road, Smyrna Section, Delaware Route 1 Corridor, Kent County, Delaware. Delaware Department of Transportation Archaeology Series No. 93. University of Delaware, Department of Anthropology, Center for Archaeological Research.

Demel, Scott J., M. Catherine Bird, Rochelle, Lurie, Jenna Tedrick Kuttruff, Anne Grauer, and Carrie Koster-Horan

1993 Report on the Excavation of $8 L L 1758$ as Contained Within the Proposed U.S. 41 Business Right-of-Way On Fowler Street Between First and Second Streets in the City of Fort Myers, Lee County, Florida. Archaeological Consultants, Inc., Sarasota, Florida. Prepared for Florida Department of Transportation, District One, Bartow, Florida.

2000 Exhumation of Two Burials Exposed During Infrastructure Improvements Along Main Street Cemetery in Downtown Downers Grove, DuPage County, Illinois. In Cultural Resources Management Report No. 827. Midwest Archaeological Research Services, Inc., Harvard, Illinois. Deming, J., Marion M. Almy, Janet S. Matthews, and Steven H. Koski

Dockall, Helen Danzeiser, Douglas K. Boyd, Martha Doty Freeman, Rolando L. Garza, Kevin E. Stork, Karl W. Kibler, and Joan E. Baker

1996 Confederate Veterans At Rest:Archaeological and Bioarchaeological Investigations at the Texas State Cemetery, Travis County, Texas. Reports of Investigations No. 107. Prewitt and Associates, Inc., Austin, Texas. 
Dockall, Helen Danzeiser, Joseph F. Powell, and D. Gentry Steele

1996 Home Hereafter: An Archaeological and Bioarchaeological Analysis of an Historic African-American Cemetery (41GV125). Reports of Investigations No. 5. Center for Environmental Archaeology, Texas A\&M University, College Station.

Dowse, W. B. H.

1902 Fastener. Patent No. 707,054. Application filed June 6, 1900. Patented August 12, 1902. Google Patents Online. Electronic document, http://www.google.com/patents ?id=heVjAAAAEBAJ\&pg=

PA1\&dq=snap+fastener+clothing\&sourc e=gbs_selected_pages\&cad $=2 \# \mathrm{v}=$ onepage $\& q \& f=$ false, accessed January 17, 2013.

Duke, Mary

2004 Roberts Cemetery, Bell County Texas. USGENWEB. Electronic document, http://files.usgwarchives. org/tx/bell/cemetery/roberts2.txt, accessed September 17, 2012.

Earls, Amy C., Christopher R. Lintz, George W. Gill, Patrick L. O’Neill, and W. Nicholas Trierweiler

1991 Investigations of Historic Cemeteries at the O.H. Ivie Reservoir, Coleman, Concho, and Runnels Counties, Texas. Mariah Technical Report No. 403. Mariah Associates, Inc., Austin, Texas.

Edgerton, Charles E.

1897 The Wire-Nail Association of 18951896. Political Science Quarterly 12(2):246-272.

Edwards, Douglas M., Lori Hager, and Robert Jackson, Pacific Legacy, and UC Davis Medical Center

2005 Former Sacramento County Hospital Burial Ground Excavation, University of California Davis Medical Center, Radiation Oncology Expansion Project. Pacific Legacy, Inc., Cameron Park, California.

Edwards, J. D., and Tom Wells

1993 Historic Louisiana Nails: Aids to the Dating of Old Buildings. The Fred B. Kniffen Cultural Resources Laboratory Monographs Series No. 2. Geoscience Publications. Department of Geography \& Anthropology, Louisiana State University, Baton Rouge.
Elia, Ricardo. J., and Al B. Wesolowsky (editors) 1991 Archaeological Excavations at the Uxbridge Almshouse Burial Ground in Uxbridge, Massachusetts. BAR International Series 564. Tempus Reparatum: Archaeological and Historical Associates Limited, Oxford, United Kingdom.

Elliott, Daniel T., and Rita F. Elliott

1989 Bethany Cemetery, Effingham County, Georgia. Ebenzer Archaeological Report Series No. 2. Elliott and Elliott, Athens, Georgia.

Entrop, Terry Ross (submitter)

2013 Shiloh Cemetery, Bell County, Texas. USGENWEB. Electronic document, http:// files.usgwarchives.net/tx/bell/cemetery/ shiloh.txt, accessed January 27, 2013.

Epstein, S. M.

1981 A Coffin Nail from the Slave Cemetery at Catoctin, Maryland. MASCA (Museum Applied Science Center for Archaeology) Journal 1(7):208-210.

Ersland, S.

2012 "Unmarked Burials Discovered During I35 Work in Troy." Temple Daily Telegram, August 29, 2012.

Espenshade, Christopher T.

2004 Historic Grave Removal and Reinterment: Final Report-Clarion County, Pennsylvania, Shippenville Borough, S.R. 0322, Section 370, Shippenville Intersection Improvement Project. Skelly and Loy, Inc., Monroeville, Pennsylvania.

Ezell, Raymond, and Clifton A. Huston

2006a Archaeological Removal of Historic Burials at the Williams-Green Cemetery (44CU134) on the Continental 181 Fund, LLC Tract in Culpeper County, Virginia. ECS MidAtlantic, LCC, Fredericksburg, Virginia.

2006b Archaeological Removal of Five Historic Burials from Site $44 S T 00613$ At the Quantico Corporate Center Tract, Stafford County, Virginia. ECS Mid-Atlantic, LLC, Fredericksburg, Virginia. 
Favret, Amy C.

2006 Archaeological Investigations of Unmarked Graves at Eastern State Hospital, Lexington, Fayette County, Kentucky. In Kentucky Archaeological Survey Report No. 119. Kentucky Archaeological Survey, Jointly Administered by the Kentucky Heritage Council and the University of Kentucky, Department of Anthropology, Lexington.

Fehrenbach, T. R.

2000 Lone Star: History of Texas and Texans. Da Capo Press. Boston, Massachusetts.

Ferguson, Bobbie H.

1983 Final Report on the McGee Creek Cemetery Relocations, Atoka County, Oklahoma. Bureau of Reclamation, McGee Creek Project, Farris, Oklahoma.

Ferguson, Bobbie. H., Stephen K. Ireland, George A. Agogino, and Richard Holloway

1993 "And They Laid Them to Rest in the Little Plot Beside the Pecos": Final Report on the Relocation of the Old Seven Rivers Cemetery, Eddy County, New Mexico, Vol. 1. Denver Office of the Bureau of Reclamation, Denver, Colorado.

Find A Grave

2013 Old Troy Cemetery, Bell County, Texas. Find A Grave. Electronic document, http:// www.findagrave.com/cgi-bin/fg.cgi?page $=$ gsr $\&$ GScid $=5806$, accessed January 13, 2013. Data derived from Randy and Laura Todd inventory, 2006.

Fontana, Bernard L.

1965 The Tale of a Nail: On the Ethnological Interpretation of Historic Artifacts. The Florida Anthropologist 18(3, Part 2):85-101.

Fontana, Bernard L., and J. Cameron Greenleaf 1962 Johnny Ward's Ranch: A Study in Historic Archaeology. Kiva 29(1-2):1-115.

Foster, Eugene, and Linda A. Nance (editors)

2002 Archaeological Investigation Report:Allen Parkway Village, 41HR886, Houston, Harris County, Texas. PBS\&J, Austin, Texas.

Fox, Anne A.

1984 A Study of Five Historic Cemeteries at Choke Canyon Reservoir, Live Oak and McMullen Counties, Texas. Choke Canyon Series No. 9. Center for Archaeological
Research, The University of Texas at San Antonio.

Frater, Jamie

2013 "Memento Mori: Victorian Death Photos," October 24, 2012. Electronic document, http://listverse.com/2012/10/24/mementomori-victorian-death-photos, accessed November 5, 2012.

Gadus, E. Frances, Joan E. Baker, and Amy E. Dase 2002 "A Mother Left to Mourn": Archaeological and Historical Investigations at a Nineteenth-Century Family Cemetery at the Jewett Mine, Freestone County, Texas. Report of Investigations No. 136. Prewitt and Associates, Inc., Austin, Texas.

Gardner, Jeffrey W.

1997 Delineation of a Historic Grave Site (9ME509), Land Management Compartment L2, Fort Benning, Muscogee County, Georgia. Brockington and Associates, Inc., Atlanta, Georgia.

2009 Union Bethel AME Church Cemetery Relocation. Brockington and Associates, Inc., Jacksonville, Florida.

Garner, Beverly, Irena Miklavcic, and Terri Brennan 2001 The Kniseley Family Cemetery, Lots 27 and 28, Concession 3, Elm Street, City of Port Colborne, Ontario. Archaeological Services, Inc., Toronto.

Garrow, Patrick H.

1989a Hopewell Cemetery Results from 11/17/88 Through 10/21/89: Revised November 4, 1989 Following Laboratory Analysis. Garrow \& Associates, Inc., Atlanta, Georgia.

1989b Archaeological Investigations within the Drennan Family Cemetery, Fayette County, Georgia. Garrow \& Associates, Inc., Atlanta, Georgia.

1990 Archaeological Investigations of the Sandy Creek Cemetery, Lot 31, Block "B," Sandy Creek Estates, Clarke County, Georgia. Garrow \& Associates, Inc., Atlanta, Georgia.

1993 Results of Monitoring the Relocation of the Cope Family Cemetery, Raleigh, North Carolina. Garrow \& Associates, Inc., Atlanta, Georgia. 
1996 Recommended Archaeological Disinterment and Reinterment Plan for the Shockley Cemetery, Jefferson, Georgia. Garrow \& Associates, Inc., Atlanta, Georgia.

Garrow, Patrick H., David Jones, and Jeffrey L. Holland

1994 An Archaeological, Genealogical, and Forensic Study of the Martin Cemetery, Douglas County, Georgia. Garrow \& Associates, Inc., Atlanta, Georgia.

Garrow, Patrick H., and Steven A. Symes

1987 Final Report: The Big Lazer Creek Unmarked Cemetery: A Multidisciplinary Investigation. Garrow \& Associates, Inc., Atlanta, Georgia.

Garrow, Patrick H., Steve A. Symes, and Henry W. Case

1985 Physical Anthropology and Archaeological Investigations of the Nancy Creek Primitive Baptist Church Cemetery, Chamblee, Georgia. Garrow \& Associates, Inc., Atlanta, Georgia.

Goldstein, Lynne G., and Jane E. Buikstra

2004 A Nineteenth-Century Rural Irish Cemetery in McDonough County, Illinois. In An Upper Great Lakes Archaeological Odyssey: Essays in Honor of Charles E. Cleland, edited by William A. Lovis, pp. 43-63. Cranbrook Institute of Science, Wayne State University Press, Detroit, Michigan.

Gordon, W. A.

2003 Coffin Plates and Competitive Display. Ph.D. dissertation, Department of Anthropology, Arizona State University, Tucson, Arizona. University Microfilms International, Ann Arbor, Michigan.

Gresham, T. H., and Gordon Martin

1999 Archaeological Disinterment of the Brassel Cemetery, Jefferson County, Georgia. Southeastern Archaeological Services, Inc., Athens, Georgia.

Grey, Amy E., M. Drake Patten, and Mark S. Warner 1993 A Preliminary Archaeological Assessment of the Venable Lane Site. Department of Anthropology, University of Virginia, Charlottesville.

Gust, Sherri, Amy Diaz, and Kelly Houck

2006 The Historic Los Angeles Cemetery (CALAN-3553) Summary Report, Los Angeles Metro Gold Line Project, East Portal Area,
Los Angeles, CA. Cogstone Resources Management Inc., Santa Ana, California.

Hacker, Debbi, and Michael Trinkley

2007 Analysis of Human Skeletal Remains Discovered by Construction Activities, Drafts Graveyard, Lexington County, South Carolina. In Chicora Research Contribution 476. Chicora Foundation, Inc. Columbia, South Carolina.

2010 Analysis of Remains from Mount Olive Cemetery, Portsmouth, Virginia. In Chicora Research Contribution No. 535. Chicora Foundation, Inc., Columbia, South Carolina.

Hacker-Norton, Debbi, and Michael Trinkley

1984 Remember Man Thou Art Dust: Coffin Hardware of the Early Twentieth Century. Research Series 2. Chicora Foundation, Inc., Columbia, South Carolina.

Hardy, Karen, Tony Blakeney, Les Copeland, Jennifer Kirkham, Richard Wrangham, and Matthew Collins

2009 Starch Granules, Dental Calculus and New Perspectives on Ancient Diet. Journal of Archaeological Science. 36(2):248-255.

Harper's Bazaar

1886 Mourning and Funeral Usages. Harper's Bazaar 19(16). Electronic document, http://hearth.library.cornell.edu/cgi/t/text/ pageviewer-idx?c=hearth;cc=hearth;rgn= full\%20text;idno=4732809_1453_ 016;didno=4732809_1453_016; view $=\mathrm{i}$ mage;seq $=0001 ;$ node $=4732809 \_1453$ 016\%3A3.1, accessed May 15, 2013.

Hassett, G., and L. Barnsley

2001 Pain Referral from the Sternoclavicular Joint: A Study in Normal Volunteers. Rheumatology 40:859-862.

Hatfield, Virginia L., Douglas K. Boyd, and Karl W. Kibler

2009 Search for Unmarked Graves at Three Historic Cemeteries Adjacent to Interstate Highway 35, Bell and McLennan Counties, Texas. Letter Report No. 804. Prewitt and Associates, Inc., Austin, Texas.

Hawkey Diane, and Charles F. Merbs

1995 Activity-Induced Musculoskeletal Stress Markers (MSM) and Subsistence Strategy Changes Among Ancient Hudson Bay Eskimos. International Journal of Osteoarchaeology 5:324-338. 
Heilen, Michael, and Marlesa A. Gray (editors) 2010 Deathways and Lifeways in the American Southwest: Tucson's Historic AlamedaStone Cemetery and the Transformation of a Remote Outpost into an Urban City. 3 vols. Statistical Research, Inc., Tucson, Arizona.

Heringer, T. M., Coroner and Norman Haywood 1980 Preliminary Report on the Casket and Human Remains from the Site of Old St. Andrew Roman Catholic Cemetery. Wanikan (Newsletter of the Thunder Bay Chapter of the Ontario Archaeological Society) 80(4):7-10.

Hill, M. C., and J. W. Pye

2012 New Home Cemetery (41FB334): Archaeological Search, Exhumation, and Reinterment of Multiple Historic Graves Along FM 1464, Sugar Land, Fort Bend County, Texas (CSJ 1415-02-032). Archeological Studies Program Report No. 145. Environmental Affairs Division, Texas Department of Transportation, Austin.

Hilliard, Jerry, James Davidson, and Lela Donat n.d. Archeological Investigation of the Droke Graveyard, 3BE655, Benton County, Arkansas. Ms. on file at the Arkansas Archeological Survey, Fayetteville.

Hillson, Simon

1996 DentalAnthropology. Cambridge University Press, Cambridge, United Kingdom.

Hjelsand, Rachael, Jason Rein, Dawn Cobb, Susan Vorreyer, and Joseph Craig

2005 The McBride Cemetery: Archaeological Mitigation of Eleven Mid-19th Century Burials, Washington County, Illinois. Environmental Compliance Consultants, Inc., Springfield, Illinois.

Hogue, S. Homes, and Jeffrey S. Alvey

2006 Final Report on Archaeological Burial Recovery at Pepper Hill I Cemetery, 22LO998, Lowndes County, Mississippi. Cobb Institute of Archaeology, Mississippi State University, Mississippi State.

Hopkins, Maren, Homer J. Thiel, and James T. Watson

2011 Excavation, Analysis, and Cultural Affinity Statement of Burial 15 from the Court Street Cemetery, AZ BB:13:156(ASM), Located at the Intersection of Queen Avenue and First Street, Tucson, Pima County,
Arizona. Northland Research, Inc., Tempe, Arizona.

Hutcheson, Alexis, David Robertson, Annie Veilleux, and Ronald F. Williamson

2008 Cemetery Investigation at the Church of the Assumption of Our Lady, Part of Lots 535 and 536, Village of Bell Ewart, Town of Innisfil, Simcoe County, Ontario. Archaeological Services, Inc., Toronto.

Jensen, Gail M.

1980 Biomechanics of the Lumbar Intervertebral Disk: A Review. Physical Therapy 60:765-773.

Jones, B. C.

1992 Archaeological Evaluation of Lions Club Lot in Cedar Key, Florida: Salvage of Historic Burials and Preservation of Weeden Island (Pasco) Burial Area. Florida Archaeological Reports No. 9. Bureau of Archaeological Research, Division of Historical Resources, Florida Department of State, Tallahassee.

Jones, David C., Patrick H. Garrow, and Jeffrey L. Holland

1996 Archaeological Disinterment of the Morrow Cemetery, Gwinnett County, Georgia. Garrow \& Associates, Inc., Atlanta, Georgia.

Jones, Dennis C., Malcolm K. Shuman

2007 The Excavation and Analysis of Unmarked Historic Burial at the Filhiol/GersonMound Site 16OU2 Within the Expanded Rightof-Way for U.S. Highway 165, Ouachita Parish, Louisiana. Surveys Unlimited Research Associates, Inc., Baton Rouge, Louisiana.

Jones, Joe B., Steven C. Pullins, Courtney Birkett, Elizabeth J. Monroe, Melissa E. Lamb, and William H. Moore

2006 Archaeological Data Recovery at Site 44PO126 Associated with the Proposed Route 288 Project, Powhatan County, Virginia. VDOT Project: 0288-072-104. William and Mary Center for Archaeological Research, The College of William and Mary, Williamsburg, Virginia.

Joseph, J. W., Mary Beth Reed, and Charles E. Cantley

1991 Agrarian Life, Romantic Death: Archaeological and Historical Testing and Data Recovery for the I-85 Northern Alternative, Spartanburg County, South 
Carolina. New South Associates Technical Report 39. New South Associates, Stone Mountain, Georgia.

Jurney, David H.

1987 Cut and Wire Nails: Functional and Temporal Interpretations. In Historic Buildings, Material Culture, and People of the Prairie Margin, edited by D. H. Jurney, and Randall W. Moir, pp. 83-96. Archaeology Research Program, Institute for the Study of Earth and Man, Southern Methodist University, Dallas, Texas.

Kataria Rajesh K., and Lawrence H. Brent

2004 Spondyloarthropathies. American Family Physician 69(12):2853-2860.

Katz, Darryl, and Judy M. Suchey

1986 Age Determination of the Male Os Pubis. American Journal of Physical Anthropology 69(4):247.

KCEN-TV

2012 "I-35 Construction Halted Near Roberts Cemetery After Unmarked Graves Found." News report on KCEN-TV, September 6, 2012. Electronic document, http://www.kcentv.com/story/19473346/ i-35-construction-halted-near-roberts-cemetery-after-unmarked-graves-found.

King, Julia A., and Douglas H. Ubelaker

1996 Living and Dying on the 17th Century Patuxent Frontier. The Maryland Historical Trust Press, Crownsville, Maryland.

King, Marsha K., and Beth P. Miller

1991 Archaeological Investigations, Haul Road Trenching, and Disturbance Documentation of the Piggery Point Burials on Deer Island, Boston, Massachusetts. The Public Archaeology Laboratory, Inc., Pawtucket, Rhode Island.

Kogon, Stephen L., and Robert G. Mayer

1995 Analysis of Coffin Hardware from Unmarked Burials Former Wesleyan Methodist Church Cemetery, Weston, Ontario. North American Archaeologist 16(2):133-162.

Kreisa, Paul P., Jacqueline M. McDowell, Gregory R. Walz, Steven R. Leigh, Jodi A. Blumenfeld, and Christopher Flynn

2004 Investigation of the Stellwagen Cemetery (11WI2546) Under HSRPA Permit
No. 2002-22 in Will County, Illinois. In Public Service Archaeology Program Research Report No. 65. Public Service Archaeology Program, University of Illinois at Urbana-Champaign.

Lansdell, Brent, and Joan Gillard

2009 Removal and Relocation of the Handsmill Cemetery, York County, South Carolina. Brockington and Associates, Inc., Charleston, South Carolina.

Larsen, Clark Spencer

1997 Bioarchaeology: Interpreting Behavior from the Human Skeleton. Cambridge Studies in Biological and Evolutionary Anthropology. Cambridge University Press, Cambridge, United Kingdom.

Larsen, Clark Spencer, Joseph Craig, Leslie E. Sering, Margaret J. Schoeninger, Katherine F. Russell, Dale L. Hutchinson, and Matthew A. Williamson

1995 Cross Homestead: Life and Death on the Midwestern Frontier. In Bodies of Evidence: Reconstructing History Through Skeletal Analysis, edited by Anne L. Grauer, pp. 139-160. Wiley-Liss, Inc., New York.

Lebo, Susan A.

1988 An Archaeological and Bioarchaeological Perspective: The Tucker (41DT104) and Sinclair (41DT105) Cemeteries of Delta County, Texas. Institute of Applied Sciences, North Texas State University, Denton.

Lee, A. B.

2002 Report of Field Investigations for the Relocation of the Hosier Family Cemetery, Butler Township, Montgomery County, Ohio, MOT-75-3.842 (PID19070). Hardlines Design Company, Columbus, Ohio.

LeeDecker, Charles H., Jonathan Bloom, Ingrid Wuebber, and Marie-Lorraine Pipes

1995 Final Archaeological Excavations at a Late 18th-Century Family Cemetery for the U.S. Route 113 Dualization, Milford to Georgetown, Sussex County, Delaware. DelDOT Archaeology Series No. 134. The Cultural Resource Group, Louis Berger \& Associates, Inc., East Orange, New Jersey, with Karen R. Rosenberg, Department of Anthropology, University of Delaware. 
LeeDecker, Charles, Jason Shellenhamer, and Stephanie Jacobe

2009 "A Vapor That Appeareth for a Little Time and Then Vanisheth Away": Archaeology of the Wrenn-Hutchison Cemetery, Chantilly, Virginia. Louis Berger Group, Inc., Washington, D.C.

Lewis, Mary E.

2007 The Bioarchaeology of Children:Perspective from Biological and Forensic Anthropology Cambridge Studies in Biological and Evolutionary Anthropology. Cambridge University Press, Cambridge, United Kingdom.

Libra13Witch

2012 "Victorian Post Mortem Photography," Unknown publication date. Online video, http://www.youtube.com/ watch? $\mathrm{v}=\mathrm{D} 7 \mathrm{~B} 3 \times 0 \mathrm{fW} 6 \mathrm{xM}$, accessed November 5, 2012.

Lipovitch, David, Eva MacDonald, Irena Miklavcic, David Robertson, and Ronald Williamson

2003 Archaeological Investigations of the Elmbank Church and Cemetery, Former Lot 8, Concession 5, Toronto Township, Peel County, Ontario. Archaeological Services, Inc., Toronto.

Little, Barbara J., Kim M. Lanphear, and Douglas W. Owsley

1992 Mortuary Display and Status in a Nineteenth-Century Anglo-American Cemetery in Manassas, Virginia. American Antiquity 57(3):397-418.

Loveday, Amos J., Jr.

1983 The Rise and Decline of the American Cut Nail Industry: A Study of the Interrelationships of Technology, Business Organization, and Management Techniques. Greenwood Press, Westport, Connecticut.

Magoon, Dane, Lynette Norr, Dale L. Hutchinson, and Charles R. Ewen

2001 An Analysis of Human Skeletal Materials from the Snow Beach Site (8WA52). Southeastern Archaeology 20(1):18-30.

Mainfort, Robert C., Jr., and James M. Davidson (editors)

2006 Two Historic Cemeteries in Crawford County, Arkansas. Arkansas Archeological Survey Research Series No. 62. Arkansas Archeological Survey, Fayetteville.
Manhein, Mary J., and Ginesse A. Listi

2007 Analysis of Human Skeletal Remains and Presentation of Associated Artifacts from the Filhiol/Gerson Mound Site (16OU2). LSU FACES Laboratory, Baton Rouge, Louisiana.

Maresh, M. M.

1970 Measurements from Roentgenograms. In Human Growth and Development, edited by Robert W. McCammon, pp. 157-200. Charles C. Thomas, Springfield, Illinois.

Matternes, Hugh B.

1998 Who Are the People in Cool Branch Cemetery (40HK9)? A Bioanthropological Case Study. Tennessee Anthropologist 23(1 \& 2):73-85.

Matternes, Hugh B., Valerie Davis, Jile Coco, Staci Richey, and Sarah Lowry (editors)

2012 Hold Your Light on Canaan's Shore: A Historical and Archaeological Investigation of the Avondale Burial Place (9BI164), Bibb County, Georgia. 2 vols. New South Associates, Stone Mountain, Georgia.

Matternes, Hugh B., Valerie Davis, Sarah McIntyre, Melissa Umberger, Faris Cadle, and Kristin Lockerman (editors)

2010 Shimmering Glimpses of the Spirit World: Archaeological Recovery and Relocation of Two Historic Cemeteries (9CH875 and 9CH1168) at Hunter Army Airfield, Chatham County, Georgia. 2 vols. New South Associates, Stone Mountain, Georgia.

Matternes, Hugh B., and Karen Serio

2005 1SC320:A Rural 19th Century Cemetery on the Outskirts of Ragland, Alabama, Saint Clair County, Alabama. In New South Associates Technical Report No. 1274. New South Associates, Stone Mountain, Georgia.

McDonald, Bradley, and Sarah Meacham

2001 Archaeological Excavation of an Unmarked Cemetery at Site 44HE950 at the Confederate Forest Development, Henrico County, Virginia. Gray \& Pape, Inc., Richmond, Virginia.

McDowell, Jacqueline M.

2000 Archaeological Investigations of the Beardstown Original City Cemetery (11CS892) in Cass County, Illinois. In Public Service Archaeology Research Report No. 46. Public Service Archaeology Program, 
Department of Anthropology, University of Illinois at Urbana-Champaign.

McDowell, Margaret A., Cheryl D. Fryar, Cynthia L. Ogden, and Katherine M. Flegal

2008 Anthropometric Reference Data for Children and Adults: United States, 2003-2006. National Health Statistics Report No. 10. Center for Disease Control and Prevention, National Center for Health Statistics, Hyattsville, Maryland.

McGowan, Kevin, Christopher Flynn, Virginia Hess, and Jodi Bluemenfeld

2009 Investigations of the Mitchell Road Cemetery (11K492) Under HSRPA Permit No. 2006-02 in Kane County, Illinois. In Public Service Archaeology Program Research Report No. 149. Public Service Archaeology \& Architecture Program, Department of Anthropology, University of Illinois at Urbana-Champaign.

McKee, Larry, and Debbie Sterbinsky

2012 Archaeological Investigation and Relocation of the Read Family Cemetery at the TVA Lagoon Creek Combined Cycle Plant, Haywood County, Tennessee. TRC Environmental Corporation, Nashville, Tennessee.

McReynolds, M. J.

1981 Archaeological Investigations at the Laredo Cemetery Site (41WB22), Webb County, Texas. Report of Investigations No. 11. Prewitt and Associates, Inc. Austin, Texas.

Meer, Rosanne M.

1990 Report of Investigations of Skeletal Remains Recovered from the Stoltz Site (B0Z0048/198807), Ozaukee County, Wisconsin. State Historical Society of Wisconsin, Burial Site Preservation Program, Madison, Wisconsin.

Michael, Ronald L.

1974 Cut Nail Manufacture: Southwestern Pennsylvania. Bulletin of the Association for Preservation Technology 6(1):99-108.

Miller, Kevin A.

1996 Archaeological Investigations at 41TV1696The Givens Grave Site, Travis County, Texas. SWCA Archaeological Report No. 96-57. SWCA, Inc. Environmental Consultants, Austin, Texas.
Mills, Ellen Susanne

1979 Graves in the Gravel: The Unmarked Cemetery of Las Vegas, New Mexico. M.A. thesis, New Mexico Highlands University, Las Vegas, New Mexico.

Montgomery Ward \& Co

1969 Montgomery Ward \& Co. Catalogue and Buyers' Guide. No 57, Spring and Summer 1895. Dover Publications, New York.

Moorees, Coenraad F. A, Elizabeth A. Fanning, and Edward E. Hunt

1963a Formation and Resorption of Three Deciduous Teeth in Children. American Journal of Physical Anthropology 21(2):205-213.

1963b Age Formation by Stages for Ten Permanent Teeth. Journal of Dental Research 42:1490-1502.

Nelson, Lee H

1963 Nail Chronology as an Aid to Dating Old Buildings. Technical Leaflet No. 15. History News 19(2).

1968 Nail Chronology as an Aid to Dating Old Buildings. Technical Leaflet No. 48. American Association for State and Local History, Nashville, Tennessee.

Nordt, L. C.

1992 Archaeological Geology of the Fort Hood Military Reservation, Fort Hood, Texas. Archaeological Resource Management Series, Research Report No. 25. U.S. Army Fort Hood.

Odintz, Mark

2012 Handbook of Texas Online, s.v. "Troy, Tx (Bell County)." Electronic document, http:// www.tshaonline.org/handbook/online/articles/hjt12, accessed November 28, 2012.

Ortner, Donald J.

2003 Identification of Pathological Conditions in Human Skeletal Remains, 2nd ed. Academic Press, San Diego, California.

Oster, Warren J., Guy G. Weaver, Jamison P. Richardson, and Jason M. Wyatt

2005 Archaeological and Osteological Investigations of the Providence Baptist Church Cemetery (40SY619), MemphisShelby County Airport, Memphis, Shelby County, Tennessee. Weaver \& Associates, LLC., Memphis, Tennessee. 
Owsley, Douglas W.

1994 Bioarcharchaeology on a Battlefield: The Abortive Confederate Campaign in New Mexico. Archaeology Notes No. 142. Museum of New Mexico, Office of Archaeological Studies, Santa Fe.

Owsley, Douglas W., William F. Hanna, Malcom L. Richardson, and Laurie E. Burgess

2003 Bioarcheological and Geophysical Investigation: The Soldiers Plot, Emmanuel Lutheran Church Cemetery, New Market, Virginia (Site No. 44SH364). ASV Special Publication Number 41, Archeological Society of Virginia. Spectrum Press, Richmond, Virginia.

Owsley, Douglas W., James K. Krakker, Milton Jacobs, and Robert W. Mann

1992 The History and Archaeology of St. James Episcopal Church, Brandy Station, Virginia (Site No. 44CU90). Bookcrafters, Fredricksburg, Virginia.

Owsley, Douglas W., Charles E. Orser, Jr., Robert Montgomery, and Claudia C. Holland

1985 An Archaeological and Physical Anthropological Study of the First Cemetery in New Orleans, Louisiana. Department of Geography and Anthropology, Louisiana State University, Baton Rouge.

Painter, Mary, Ann L. Magennis, Christian J. Zier, Nell Mitchell, Lawrence B, Conyers, and John D. Kennedy

2002 Archaeological and Osteological Investigations of Cemetery 2 on the Grounds of the Colorado Mental Health Institute at Pueblo, Pueblo County, Colorado. Centennial Archaeology, Inc., and Colorado State University, Fort Collins.

Parrington, Michael, Daniel G. Roberts, Stephanie A. Pinter, and Janet C. Wideman

1989 The First African Baptist Church Cemetery: Bioarchaeology, Demography, and Acculturation of Early Nineteenth Century Philadelphia Blacks Vol. I, Historical and Archaeological Documentation. John Milner Associates, Inc., Philadelphia, Pennsylvania.

Pearce, Robert J.

1989 Excavation of the Wise Family Pioneer Cemetery and Homestead, Lot 17, Concession 2, Town of Richmond Hill. Museum of Indian Archaeology, London, and Affiliate of the University of Western Ontario.
Pearson, Charles E.

1978 The Rabbit Hill Site: A Late Nineteenth Century Southern Plains Indian Burial at Fort Sill, Oklahoma. Bulletin of the Oklahoma Anthropological Society 27:171-178.

Perry, Warren R., Jean Howson, and Barbara A. Bianco (editors)

2006 New York African Burial Ground, Archaeology Final Report. 4 vols. Howard University, Washington, D.C.

Peter, D. E., Marsha Prior, Melissa M. Green, and Victoria G. Clow (editors)

2000 Freedman's Cemetery: A Legacy of a Pioneer Black Community in Dallas, Texas. 2 vols. Special Publication No. 6. Geo-Marine, Inc., Plano, Texas. Report No. 21, Archaeology Studies Program, Environmental Affairs Division, Texas Department of Transportation, Austin.

Phillips, Maureen Kathleen

1989 A Revised Chronology of Cut Nails in New England 1790-1820: A Case Study of the Spencer-Pierce-Little House Addition. M.A. thesis, Boston University, Boston, Massachusetts.

Pike, M. V., and Janice Gray Armstrong (editors) 1980 A Time to Mourn: Expressions of Grief in Nineteenth Century America. The Museums at Stony Brook, Stony Brook, New York.

Plausinis, Derek, Laith M. Jazrawi, Joseph D. Zuckerman, and Andrew S. Rokito

2006 Anatomy and Biomechanics of the Shoulder. In Sports Medicine, edited by Anthony A. Schepsis and Brian D. Busconi, pp. 169-184. Lippincott Williams and Wilkins, Philadelphia, Pennsylvania.

Pokrant, Marie E., Amy C. Favret, and Elizabeth A. Murray

2011 Archaeological Investigation of the Diuguid/ Slack Cemetery-Site 15CL87, LG\&E/ Kentucky Utilities Services Company, Ghent Generating Station, Proposed Landfill Project, Carroll and Gallatin Counties, Kentucky. GAI Consultants, Inc., Cincinnati, Ohio.

Pollack, David, Peter Killoran, and Kim McBride

2011 Archaeological Investigations of the Horse Park Cemetery (15FA315), Fayette County, Kentucky. KAS Report No. 204. Kentucky Archaeological Survey, Lexington. Jointly administered by Kentucky Heritage 
Council and University of Kentucky, Department of Anthropology, Lexington.

Pomfret, James

2003 Disinterment and Relocation of an Abandoned Cemetery in Stewart County, Georgia. GDOT Project No.EDS-27(173). Cultural Resources Division, Georgia Department of Transportation, Atlanta.

Powell, Gina S.

2000 Emergency Excavations and Preliminary Analyses of Artifacts and Skeletal Remains from the St. Francis Regis Cemetery, Kansas City, Missouri. CAR Project 1128. Center for Archaeological Research, Southwest Missouri State University, Springfield.

Priess, Peter J.

1970 Penny Wise, Penny Foolish:The Description of Nail Sizes. Historical Archaeology 3(3):8-9.

1973 Wire Nails in North America. Bulletin of the Association for Preservation Technology 5:87-92.

Pye, Jeremy W.

2007 A Look Through the Viewing Glass: Social Status and Grave Analysis in a 19th Century Kansas Cemetery. M.A. thesis, University of Arkansas, Fayetteville.

2010a Analysis of Burial Container Construction and Elaboration at the Tucson City Cemetery, Tucson, Arizona. Department of Anthropology, University of Florida, Gainesville.

2010b Typology and Analysis of Burial Container Hardware Recovered from the Excavations of Rambo Cemetery, Rome, Georgia. Department of Anthropology, University of Florida, Gainesville.

2011a Typology and Analysis of Burial Container Hardware Recovered from the Excavations in a 19th Century Pioneer Cemetery, Brazoria County, Texas. Department of Anthropology, University of Florida, Gainesville.

2011b Typology and Analysis of Mortuary Artifacts Recovered from Excavations in the 20th Century, New Home Cemetery, Fort Bend County, Texas. Department of Anthropology, University of Florida, Gainesville.
Raemsch, Carol A., and J. W. Bouchard

2000 The Henry Lehman Family Cemetery: A Unique Contribution to NineteenthCentury Domestic Archaeology. In Nineteenth and Early Twentieth-Century Domestic Site Archaeology in New York State, edited by J. P. Hart and Charles L. Fisher, pp. 95-124. New York State Museum Bulletin, No. 495. The University of the State of New York, New York State Education Department, Albany.

Rauschenburg, B. L.

1990 Coffin Making and Undertaking in Charleston and Its Environs, 1705-1820.

Journal of Early Southern Decorative Arts 16(1):19-63.

Reid, D. J., and M. C. Dean

2006 Variation in Modern Human Enamel Formation Times. Journal of Human Evolution 50:329-346.

Reynolds, Michael, and Erin Kane

2010 Relocation of the Rambo Family Cemetery, Rome, Floyd County, Georgia: Final Report. Brockington and Associates, Inc., Atlanta, Georgia.

Rhine, Stanley

1990 Non-Metric Skull Racing. In Skeletal Attribution of Race: Methods for Forensic Anthropology, edited by George W. Gill and Stanley Rhine, pp. 9-20. Museum of Anthropology Anthropological Papers No. 4. Maxwell Museum of Anthropology, University of New Mexico, Albuquerque.

Richards, Patricia B.

1997 Unknown Man No. 198: The Archaeology of the Milwaukee County Poor Farm Cemetery. Ph.D. dissertation, Department of Anthropology, The University of Wisconsin, Milwaukee. University Microfilms International, Ann Arbor, Michigan.

Richards, Patricia B., and Matthias W. Kastell

1993 Archaeological Excavations at the Almshouse Burial Ground, Milwaukee County Poorhouse, Wauwatosa, Wisconsin. 2 vols. Report of Investigations, Number 333. Great Lakes Archaeological Research Center, Inc., Milwaukee, Wisconsin.

Rinehart, Charles J., Megan Rupnik, J. Lee Tippett, Stephanie Jacobe, Stuart Fiedel, and Eric Voigt 
2009 Data Recovery at Guinea Road Cemetery (Site 44Fx1664) Route 236 (Little River Turnpike), Fairfax County, Virginia. VDOT Project 0236-029-120, RW201; PPMS No. 17671; VDHR File No. 2004-0680. The Louis Berger Group, Richmond, Virginia.

Roberts Cemetery Association

2012 Untitled map of graves and headstones in Roberts Cemetery, by the Roberts Cemetery Association. Map in possession of association representative Mr. Wayne Randolph.

Roberts, Charlotte, and Keith Manchester

1995 The Archaeology of Disease, 2nd ed. Cornell University Press, New York.

Robertson, D.

2012 "Grave Site Discovery Delays I-35 Expansion Project." News report on YNN (Time Warner Cable news), September 4, 2012. Electronic document, http:// austin.ynn.com/content/top_stories/ 288051/grave-site-discovery-delays-i-35expansion-project.

Rose, Jerome C. (editor)

1983 Cedar Grove Historic Cemetery: A Study in Bio-History. Arkansas Archaeological Survey Project No. 528. Fayetteville, Arkansas.

1985 Gone to a Better Land: A Biohistory of a Rural Black Cemetery in the PostReconstruction South. Research Series No. 25. Arkansas Archeological Survey, Fayetteville.

Ross-Stallings, Nancy A., Christopher D. Koeppel, Stephen P. Mawrocki, Ryan J. Peterson, and Gaby Kienitz

2009 Dear Ones Remembered: The Relocation of the Wright-Whitesell-Gentry Family Cemetery in Marion County, Indiana. Indiana Archaeology 4(1):178-206.

Rothschild, B. M., and S. Behnam

2005 The Often Overlooked Digital Tuft: Clues to Diagnosis and Pathophysiology of Neuropathic Disease and Spondyloarthropathy. Annals of the Rheumatic Diseases 64:286-290.

Rozek, Barbara J.

2003 Come to Texas: Attracting Immigrants 1865-1915. Centennial Series of the Association of Former Students No. 9. Texas A\&M University, College Station.
Sander, Robert

2001 Otitis Externa: A Practical Guide to Treatment and Prevention. American Family Physician 63(5):927-937.

Saunders, Shelley, D. Ann Herring, Gerald Boyce

1995 Can Skeletal Samples Accurately Represent the Living Populations They Come From? The St. Thomas' Cemetery Site, Belleville, Ontario. In Bodies of Evidence: Reconstructing History Through Skeletal Analysis, edited by Anne L. Grauer, pp. 69-90. Wiley-Liss, Inc., New York.

Saunders, Shelley R., and Richard Lazenby

1991 The Links that Bind: The Harvie Family Nineteenth Century Burying Ground. In Occasional Papers in Northeastern Archaeology No. 5. Copetown Press, Dundas, Ontario.

Schaefer, Maureen, Sue Black, and Louise Scheuer 2009 Juvenile Osteology: A Laboratory and Field Manual.Academic Press, San Diego, California.

Schermer, Shirley J., Robin M. Lillie, Jonathan R. Sellars, and Marlin Ingalls

2006 Investigation of Inadvertent Discovery of Historic Grave at Tallyn's Ranch, at the South Boundary of Site 13DA185, West Des Moines, Dallas County, Iowa. Contract Completion Report No. 1466. Office of the State Archaeologist, The University of Iowa, Iowa City.

Scheuer, L., and S. MacLaughlin-Black

1994 Age Estimation from the Pars Basilaris of the Fetal and Juvenile Occipital Bone. The International Journal of Osteoarchaeology 4:377-380.

Schneider, Sven Raphael

2010 Collar Pin Guide. Gentleman's Gazette. Electronic document, http:// w w w. gentlem a n s gazette.com/ collarpin, accessed September 10, 2013.

Schnell, Frank T.

1983 Report on Examination of Graveyard at Carmouche Range, Fort Benning, Georgia. Columbus Museum of Arts and Sciences, Columbus, Georgia.

Schumacher, Jr., H. Ralph

1988 Primer on the Rheumatic Diseases, 9th ed. Arthritis Foundation, Atlanta, Georgia. 
Sewell, Kristen, and Patrick Stanton

2008 Dove Cemetery: Reflections on Cultural Identity at the Edge of Western ExpansionThe Excavation and Interpretation of Dove Cemetery, CA-SLO-1892H, San Luis Obispo County, California. Technical Report 06-55. Statistical Research, Inc., Redlands, California.

Shah, Monica, and Cally Lence

2003 Final Report: Monitoring the Disinterment of Five Graves from the Obringer Cemetery, a Late Nineteenth-Century Family Burying Ground, within the Knight Hawk Mine Expansion Permit Area, Jackson County, Illinois. In Cultural Resources Management Report No. 1104. American Resources Group, Ltd., Carbondale, Illinois.

Shogren, Michael G., Kenneth R. Turner, and Jody C. Perroni

1989 Elko Switch Cemetery: An Archaeological Perspective. Report of Investigations No. 58. Division of Archaeology, Alabama State Museum of Natural History, Tuscaloosa.

Shuler, Kristrina Andrea

2007 Lance Hall Cemetery Excavation, Circular Congregational Church, Charleston, South Carolina. Brockington and Associates, Inc., Charleston, South Carolina.

Shuler, Kristrina A., and Michael P. Hendrix

2004 Cemetery Relocation at the Future Site of the Children's Research Institute, Medical University of South Carolina, Charleston, South Carolina, Final Report. Brockington and Associates, Inc., Charleston, South Carolina.

Shuler, Kristrina Andrea, Eric C. Poplin, and Ralph Bailey, Jr.

2005 Cemetery Relocation at Site 38CH1648, Johnson Hagood Stadium, The Citadel, Charleston, South Carolina. Brockington and Associates, Inc., Charleston, South Carolina.

Sivapathasundharan, B.

2009 Diseases in the Periodontium. In Shafers Textbook of Oral Pathology, 6th ed., edited by E. R. Rajendran and B. Sivapathasundharan, pp. 372-408. Elsevier Press, New York.

Smith, J. B.

2012 "Grave Discovery: Unmarked Burial Sites near Troy Unlikely to Delay I-35 Work." Waco Tribune-Herald, September 6, 2012.
Smits, N. J., and Jo Reese

2005 Archaeological Exploration of Multnomah County's Morrison Property at SE 20th and Morrison, Portland, Oregon. Archaeological Investigations Northwest, Inc., Portland, Oregon.

South, Stanley A.

1979 The General, the Major, and the Angel: The Discovery of General William Moultrie's Grave. Research Manuscript Series, No. 146. Institute of Archeology and Anthropology, University of South Carolina, Columbia.

Spencer, Susan D.

2002 Manslick Road Cemetery, Burial \#34. In unpublished manuscript, Program of Archaeology, University of Louisville, Louisville, Kentucky.

Sprague, Roderick

2005 BurialTerminology:A Guide for Researchers. Altamira Press, Lanham, Maryland.

Springate, Megan E.

2011 Coffin Handles from the African Burial Ground, New York City: Notes on Their Source and Context. The African Diaspora Archaeology Network Newsletter (June):1-10.

State Highway Department

1921 Plan and Profile of Proposed State Highway. Bell County, from Falls County to Williamson Co. Line. State of Texas, State Highway Department. Map identification numbers illegible.

1931-1932 Plan and Profile of Proposed State Highway. Bell County From 2 MI. N. of Temple to Falls County Line. Approved July 15, 1931. Fiscal Year 1932. Scale 1 $\mathrm{IN}=3000 \mathrm{ft}$.

Stewart, T. D.

1979 Essentials of Forensic Anthropology. Thomas, Springfield, Illinois.

Stone, M. C.

1883 Coat Spring. Patent No. 281,578.

Application filed December 24, 1881. Patented July 17, 1883. Electronic document, http://www.google.com/patents?id= MbhKAAAAEBAJ\&pg=PA1\&dq= patent:281578\&source $=$ gbs_selected_p ages\&cad=1\#v=onepage\&q\&f=false, accessed January 17, 2013. 
Strezewski, M.

2003 "Ellen We Miss TheeAtHome":Archaeological Investigations at the Michigan City Old Graveyard (12Le348), LaPorte County, Indiana. Reports of Investigations 308. IPFW Archaeological Survey. Indiana University-Purdue University at Fort Wayne, Indiana.

Sutherland, Fred

2006 Use, Reuse, and Desecration: Analysis and Interpretation of the Lucy Kimball Mead Tomb, Littleton, Massachusetts. Honor's thesis, Boston University, Boston, Massachusetts.

Swauger, J. L.

1959 An American Burial Technique of the Early 19th Century. Pennsylvania Archaeologist 29(1):38-39.

Taccari, R., A. Spadaro, V. Riccieri, R. Guerrisi, V. Guerrisi, and A. Zoppini

1992 Sternoclavicular Joint Disease in Psoriatic Arthritis. Annals of the Rheumatic Diseases 51:372-374.

Taylor, A. J., Anne A. Fox, and I. Waynne Cox 1986 Archaeological Investigations at Morgan Chapel Cemetery (41BP200), A Historic Cemetery in Bastrop County, Texas. Archaeological Survey Report, No. 146. Center for Archaeological Research, The University of Texas at San Antonio.

Texas Almanac

2010 Texas Almanac Online, s.v. "Population Histories of Counties from 1850-2010." Electronic document, http://www.texasalmanac.com/sites/default/files/images/ topics/ctypophistweb2010.pdf, accessed February 7, 2013.

Texas State Highway Department

1949-1952 Right of Way Map. Bell County from North of Temple to Falls Co. Line. U.S. Highway No. 81. Control 15, Section 4, Job 13. Office of the Resident Engineer, Belton, Texas. District No. 9., July, 1949.

1957-1958 Plans of Proposed State Highway Improvement, Bell County, I.H. 35 (U.S. Highway No. 81) from 2.0 Miles North Temple to Falls Co. Line. Federal Aid Project No. I 40 (16) OLD and I-35-4(3)307 NEW. Certified Correct, December 20, 1957. Recommended for Approval, January 3, 1958.
Tharp, Brent W.

1996 "Preserving Their Form and Features": The Role of Coffins in the American Understanding of Death, 1607-1870. Ph.D. dissertation, Department of Anthropology, The College of William and Mary, Williamsburg, Virginia. University Microfilms International, Ann Arbor, Michigan.

Thiel, J. Homer

2012 Identification of the Pima Tribe No. 10, Improved Order of Red Men Plot Within the Court Street Cemetery, AZ BB:13:156 (ASM), Tucson, Pima County, Arizona. In Technical Report No. 2011-09. Desert Archaeology, Inc., Tucson, Arizona.

Thiel, J. Homer, and Michael M. Margolis

2007 Excavation and Analysis of Burials 13 and 14 from the Court Street Cemetery, $A Z$ BB:13:156 (ASM), Tucson, Pima County, Arizona. Project Report No. 07-136. Desert Archaeology, Inc., Tucson, Arizona.

Thiel, J. Homer, and John McClelland

2007 Excavation and Analysis of Burial 5 from the Barrio Libre Cemetery, AZ BB:13:495 (ASM), Tucson, Pima County, Arizona. In Project Report No. 07-127. Desert Archaeology, Inc., Tucson, Arizona.

Thomas, Brian

2000 Disinterment for Reburial of William and Anne C. Amis from Cemetery in the Greenwood Industrial Park, Henry County, Georgia. TRC Garrow Associates, Inc., Atlanta, Georgia.

Thomas, Larissa A.

2000 Disinterment for Reburial of Harrison and Catherine Nix from Family Cemetery near Snellville, Gwinnett County, Georgia. TRC Garrow Associates, Inc., Atlanta, Georgia.

Thomas, Ronald A., Betty C. Zebooker, Christopher M. Hazel, and David L. Weinberg

2000 Archaeological Investigations at the Mother UAME Church Cemetery (7NC-E-132) Wilmington, Delaware. MAAR Associates, Inc., Newark, Delaware.

Thoms, Alston V.

2001 The Matagorda Cemetery Project: Unmarked Graves and Community Heritage. Technical Report No. 5. Center for Ecological Archaeology, Texas A\&M University, College Station. 
Tíne, Angela L., and Douglas K. Boyd

2003 Archeological Excavation and Reburial of Unmarked Graves in the Pioneer Cemetery (41BO202), Brazoria County, Texas. Reports of Investigation No. 139. Prewitt and Associates, Inc., Austin. Report No. 59, Archeological Studies Program, Environmental Affairs Division, Texas Department of Transportation, Austin.

Tiné, Angela L., Judy Cooper, and Michelle Wurtz 2002 Archaeological and Bioarchaeological Investigations at Potter's Field / Greenwood Cemetery Along Clyde Lane, Dallas, Texas. Miscellaneous Reports of Investigations, Number 241. Geo-Marine, Inc., Plano, Texas.

Tippet, Lee, Stephanie Jacobe, and Stuart Fiedel

2009 Data Recovery at the Lackey Cemetery (Site 44RB0509 and VDHR No. 081-7093)

Interstate-81 NB Truck Climbing Lanes, Rockbridge County, Virginia. VDOT Project:00081-081-708, P101; PPMS No.:84363; VDHR File No.:2007-1094. The Louis Berger Group, Inc., Richmond, Virginia.

Todd, Randy, and Laura Todd

2006 Old Troy Cemetery, Bell County, Texas. USGENWEB. Electronic document, http:// files.usgwarchives.net/tx/bell/cemetery/ oldtroy1.txt, accessed January 10, 2013.

Todd, T. W.

1921 Age Changes in the Pubic Bone. I:The Male White Pubis. American Journal of Physical Anthropology 3(3):285-334.

Trinkley, Michael, and Debi Hacker-Norton

1984 Analysis of Coffin Hardware From 38CH778, Charleston County, South Carolina. In Chicora Foundation Research Series No. 3. Chicora Foundation, Inc., Columbia, South Carolina.

Trinkley, Michael, Debi Hacker, and Nicole Southerland

2009 Removal of Four Burials from St. Johannes Cemetery, Bensenville, Illinois. In Chicora Research Contribution No. 519. Chicora Foundation, Inc., Columbia, South Carolina.

2010 Removal of One Burial from St. Johannes Cemetery, Bensenville, Illinois. In Chicora Research Contribution No. 530, Chicora Foundation, Inc., Columbia, South Carolina.
2011 Son Cemetery: A Bioanthropological Investigation of a Small Lexington County, South Carolina Burial Ground. In Chicora Foundation Research Series No. 73. Chicora Foundation, Inc., Columbia, South Carolina.

Trotter, Mildred, and Goldine C. Gleser

1958 A Re-Evaluation of Estimation of Stature Based on Measurements of Stature Taken During life and of Long Bones After Death. American Journal of Physical Anthropology 16:79-123.

Troy Country Sun

2012 "Unmarked Graves Discovered." Troy Country Sun 25: 14, September 6, 2012.

Trubitt, Mary Beth D., Dawnie W. Steadman, and Anne Grauer

1999 Report of Excavations at Dunning Cemetery No. 2. Cultural Resource Management Report No. 625. Midwest Archaeological Services, Inc., Harvard, Illinois.

Trudeau, Mary F.

2005 Relocation of the Historic Neal (Big Cove) Cemetery, Madison County, Alabama. Alexander Archaeological Consultants, Inc., Wildwood, Georgia.

Turpin, Solveig A., and Leland C. Bement 2002a Relocation of the Craddock Cemetery, 41BP581, Three Oaks Mine, Bastrop County, Texas. Technical Report 17. TAS, Inc., Austin, Texas.

2002b Relocation of the Nisbett and Anderson Cemeteries, 41RT189 and 41RT350, Pit 6, Calvert Mine, Robertson County, Texas. Technical Report 19. TAS, Inc., Austin, Texas.

Ubelaker, Douglas H.

1989 Human Skeletal Remains: Excavation, Analysis and Interpretation, 2nd ed. Taraxacum, Inc., Washington, D.C.

Ubelaker, Douglas H, and Erica B. Jones (editors) 2003 Human Remains from Voegtly Cemetery, Pittsburgh, Pennsylvania. Smithsonian Contributions to Anthropology, No. 46. Smithsonian Institution Press, Washington, D.C.

U.S. Bureau of the Census

Bell County, 1870, 1880, 1900, 1910

Johnson County, 1910 
United States Census

1880 Federal Census Mortality Schedules:Texas, 1880. T1134, Roll 56; Location: Troy, Texas and Bell County, Texas. National Archives and Records Administration, Washington D.C.

United States Department of Agriculture

2012 Web Soil Survey, Natural Resource Conservation Service. Electronic document, http://websoilsurvey.nrcs.usda. gov/app, accessed October 2012.

Veilleux, Annie, and David Robertson

2008 Stage 2 Archaeological Assessment, Bridgepoint Health Master Plan, City of Toronto, Ontario. Archaeological Services, Inc., Toronto.

Victoriana Magazine

2012 Victorian Etiquette for Funerals. Reprinted from "Mourning and Funeral Usages." Harper's Bazaar, April 17, 1886. Electronic document, http://www.victoriana.com/library/harpers/ funeral.html, accessed May 15, 2013.

Walwer, Gregory F.

1996 Combining Archival and Archeological Research: The Connecticut School for Boys Cemetery. CRM 19(10):82003.

Ward, Trawick, and Martha Graham

1978 The Archaeo-Osteology of Three Historic Cemeteries in Person County, N.C. The Research Laboratories of Anthropology, University of North Carolina, Chapel Hill.

Warinner, Christina

2012 Tracking Ancient Diseases Using ... Plaque. TED Conferences, L.L.C. Electronic document, http://www.ted. com/talks/christina_warinner_tracking_ancient_diseases_using_plaque.html, accessed January 13, 2012.

Weaver, Guy G., Jeremy W. Blazier, Anna R. Lunn, and Warren J. Oster

2011 Archaeological Monitoring and Cemetery Relocation at the Callender Court Site (40SU251), Hendersonville, Sumner County, Tennessee. Weaver \& Associates, LLC, Memphis, Tennessee.

Weaver, Guy G., Zachary Konkol, and Anna Lunn

2010 AReport on the Relocation of an Abandoned Historical Cemetery on Callender Court, (Archaeological Site 40SU251),
Hendersonville, Sumner County, Tennessee. Weaver \& Associates, LLC, Memphis, Tennessee.

Wells, Tom

1993 Nail Dating: Identifying Chronologically Significant Features on Nails. M.A. thesis, Department of Anthropology, Louisiana State University, Baton Rouge.

1998 Nail Chronology:The Use of Technologically Derived Features. Historical Archaeology 32(2):78-99.

Wild, Michael J.

2001 Archaeological Disinterment at the FoxAbbott Family Cemetery Near Calhoun, Gordon County, Georgia. TRC Garrow Associates, Inc., Atlanta, Georgia.

2002 Results of Archaeological Verification of Grave Removal in 0.927 Acre Tract on North Side of Nancy Creek Baptist Church Cemetery, Chamblee, Georgia. TRC Garrow Associates, Inc., Atlanta, Georgia.

Williamson, Christian

2005 Sacred Trust: The Voluntary Removal and Reburial of Human Remains from a Historic Cemetery in Louisiana. M.A. thesis, Louisiana State University, Baton Rouge.

Wilson, Kristin

1997 Disinterment/Reinterment of the Shockley Cemetery, Jefferson, Georgia. TRC Garrow Associates, Inc., Atlanta, Georgia.

1998a Archaeological Disinterment of the Fuller Cemetery, Calhoun, Georgia. TRC Garrow Associates, Inc., Atlanta, Georgia.

1998b Archaeological Disinterment/Reinterment of the Pine Ridge Cemetery, Butts County, Georgia. TRC Garrow Associates, Inc., Atlanta, Georgia.

1998c Archaeological Disinterment of the Oliver Family Grave Sites, Roanoke, Virginia.TRC Garrow Associates, Inc., Atlanta, Georgia.

1998d Archaeological Disinterment of the Turner Cemetery, Marshal County, Mississippi. TRC Garrow Associates, Inc. Atlanta, Georgia.

1998e Results of Disinterment/Reinterment of the Final 13 Graves at Pleasant Hill Baptist 
Church Cemetery, Duluth, Georgia. TRC Garrow Associates, Inc., Atlanta, Georgia.

Wilson, Mike

1968 Two Historic Burials in the Three Forks Locale. Bulletin of the Oklahoma Anthropological Society 17:75-86.

Winchell, Frank, Jerome C. Rose, and Randall W. Moir

1992 Bioanthropological Investigation of Nineteenth Century Burials at Site 41DT105: Cultural Resource Studies for Cooper Lake, Delta County, Texas. Archaeology Research Program, Department of Anthropology, Southern Methodist University. Dallas, Texas.

1995 Health and Hard Times: A Case Study from the Middle to Late Nineteenth Century in Eastern Texas. In Bodies of Evidence: Reconstructing History Through Skeletal Analysis, edited by Anne L. Grauer, pp. 161-172. Wiley-Liss, New York.
Wood, W. Dean

2008 Report on the Disinterment and Relocation of the James and Sarah Barnes Cemetery, Bibb County, Georgia. Southern Research, Historic Preservation Consultants, Inc., Ellerslie, Georgia.

Wood, W. D., Karen Ramey Burns, and Steve R. Lee 1986 The Mt. Gilead Cemetery Study:An Example of Biocultural Analysis from Western Georgia. Southeastern Archaeological Services, Inc., Athens, Georgia.

Woodley, P. J.

1992 The Stirrup Court Cemetery Coffin Hardware. Ontario Archaeology 53:45-63.

Young, Amy L.

1991 Nailing Down the Pattern in Historical Archaeology. M.A. thesis, The University of Tennessee, Knoxville. 



\section{APPENDIX A: Tabulated Data on Mortuary Hardware: Hardware Catalogs, Historic Cemetery Reports, and Cemetery Artifact Comparisons}

Compiled by Jeremy W. Pye 

Appendix A: Mortuary Hardware
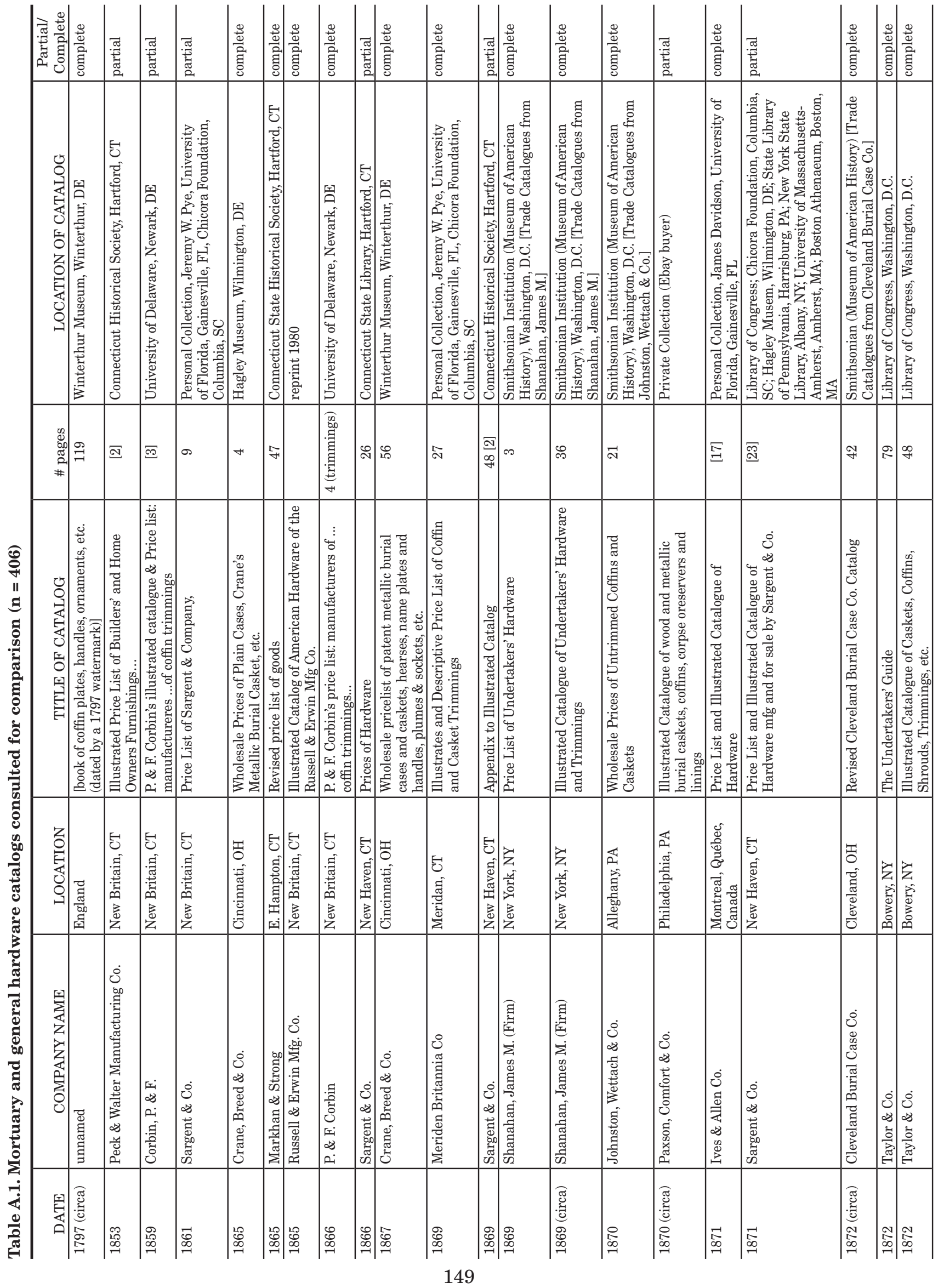
Investigations at Roberts Cemetery

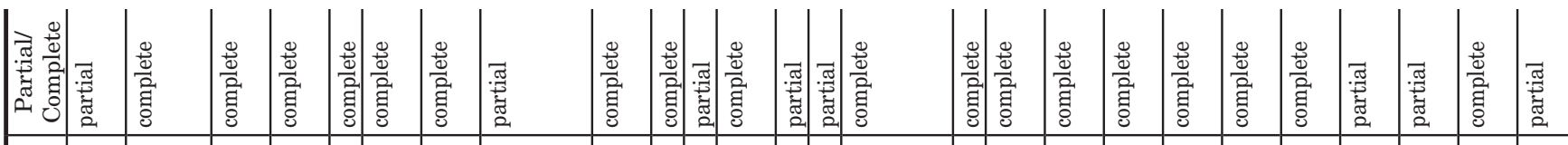

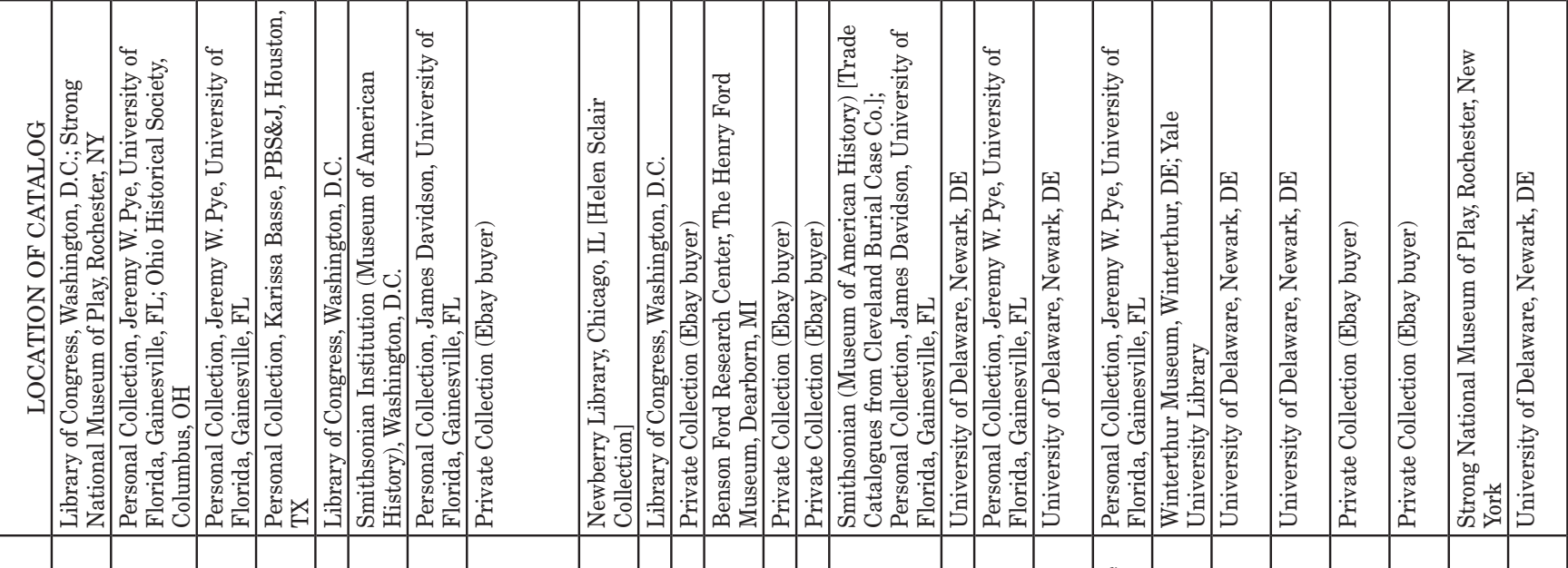

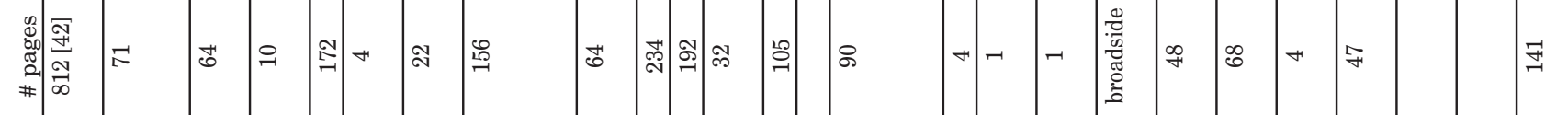

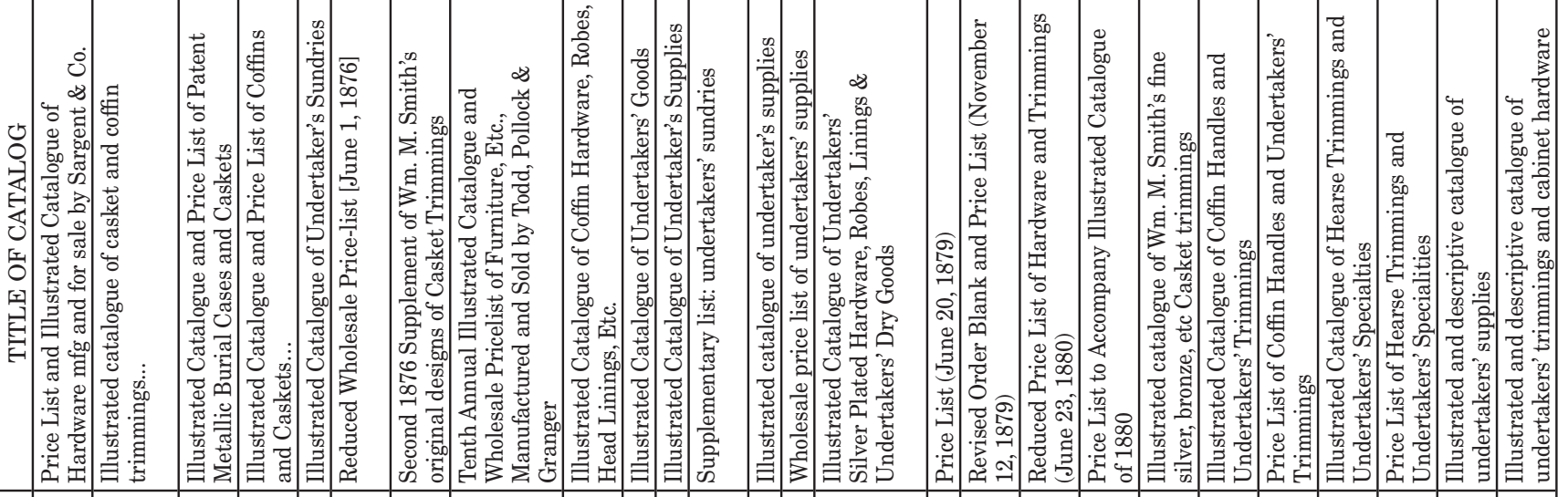

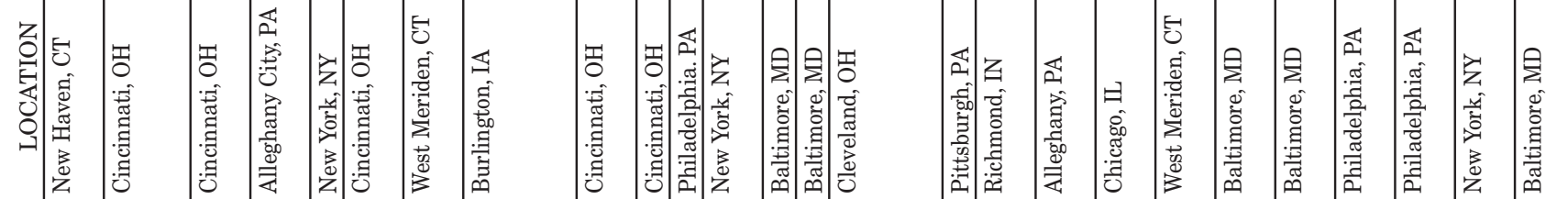

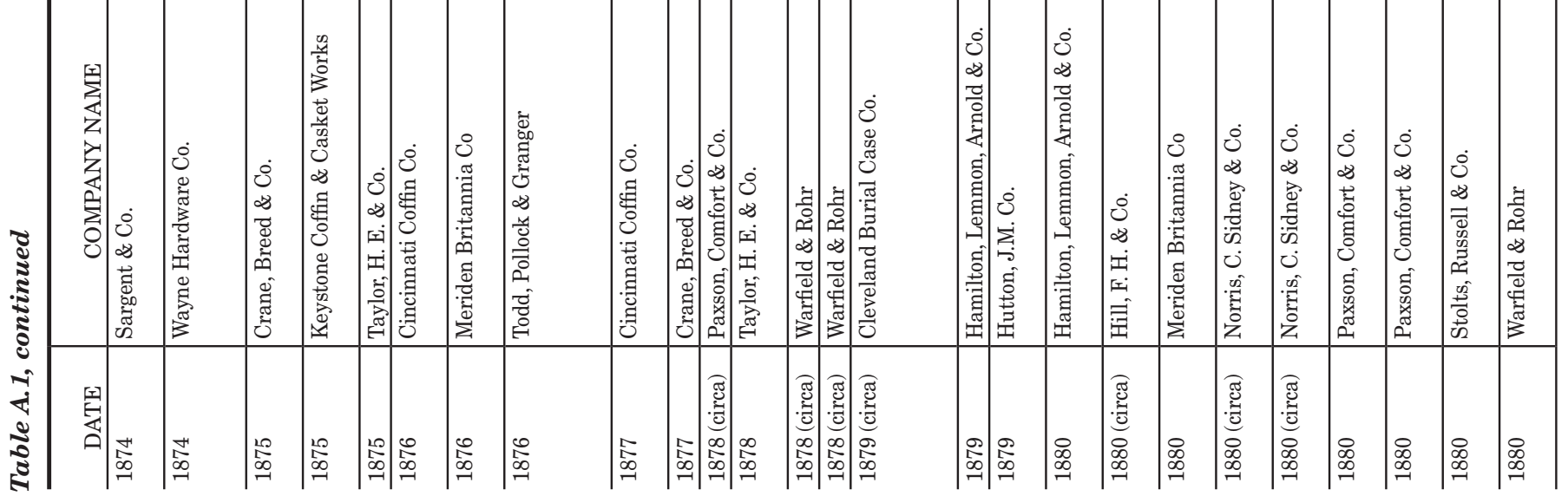


Appendix A: Mortuary Hardware

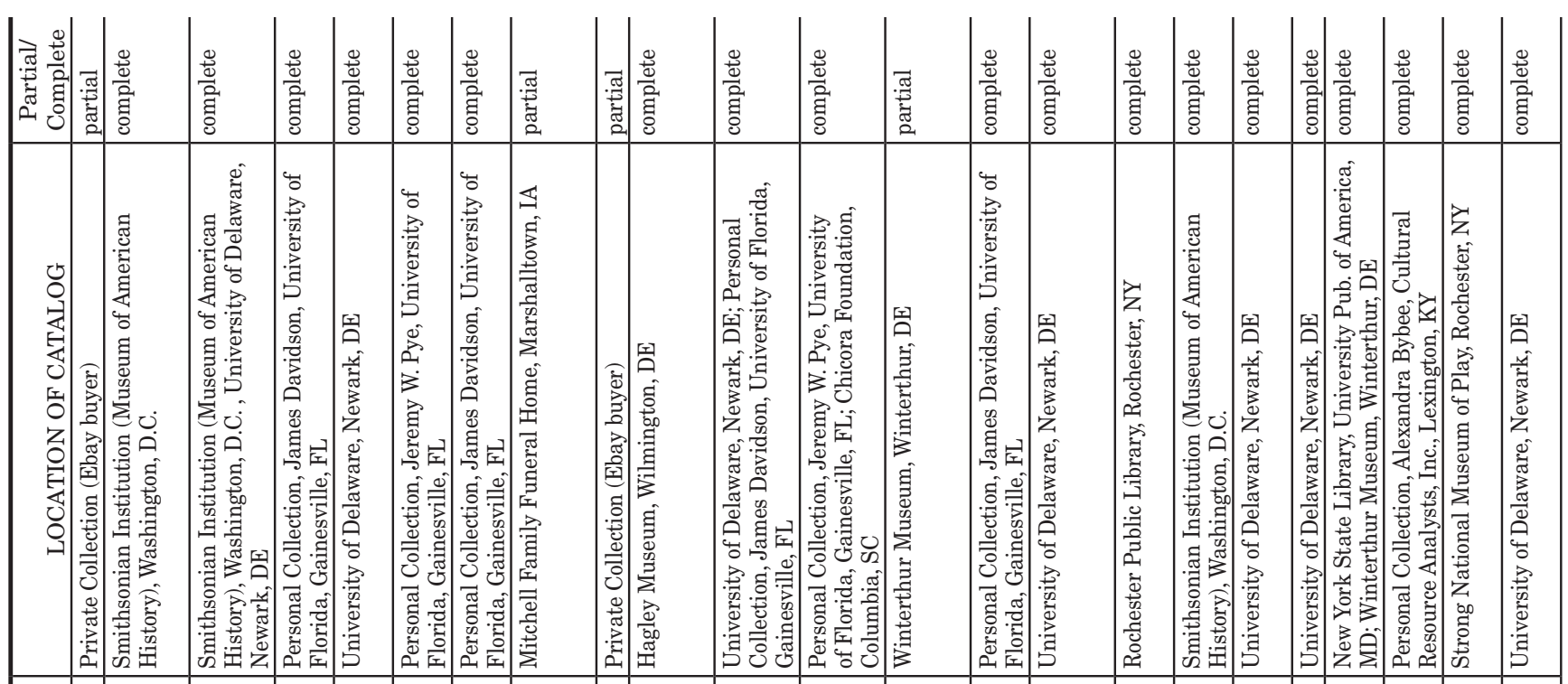

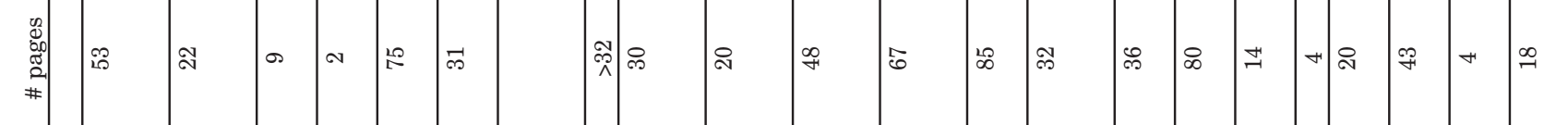

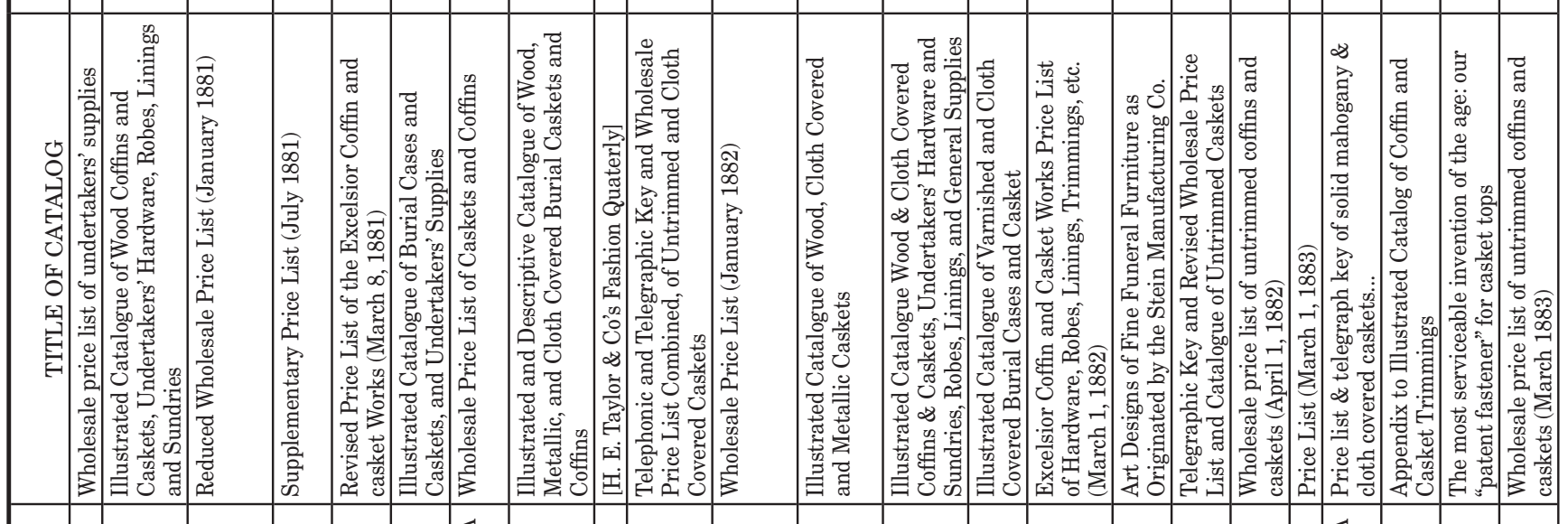

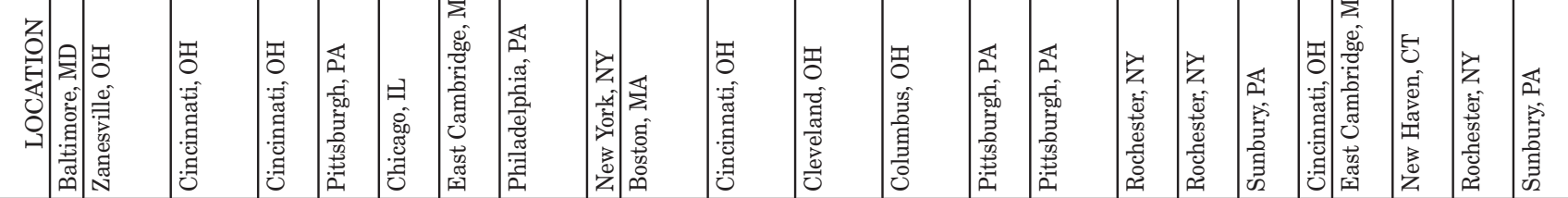

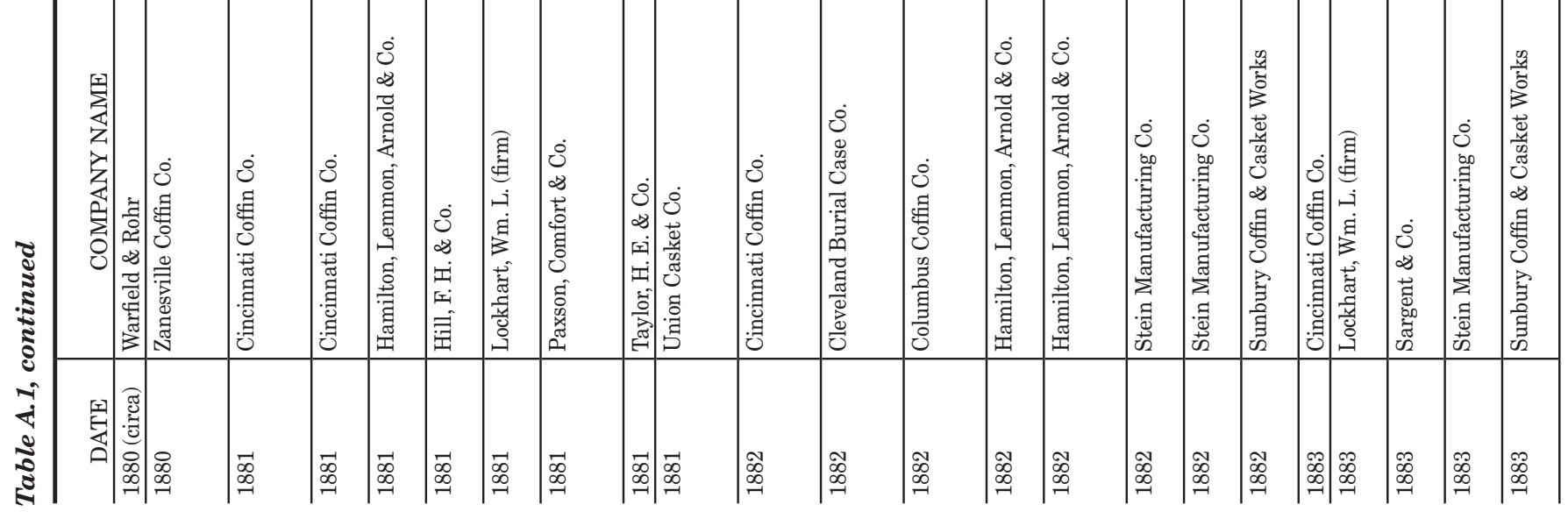


Investigations at Roberts Cemetery

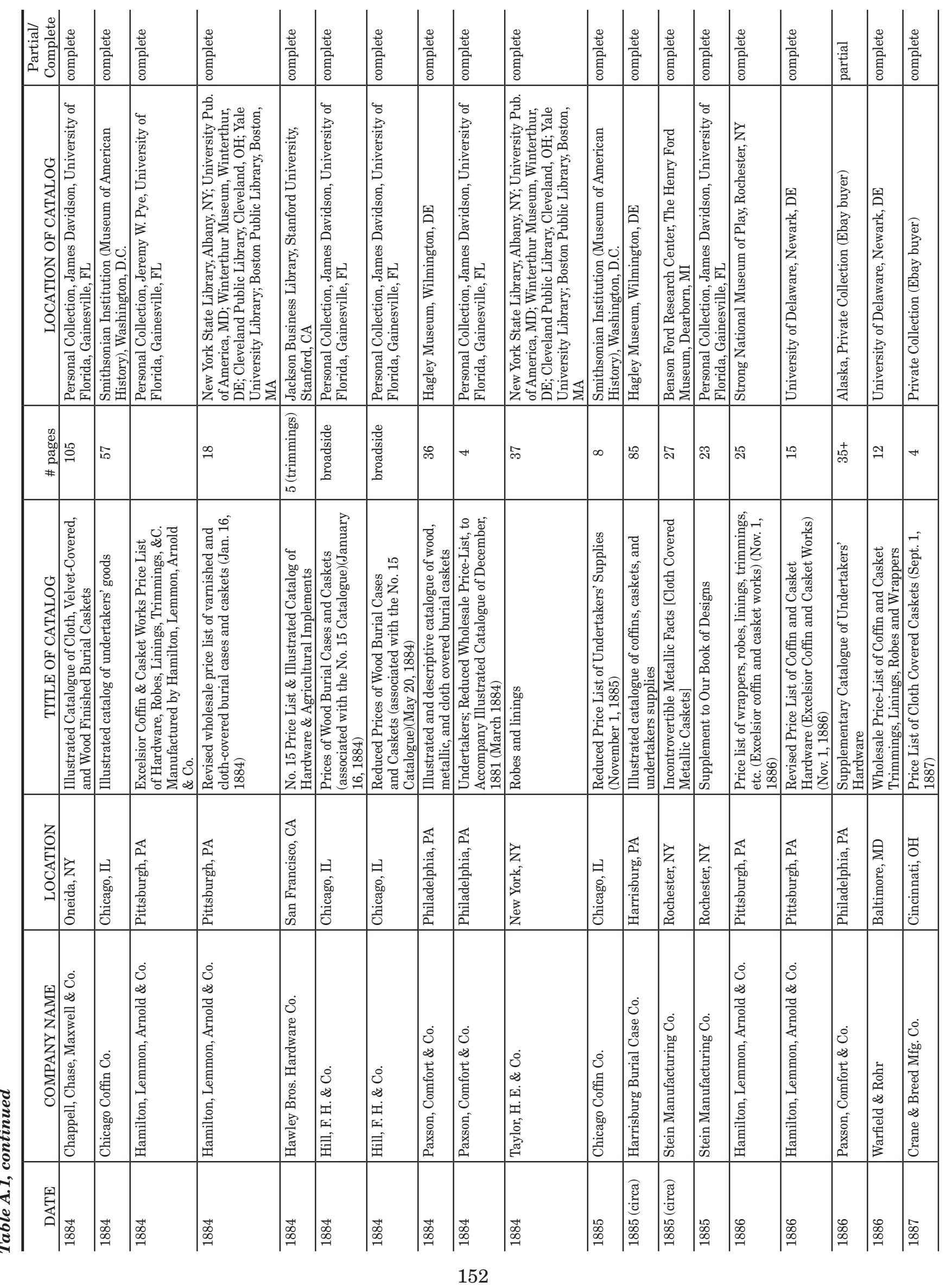


Appendix A: Mortuary Hardware

\begin{tabular}{|c|c|c|c|c|c|c|c|c|c|c|c|c|c|c|c|c|c|c|c|c|}
\hline & & 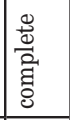 & 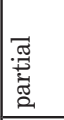 & 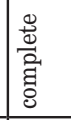 & 总 & 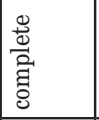 & 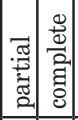 & 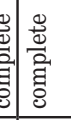 & 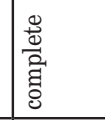 & 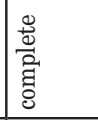 & 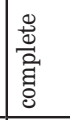 & 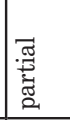 & 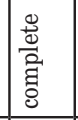 & 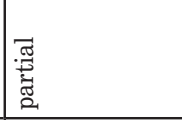 & 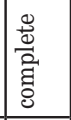 & 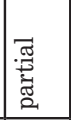 & 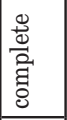 & 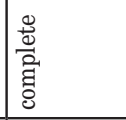 & 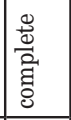 & 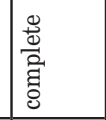 \\
\hline 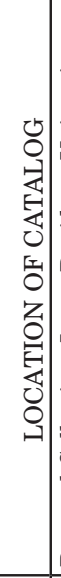 & 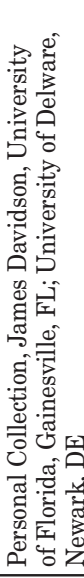 & 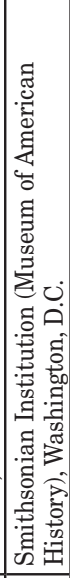 & 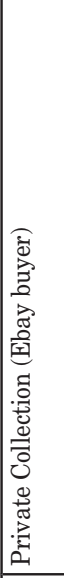 & 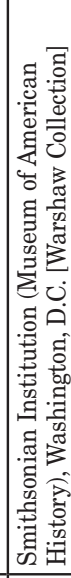 & 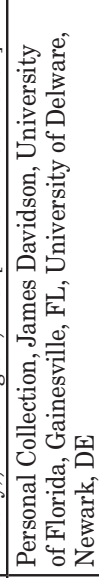 & 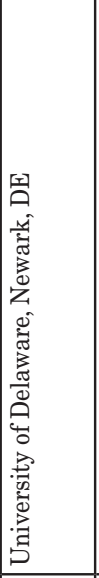 & 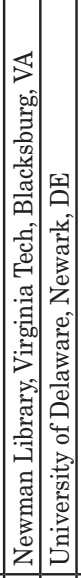 & 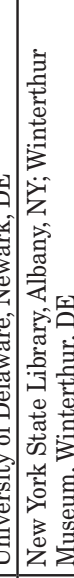 & 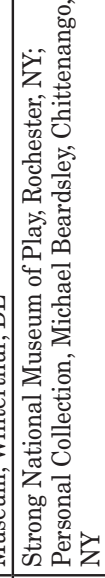 & 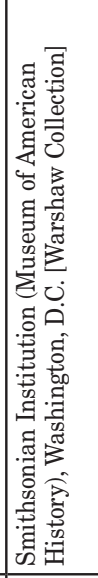 & 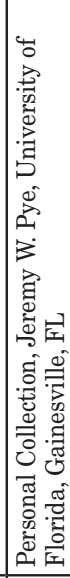 & 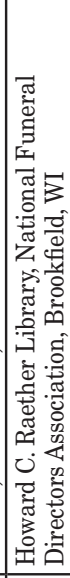 & 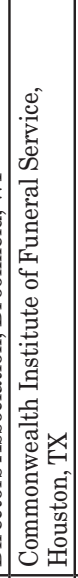 & 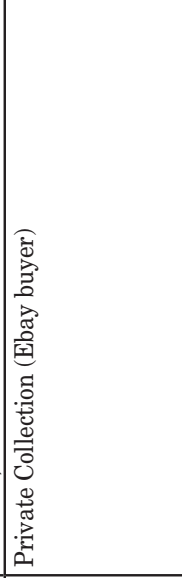 & 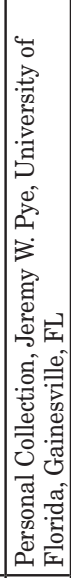 & 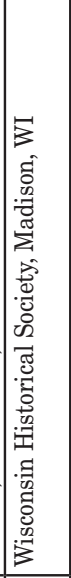 & 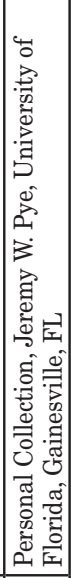 & 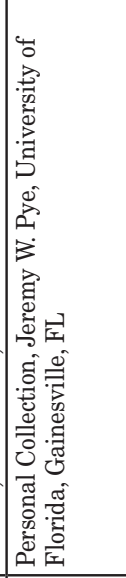 & 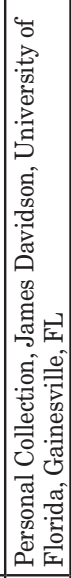 & 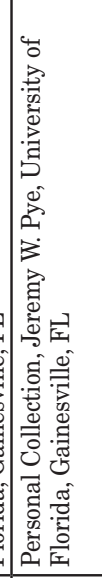 \\
\hline 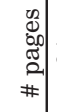 & मे & ลి & ఫే & $\stackrel{一}{8}$ & 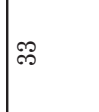 & 190 & 청 & p & 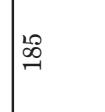 & $\stackrel{\infty}{\infty}$ & $\infty$ & & $\vec{s}$ & & $\begin{array}{l}\infty \\
\stackrel{\infty}{\sim}\end{array}$ & $\Xi$ & 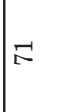 & & $\stackrel{\circ}{\circ}$ & \\
\hline 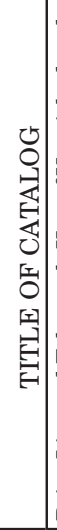 & 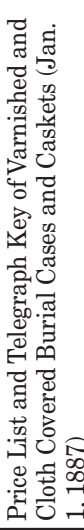 & 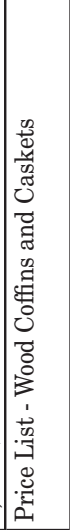 & 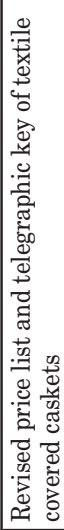 & 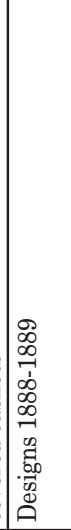 & 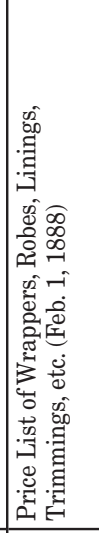 & 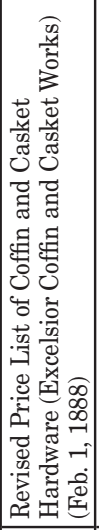 & & 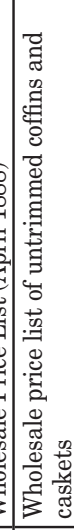 & 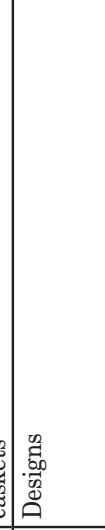 & 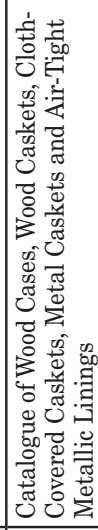 & 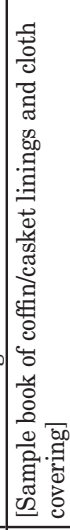 & 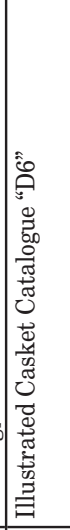 & 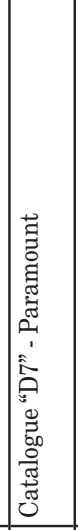 & 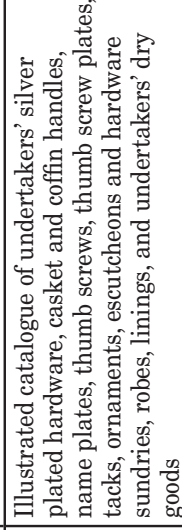 & 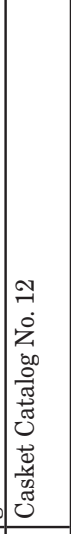 & 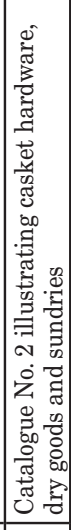 & 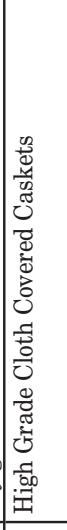 & 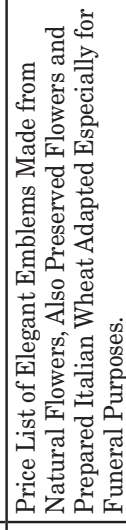 & 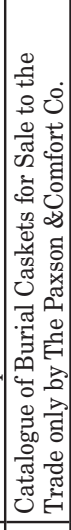 & 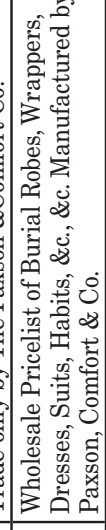 \\
\hline
\end{tabular}

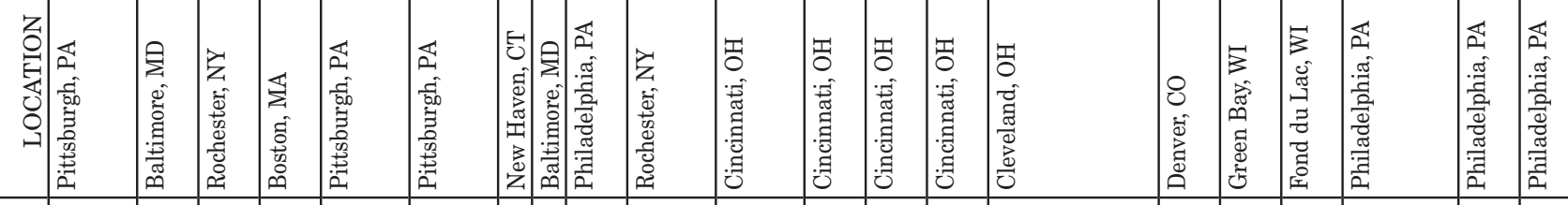

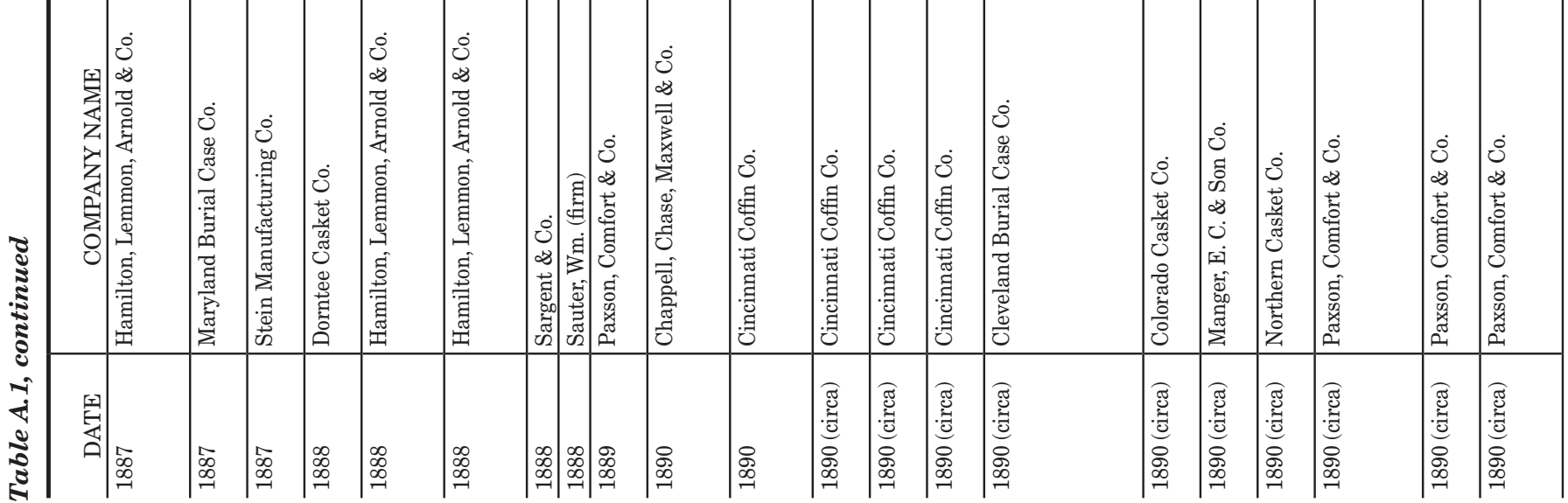


Investigations at Roberts Cemetery

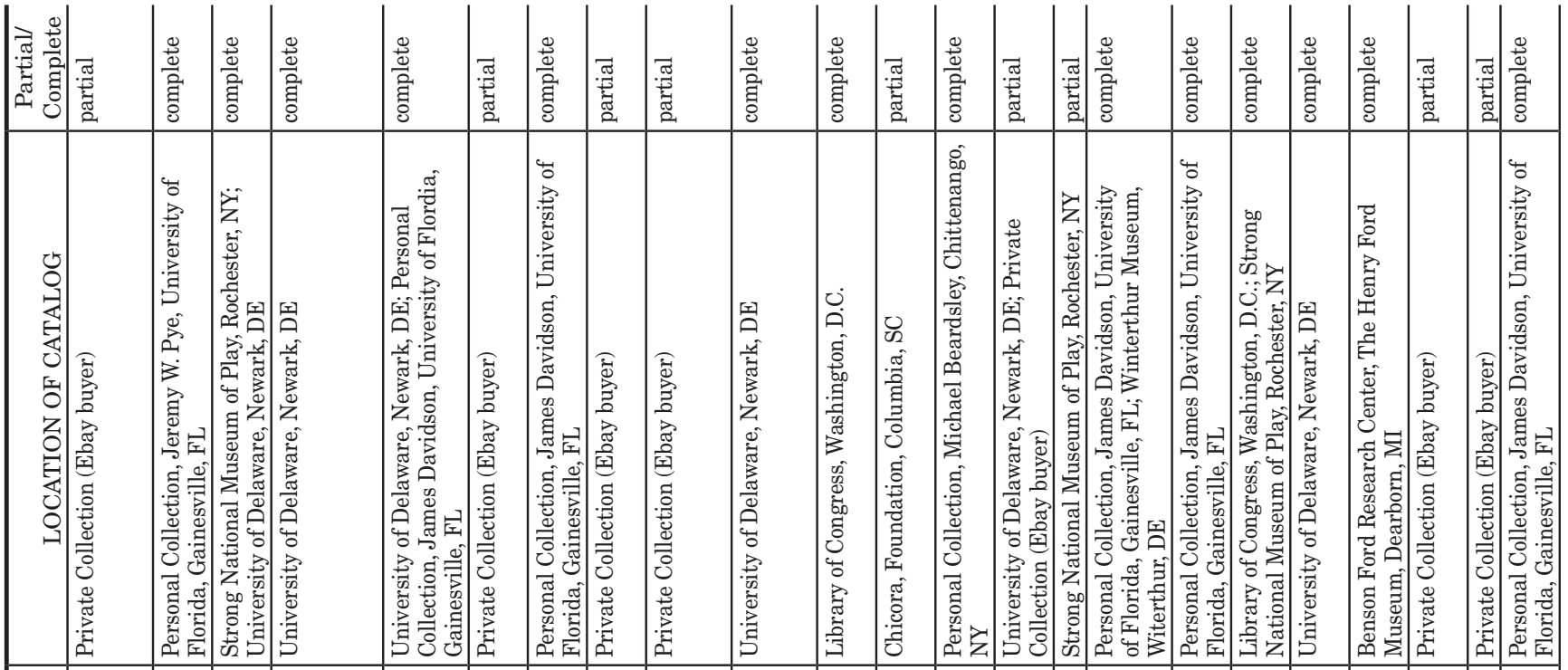

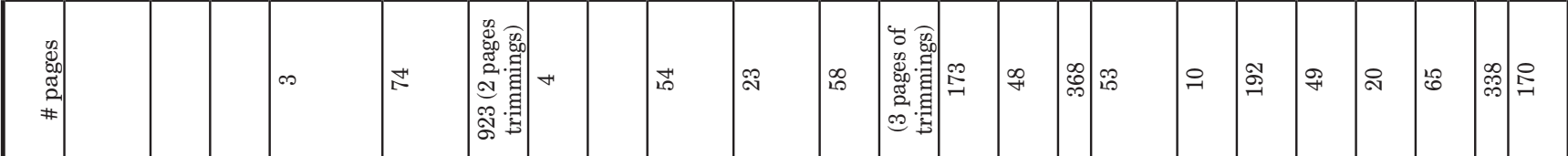

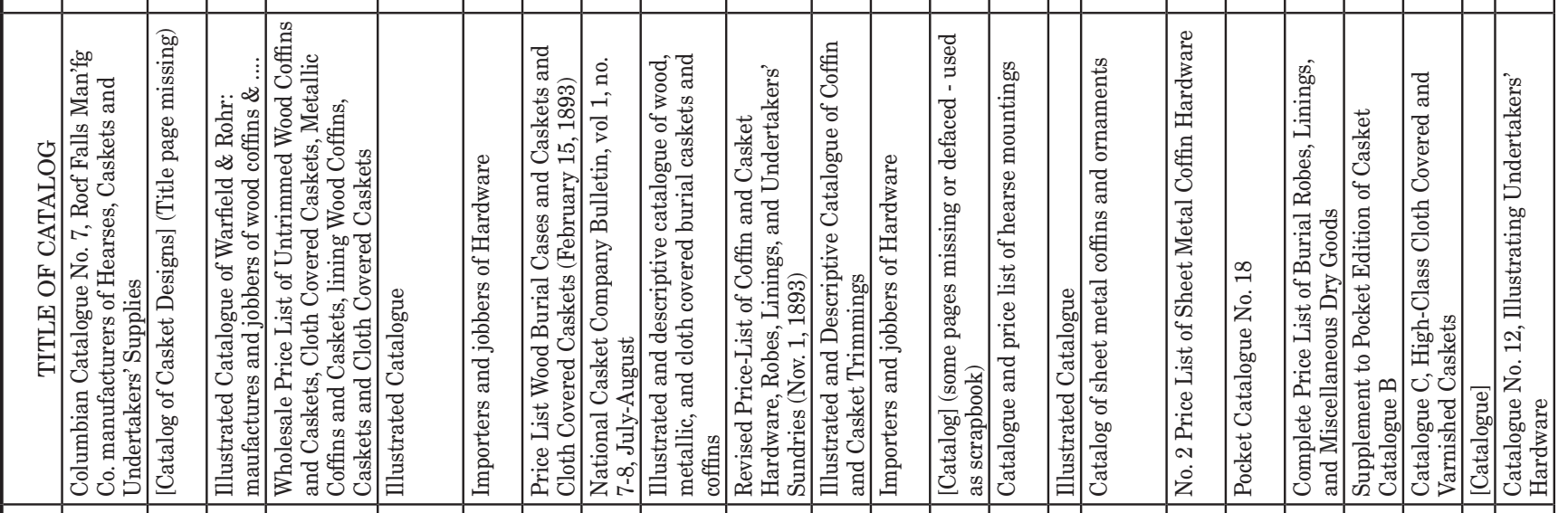

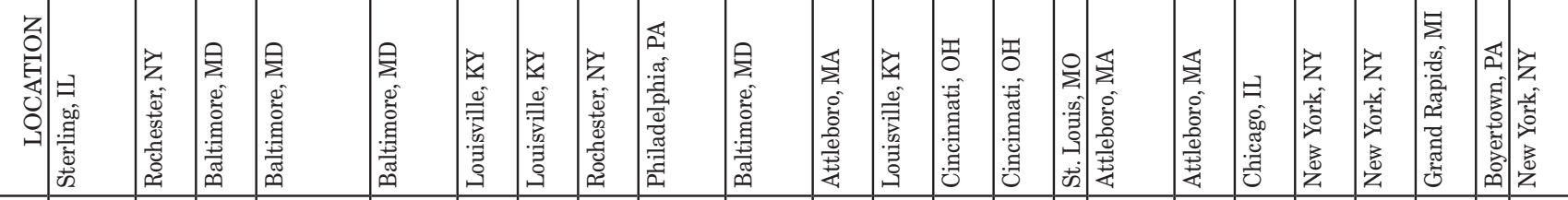

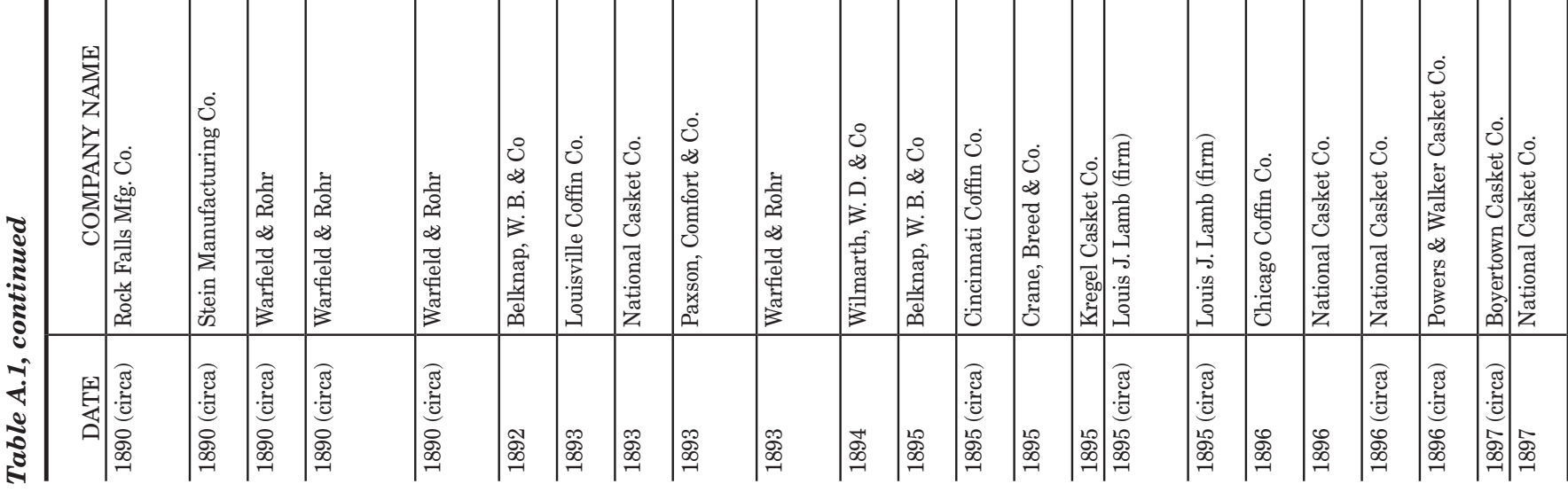


Appendix A: Mortuary Hardware

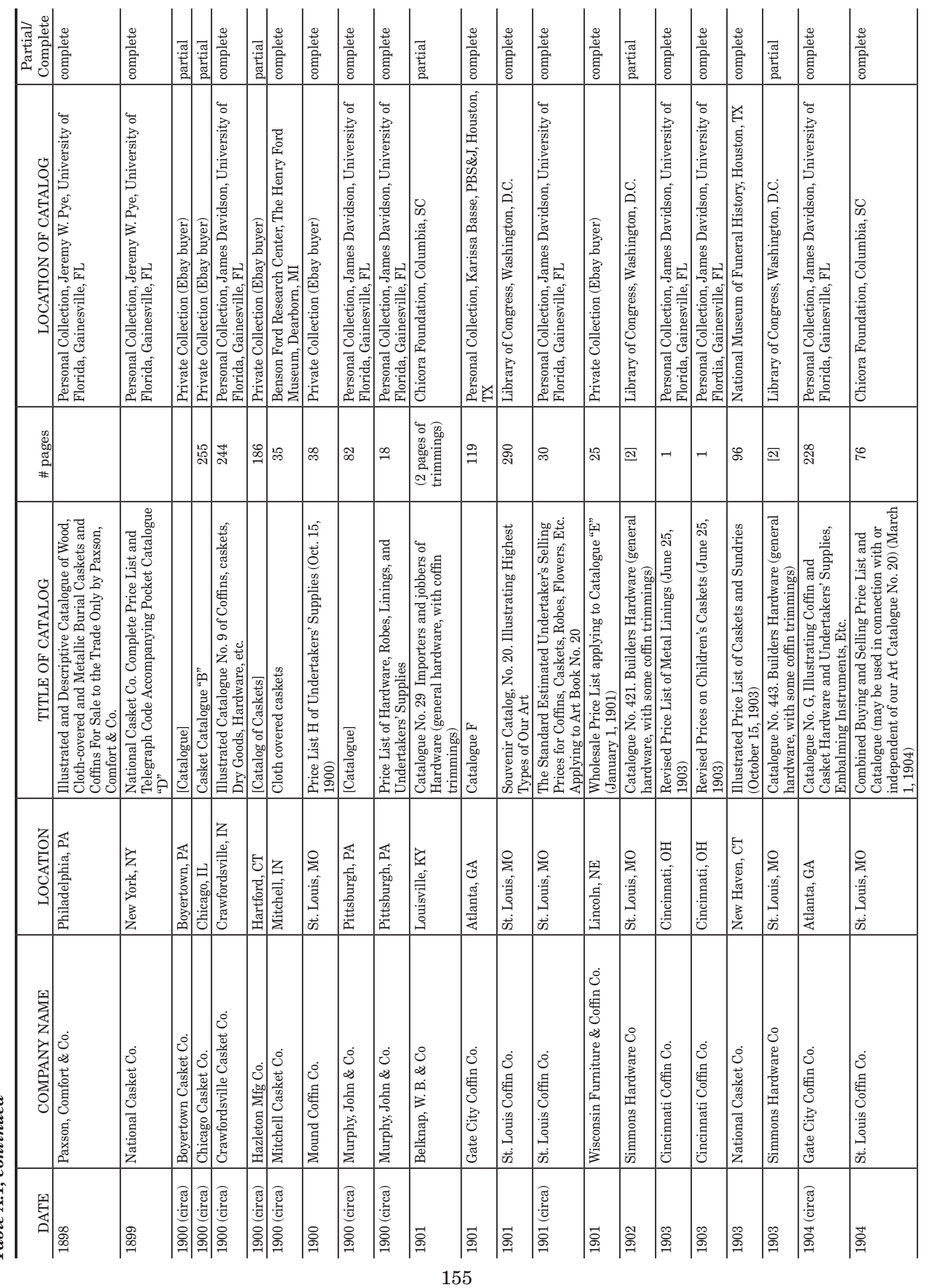




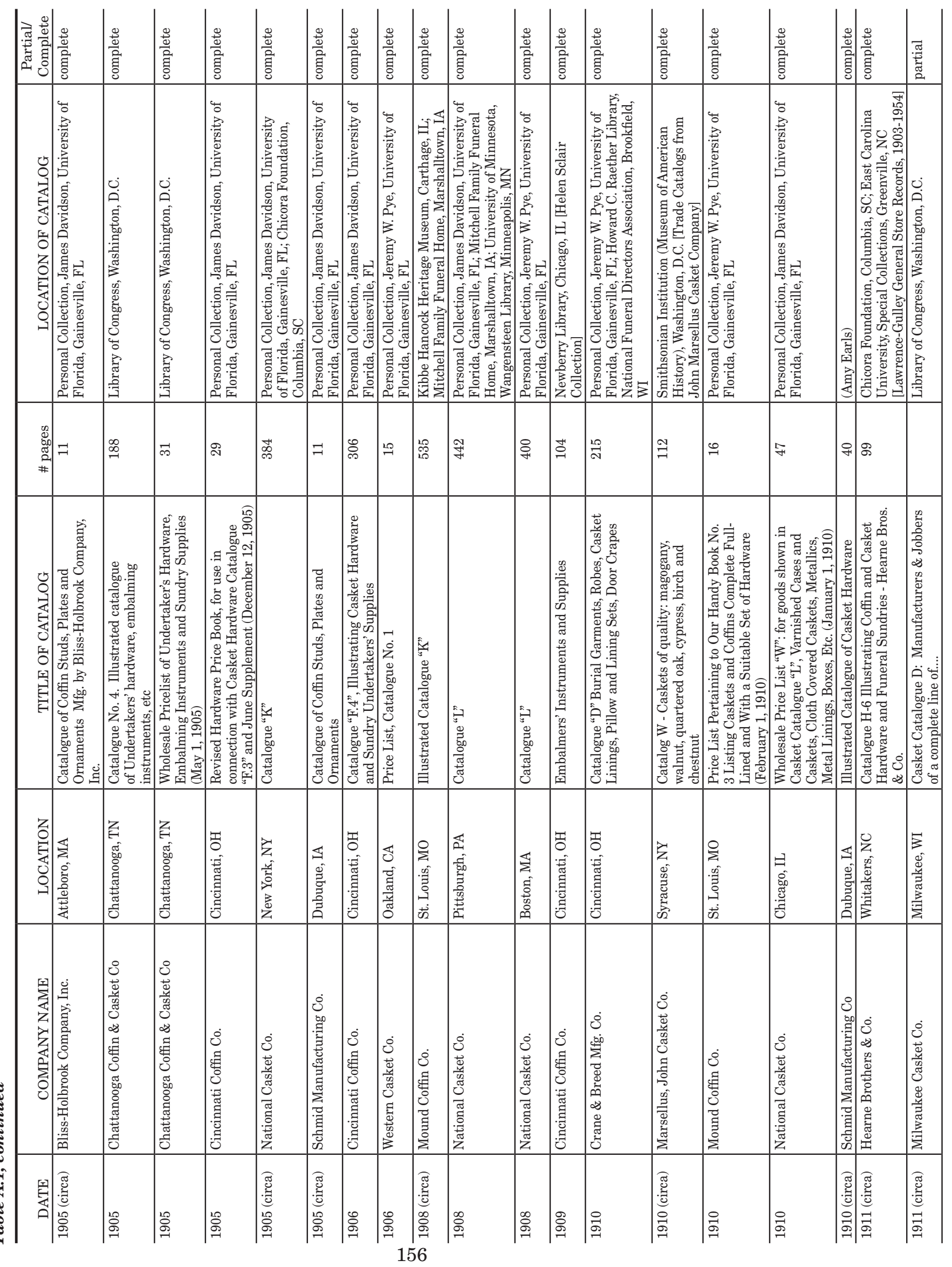




\section{Appendix A: Mortuary Hardware}

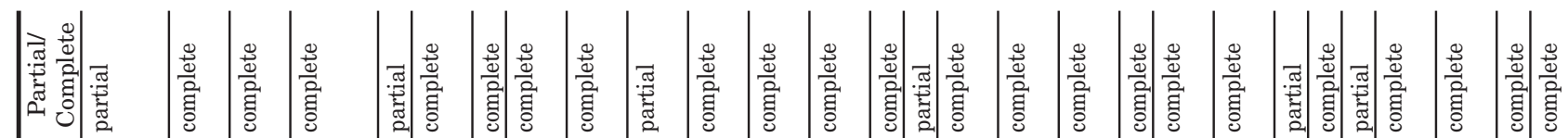

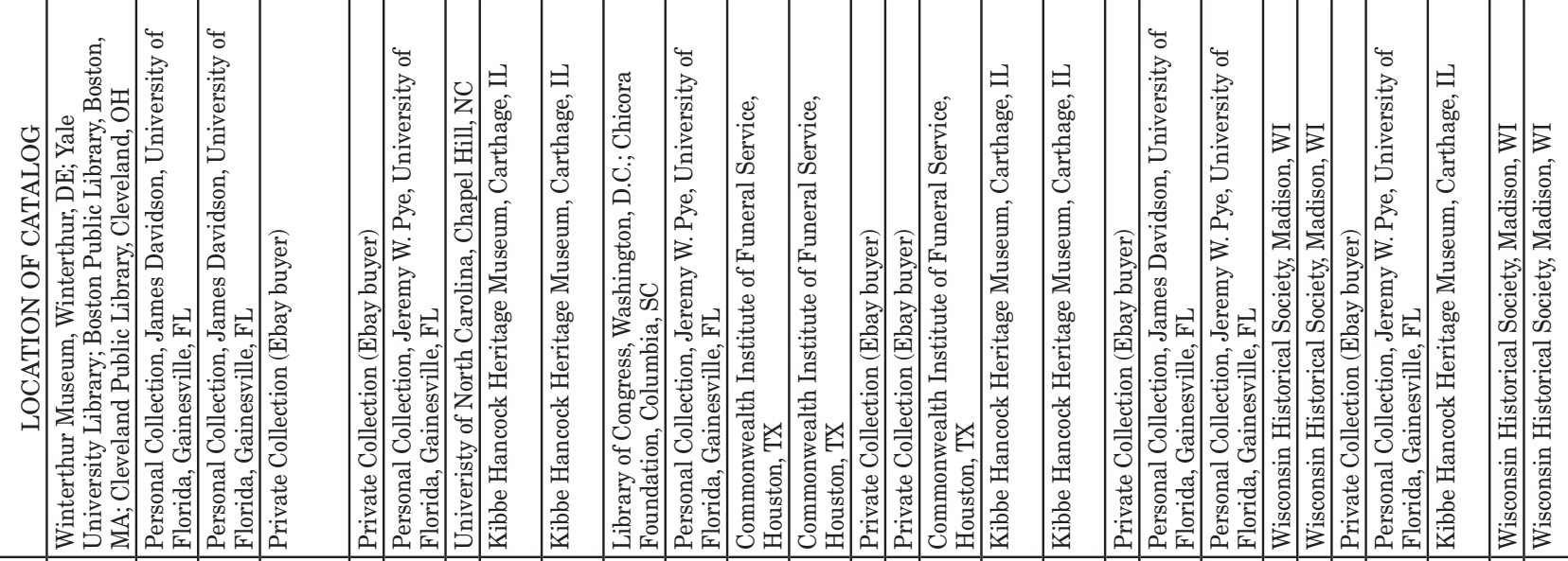

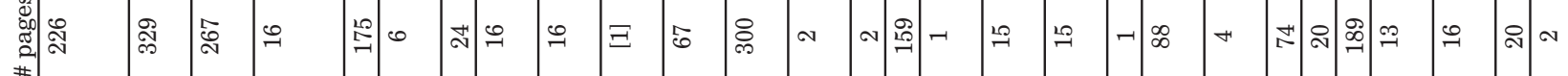

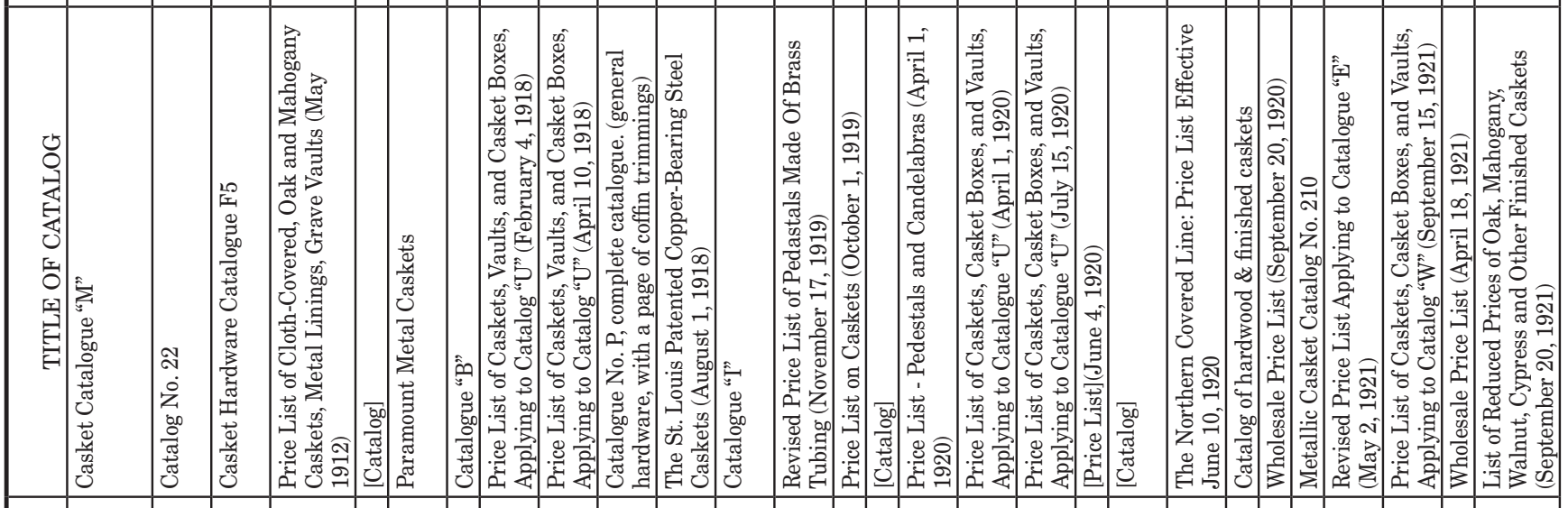

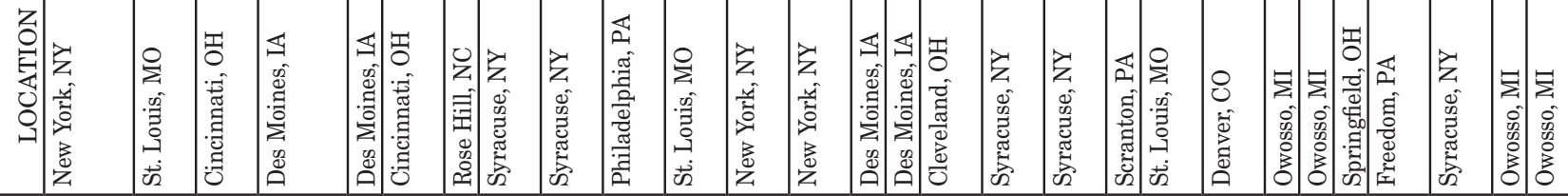

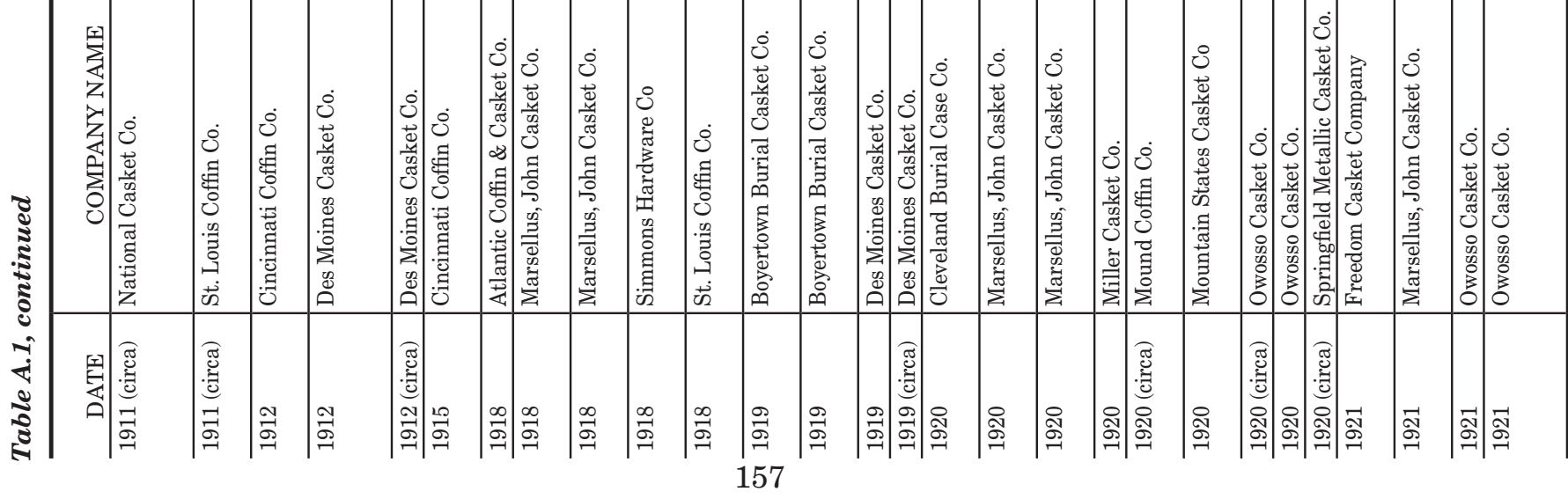


Investigations at Roberts Cemetery

\begin{tabular}{|c|c|c|c|c|c|c|c|c|c|c|c|c|c|c|c|c|c|c|c|c|c|}
\hline 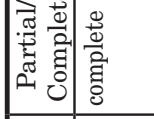 & $\begin{array}{l}\text { 迆 } \\
\text { : } \\
\text { : }\end{array}$ & 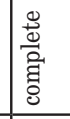 & 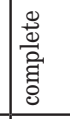 & 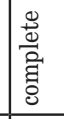 & 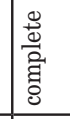 & 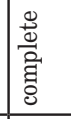 & 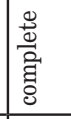 & 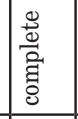 & 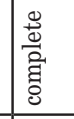 & 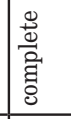 & 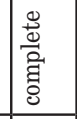 & 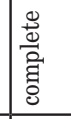 & 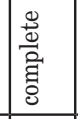 & 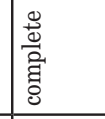 & 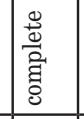 & 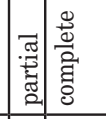 & 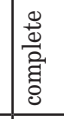 & 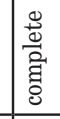 & 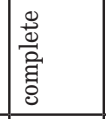 & 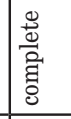 & \begin{tabular}{|l} 
\\
: \\
: \\
:
\end{tabular} \\
\hline 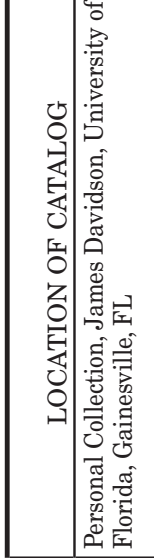 & 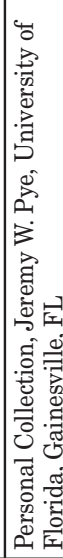 & 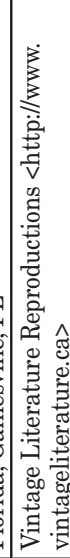 & 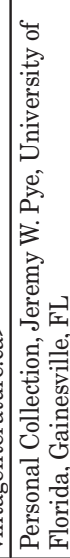 & 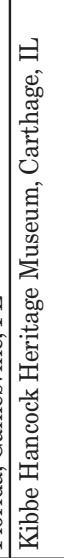 & 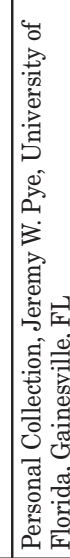 & 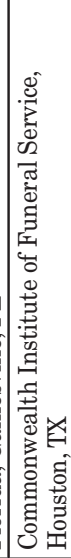 & 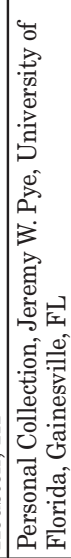 & 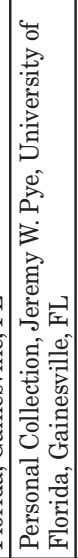 & 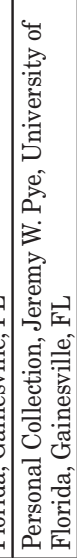 & 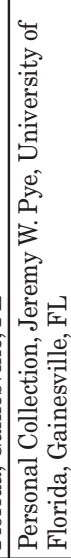 & 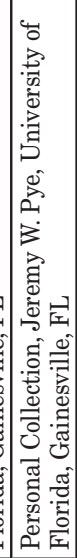 & 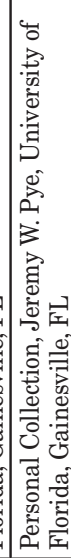 & 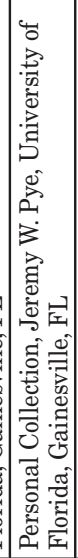 & 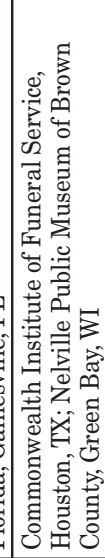 & 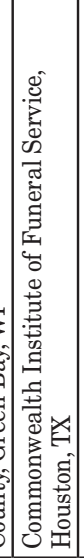 & 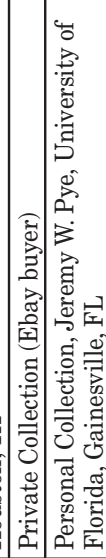 & 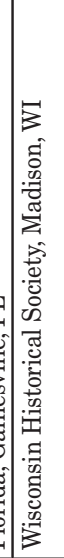 & 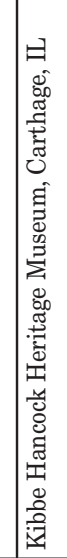 & 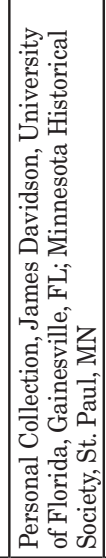 & 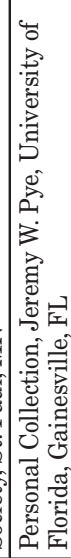 & 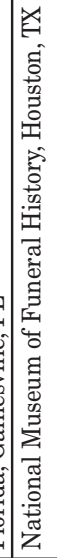 \\
\hline
\end{tabular}

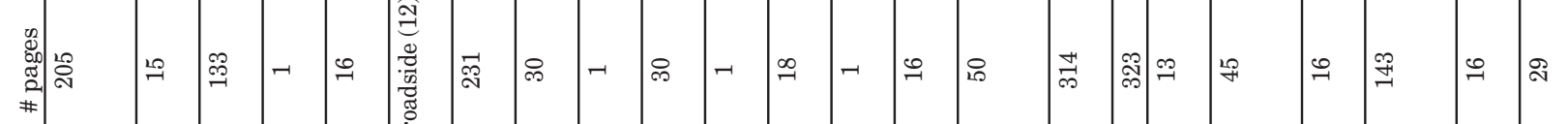

\begin{tabular}{|c|c|c|c|c|c|c|c|c|c|c|c|c|c|c|c|c|c|c|c|c|c|c|}
\hline 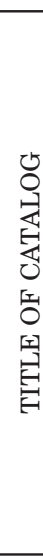 & 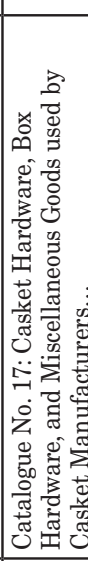 & 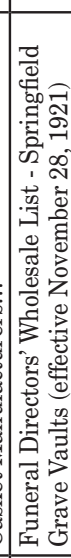 & 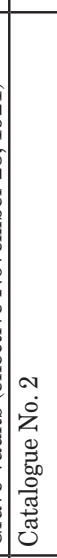 & 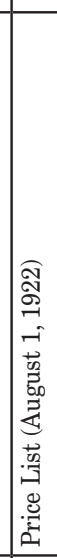 & 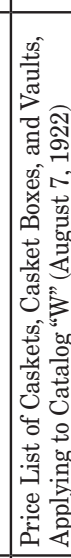 & 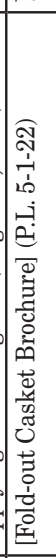 & 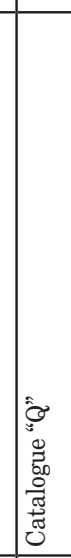 & 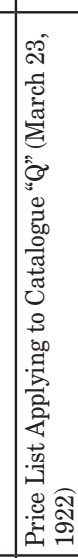 & 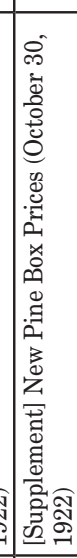 & 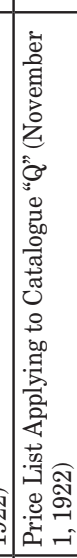 & 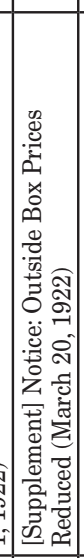 & 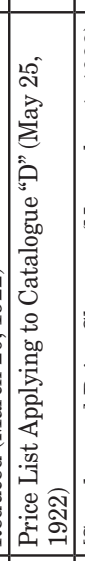 & 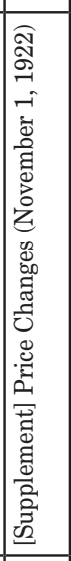 & 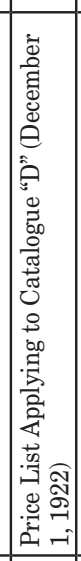 & 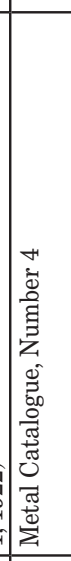 & 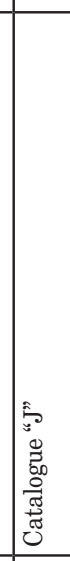 & 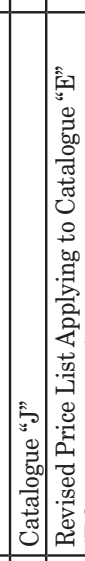 & 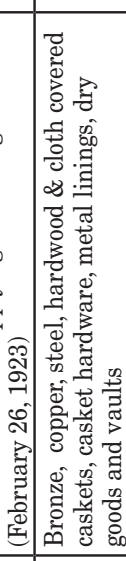 & 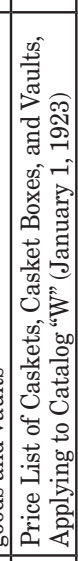 & 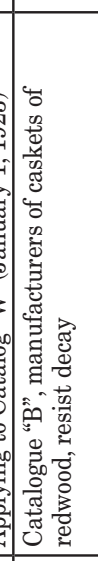 & 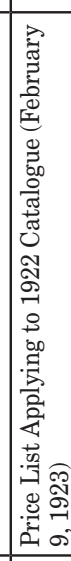 & 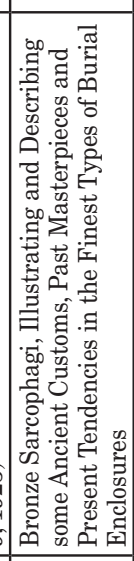 \\
\hline 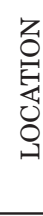 & 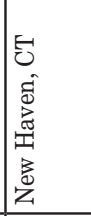 & 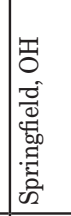 & 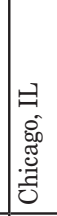 & & 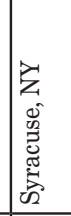 & 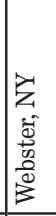 & 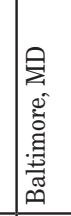 & 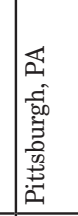 & 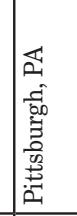 & 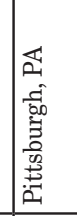 & 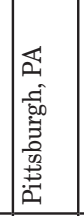 & 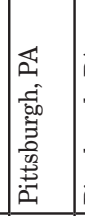 & 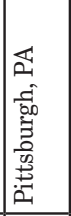 & 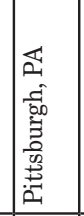 & 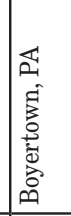 & 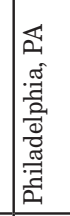 & 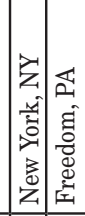 & 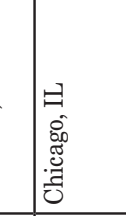 & 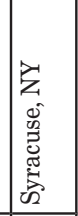 & 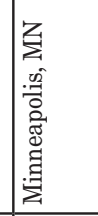 & 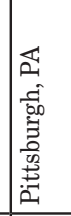 & 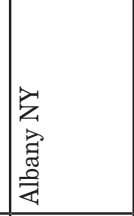 \\
\hline 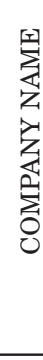 & 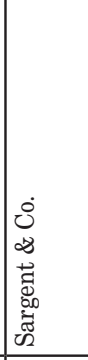 & 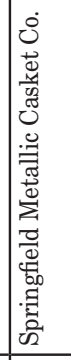 & 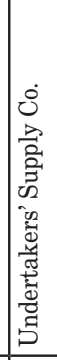 & & 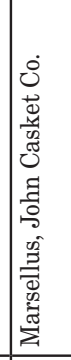 & 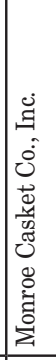 & 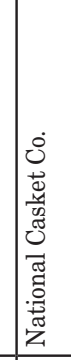 & 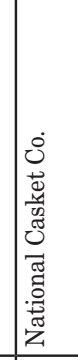 & 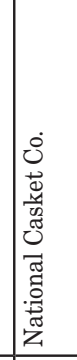 & 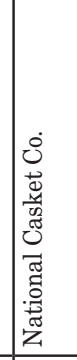 & 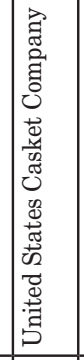 & 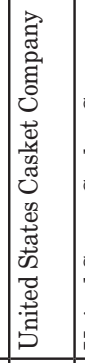 & 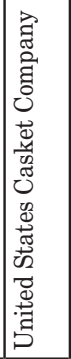 & 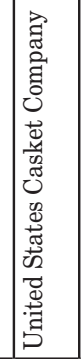 & 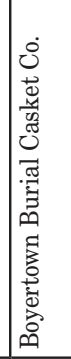 & 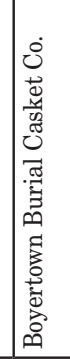 & 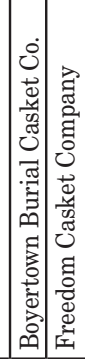 & 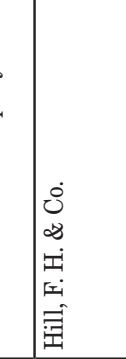 & 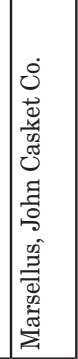 & 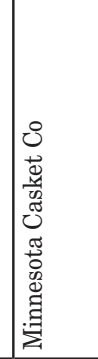 & 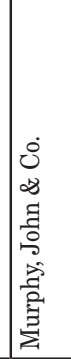 & 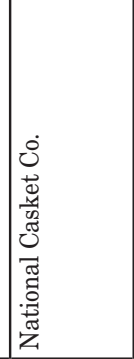 \\
\hline 罢 & 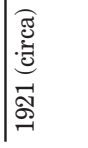 & $\mid \overrightarrow{\mathcal{J}}$ & 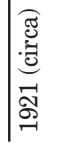 & 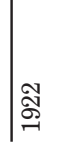 & 墕 & 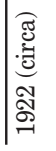 & 胥 & 墕 & 胥 & 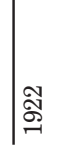 & 令 & |ू్య & |్ু్త్ & 鴊 & ๙ొఖ & 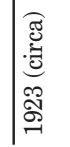 & 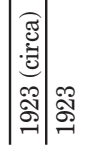 & 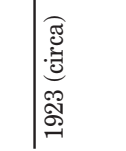 & 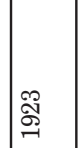 & 骨 & 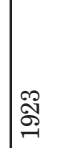 & ๙্] \\
\hline
\end{tabular}


Appendix A: Mortuary Hardware

(1)

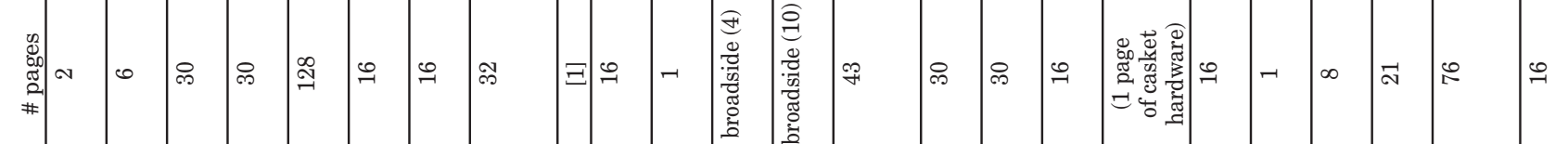

\begin{tabular}{|c|c|c|c|c|c|c|c|c|c|c|c|c|c|c|c|c|c|c|c|c|c|}
\hline & & & & & & & & & & & & & & & & & & & & & \\
\hline 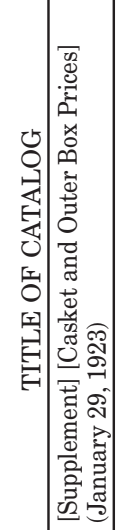 & 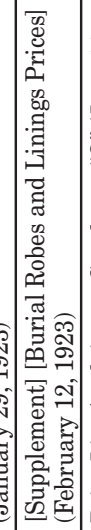 & 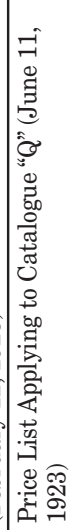 & 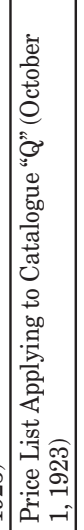 & 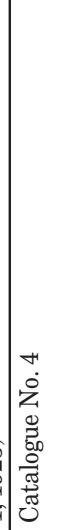 & 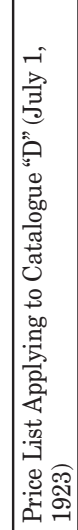 & 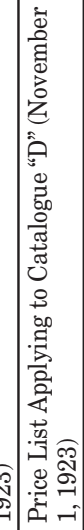 & 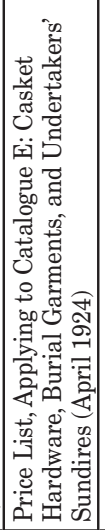 & 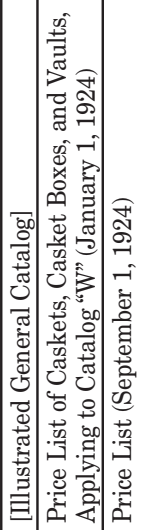 & 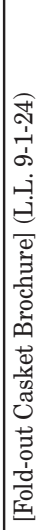 & 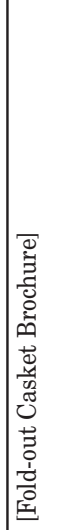 & 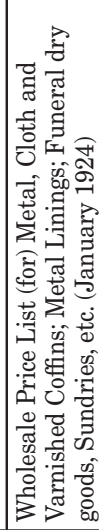 & 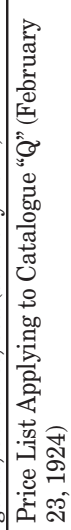 & 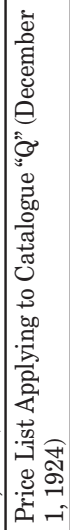 & 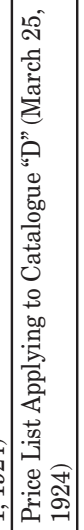 & 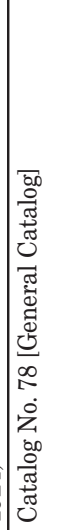 & 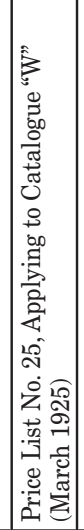 & 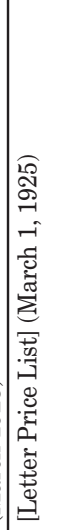 & 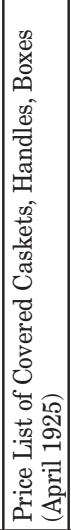 & 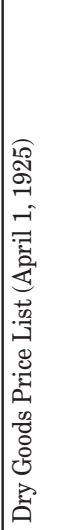 & 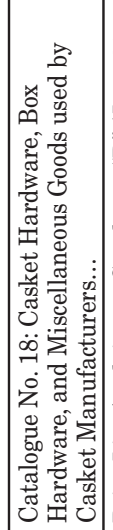 & 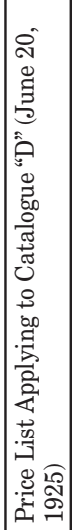 \\
\hline
\end{tabular}

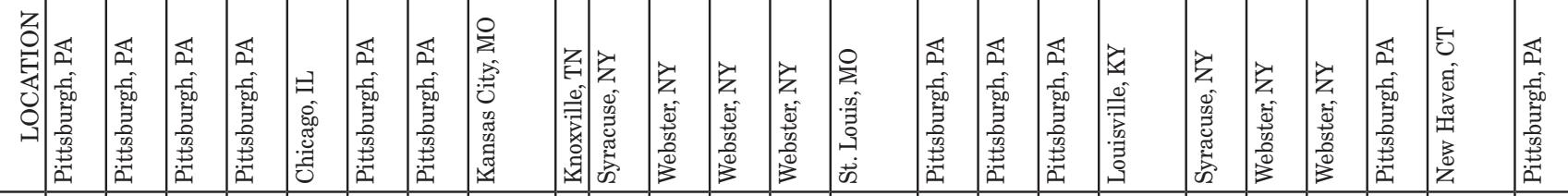

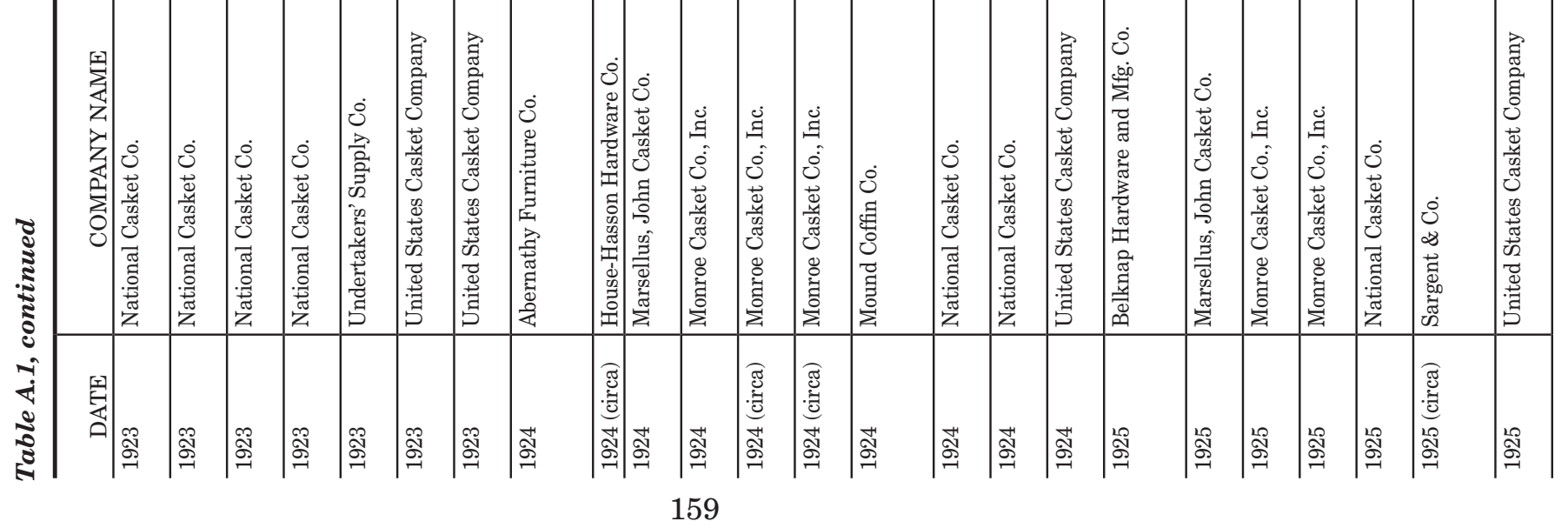


Investigations at Roberts Cemetery

\begin{tabular}{|c|c|c|c|c|c|c|c|c|c|c|c|c|c|c|c|c|c|c|c|c|c|}
\hline 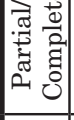 & & 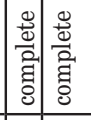 & 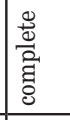 & 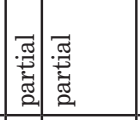 & 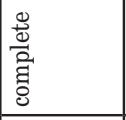 & 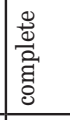 & 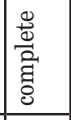 & 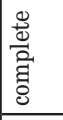 & 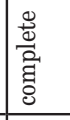 & 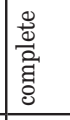 & 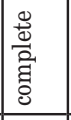 & 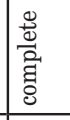 & 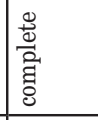 & 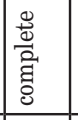 & 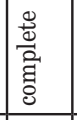 & 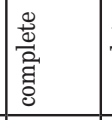 & 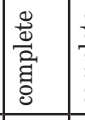 & 总 & 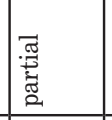 & 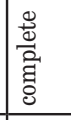 & 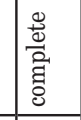 \\
\hline 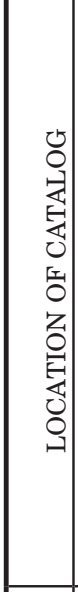 & 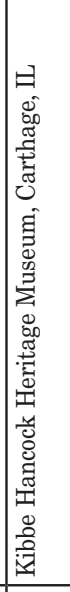 & 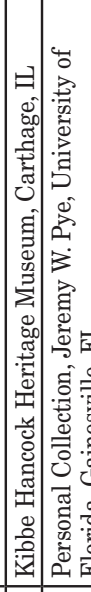 & 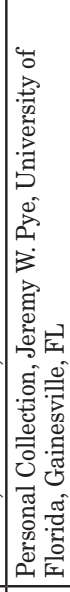 & 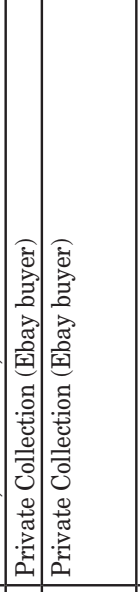 & 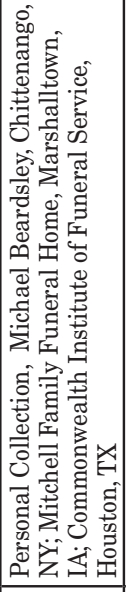 & 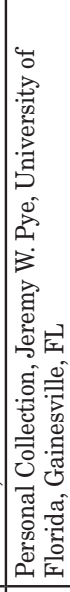 & 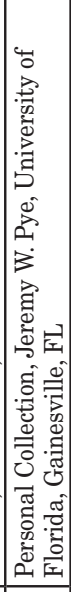 & 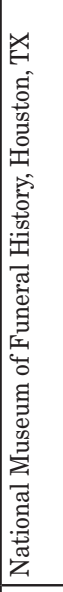 & 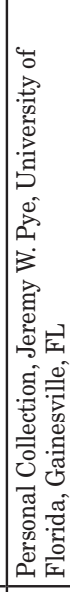 & 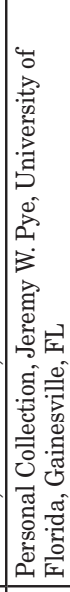 & 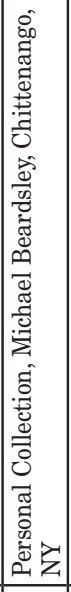 & 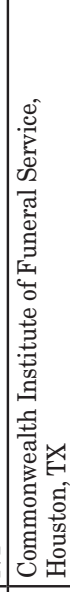 & 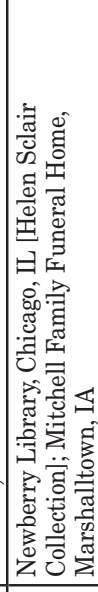 & 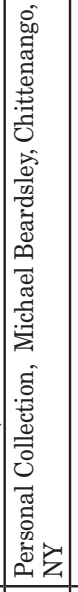 & 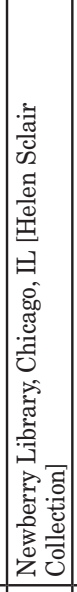 & 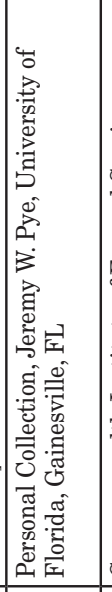 & 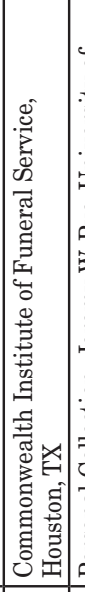 & 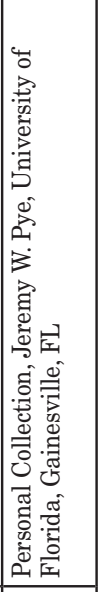 & 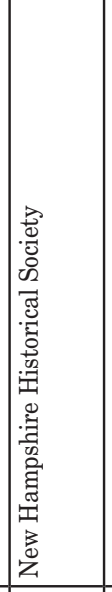 & 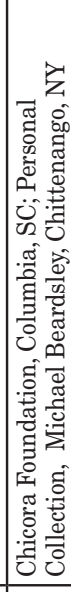 & 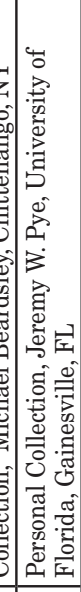 \\
\hline $\begin{array}{l}\text { aे } \\
0 \\
0 \\
2 \\
\# \\
\#\end{array}$ & 하 & 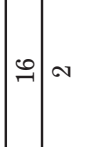 & $\dashv$ & $=$ & ș & $\neg$ & $\neg$ & N & $-r$ & $\neg$ & ๓ి & $\stackrel{\mathbb{N}}{\stackrel{\sim}{\sim}}$ & $\delta$ & $\stackrel{5}{\stackrel{5}{10}}$ & 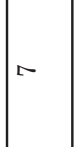 & $\infty$ & 局 & 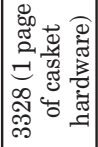 & F & 농 & $\infty$ \\
\hline 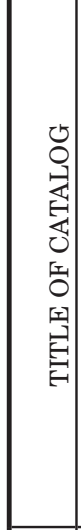 & 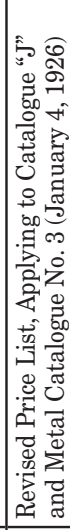 & 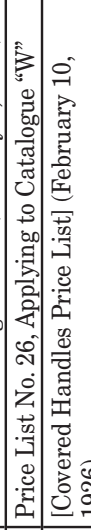 & 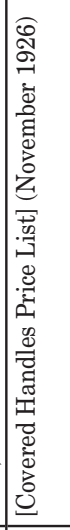 & 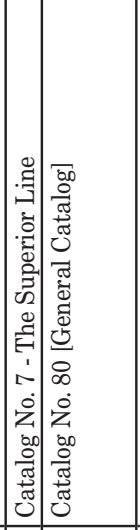 & 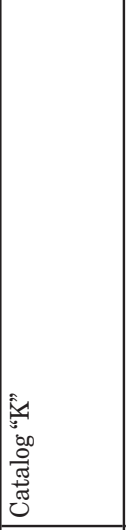 & 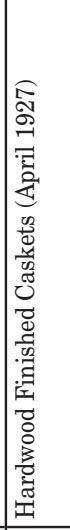 & 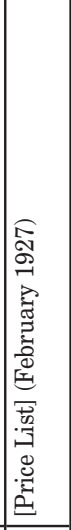 & 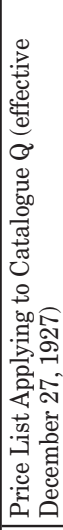 & 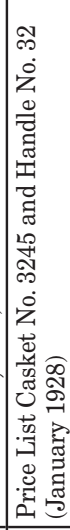 & 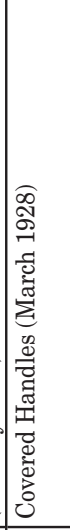 & 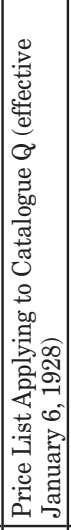 & 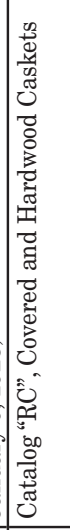 & 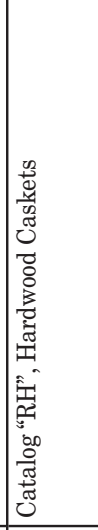 & 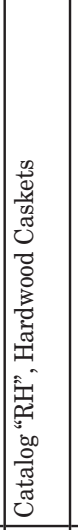 & 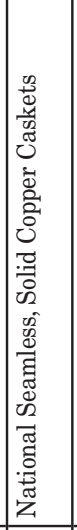 & 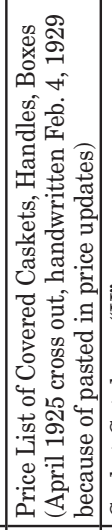 & 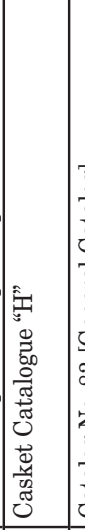 & 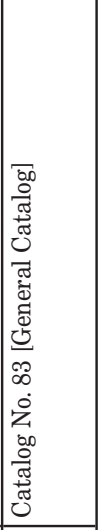 & 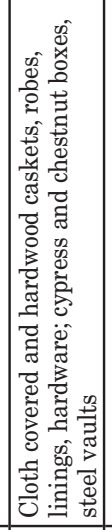 & 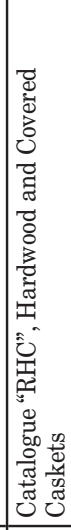 & 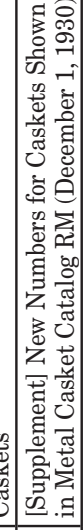 \\
\hline
\end{tabular}

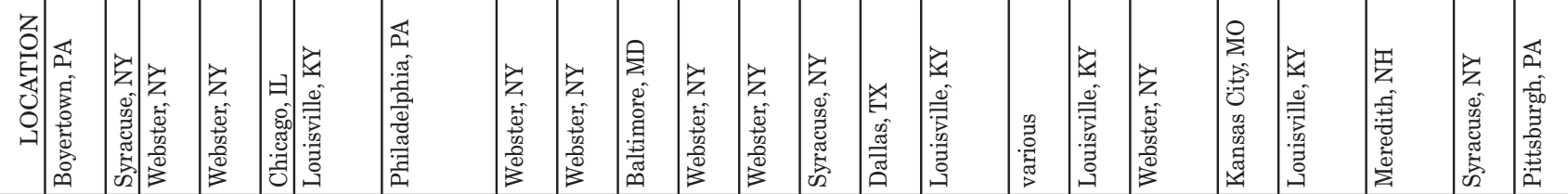

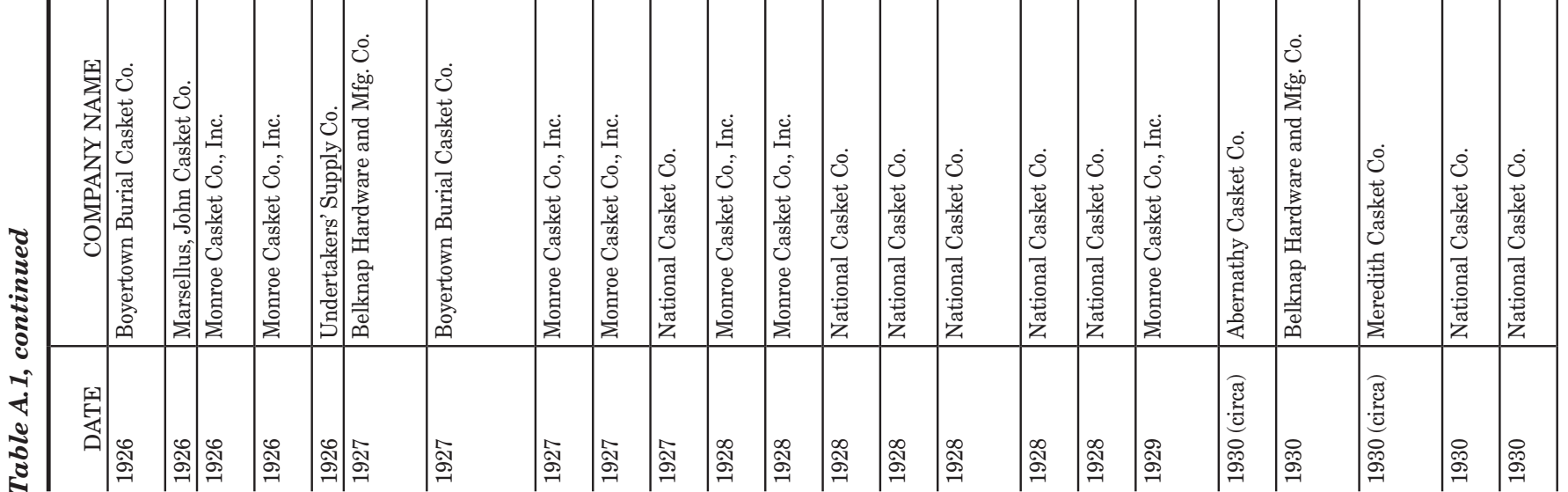


Appendix A: Mortuary Hardware

\begin{tabular}{|c|c|c|c|c|c|c|c|c|c|c|c|c|c|c|c|c|}
\hline 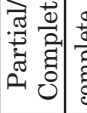 & & 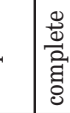 & $\mid$ & 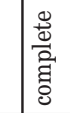 & 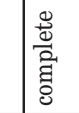 & 嵒 & 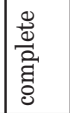 & $\mid$ & 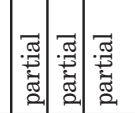 & 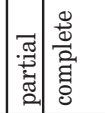 & 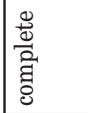 & 总 & 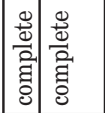 & 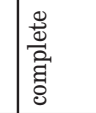 & 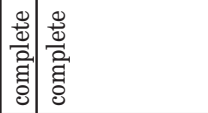 & 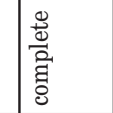 \\
\hline 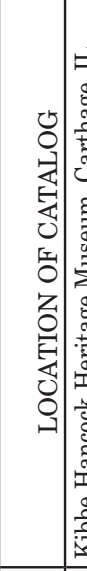 & 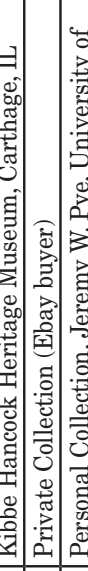 & 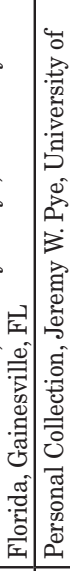 & 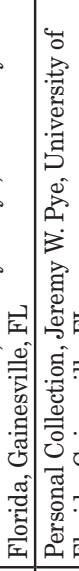 & 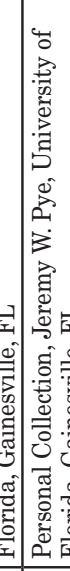 & 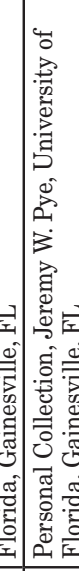 & 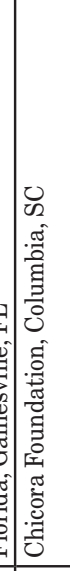 & 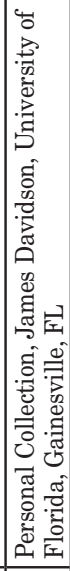 & 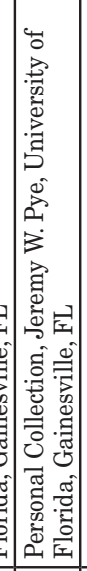 & 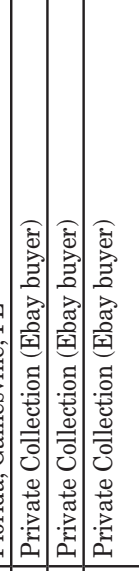 & 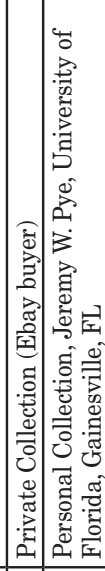 & 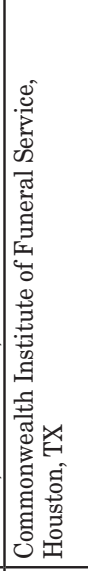 & 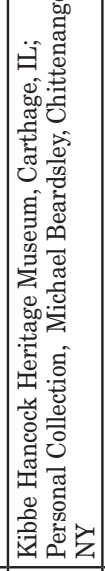 & 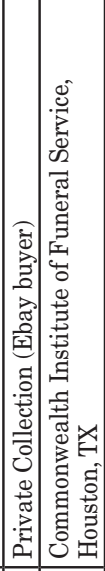 & 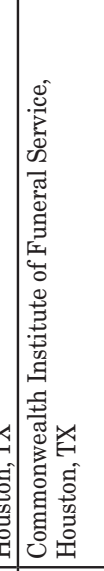 & 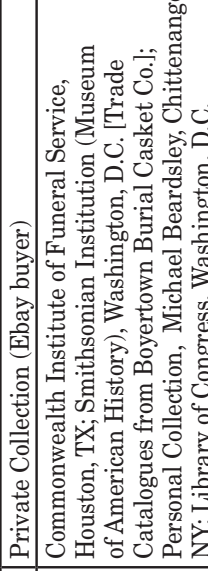 & 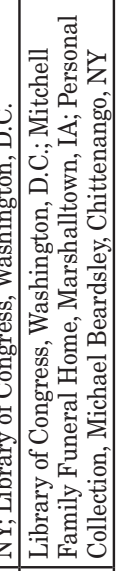 \\
\hline
\end{tabular}

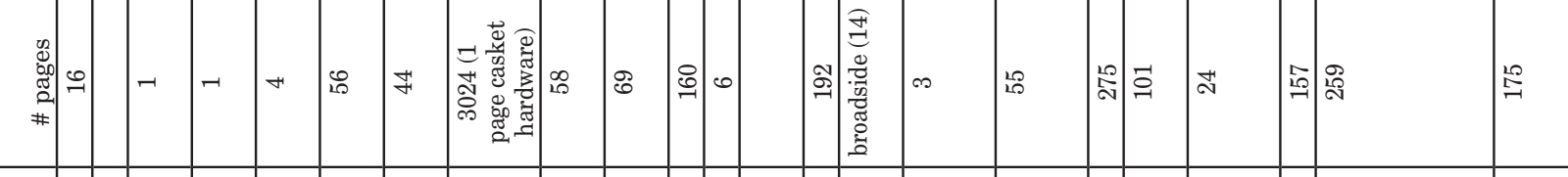

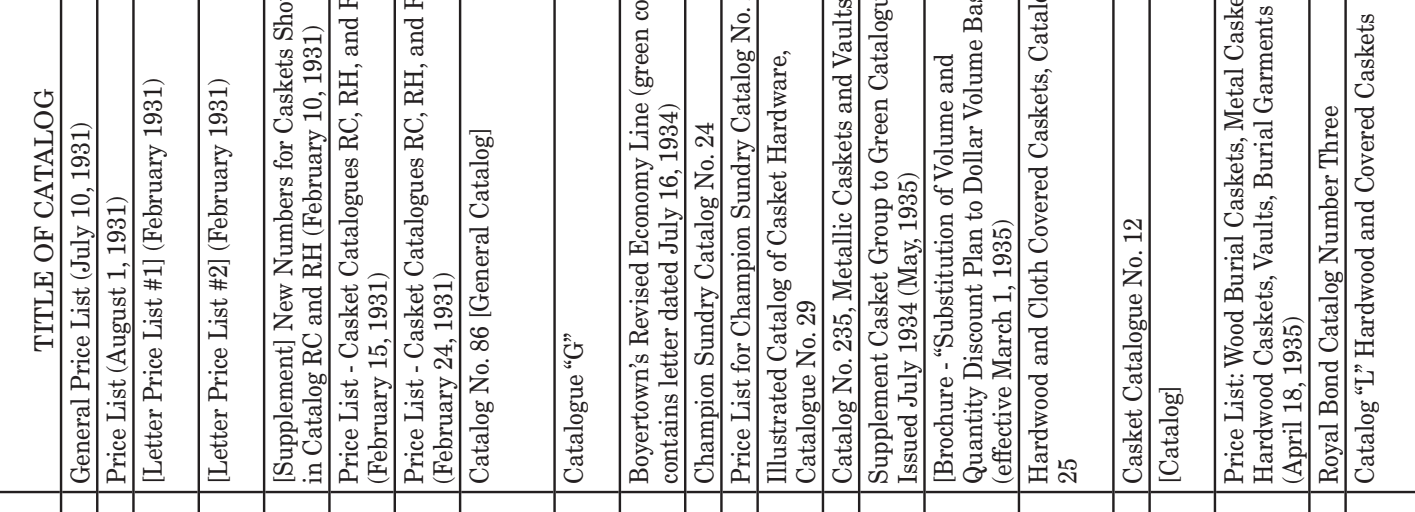

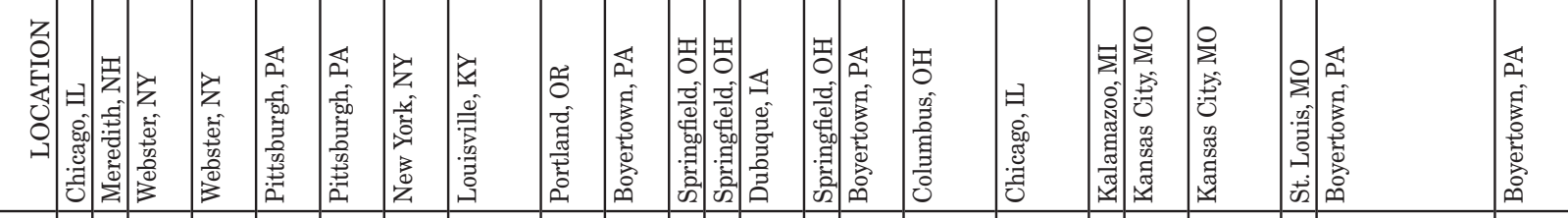

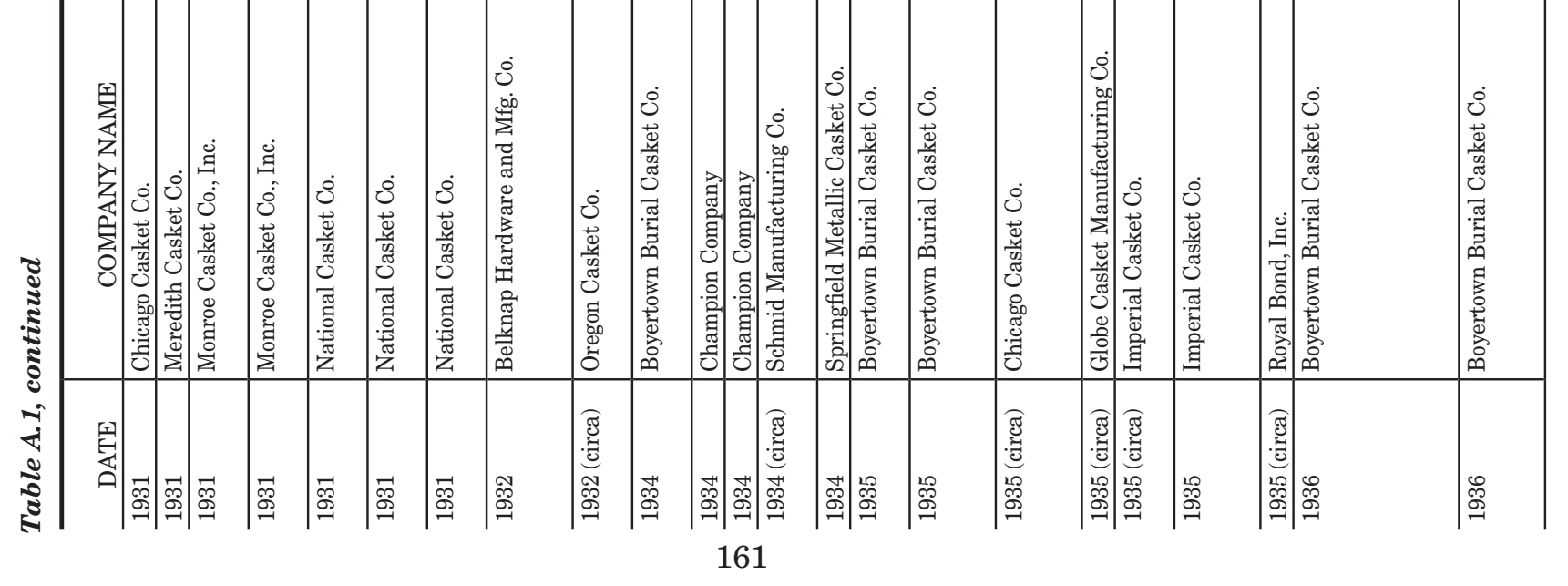




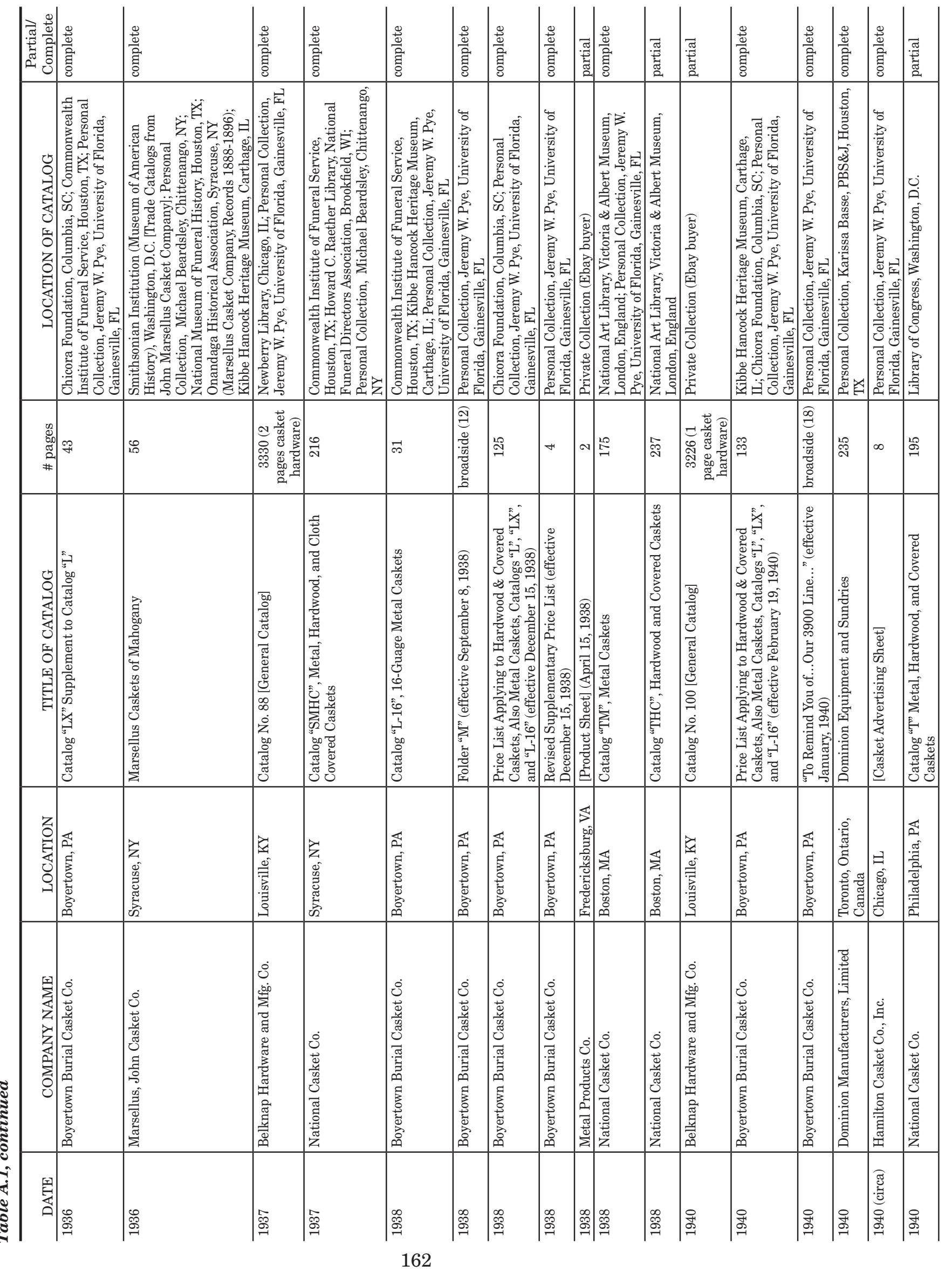


Appendix A: Mortuary Hardware

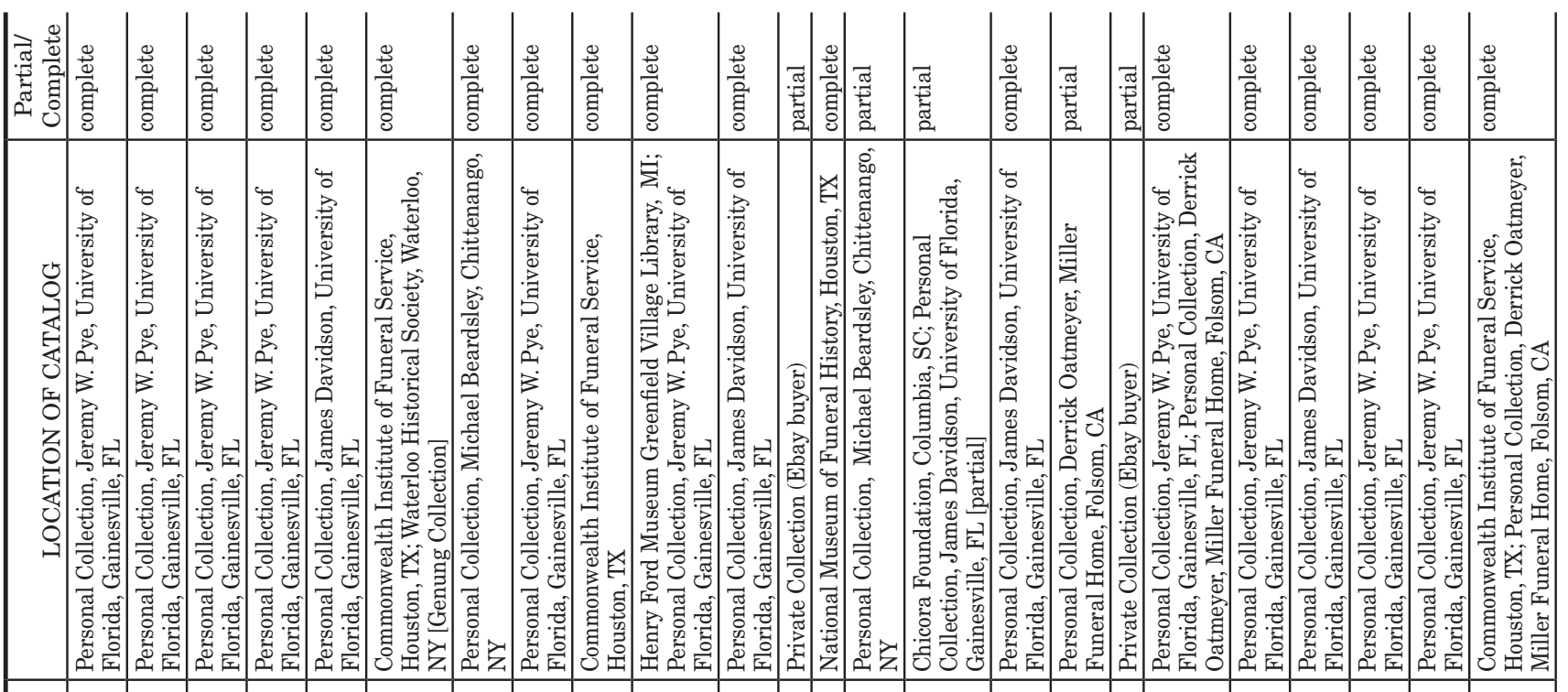

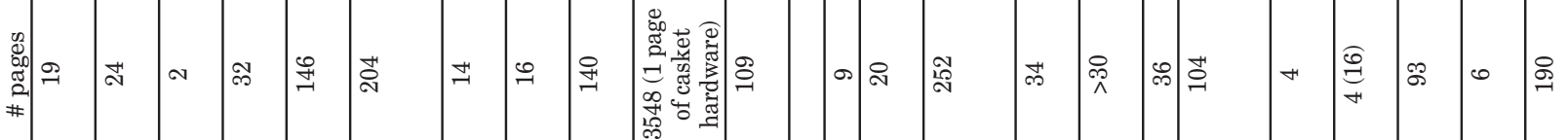

\begin{tabular}{|c|c|c|c|c|c|c|c|c|c|c|c|c|c|c|c|c|c|c|c|c|}
\hline 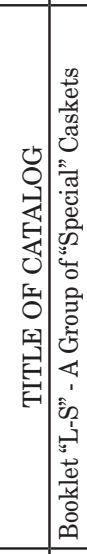 & 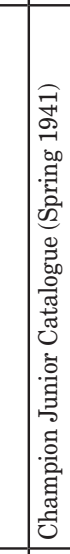 & 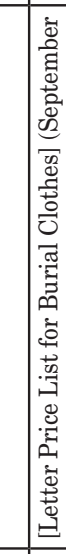 & 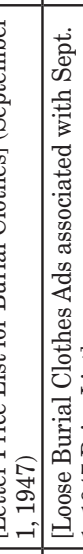 & & 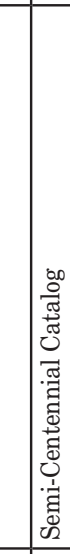 & & 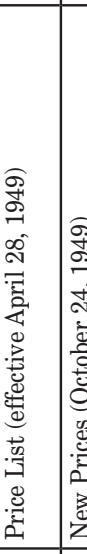 & 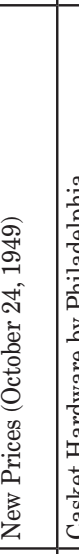 & & 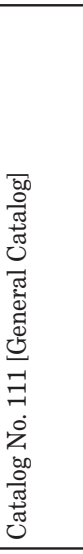 & 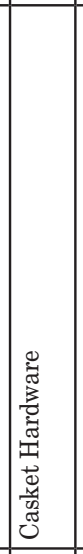 & 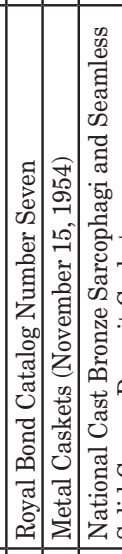 & 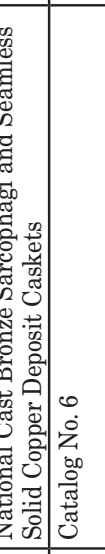 & 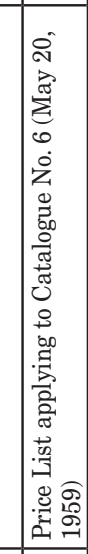 & 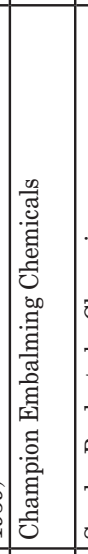 & 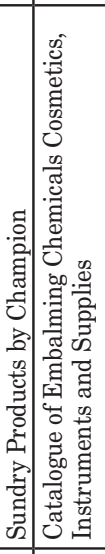 & 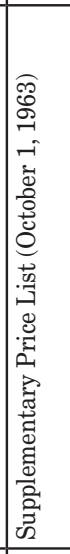 & 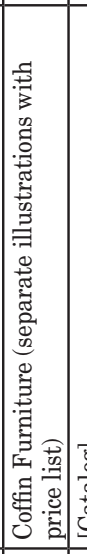 & 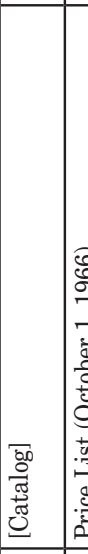 & 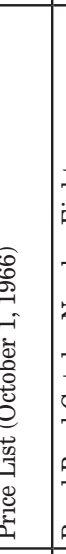 \\
\hline \begin{tabular}{l|l} 
\\
0
\end{tabular} & 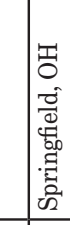 & 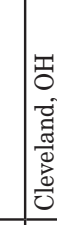 & 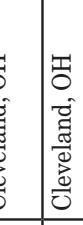 & 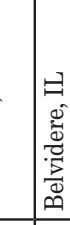 & 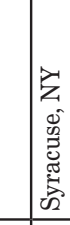 & & 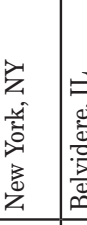 & 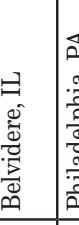 & 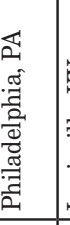 & 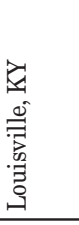 & 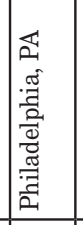 & 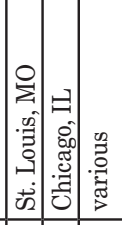 & 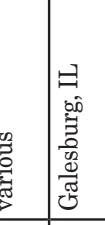 & 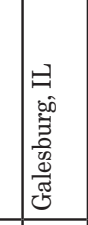 & 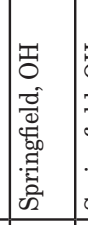 & 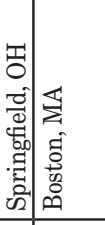 & 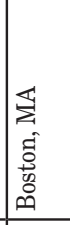 & 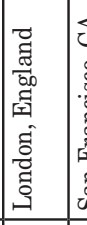 & 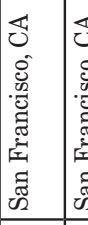 & 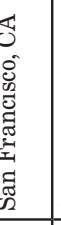 \\
\hline 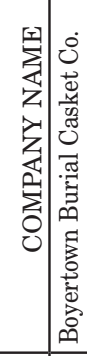 & 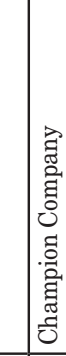 & 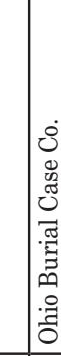 & 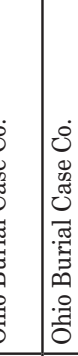 & 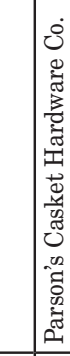 & 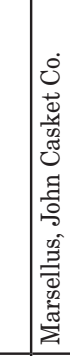 & & 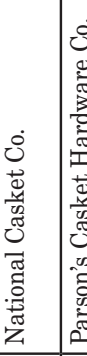 & 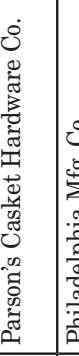 & 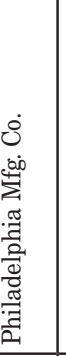 & 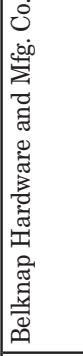 & 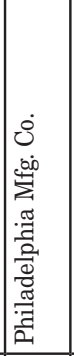 & 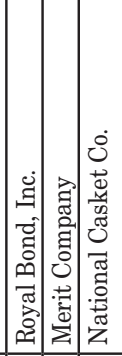 & 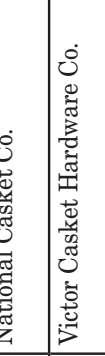 & 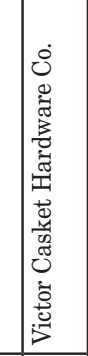 & 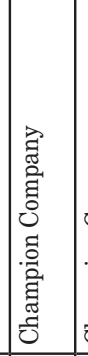 & 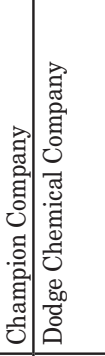 & 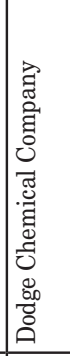 & 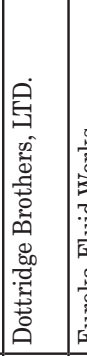 & 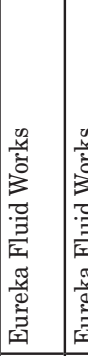 & 象 \\
\hline 国 & F্ & & & & 否 & & 鮝 & 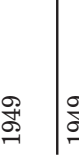 & 悉 & 喿 & . & 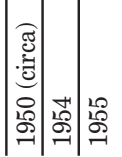 & 惫 & 骂 & 㦯 & 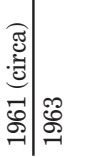 & 㤎 & 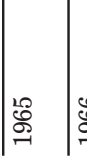 & 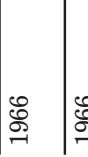 & : \\
\hline
\end{tabular}


Investigations at Roberts Cemetery

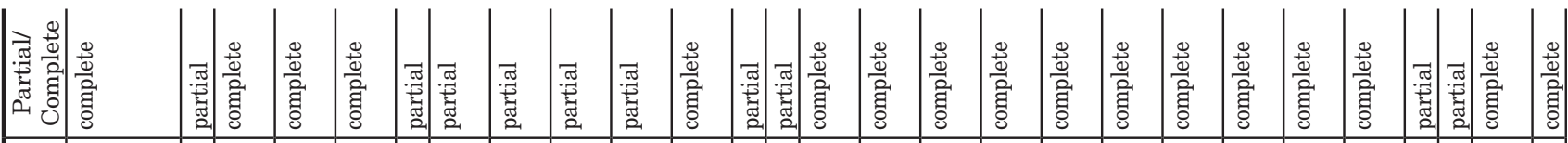

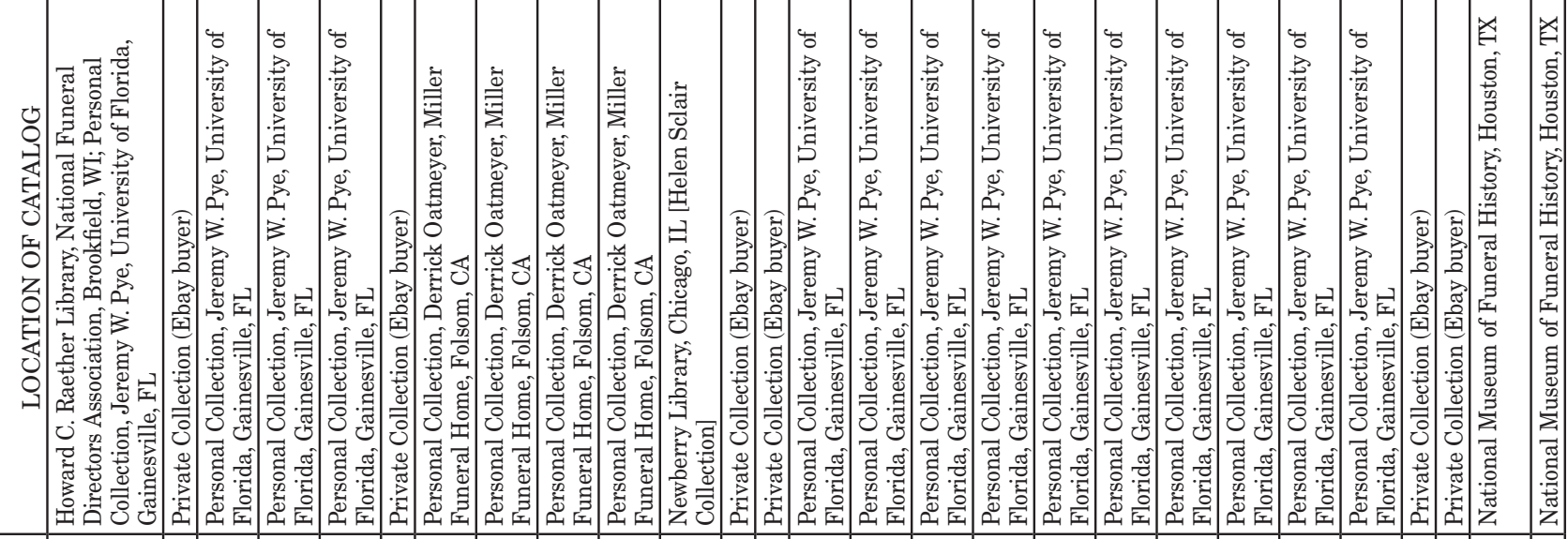

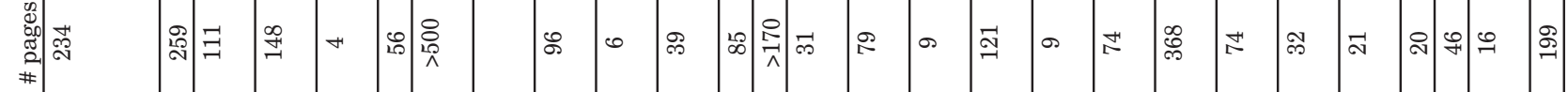

\begin{tabular}{|c|c|c|c|c|c|c|c|c|c|c|c|c|c|c|c|c|c|c|c|c|c|c|}
\hline 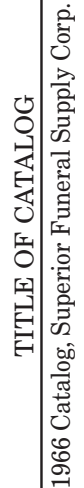 & 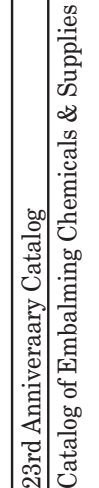 & 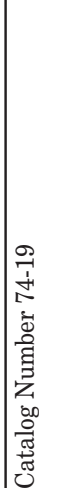 & 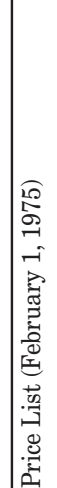 & 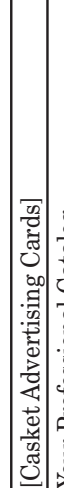 & 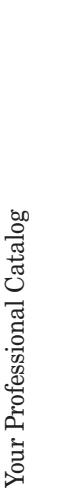 & 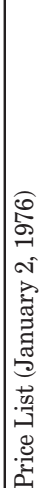 & 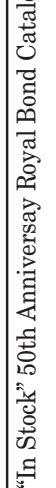 & 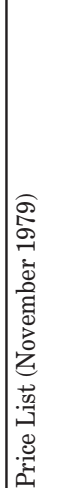 & 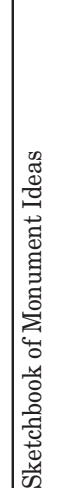 & 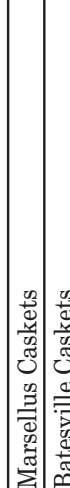 & 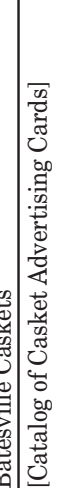 & 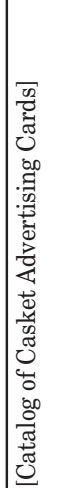 & 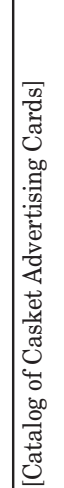 & 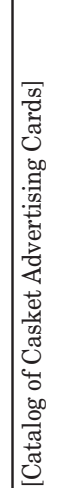 & 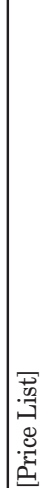 & 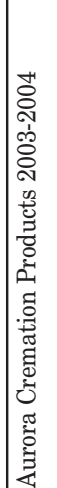 & 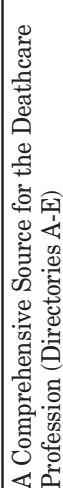 & 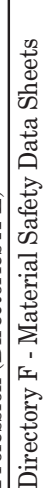 & 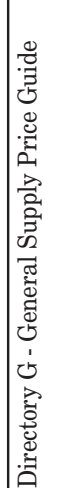 & 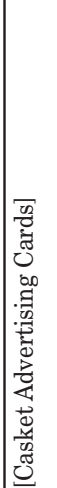 & & 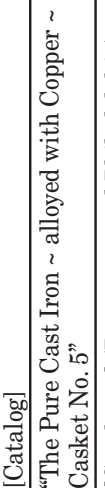 \\
\hline
\end{tabular}

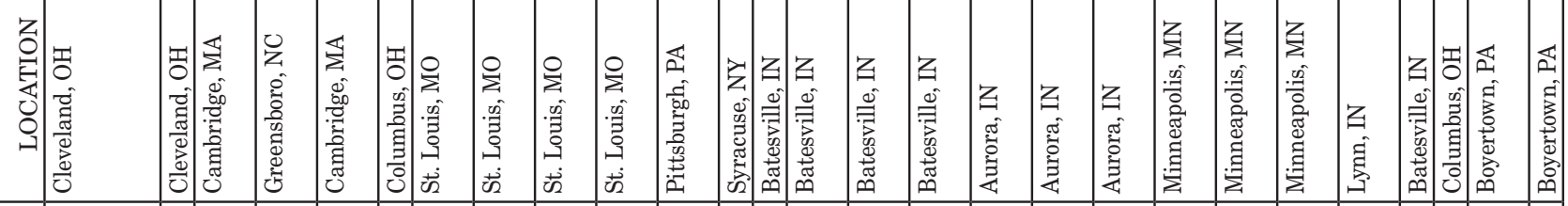

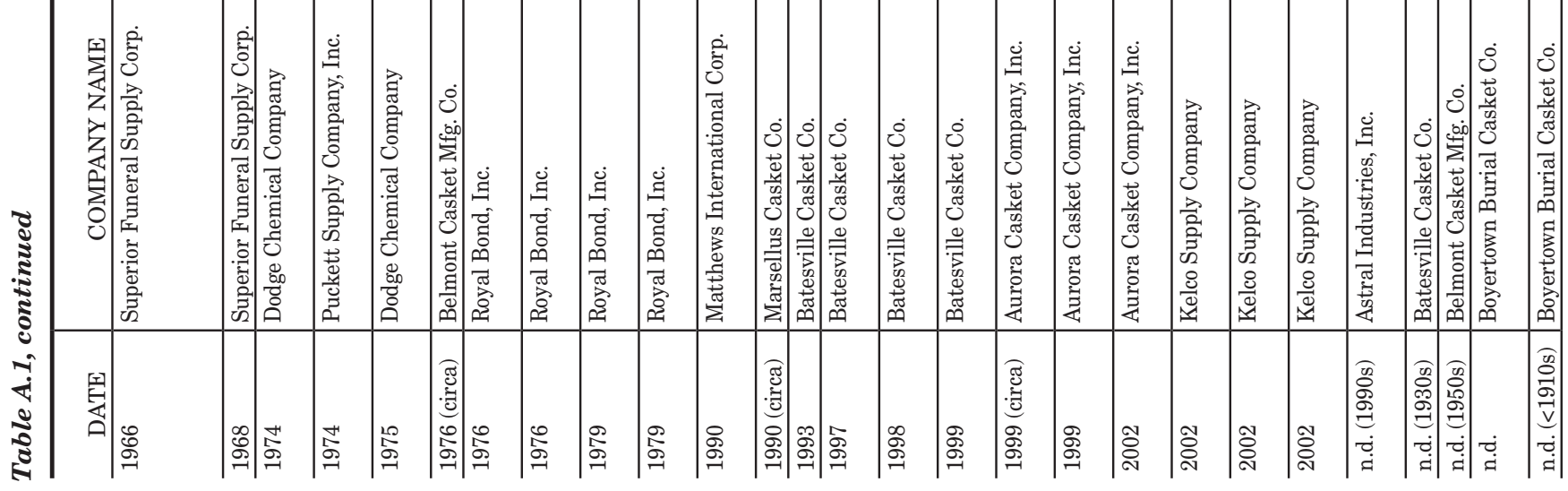


Appendix A: Mortuary Hardware

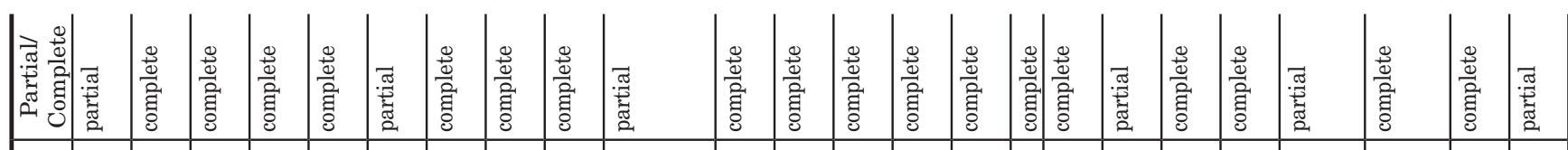

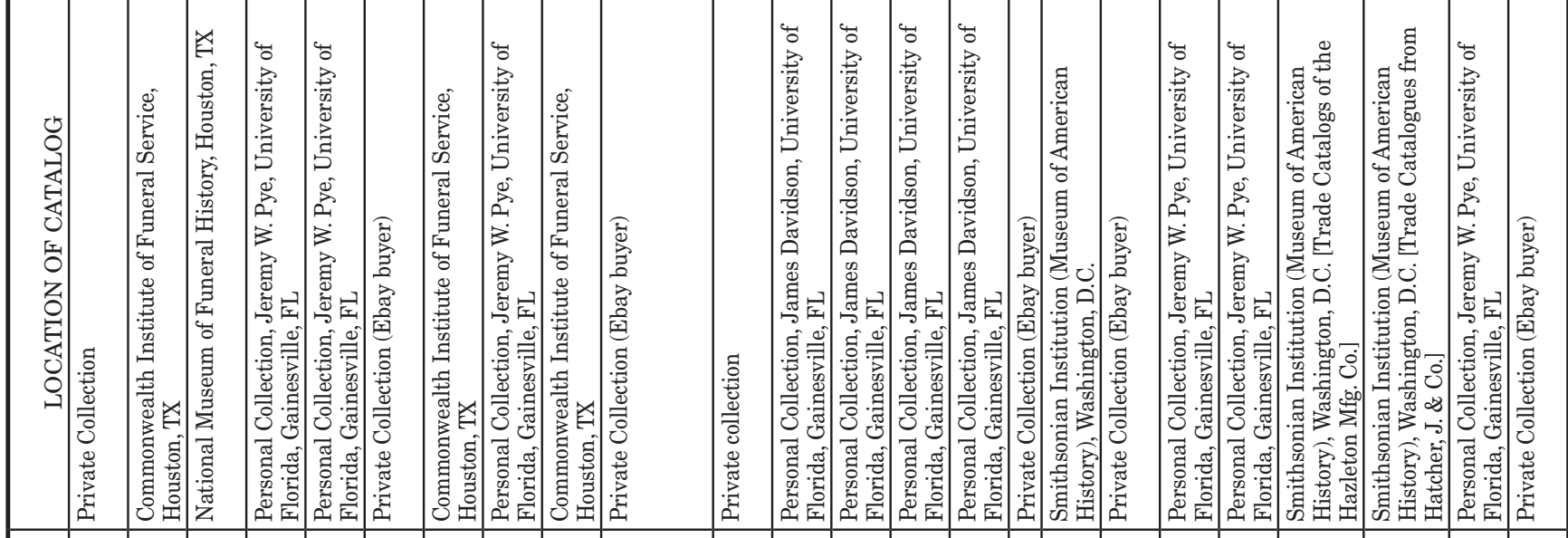

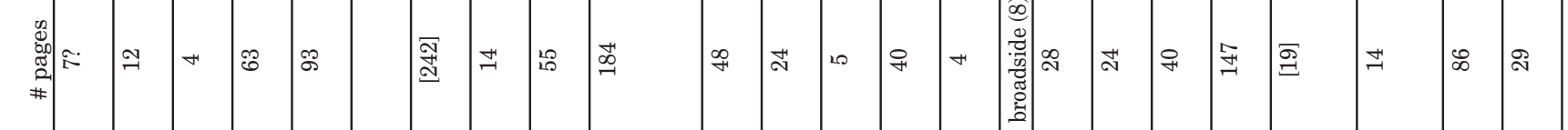

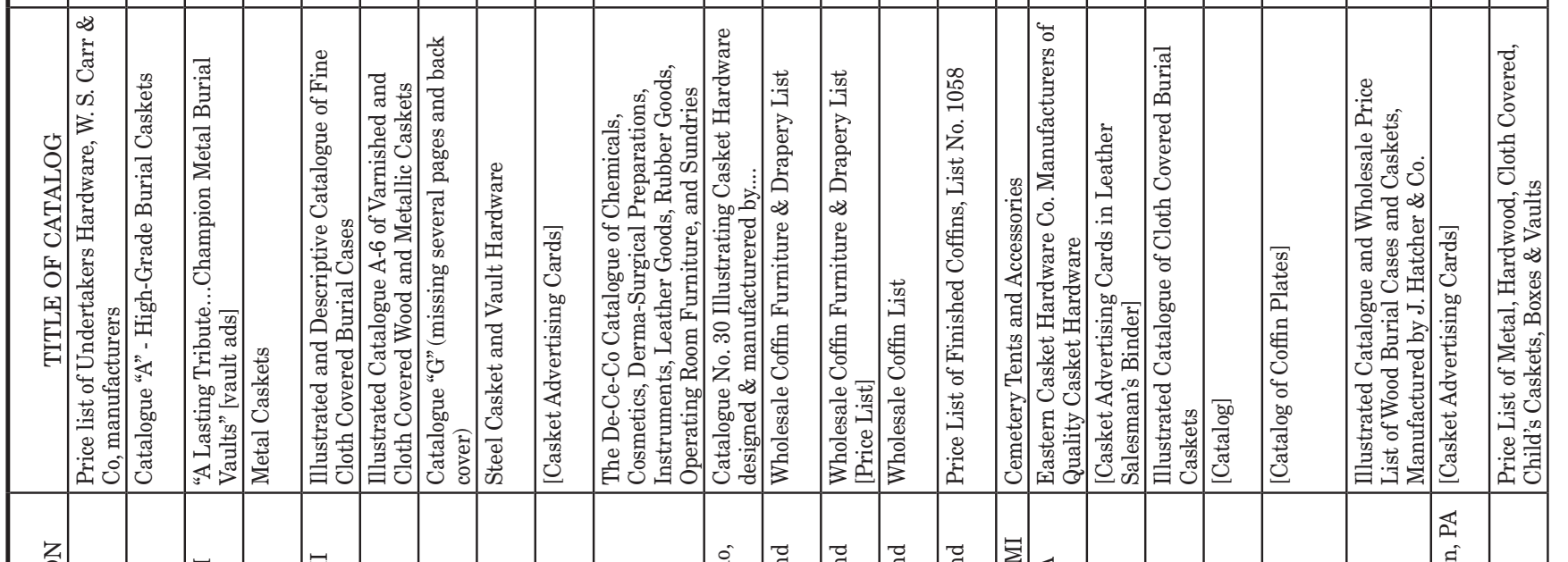

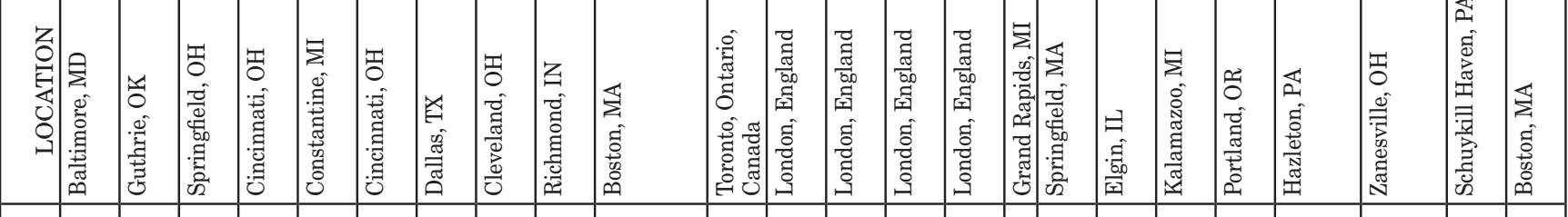

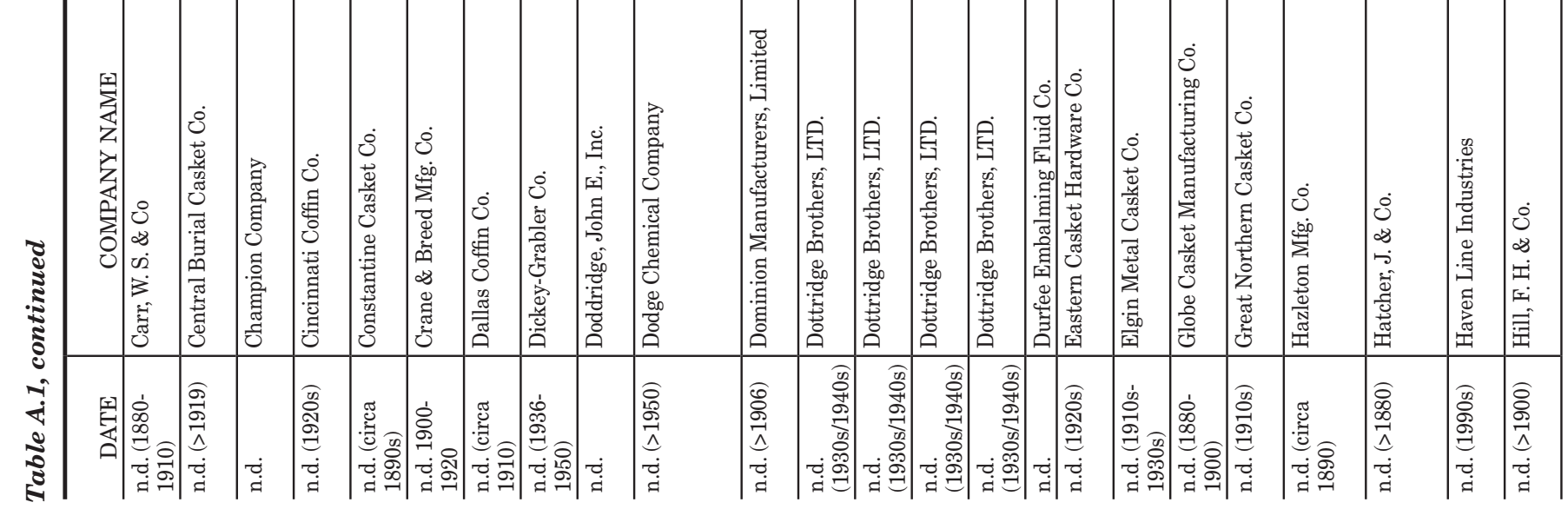


Investigations at Roberts Cemetery

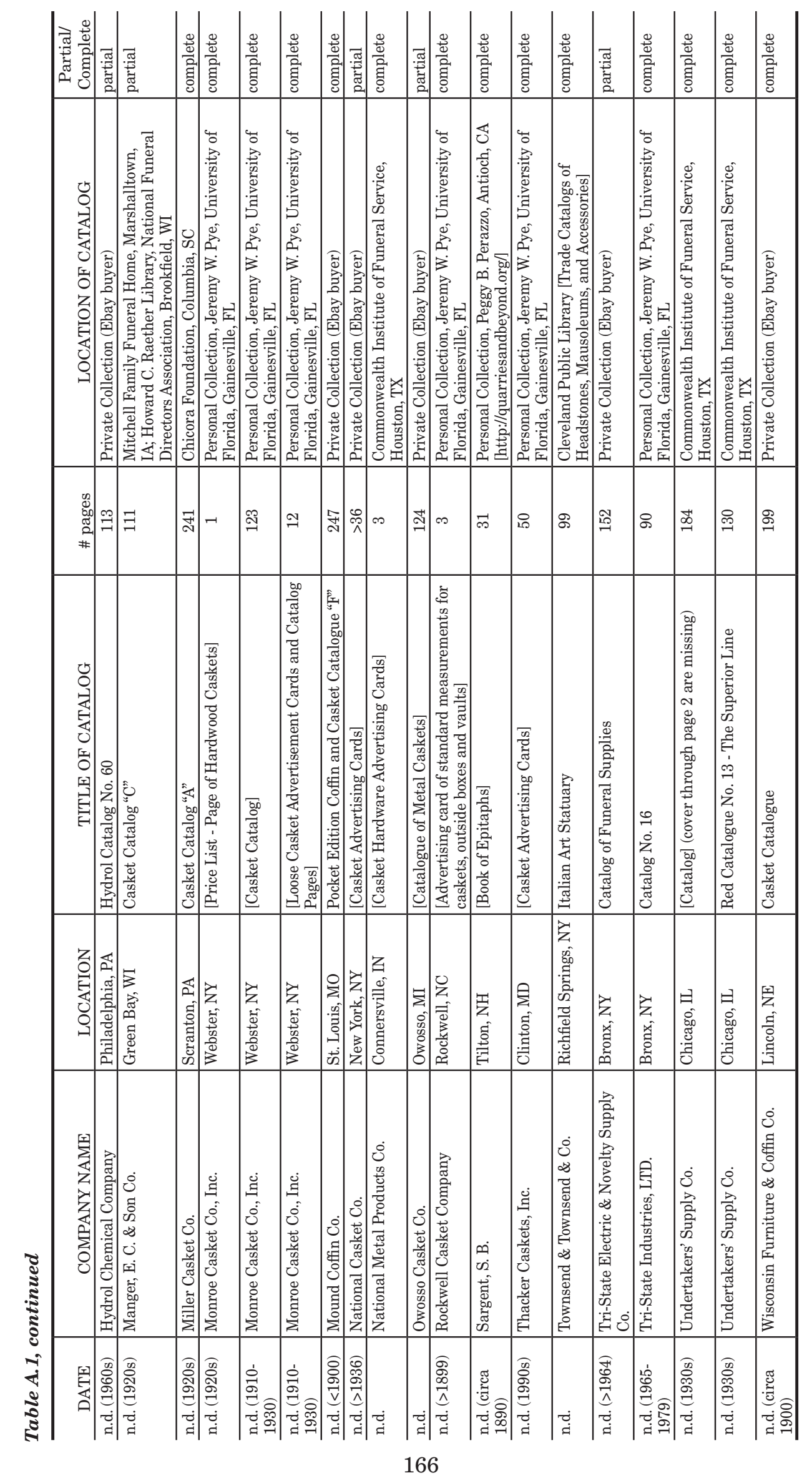




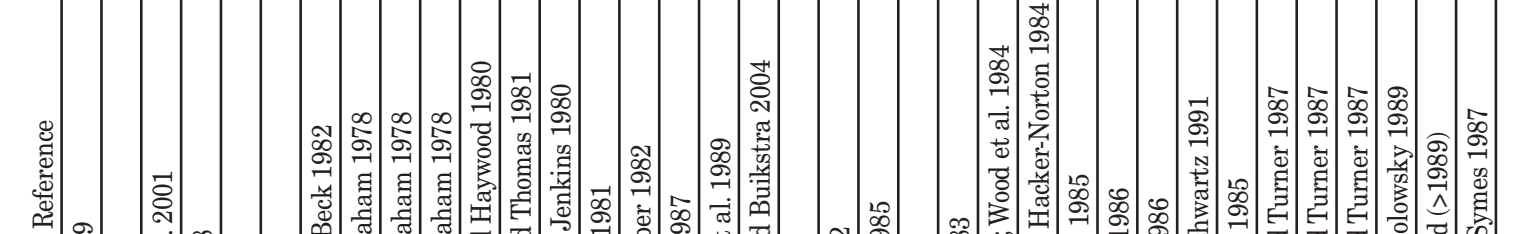

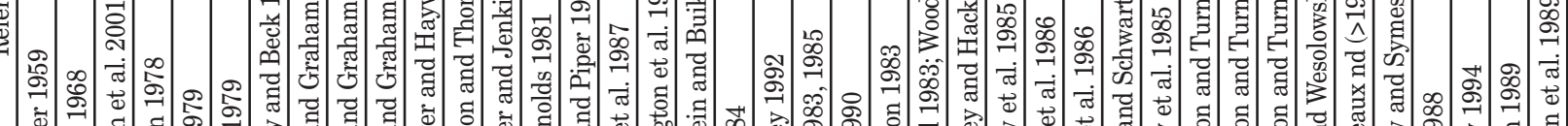
范

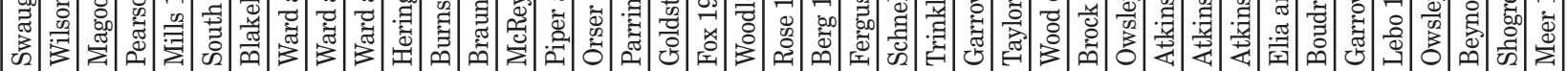

\section{占诘国国国}

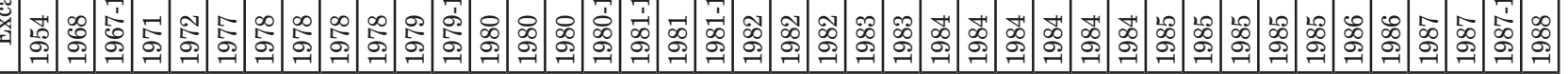

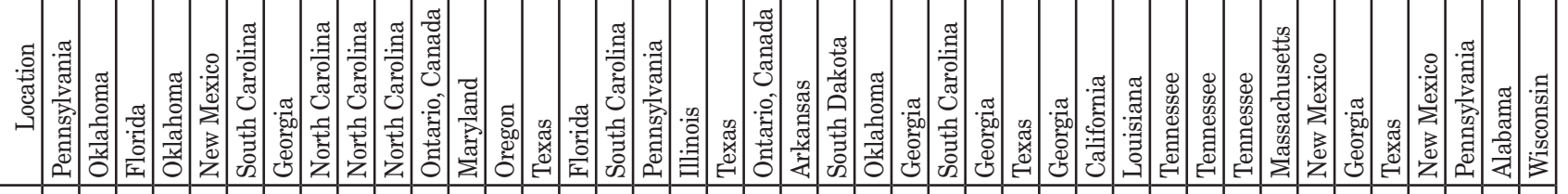

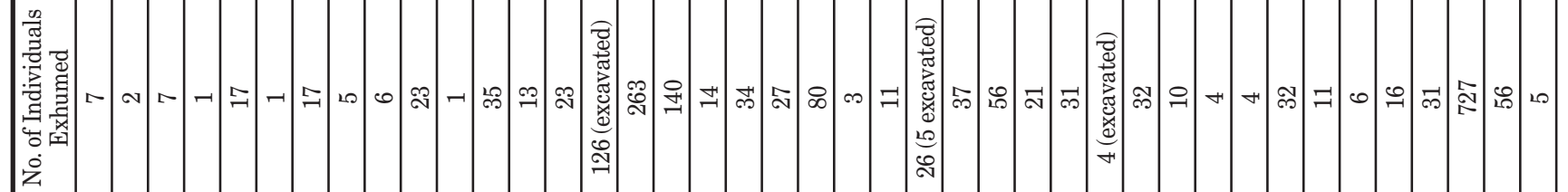

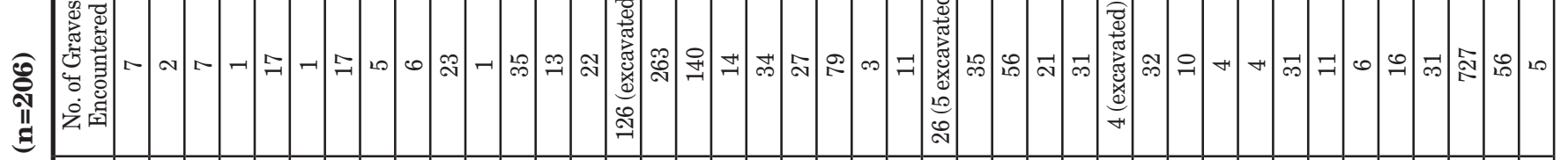

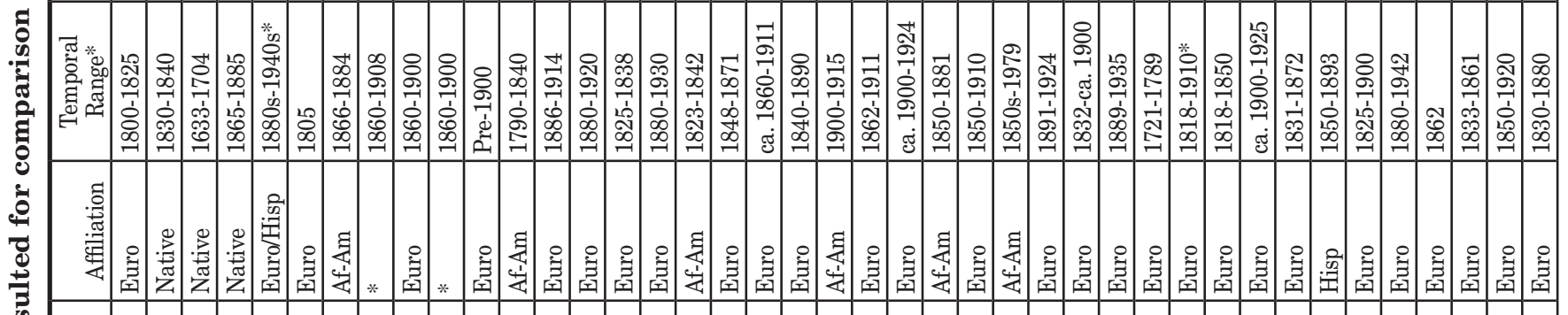

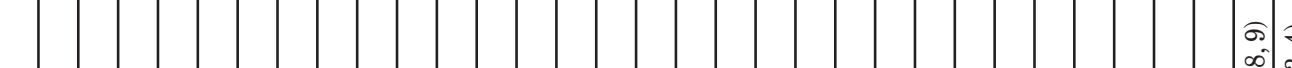

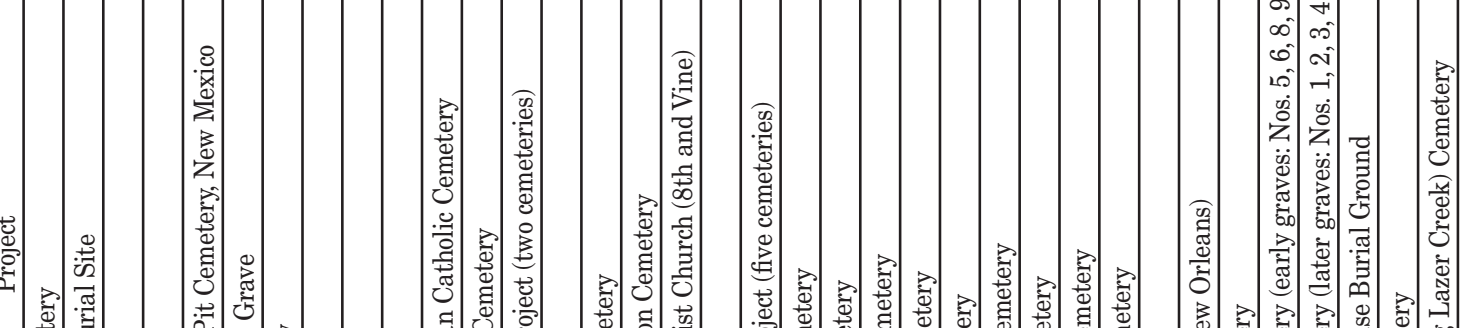

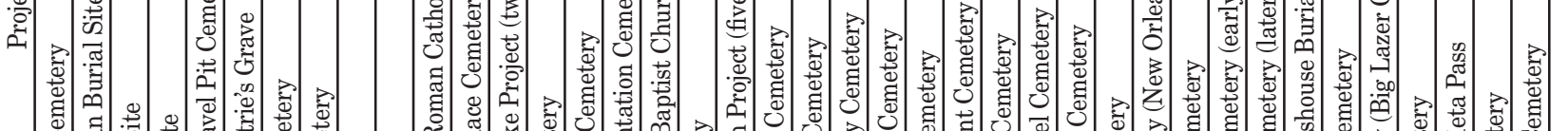

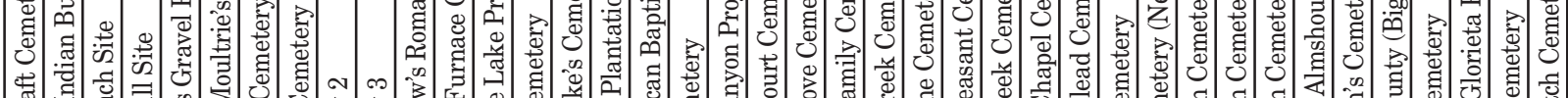

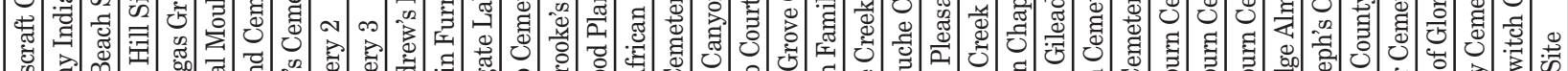

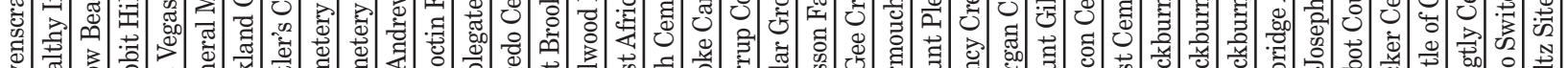

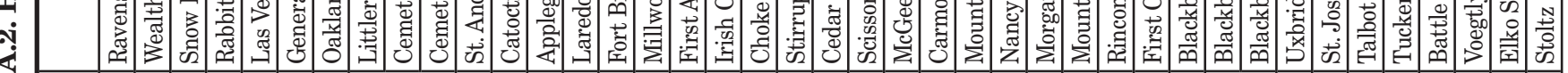
至 


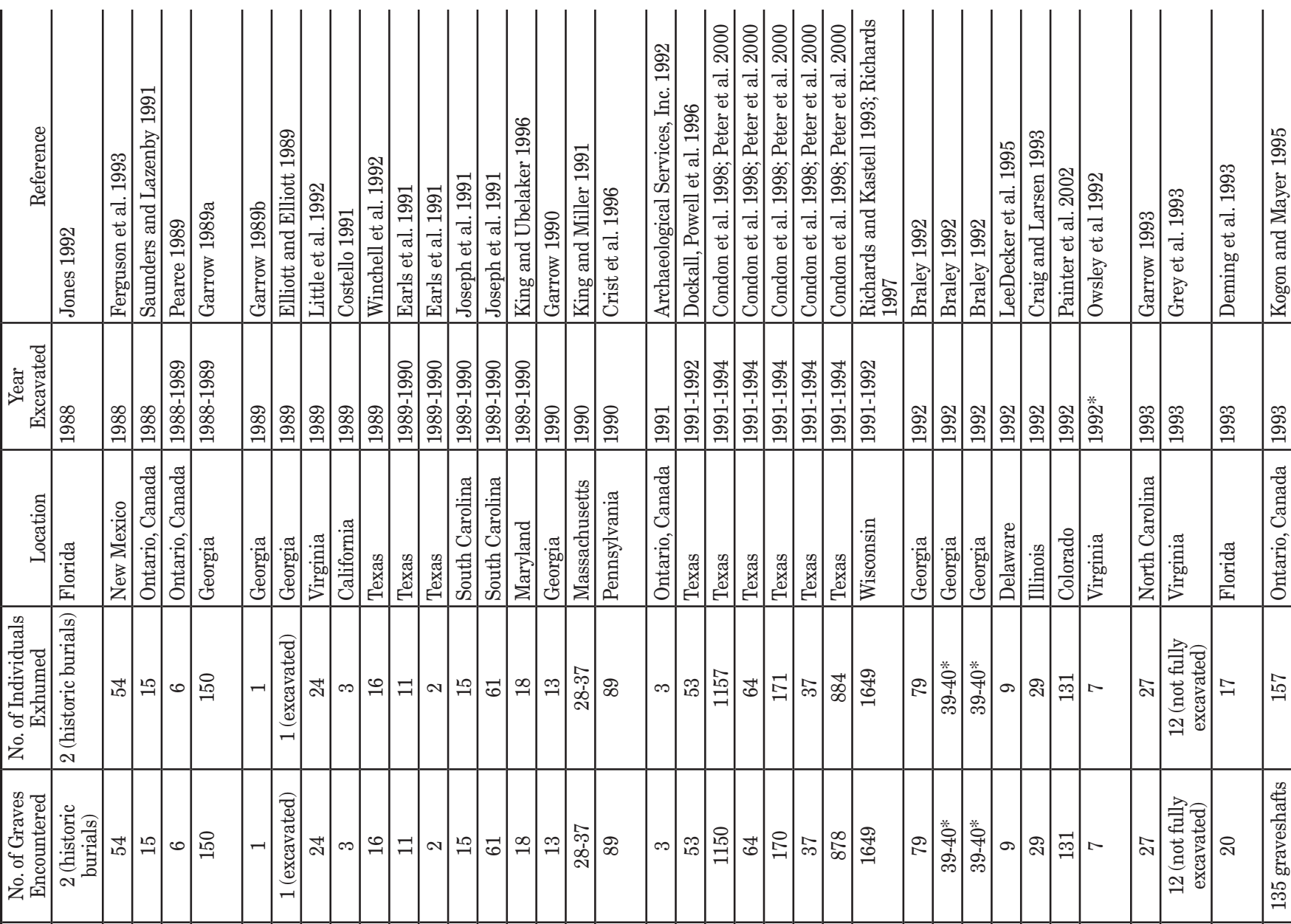

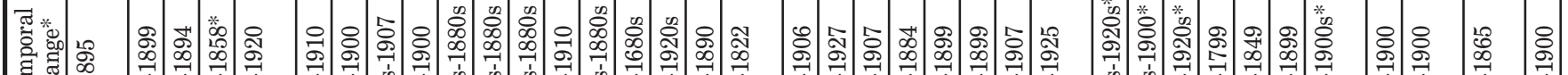

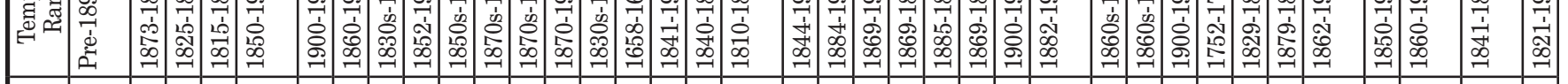

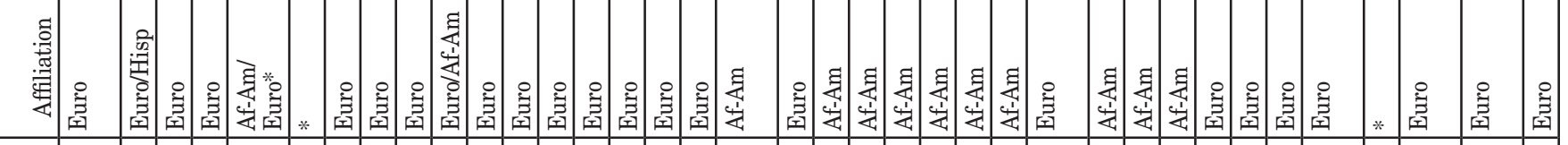

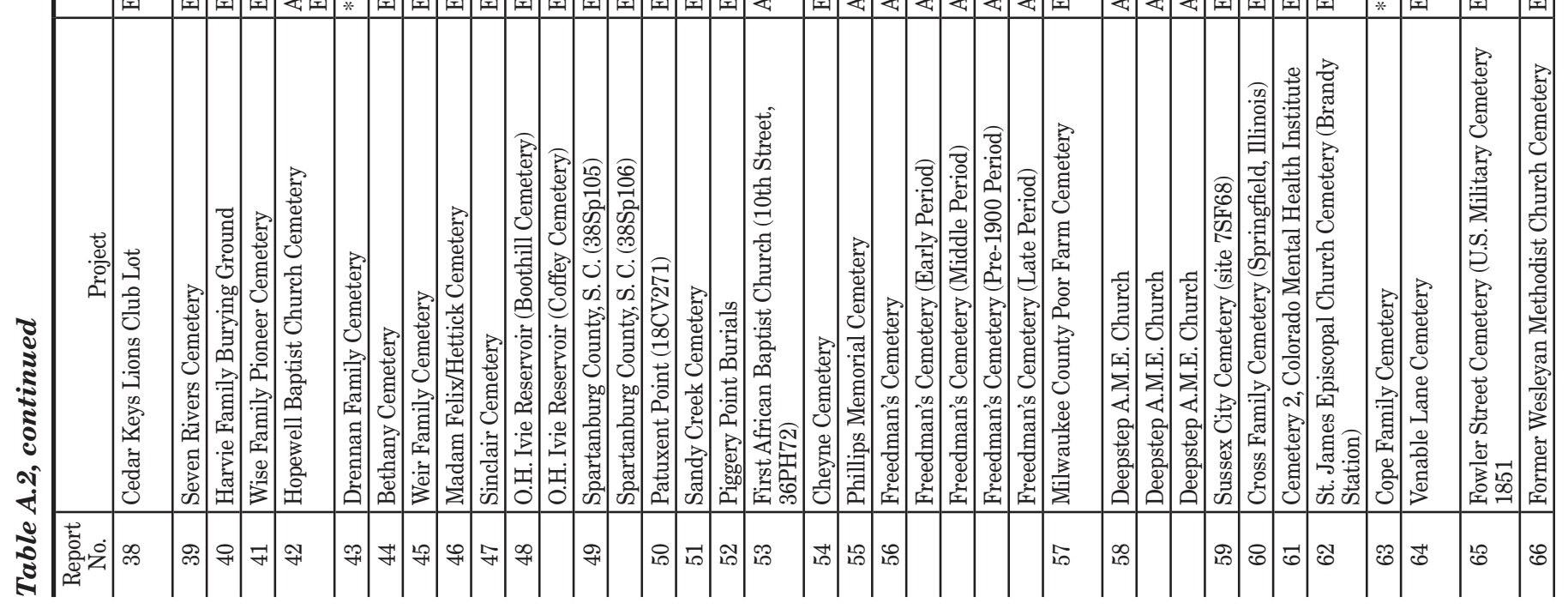




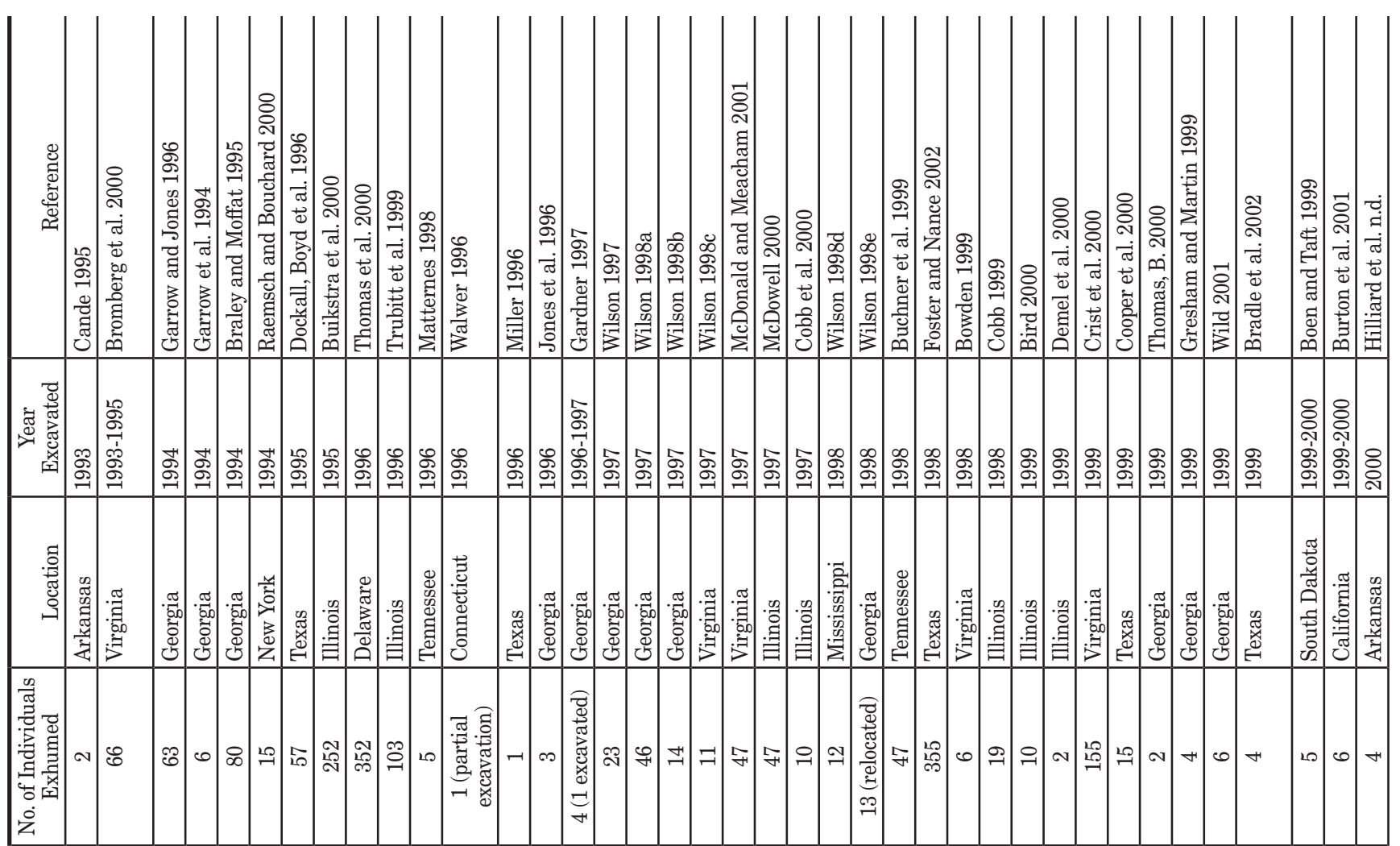

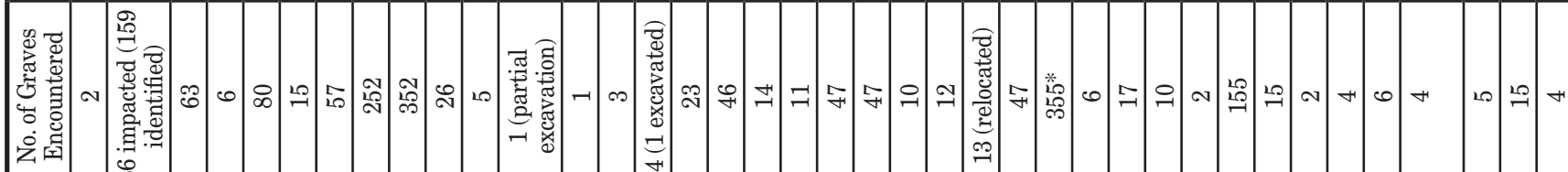

8

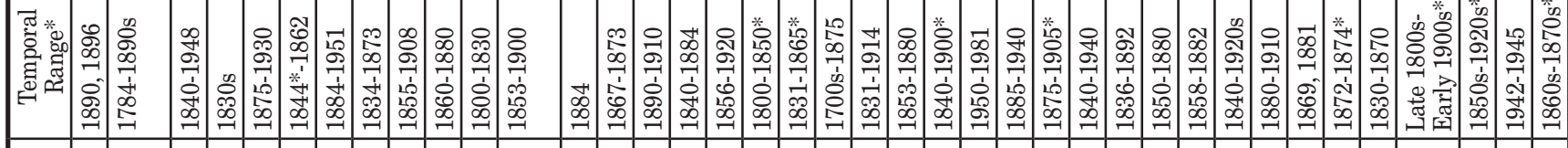

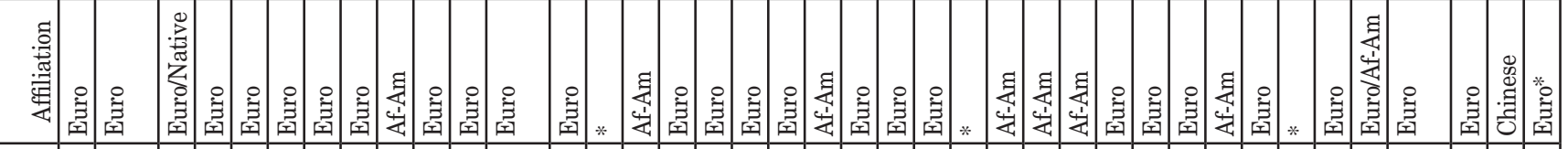

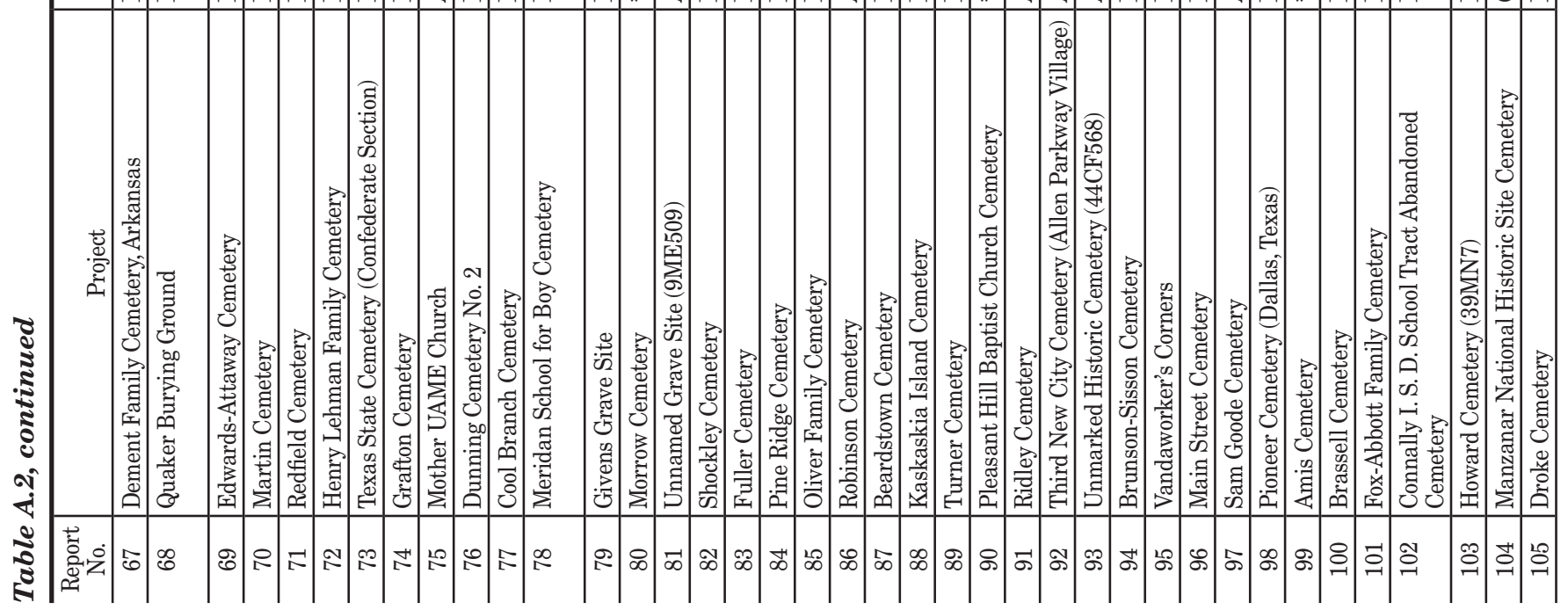




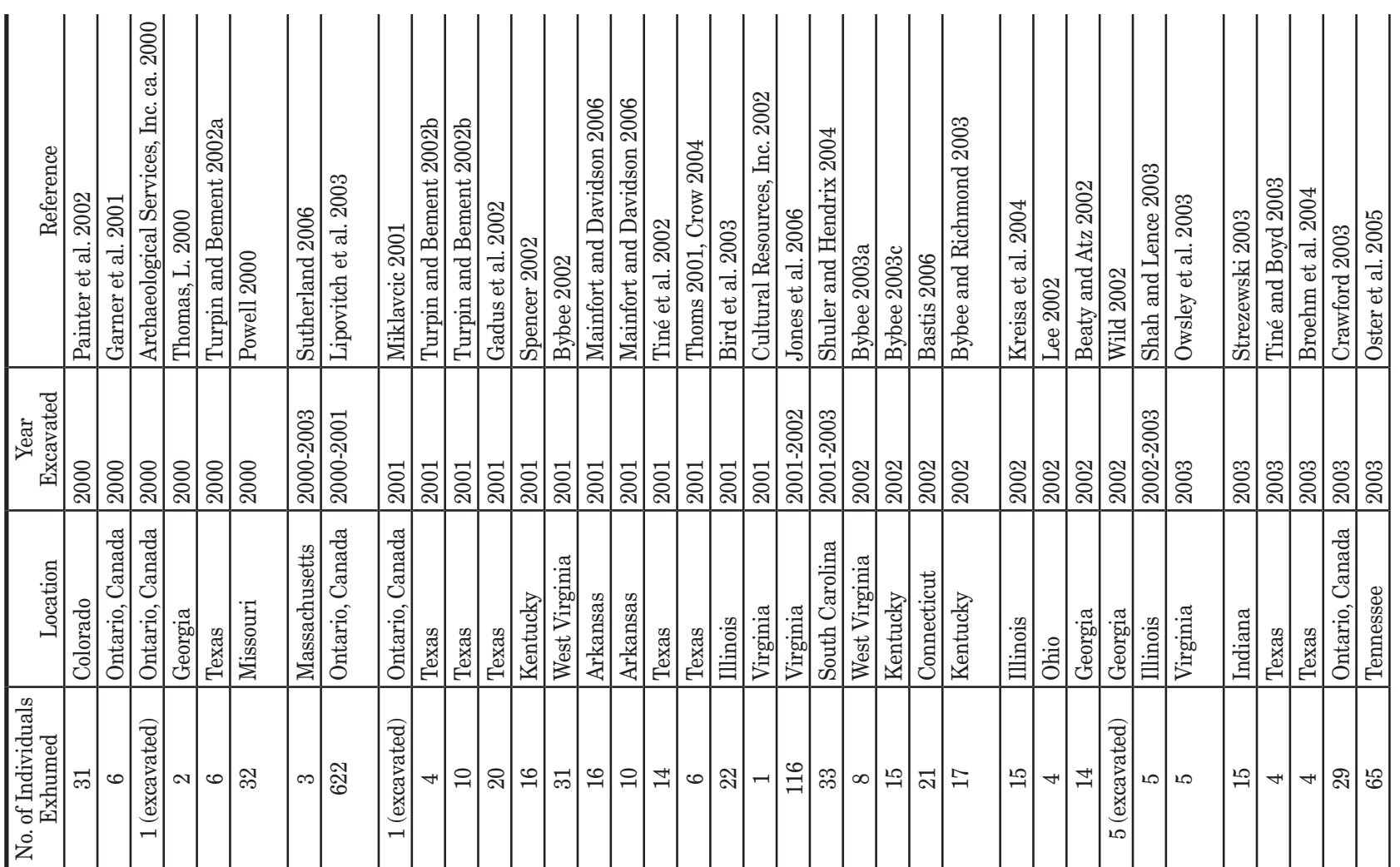

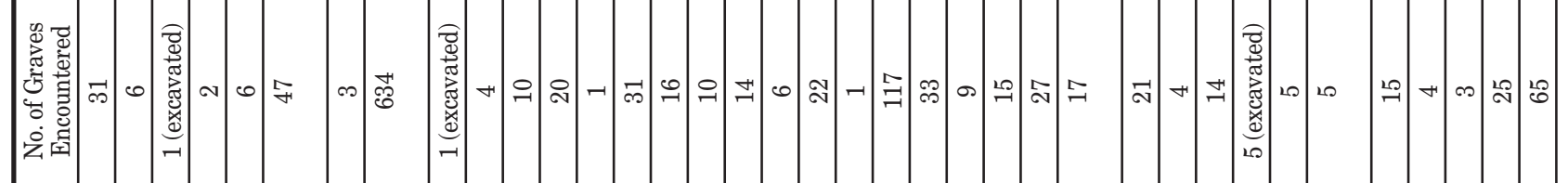

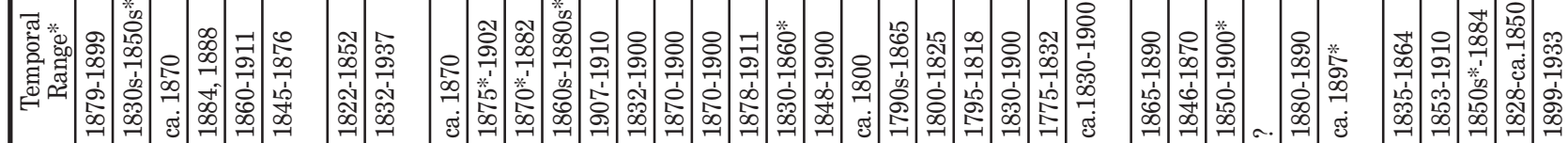

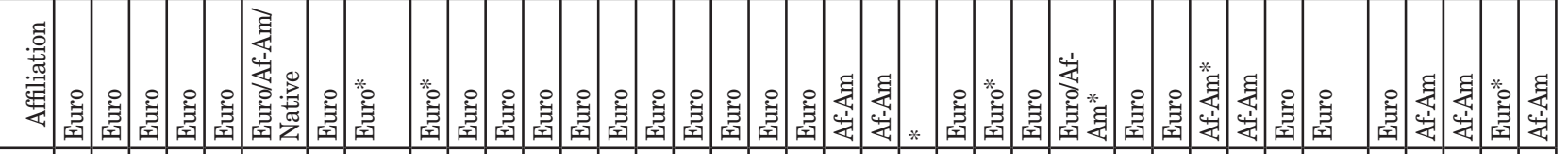

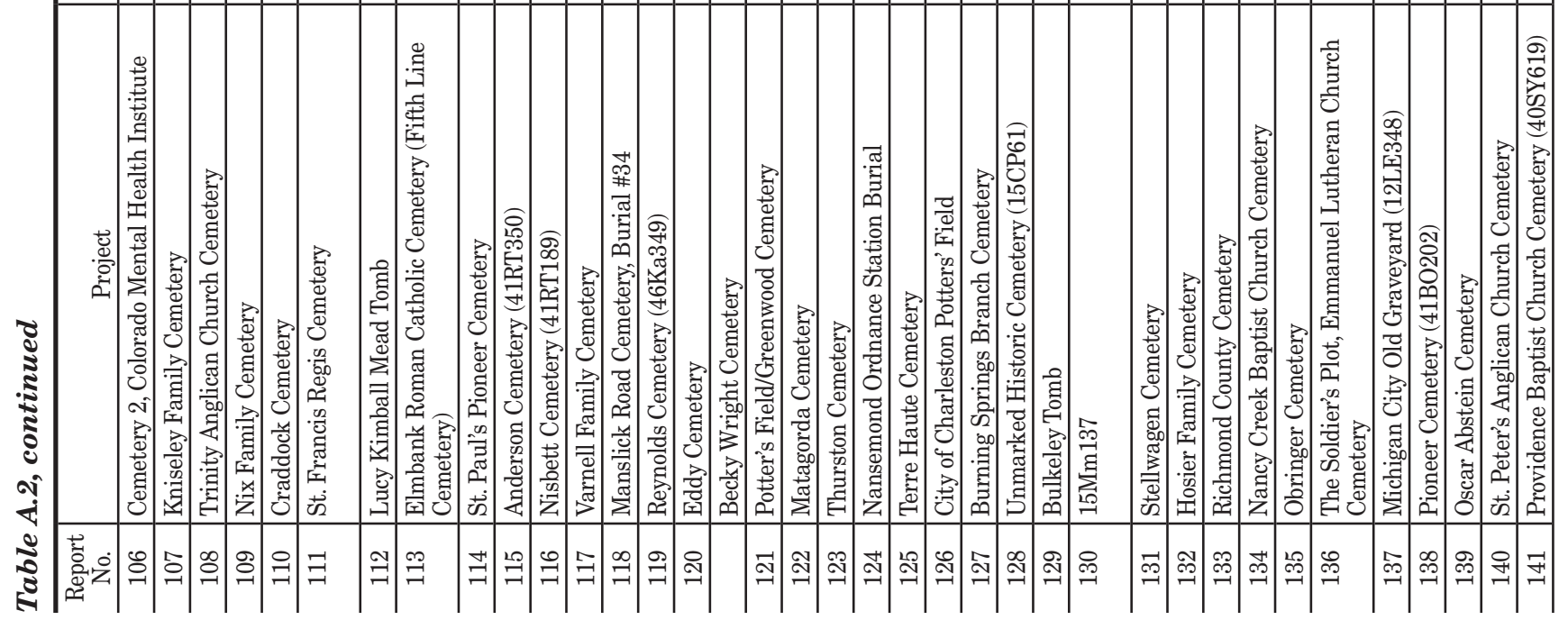




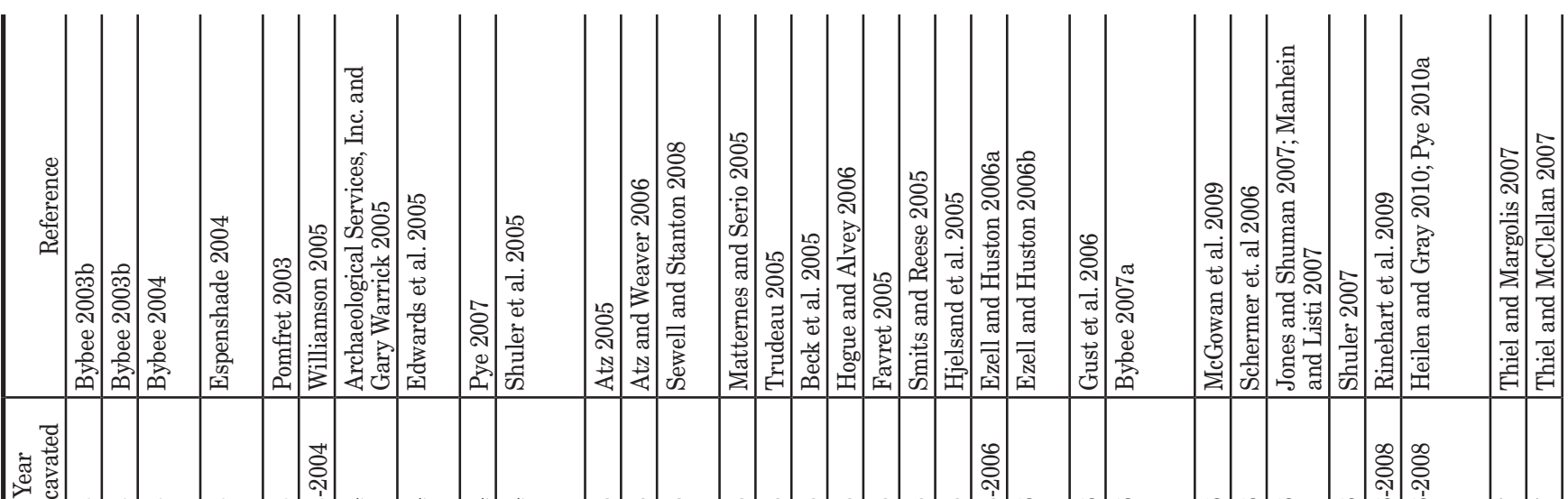

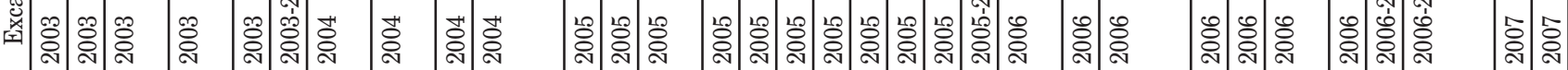

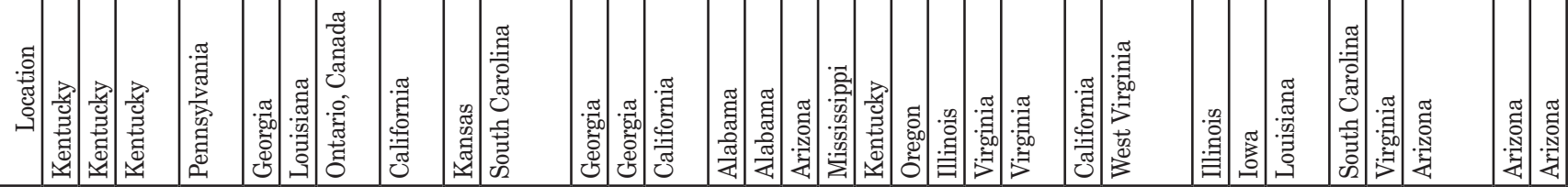

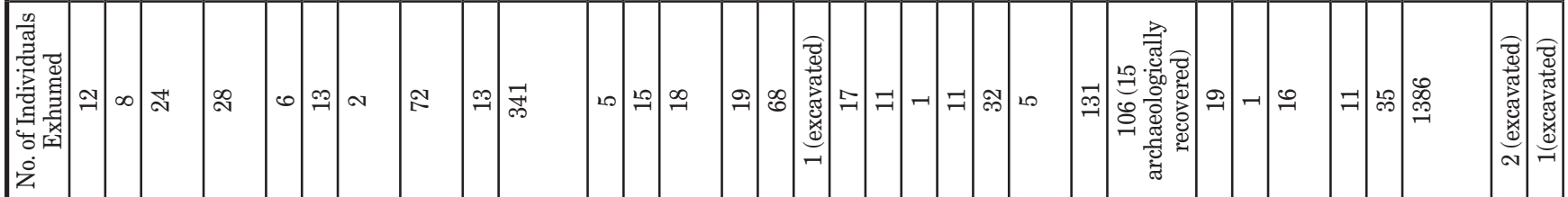

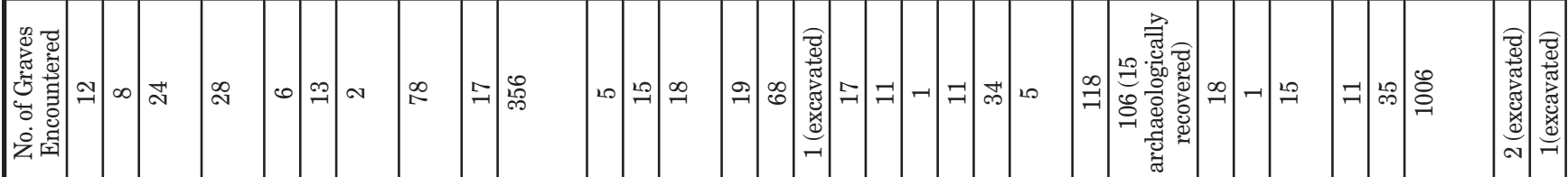

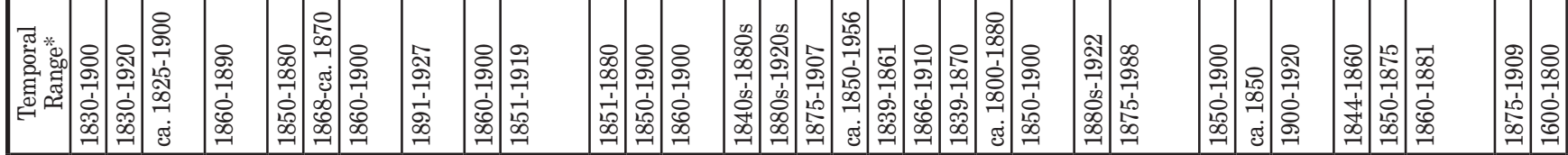

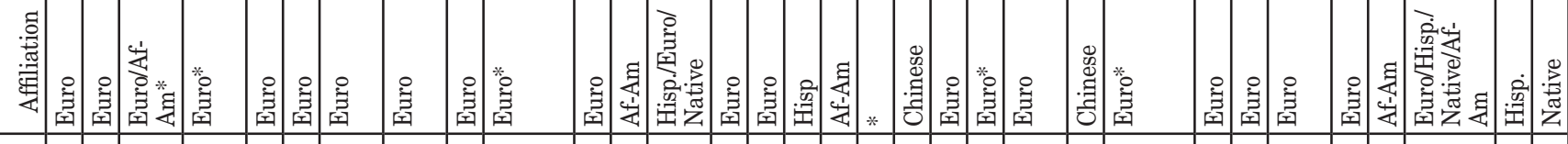

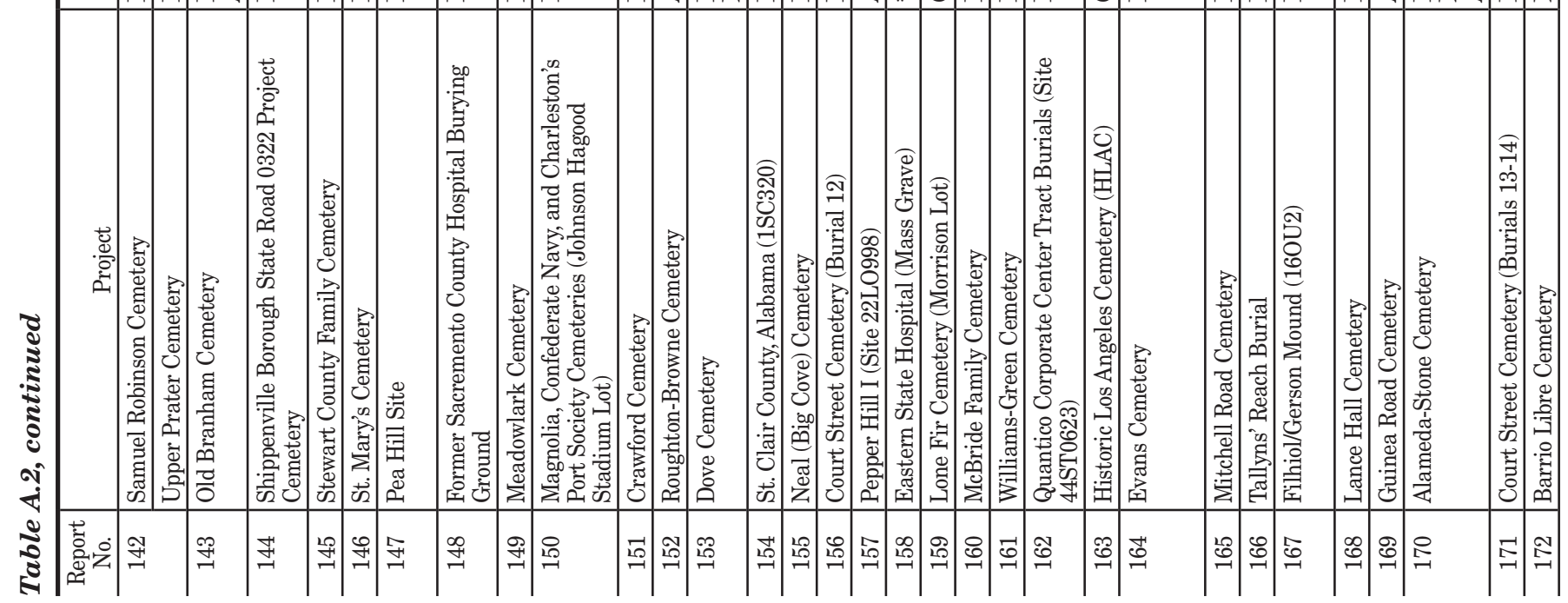




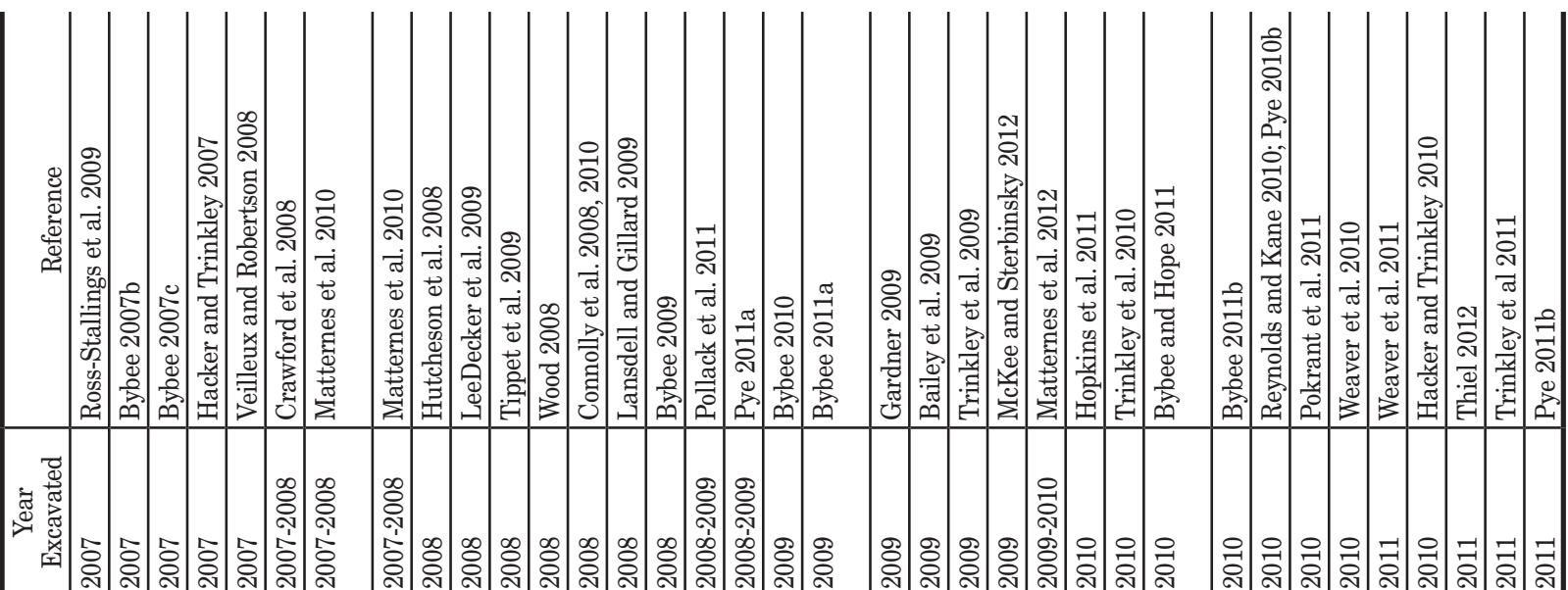

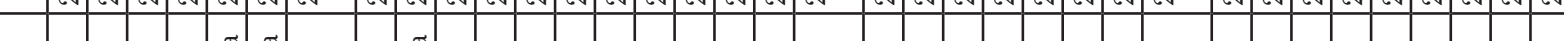

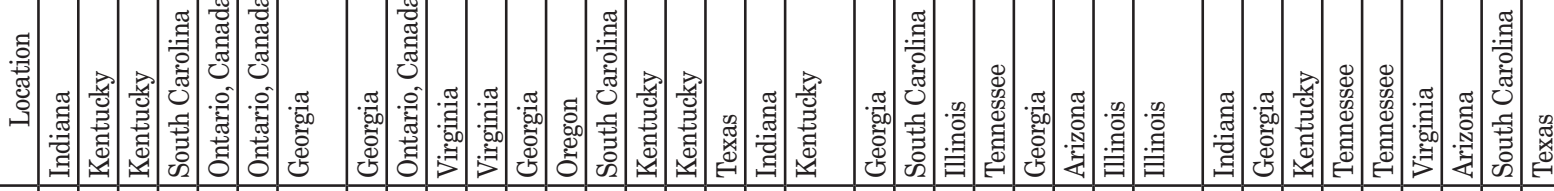

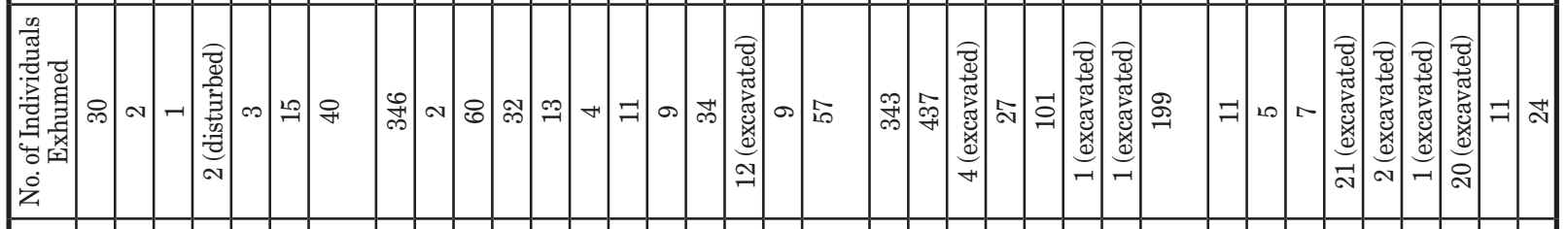

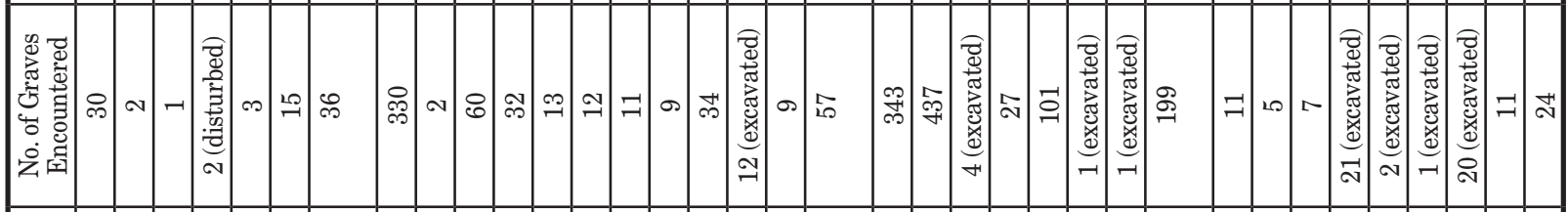

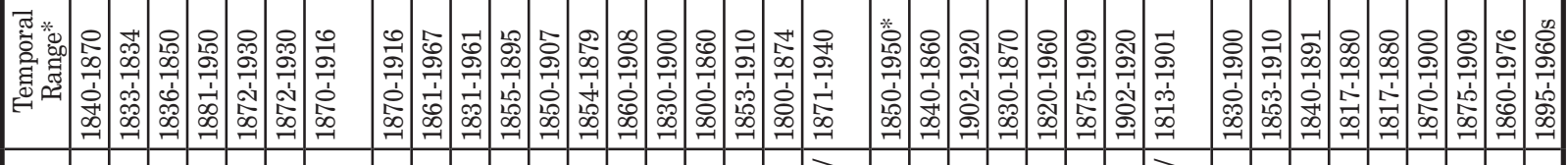

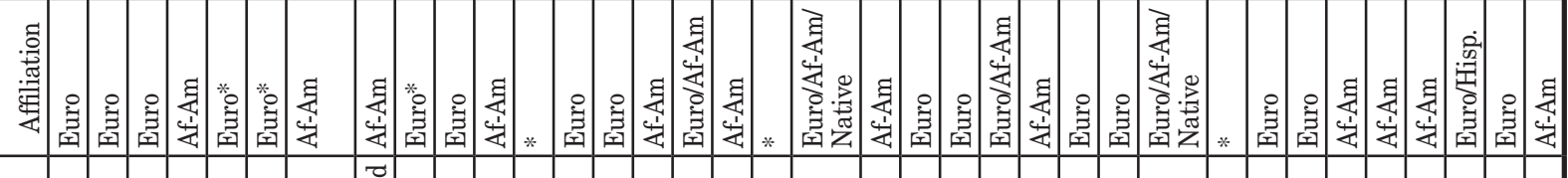

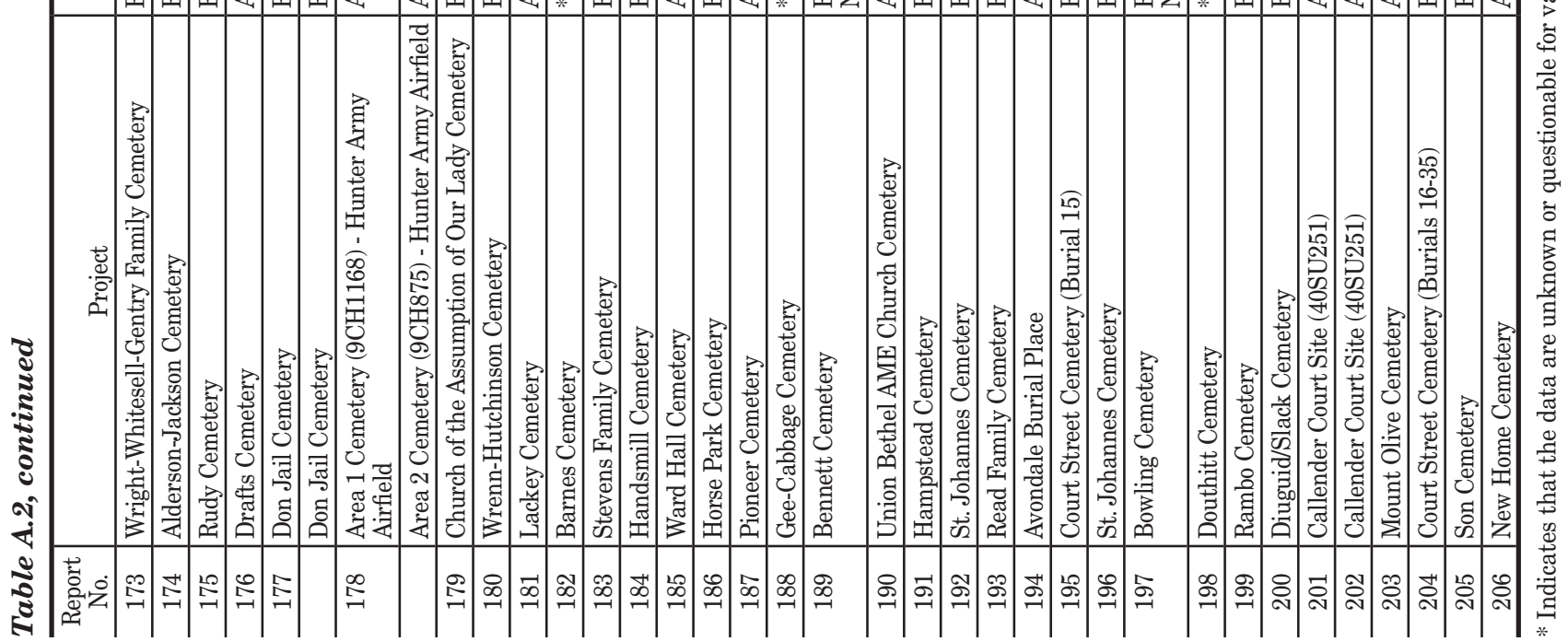




\section{replace with tabloid table A.3}


Investigations at Roberts Cemetery

\section{replace with tabloid table A.3}




\section{replace with tabloid table A.3}




\section{back side of tabloid table}




\title{
APPENDIX B: Tabulated Osteological Data for Four Excavated Historic Burials at Roberts Cemetery, Bell County, Texas
}

\author{
Compiled by Catrina Whitley
}



This appendix presents tabulated metric and nonmetric osteological data on the human skeletal remains associated with four unmarked historic graves excavated at Roberts Cemetery. in Bell County, Texas, in September 2012. The examination of the remains was conducted at the Prewitt and Associates, Inc., laboratory in Austin on October 1 and 2, 2012, and the data analyses were completed in the following weeks. The osteology data recording methods and scoring codes are from Buikstra and Ubelaker (1994). The tables in this appendix are as follows:

Table B.1. Skeletal element condition

Table B.2. Sex estimation scores

Table B.3. Age estimation

Table B.4. Biological affinity

Table B.5. Cranial metrics

Table B.6. Postcranial metrics

Table B.7. Immature postcranial metrics for Burial 4

Table B.8. Nonmetric traits

Table B.9. Dental data for Burial 1

Table B.10. Dental data for Burial 2

Table B.11. Dental data for Burial 3

Table B.12. Dental data for Burial 4

\section{REFERENCE CITED}

Buikstra, Jane, and Douglas Ubelaker

1994 Standards for Data Collection from Human Skeletal Remains. Arkansas Archeological Survey, Fayetteville.

Table B.1. Skeletal element condition

\begin{tabular}{|c|c|c|c|c|c|c|c|c|}
\hline \multirow[b]{2}{*}{ Element } & \multicolumn{2}{|c|}{ Burial 1} & \multicolumn{2}{|c|}{ Burial 2} & \multicolumn{2}{|c|}{ Burial 3} & \multicolumn{2}{|c|}{ Burial 4} \\
\hline & Left & Right & Left & Right & Left & Right & Left & Right \\
\hline Frontal & 1 & - & 3 & - & 1 & - & 1 & 1 \\
\hline Parietal & 1 & 1 & 2 & 2 & 1 & 1 & 1 & 1 \\
\hline Temporal & 1 & 1 & 0 & 2 & 1 & 1 & 1 & 1 \\
\hline Occipital & 1 & - & 2 & - & 1 & - & 1 & 1 \\
\hline Sphenoid & 99 & - & 3 & - & 99 & - & 99 & 99 \\
\hline Nasal & 99 & 99 & 99 & 99 & 2 & 2 & 99 & 99 \\
\hline Zygomatic & 1 & 1 & 0 & 1 & 1 & 0 & 1 & 1 \\
\hline Lacrimal & 99 & 99 & 99 & 99 & 99 & 99 & 99 & 99 \\
\hline Maxilla & 1 & 1 & 0 & 3 & 1 & 2 & 1 & 1 \\
\hline Palatine & 3 & 1 & 0 & 0 & 1 & 2 & 1 & 1 \\
\hline Maxillary teeth & 7 & 7 & 1 & 4 & 8 & 8 & 6 & 7 \\
\hline Mandibular teeth & 7 & 7 & 4 & 5 & 8 & 8 & 6 & 7 \\
\hline Mandible & 1 & 1 & 2 & 0 & 2 & 1 & 1 & 1 \\
\hline Clavicle & 1 & 1 & 1 & 1 & 1 & 1 & 1 & 2 \\
\hline Scapula & 2 & 2 & 2 & 2 & 2 & 2 & 3 & 3 \\
\hline Sternum & 1 & 1 & 0 & 0 & 3 & & 99 & 99 \\
\hline Ribs* & $12 / 2$ & $12 / 2$ & $11 / 2$ & $10 / 2$ & & & $6 / 1$ & $7 / 0$ \\
\hline Humerus & 2 & 1 & 1 & 1 & 1 & 1 & 1 & 1 \\
\hline Radius & 1 & 1 & 1 & 1 & 1 & 1 & 1 & 1 \\
\hline Ulna & 1 & 1 & 1 & 1 & 1 & 1 & 1 & 1 \\
\hline Carpals* & $5 / 1$ & $8 / 1$ & $8 / 1$ & $8 / 1$ & $8 / 1$ & $4 / 1$ & $3 / 1$ & $2 / 1$ \\
\hline Metacarpals* & $5 / 1$ & $8 / 1$ & $5 / 1$ & $5 / 1$ & $5 / 1$ & $4 / 1$ & $5 / 5$ & $3 / 2$ \\
\hline Phalanges* & $13 / 1$ & $14 / 1$ & $14 / 1$ & 14 & 26 & - & $5 / 5$ & $9 / 9$ \\
\hline
\end{tabular}




\section{Investigations at Roberts Cemetery}

Table B.1, continued

\begin{tabular}{|c|c|c|c|c|c|c|c|c|}
\hline \multirow[b]{2}{*}{ Element } & \multicolumn{2}{|c|}{ Burial 1} & \multicolumn{2}{|c|}{ Burial 2} & \multicolumn{2}{|c|}{ Burial 3} & \multicolumn{2}{|c|}{ Burial 4} \\
\hline & Left & Right & Left & Right & Left & Right & Left & Right \\
\hline Cervical vertebrae* & $7 / 1$ & - & $7 / 2$ & - & $7 / 1$ & - & $7 / 1$ & - \\
\hline Thoracic vertebrae* & $12 / 2$ & - & $11 / 4$ & - & $12 / 2$ & - & $12 / 1$ & - \\
\hline Lumbar vertebrae* & $5 / 1$ & - & $5 / 1$ & - & $5 / 2$ & - & $5 / 1$ & - \\
\hline Sacrum & 1 & 1 & 2 & - & 1 & 1 & 1 & 1 \\
\hline Ilium & 2 & 1 & 2 & 2 & 2 & 2 & 1 & 1 \\
\hline Ischium & 1 & 1 & 1 & 1 & 1 & 1 & 1 & 1 \\
\hline Pubis & 1 & 1 & 1 & 2 & 2 & 1 & 1 & 1 \\
\hline Femur & 1 & 1 & 1 & 1 & 1 & 1 & 1 & 1 \\
\hline Patella & 1 & 1 & 0 & 2 & 0 & 1 & 1 & 1 \\
\hline Tibia & 1 & 1 & 2 & 2 & 1 & 1 & 1 & 1 \\
\hline Fibula & 1 & 1 & 1 & 2 & 1 & 1 & 1 & 1 \\
\hline Metatarsals* & $5 / 1$ & $5 / 1$ & $5 / 1$ & $5 / 2$ & $5 / 1$ & $5 / 1$ & $0 / 0$ & $5 / 2$ \\
\hline Tarsals* & $7 / 1$ & $7 / 1$ & $4 / 1$ & $7 / 1$ & $7 / 1$ & $6 / 1$ & $1 / 1$ & $2 / 2$ \\
\hline Phalanges* & $8 / 1$ & $14 / 1$ & $11 / 1$ & $6 / 2$ & 24 & - & $1 / 1$ & $7 / 2$ \\
\hline
\end{tabular}

Notes: ${ }^{*}=$ grouped elements. The first number indicates the number of elements present, and the second indicates the condition of the majority of elements. Condition: $0=$ missing; $1=75-100 \%$ complete; $2=$ $25-75 \%$ complete; $3=<25 \%$ complete; 99 = unable to score because skeletal remains were too damaged and fragmented for assessment. See Buikstra and Ubelaker 1994 for more definitions of the scores.

Table B.2. Sex estimation scores

\begin{tabular}{|c|c|c|c|c|}
\hline & Burial 1 & Burial 2 & Burial 3 & Burial 4 \\
\hline \multicolumn{5}{|l|}{ Cranial Observations } \\
\hline Forehead & 5 & - & 4 & - \\
\hline Nuchal crest & 5 & - & & - \\
\hline Mastoid process & 4 & - & 3 & - \\
\hline Supra-orbital margin & - & - & 4 & - \\
\hline Glabella & 5 & - & 4 & - \\
\hline Mental eminence & 4 & - & 4 & - \\
\hline \multicolumn{5}{|l|}{ Os Coxae Morphology } \\
\hline Ventral arc & 5 & - & 5 & - \\
\hline Subpubic concavity & 5 & - & - & - \\
\hline Ischiopubic ramus ridge & 5 & 5 & - & - \\
\hline Greater sciatic notch & 5 & 4 & 5 & - \\
\hline Preauricular sulcus & 5 & - & 5 & - \\
\hline Ilaic blade & 5 & 4 & - & - \\
\hline Diameter of femoral head & 5 & 5 & 3 & \\
\hline Sex Estimation & male & male & male & unknown \\
\hline
\end{tabular}

Notes: $-=$ unobservable; 1 = female; $2=$ probable female; $3=$ ambiguous; $4=$ probable male; $5=$ male. 
Table B.3. Age estimation

\begin{tabular}{|c|c|c|c|c|c|c|c|c|}
\hline \multirow[b]{2}{*}{ Age Criteria } & \multicolumn{2}{|c|}{ Burial 1} & \multicolumn{2}{|c|}{ Burial 2} & \multicolumn{2}{|c|}{ Burial 3} & \multicolumn{2}{|c|}{ Burial 4} \\
\hline & Score & Est. & Score & Est. & Score & Est. & $\begin{array}{c}\text { Measurement } \\
(\mathrm{mm})\end{array}$ & Est. \\
\hline Auricular surface & $3-4$ & $28-35$ & $6-7$ & $45-60$ & $1-2$ & $20-29$ & & \\
\hline $\begin{array}{l}\text { Suchey-Brooks- } \\
\text { pubic symphysis }\end{array}$ & $3 b-4 a$ & $30-40$ & - & - & $1 b-2 a$ & $20-25$ & & \\
\hline $\begin{array}{l}\text { Todd phase-pubic } \\
\text { symphysis }\end{array}$ & P6-P7 & $30-40$ & - & - & 2 & $20-21$ & & \\
\hline $\begin{array}{l}\text { Clavicle-medial } \\
\text { fusion }\end{array}$ & & & & & open & $20-29$ & & \\
\hline Ischial crest & & & & & fused & $>17 />23$ & & \\
\hline Ischial tuberosity & & & & & fused & $>20-23$ & & \\
\hline $\begin{array}{l}\text { Sacrum- } \\
\text { 1st-2nd segments }\end{array}$ & & & & & open & $<27$ & & \\
\hline M3 eruption & & & & & in occlusion & $>20-21$ & & \\
\hline Pars basilaris & & & & & & & 23.53 & 2 yr $3 \mathrm{mo}$. \\
\hline Basilar part length & & & & & & & 16.97 & $1 \mathrm{yr} 3 \mathrm{mo}$. \\
\hline Clavicle & & & & & & & 65.51 & $1.5-2.5 \mathrm{yr}$ \\
\hline Humerus & & & & & & & 113.3 & $1.5-2 \mathrm{yr}$ \\
\hline Femur & & & & & & & 138.57 & $1-1.5 \mathrm{yr}$ \\
\hline Tooth development & & & & & & & & $1 \pm 4 \mathrm{mo}$ \\
\hline Age Estimation & & $30-40$ & & $45-60$ & & $20-27$ & & $\sim 1.5$ \\
\hline
\end{tabular}

Note: - = unable to score. See Buikstra and Ubelaker 1994 for definitions of the scores.

Table B.4. Biological affinity

\begin{tabular}{|c|c|c|c|c|}
\hline Attribute & Burial 1 & Burial 2 & Burial 3* & Burial 4 \\
\hline Inion hook & No & slight & Yes & - \\
\hline Metopic trace & No & - & No & - \\
\hline Major sutures simple & No & - & No & - \\
\hline Sloping eye orbits & - & - & - & - \\
\hline Depressed nation & - & - & No & - \\
\hline "Tower" nasals & - & - & Yes & - \\
\hline Large nasal spine & Yes & - & Yes & - \\
\hline Retreating zygomatics & - & - & - & - \\
\hline No prognathism & Yes & - & slight & - \\
\hline Carabelli's cusp & No & Yes & Yes & - \\
\hline Parabolic dental arcade & - & - & No & - \\
\hline Bilobate chin & slight & - & No & - \\
\hline Prominent chin & Yes & No & Yes & - \\
\hline Pinched \& slanted ascending ramus & - & - & No & - \\
\hline Straight gonial angle & Yes & No & Yes & - \\
\hline Rounded external auditory meatus & oval & - & oval & - \\
\hline Oval window visible & Yes & - & Yes & - \\
\hline Palatine suture bulging & - & - & - & - \\
\hline S-shaped zygomatic-maxillary suture & - & - & - & - \\
\hline Shovel shaped incisors & No & No & Yes & - \\
\hline Biological Affinity Assessment & Caucasian & Caucasian & Caucasian & Unknown \\
\hline
\end{tabular}

Notes: - = unobservable; * = femoral shaft flattened; distal intertrochanteric length $30.13 \mathrm{~mm} \mathrm{~L} \mathrm{and}$ $30.08 \mathrm{~mm}$ R; shovel-shaped incisors level 2 


\section{Investigations at Roberts Cemetery}

Table B.5. Cranial metrics (in mm)

\begin{tabular}{|c|c|c|c|c|c|c|c|c|}
\hline \multirow[b]{2}{*}{ Element } & \multicolumn{2}{|c|}{ Burial 1} & \multicolumn{2}{|c|}{ Burial 2} & \multicolumn{2}{|c|}{ Burial 3} & \multicolumn{2}{|c|}{ Burial $4 *$} \\
\hline & Left & Right & Left & Right & Left & Right & Left & Right \\
\hline \multicolumn{9}{|l|}{ Adult measurements } \\
\hline Mastoid length & - & - & - & - & - & - & - & - \\
\hline Ascending ramus & - & - & - & - & 67.16 & - & - & - \\
\hline Chin height & 0 & - & - & - & 32.77 & - & - & - \\
\hline Height on mandibular body & - & 66.95 & - & - & 30.4 & - & - & - \\
\hline $\begin{array}{l}\text { Breadth of mandibular } \\
\text { body }\end{array}$ & 14.49 & 15.13 & - & - & 11.03 & 13.66 & - & - \\
\hline Bigonial width & - & - & - & - & - & - & - & - \\
\hline Bicondylar breadth & 126.18 & - & - & - & - & - & - & - \\
\hline Minimum ramus breadth & 32.16 & 31.54 & - & - & 33.3 & - & - & - \\
\hline Maximum ramus breadth & 41.74 & 40.01 & - & - & 38.58 & - & - & - \\
\hline Maximum ramus height & - & - & - & - & - & - & - & - \\
\hline Mandibular length & - & - & - & - & - & - & - & - \\
\hline \multicolumn{9}{|l|}{ Immature measurements } \\
\hline Petrous and mastoid & - & - & - & - & - & - & - & 61.1 \\
\hline $\begin{array}{l}\text { Basilar part of occipital } \\
\text { length }\end{array}$ & - & - & - & - & - & - & 16.97 & \\
\hline $\begin{array}{l}\text { Basilar part of occipital } \\
\text { width }\end{array}$ & - & - & - & - & - & - & 27.6 & \\
\hline Pars-basilaris & - & - & - & - & - & - & 23.53 & \\
\hline Mandible-length of body & - & - & - & - & - & - & - & 50.07 \\
\hline Mandible-width of arc & - & - & - & - & - & - & - & 26.05 \\
\hline $\begin{array}{l}\text { Mandible-full length of half } \\
\text { mandible }\end{array}$ & - & - & - & - & - & - & 74.75 & - \\
\hline
\end{tabular}

Note: All measurements that are not side-specific are recorded in the left column; - = unable to measure.

Table B.6. Postcranial metrics (in mm; adults only)

\begin{tabular}{l|c|c|c|c|c|c}
\hline \multirow{2}{*}{ Element } & \multicolumn{2}{c|}{ Burial 1 } & \multicolumn{2}{c}{ Burial 2 } & \multicolumn{2}{c}{ Burial 3 } \\
\cline { 2 - 8 } & Left & Right & Left & Right & Left & Right \\
\hline Humerus & & & & & & \\
\hline Maximum length & - & 312 & 334.5 & - & 320 & - \\
\hline Maximum diameter & - & 26.17 & 20.52 & - & 22.43 & - \\
\hline Minimum diameter & - & 21.46 & 16.43 & - & 16.49 & - \\
\hline Vertical maximum & - & 44.9 & 45.29 & - & 46.36 & - \\
\hline Maximum diameter of head & - & 45.11 & 45.54 & - & 46.83 & - \\
\hline Transverse diameter of head & - & 42.15 & 41.03 & - & 41.68 & - \\
\hline Biepicondylar width & - & 63 & 61.5 & - & 53 & - \\
\hline Circumference & - & - & 60 & - & 66 & - \\
\hline
\end{tabular}


Table B.6, continued

\begin{tabular}{|c|c|c|c|c|c|c|}
\hline \multirow[b]{2}{*}{ Element } & \multicolumn{2}{|c|}{ Burial 1} & \multicolumn{2}{|c|}{ Burial 2} & \multicolumn{2}{|c|}{ Burial 3} \\
\hline & Left & Right & Left & Right & Left & Right \\
\hline \multicolumn{7}{|l|}{ Radius } \\
\hline Maximum length & 261 & - & 274 & - & - & 242 \\
\hline A-p diameter & 13.25 & - & - & - & - & - \\
\hline M-l diameter & 17.83 & - & - & - & - & - \\
\hline Ulna & & $*$ & & & & \\
\hline Maximum length & - & 277 & 261 & - & 265 & - \\
\hline Minimum circumference & - & 40 & 34 & - & 39 & - \\
\hline $\mathrm{A}-\mathrm{p}$ diameter & - & 18.16 & 1361 & - & 13.46 & - \\
\hline M-l diameter & - & 18.31 & 13.82 & - & 15.23 & - \\
\hline Physiological length & - & 249 & 241 & - & 233 & - \\
\hline Femur & $*$ & $*$ & & & & \\
\hline Maximum length & 450 & 449 & - & - & 447 & 447.5 \\
\hline Bicondylar length & 448 & 447 & - & - & 443 & 441.5 \\
\hline Midshaft circumference & 103 & - & 84 & - & 85 & 85 \\
\hline A-p diameter & 32.52 & - & - & - & 27.35 & 27.56 \\
\hline Transverse diameter & 34.22 & - & - & - & 26.25 & 25.7 \\
\hline Head diameter & 48.4 & - & 47.56 & 49.07 & 43.18 & 44.08 \\
\hline Bicondylar width & 86 & - & 83 & 83 & 72 & - \\
\hline A-p subtrochanteric diameter & 32.01 & - & 25.93 & - & 26.21 & - \\
\hline $\mathrm{M}-\mathrm{l}$ subtrochanteric diameter & 34.82 & - & 31.57 & - & 33.51 & - \\
\hline Tibia & & & & & $*$ & \\
\hline Maximum length & 392 & - & - & - & 362.61 & - \\
\hline Circumference (nf) & 104 & - & 90 & 92 & 99 & 101 \\
\hline A-p diameter $(n f)$ & 36 & - & 32.5 & 33.58 & 34.99 & 35.93 \\
\hline M-l diameter (nf) & 27.52 & - & 24.34 & 24.65 & 27.03 & 27.48 \\
\hline Proximal epiphyseal breadth & 79 & - & - & - & 70 & 71 \\
\hline Distal epiphyseal breadth & 52 & - & - & - & - & 46 \\
\hline \multicolumn{7}{|l|}{ Fibula } \\
\hline Maximum length & 383 & - & - & - & - & - \\
\hline Maximum diameter & 16.88 & - & - & - & - & - \\
\hline \multicolumn{7}{|l|}{ Scapula } \\
\hline Maximum height & - & - & - & - & - & - \\
\hline Maximum breadth & - & - & - & - & - & - \\
\hline \multicolumn{7}{|l|}{ Clavicle } \\
\hline Maximum length & 164 & - & 148.5 & - & 143 & 139.5 \\
\hline Anterior diameter & 12.77 & - & 12.29 & - & 12.65 & 13.67 \\
\hline Superior diameter & 12.5 & - & 9.36 & - & 11.01 & 10.68 \\
\hline \multicolumn{7}{|l|}{ Os coxa } \\
\hline \multirow[t]{2}{*}{ Maximum length } & 230.5 & - & - & - & - & - \\
\hline & - & - & - & - & - & - \\
\hline Ischial length & - & - & - & - & - & - \\
\hline Pubis length & - & - & - & - & - & - \\
\hline Iliac breadth & 159 & - & - & - & - & - \\
\hline \multicolumn{7}{|l|}{ Sacrum } \\
\hline Anterior length & 104.16 & - & - & - & 108.63 & - \\
\hline Anterior superior breadth & 99.45 & - & - & - & 104.4 & - \\
\hline Maximum transverse diameter base & 57.06 & - & 37.02 & - & 51.3 & - \\
\hline
\end{tabular}

Notes: $*$ reconstructed element at one location; - = too fragmented to measure. 
Investigations at Roberts Cemetery

Table B.7. Immature postcranial metrics (in $\mathrm{mm}$ ) for Burial 4

\begin{tabular}{|c|c|c|}
\hline \multirow[b]{2}{*}{ Element } & \multicolumn{2}{|c|}{ Burial 4} \\
\hline & Left & Right \\
\hline \multicolumn{3}{|l|}{ Clavicle } \\
\hline Length & 65.51 & - \\
\hline Diameter & 6.07 & - \\
\hline \multicolumn{3}{|l|}{ Ilium } \\
\hline Length & 49.97 & 49.33 \\
\hline Width & 58.84 & 58.04 \\
\hline \multicolumn{3}{|l|}{ Ischium } \\
\hline Length & 34.09 & - \\
\hline Width & 21.36 & 21.45 \\
\hline \multicolumn{3}{|l|}{ Pubis } \\
\hline Length & 27.77 & 28.23 \\
\hline \multicolumn{3}{|l|}{ Humerus } \\
\hline Length & 113.3 & 113.8 \\
\hline Width & 25.97 & 25.61 \\
\hline Diameter & 10.54 & 10.68 \\
\hline \multicolumn{3}{|l|}{$U \ln a$} \\
\hline Length & - & 92.98 \\
\hline Diameter & - & 7.55 \\
\hline \multicolumn{3}{|l|}{ Radius } \\
\hline Length & - & 85.02 \\
\hline Diameter & - & 7.13 \\
\hline \multicolumn{3}{|l|}{ Femur } \\
\hline Length & - & 138.57 \\
\hline Width & - & 34.84 \\
\hline Diameter & - & 10.89 \\
\hline \multicolumn{3}{|l|}{ Tibia } \\
\hline Length & 114.14 & 113.98 \\
\hline Diameter & 11.41 & 11.26 \\
\hline
\end{tabular}

Note: - = too fragmented to measure.

Table B.8. Nonmetric traits (adults only)

\begin{tabular}{|c|c|c|c|c|c|c|c|c|c|}
\hline \multirow[b]{2}{*}{ Trait } & \multicolumn{3}{|c|}{ Burial 1} & \multicolumn{3}{|c|}{ Burial 2} & \multicolumn{3}{|c|}{ Burial 3} \\
\hline & Left & Middle & Right & Left & Middle & Right & Left & Middle & Right \\
\hline Metopic suture & & 9 & & & 9 & & & 0 & \\
\hline Supraorbital notch & 1 & & 2 & 9 & & 9 & 1 & & 1 \\
\hline Supraorbital foramen & 0 & & 0 & 9 & & 9 & 1 & & 1 \\
\hline Infraorbital suture & 9 & & 9 & 9 & & 9 & 9 & & 9 \\
\hline Multiple infraorbital foramina & 0 & & 2 & 9 & & 9 & 9 & & 9 \\
\hline Zygomatic-facial foramina & 0 & & 6 & 9 & & 2 & 1 & & 1 \\
\hline Parietal foramen & 0 & & 0 & 9 & & 9 & 9 & & 1 \\
\hline Epipteric bone & 9 & & 9 & 9 & & 9 & 9 & & 9 \\
\hline Coronal ossicle & 9 & & 9 & 9 & & 9 & 9 & & 9 \\
\hline Bregmatic bone & & 0 & & & 9 & & & 9 & \\
\hline Sagittal ossicle & & 9 & & & 9 & & & 9 & \\
\hline Apical bone & & 9 & & & 9 & & & 9 & \\
\hline Lambdoid ossicle & 9 & & 9 & 9 & & 9 & 9 & & 9 \\
\hline Asterionic bone & 9 & & 9 & 9 & & 9 & 9 & & 9 \\
\hline
\end{tabular}


Table B.8, continued

\begin{tabular}{|c|c|c|c|c|c|c|c|c|c|}
\hline \multirow[b]{2}{*}{ Trait } & \multicolumn{3}{|c|}{ Burial 1} & \multicolumn{3}{|c|}{ Burial 2} & \multicolumn{3}{|c|}{ Burial 3} \\
\hline & Left & Middle & Right & Left & Middle & Right & Left & Middle & Right \\
\hline $\begin{array}{l}\text { Ossicle in occipito-mastoid } \\
\text { suture }\end{array}$ & 9 & & 9 & 9 & & 9 & 9 & & 9 \\
\hline Parietal notch bone & 9 & & 9 & 9 & & 9 & 9 & & 9 \\
\hline Inca bone & & 9 & & & 9 & & & 0 & 0 \\
\hline Condylar canal & 9 & & 9 & 9 & & 9 & 9 & & 9 \\
\hline Divided hypoglossal canal & 2 & & 0 & 9 & & 9 & 9 & & 9 \\
\hline $\begin{array}{l}\text { Flexure of superior sagittal } \\
\text { sulcus }\end{array}$ & & 1 & & & 9 & & & 1 & \\
\hline Foramen ovale incomplete & 9 & & 9 & 9 & & 9 & 9 & & 9 \\
\hline Foramen spinosum incomplete & 9 & & 9 & 9 & & 9 & 9 & & 9 \\
\hline Pterygo-spinous bridge & 9 & & 9 & 9 & & 9 & 9 & & 9 \\
\hline Tympanic dihiscence & 9 & & 9 & 9 & & 9 & 9 & & 9 \\
\hline Auditory exostosis & 9 & & 9 & 9 & & 9 & 9 & & 9 \\
\hline Mastoid foramen location & 0 & & 0 & 9 & & 1 & & & 1 \\
\hline Mastoid foramen number & 2 & & 0 & 9 & & 1 & 1 & & 2 \\
\hline Mental foramen & 1 & & 0 & 9 & & 9 & 1 & & 1 \\
\hline Mandibular torus & 1 & & 1 & 9 & & 9 & 9 & & 0 \\
\hline Mylohyoid bridge location & 0 & & 0 & 9 & & 9 & 0 & & 9 \\
\hline Mylohyoid bridge degree & 0 & & 0 & 9 & & 9 & 0 & & 9 \\
\hline Atlas bridging - lateral & 0 & & 0 & 9 & & 9 & 0 & & 0 \\
\hline Atlas bridging - posterior & 0 & & 0 & 9 & & 9 & 0 & & 0 \\
\hline Accessory transverse foramina & 1 & & 1 & 9 & & 9 & 0 & & 0 \\
\hline Septal aperture & 0 & & 0 & 9 & & 0 & 0 & & 9 \\
\hline
\end{tabular}

Notes: 0 = absent; 1 = present; 9 = unobservable. See Buikstra and Ubelaker 1994 for more definitions of the scores.

Table B.9. Dental data for Burial 1

Variable
$\begin{aligned} & \text { Presence } \\ & \text { Maxilla }\end{aligned}$




\section{Investigations at Roberts Cemetery}

Table B.9, continued

Variable
$\begin{aligned} & \text { Presence } \\ & \text { Mandible Resption }\end{aligned}$

Notes: $\mathrm{L}=$ left; $\mathrm{R}=$ right; $\mathrm{C}=$ canine; $\mathrm{I}=$ incisor; $\mathrm{M}=$ molar; $\mathrm{P}=$ premolar; $-=$ unable to score; $0=$ absent.

See Buikstra and Ubelaker 1994 for more definitions of the scores.

Table B.10. Dental data for Burial 2

\begin{tabular}{|c|c|c|c|c|c|c|c|c|c|}
\hline Variable & Presence & Resorption & $\begin{array}{c}\text { Abscess } \\
\text { Type }\end{array}$ & $\begin{array}{c}\text { Abscess } \\
\text { Size }\end{array}$ & Calculus & $\begin{array}{c}\text { Hypoplasia } \\
\text { Type }\end{array}$ & $\begin{array}{c}\text { Distance } \\
\text { to CEJ } \\
(\mathrm{mm})\end{array}$ & $\begin{array}{c}\text { Caries } \\
\text { Location }\end{array}$ & $\begin{array}{c}\text { Caries } \\
\text { Size } \\
\end{array}$ \\
\hline \multicolumn{10}{|c|}{ Maxilla } \\
\hline LM3 & 3 & - & - & - & - & - & - & - & - \\
\hline LM2 & 3 & - & - & - & - & - & - & - & - \\
\hline LM1 & 3 & - & - & - & - & - & - & - & - \\
\hline LP4 & 3 & - & - & - & - & - & - & - & - \\
\hline LP3 & 3 & - & - & - & - & - & - & - & - \\
\hline $\mathrm{LC}$ & 3 & - & - & - & - & - & - & - & - \\
\hline $\mathrm{LI} 2$ & 3 & - & - & - & - & - & - & - & - \\
\hline LI1 & 1 & - & - & - & 0 & 0 & 0 & 0 & 0 \\
\hline RI1 & 3 & - & - & - & - & - & - & - & - \\
\hline $\mathrm{RI} 2$ & 3 & - & - & - & - & - & - & - & - \\
\hline $\mathrm{RC}$ & 3 & - & - & - & - & - & - & - & - \\
\hline RP3 & 1 & - & - & - & 1 & 0 & 0 & 0 & 0 \\
\hline $\mathrm{RP} 4$ & 1 & - & - & - & 1 & 0 & 0 & 0 & 0 \\
\hline RM1 & 3 & - & - & - & - & - & - & - & - \\
\hline RM2 & 2 & 1 & - & - & 2 & 0 & 0 & 0 & 0 \\
\hline RM3 & 2 & 1 & - & & 1 & 0 & 0 & 3 & $\begin{array}{c}2.83 \mathrm{M} / \\
\mathrm{D} \times 2.86 \\
\mathrm{~B} / \mathrm{L}\end{array}$ \\
\hline \multicolumn{10}{|l|}{ Mandible } \\
\hline LM3 & 3 & - & - & - & - & - & - & - & - \\
\hline LM2 & 1 & - & - & - & 1 & 0 & 0 & 0 & - \\
\hline LM1 & 3 & - & - & - & - & - & - & - & - \\
\hline LP4 & 1 & - & - & - & 0 & 0 & 0 & 3 lingual & - \\
\hline
\end{tabular}


Table B.10, continued

\begin{tabular}{l|c|c|c|c|c|c|c|c|c}
\hline Variable & Presence & Resorption & $\begin{array}{c}\text { Abscess } \\
\text { Type }\end{array}$ & $\begin{array}{c}\text { Abscess } \\
\text { Size }\end{array}$ & Calculus & $\begin{array}{c}\text { Hypoplasia } \\
\text { Type }\end{array}$ & $\begin{array}{c}\text { Distance } \\
\text { to CEJ } \\
\text { (mm) }\end{array}$ & $\begin{array}{c}\text { Caries } \\
\text { Location }\end{array}$ & $\begin{array}{c}\text { Caries } \\
\text { Size }\end{array}$ \\
\hline LP3 & 1 & - & - & - & 0 & 0 & 0 & 0 & - \\
\hline LC & 3 & - & - & - & - & - & - & - & - \\
\hline LI2 & 1 & - & - & - & 0 & 5 & 7.53 & 0 & - \\
\hline LI1 & 1 & - & - & - & 0 & 0 & 0 & 0 & - \\
\hline RI1 & 3 & - & - & - & - & - & - & - & - \\
\hline RI2 & 1 & - & - & - & 0 & 0 & 0 & 0 & - \\
\hline RC & 3 & - & - & - & - & - & - & - & - \\
\hline RP3 & 1 & - & - & - & 0 & 0 & 0 & 0 & - \\
\hline RP4 & 1 & - & - & - & 2 & 0 & 0 & 2 & - \\
\hline RM1 & 3 & - & - & - & - & - & - & - & - \\
\hline RM2 & 3 & 2 & - & - & - & - & - & - & - \\
\hline RM3 & 2 & - & - & - & 0 & 0 & 0 & 0 & - \\
\hline
\end{tabular}

Notes: $\mathrm{L}=$ left; $\mathrm{R}=$ right; $\mathrm{C}=$ canine; $\mathrm{I}=$ incisor; $\mathrm{M}=$ molar; $\mathrm{P}=$ premolar; $-=$ unable to score; 0 = absent; \# - unable to score due to extensive calculus. See Buikstra and Ubelaker 1994 for more definitions of the scores.

Table B.11. Dental data for Burial 3

\begin{tabular}{|c|c|c|c|c|c|c|c|c|c|}
\hline Variable & Presence & Resorption & $\begin{array}{c}\text { Abscess } \\
\text { Type }\end{array}$ & $\begin{array}{c}\text { Abscess } \\
\text { Size }\end{array}$ & Calculus & $\begin{array}{c}\text { Hypoplasia } \\
\text { Type }\end{array}$ & $\begin{array}{c}\text { Distance } \\
\text { to CEJ } \\
(\mathrm{mm})\end{array}$ & \begin{tabular}{c|} 
Caries \\
Location \\
\end{tabular} & $\begin{array}{c}\text { Caries } \\
\text { Size }\end{array}$ \\
\hline \multicolumn{10}{|c|}{\begin{tabular}{l|l} 
Maxilla & \\
\end{tabular}} \\
\hline LM3 & 2 & 1 & 0 & 0 & 1 & 0 & 0 & 0 & 0 \\
\hline LM2 & 2 & 1 & 0 & 0 & 1 & 0 & 0 & 0 & 0 \\
\hline LM1 & 2 & 1 & 0 & 0 & 1 & 0 & 0 & 0 & 0 \\
\hline LP4 & 2 & 1 & 0 & 0 & 2 & 0 & 0 & 0 & 0 \\
\hline LP3 & 2 & 1 & 0 & 0 & 1 & 0 & 0 & 0 & 0 \\
\hline $\mathrm{LC}$ & 2 & 1 & 0 & 0 & 1 & 0 & 0 & 0 & 0 \\
\hline $\mathrm{LI} 2$ & 2 & 1 & 0 & 0 & 1 & 0 & 0 & 0 & 0 \\
\hline LI1 & 2 & 1 & 0 & 0 & 1 & 0 & 0 & 0 & 0 \\
\hline RI1 & 2 & 1 & 0 & 0 & 1 & 0 & 0 & 0 & 0 \\
\hline $\mathrm{RI} 2$ & 2 & 1 & 0 & 0 & 1 & 0 & 0 & 0 & 0 \\
\hline $\mathrm{RC}$ & 2 & 1 & 0 & 0 & 1 & 0 & 0 & 0 & 0 \\
\hline RP3 & 2 & 1 & 0 & 0 & 2 & 0 & 0 & 0 & 0 \\
\hline RP4 & 2 & 1 & 0 & 0 & 1 & 0 & 0 & 0 & 0 \\
\hline RM1 & 1 & - & - & - & 1 & 0 & 0 & 0 & 0 \\
\hline RM2 & 1 & - & - & - & 1 & 0 & 0 & 0 & 0 \\
\hline RM3 & 1 & - & - & - & 1 & 0 & 0 & 0 & 0 \\
\hline \multicolumn{10}{|l|}{ Mandible } \\
\hline LM3 & 2 & 0 & 0 & 0 & 1 & & 0 & 0 & 0 \\
\hline LM2 & 2 & 0 & 0 & 0 & 1 & & 0 & 0 & 0 \\
\hline LM1 & 1 & 0 & 0 & 0 & 1 & & 0 & 0 & 0 \\
\hline LP4 & 1 & 0 & 0 & 0 & 1 & & 0 & 0 & 0 \\
\hline LP3 & 1 & 1 & 0 & 0 & 1 & & 0 & 0 & 0 \\
\hline $\mathrm{LC}$ & 2 & 1 & 0 & 0 & 2 & 1 & $3.78,4.85$ & 0 & 0 \\
\hline $\mathrm{LI} 2$ & 2 & 2 & 0 & 0 & 3 & & 0 & 0 & 0 \\
\hline LI1 & 2 & 2 & 0 & 0 & 3 & & 0 & 0 & 0 \\
\hline RI1 & 2 & - & - & - & 3 & & 0 & 0 & 0 \\
\hline
\end{tabular}




\section{Investigations at Roberts Cemetery}

Table B.11, continued

\begin{tabular}{l|c|c|c|c|c|c|c|c|c}
\hline Variable & Presence & Resorption & $\begin{array}{c}\text { Abscess } \\
\text { Type }\end{array}$ & $\begin{array}{c}\text { Abscess } \\
\text { Size }\end{array}$ & Calculus & $\begin{array}{c}\text { Hypoplasia } \\
\text { Type }\end{array}$ & $\begin{array}{c}\text { Distance } \\
\text { to CEJ } \\
\text { (mm) }\end{array}$ & $\begin{array}{c}\text { Caries } \\
\text { Location }\end{array}$ & $\begin{array}{c}\text { Caries } \\
\text { Size }\end{array}$ \\
\hline RI2 & 2 & - & - & - & 3 & & 0 & 0 & 0 \\
\hline RC & 2 & - & - & - & 3 & & $\#$ & 0 & 0 \\
\hline RP3 & 2 & - & - & - & 2 & & 0 & 0 & 0 \\
\hline RP4 & 2 & - & - & - & 2 & & 0 & 0 & 0 \\
\hline RM1 & 2 & - & - & - & 1 & & 0 & 0 & 0 \\
\hline RM3 & 2 & 0 & 0 & 0 & 1 & & 0 & 0 & 0 \\
\hline
\end{tabular}

Notes: $\mathrm{L}=$ left; $\mathrm{R}=$ right; $\mathrm{C}=$ canine; $\mathrm{I}=$ incisor; $\mathrm{M}=$ molar; $\mathrm{P}=$ premolar; $-=$ unable to score;. 0 = absent; \# = unable to score due to extensive calculus. See Buikstra and Ubelaker 1994 for more definitions of the scores.

Table B.12. Dental data for Burial 4

\begin{tabular}{|c|c|c|c|c|c|}
\hline Tooth & Presence & Development & Caries & Calculus & Abscesses \\
\hline \multicolumn{6}{|l|}{ Maxillary } \\
\hline RPM1 & 1 & 3 & 0 & 0 & - \\
\hline RM2 & 1 & 6 & 0 & 0 & - \\
\hline RM1 & 1 & 9 & 0 & 0 & - \\
\hline $\mathrm{RC}$ & 1 & 6 & 0 & 0 & - \\
\hline $\mathrm{RI} 2$ & 1 & 10 & 0 & 0 & - \\
\hline RI1 & 1 & 10 & 0 & 0 & - \\
\hline LI1 & 1 & 10 & 0 & 0 & - \\
\hline $\mathrm{LI} 2$ & 1 & 10 & 0 & 0 & - \\
\hline $\mathrm{LC}$ & 1 & 6 & 0 & 0 & - \\
\hline LM1 & 1 & 9 & 0 & 0 & - \\
\hline LM2 & 1 & 6 & 0 & 0 & - \\
\hline LPM1 & 1 & 3 & 0 & 0 & - \\
\hline \multicolumn{6}{|l|}{ Mandibular } \\
\hline RPM1 & 8 & 3 & 0 & 0 & - \\
\hline RM2 & 8 & 6 & 0 & 0 & - \\
\hline RM1 & 8 & 0 & 0 & 0 & - \\
\hline $\mathrm{RC}$ & 8 & 9 & 0 & 0 & - \\
\hline $\mathrm{RI} 2$ & 6 & - & 0 & 0 & - \\
\hline RI1 & 1 & 10 & 0 & 0 & - \\
\hline PI1 & 8 & 4 & 0 & 0 & - \\
\hline PI1 & 8 & 4 & 0 & 0 & - \\
\hline LI1 & 1 & 10 & 0 & 0 & - \\
\hline LI2 & 6 & - & 0 & 0 & - \\
\hline $\mathrm{LC}$ & 8 & 9 & 0 & 0 & - \\
\hline LM1 & 8 & - & 0 & 0 & - \\
\hline LM2 & 8 & 6 & 0 & 0 & - \\
\hline LPM1 & 8 & 3 & 0 & 0 & - \\
\hline
\end{tabular}

Notes: $\mathrm{L}=$ left; $\mathrm{R}$ = right; $\mathrm{C}=$ canine; $\mathrm{I}=$ incisor; $\mathrm{M}=$ molar; $\mathrm{P}=$ premolar; $\mathrm{PM}=$ permanent molar;

$\mathrm{PI}=$ permanent incisor; $-=$ unable to score; 0 = absent. See Buikstra and Ubelaker 1994 for more definitions of the scores. 


\section{APPENDIX C: List of People Who May Be Buried in Unmarked Graves at Roberts Cemetery as Revealed in an Analysis of Death Certificates}

Compiled by Terri Myers and

Douglas K. Boyd 

Appendix C: People Who Are or May Be Buried at Roberts Cemetery

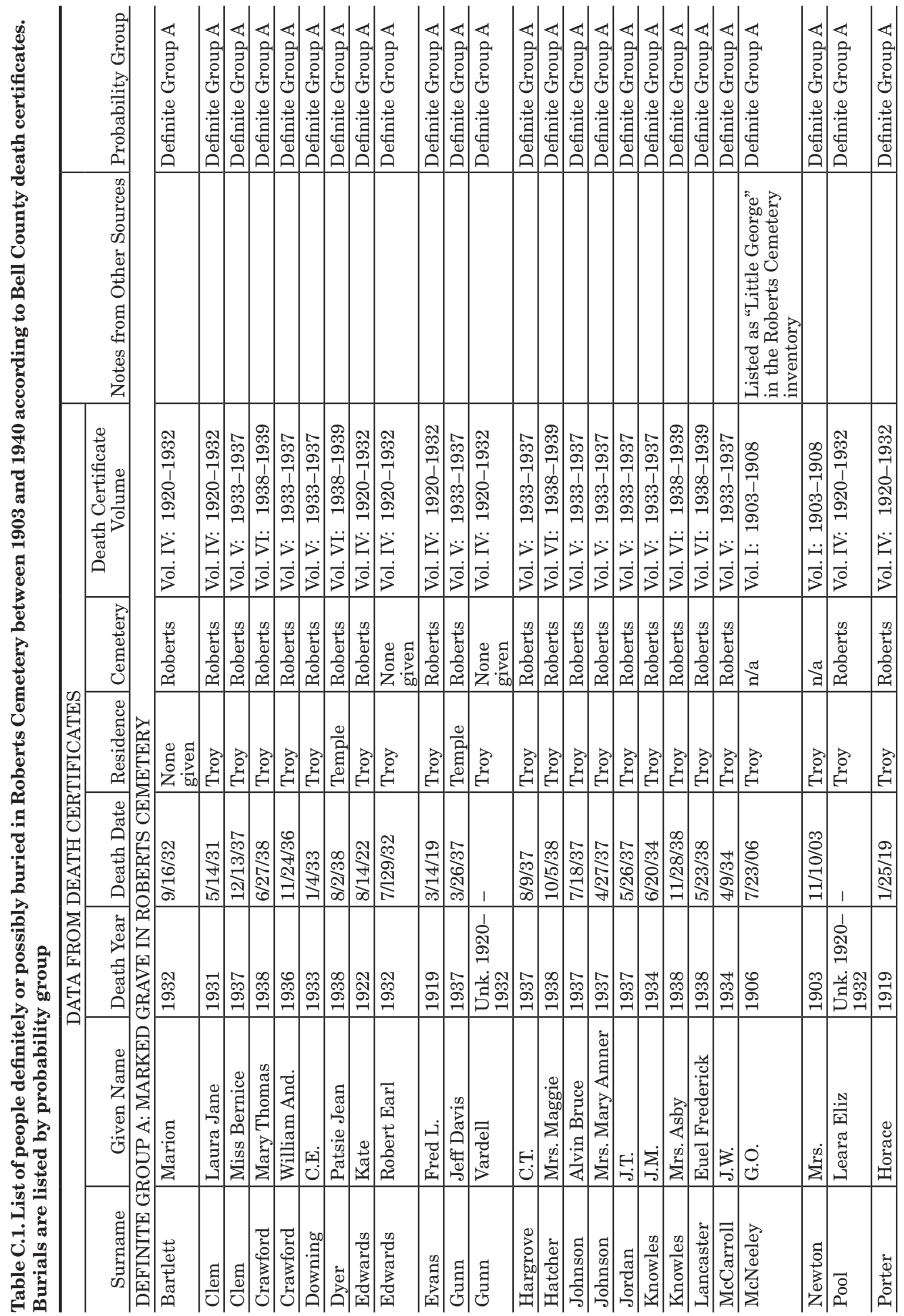




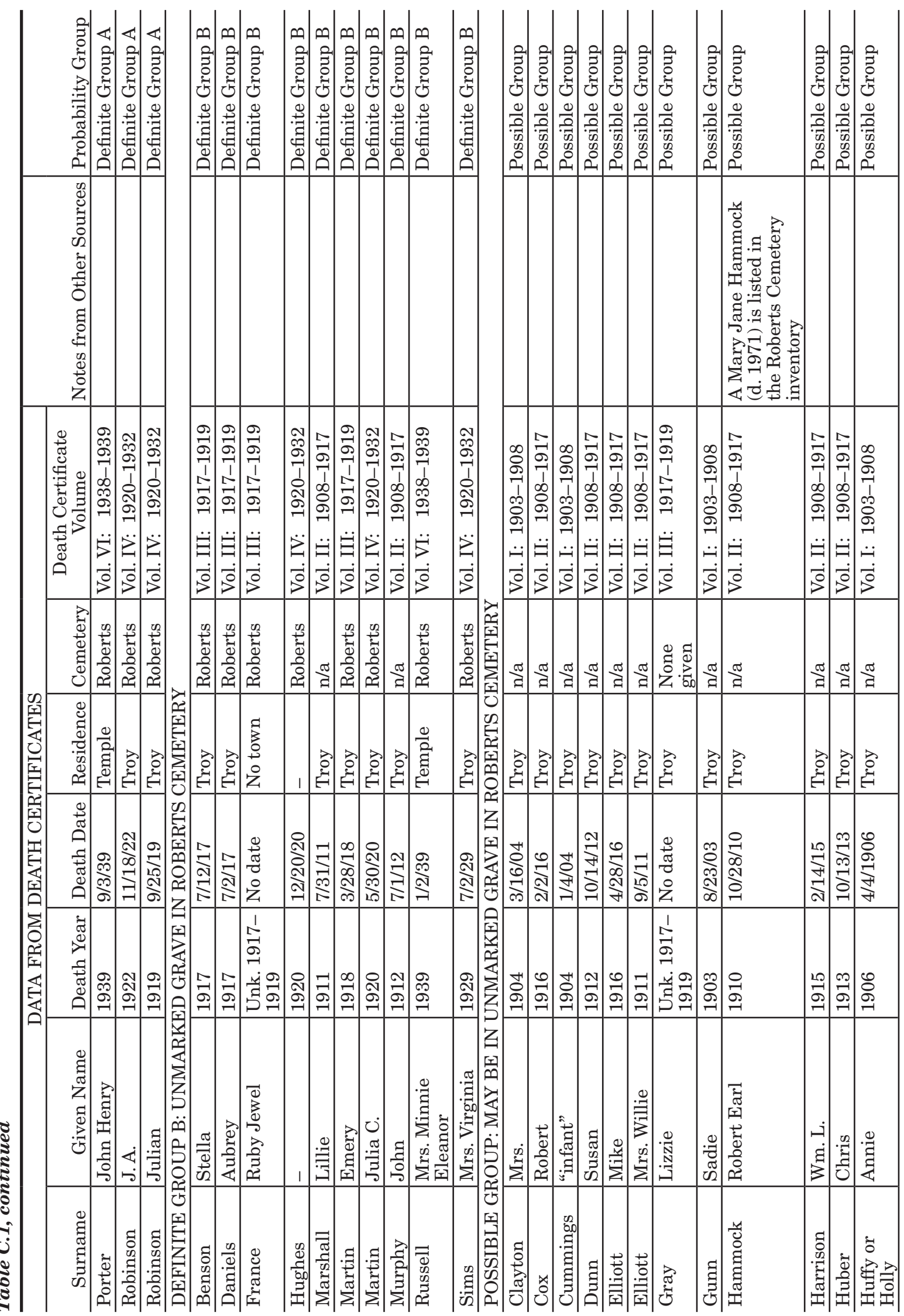


Appendix C: People Who Are or May Be Buried at Roberts Cemetery

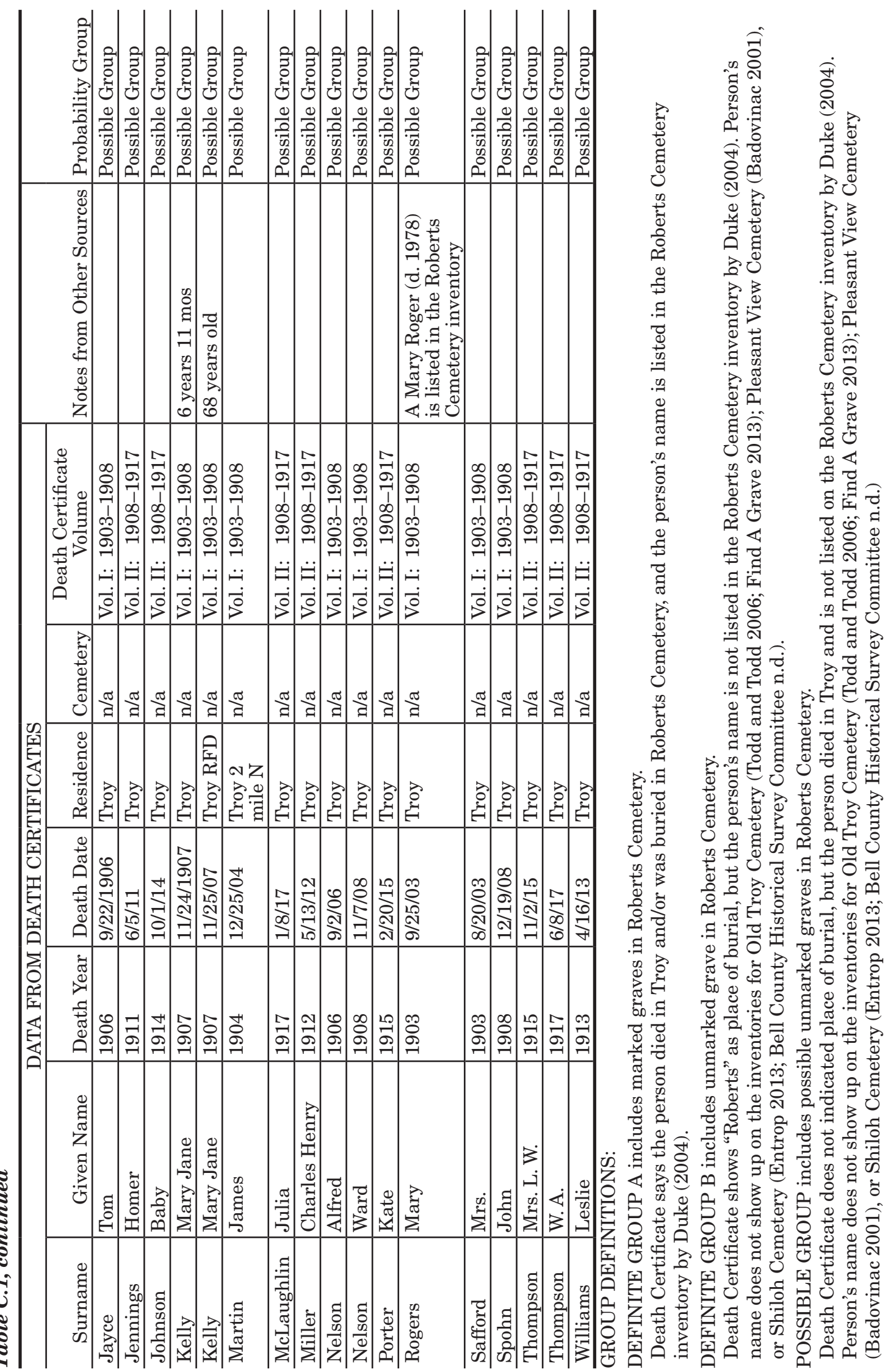





\section{APPENDIX D: List of Burials in Roberts Cemetery, Bell County, Texas, 1886 to 2004}

Inventory compiled by Mary Duke, April 2004, for the USGenWeb Project 

This appendix contains an inventory of 633 marked burials in Roberts Cemetery dating from 1886 through 2004. This information was compiled by Mary Duke in April 2004 and posted online as part of the USGenWeb Project. The online version presents the burial list in alphabetical order, while the table presented here is in chronological order by death date. The online inventory provides this notice regarding use of these data:

ROBERTS CEMETERY, West side of IH 35 Troy, Texas

Inventory taken April 2004

Submitted By: Mary Duke, mld71124@dukenet.us

*****************************************************************************************

USGENWEB ARCHIVES NOTICE: These electronic pages may NOT be reproduced in any format for profit or presentation by any other organization or persons. Persons or organizations desiring to use this material, must obtain the written consent of the contributor, or the legal representative of the submitter, and contact the listed USGenWeb archivist with proof of this consent. The submitter has given permission to the USGenWeb Archives to store and file permanently for free access.

*****************************************************************************************

The Roberts Cemetery inventory is reproduced here with written permission from Mary Duke, and the USGenWeb archivist has been provided with proof of this consent.

\section{REFERENCE CITED}

Duke, Mary

2004 Roberts Cemetery, Bell County Texas. USGENWEB. Electronic document, http://files.usgwarchives. org/tx/bell/cemetery/roberts2.txt, accessed September 17, 2012. 
Investigations at Roberts Cemetery

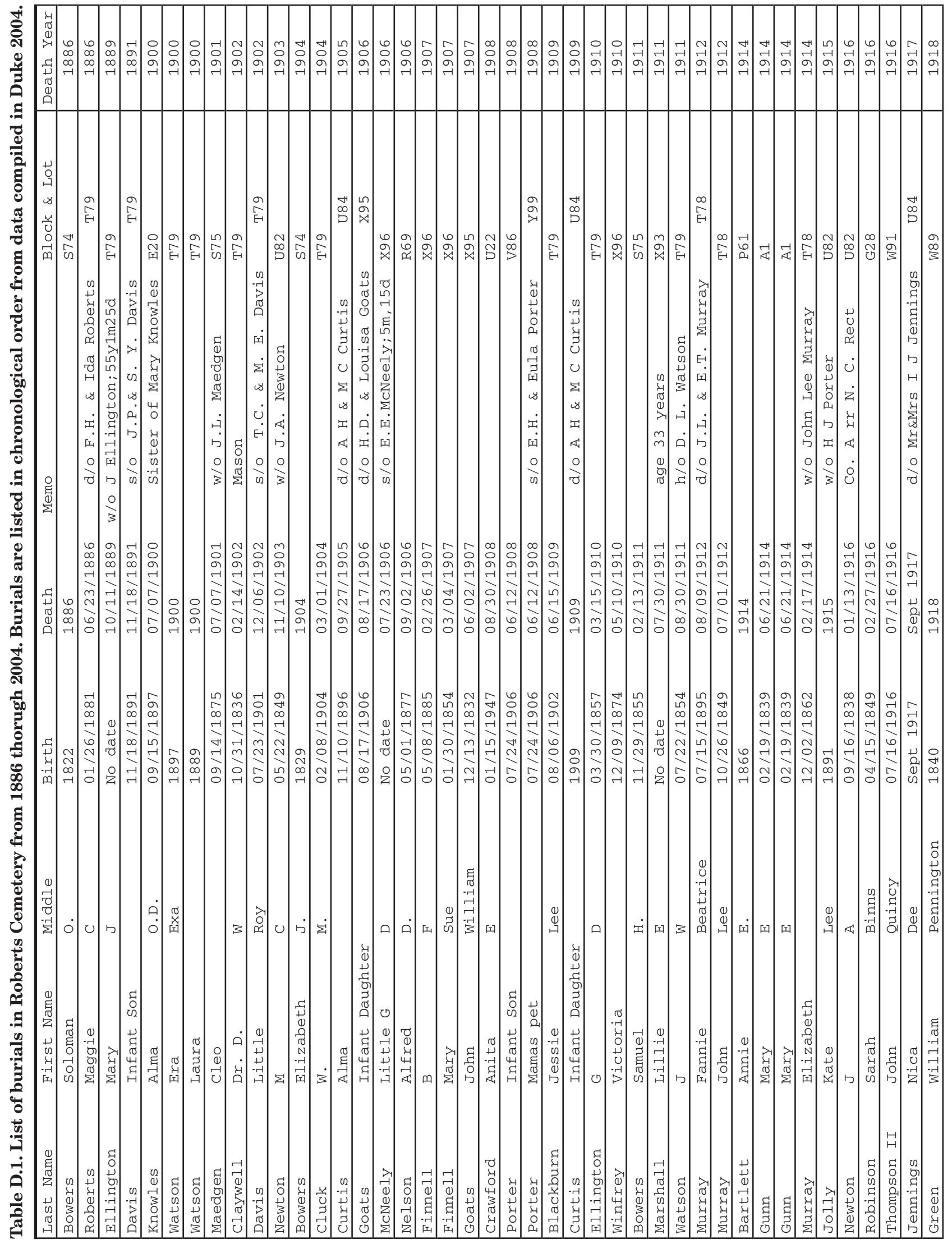




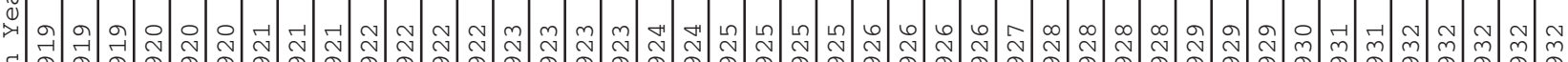

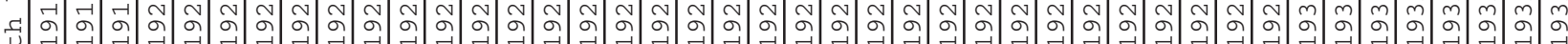

\begin{tabular}{l}
+ \\
0 \\
0 \\
$\mapsto$ \\
\hline
\end{tabular}

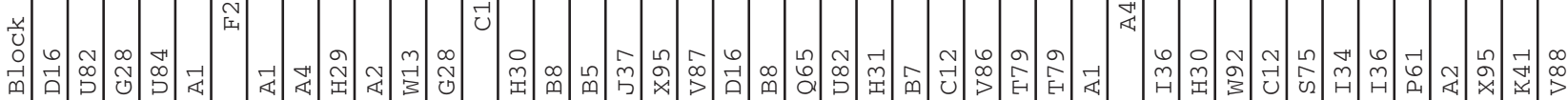

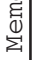

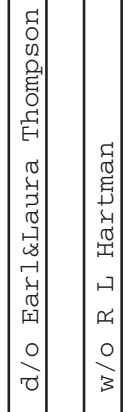

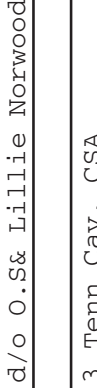

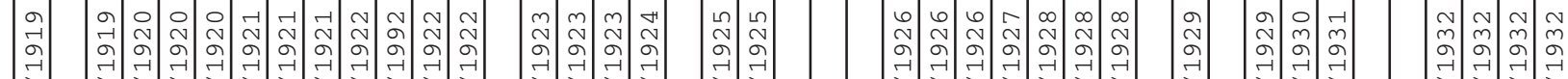

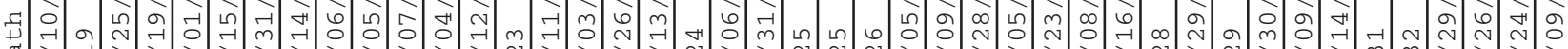

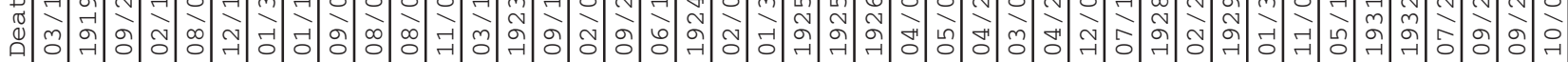

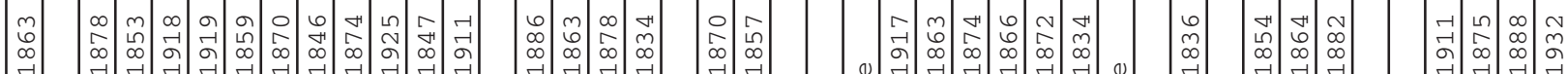

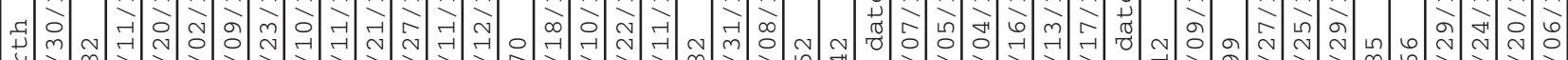

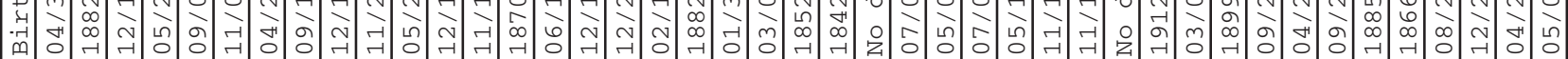

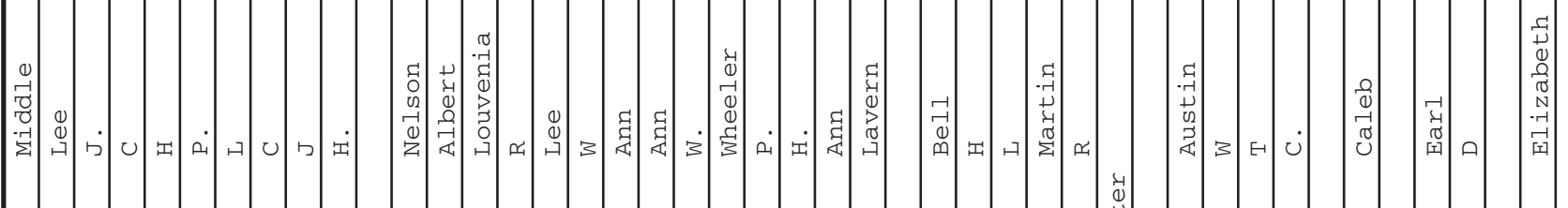

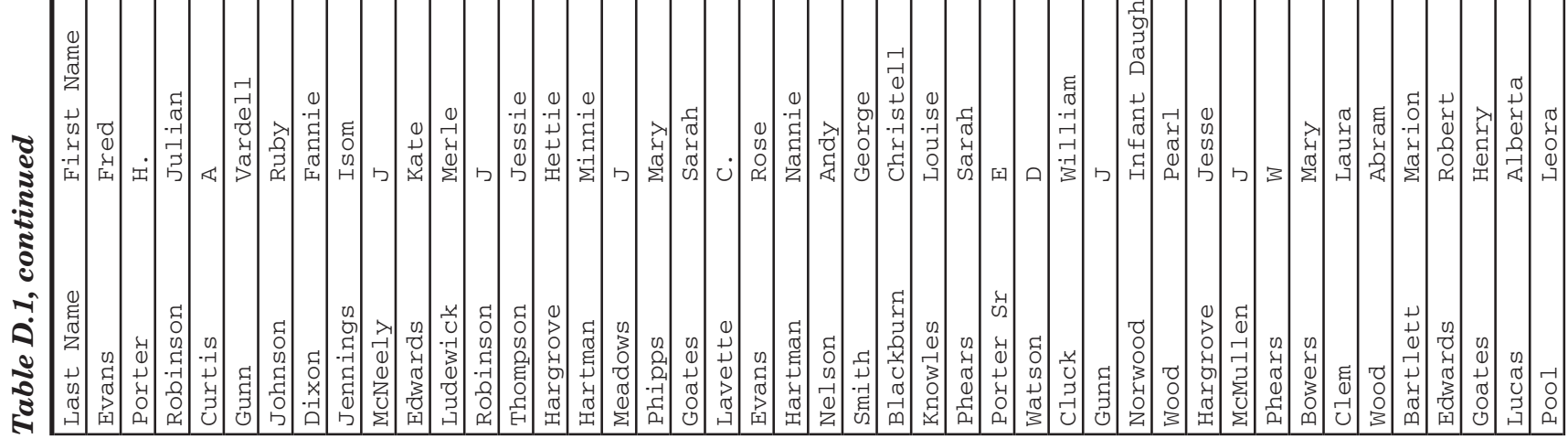


అ্র

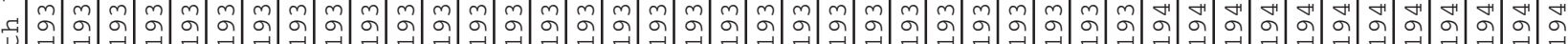

\begin{tabular}{l}
+ \\
\hdashline \\
\hdashline \\
\hline
\end{tabular}

»

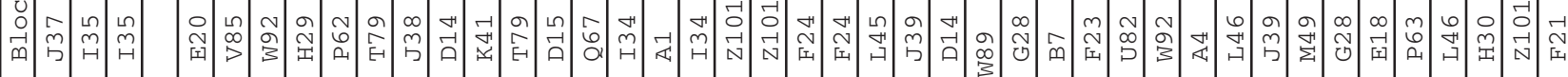

畩
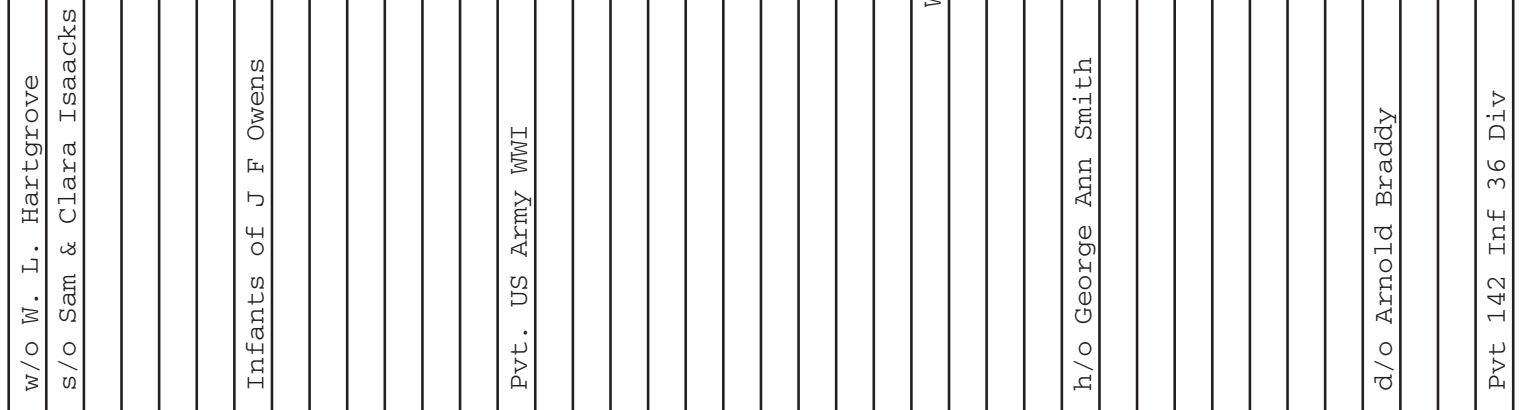

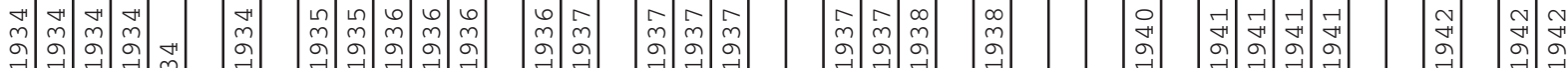

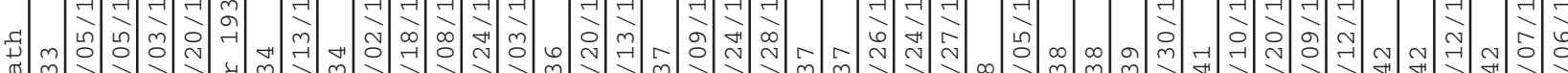

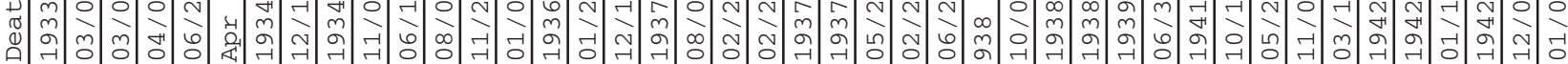

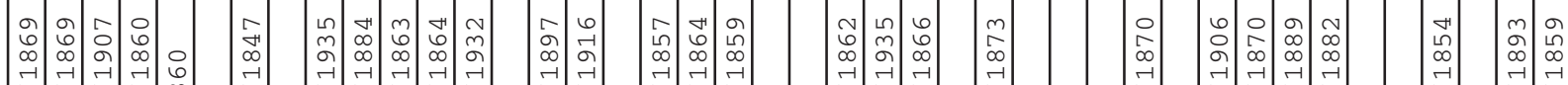

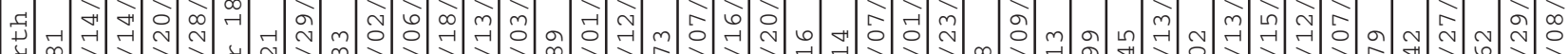

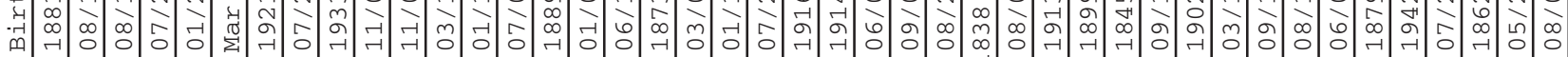

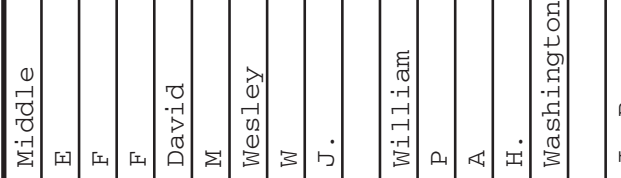

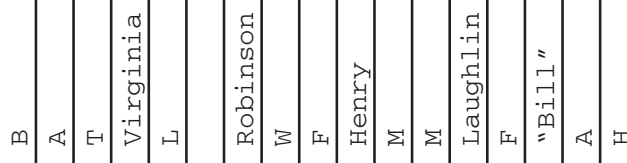

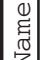

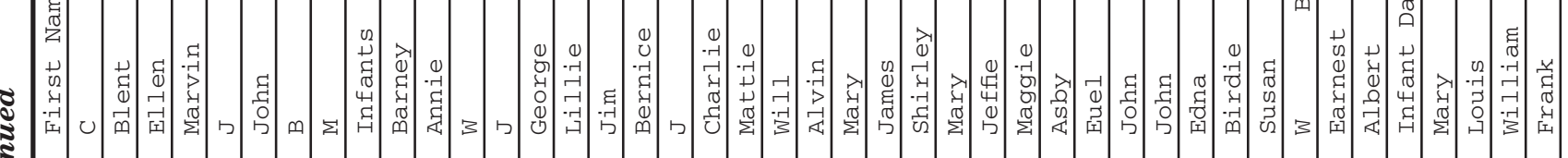

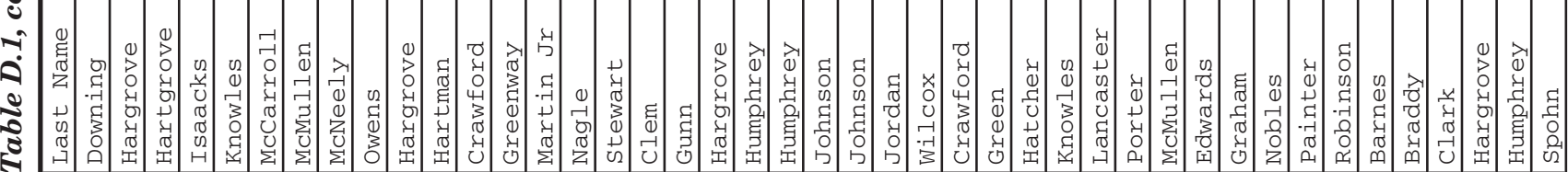


$\sqrt[\varpi]{\infty}$ ज্ 西

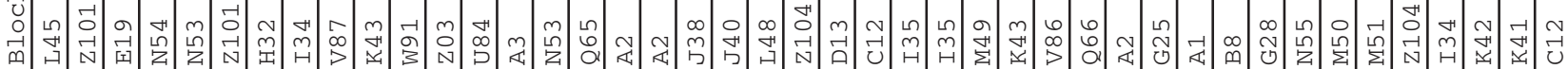

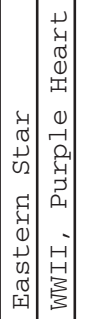

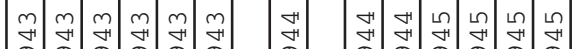

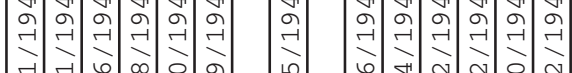

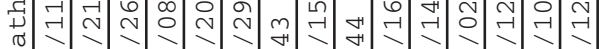

वै
索

菅

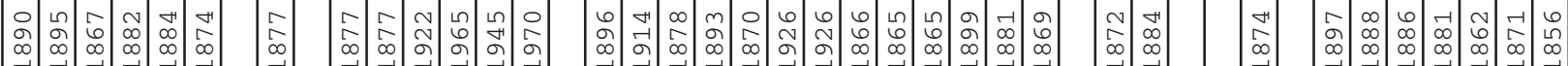

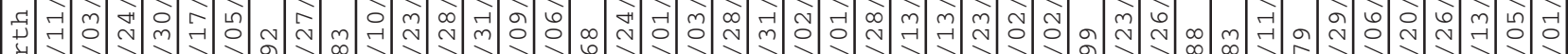

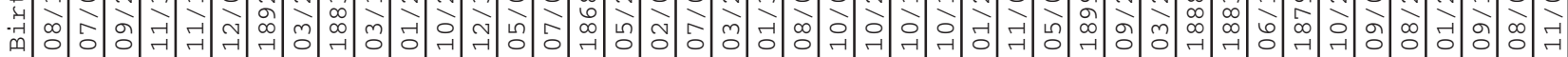

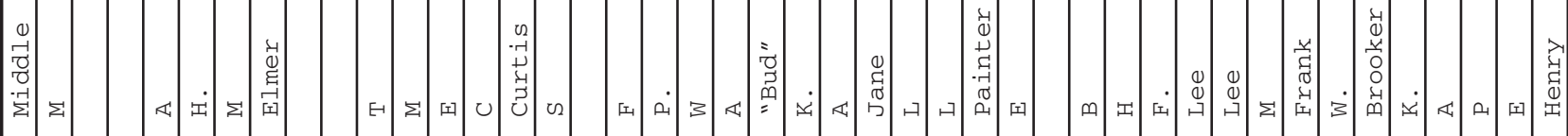

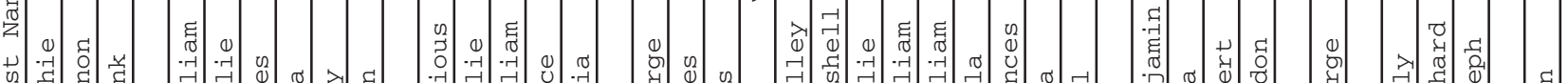

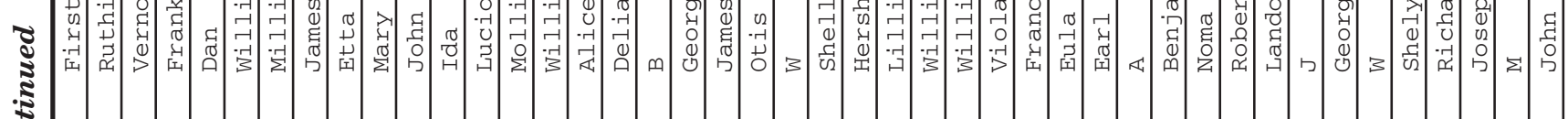

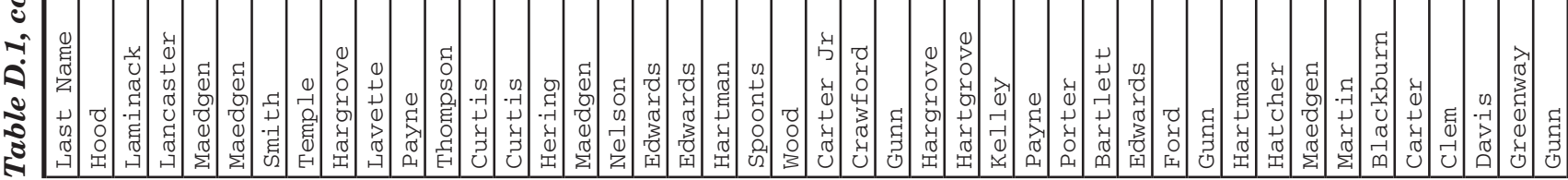




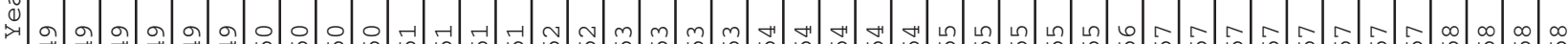

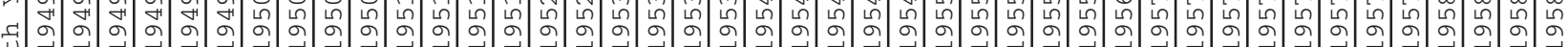

常

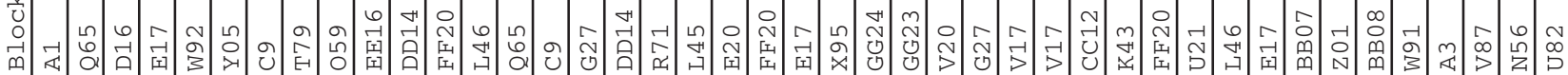

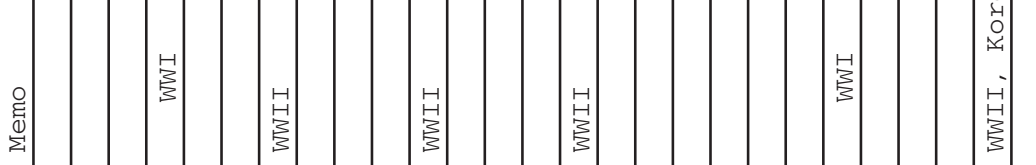

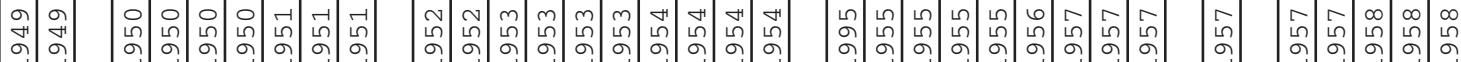

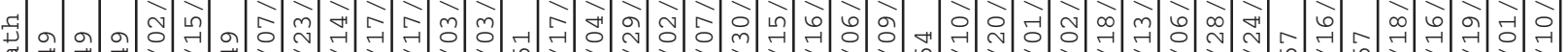

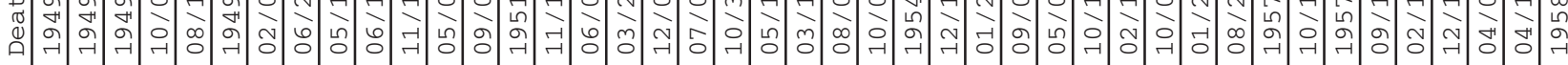

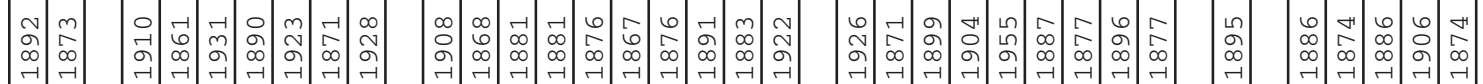

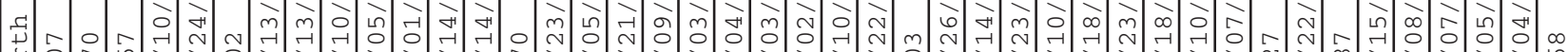

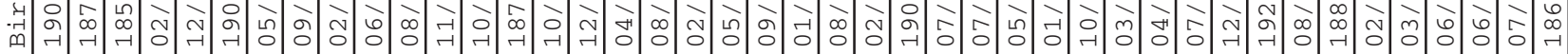

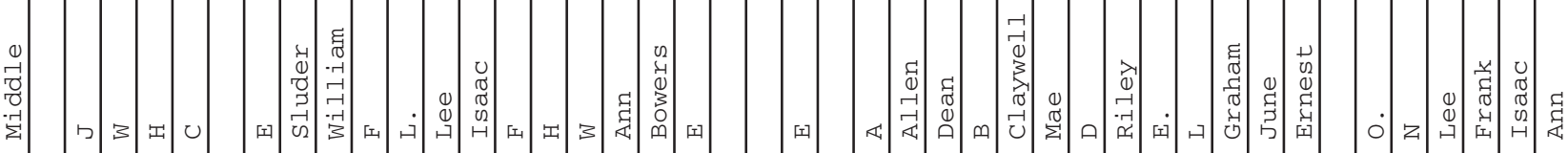

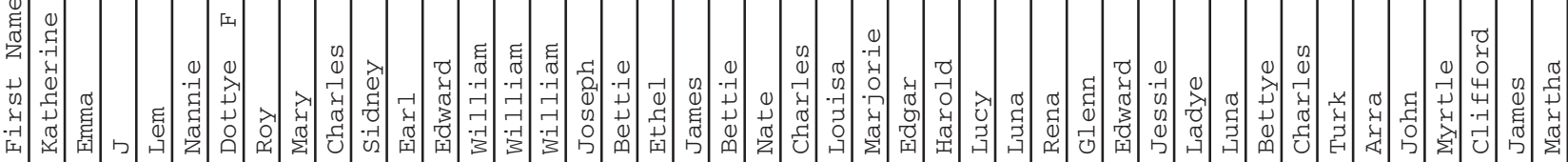


શ્ર

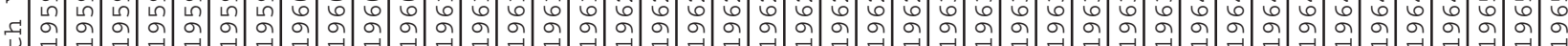

学

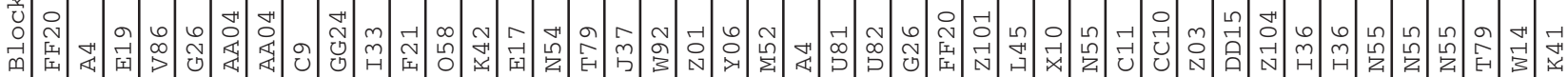

离

客

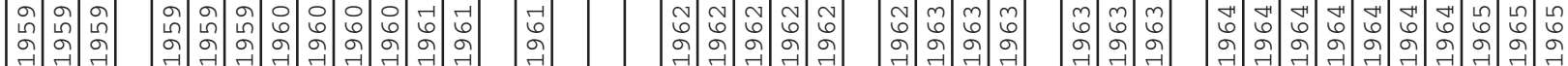

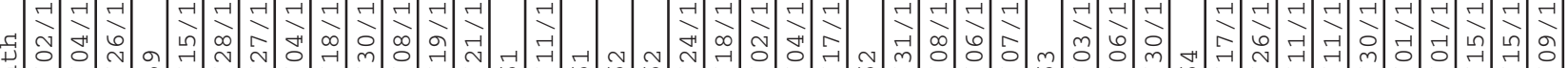

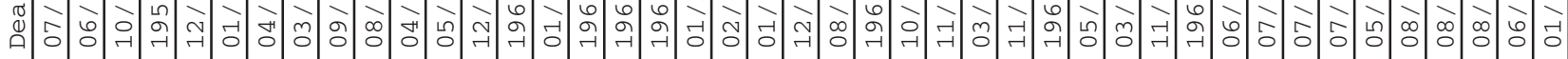

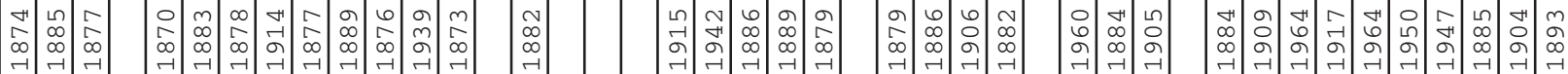
ज्ञ

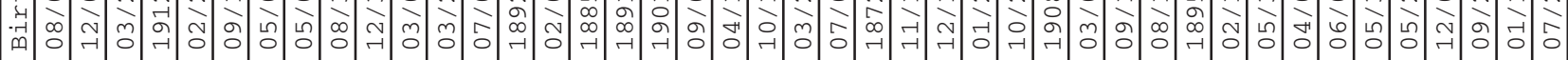

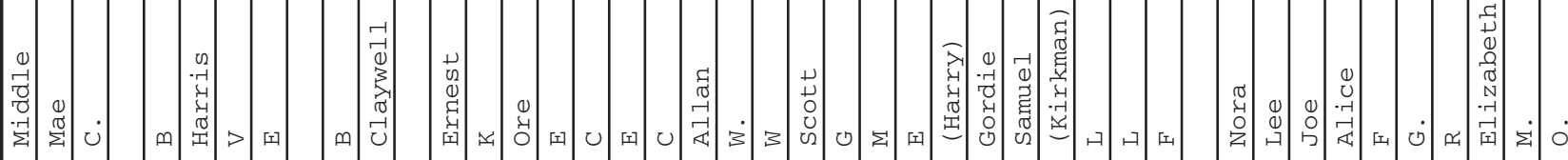

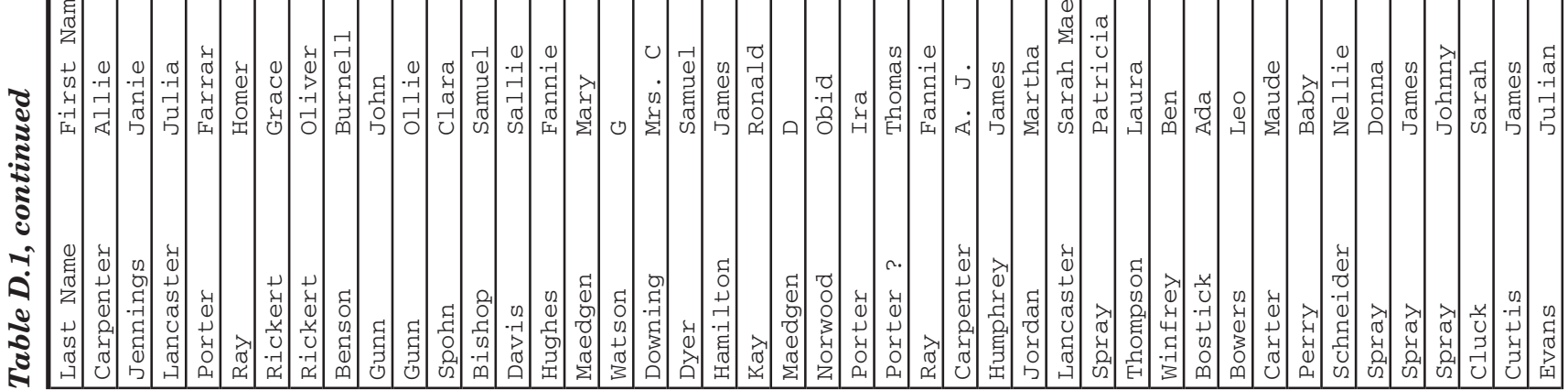




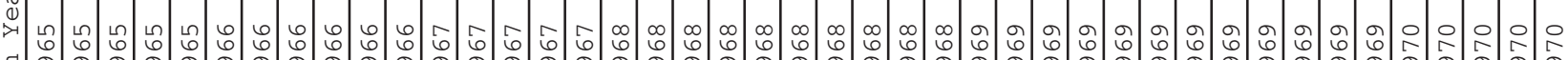
구

\begin{tabular}{l}
+ \\
0 \\
\hline \\
\hline \\
\hline
\end{tabular}

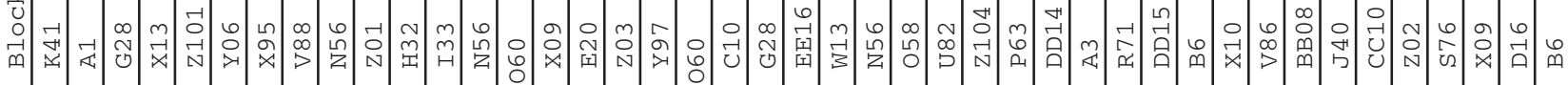

点

$\Sigma$

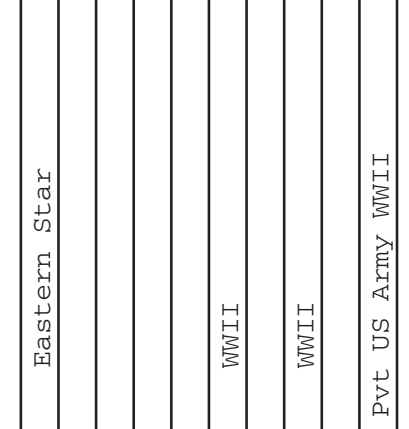

$x$
0
0
0
$\Sigma$
0
0
0
0
$\ddots$
4
0
0
4
0
0
0
0
0
0
0

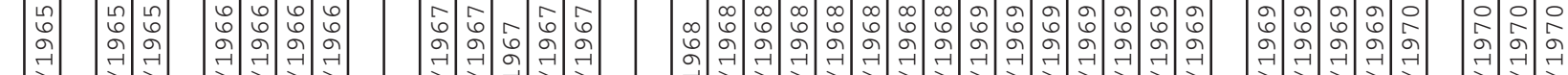

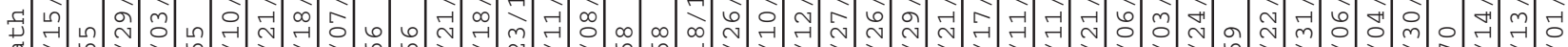

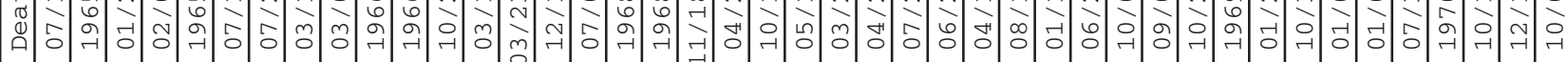

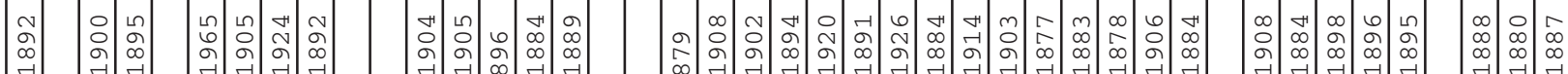

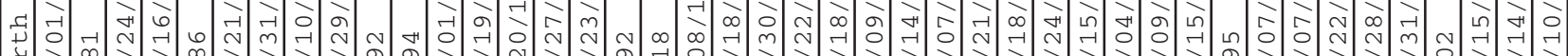

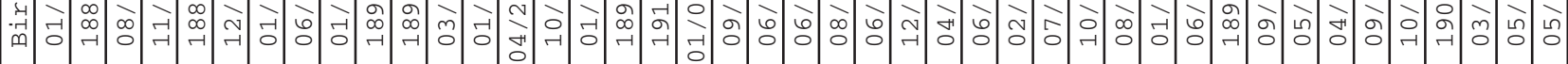

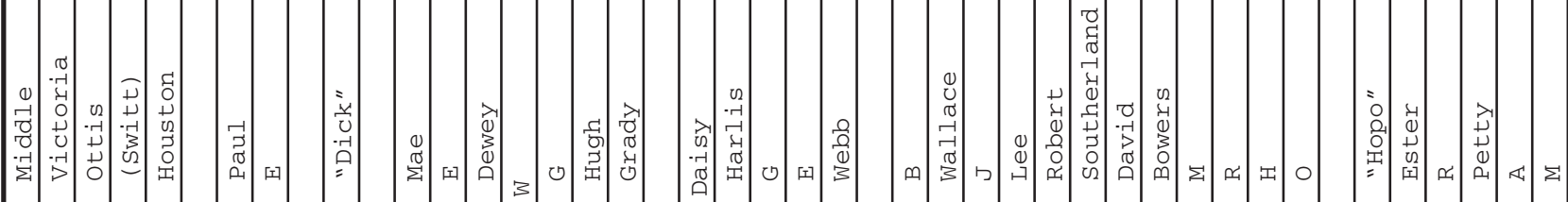

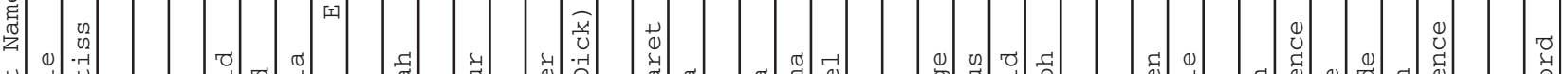

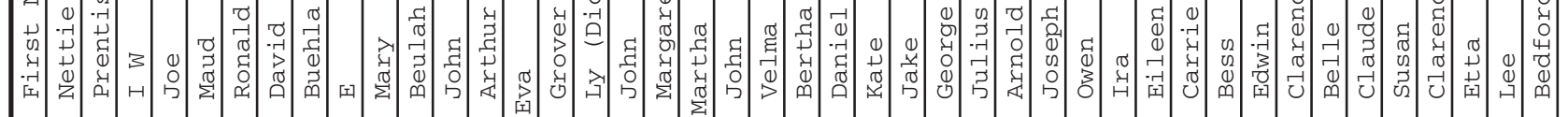
(1) 殅

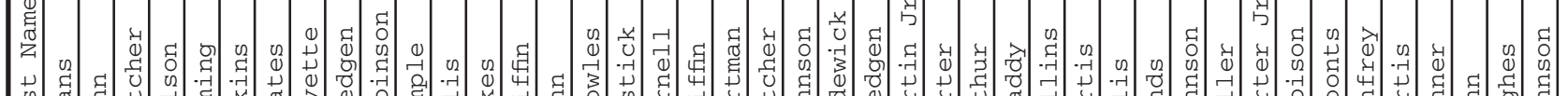

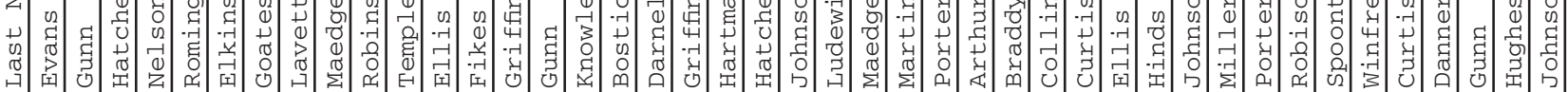




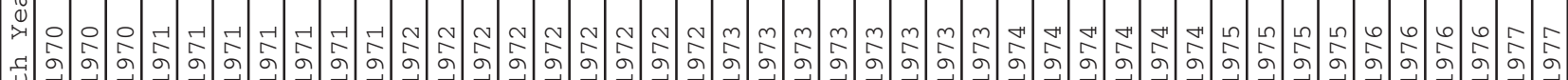

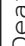

苍

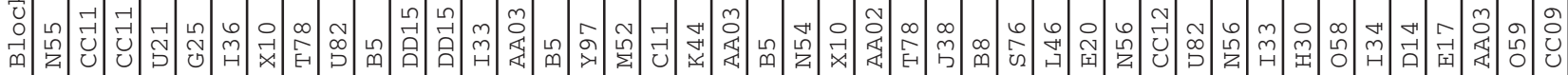

ֻัฒ

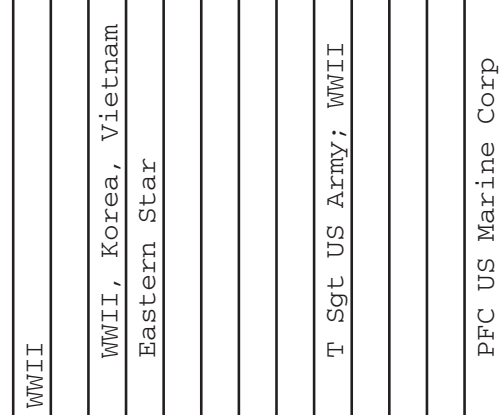

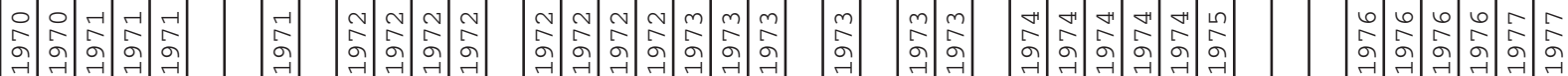

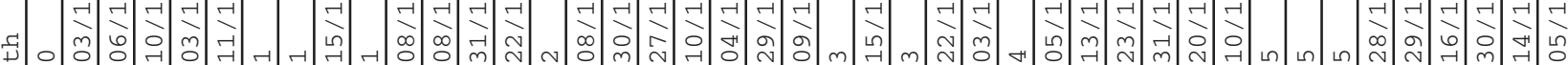

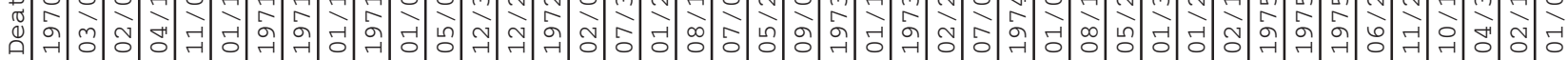

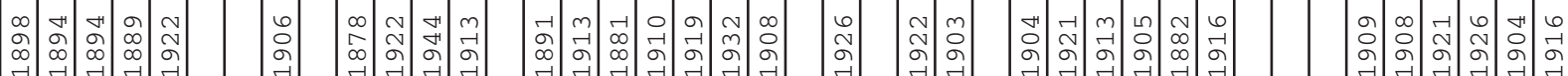

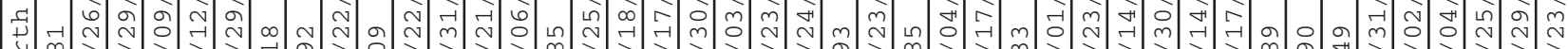

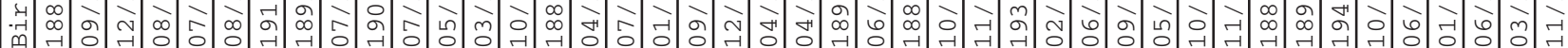

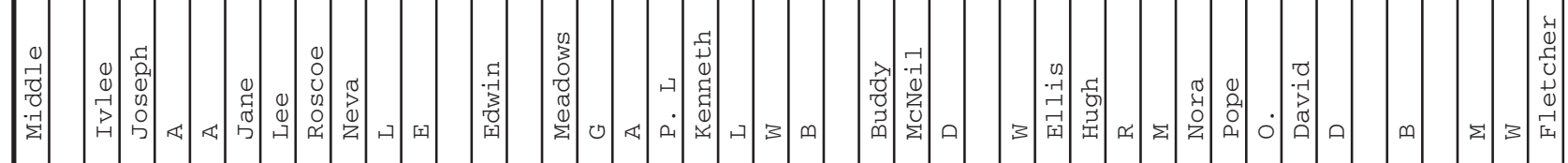

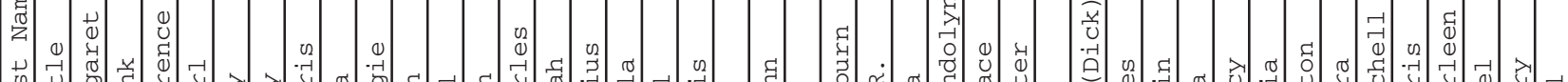

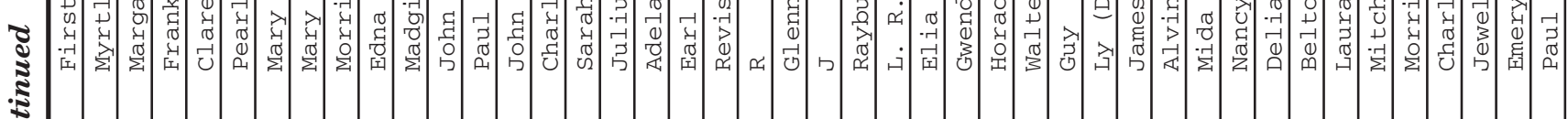

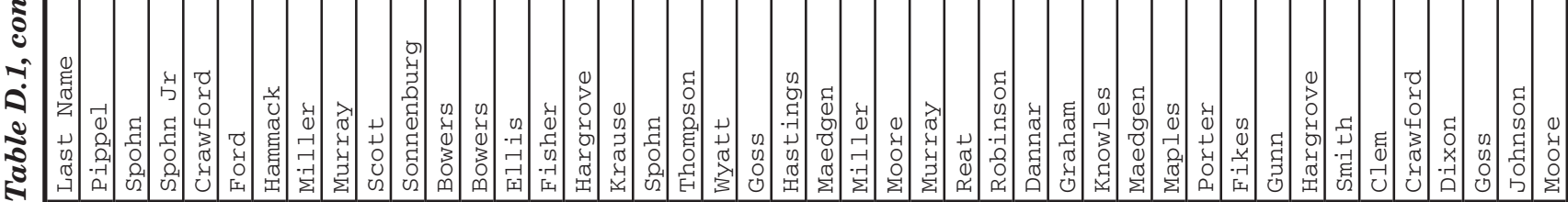




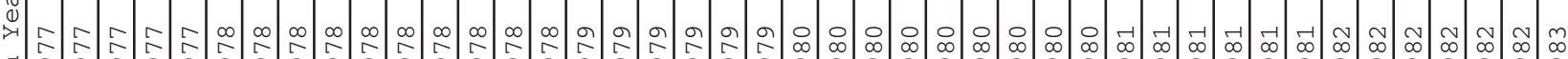

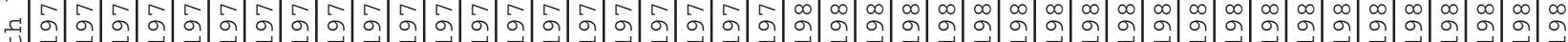
离

怘

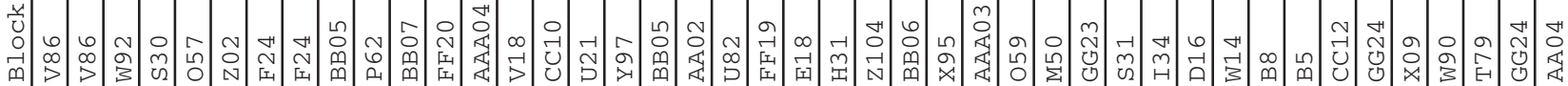

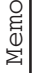
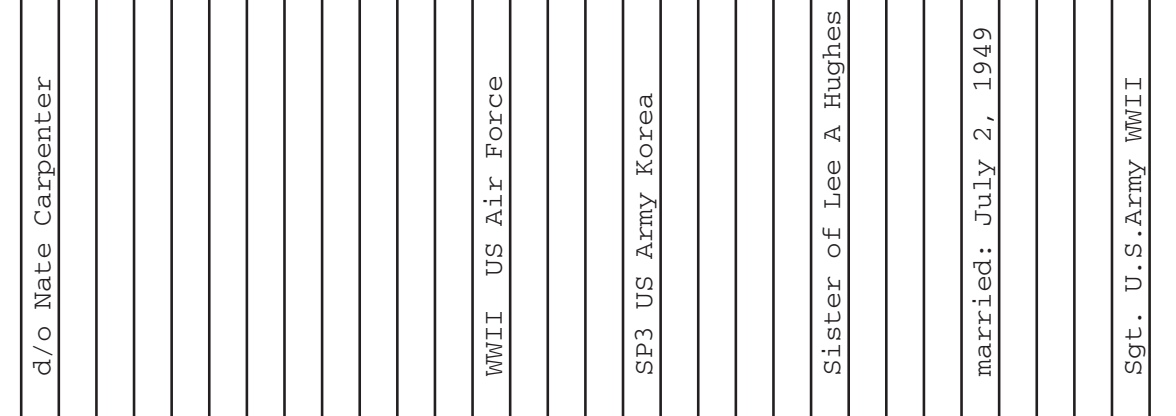

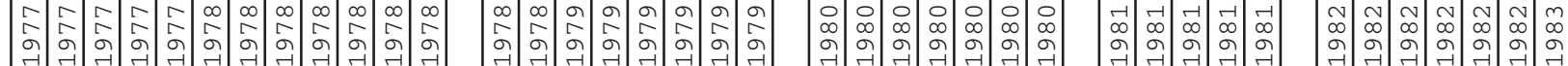

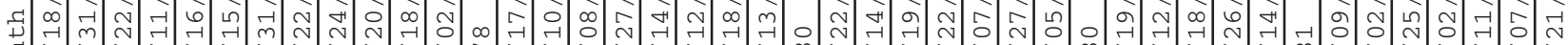

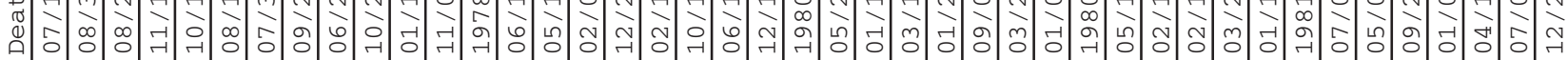

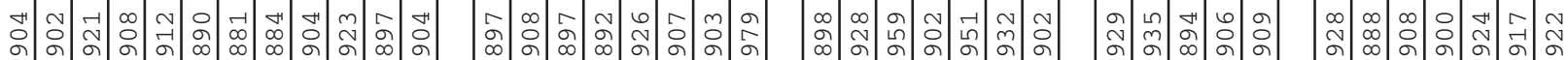

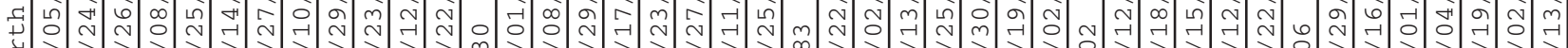
न्न म्न

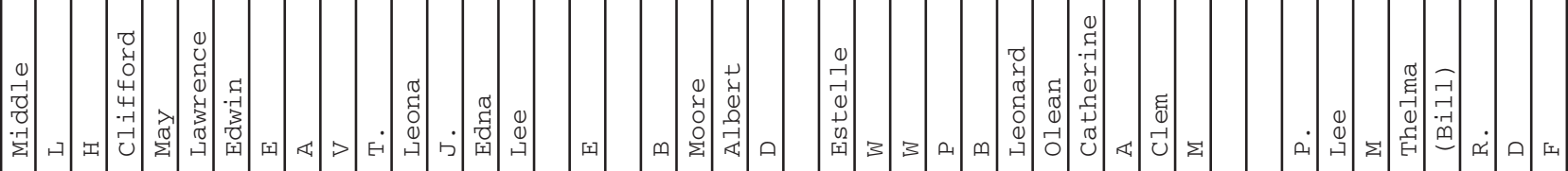

告

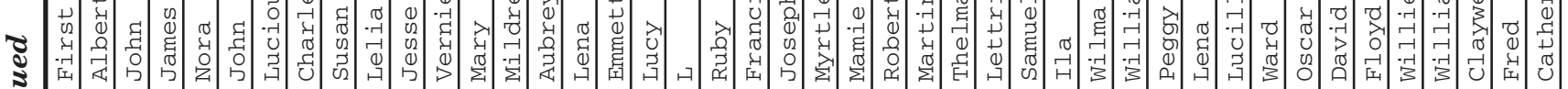

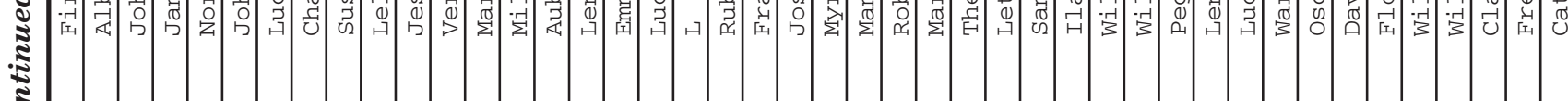

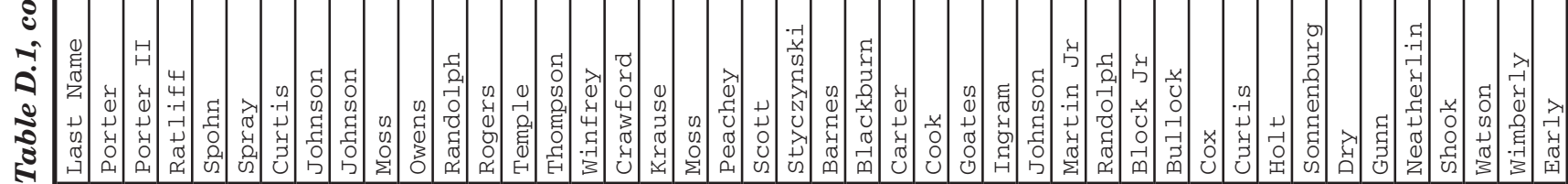




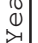

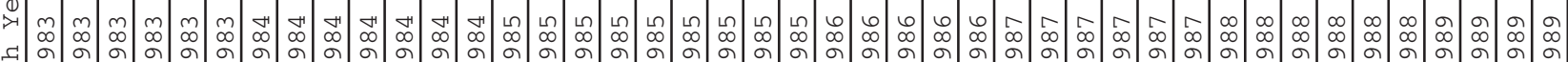
西

苍

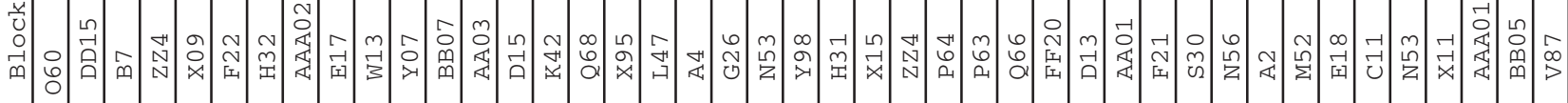

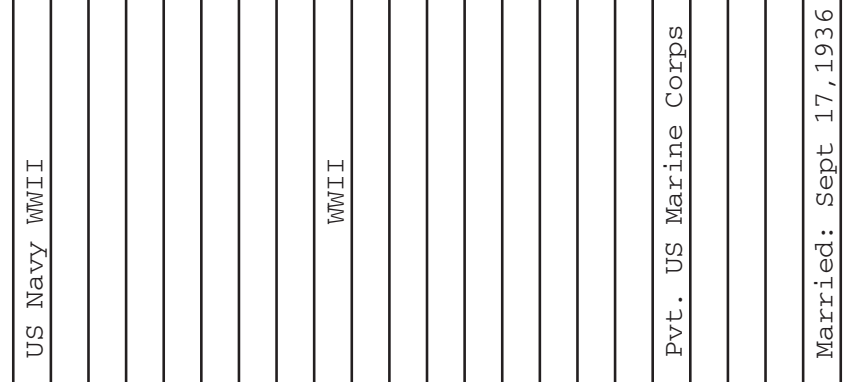

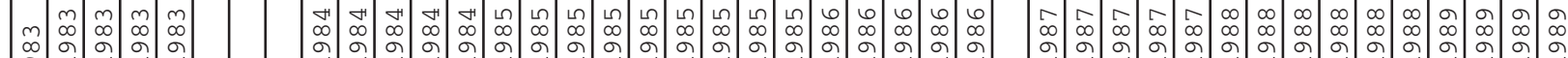

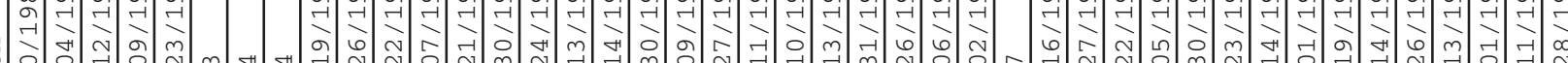

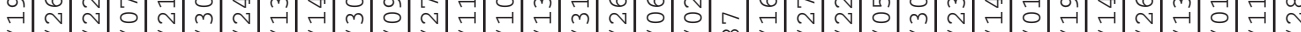

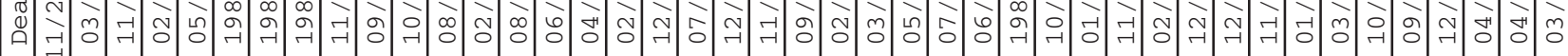

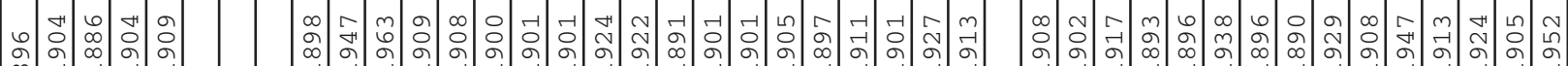

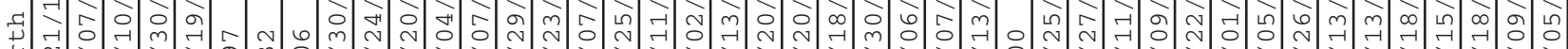
굼 त)

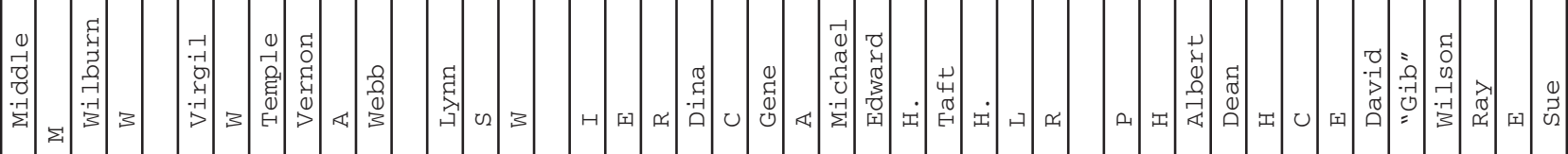

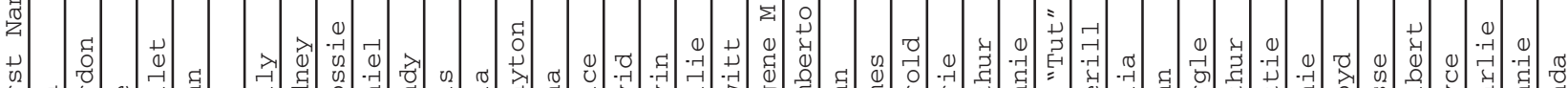

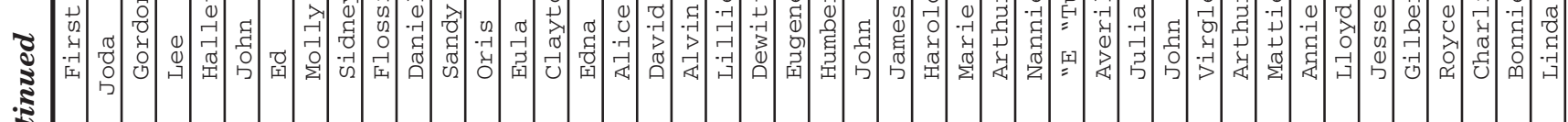

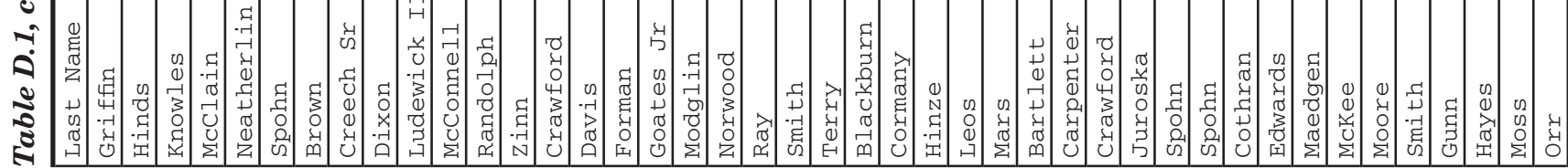


니

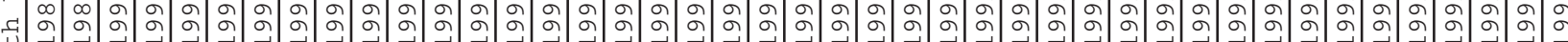

\begin{tabular}{l}
+ \\
0 \\
\hline \\
\hline \\
\hline
\end{tabular}

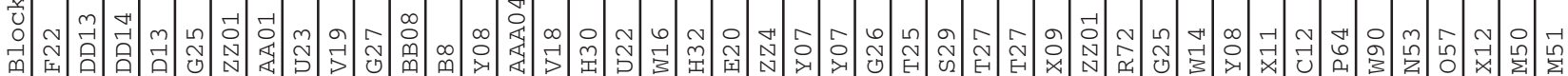

离

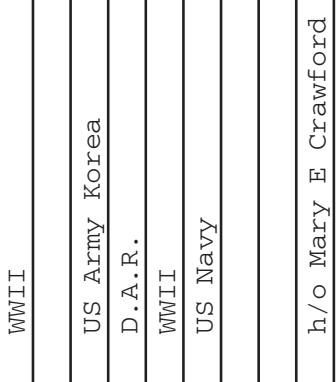

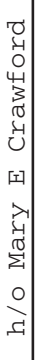

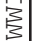

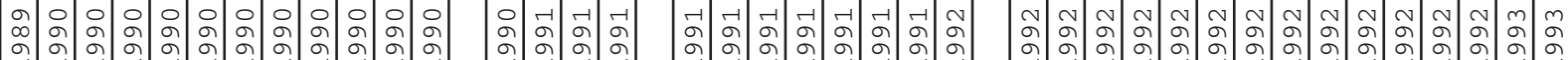

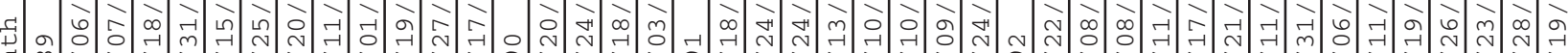

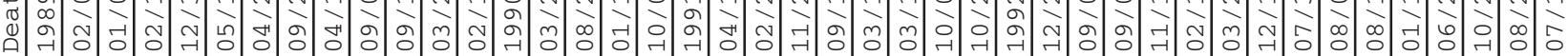

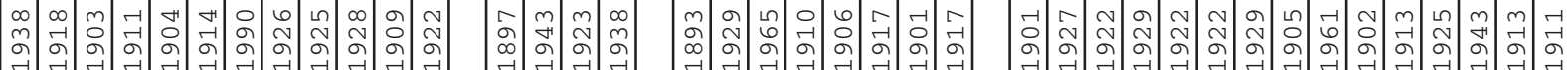

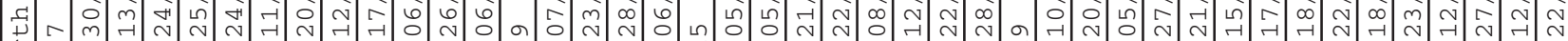

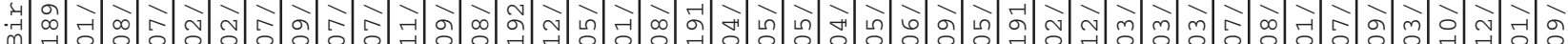

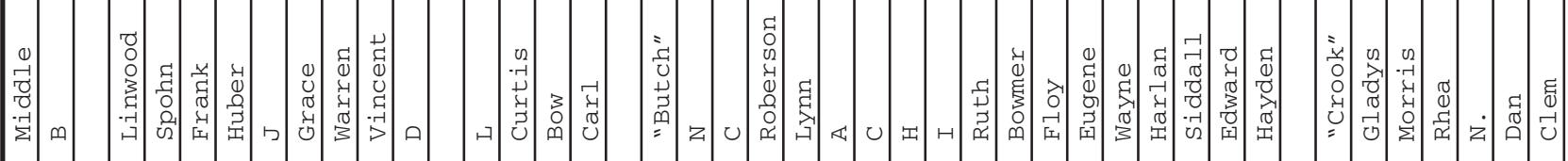

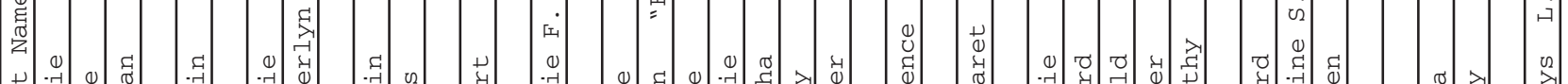

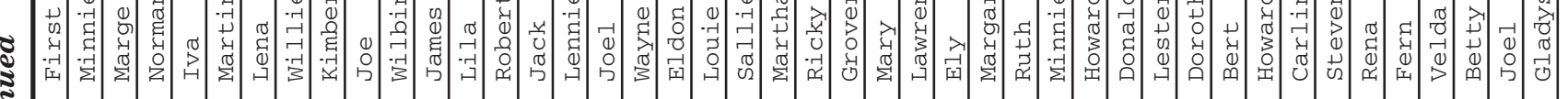

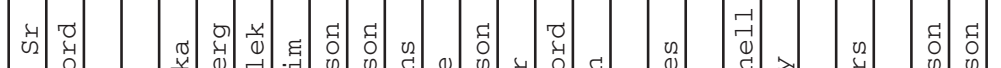

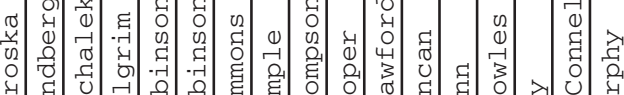

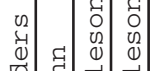

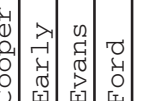

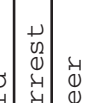

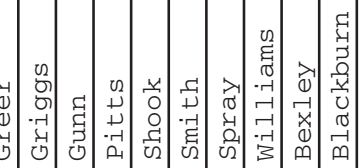




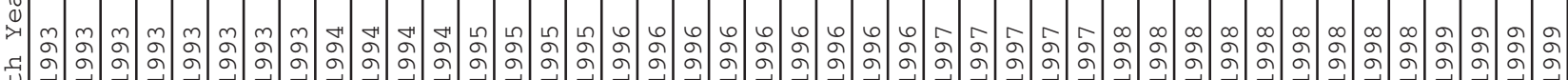
西

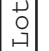

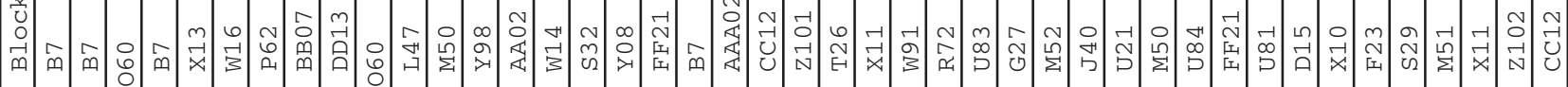

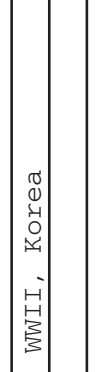

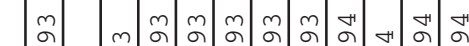

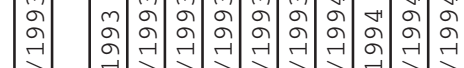

관

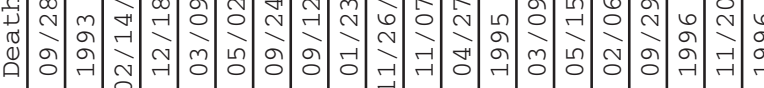

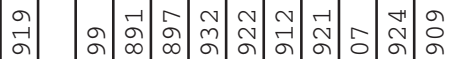

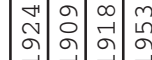

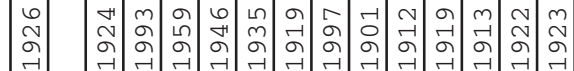

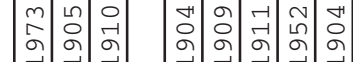

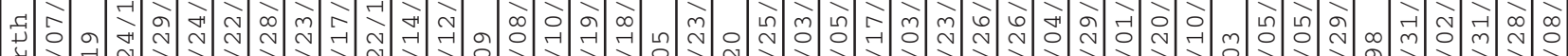
ज्ञ

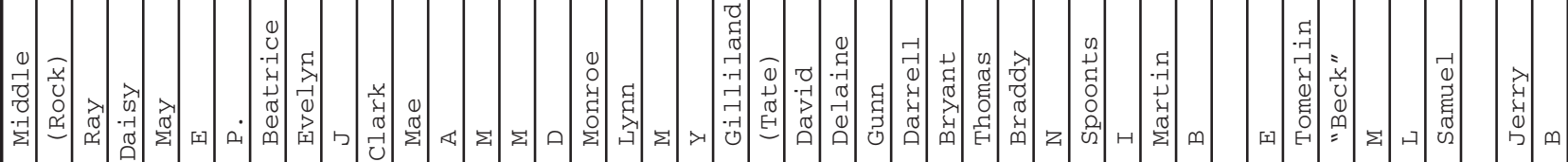

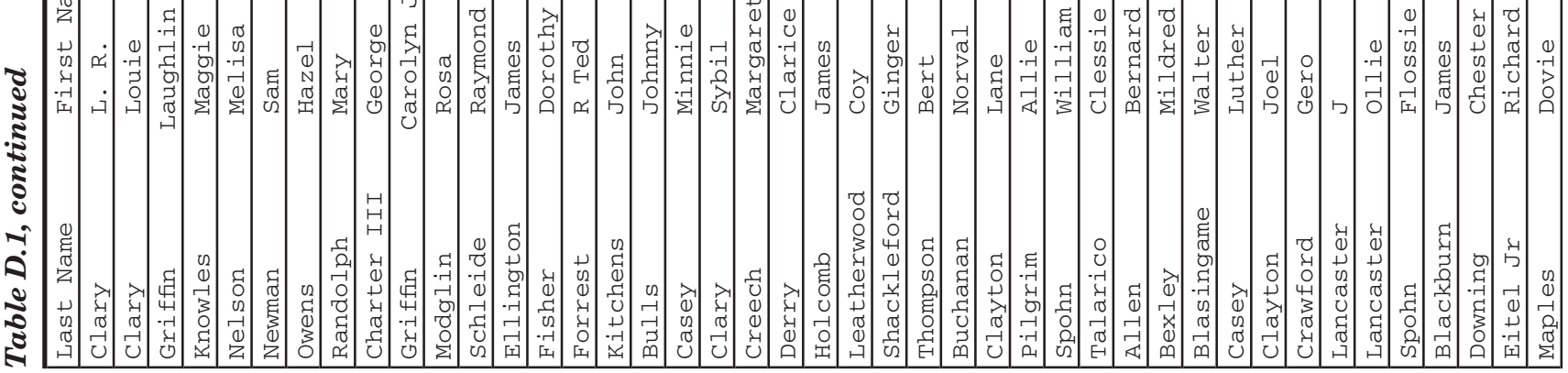




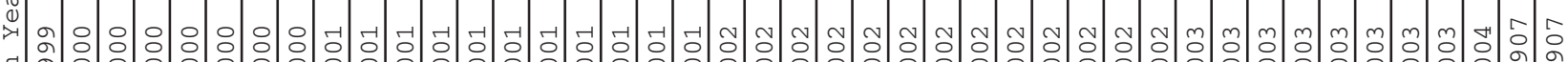

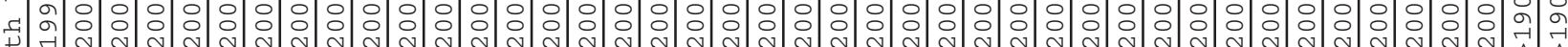
西

齐

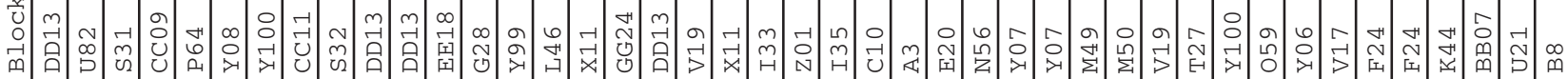

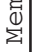
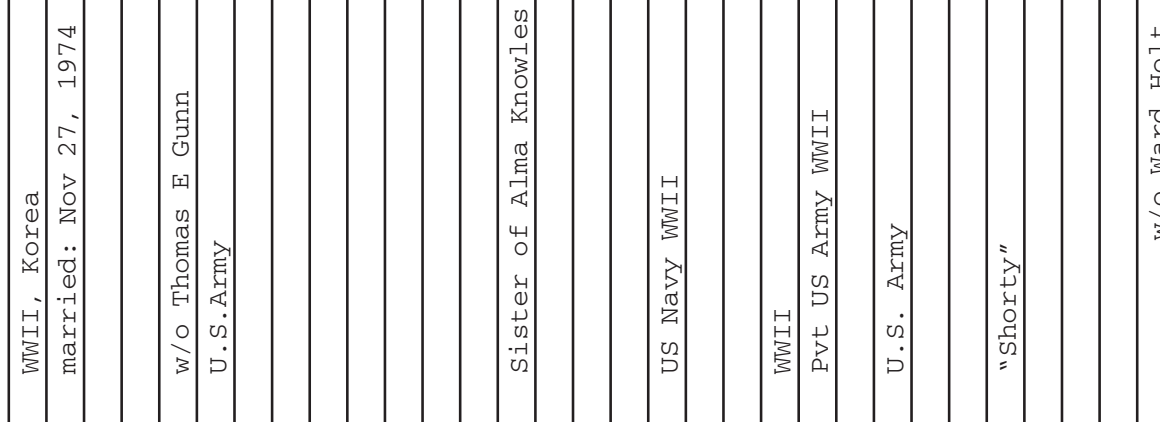

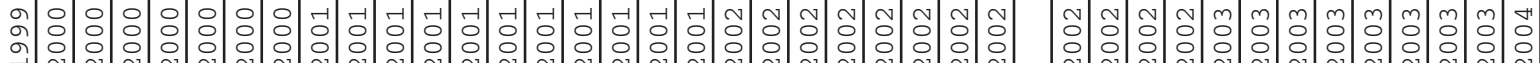

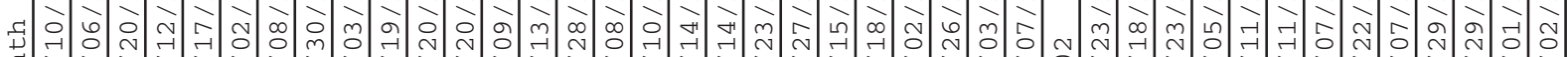
票

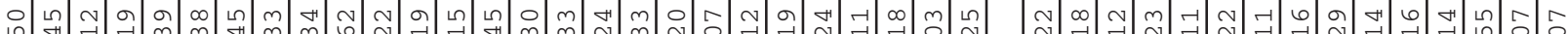

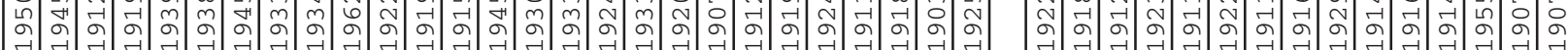

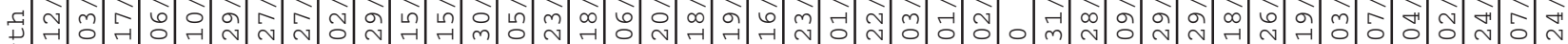
.

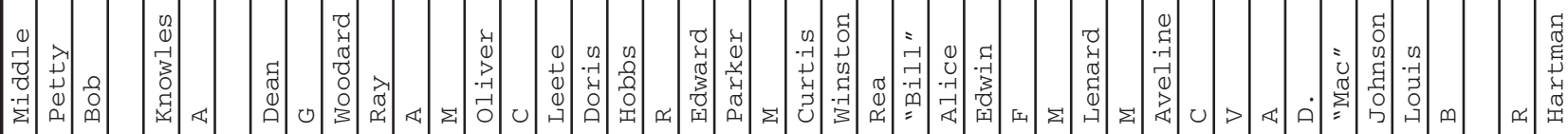

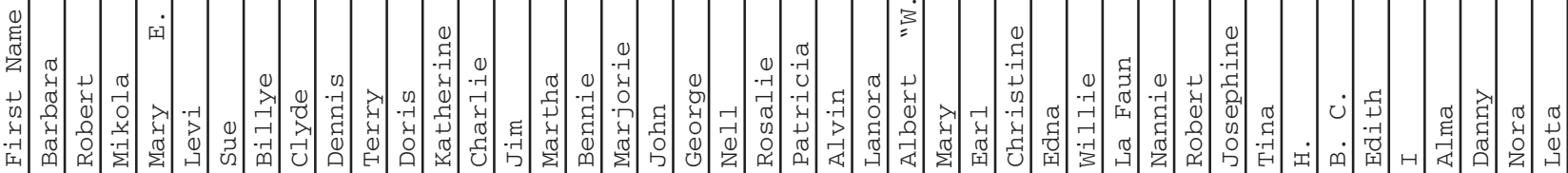

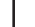

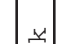
(1)

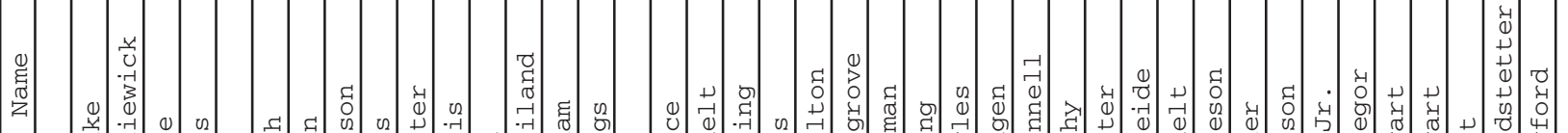

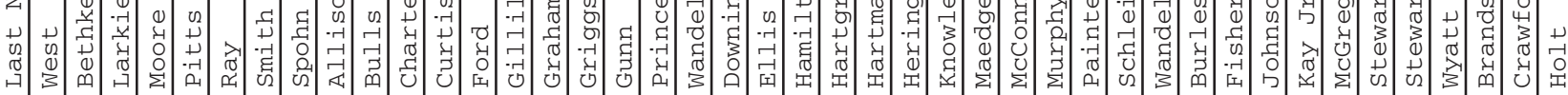




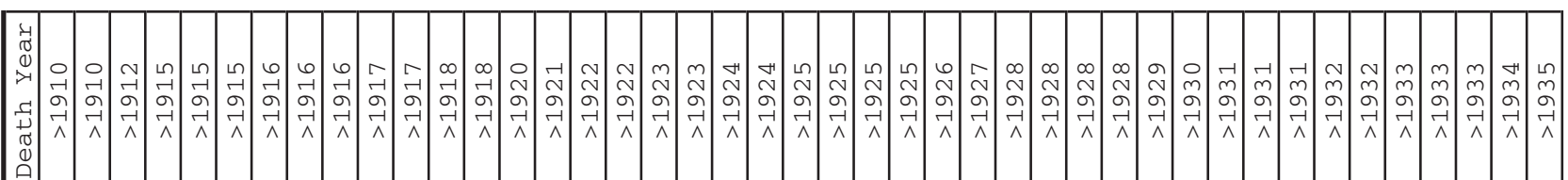

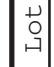

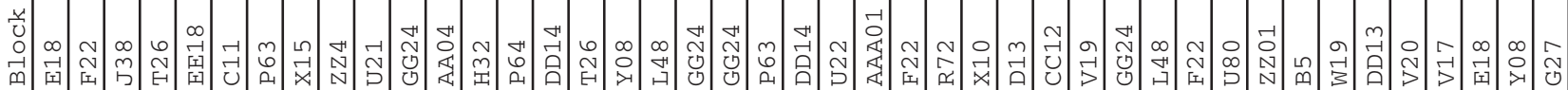

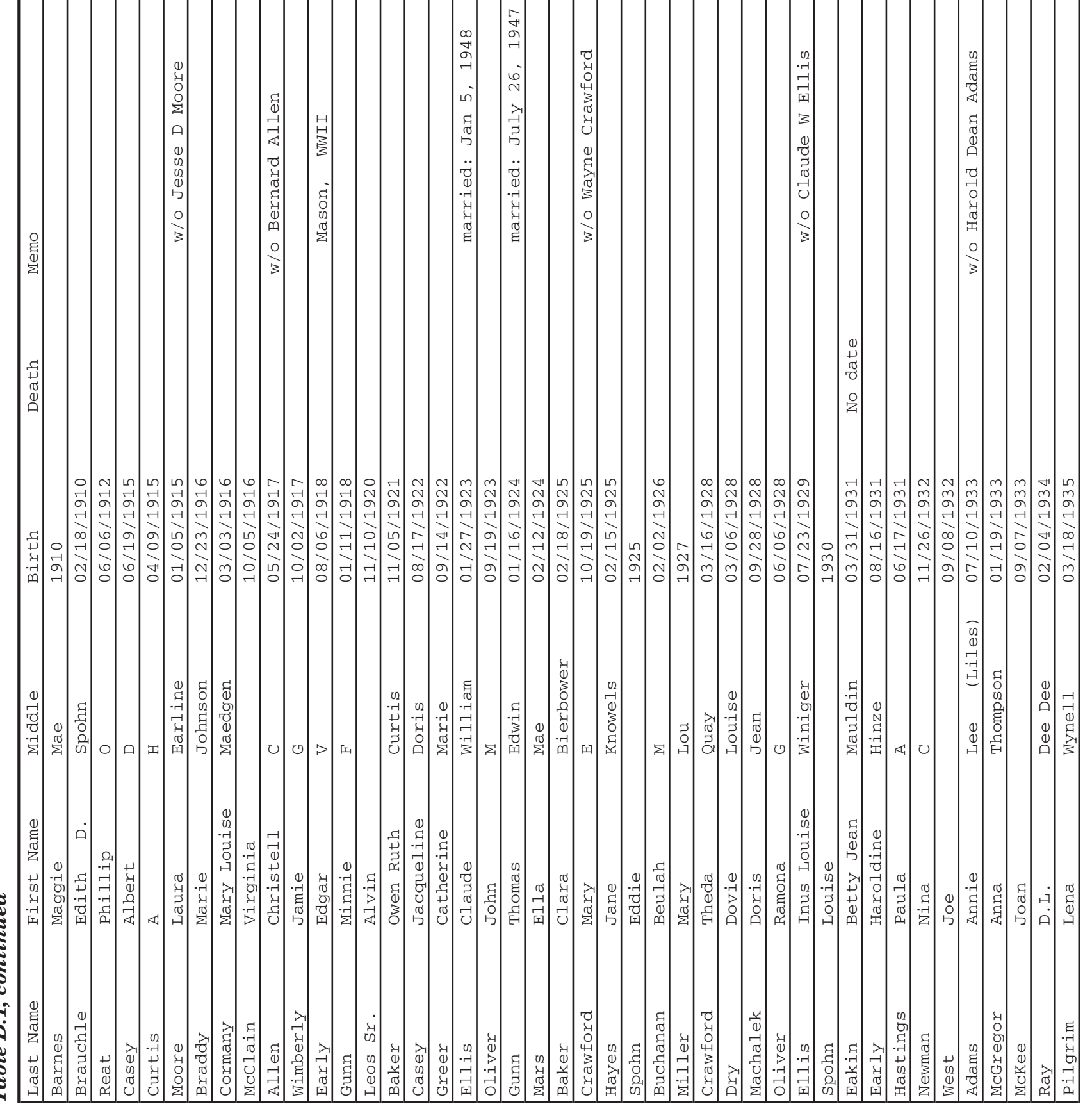




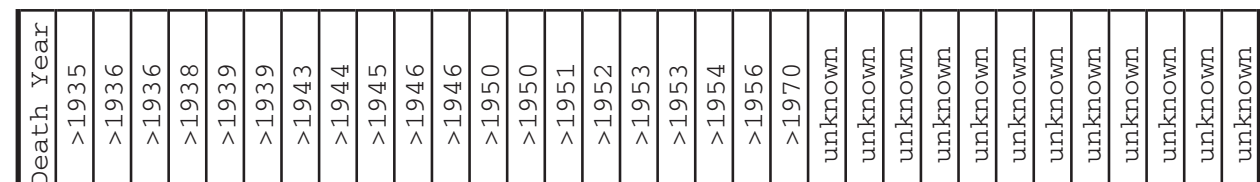

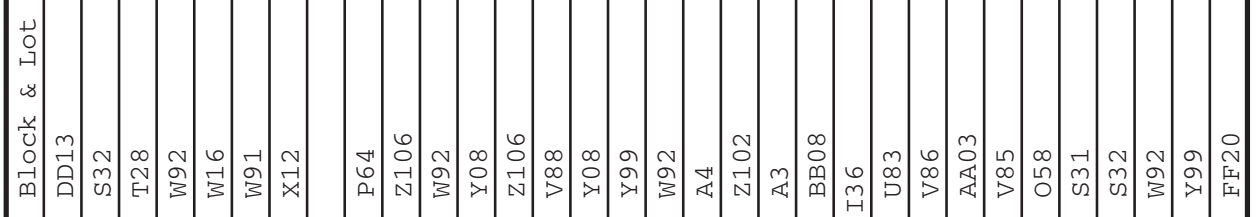

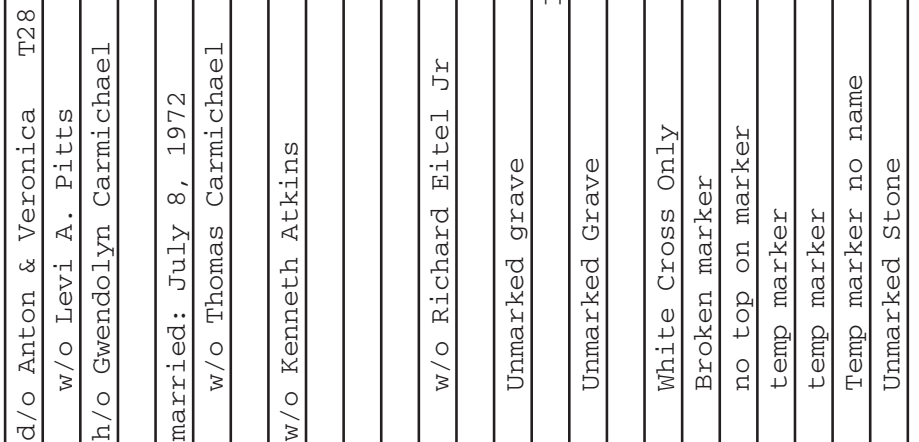

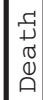

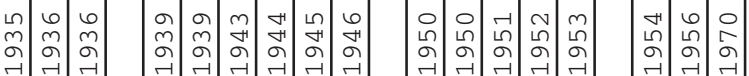

ज्ञ

न्ने

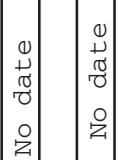

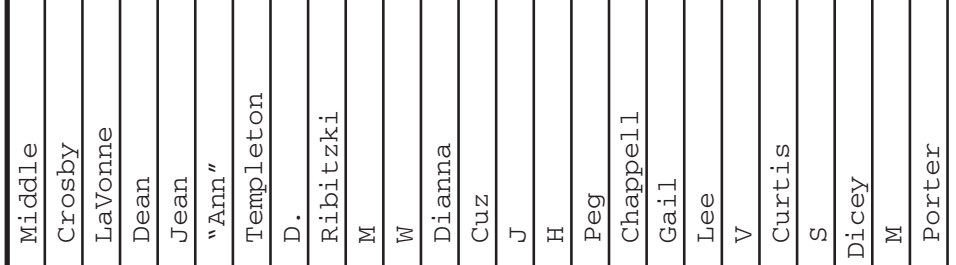

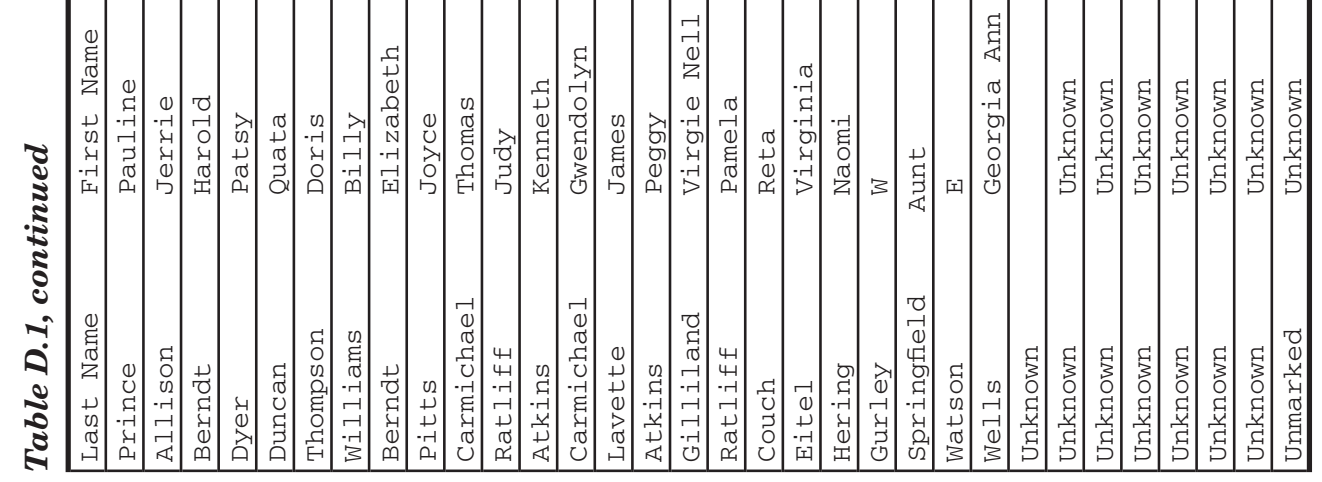


APPENDIX E: DNA Analysis Reports 

This appendix contains the official DNA analysis reports provided to Prewitt and Associates, Inc. by the Laboratory Corporation of America. These reports are as follows [to be paginated in final report]:

Pages 216 and $217 \quad$ Results of comparison between DNA from teeth of Burial 2 with DNA from siblings Don and Dorothy Thomas

Pages 218 and $219 \quad$ Results of comparison between DNA from teeth of Burial 2 with DNA from siblings Georgia Elliott and Carolyn (Elliott) Pillans

Page 220

Negative results on the extraction of DNA from Burial 3 teeth (for comparison with Thomas siblings' DNA)

Page 221

Negative results on the extraction of DNA from Burial 3 teeth (for comparison with Elliott siblings' DNA)

Page 222

Negative results on the extraction of DNA from Burial 3 teeth (for comparison with Florence Boren's DNA)

Page 223

Negative results on the extraction of DNA from Burial 1 teeth (for comparison with Thomas siblings' DNA)

Page 224

Negative results on the extraction of DNA from Burial 1 teeth (for comparison with Elliott siblings' DNA)

Page 225

Negative results on the extraction of DNA from Burial 1 teeth (for comparison with Florence Boren's DNA)

Page 226

Negative results on the extraction of DNA from Burial 1 long bone (femur) section.

Page 227

Negative results on the extraction of DNA from Burial 3 long bone (femur) section.

Page 228

Negative results on the extraction of DNA from Burial 4 long bone (femur) section. 


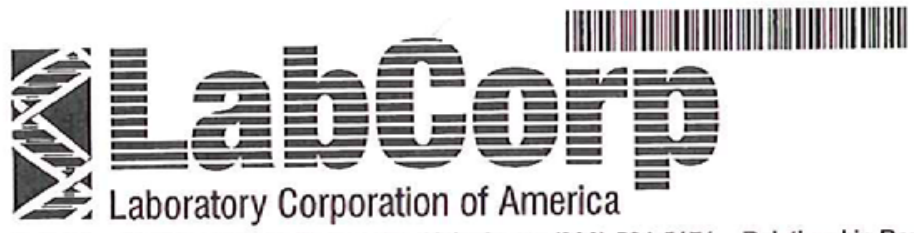

P.O. Box 2230 Burlington, NC 27216 Telephone: (336) 584-5171 Relationship Report
Account Information

Account Number: $\mathbf{4 2 6 0 9 0 3 5}$

Tx Private Paternity Account

Acct Ref 1:

Acct Ref 2:

Acct $\operatorname{Ref} 3$ :

Lubbock, TX 79417
LabCorp Case \# C0Q-019416

\begin{tabular}{ll} 
Relationship & Party \\
\hline Acked. Son 1 & THOMAS, DON \\
Acked. Daughter 1 & THOMAS, DOROTHY \\
Unknown 1 & BURIAL, TWO
\end{tabular}

$\begin{array}{lll} & \text { Race } & \underline{\text { Date(s) Drawn }} \\ \text { 2CR-5006-0 } & \text { None given } & 12 / 21 / 2012 \\ \text { 2CR-5005-0 } & \text { None given } & 12 / 21 / 2012 \\ \text { 2CO-5001-0 } & \text { None given } & 09 / 21 / 2012\end{array}$

DNA Analysis
\begin{tabular}{|c|c|c|c|c|c|c|c|c|c|c|}
\hline & D3S1358 & D7S820 & vWA & FGA & D8S1179 & D21S11 & D18S51 & D5S818 & D13S317 & D16S539 \\
\hline AS1 & 16,17 & 11,13 & 18 & 20,22 & 11,13 & 29 & 19 & 11,12 & 11,14 & 11,13 \\
\hline AD1 & 15,16 & 11,13 & 17,19 & 22,25 & 12,13 & 30 & 19 & 12 & 11,14 & 9,12 \\
\hline UM1 & 15,16 & 9,10 & 17,18 & 20,24 & 13,14 & 29,30 & 16,18 & 11,12 & 11,12 & 12,13 \\
\hline
\end{tabular}

DNA Analysis
\begin{tabular}{|c|c|c|c|c|c|c|c|c|c|}
\hline TAS1 & TH01 & D2S1338 & Penta D & F13B & LPL & Penta E & FESFPS & Penta C & D22S1045 \\
\hline ASI & 7 & 17,25 & 9,12 & 9,10 & 10 & 7,12 & 10,13 & 12 & 11,15 \\
\hline ADI & 7 & 17,25 & 9,12 & 10 & 10 & 13,16 & 10 & 12,13 & 11,15 \\
\hline UMI & 8 & 20,21 & 11,13 & 6,7 & 10,12 & 8,15 & 11 & 7,10 & 11,15 \\
\hline
\end{tabular}

DNA Analysis
\begin{tabular}{|c|c|}
\hline DISI & D1656 \\
\hline ASI & $15.3,17.3$ \\
\hline ADI & $14,15.3$ \\
\hline UMI & 14 \\
\hline
\end{tabular}

ABI Y-Chromosome
\begin{tabular}{|c|c|c|c|c|c|c|c|}
\hline & DYS389I & DYS 390 & DYS 458 & DYS 19 & DYS $385 a / b$ & DYS 393 & DYS 392 \\
\hline ASI & 13 & 25 & 14 & 14 & 11,14 & 13 & 13 \\
\hline UMI & 13 & 24 & 19 & 16 & 11 & 13 & 11 \\
\hline
\end{tabular}

ABI Y-Chromosome
\begin{tabular}{|c|c|c|c|}
\hline PSI & Y-GATA-H4 & DYS 437 & DYS 448 \\
\hline AMI & 12 & 15 & 19 \\
\hline UMI & 11 & 14 & 22 \\
\hline
\end{tabular}

Conclusion:

See Page 2 for conclusion. 


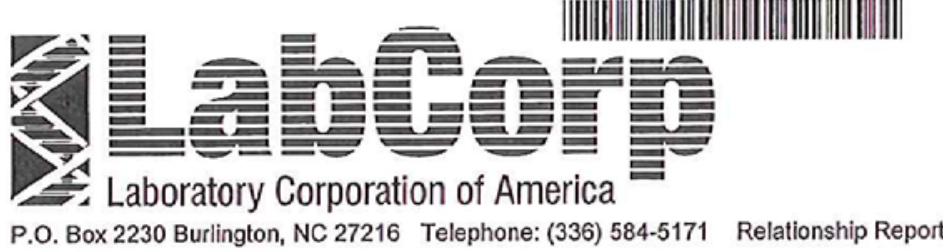

LabCorp Case \# C0Q-019416

\begin{tabular}{ll} 
Relationship & Party \\
\hline Acked. Son 1 & THOMAS, DON \\
Acked. Daughter 1 & THOMAS, DOROTHY \\
Unknown 1 & BURIAL, TWO
\end{tabular}

\author{
Account Information \\ Account Number: $\mathbf{4 2 6 0 9 0 3 5}$ \\ Tx Private Paternity Account \\ Acct Ref 1: \\ Acct Ref 2: \\ Acct Ref 3: \\ Lubbock, TX 79417
}

\section{Conclusion:}

The purpose of this study is to determine if the remains of the individual labeled Burial Two is the paternal grandfather of DOROTHY THOMAS and DON THOMAS. Using the genetic markers found in the testing, there are exclusions in the following systems: Penta E, DYS390, DYS458, DYS19, DYS385a/b, DYS392, Y-GATA-H4, DYS437, DYS448. These results indicate that the individual labeled Burial Two is not the paternal grandfather of DOROTHY THOMAS and DON THOMAS.

I, the undersigned Director, upon bejrg duly sworn on oath, do depose and state that I read the foregoing report on the analysis of specimens from the above nanfed/iofividuals, signed by myself, and under penalties for perjury it is my belief that the facts and results therein are true'gnggorpest

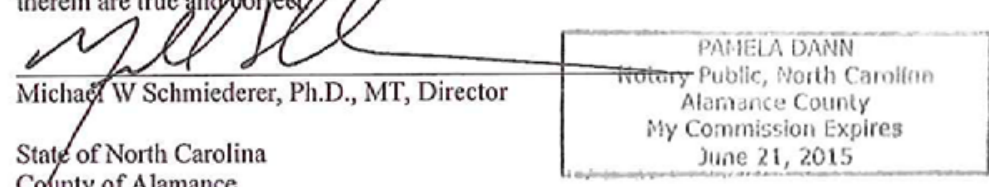

CQunty of Alamance

Pamela Dants

$\mathrm{I}$, , certify that Michael W Schmiederer, Ph.D., MT personally came before me this day and acknowledged that he (or she) is an employee of Laboratory Corporation of America Holdings, a corporation, and that as an employee being authorized to do so, executed the foregoing on behalf of the corporation.

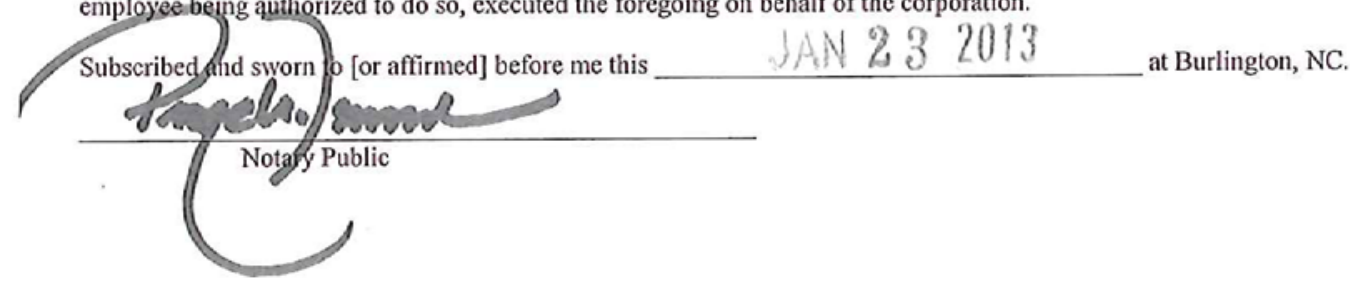




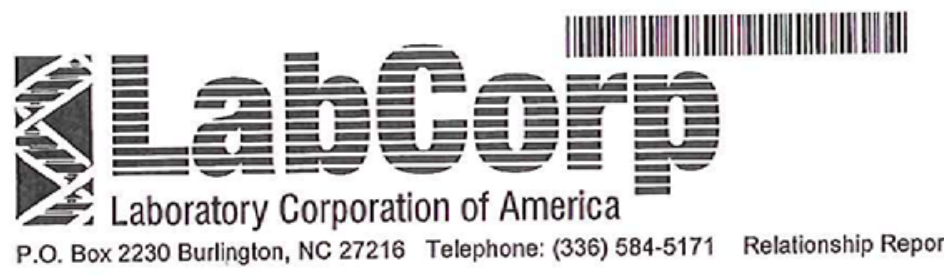

Account Information Account Number: $\mathbf{4 2 6 0 9 0 3 5}$ Tx Private Paternity Account Acct Ref 1:

Acct Ref 2:

Acct Ref 3:

Lubbock, TX 79417

\section{LabCorp Case \# C0Q-019415}

$\begin{array}{ll}\text { Relationship } & \underline{\text { Party }} \\ \text { Acked. Daughter 1 } & \text { ELLIOTT, GEORGIA } \\ \text { Acked. Daughter 2 } & \text { PILLANS, CAROLYN J } \\ \text { Unknown 1 } & \text { BURIAL, TWO }\end{array}$

$\underline{\text { Race }}$

2CR-5003-0 None given

2CR-5007-0 None given

2CO-5001-0 None given
Date(s) Drawn

$12 / 21 / 2012$

$12 / 21 / 2012$

$09 / 21 / 2012$

\begin{tabular}{|c|c|c|c|c|c|c|c|c|c|c|}
\hline 39 & D3S1358 & D7S820 & vWA & FGA & D8S1179 & D21S11 & D18S51 & D5S818 & D13S317 & D16S539 \\
\hline ADI & 14,17 & 9,11 & 17,18 & 23,24 & 13 & $30,32.2$ & 14,17 & 11,13 & 8,12 & 10,11 \\
\hline AD2 & 14,17 & 8,9 & 17,18 & 21 & 13,14 & $30,31.2$ & 15,17 & 9,11 & 10,14 & 10,13 \\
\hline UMI & 15,16 & 9,10 & 17,18 & 20,24 & 13,14 & 29,30 & 16,18 & 11,12 & 11,12 & 12,13 \\
\hline PI & 0.71 & 1.08 & 1.34 & 0.96 & 1.34 & 0.91 & 0.60 & 0.81 & 0.72 & 0.97 \\
\hline
\end{tabular}

DNA Analysis

DNA Analysis
\begin{tabular}{|c|c|c|c|c|c|c|c|c|c|c|}
\hline & TH01 & D2S1338 & Penta D & F13B & LPL & Penta E & FESFPS & Penta C & D22S1045 & DIS1656 \\
\hline AD1 & 6 & 19,21 & 12,13 & 8,10 & 11,12 & 7,11 & 10,12 & 9,12 & 11 & 12,16 \\
\hline AD2 & 6,7 & 17,21 & 12,13 & 6,10 & 10,11 & 7,11 & 10,13 & 9,12 & 11 & 13,18 \\
\hline UM1 & 8 & 20,21 & 11,13 & 6,7 & 10,12 & 8,15 & 11 & 7,10 & 11,15 & 14 \\
\hline PI & 0.60 & 2.60 & 1.07 & 1.26 & 1.01 & & 0.58 & 0.71 & 1.73 & 0.50 \\
\hline
\end{tabular}

Conclusion:

The purpose of this study is to determine if the remains of the individual labeled Burial Two is the paternal great-grandfather of GEORGIA ELLIOTT and CAROLYN J. PILLANS. Using the genetic markers found in the testing, the likelihood ratio for great-grandfather versus unrelated is 0.3 to 1 . This value is inconclusive as to biological relationship. A more definitive conclusion may be reached if additional relatives are submitted for testing.

I, the undersigned Director, upon being duly sworn on oath, do depose and state that I read the foregoing report on the analysis of specimens from the above naned infividuals, signed by myself, and under penalties for perjury it is my belief that the facts and results therein are true and eorrec

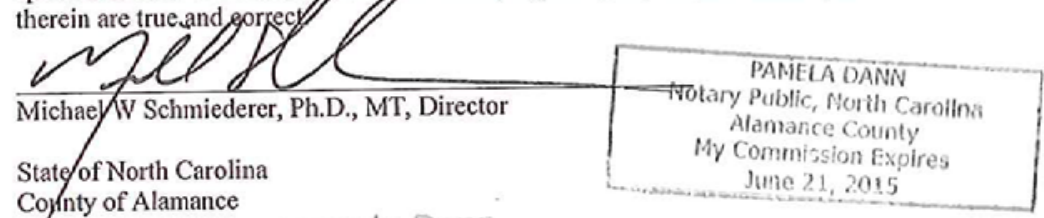

Copinty of Alamance

I

ramela Dann

certify that Michael W Schmiederer, Ph.D., MT personally came before me this day and acknowledged that he (or she) is an employee of Laboratory Corporation of America Holdings, a corporation, and that as an employee being aultiorized to do so, executed the foregoing on behalf of the corporation. 2013

Subscribed and sworn to [or affirmed] before me this ? at Burlington, NC. 


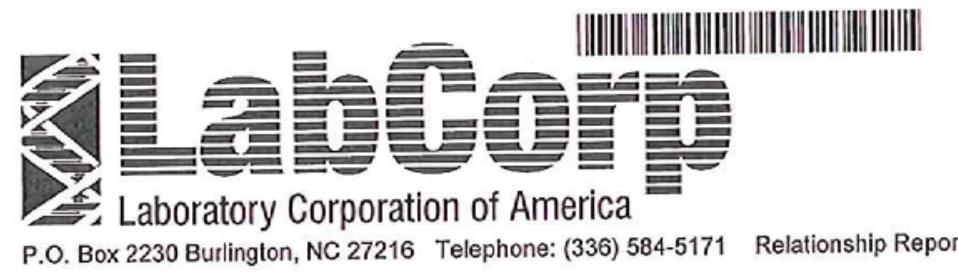

LabCorp Case \# C0Q-019414

Relationship Acked. Daughter 1 Unknown 1

Party

BOREN, FLORENCE L BURIAL, TWO
Account Information

Account Number: 42609035

Tx Private Paternity Account

Acct Ref 1:

Acct Ref 2:

Acct Ref 3:

Lubbock, TX 79417

\begin{tabular}{|c|c|c|c|c|c|c|c|c|c|c|}
\hline & D3S1358 & D7S820 & vWA & FGA & D8S1179 & D21S1I & D18S51 & D5S 818 & D13S317 & D16S539 \\
\hline AD1 & 15 & 8 & 16,17 & 19,22 & 10 & 27,28 & 19 & 11,12 & 11,12 & 9,14 \\
\hline UMI & 15,16 & 9,10 & 17,18 & 20,24 & 13,14 & 29,30 & 16,18 & 11,12 & 11,12 & 12,13 \\
\hline PIE & 1.47 & 0.50 & 0.95 & 0.50 & 0.50 & 0.50 & 0.50 & 1.19 & 1.35 & 0.50 \\
\hline
\end{tabular}

DNA Analysis
\begin{tabular}{|c|c|c|c|c|c|c|c|c|c|c|}
\hline & TH01 & D2S1338 & Penta D & F13B & LPL & Penta E & FESFPS & Penta C & D22S1045 & DIS1656 \\
\hline AD1 & 6,9 & 21 & 7,9 & 8,10 & 10 & 5,18 & 10 & 11 & 15 & $13,17.3$ \\
\hline UMI & 8 & 20,21 & 11,13 & 6,7 & 10,12 & 8,15 & 11 & 7,10 & 11,15 & 14 \\
\hline PI & 0.50 & 7.97 & 0.50 & 0.50 & 1.07 & \multicolumn{2}{|c|}{0.50} & 0.50 & 1.19 & 0.50 \\
\hline
\end{tabular}

Conclusion:

The purpose of this study is to determine if the individual labeled Burial Two is the paternal grandfather of FLORENCE L. BOREN. Using the genetic markers found in the testing, the likelihood ratio for grandfather versus unrelated is 0.0056 to 1 . This value indicates that this individual is 179 times more likely to be unrelated to FLORENCE L. BOREN as opposed to related. This finding does not support the claim that the individual labeled Burial Two is the paternal grandfather of FLORENCE L. BOREN.

I, the undersigned Director, upon being duly sworn on oath, do depose and state that I read the foregoing report on the analysis of specimens from the above named indiyiduals, signed by myself, and under penalties for perjury it is my belief that the facts and results therein are true and correct.

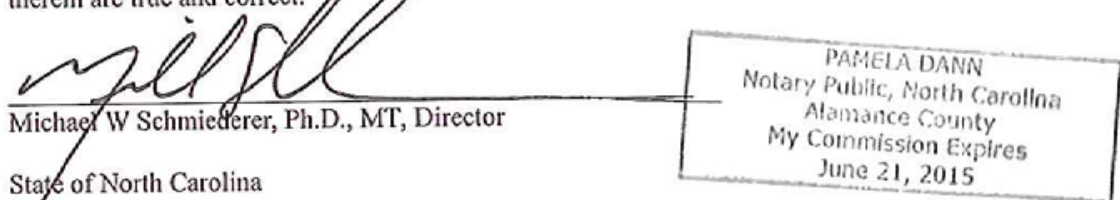

County of Alamance

Pamela Dann

certify that Michael W Schmiederer, Ph.D., MT personally came before me this day and acknowledged that he (or she) is an employee of Laboratory Corporation of America Holdings, a corporation, and that as an employee being authorized to go so, exequted the foregoing on behalf of the corporation 2013

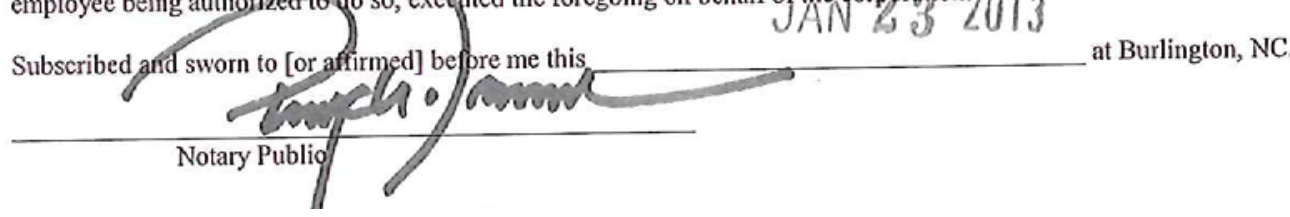




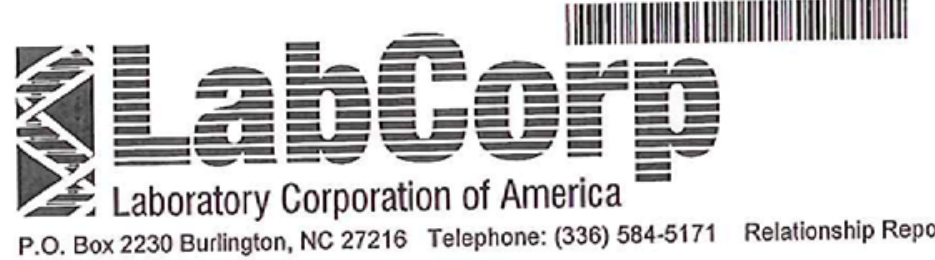

Account Information

Account Number: $\mathbf{4 2 6 0 9 0 3 5}$

Tx Private Paternity Account

Acct Ref 1:

Acct Ref 2:

Acct Ref 3:

Lubbock, TX 79417

LabCorp Case \# C0Q-019419

$\underline{\text { Relationship }}$

Acked. Son 1

Acked. Daughter 1

Party

THOMAS, DON

$\underline{\text { Race }}$

Date(s) Drawn

Unknown

THOMAS, DOROTHY

BURIAL, THREE

$\begin{array}{ll} & \text { Race } \\ \text { 2CR-5006-0 } & \text { None given } \\ \text { 2CR-5005-0 } & \text { None given } \\ \text { 2CO-5006-0 } & \text { None given }\end{array}$

$12 / 21 / 2012$

$12 / 21 / 2012$

$09 / 13 / 2012$

Conclusion:

No DNA profile could be obtained after repeated extractions and testing from the teeth of Burial Three (2CO-5006-0). Another sample Th

from Burial Three would ne

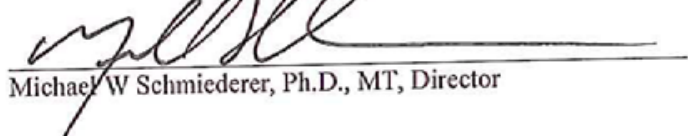




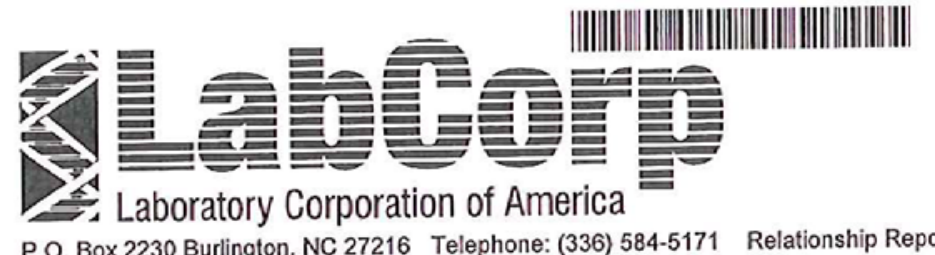

P.O. Box 2230 Burlington, NC 27216 Telephone: (336) 584-5171 Relationship Report
Account Information Account Number: 42609035 Tx Private Paternity Account Acct Ref 1: Acct Ref 2: Acct Ref 3: Lubbock, TX 79417

\section{LabCorp Case \# C0Q-019418}

Relationship

Acked. Daughter 1 Acked. Daughter 2

Unknown 1
Party

ELLIOTT, GEORGIA

PILLANS, CAROLYN J BURIAL, THREE

Conclusion:

No DNA profile could be obtained after repeated extractions and testing from the teeth of Burial Three (2CO-5006-0). Another sample from Burial Three would need/o be gromitted for a comparison with GEORGIA ELLIOTT and CAROLYN J. PILLANS.

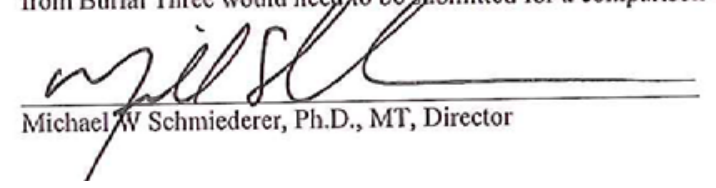




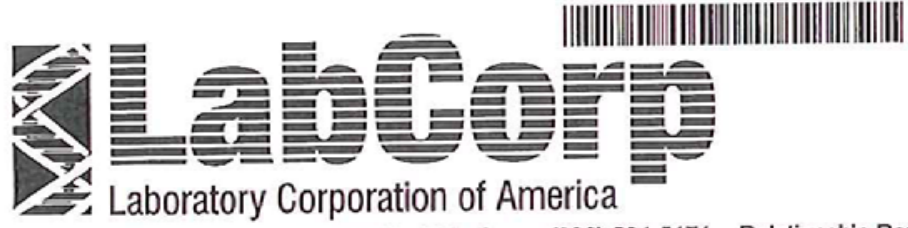

P.O. Box 2230 Burlington, NC 27216 Telephone: (336) 584-5171 Relationship Report
Account Information

Account Number: 42609035

Tx Private Paternity Account

Acct Ref 1:

Acct Ref 2:

Acct Ref 3:

Lubbock, TX 79417
LabCorp Case \# C0Q-019417

Relationship

Acked. Daughter 1

Unknown 1 $\underline{\text { Party }}$

BOREN, FLORENCE L BURIAL, THREE

$\begin{array}{ll}\text { 2CR-5004-0 } & \text { Race } \\ \text { 2CO-5006-0 } & \text { None given }\end{array}$

Date(s) Drawn

$12 / 21 / 2012$

$09 / 13 / 2012$

Conclusion:

No DNA profile could be obtainect after repeated extractions and testing from the teeth of Burial Three (2CO-5006-0). Another sample from Burial Three would need t/ be sybmitted for a comparison with FLORENCE L. BOREN.

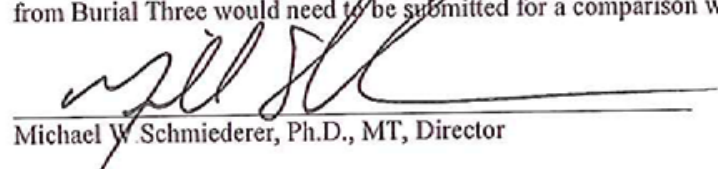




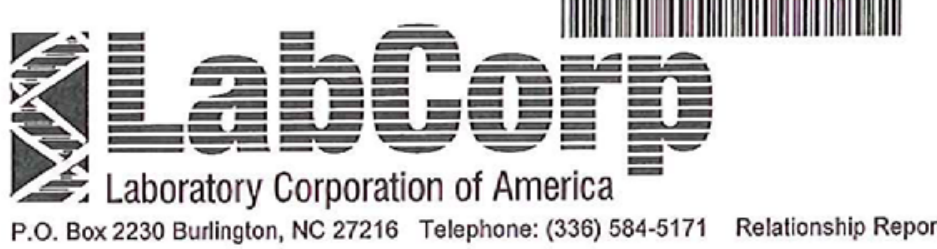

Account Information

Account Number: $\mathbf{4 2 6 0 9 0 3 5}$

Tx Private Paternity Account

Acct Ref 1:

Acct Ref 2:

Acct Ref 3:

Lubbock, TX 79417

LabCorp Case \# C0Q-015195

Relationship

Acked. Son 1

Acked. Daughter 1

Unknown Male 1 $\underline{\text { Party }}$

THOMAS, DON

THOMAS, DOROTHY

BURIAL, ONE

$\begin{array}{ll} & \text { Race } \\ 2 \mathrm{CR}-5006-0 & \text { None given } \\ 2 \mathrm{CR}-5005-0 & \text { None given } \\ 2 \mathrm{CO}-5005-0 & \text { None given }\end{array}$

Date(s) Drawn

$12 / 21 / 2012$

$12 / 21 / 2012$

$09 / 21 / 2012$

\section{Conclusion:}

No DNA profile could be obtained afternepeated extractions and testing from the teeth of Burial One (2CO-5005-0). Another sample from Burial One would need ty oe sybmitted for a comparison with DON THOMAS and DOROTHY THOMAS.

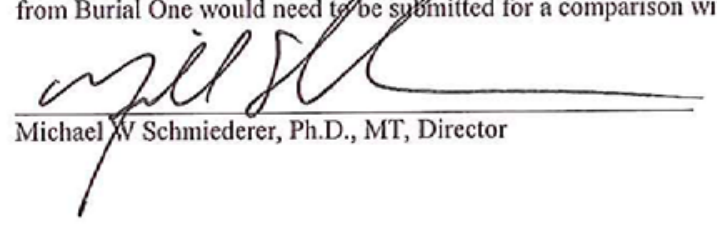




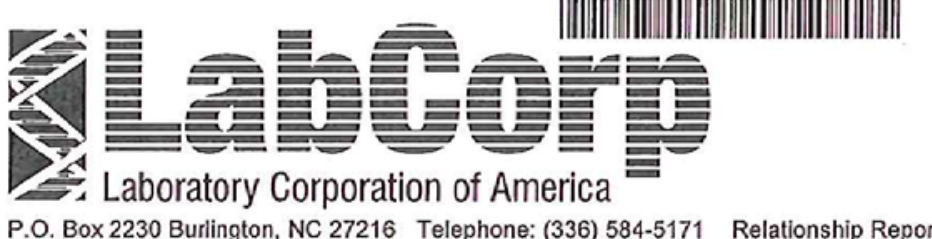

P.O. Box 2230 Burlington, NC 27216 Telephone: (336) 584-5171 Relationship Report
Account Information

Account Number: $\mathbf{4 2 6 0 9 0 3 5}$

Tx Private Paternity Account

Acct Ref 1:

Acct Ref 2:

Acct Ref 3:

Lubbock, TX 79417

LabCorp Case \# C0Q-016839

Relationship

Acked. Daughter 1

Acked. Daughter 2

$\underline{\text { Party }}$

ELLIOTT, GEORGIA

PILLANS, CAROLYN J

$\underline{\text { Race }}$

2CR-5003-0 $\overline{\text { None given }}$

2CR-5007-0 None given

2CO-5005-0 None given
Date(s) Drawn

$12 / 21 / 2012$

$12 / 21 / 2012$

$09 / 21 / 2012$

Conclusion:

No DNA profile could be obtained after repeated extractions and testing from the teeth of Burial One (2CO-5005-0). Another sample from Burial One would need fo be syrmitted for a comparison with GEORGIA ELLIOTT and CAROLYN J. PILLANS.

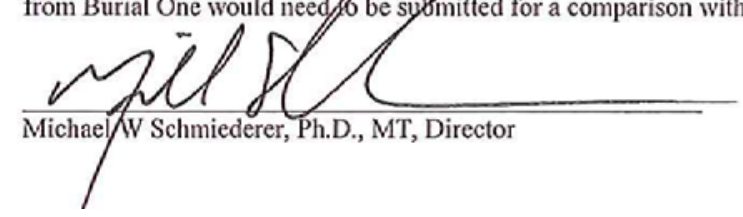




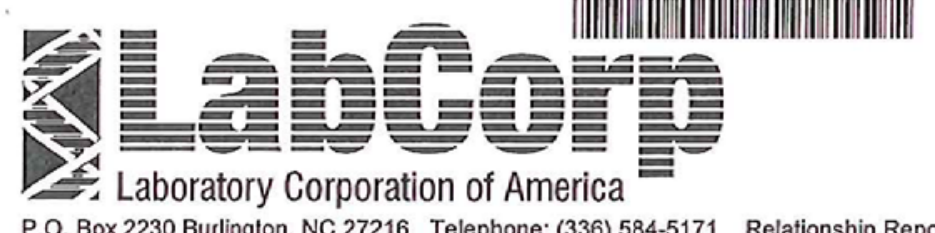

P.O. Box 2230 Burlington, NC 27216 Telephone: (336) 584-5171 Relationship Report
Account Information

Account Number: $\mathbf{4 2 6 0 9 0 3 5}$

Tx Private Paternity Account Acct Ref 1:

Acct Ref 2:

Acct Ref 3:

Lubbock, TX 79417

LabCorp Case \# C0Q-016840

Relationship

Acked. Daughter 1

$\underline{\text { Party }}$

BOREN, FLORENCE L

BURIAL, ONE

$\begin{array}{ll}\text { 2CR-5004-0 } & \text { Race } \\ \text { 2COucasian } \\ \text { Co05-0 } & \text { None given }\end{array}$

Date(s) Drawn

Unknown Male 1

,

2CO-5005-0 None given

\begin{tabular}{l}
$09 / 21 / 2012$ \\
\hline $12 / 21 / 2012$
\end{tabular}

Conclusion:

No DNA profile could be obtgined affer repeated extractions and testing from the teeth of Burial One (2CO-5005-0). Another sample from Burial One would neg to be submitted for a comparison with FLORENCE L. BOREN.

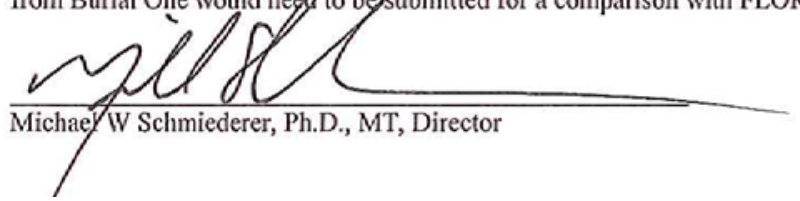




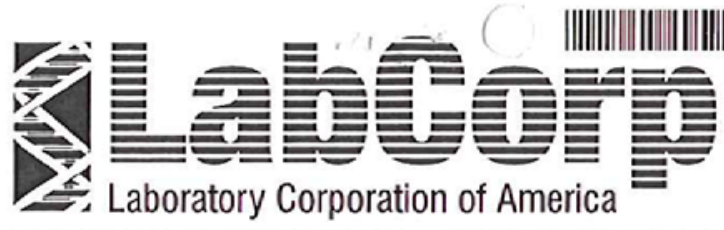

P.O. Box 2230 Burlington, NC 27216 Telephone: (336) 584-5171 Relationship Report

LabCorp Case \# C0Q-056552

\section{$\underline{\text { Relationship }}$}

Unknown Male 1

\section{$\underline{\text { Party }}$}

BURIAL 1, FEMUR

\section{||||||||||||||||||||||}

count Information Account Number: $\mathbf{4 2 6 0 9 0 3 5}$ Tx Private Paternity Account Acct Ref 1: Acct Ref 2; Acct Ref 3:

LUBBOCK, TX 79416

$\underline{\text { Race }}$

33J-0012-0 None given

Date(s) Drawn 03/18/2013

\section{RECEIVED}

MAY 0 4. REC'D

Prewitt \& Associates, the.

Conclusion:

No DNA profile could be obtained, afer repeated extractions and testing, from the femur of Burial One (33J-0012-0). No relationship comparisons could be perforned of this sample.

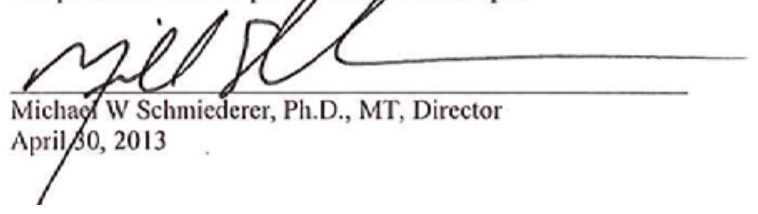




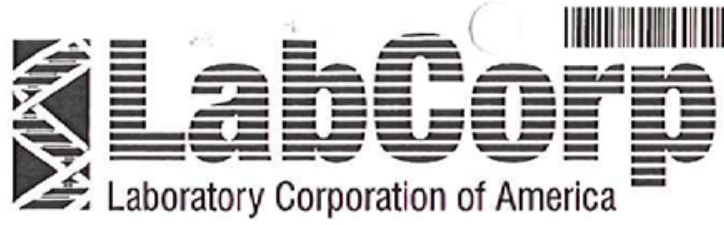

P.O. Box 2230 Burlington, NC 27216 Telephone: (336) 584-5171 Relationship Report

LabCorp Case \# C0Q-056553

\section{Relationship}

Unknown Male 2 $\underline{\text { Party }}$

BURIAL 3, FEMUR

33J-0013-0 $\quad \begin{array}{ll}\text { Race } & \underline{\text { Date(s) Drawn }} \\ \text { None given } & 03 / 18 / 2013\end{array}$

ccount Information

Account Number: $\mathbf{4 2 6 0 9 0 3 5}$

Tx Private Paternity Account

Acct Ref 1:

Acct Ref 2:

Acct Ref 3:

LUBBOCK, TX 79416

Conclusion:

No DNA profile could be obtained, after repeated extractions and testing, from the femur of Burial Three (33J-0013-0). No relationship comparisons could be perfolmed $A$ this sample.

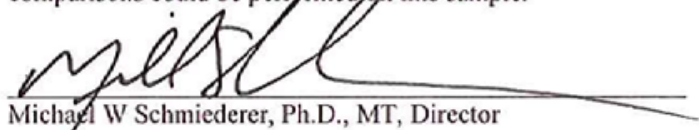

Apris 30,2013

1 


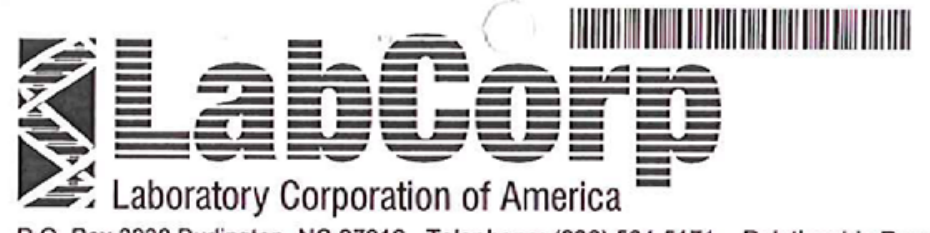

P.O. Box 2230 Burlington, NC 27216 Telephone: (336) 584-5171 Relationship Report

LabCorp Case \# C0Q-056554

Relationship

Unknown Male 3 $\underline{\text { Party }}$

BURIAL 4, FEMUR
33J-0014-0 count Information Account Number: $\mathbf{4 2 6 0 9 0 3 5}$ Tx Private Paternity Account Acct Ref 1:

Acct Ref 2:

Acct Ref 3:

LUBBOCK, TX 79416 $\underline{\text { Race }}$

None given
Date(s) Drawn

$03 / 18 / 2013$

\section{Conclusion:}

No DNA profile could be obtained, ager repeated extractions and testing, from the femur of Burial Four (33J-0014-0). No relationship comparisons could be perfoyned gry his sample.

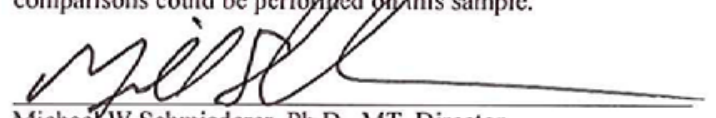

Michae W Schmiederer, Ph.D., MT, Director

April 30,2013

I 
APPENDIX F: Reinterment Agreement between the Texas Department of Transportation and the Roberts Cemetery Association, September 2012 



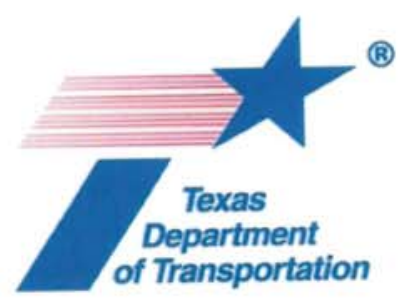

\section{TEXAS DEPARTMENT OF TRANSPORTATION Agreement to Re-inter Unmarked Burials}

CONTROL: 0015-04-067

COUNTY: Bell/Falls/McLennan

PROJECT: $\quad$ IH 35 From NLP 363 to FM 2837

Unmarked burials have been discovered during construction of the above-mentioned Interstate (IH) 35 expansion project adjacent to Roberts Cemetery in Troy, Texas. These burials are in an area that appears to have been on the Roberts Cemetery property when IH 35 was originally constructed in 1957 . The Roberts Cemetery Association, hereinafter called the "Owner", hereby grants to the Texas Department of Transportation, hereinafter called the "State", permission to re-inter the unmarked burials in Roberts Cemetery based upon the following terms and conditions:

1) That the Owner will provide a place within the cemetery boundaries to re-inter the recovered burials

2) That the State will temporarily hold the remains, pending completion of identification efforts

3) That the State will provide all necessary equipment and personnel for re-interment of the burials within the cemetery, including a backhoe, operator and wooden boxes to hold the remains; and

4) If descendants are verified, and if they wish to re-inter the remains of their ancestor(s) in another cemetery, the State will work with the Owner and the descendants to accomplish this in accordance with all state and local regulations. 
Reinterment Agreement

Roberts Cemetery

Page 2 of 2

\section{AGREED:}

Roberts Cemetery Association Board Members Owner
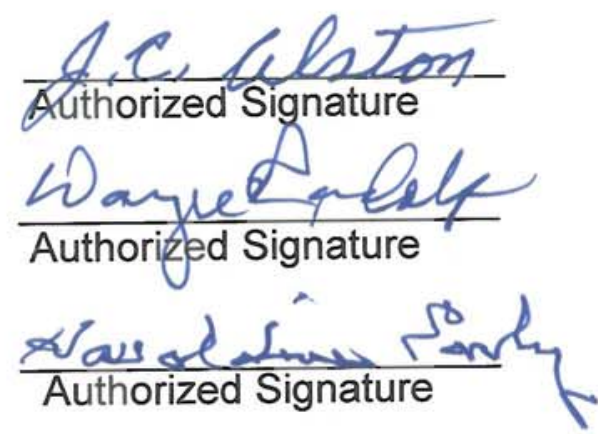

Better Bubes

Authorized Signature

$\frac{\operatorname{Ses} x}{\text { Date }}, 2012$
Albin A. Petter, P.E. State's Representative

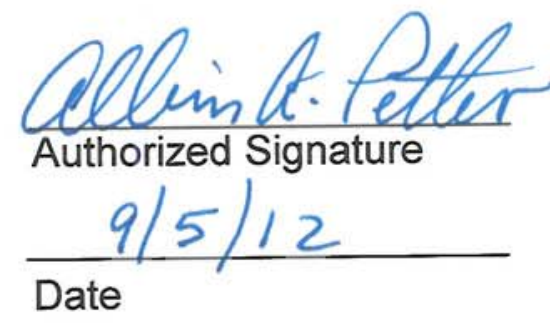

Contact Information: See below:

Address:

Contact name and phone number: Day

Night

$$
\begin{aligned}
& \text { Haroldine Early: } \\
& \text { J.C. Alston: } \\
& \text { Wayne Randolph: } \\
& \text { Betty Jo Bulls: }
\end{aligned}
$$

